UNIVERSIDADE DE SÃO PAULO

ESCOLA DE ENGENHARIA DE SÃO CARLOS

DEPARTAMENTO DE ENGENHARIA DE ESTRUTURAS

\title{
ANÁLISE DA PERDA DE PROTENSÃO EM PONTES PROTENDIDAS DE MADEIRA
}

\section{FERNANDO SÉRGIO OKIMOTO}

Tese apresentada à Escola de Engenharia de São Carlos, da Universidade de São Paulo, como parte dos requisitos necessários à obtenção do título de Doutor em Engenharia de Estruturas.

ORIENTADOR: Prof. Dr. Carlito Calil Junior

São Carlos

Outubro de 2001 


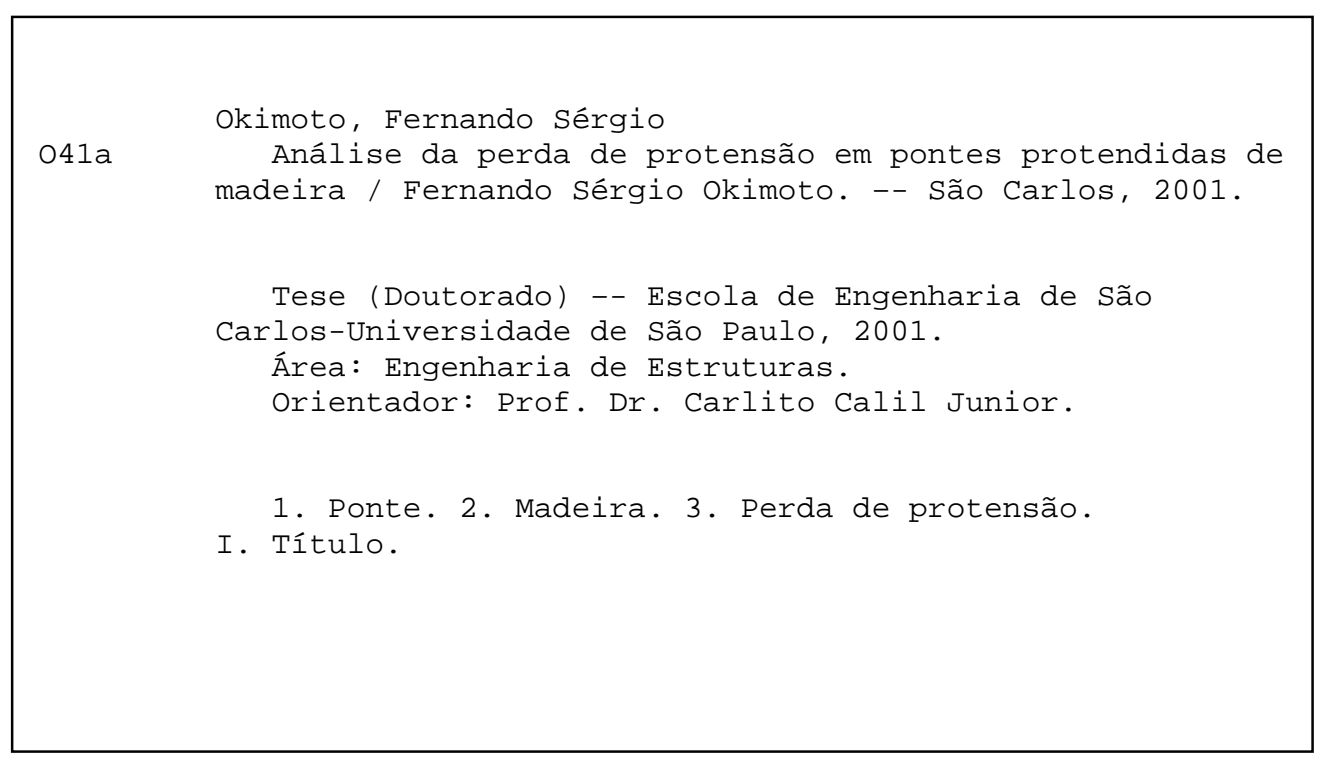


À Cristina M. P. Baron Okimoto e ao nosso bebê. 


\section{AGRADECIMENTOS}

Agradeço ao Prof. Calil cuja dedicação, orientação e incentivos foram fundamentais na realização deste trabalho.

Agradeço ao Prof. Rocco pelo empenho e orientação, também, fundamentais no processo do trabalho.

Aos alunos Ricardo C. Stamato e Gustavo Galembeck pelo excelente trabalho executado nos programas computacionais.

Ao Prof. Marcos Antonio Melo e Oliveira da Universidade de Uberaba e seu, então reitor, Prof. Marcelo, pelo fornecimento de parte da madeira de pinus utilizada na pesquisa.

Aos amigos e colegas de trabalho do LaMEM que ajudaram a realização deste trabalho, especialmente o Jaime, que participou ativamente da parte experimental deste trabalho.

Aos companheiros Jan, Odara e Luna pela compreensão silenciosa nos momentos difíceis.

Aos meus pais Fernando e Yolanda e aos meus sogros Giácomo e Sueli pela compreensão das minhas faltas decorrentes da realização do trabalho.

Ao amigo Carlos Manoel Gomes por conversar comigo sobre outras coisas. 


\section{SUMÁRIO}

LISTA DE FIGURAS E QUADROS iv

SIGLAS ix

SÍMBOLOS $\quad$ x

RESUMO

ABSTRACT Xii

1 INTRODUÇÃO

1.1 Generalidades 4

1.2 Justificativa 4

1.3 Objetivos 6

2 REVISÃO BIBLIOGRÁFICA

$\begin{array}{ll}2.1 \text { Introdução } & 7\end{array}$

2.2 A Madeira como Material de Construção de Pontes 7

2.3 Arranjos de Pontes de Madeira 13

2.3.1 Introdução 13

$\begin{array}{ll}\text { 2.3.2 Pontes em Viga } & 13\end{array}$

Vigas simples de peças roliças $\quad 14$

Vigas compostas de peças roliças $\quad 14$

Vigas simples de peças serradas $\quad 15$

Vigas compostas de peças serradas 16

Vigas laminadas coladas 17

Vigas compostas por peças serradas e compensados 17

Vigas treliçadas 18

2.3.3 Pontes em Arco 18

2.3.4 Pontes em Pórtico $\quad 21$

2.3.5 Pontes em Placa 22 
2.3.6 Pontes Estaiadas e Pênseis $\quad 23$

2.4 Ações em Pontes de Madeira 24

2.5 Combinações das Ações em Pontes de Madeira 35

2.6 Conceitos e Aplicações de Pontes Protendidas de Madeira 38

2.7 Estudo das Pontes Protendidas de Madeira no Brasil 44

2.8 Perda de Protensão $\quad 49$

$\begin{array}{ll}2.9 \text { Viscoelasticidade } & 60\end{array}$

2.10 Conclusões $\quad 64$

3 MATERIAIS E MÉTODOS 66

3.1 Introdução 66

$\begin{array}{ll}3.2 \text { Metodologia Teórica } & 66\end{array}$

Análise teórica da Deformação Lenta 66

Análise teórica da Relaxação $\quad 68$

Diretrizes de dimensionamento do PPM v. $3.0 \quad 68$

Rotina de Cálculo utilizada no AEP v. $1.0 \quad 69$

$\begin{array}{ll}3.3 \text { Metodologia Experimental } & 78\end{array}$

3.3.1 Análise de Fluência $\quad 78$

3.3.2 Análise da perda de protensão em Corpos de Prova 81

3.3.3 Tabuleiros como Corpos de Prova $\quad 89$

3.3.4 Ensaios de Pontes de campo 90

3.4 Sistematização dos Resultados 93

4. RESULTADOS E DISCUSSÕES 94

4.1 Introdução 94

4.2 Análise de Fluência 95

$\begin{array}{ll}\text { 4.3 Análise de Perdas de Protensão em C. Prova } & 124\end{array}$

4.4 Análise de Perdas de Protensão em Tabuleiros $\quad 140$

4.5 Análise de Perdas de Protensão em Pontes 146

4.6 Programa de Projeto e Dimensionamento - PPM v3.0 154

4.7 Programa de Análise Estrutural de Placas - AEP v1.0 164

4.8 Análise Estrutural de Placas via Prova de Carga, SAP2000 e AEP v1.0 174 
5. CONCLUSÕES

ANEXOS

ANEXO 1: CD-ROM com os Programas PPM v.3.0 e AEP v. 1.0

REFERÊNCIAS BIBLIOGRÁFICAS

BIBLIOGRAFIA COMPLEMENTAR 


\section{LISTA DE FIGURAS E QUADROS}

\section{Figuras}

Figura 1.1 - Sistema de tabuleiro de madeira laminada protendida transversalmente

Figura 1.2 - Tabuleiro em seção T

Figura 2.1 -Ponte da Capela (1333). Fonte FISCHER, J. - STEP E17 (1995)

Figura 2.2 - Sistema treliçado de Palladio em "Architecture" (1570). Fonte RITTER (1992)

Figura 2.3 - Treliça de Howe (1840). Fonte RITTER (1992).

Figura 2.4 - Treliça de Pratt (1844). Fonte RITTER (1992).

Figura 2.5 - Ponte em Viga com peças roliças simples

Figura 2.6 - Ponte em Viga com peças roliças compostas

Figura 2.7 - Ponte Barragem (Viga com peças serradas simples)

Figura 2.8 - Seção de Vigas com peças serradas simples

Figura 2.9 - Ponte com Vigas Laminadas Coladas

Figura 2.10 - Seção típica de vigas compostas por peças serradas e chapas de compensado

Figura 2.11 - Pontes Treliçadas

Figura 2.12 - Nomenclatura de pontes em arco. Fonte O'CONNOR, C. (1975)

Figura 2.13 - Pontes em arco.

Figura 2.14 - Pontes em Pórtico

Figura 2.15 - Pontes em placas.

Figura 2.16 - Esquemas de Pontes Estaiadas e Pênseis

Figura 2.17 - Ponte Estaiada e Pênseis

Figura 2.18 - Veículos-Tipo

Figura 2.19 - Veículos-Tipo usuais.

Figura 2.20 - Veículos ferroviários .

Figura 2.21 - Força Longitudinal em Pontes Rodoviárias.

Figura 2.22 - Força Longitudinal em Pontes Ferroviárias.

Figura 2.23 - Vento sobre Passarela. 
Figura 2.24 - Vento sobre Veículo.

Figura 2.25 - Vento sobre Trem.

Figura 2.26 - Impacto Lateral.

Figura 2.27 - Carga no Guarda-Corpo.

Figura 2.28 - Carga no Guarda-Rodas.

Figura 2.29 - Exemplo de Juntas de Topo adjacentes

Figura 2.30 - Barra ( $\phi$ de $32 \mathrm{~mm}$ ) e sistema de ancoragem

Figura 2.31 - Aplicação da Protensão - Cilindros

Figura 2.32 - Aplicação da Protensão - Bombas

Figura 2.33 - Guarda-corpos e Guarda-rodas

Figura 2.34 - Ponte Protendida Badgley Fork

Figura 2.35 - Ponte Protendida Hope Station

Figura 2.36 - Ponte Protendida Poverty Run

FIGURA 2.37 - Perda de Protensão: Resultados Experimentais PRATA (1995)

FIGURA 2.38 - Propriedade Elásticas das placa - Torção Pura- VELOSO (1998)

FIGURA 2.39 - Propriedade Elásticas das placa - Flexão Pura - VELOSO (1998)

Figura 2.40 - Perda de Protensão e sistemas de Reprotensão TAYLOR \& CSAGOLY (1979) apud RITTER (1992)

Figura 2.41 - Espaçamento entre barras de protensão

Figura 2.42 - Perda de Carga - RITTER et al (1990)

Figura 2.43 - Perda de Carga - RITTER et al (1990)

Figura 2.44 - Comparação da Perda de Protensão nas Ponte Herbert Creek e Wheeler

Figura 2.45-Perda de Protensão na Ponte Mormon Creek (1989-1991)

Figura 2.46 - Corpos de Prova - QUENNEVILLE \& DALEN (1994)

Figura 2.47 - Tabela das série ensaiados por QUENNEVILLE \& DALEN (1994)

Figura 2.48 - Curvas de Perdas de Protensão e do Teor de Umidade

Série 1: Umidade ambiente de $50 \%$; sem reprotensão

Figura 2.49 - Curvas de Perdas de Protensão e do Teor de Umidade

Série 8: Umidade ambiente de 80\%; reprotensões em 3, 7, 28 e 56 dias

Figura 2.50 - Modelo Reológico de QUENNEVILLE \& DALEN (1994)

Figura 2.51 - Corpo de Prova - Fonte: QUENNEVILLE \& DALEN (1996)

Figura 2.52 - Características dos C. de Prova - Fonte: QUENNEVILLE \& DALEN (1996)

Figura 2.53 - Resultados da Perda de Protensão nas: a) Séries A; b) Séries C - Fonte: QUENNEVILLE \& DALEN (1996)

Figura 2.54 - Resultados da Perda de Protensão: a) Efeito do Comprimento; b) Efeitos do Perímetro - Fonte: QUENNEVILLE \& DALEN (1996) 
Figura 2.55 - Resultados da Perda de Protensão com o ajuste proposto - Fonte: QUENNEVILLE \& DALEN (1996)

Figura 2.56 - MOSES et al (1999) - a) Corpo de Prova; b) Modelo Reológico utilizado; c)

Série $80 \%=>65 \%=>80 \%$; d) Série $50 \%=>65 \%=>50 \%$.

Figura 2.57 - MOSES et al (1999) - Ajustes para variações de: a) Seção transversal; b) Comprimentos; c) Constantes Elásticas; d) Parâmetro de Viscosidade; e) Níveis de Protensão Inicial; f) Módulos de Elasticidade.

Figura 2.58 - Curva de Deformação lenta

Figura 2.59 - Modelos Matemáticos de Hooke e Newton

Figura 2.60 - Modelos Matemáticos de Maxwell, Kelvin e Burger

Figura 3.1 - Modelos Matemáticos para representar a Deformação Lenta

Figura 3.2 - Modelos Matemáticos representando graficamente a Relaxação

Figura 3.4 - Pórtico de ensaio de Deformação lenta e Corpo de Prova

Figura 3.5 - Esquema dos Corpos de Prova para o Ensaio de Deformação Lenta.

Figura 3.6 - Corpo de Prova para o Ensaio de Perda de Protensão.

Figura 3.7 - Tabuleiros para o Ensaio de Perda de Protensão.

Figura 3.8 - Instrumentação dos Tabuleiros para o Ensaio de Perda de Protensão.

Figura 3.9 - Ponte Millcross Road - Lancaster

Figura 3.10 - Ponte Birch Creek - Sullivan

Figura 4.1 - Corpo de Prova de Deformação Lenta

Figura 4.2 - Caracterização das Madeiras de Pinus Taeda: Compressão paralela

Figura 4.3 - Caracterização das Madeiras de Pinus Taeda: Compressão normal

Figura 4.4 - Caracterização das Madeiras de Eucalipto Citriodora: Compressão paralela

Figura 4.5 - Caracterização das Madeiras de Eucalipto Citriodora: Compressão normal

Figura 4.6 - Resultados da Caracterização - Pinus Taeda

Figura 4.7 - Resultados da Caracterização - Eucalipto Citriodora

Figura 4.8 - Sala Climatizada - $1^{\circ}$ Conjunto de C.P.

Figura 4.9 - Sala Climatizada - Equipamento de Aquisição de Dados

Figura 4.10 - Corpos de Prova do terceiro conjunto (tabela 4.3)

Figura 4.11 - Tabuleiros ensaiados (fig. 3.7)

Figura 4.12 - Millcross Road (Red Oak - $L=760 \mathrm{~cm}, B=800 \mathrm{~cm}$; $\mathrm{h}=41 \mathrm{~cm}$ ) - Lancaster (fig. 3.9)

Figura 4.13 - Birch Creek (American Beech - $L=640 \mathrm{~cm}, B=980 \mathrm{~cm} ; \mathrm{h}=41 \mathrm{~cm}$ ) - Sullivan (fig. 3.10)

Figura 4.14a - Estrutura do PPM V. 3.0

Figura 4.14b - Sobre o PPM Ed 1.0

Figura 4.14c - Esclarecimentos

Figura 4.15 - Tela de Entrada do PPM V. 3.0 
Figura 4.16 - Tela de Resultados do PPM V. 3.0

Figura 4.17 - Tela 1 de Detalhamento do PPM V. 3.0

Figura 4.18 - Tela 3 de Detalhamento do PPM V. 3.0

Figura 4.19 - Telas da Lista de Materiais do PPM V. 3.0

Figura 4.20 - Tópicos da Ajuda do PPM V. 3.0: - Índice

Figura 4.21 - Tela Inicial do arquivo de Ajuda do PPM V. 3.0

Figura 4.22 - Tela de Créditos do arquivo de Ajuda do PPM V. 3.0

Figura 4.23 - Tela Principal do AEP v. 1.0 - Integrado

Figura 4.24 - Tela de Veículos para o AEP v. 1.0 - Integrado

Figura 4.25 - Tela Sobre do AEP v. 1.0

Figura 4.26 - Tela Principal do AEP v. 1.0

Figura 4.27 - Tela Resultados do AEP v. 1.0 - Dados

Figura 4.28 - Tela Resultados do AEP v. 1.0 - Deslocamentos

Figura 4.29 - Tela Resultados do AEP v. 1.0 - Solicitações

Figura 4.30 - Tela Resultados do AEP v. 1.0 - Impressão

Figura 4.31 - Tela do arquivo Ajuda do AEP v. 1.0

Figura 4.32 - Prova de Carga na Ponte de Lancaster

Figura 4.33 - Prova de Carga na Ponte de Sullivan

Figura 4.34 - Tela About SAP2000 Non Linear 


\section{Quadros}

Tabela 2.1 - Pesos específicos dos materiais de construção usuais.

Tabela 2.2 - Cargas dos Veículos.

Tabela 2.3 - Características dos Veículos.

Tabela 2.4 - Cargas das Composições.

Tabela 2.5 - Fatores de Redução $\rho$.

Tabela 2.6 - Características de Locomotivas e Vagões no Brasil.

Tabela 2.7 - Ações permanentes de pequena variabilidade.

Tabela 2.8 - Ações permanentes de grande variabilidade.

Tabela 2.9 - Ações variáveis.

Tabela 2.10 - Fatores de combinação e de utilização.

Tabela 2.11 - Classes de Resistência para Coníferas

Tabela 2.12 - Classes de Resistência para Dicotiledôneas

Tabela 2.13 - Resultados da Madeira de Pinus Elliottii (Coníferas C 25)

Tabela 2.14 - Resultados da Madeira de Eucalipto Citriodora (Dicotiledôneas C 40)

Tabela 2.15 - Fator de Redução de Rigidez - Comparativo com valores da literatura

Tabela 2.16 - Equações empíricas da reologia - Fonte BODIG \& JAYNE (1982)

Tabela 2.17 - Valores das constantes para o Modelo de Burger - Fonte FRIDLEY (1992)

Tabela 3.1 - Perda de Protensão - Diagrama de sinais das Variáveis Principais

Tabela 3.2 - Perda de Protensão - Ensaios das Variáveis Principais

Tabela 3.3 - Perda de Protensão - $1^{\circ}$ - $2^{\circ}$ mês

Tabela 3.4 - Perda de Protensão - $3^{\circ}$ - $4^{\circ}$ mês

Tabela 3.5 - Perda de Protensão - $5^{\circ}$ - $6^{\circ}$ mês - Repetição

Tabela 3.6 - Perda de Protensão - $7^{\circ}$ - $8^{\circ}$ mês - Repetição

Tabela 3.7 - Perda de Protensão - $9^{\circ}$ - $10^{\circ}$ mês - Secagem e Variações

Tabela 4.1 - Perda de Protensão - $1^{\circ}$ Conjunto Ensaiado

Tabela 4.2 - Perda de Protensão - $2^{\circ}$ Conjunto Ensaiado

Tabela 4.3 - Perda de Protensão - $3^{\circ}$ Conjunto Ensaiado 


\section{SIGLAS}

AASHTO American Association of State Highway and Transportation Officials.

ABNT Associação Brasileira de Normas Técnicas.

ASCE American Society of Civil Engineering.

AUSTIM Australian - United States Timber Program.

CJCE Canadian Journal of Civil Engineering.

EBRAMEM Encontro Brasileiro da Madeira e das Estruturas de Madeira.

EESC Escola de Engenharia de São Carlos.

FHWA Federal Highway Administration.

FPL Forest Products Laboratory.

FS Forest Service.

IBRAMEM Instituto Brasileiro da Madeira e das Estruturas de Madeira.

LVL Laminated Veneer Lumber (chapas laminadas prensadas).

MLC Madeira Laminada Colada.

MLP Madeira Laminada Protendida.

MNR Ontario Ministry of Natural Resources.

NBR Norma Brasileira Registrada

OHBDC Ontario Highway Bridge Design Code.

OMT Ontario Ministry of Transportation and Communications (OMTC).

RN Research Note.

RP Research Paper.

SRR Structural Research Report.

TBI Timber Bridge Initiative.

TBIRC Timber Bridge Information Resource Center.

TRB Transportation Research Board.

TRR Transportation Research Record.

USDA United States Department of Agriculture.

UW University of Wisconsin. 


\section{SímBOLOS}

ha hectares;

$E_{\mathrm{L}} \quad$ Módulo de elasticidade do material madeira;

$\mathrm{E}_{\mathrm{T}} \quad$ Módulo de elasticidade do arranjo transversal em madeira;

$\mathrm{G}_{\mathrm{LT}} \quad$ Módulo de elasticidade à torção do arranjo transversal em madeira;

h Altura do modelo; altura do tabuleiro.

L Comprimento dos modelos, Vão dos tabuleiros;

$\sigma_{\mathrm{N}} \quad$ Nível de protensão de projeto;

$\sigma_{\mathrm{Ni}} \quad$ Nível de protensão aplicada inicialmente;

U Umidade em \%;

$\mathrm{f}_{\mathrm{c} 0, \mathrm{k}} \quad$ Valor característico da resistência à compressão paralela às fibras da madeira;

$f_{v, k} \quad$ Valor característico da resistência cisalhamento paralelo às fibras da madeira;

$\mathrm{f}_{\mathrm{c} 90, \mathrm{~d}} \quad$ Valor de projeto da resistência à compressão normal às fibras da madeira;

$\mathrm{E}_{\mathrm{c} 0, \mathrm{~m}} \quad$ Valor médio do módulo de elasticidade paralelo da madeira;

$\rho_{\text {bas,m }}$ Valor da densidade básica da madeira;

$\rho_{\text {apar }} \quad$ Valor da densidade aparente da madeira;

$\mathrm{C}_{\mathrm{BJ}} \quad$ Fator redutor de rigidez longitudinal do arranjo;

$\mathrm{f}_{\mathrm{y}} \quad$ Tensão de escoamento do aço das barras;

$\sigma_{\mathrm{s}} \quad$ Tensão de escoamento de projeto do aço das barras;

$\mathrm{A}_{\mathrm{s}} \quad$ Área de aço das barras;

$S_{p} \quad$ Espaçamento entre barras de aço;

$\mathrm{k}_{1}, \mathrm{k}_{2}$ Constantes elásticas;

$\checkmark \quad$ Viscosidade do material; 


\section{RESUMO}

OKIMOTO, F.S. (2001). Análise da Perda de Protensão em Pontes Protendidas de Madeira. São Carlos, 2001. Tese de Doutorado - Escola de Engenharia de São Carlos, Universidade de São Paulo.

Este trabalho tem como objetivo o estudo teórico e experimental de pontes protendidas de madeira para análise da perda de protensão com o tempo dos tabuleiros construídos com madeiras de espécies de reflorestamento. Portanto, foram realizadas análises de fluência da madeira quando submetida a tensões de compressão normal às suas fibras e de relaxação de conjuntos protendidos construídos com diferentes variáveis. Realizou-se, também, avaliações de tabuleiros em laboratório. Finalmente, os resultados foram sistematizados e incorporados a um programa computacional para o projeto e dimensionamento das pontes protendidas de madeira que automatizando o cálculo destas estruturas e servindo como um mecanismo de transferência do conhecimento.

Palavras-chave: ponte, madeira, perda de protensão, dimensionamento, programa computacional. 


\section{ABSTRACT}

OKIMOTO, F.S. (1999). Stress Losses Analysis in Stress-Laminated Timber Bridge Decks. São Carlos, 2001. PhD Thesis - Escola de Engenharia de São Carlos, São Paulo University.

The aim of this work is the theoretical and experimental studies of stress losses in stress-laminated timber bridges using reforestation species. For this purpose, creep in compression perpendicular to the grain and relaxation of stressed groups were analysed with different variables. The idea was to evaluate these structures using laboratory decks. Finally, the results were systematised and incorporated to design software. That procedure will allow an automatic and quick design of these structures and it serves as a transfer mechanism of the knowledge.

Keywords: bridge, timber, lumber, stress losses, design, software. 


\section{INTRODUÇÃO}

O conceito de pontes de tabuleiro laminado protendido surgiu no Canadá, na região de Ontário, em 1976 onde o sistema de tabuleiro de ponte utilizado era o laminado pregado. O sistema laminado pregado consiste em vigas de madeira serrada posicionados, ao longo do vão, uma adjacente a outra e conectadas por pregos. Devido ao carregamento cíclico e as condições químicas impostas ao sistema (sal utilizado para o degelo), surgiram diversos problemas que comprometiam o desempenho e a função para os quais foram projetados. Um dos problemas encontrados foi a delaminação dos tabuleiros laminados pregados que corresponde a perda de continuidade transversal do tabuleiro, por separação das peças ou por ineficiência do sistema de distribuição das ações. Como a funcionalidade estrutural deste sistema depende da capacidade de transferência das ações da roda entre as lâminas adjacentes, apenas as vigas imediatamente abaixo das rodas eram solicitadas. A solução adotada foi a implementação de um novo sistema de transferência transversal de esforços nestes tabuleiros, pela utilização de barras posicionadas transversalmente ao tabuleiro e submetidas a um tensionamento que comprime as vigas de madeira, fazendo com que surjam propriedades de resistência e elasticidade na direção transversal. Como resultado, a ponte voltou a operar com capacidade plena de tráfego, sendo que as flechas medidas no tabuleiro foram da ordem de $50 \%$ dos valores anteriores mesmo com a capacidade elevada, demonstrando a grande eficácia estrutural do novo sistema. Este fato gerou estudos da aplicação do sistema protendido em projetos de novas construções. A figura 1.1 ilustra o sistema de madeira laminada protendida transversalmente. 


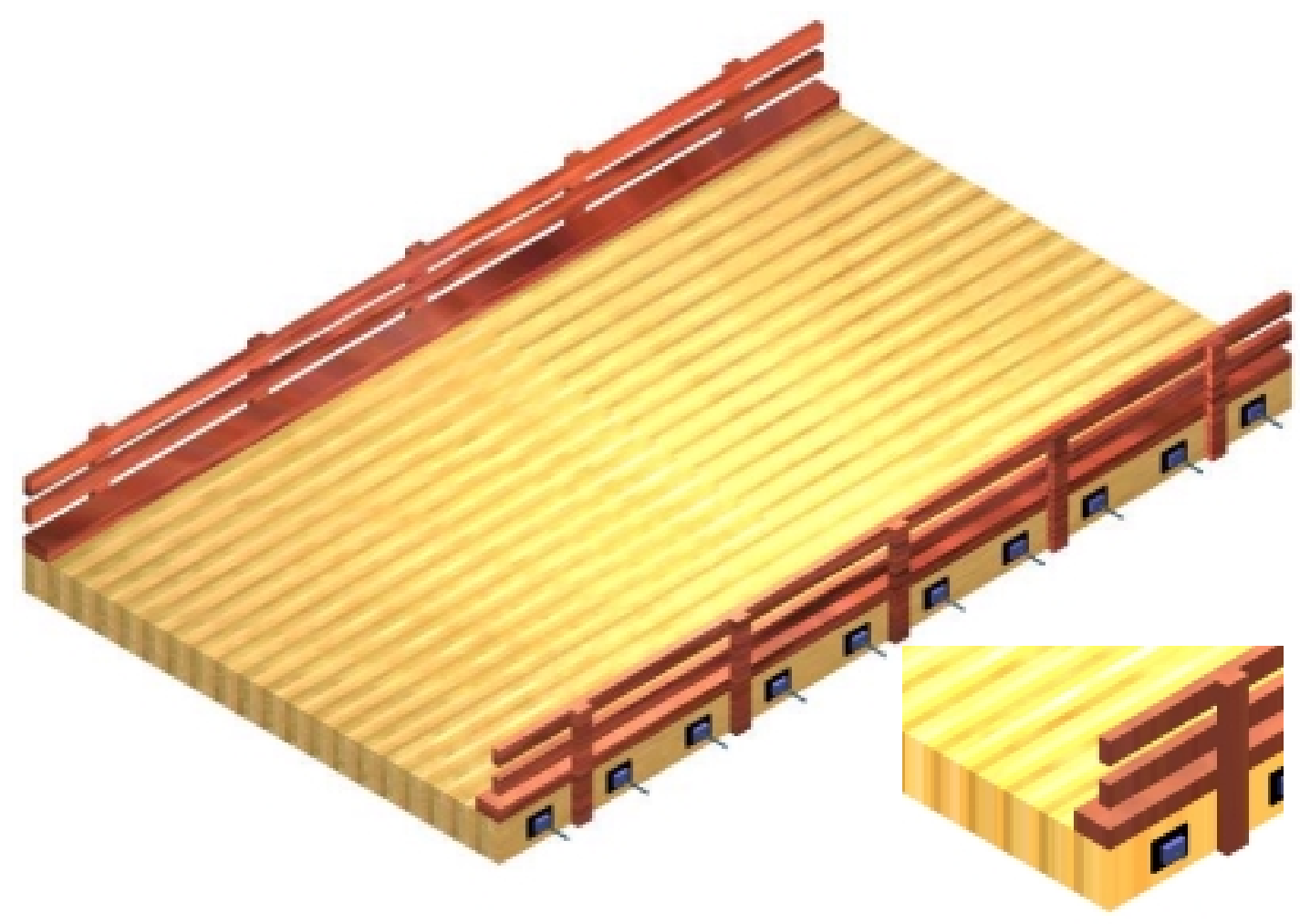

Figura 1.1 - Sistema de tabuleiro de madeira laminada protendida transversalmente

Segundo TAYLOR \& WALSH (1983), o sucesso do sistema no Canadá fez com que o Ministério de Transportes e Comunicações de Ontário (Ontario Ministry of Transportation and Communications - OMT) coordenasse um programa de pesquisas e desenvolvimento, que levou à construção da primeira ponte com esta nova concepção. A ponte Fox Lake Road foi construída sobre o West River, na cidade de Espanola, Ontário, em 1981, pelo Ministério de Recursos Naturais de Ontário (Ontario Ministry of Natural Resources - MNR).

Devido à flexibilidade do sistema, novas aplicações foram pesquisadas e desenvolvidas. Uma das limitações da utilização do sistema de lâminas (serradas maciças) longitudinais com protensão transversal é a limitação de seções transversais disponíveis no mercado restringindo a construção de tabuleiros com vãos livres entre 10m e 12m (OLIVA et al. - 1988). 
Além do sistema com tabuleiro disposto longitudinalmente com protensão transversal, outras aplicações foram desenvolvidas para o sistema protendido, como por exemplo o tabuleiro em seção T (figura 1.2). Todas as variações possibilitam alcançar vão maiores, sendo estrutural e economicamente competitivos.

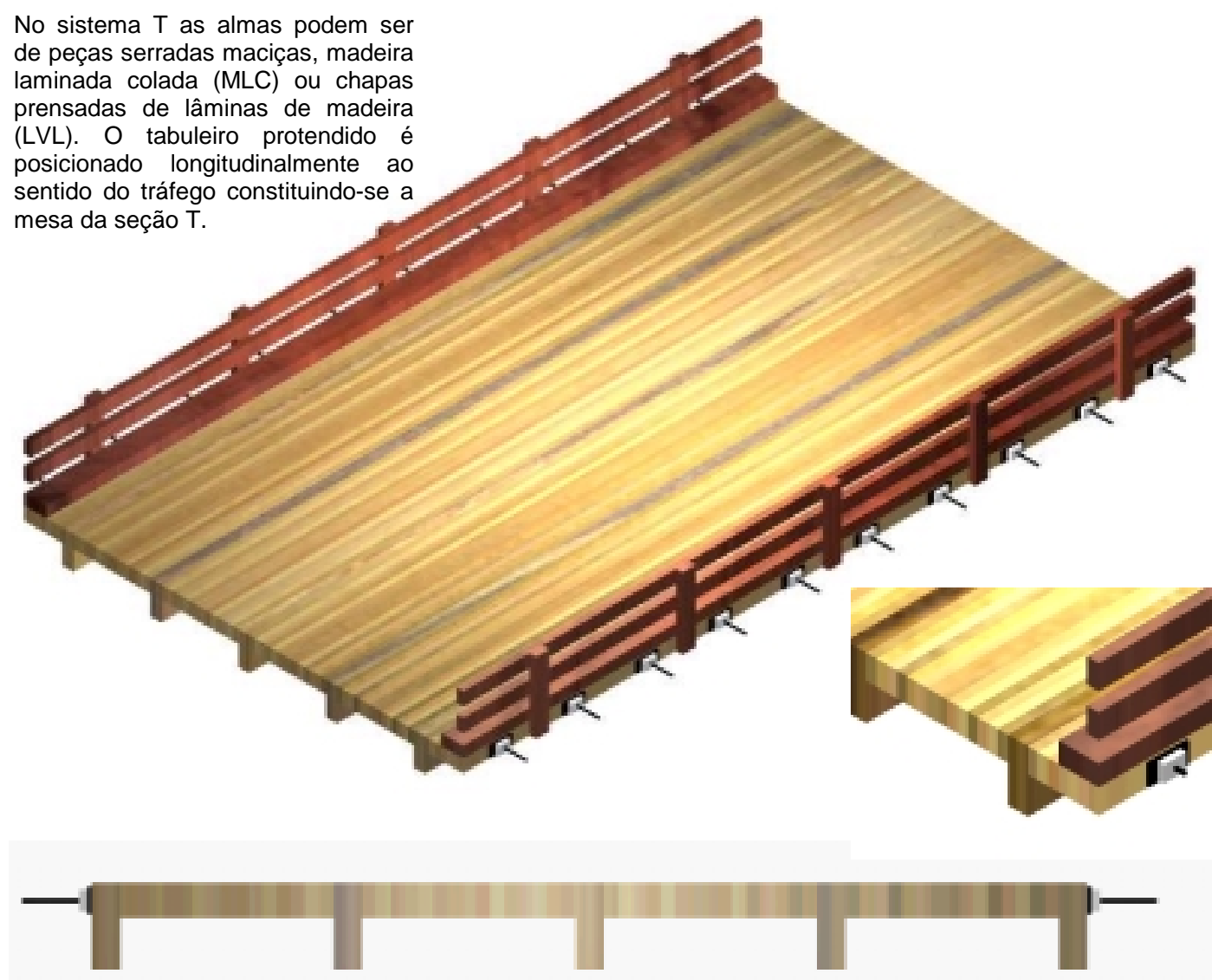

Figura 1.2 - Tabuleiro em seção T

A aplicação do conceito de protensão transversal em tabuleiros em madeira para pontes tem sido estudada e utilizada em várias partes do mundo. TAYLOR \& KEITH (1994) apresentam algumas pontes construídas com este sistema na Austrália e citam que na Suíça esteriam sendo desenvolvidos critérios normativos para o sistema em MLP. No Japão também foi aplicado o sistema (USUKI et al. - 1994) na Yunosawa Bridge em 1993 onde utilizouse a madeira do cedro japonês cujos diâmetros das toras são da ordem de $15 \mathrm{~cm}$ a $20 \mathrm{~cm}$ e, por isso, as vigas são constituídas por peças de MLC. 


\subsection{Generalidades}

Este trabalho pretende complementar os estudos iniciados por OKIMOTO (1997) que sugere como tópicos a serem avaliados: o estudo da perda de protensão com o tempo; os estudos da influência da fluência na compressão normal às fibras da madeira e a análise experimental em protótipos.

Para o entendimento do sistema protendido transversalmente utilizando-se de peças simples serradas percebe-se que a análise das perdas de protensão no tempo é fundamental para que se possa utilizar estas estruturas com segurança. Como conseqüência disso devem-se estudar as implicações importantes no processo de perda de tensão no tempo, tais como a fluência da madeira quando submetida a tensões de compressão normal às fibras e as influências causadas pelos sistemas de protensão na relaxação dos conjuntos protendidos

Outra questão importante é a disseminação do conhecimento adquirido com estes estudos ao meio científico e técnico, possibilitando que outros pesquisadores desenvolvam o sistema protendido e arquitetos e engenheiros possam utilizar-se desta tecnologia.

\subsection{Justificativa}

A utilização estrutural da madeira como material de construção em estruturas correntes é ínfima e se concentra, basicamente, nas estruturas de cobertura. Até mesmo no campo das coberturas os sistemas com outros materiais tem sido estudados e aplicados na tentativa de encontrar soluções viáveis técnica e economicamente. A competitividade do mercado interno associada à abertura crescente ao mercado externo tem provocado uma crescente corrida na procura de materiais, técnicas e tecnologias alternativas. Neste sentido, a utilização da madeira em estruturas correntes, 
que é um material renovável disponível, tem se mostrado uma alternativa coerente com as exigências financeiras, humanas e políticas deste novo século.

A necessidade de novas pontes no Brasil é evidente se verificarmos que 0 território nacional ainda possui taxas de ocupação extremamente baixas em algumas áreas, principalmente nas regiões Norte, Centro-Oeste e Nordeste. Nas áreas mais ocupadas também existe a possibilidade de crescimento das rodovias federais e estaduais. No âmbito municipal, urbano ou rural, existem inúmeras possibilidades de aplicação do sistema protendido em pontes e viadutos de pequenos vãos em todo território nacional. Outra possibilidade é a recuperação das pontes e viadutos existentes que estiverem com deficiência estrutural, de utilização ou estética. Assim, a investigação de novas tecnologias que sejam competitivas no sentido técnico e econômico é fundamental para minimizar o orçamento, principalmente municipal, destinado a estas benfeitorias. As pontes de pequenos vãos para vias secundárias ou rurais, com baixo custo, proporcionariam melhoramentos significativos da rede viária e, por conseqüência, o conforto de seus usuários. Em recente pesquisa, o LaMEM constatou a necessidade de recuperação ou construção de pontes e passarelas em diversos municípios do país, através de contatos diretos com as secretarias de obras das respectivas prefeituras. Em um âmbito estadual, - Departamento de Estradas de Rodagem de Mato Grosso do Sul (DERSUL) pertencente à Secretaria de Estado de Habitação e InfraEstrutura constatou que existem aproximadamente $20455 \mathrm{~m}$ de pontes em madeira nos $12027 \mathrm{~km}$ de rodovias estaduais. Isto equivale a dizer que em cada $3 \mathrm{~km}$ de rodovia estadual existe uma ponte de madeira deficiente com 5 m de vão.

A utilização de espécies de madeiras de reflorestamento na construção de pontes com esta tecnologia propiciará a diminuição de custos com os materiais, sem implicar no aumento dos custos construtivos (a tecnologia da 
madeira protendida pode ser considerada como um sistema totalmente préfabricado incidindo no tema da industrialização das estruturas de madeira) e, também, do ônus aos ecossistemas naturais do país. O presente trabalho pretende se encaixar neste contexto, ao incentivar a utilização das madeiras de Eucalipto e Pinus, ambas de florestamento e reflorestamento, com áreas plantadas no Estado de São Paulo de 715594 ha e 219600 ha (FLORESTAR ESTATÍSTICO), respectivamente, representando materiais de excelente desempenho a baixo custo e impacto ambiental.

\subsection{Objetivos}

Este trabalho tem como objetivo geral o estudo teórico e experimental da perda de protensão com o tempo em tabuleiros protendidos de madeira.

Para tanto, tem-se como objetivos específicos:

- Estudo teórico e experimental da fluência da madeira na solicitação compressão normal às fibras;

- Análise numérica do comportamento estrutural dos tabuleiros;

- Análise de segurança em serviço destas estruturas;

- Proposta de critério de dimensionamento destas estruturas pelo método dos estados limites;

- Criação de mecanismos de transferência de conhecimentos sobre o sistema protendido;

- Apresentação de um software para o dimensionamento destas estruturas. 


\section{REVISÃO BIBLIOGRÁFICA}

\subsection{Introdução}

A revisão da literatura deste capítulo pode ser dividida em quatro blocos diferentes. O primeiro, que é conceitual, engloba os itens 2.2, 2.3 e o 2.4. $\mathrm{O}$ item 2.2 aborda o material madeira na aplicação estrutural de passarela, viadutos e principalmente pontes oferecendo um breve histórico desta utilização. No item seguinte são apresentados os principais arranjos de pontes, passarelas ou viadutos em madeira com suas principais características. Os itens 2.4 e 2.5 são sistematizações dos requisitos normativos nacionais no que diz respeito às ações usuais em pontes de madeira e combinações. No segundo bloco, constituído pelos itens $2.6 \mathrm{e}$ 2.7, estão apresentados os principais conceitos envolvidos no sistema de tabuleiros de peças serradas protendido transversalmente, algumas variações desta tecnologia e um retrospecto dos tópicos estudados sobre o assunto até o momento no Brasil. O terceiro bloco abrangendo do item $2.8 \mathrm{e}$ 2.9 constitui a revisão bibliográfica específica a ser abordada neste trabalho. Finalizando com as conclusões no item 2.10, o quarto bloco.

\subsection{A Madeira como Material de Construção de Pontes}

A madeira, sendo um material renovável, tem estado presente em toda a história da humanidade. Como material de construção, a madeira é abundante, versátil e possui baixo ônus ambiental. Por ser renovável, se 
forem respeitados critérios de sustentabilidade, bem como de proteção e combate de desastres naturais estar-se-á garantindo a disponibilidade deste nobre material às futuras gerações.

Provavelmente a madeira foi o primeiro material utilizado em pontes. As características desejáveis da madeira para esta utilização estrutural são, basicamente, sua elevada relação resistência peso, baixo custo tecnológico, estética e capacidade de absorção de cargas de curta duração. Ao contrário da crença popular, grandes elementos de madeira possuem resistência ao fogo igual ou superior aos outros materiais mais comuns. Pontes de madeira não necessitam equipamentos especiais para instalação e geralmente são construídas sem mão-de-obra altamente especializada. A pré-fabricação e a industrialização são facilmente aplicadas (RITTER, 1992).

O conceito errôneo de que a madeira possui vida útil curta tem atrapalhado a utilização da madeira na construção. Embora a madeira seja um material suscetível à deterioração e ao ataque de agentes biológicos sobre determinadas condições é, indiscutivelmente, um material muito durável quando protegido da variação de umidade, possuindo ou não durabilidade natural elevada. Muitas pontes cobertas, construídas no século 19, ainda estão em uso, pois seus elementos principais estão protegidos da ação direta das intempéries.

Em construções modernas raramente é prática e economicamente viável cobrir as pontes. Apesar disso, as decisões podem ser sociais e/ou culturais. Entretanto, o uso de preservativos tem estendido a vida útil da madeira exposta. Eles as têm protegido por períodos superiores a 50 anos. Além disso, a madeira preservada requer pouca manutenção e nenhuma pintura. 
Outro conceito errado sobre a madeira como um material de construção de ponte é que sua utilização esteja limitada a pequenas estruturas. Esta questão advém, provavelmente, do fato de que as árvores comercializadas possuem dimensões limitadas sendo extraídas antes de atingir diâmetros grandes. O advento da madeira laminada colada (MLC), por volta de 1950, forneceu aos projetistas algumas alternativas embora ainda existam limites de ordem industrial nas dimensões. Uma peça de MLC possui, como regra geral, maior resistência, rigidez e qualidade que as peças serradas da madeira original, possibilitando ainda, a obtenção de elementos de grandes dimensões através de árvores pequenas.

As primeiras pontes de madeira foram construídas pelo homem do período neolítico por volta de 15000 AC (STEINMAN, 1953). Provavelmente, muitas pontes de madeira foram construídas nos últimos 800 anos AC pelos Persas, Babilônios, Gregos, Romanos e Chineses embora exista pouca literatura disponível descrevendo os projetos. Uma das mais antigas pontes registradas apresentava 10,7 m de largura com $183 \mathrm{~m}$ de comprimento construída em 793 AC sobre o rio Eufrates, na Babilônia.

Uma das mais antigas pontes ainda em utilização é a Kappelbrücke (ponte da capela - figura 2.1) localizada na cidade suíça de Lucerna que foi construída em 1333. É uma ponte coberta possuindo $285 \mathrm{~m}$ de comprimento e constituída por vãos de vigas simples sobre pilares de madeira intercalados. Obviamente, ela foi reconstruída ao longo dos séculos e diminuída para $22 \mathrm{~m}$ no século 19. Em Agosto de 1993 um incêndio destruiu grande parte de sua estrutura. Em Abril de 1994, depois de recuperada, ela foi reinaugurada como passarela para pedestres.

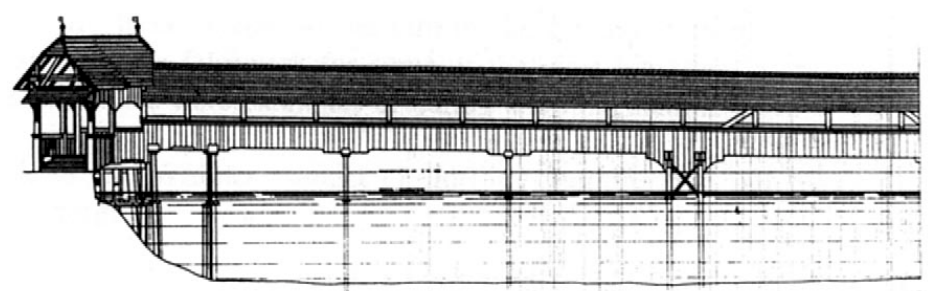

Figura 2.1 -Ponte da Capela (1333). Fonte FISCHER, J. - STEP E17 (1995) 
Até o século 15 a literatura sobre as pontes é limitada e incompleta. Por volta de 1570, Andrea Palladio escreve "Architecture", onde descreve alguns projetos (chamados naquela época de invenções) de pontes de madeira. Ele registrou o arco de madeira e a primeira ilustração de um sistema treliçado (figura 2.2).

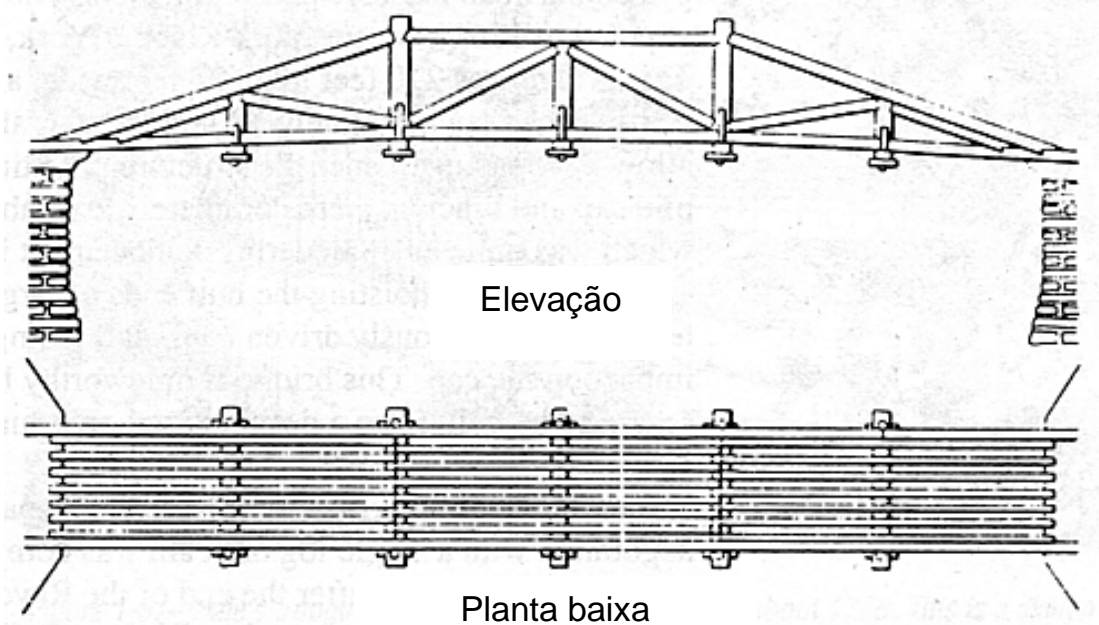

Figura 2.2 - Sistema treliçado de Palladio em "Architecture" (1570). Fonte RITTER (1992)

Somente por volta do século 18 é que, na Europa, a atenção foi voltada às benfeitorias públicas. A engenharia começava a ser reconhecida como profissão.

Nos EUA, com a construção de rodovias e o auge das ferrovias, houve uma grande demanda de pontes. Foi quando surgiram as primeiras pontes cobertas e se estima que mais de 10000 pontes cobertas foram construídas de 1805 a 1885 (RITTER, 1992). 
Até 1840 as pontes eram construídas empiricamente, por tentativa e erro, sem qualquer análise de tensões ou deformações e nenhum desenvolvimento havia ocorrido até que William Howe, de Massachusetts, patenteou sua treliça longa (figura 2.3). Incluía, também, uma análise completa das tensões utilizando ferramentas matemáticas existentes na época. Em seguida, Thomas W. Pratt e Calleb Pratt patentearam sua viga treliçada (figura 2.4).
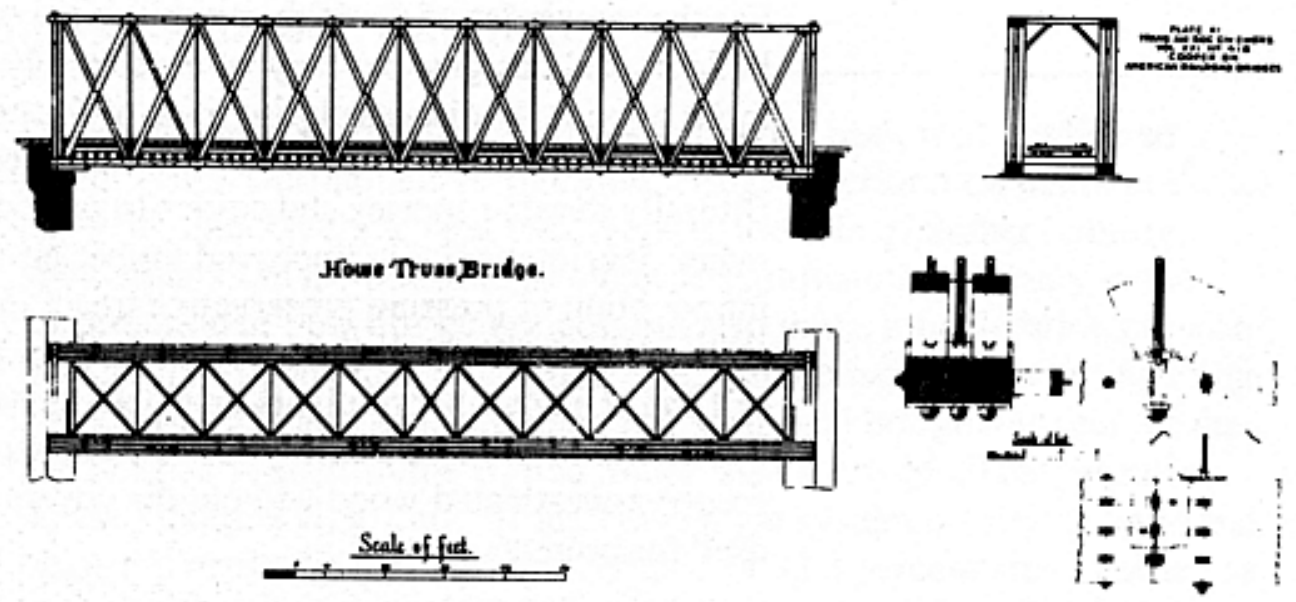

Figura 2.3 - Treliça de Howe (1840). Fonte RITTER (1992).

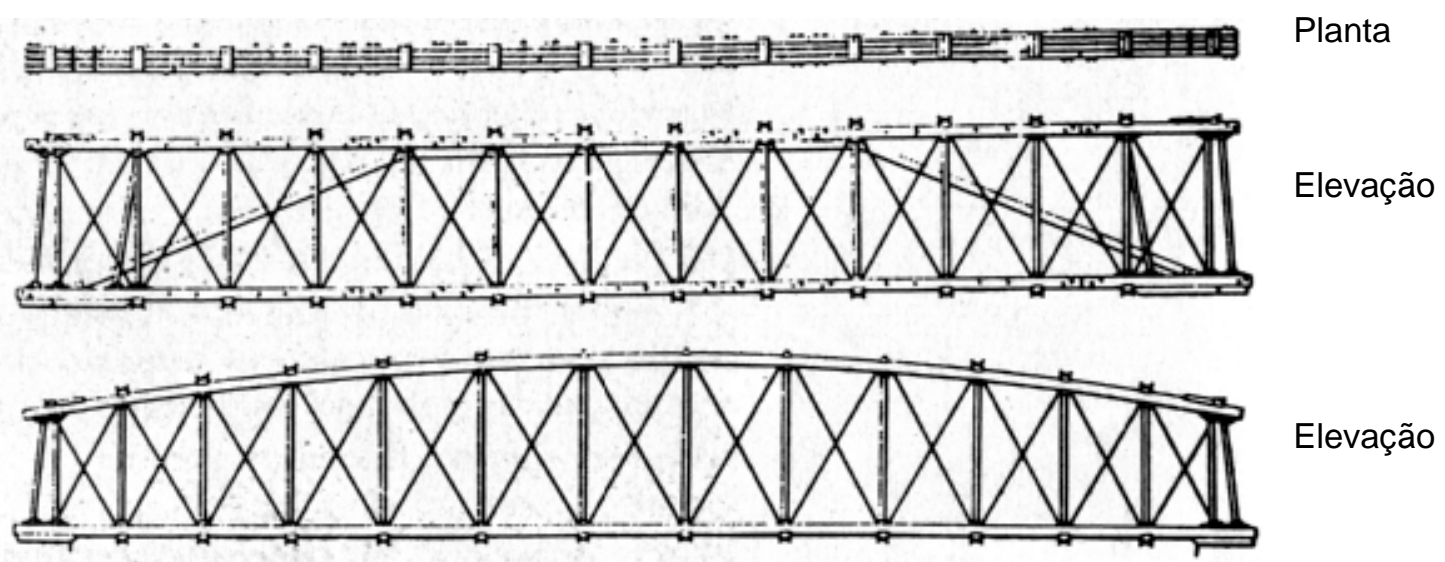

Figura 2.4 - Treliça de Pratt (1844). Fonte RITTER (1992).

A partir da segunda metade do século 19 as pontes de ferro fundido começaram a se difundir e se tornaram competitivas com as de madeira. $\mathrm{Na}$ última década desse século era o material mais utilizado em pontes. 
No começo do século 20 as pontes de aço já eram menos onerosas que as de madeira e o concreto armado se tornou mais popular nos tabuleiros das pontes (RITTER, 1992).

As pontes de madeira se desenvolveram lentamente até que, em meados da década de 40, surgiu o conceito de madeira laminada colada. Nas décadas seguintes, nos Estados Unidos da América, a madeira se tornara 0 material mais utilizado em pontes. Na década de 80 com novos conceitos de placa protendida renovou-se o interesse pelas pontes de madeira (RITTER, 1992).

O futuro da madeira como material de construção de pontes, como para qualquer outra aplicação estrutural da madeira, está garantido se pensada a viabilidade técnica que os vários sistemas estruturais e construtivos oferecem.

Como acredita JOHNSON (apud RITTER 1992), a ascensão da utilização do concreto e do aço se fundamentou nos esforços das suas respectivas indústrias. Elas produziram informações técnicas de seus produtos e distribuíram aos meios acadêmicos e técnicos, levando a um aumento da utilização, prestígio e posição de seus produtos no mercado. Em conseqüência disso, os materiais que não forneceram o mesmo nível de informações, como a madeira, tiveram um declínio neste mercado. É importante ressaltar as diferenças entre as indústrias do cimento e do aço com a da madeira. As primeiras, em todo o mundo, sempre estiveram sobre o controle centralizado de monopólios o que facilitou a produção e transferência de informações técnicas. Já a indústria da madeira consiste em diversas companhias, geralmente assumindo parte do sistema produtivo como extração, beneficiamento, tratamento ou comercialização.

RITTER (1992) diz que, dado o potencial de mercado e as vantagens técnicas e econômicas da madeira, o sucesso futuro em pontes depende de 
três fatores na ordem: 1. Educação dos engenheiros e arquitetos sobre as características do material e performance dos sistemas estruturais; 2. Pesquisas contínuas no desenvolvimento de novos sistemas e o aperfeiçoamento dos existentes; 3 . Um efetivo sistema de transferência de tecnologia para disseminar, aos usuários, informações de projeto, construção e manutenção.

\subsection{Arranjos de Pontes de Madeira}

\subsubsection{Introdução}

As pontes de madeira seguem, em linhas gerais, os mesmos sistemas estruturais de outros materiais. Por outro lado, como o material madeira é extremamente versátil e associando-se ao quesito leveza, têm-se soluções únicas para algumas situações. Pode-se trabalhar na questão de concepção de projeto basicamente com elementos lineares e planos. Além da madeira maciça, em toras ou serradas, dispõem-se de composições destes elementos como chapas de madeira laminada compensada, laminated veneer lumber (LVL - chapa laminada prensada de madeira), madeira recomposta (MDF), etc.

\subsubsection{Pontes em Viga}

As pontes em vigas são as mais práticas e comumente encontradas para pontes de madeira. As vigas são, geralmente, utilizadas na forma de vão único (vigas bi-apoiadas). Quando o comprimento a cobrir é excessivo podese construir apoios intermediários (vigas contínuas). Este fato se deve à dificuldade de emendas no sentido longitudinal para os grandes esforços oriundos da flexão. As variações de seção transversal são apresentadas a seguir. 
Vigas simples de peças roliças (figura 2.5)

É a seção mais simples de se obter, mas sua utilização deve ser orientada por algumas disposições construtivas e cuidados especiais. Em primeiro lugar deve-se atentar ao fato de que nas toras, diferentemente das seções serradas, há a presença do alburno que é a porção de menor resistência mecânica. A durabilidade natural do alburno também é baixa, mas por outro lado é mais fácil o tratamento químico sobre pressão por ser mais permeável (menos denso). Outra questão relevante é a de que a geometria cônica das toras faz com que seja obrigatório algum tipo de regularização como os tabuleiros de concreto armado e compensações longitudinais entre os diâmetros do topo e da base. Das espécies utilizadas em construções de pontes pode-se obter diâmetros da base de $70 \mathrm{~cm}$ ou mais. Os comprimentos disponíveis dependem das espécies utilizadas, podendo ultrapassar $20 \mathrm{~m}$, por exemplo, para o Eucalipto citriodora. De qualquer forma, trata-se de comprimentos muito acima dos limites impostos pelas serrarias nos desdobros.
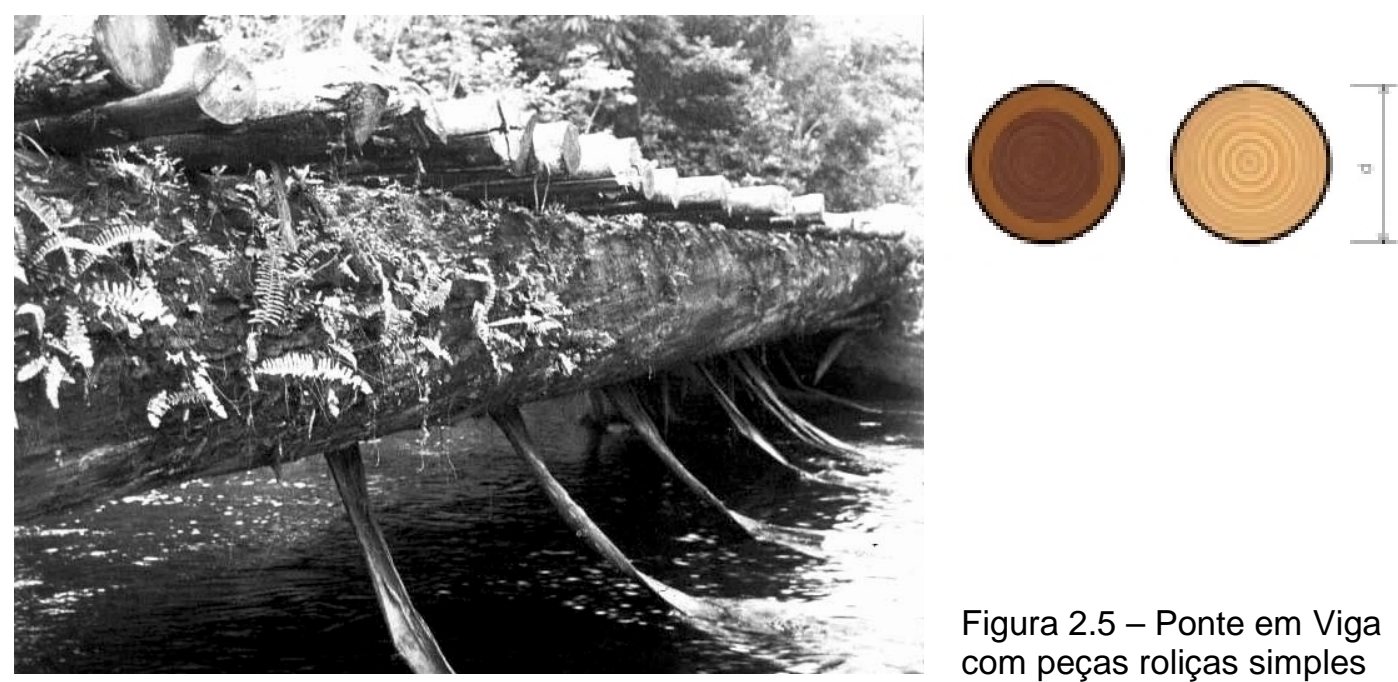

Vigas compostas de peças roliças (figura 2.6)

Pelas questões expostas anteriormente, principalmente com relação às baixas propriedades mecânicas do alburno e os altos comprimentos obtidos, HELLMEISTER, 1978 associou duas ou mais seções roliças. Esta associação geralmente é realizada por parafusos passantes transversais 
associados a elementos de absorção das tensões de cisalhamento tais como tarugos ou anéis metálicos. Obviamente estas associações permitem utilizar toras de diâmetros menores aumentando a relação rigidez peso da viga. Deve-se lembrar que existem perdas significativas de resistência e rigidez da seção (enfraquecimentos das seções e flexibilidade das ligações) limitando o número ideal de seções associadas.

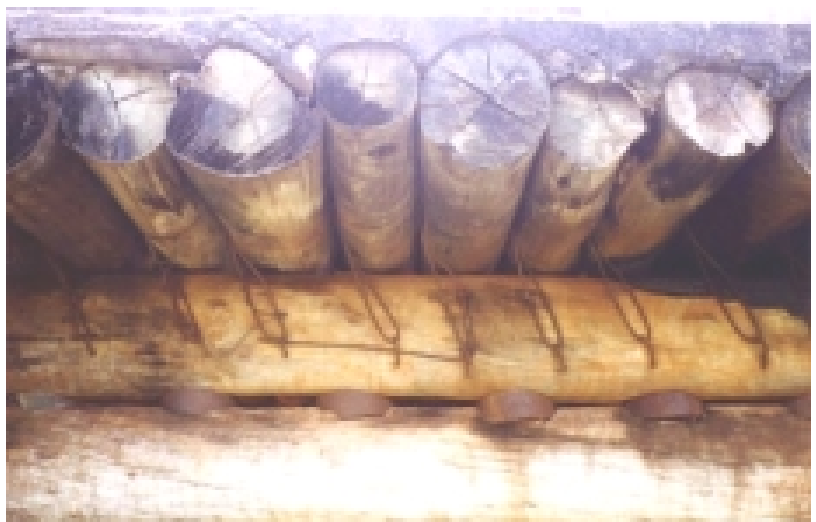

Vigas simples de peças serradas
Figura 2.6 - Ponte em Viga com peças roliças compostas
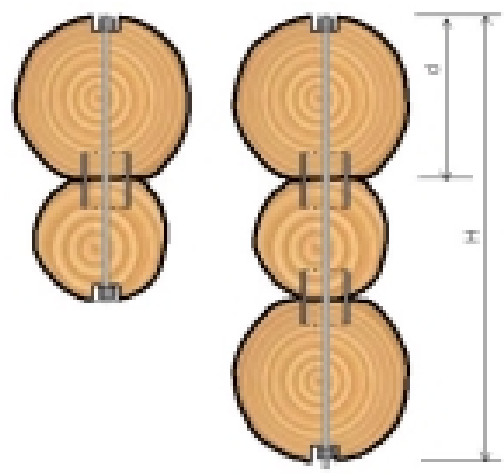

As pontes em vigas que utilizam peças maciças serradas são, em princípio, as de menores vãos. Os vãos raramente ultrapassam $4 \mathrm{~m}$ sem que grandes seções (difíceis de encontrar) sejam necessárias. As seções dos elementos geralmente variam de $10 \mathrm{~cm} \times 30 \mathrm{~cm} \times \mathrm{cm}$ até $20 \mathrm{~cm} \times 50 \mathrm{~cm} \times \mathrm{cm}$ e os comprimentos de $3 \mathrm{~m}$ a7 $\mathrm{m}$. A geometria facilita as ligações entre os elementos da superestrutura bem como desta com a infra-estrutura.

Um tipo particular das pontes em vigas é a ponte barragem (figura 2.7). Elas são destinadas às travessias de grandes rios de pequena profundidade como os encontrados no pantanal Mato-grossense. Estas estruturas são chamadas pontes barragens porque seus vários pilares dispostos próximos entre si (geralmente 2 ou $3 \mathrm{~m}$ ) formam uma barreira visual e física ao longo do rio. Geralmente são construídas em vigas simplesmente apoiadas em consoles sobre os pilares. 

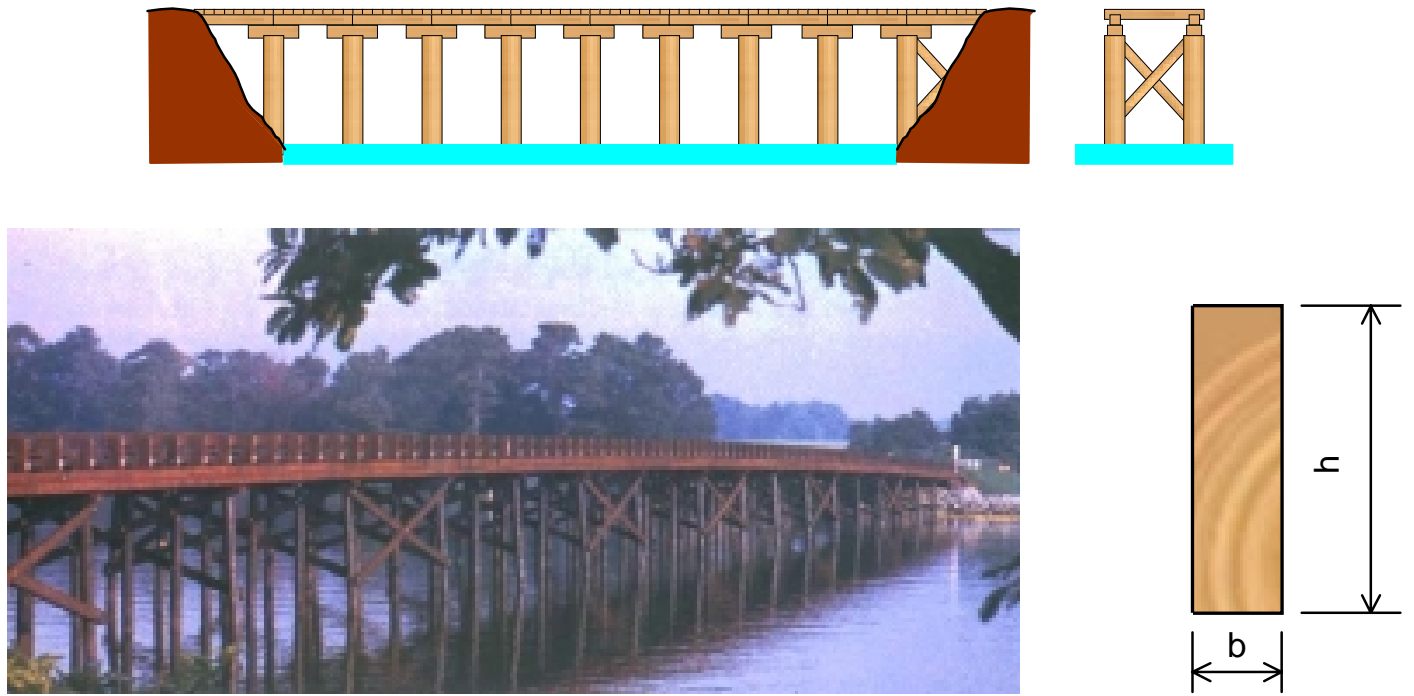

Figura 2.7 - Ponte Barragem (Viga com peças serradas simples)

\section{Vigas compostas de peças serradas (figura 2.8)}

A função básica destas associações é aumentar a rigidez dos elementos seguindo os mesmos princípios de montagem da associação de toras (parafusos passantes e tarugos) mas com as vantagens de possuírem maior área de contato, linearidade longitudinal e peças mais resistentes. As associações usuais em $\mathrm{T}$, I ou $\mathrm{H}$, muito comuns em estruturas de cobertura, não são indicadas aqui já que as ações são elevadas e as possibilidades de ligações entre as seções são limitadas.
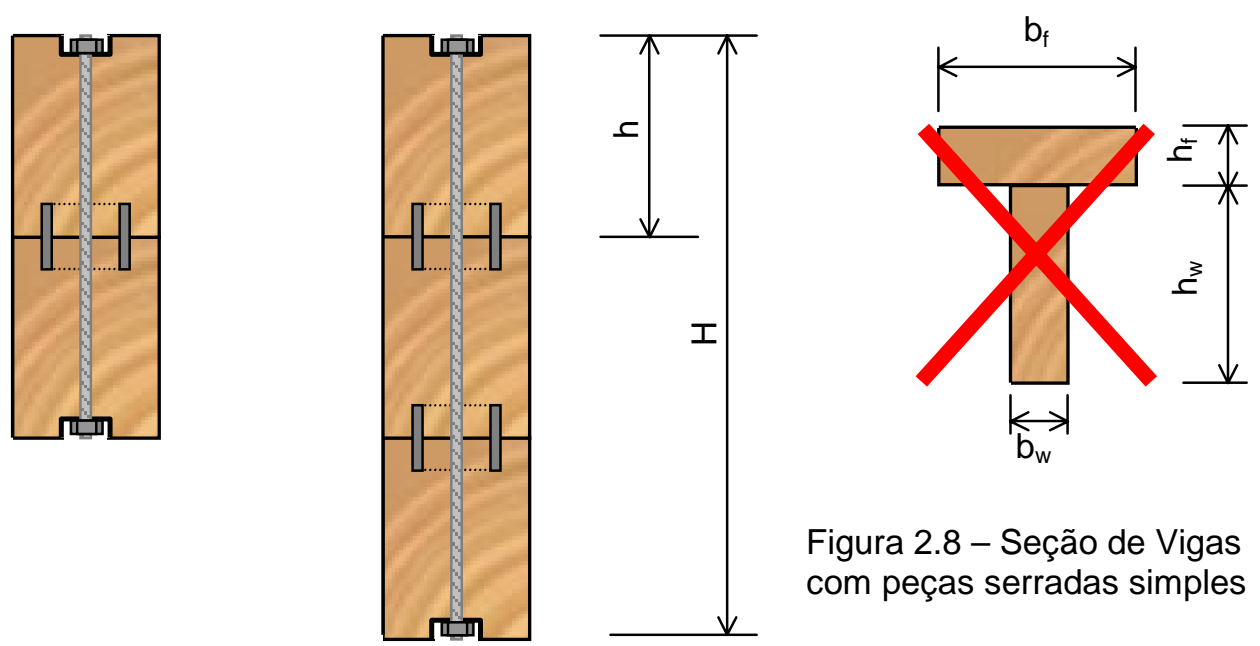

Figura 2.8 - Seção de Vigas com peças serradas simples

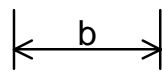




\section{Vigas laminadas coladas (figura 2.9)}

As vigas laminadas coladas são, atualmente, objeto de estudo em várias partes do mundo. Podem ser fabricadas com qualquer seção transversal, observadas apenas as restrições industriais (as prensas geralmente não fabricam alturas de seção maiores que $1,5 \mathrm{~m}$ ) e de transporte da peça. Existem padronizações nas dimensões, mas é recomendável consultar o fabricante específico. Podem ser utilizadas em pontes com vãos superiores a $20 \mathrm{~m}$ desde que seja possível transportar tais elementos até o local da obra ou se utilize emendas longitudinais. Outras características das peças laminadas coladas é que podem ser fabricadas com diferentes formatos (vigas curvas, seções variáveis, etc.) e a qualidade do material produzido é maior que da madeira original. Estão sendo utilizadas vigas de MLC com armadura (passiva ou ativa) de aço ou fibras plásticas.
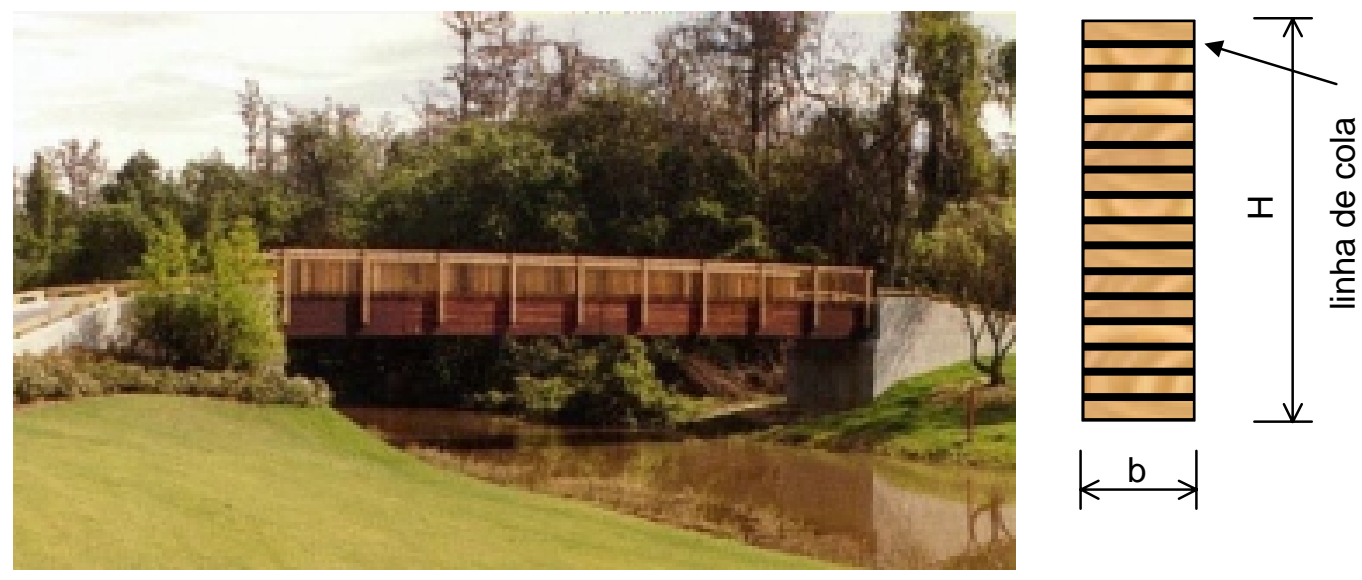

Figura 2.9 - Ponte com Vigas Laminadas Coladas

Vigas compostas por peças serradas e compensados (figura 2.10)

Elementos mais utilizados em estruturas de coberturas, as vigas compostas permitem seções de alta resistência e rigidez, permitindo a aplicação em pontes de madeira. Geralmente são associações de peças serradas dispostas nas mesas (também como travamento interno) absorvendo as tensões normais e chapas estruturais de madeira compensada, LVL (laminated veneer lumber), MDF (madeira recomposta) ou OSB (oriented strand boards) como alma para absorver as tensões tangenciais. 


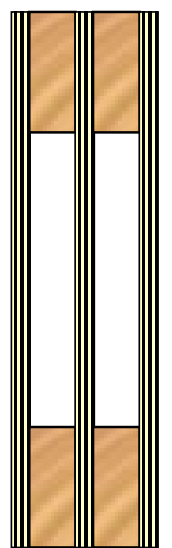

$\stackrel{\mathrm{b}}{\longleftrightarrow}$

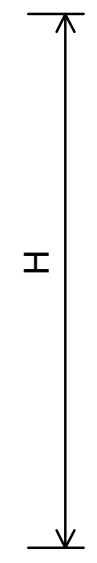

Figura 2.10 - Seção típica de vigas compostas por peças serradas e chapas de compensado

\section{Vigas treliçadas (figura 2.11)}

As treliças sempre foram muito utilizadas nas estruturas de madeira e aço. Suas geometrias permitem estruturas de elevada rigidez, com baixo peso final. Em madeira, as treliças são basicamente construídas com peças serradas, roliças ou laminadas coladas. Obviamente esta utilização depende da região em questão, pois variam a disponibilidade de materiais, o domínio das tecnologias e a tradição de construção. As ligações podem ser realizadas por pregos, parafusos, cavilhas, anéis, chapas com dentes estampados, etc. O que caracteriza uma treliça é que seus elementos estarão submetidos predominantemente às tensões normais.

Existem muitos tipos de treliças (ou associações destas com outras estruturas) e na figura 2.11 apresentam-se alguns deles.

\subsubsection{Pontes em Arco}

Os arcos têm sido muito utilizados em estruturas de pontes de madeira desde a antiguidade. O principal fator para esta prática é que as altas solicitações oriundas da flexão que ocorreriam em vigas passam a atuar em escala menor nos arcos onde predominam as tensões de compressão. Outro fator relevante é a estética proporcionada pelos arcos em pontes onde são, praticamente, ícones destas estruturas. Na figura 2.12 estão algumas 
definições relacionadas às pontes em arco, e em seguida, na figura 2.13, algumas ilustrações da tipologia usual.
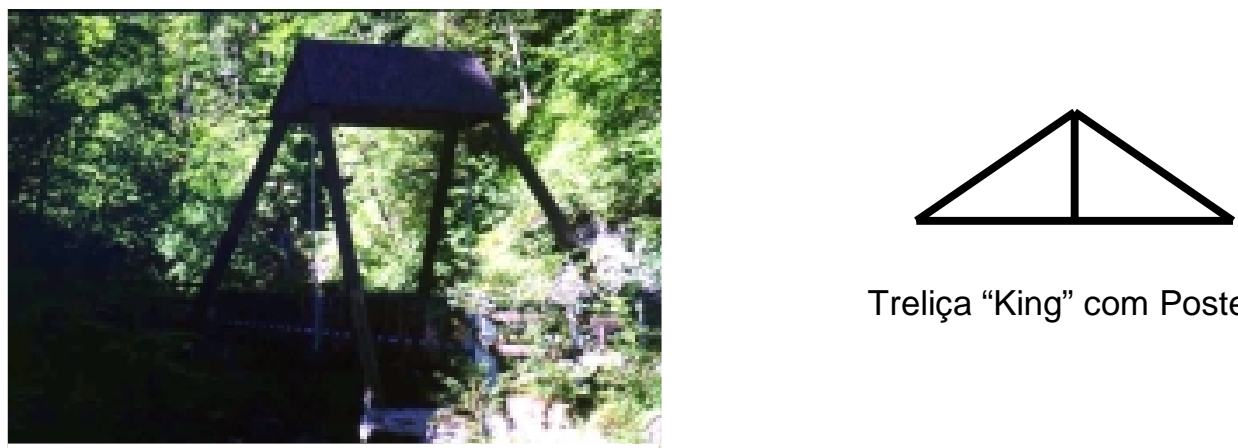

Treliça "King" com Postes
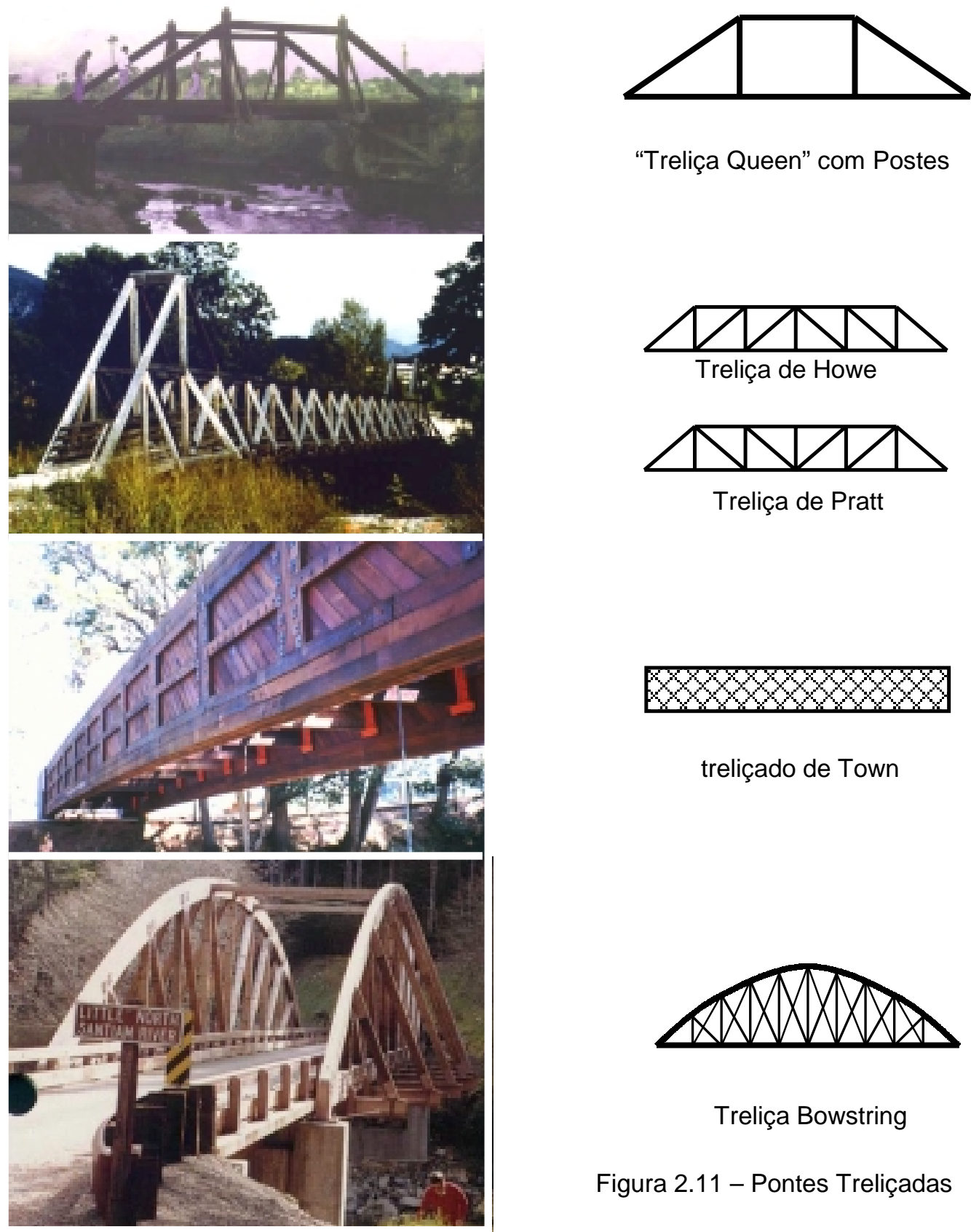

“Treliça Queen” com Postes
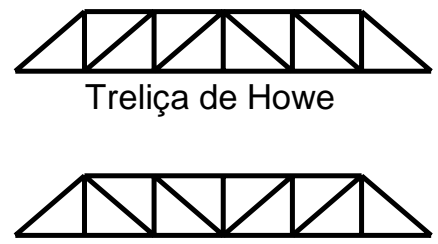

Treliça de Pratt

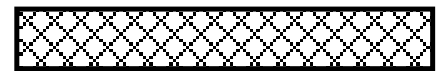

treliçado de Town

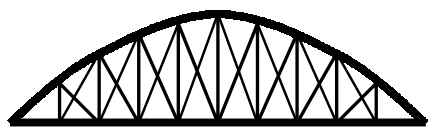

Treliça Bowstring

Figura 2.11 - Pontes Treliçadas 


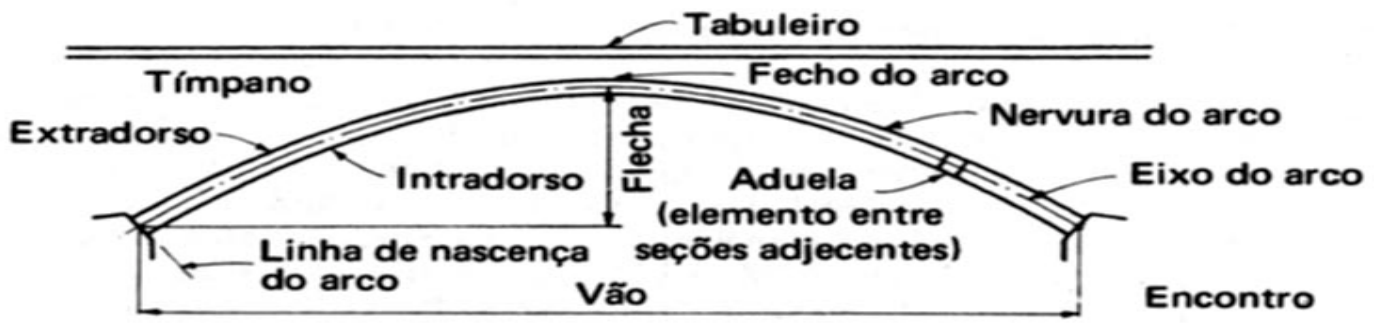

Figura 2.12 - Nomenclatura de pontes em arco. Fonte O'CONNOR, C. (1975)

Como a madeira é um material natural (não moldável), as seções usualmente utilizadas para pontes em arco são as peças de madeira serrada para os arcos treliçados ou peças laminada colada quando os elementos são de alma cheia. Os vãos alcançados por estes sistemas chegam a 30 metros, para peças de alma cheia, e mais de $50 \mathrm{~m}$, se utilizados arcos treliçados.
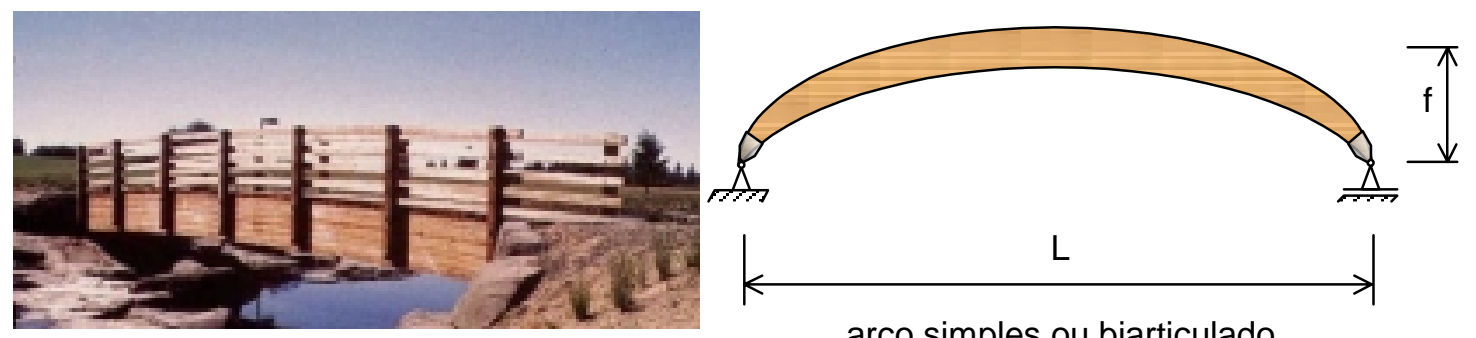

arco simples ou biarticulado
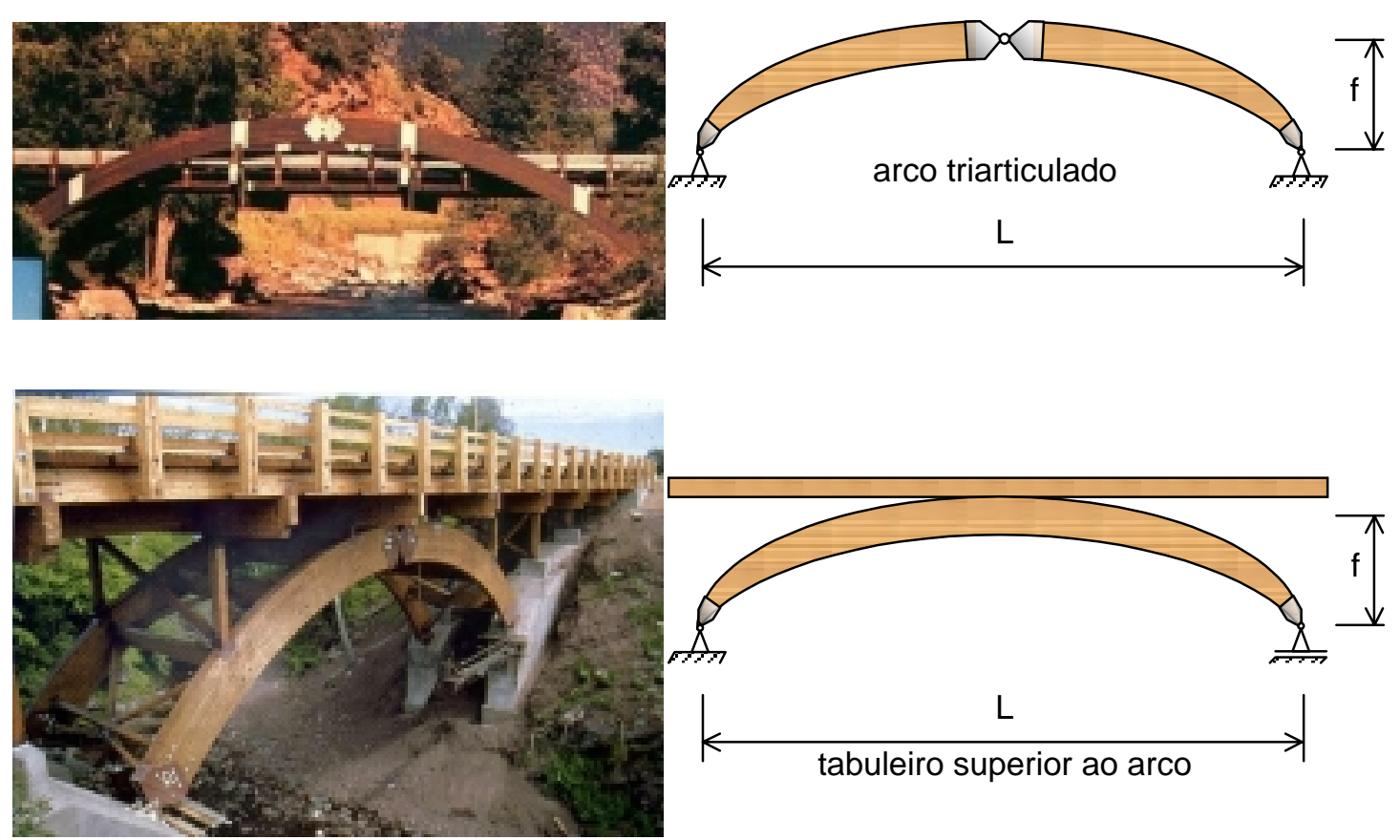

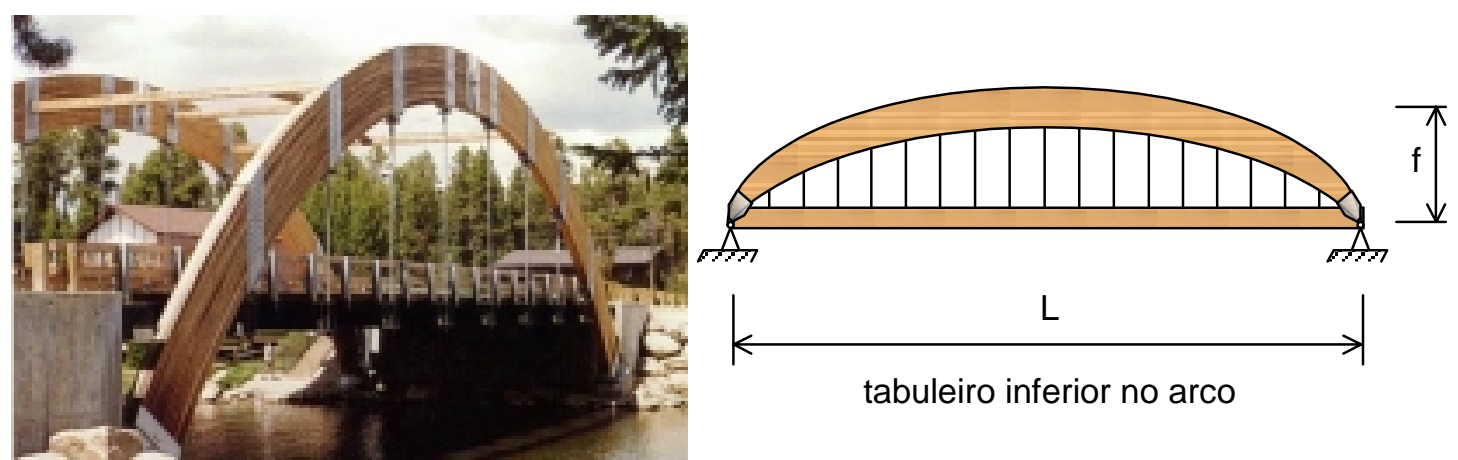

tabuleiro inferior no arco
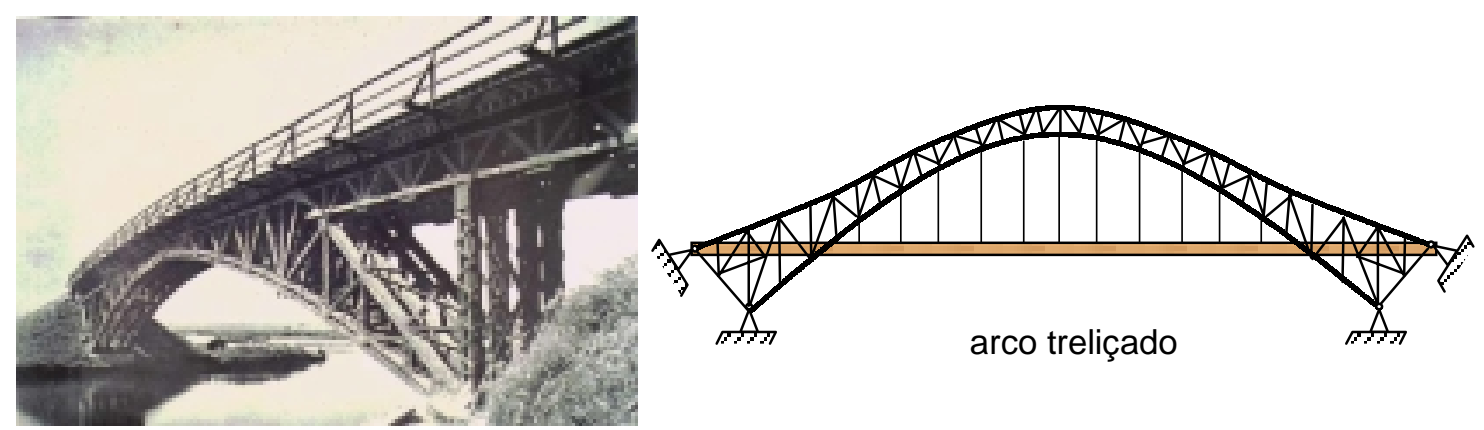

Figura 2.13 - Pontes em arco.

\subsubsection{Pontes em Pórtico (figura 2.14)}

Os pórticos são desejáveis porque os sistemas têm a finalidade de transmitir as cargas de apoios intermediários para as extremidades e permitem uma distribuição mais homogênea das solicitações. O maior problemas dos pórticos são as emendas e as ligações ângulo, onde altas solicitações encontram baixas resistência e rigidez do material e das ligações. Estas estruturas são aplicáveis para vãos médios (em torno de 30m). Atenção especial deve ser dada à questão das emendas devido à ação dinâmica para a qual a ponte deve ser projetada.
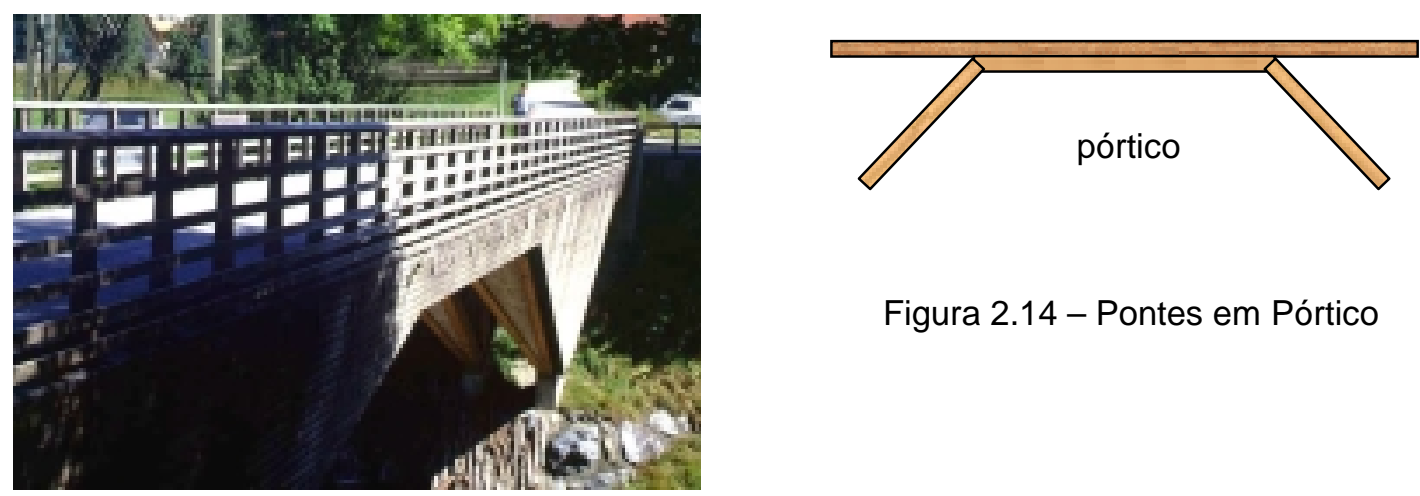

Figura 2.14 - Pontes em Pórtico 


\subsubsection{Pontes em Placa}

Neste sistema às vezes definido de forma simplista por tabuleiro, a superestrutura da ponte é a própria placa não havendo outros elementos contribuindo para distribuir as ações para a subestrutura da ponte (tais como vigas e transversinas). O comportamento de placa é desejável no sentido que a placa (quando rígida) é totalmente mobilizada pelas ações fazendo com que sejam desnecessários elementos discretos como longarinas para aumentar a rigidez do sistema. Por outro lado, o conjunto da placa passa a necessitar alturas maiores que o tabuleiro comum de distribuição (quanto pior for o sistema que une os elementos na forma de placa maior será a seção necessária destes elementos). As pontes em placa cujas seções transversais usuais são apresentadas na figura 2.15, geralmente se destinam a pontes de pequenos vãos, isto é, até $10 \mathrm{~m}$.

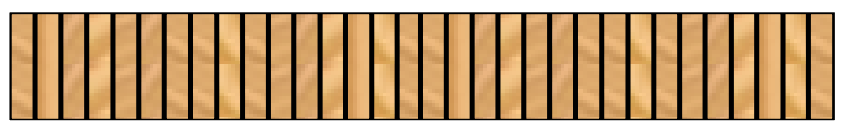

placa laminada colada

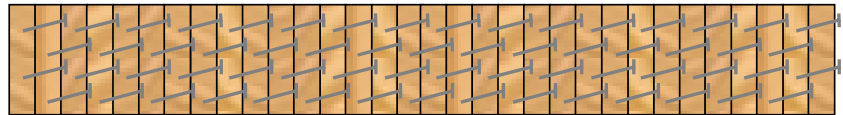

placa laminada pregada

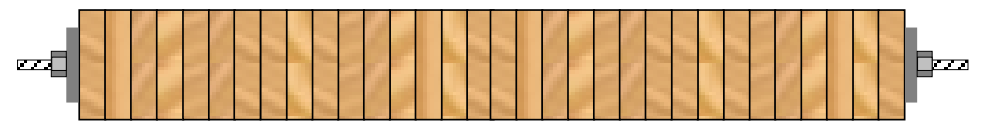

placa laminada parafusada

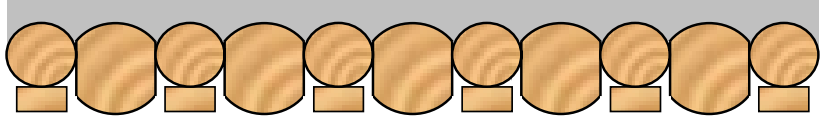

placa composta de concreto e madeira roliça

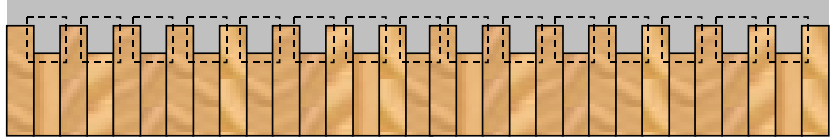

placa composta concreto e madeira serrada

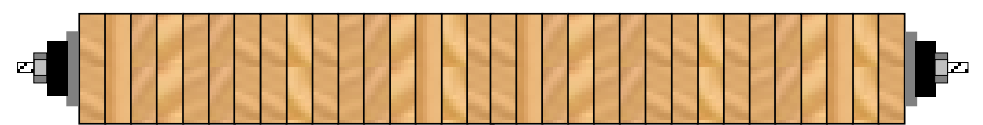

placa laminada protendida

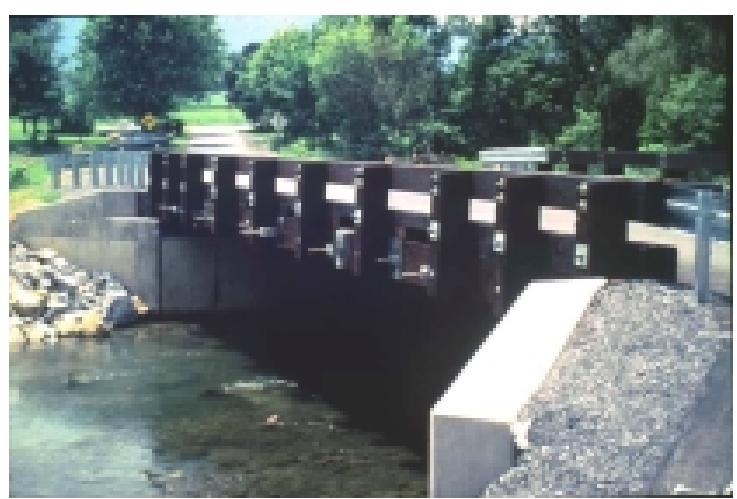

Figura 2.15 - Pontes em placas. 


\subsubsection{Pontes Estaiadas e Pênseis}

Os sistemas estaiados e pênseis (figuras 2.16 e 2.17) são destinados a pontes de grandes vãos (acima de $50 \mathrm{~m}$ ). Podem alcançar a faixa de uma centena de metros mas, também, serem aplicados a vãos menores. Se pensarmos em vãos menores, o projeto das vigas de rigidez (ou tabuleiro) e a altura das torres seriam simplificados podendo ser uma alternativa. As vigas de rigidez podem ser maciças (serrada ou laminada colada) ou treliçadas. As torres, em madeira, aço ou concreto armado, podem ser verticais ou inclinadas. Os sistemas de cabos são geralmente realizados por cordoalhas de aço e podem estar dispostos em planos longitudinais normais ou inclinados em relação aos tabuleiros.

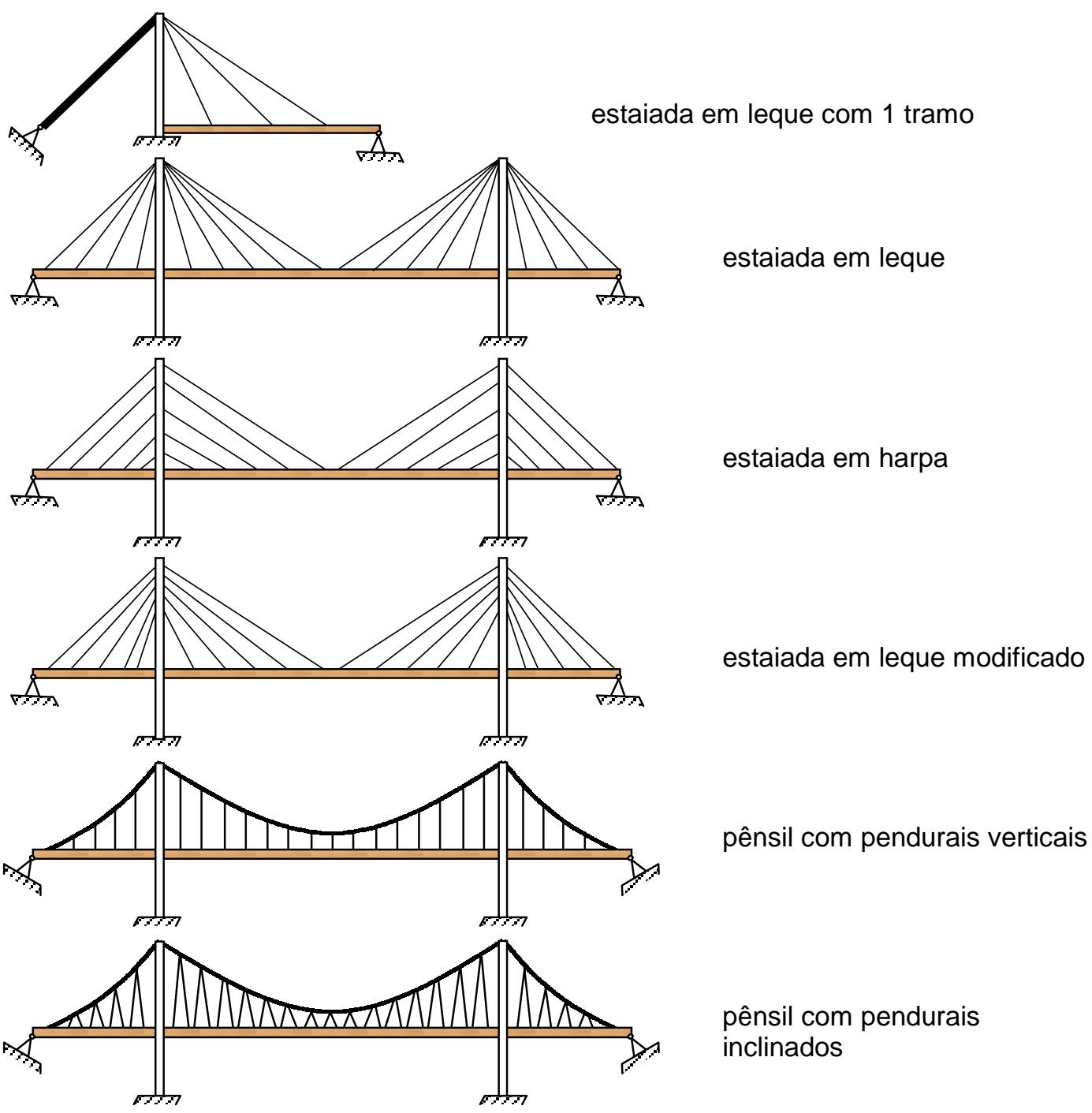

Figura 2.16 - Esquemas de Pontes Estaiadas e Pênseis 

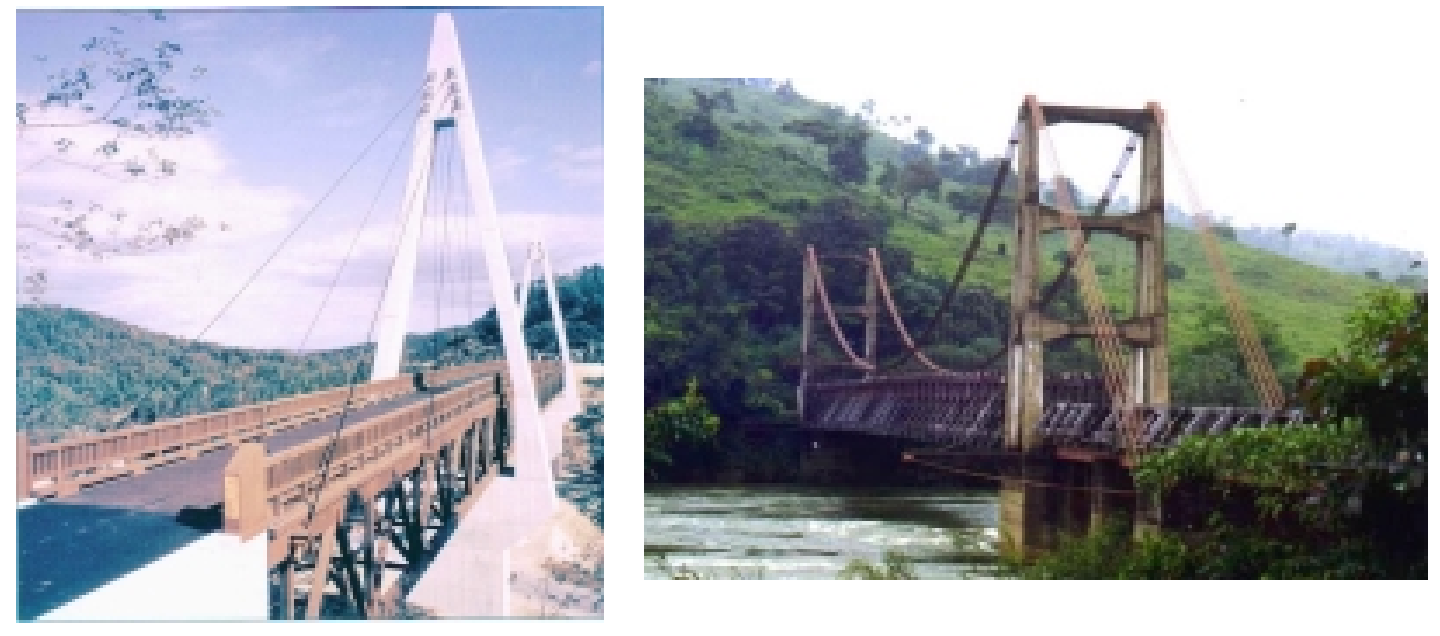

Figura 2.17 - Ponte Estaiada e Pênseis

\subsection{Ações em Pontes de Madeira}

O texto aqui apresentado foi baseado na normalização nacional sobre o assunto. Foram estudadas as seguinte normas e textos:

NBR-7190 (1997). Projeto de estruturas de madeira.

NBR-6120 (1980) - Cargas para o cálculo de estruturas de edificações.

NBR-6123 (1988) - Forças devidas ao vento em edificações.

NBR-7187 (1986) - Projeto e execução de pontes de concreto armado e protendido.

NBR-7188 (1984) - Carga móvel em ponte rodoviária e passarela de pedestre.

NBR-7189 (1985) - Cargas móveis para projeto estrutural de obras rodoviárias.

NBR-8681 (1984) - Ações e segurança nas estruturas.

PNB-428 (1974) - Pontes e viadutos ferroviários. Cargas para o projeto.

PFEIL, W. Pontes em concreto armado. 2 Volumes. LTC. 4a. Ed. Rio de Janeiro, 1990.

EL DEBS, M.K. \& TAKEIA, T.. Pontes de concreto - Notas de aula, fascículo 2 - Ações nas pontes. EESC. São Carlos, 1995. 
2.4.1 Tipos de Ações

Ações Permanentes: ocorrem durante toda a vida útil da construção.

Ações Acidentais: ocorrência é significativa na vida útil da construção.

Ações Excepcionais: probabilidade de ocorrência é muito baixa e de curta duração.

2.4.2 Ações Usuais em Pontes de Maeira

1) Cargas Permanentes.

- Constituídas pelo Peso Próprio dos elementos estruturais.

Madeira na classe de umidade 1 (12\%).

Elementos metálicos das conexões: $3 \%$ do pp da madeira.

Admite-se uma variação de no máximo $10 \%$ entre o peso próprio real e o estimado inicialmente.

- Peso Próprio dos elementos não estruturais.

Revestimentos, guarda-corpo, guarda-rodas, lastros, etc.

- Ações diretas ou indiretas avaliadas como permanentes.

Tabela 2.1 - Pesos específicos dos materiais de construção usuais.

\begin{tabular}{cc}
\hline Material & Peso $\left(\mathrm{kN} / \mathrm{m}^{3}\right)$ \\
\hline Concreto Simples & 24 \\
\hline Concreto Armado & 25 \\
\hline Revestimento Asfáltico & 24 \\
\hline Aço & 78 \\
\hline Lastro de Brita & 17 \\
\hline Madeira & 6 a 12
\end{tabular}

\section{2) Cargas Acidentais Verticais.}

São ações variáveis que atuam em função da utilização da construção (pessoas e veículos). 
- Passarelas de Pedestres.

Classe única com $\mathrm{p}=5 \mathrm{kN} / \mathrm{m}^{2}$, sem impacto.

- Pontes Rodoviárias.

As pontes são divididas em três (3) classes:

- Classe 45: Veículo-Tipo pesando 450 kN.

- Classe 30: Veículo-Tipo pesando $300 \mathrm{kN}$.

- Classe 12: Veículo-Tipo pesando 120 kN.

Os trens-tipos são descritos na tabela 2.2 ilustrada pela figura 2.18.

Tabela 2.2 - Cargas dos Veículos.

\begin{tabular}{|c|c|c|c|c|c|c|c|c|}
\hline \multirow{3}{*}{$\begin{array}{c}\text { Classe } \\
\text { da } \\
\text { Ponte }\end{array}$} & \multicolumn{3}{|c|}{ Veículo } & \multicolumn{5}{|c|}{ Carga uniformemente distribuída } \\
\hline & \multirow[t]{2}{*}{ Tipo } & \multicolumn{2}{|c|}{ Peso tota } & \multicolumn{2}{|c|}{$\bar{p}$} & \multicolumn{2}{|c|}{$\mathbf{p}^{\prime}$} & \multirow{2}{*}{$\begin{array}{c}\text { Disposição } \\
\text { da carga }\end{array}$} \\
\hline & & $\mathrm{kN}$ & $\mathrm{tf}$ & $\mathrm{kN} / \mathrm{m}^{2}$ & $\mathrm{kgf} / \mathrm{m}^{2}$ & $\mathrm{kN} / \mathrm{m}^{2}$ & $\mathrm{kgf} / \mathrm{m}^{2}$ & \\
\hline 45 & 45 & 450 & 45 & 5 & 500 & 3 & 300 & Carga $\mathbf{p}$ em toda $a$ \\
\hline 30 & 30 & 300 & 30 & 5 & 500 & 3 & 300 & \\
\hline 12 & 12 & 120 & 12 & 4 & 400 & 3 & 300 & Carga p' nos passeios \\
\hline
\end{tabular}
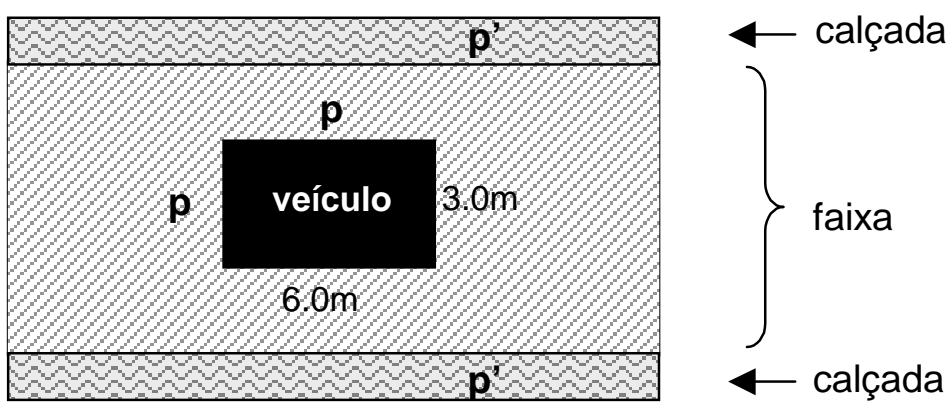

Planta do Trem-Tipo

Tabela 2.3 - Características dos Veículos.

\begin{tabular}{lcccc}
\hline & Unidade & Tipo 45 & Tipo 30 & Tipo 12 \\
\hline Quantidade de eixos & Eixo & 3 & 3 & 2 \\
\hline Peso Total do Veículo & $\mathrm{kN}-\mathrm{tf}$ & $450-45$ & $300-30$ & $120-12$ \\
\hline Peso de cada roda dianteira & $\mathrm{kN}-\mathrm{tf}$ & $75-7,5$ & $50-5$ & $20-2$ \\
\hline Peso de cada roda traseira & $\mathrm{kN}-\mathrm{tf}$ & $75-7,5$ & $50-5$ & $40-2$ \\
\hline Peso de cada roda intermediária & $\mathrm{kN}-\mathrm{tf}$ & $75-7,5$ & $50-5$ & - \\
\hline Largura de contato b1 de cada roda dianteira & $\mathrm{m}$ & 0,50 & 0,40 & 0,20 \\
\hline Largura de contato b3 de cada roda traseira & $\mathrm{m}$ & 0,50 & 0,40 & 0,30 \\
\hline Largura de contato b2 de cada roda intermediária & $\mathrm{m}$ & 0,50 & 0,40 & - \\
\hline Comprimento de contato de cada roda & $\mathrm{m}$ & 0,20 & 0,20 & 0,20 \\
\hline Área de contato de cada roda & $\mathrm{m}$ & $0,20 \times \mathrm{b}$ & $0,20 \times \mathrm{b}$ & $0,20 \times \mathrm{b}$ \\
\hline Distância entre eixos & $\mathrm{m}$ & 1,50 & 1,50 & 3,00 \\
\hline Distância entre os centros de roda de cada eixo & $\mathrm{m}$ & 2,00 & 2,00 & 2,00 \\
\hline
\end{tabular}


Os veículos-tipos a seguir estão descritos na tabela 2.3.
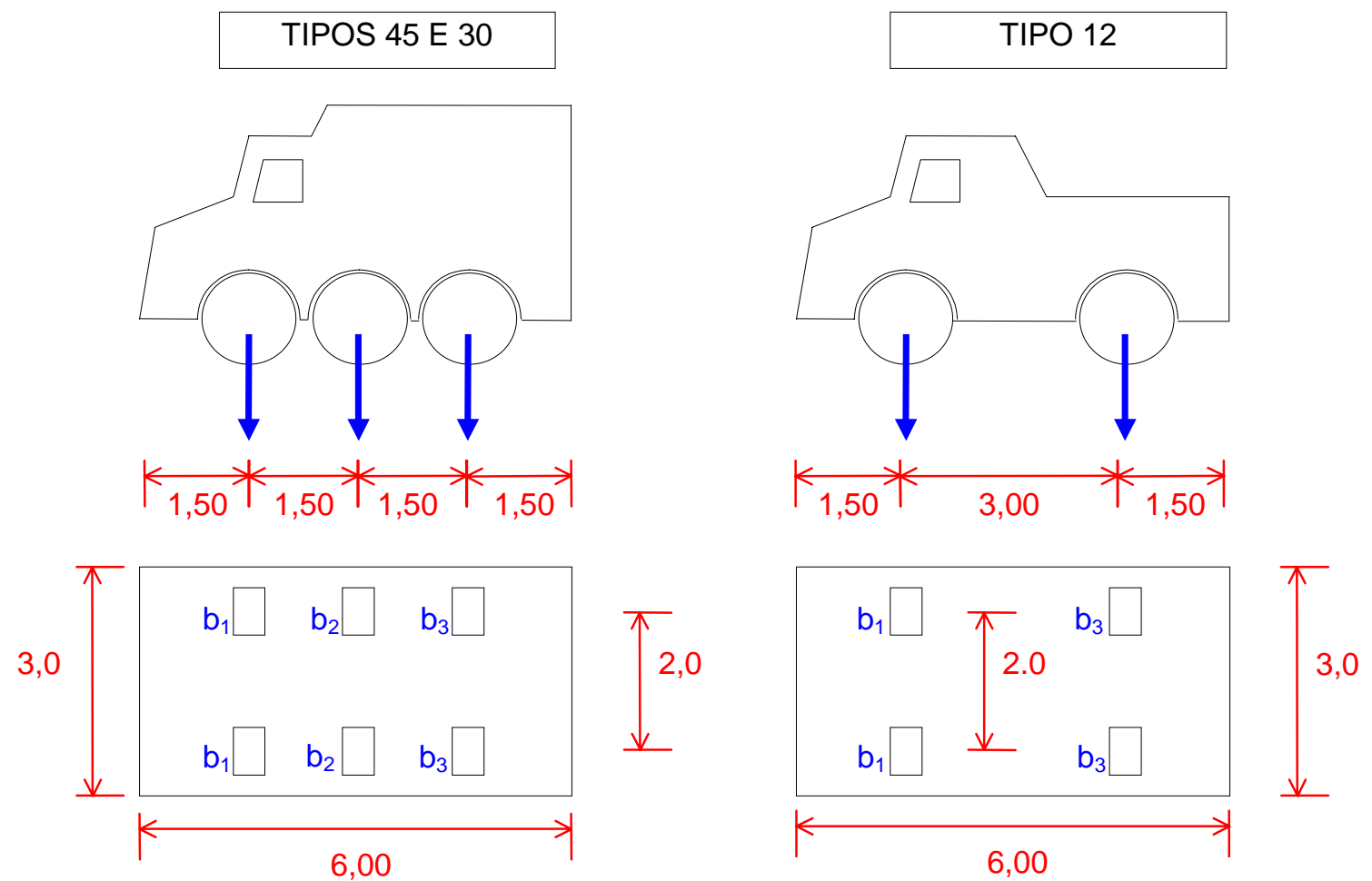

Figura 2.18 - Veículos-Tipo

A disposição do trem-tipo deve prever a situação mais desfavorável desconsiderando carregamentos que reduzam solicitações.

Ex.: Para Momento negativo (a) e para Momentos positivos (b).

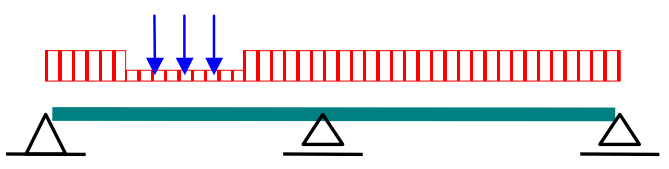

(a)

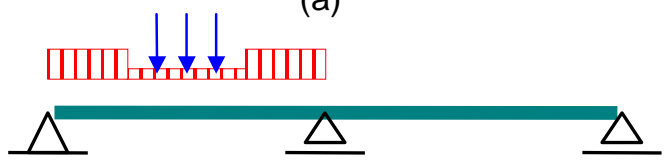

(b)

No Brasil os veículos usuais estão limitados pela chamada lei da balança que prevê o peso máximo por eixo de $100 \mathrm{kN}$ e o seguinte gabarito e cargas legais: 

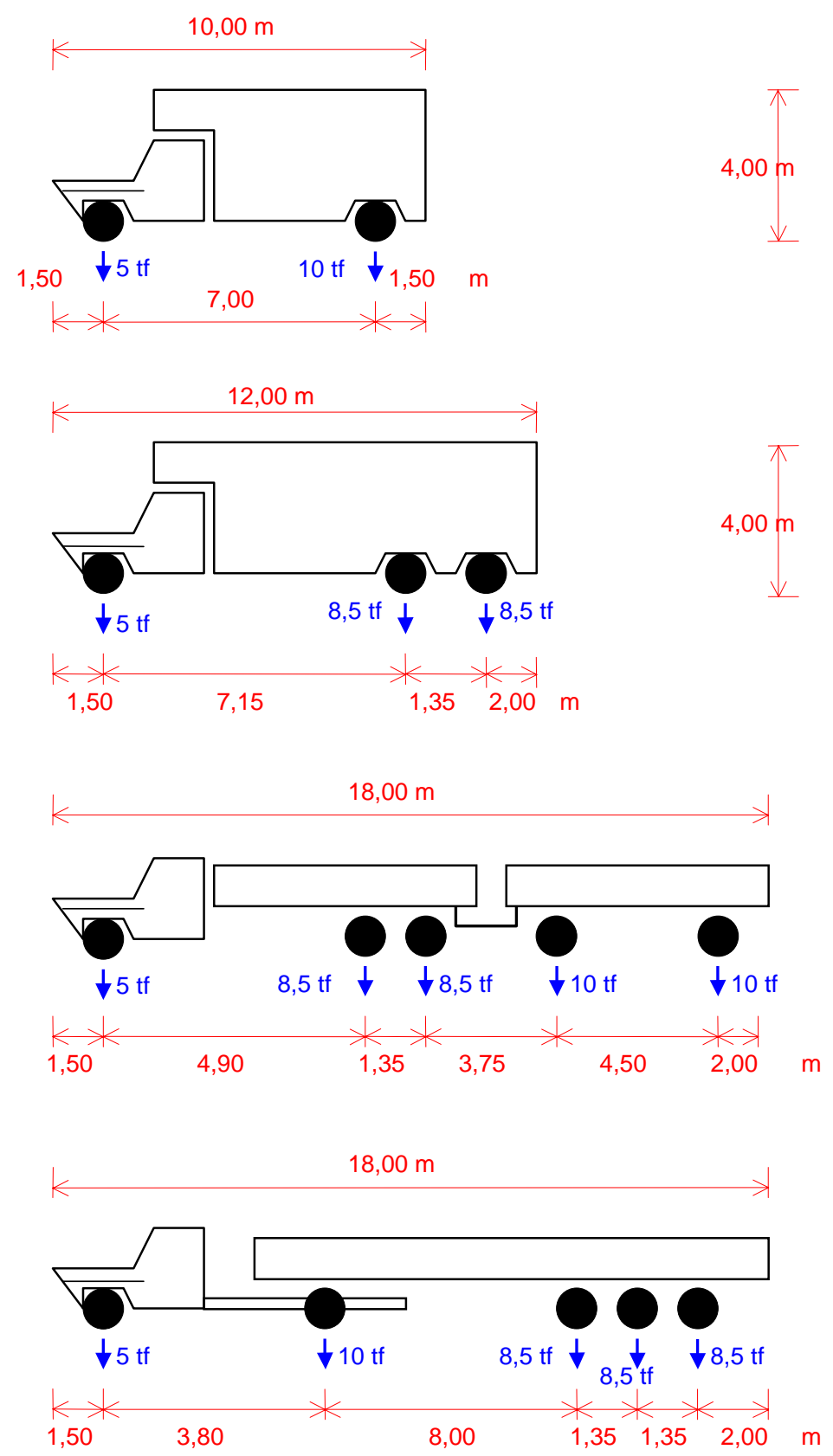

Figura 2.19 - Veículos-Tipo usuais.
$2,60 \mathrm{~m}$

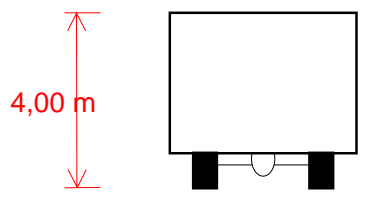

$15 \mathrm{tf}$

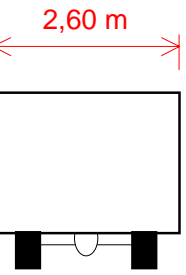

$22 \mathrm{tf}$

- Pontes Ferroviárias.

As pontes estão definidas em quatro (4) classes:

- TB-360: Quando há transporte de minério de ferro ou equivalente.

- TB-270: Carga em geral.

- TB-240: Para verificação de estabilidade e projeto de reforço.

- TB-170: Transporte de Passageiros. 
Os trens-tipos são da forma.

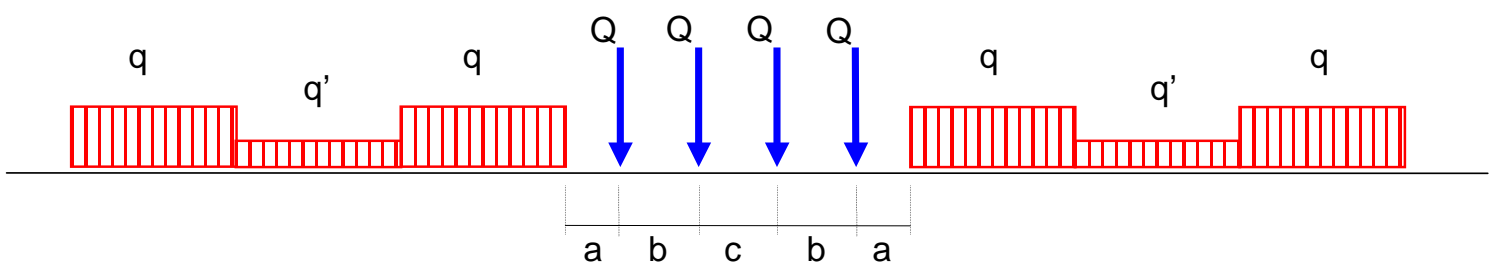

Tabela 2.4 - Cargas das Composições.

\begin{tabular}{ccccccc}
\hline Classe & Q $(\mathrm{kN})$ & $\mathrm{q}(\mathrm{kN} / \mathrm{m})$ & $\mathrm{q}^{\prime}(\mathrm{kN} / \mathrm{m})$ & $\mathrm{a}(\mathrm{m})$ & $\mathrm{b}(\mathrm{m})$ & $\mathrm{c}(\mathrm{m})$ \\
\hline TB-360 & 360 & 120 & 20 & 1,00 & 2,00 & 2,00 \\
\hline TB-270 & 270 & 90 & 15 & 1,00 & 2,00 & 2,00 \\
\hline TB-240 & 240 & 80 & 15 & 1,00 & 2,00 & 2,00 \\
\hline TB-170 & 170 & 25 & 15 & 11,00 & 2,50 & 5,00 \\
\hline
\end{tabular}

Quando houver três ou mais linhas de tráfego, procurar a situação mais desfavorável entre as situações:

- 2 vias carregadas na situação crítica e as demais descarregadas.

- todas as vias carregadas mas com redução $\rho$ nas cargas.

Tabela 2.5 - Fatores de Redução $\rho$.

\begin{tabular}{cccc}
\hline $\mathrm{n}^{\circ}$ de vias & 3 & 4 & 5 \\
\hline redutor $\rho$ & 0,73 & 0,66 & 0,59 \\
\hline
\end{tabular}

No Brasil os veículos ferroviários usuais são:

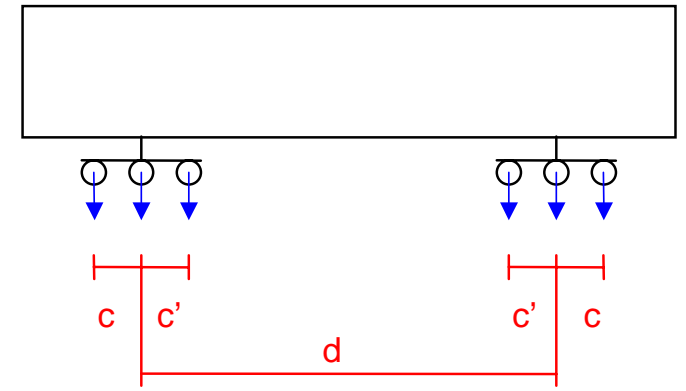

Locomotiva diesel-elétrica

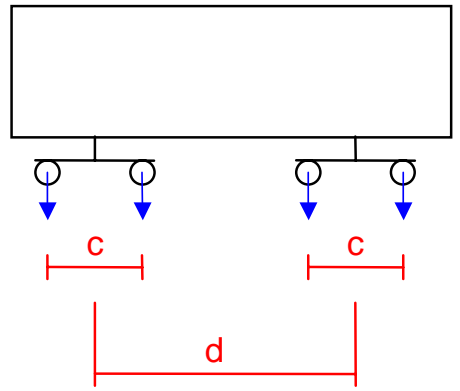

Vagão

Figura 2.20 - Veículos ferroviários . 
Tabela 2.6 - Características de Locomotivas e Vagões no Brasil.

\begin{tabular}{|c|c|c|c|c|c|c|c|}
\hline \multirow{2}{*}{\multicolumn{2}{|c|}{ Tipo }} & \multicolumn{2}{|c|}{$\begin{array}{l}\text { Dist. entre } \\
\text { eixos }(m)\end{array}$} & \multirow{2}{*}{$\begin{array}{c}\text { Dist. entre } \\
\text { truques }(m) \\
d\end{array}$} & \multirow[t]{2}{*}{$\begin{array}{l}\text { Carga por } \\
\text { eixo }(k N)\end{array}$} & \multirow[t]{2}{*}{$\begin{array}{c}\text { Peso } \\
\text { Tot }(k N)\end{array}$} & \multirow[t]{2}{*}{$\begin{array}{c}\text { Bitola } \\
(\mathrm{m})\end{array}$} \\
\hline & & C & $c^{\prime}$ & & & & \\
\hline Locomotiva & $\begin{array}{c}\text { GE U20-C } \\
3371 \\
3401 \\
3501 \\
\text { GE U23-C }\end{array}$ & $\begin{array}{l}1,60 \\
1,60 \\
2,07 \\
1,70 \\
2,02\end{array}$ & $\begin{array}{l}1,91 \\
1,91 \\
2,07 \\
2,11 \\
2,12\end{array}$ & $\begin{array}{c}12,36 \\
9,60 \\
12,73 \\
9,20 \\
12,47\end{array}$ & $\begin{array}{l}180 \\
246 \\
272 \\
276 \\
300\end{array}$ & $\begin{array}{l}1080 \\
1480 \\
1630 \\
1660 \\
1800\end{array}$ & $\begin{array}{l}1,00 \\
1,60 \\
1,60 \\
1,60 \\
1,60\end{array}$ \\
\hline Vagão & $\begin{array}{l}\text { HAD } \\
\text { ADE } \\
\text { ADF } \\
\text { LE } \\
\text { TCPE }\end{array}$ & $\begin{array}{l}1,58 \\
1,73 \\
1,78 \\
1,73 \\
1,73\end{array}$ & $\begin{array}{l}- \\
- \\
- \\
-\end{array}$ & $\begin{array}{c}6,09 \\
5,41 \\
6,30 \\
15,15 \\
8,55\end{array}$ & $\begin{array}{l}200 \\
250 \\
298 \\
250 \\
250\end{array}$ & $\begin{array}{c}800 \\
1000 \\
1190 \\
1000 \\
1000\end{array}$ & $\begin{array}{l}1,00 \\
1,60 \\
1,60 \\
1,60 \\
1,60\end{array}$ \\
\hline
\end{tabular}

Composição mais pesada em operação é a que transporta minério de ferro com 4 locomotivas (de 1800 kN) e 100 vagões (de 1190 kN).

\section{3) Impacto Vertical.}

O impacto vertical é considerado uma ação de curta duração.

Para considerar o efeito dinâmico do impacto vertical sobre as cargas móveis verticais deve-se multiplicá-las por:

$$
\varphi=1+\frac{\alpha}{40+\mathrm{L}} \quad \text { onde: }
$$

$L= \begin{cases}\text { Ponte em Viga: } & \text { vão teórico do tramo. } \\ \text { Ponte em Placa: } & \text { menor dos vãos. }\end{cases}$

$\alpha= \begin{cases}\text { 50: } & \text { Pontes ferroviárias. } \\ \text { 20: } & \text { Pontes rodoviárias com revestimento de madeira. } \\ \text { 12: } & \text { Pontes rodoviárias com rev. de concreto ou asfalto. }\end{cases}$

Não se considera o impacto em:

- encontros.

- pilares maciços.

- fundações.

- passeios. 
Devido à maior resistência da madeira às cargas de curta duração, na verificação da segurança nos estados limites últimos, as solicitações nas peças de madeira devidas ao impacto vertical serão multiplicadas por 0,75.

Para os elementos metálicos deve-se considerar a totalidade do impacto vertical.

\section{4) Forças Longitudinais.}

São forças de curta duração devidas à aceleração e à frenagem dos veículos.

- Pontes Rodoviárias.

$F_{\text {long }}$ deve ser aplicada sem impacto, $2.00 \mathrm{~m}$ acima da superfície de rolamento.

$\mathrm{F}_{\text {long }} \geq\left\{\begin{array}{c}\cdot 5 \% \text { do carregamento total do tabuleiro com carga móvel } \\ \text { uniformemente distribuída. (aceleração) } \\ \quad 30 \% \text { do veículo-tipo para cada faixa de tráfego. (frenagem) } \\ \quad \mathrm{F}_{\text {long }}\end{array}\right.$

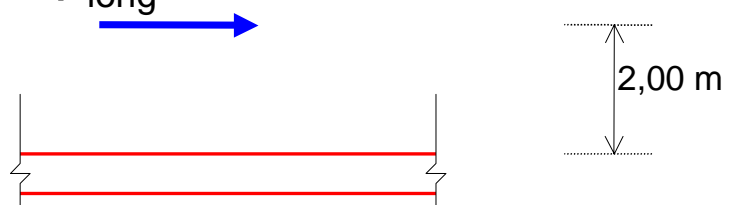

Figura 2.21 - Força Longitudinal em Pontes Rodoviárias.

- Pontes Ferroviárias.

$F_{\text {long }}$ deve ser aplicada sem impacto, $2.40 \mathrm{~m}$ acima do topo do trilho. Se for via múltipla, aplicar somente em uma linha.

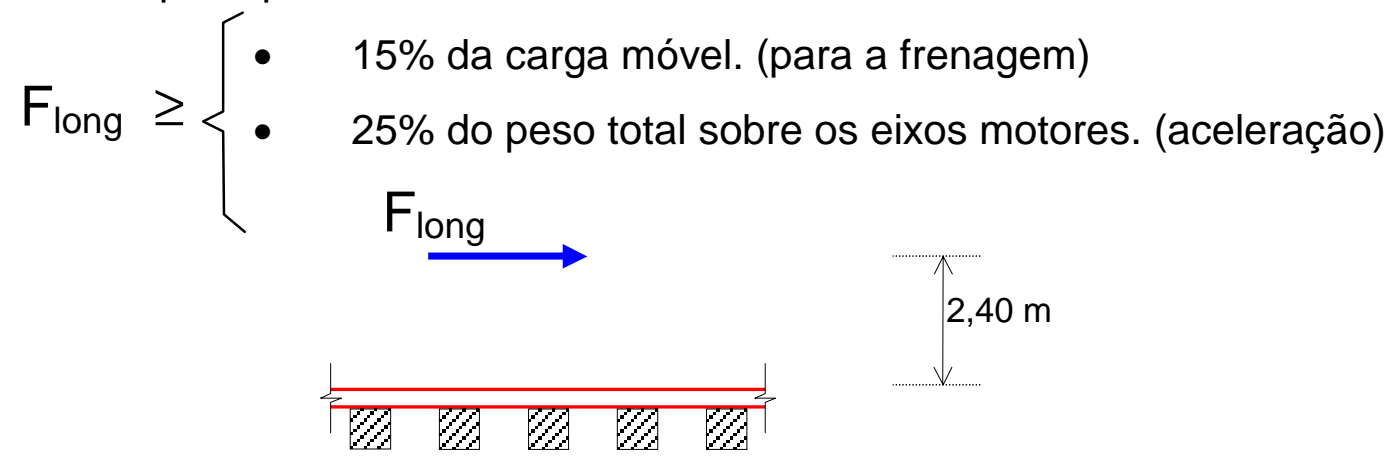

Figura 2.22 - Força Longitudinal em Pontes Ferroviárias. 


\section{5) Força Centrífuga.}

Força de curta duração que acontece em pontes curvas.

- Pontes Rodoviárias.

$F_{\text {cent }}$ aplicada a uma altura de $2,00 \mathrm{~m}$ acima da superfície de rolamento com impacto vertical no peso.

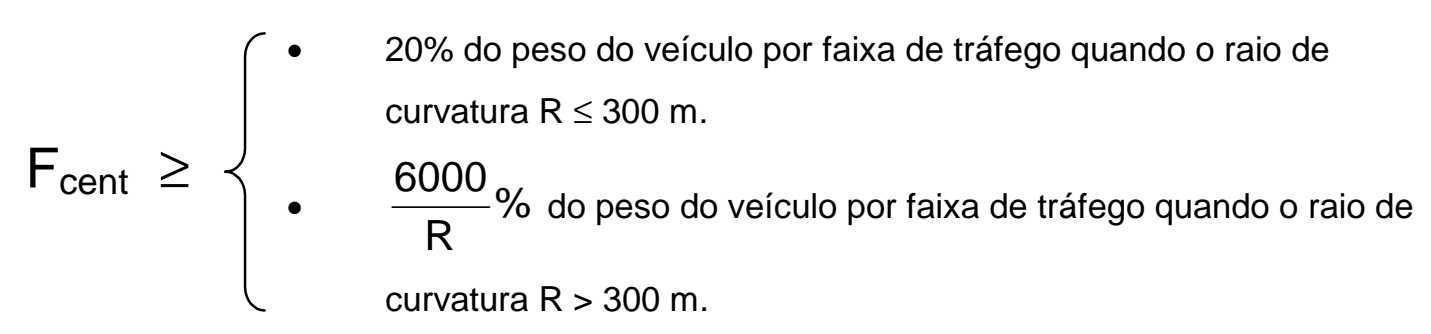

- Pontes Ferroviárias.

$F_{\text {cent }}$ aplicada com impacto vertical no peso, a uma altura de $1.60 \mathrm{~m}$ acima do topo dos trilhos.

$$
F_{\text {cent }} \geq\left\{\begin{array}{r}
\quad \text { Bitola } 1,60 \mathrm{~m}: 12 \% \text { da carga móvel quando } R \leq 1000 \mathrm{~m} . \\
\frac{12000}{\mathrm{R}} \% \text { quando } \mathrm{R}>1000 \mathrm{~m} . \\
\qquad \quad \text { Bitola } 1,00 \mathrm{~m}: 8 \% \text { da carga móvel quando } \mathrm{R} \leq 600 \mathrm{~m} . \\
\frac{4800}{\mathrm{R}} \% \text { quando } \mathrm{R}>600 \mathrm{~m} .
\end{array}\right.
$$

\section{6) Vento.}

A natureza da ação do vento é de curta duração.

A ação do vento nas edificações segue o disposto na NBR-6123.

Pela NBR-7190/97 a ação do vento sobre veículos e pedestres deve ser considerada como segue:

\section{- Passarela de Pedestres}

Com valor característico igual a $1,80 \mathrm{kN} / \mathrm{m}$ (horizontal) aplicado a uma altura de $0,85 \mathrm{~m}$ acima do piso. 
$q_{v}($ NBR-6123)

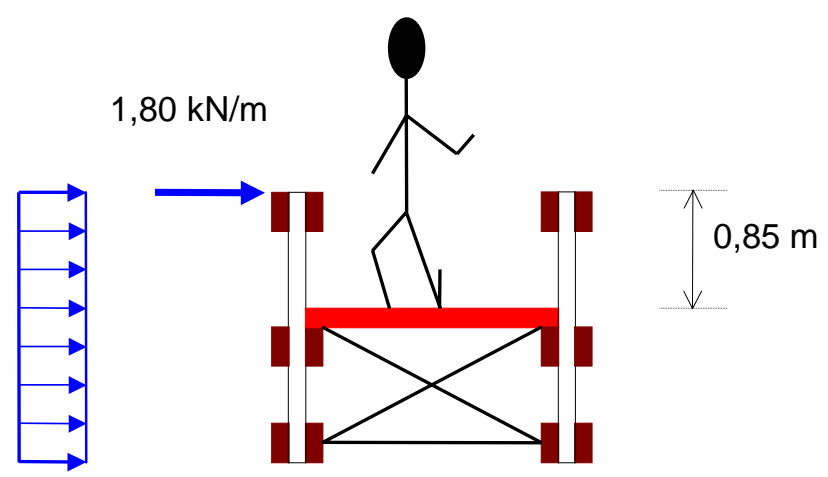

Figura 2.23 - Vento sobre Passarela.

- Pontes Rodoviárias

Com valor característico igual a 2,00 kN/m (horizontal) aplicado a uma altura de $1.20 \mathrm{~m}$ acima da superfície de rolamento.

$q_{v}($ NBR-6123)

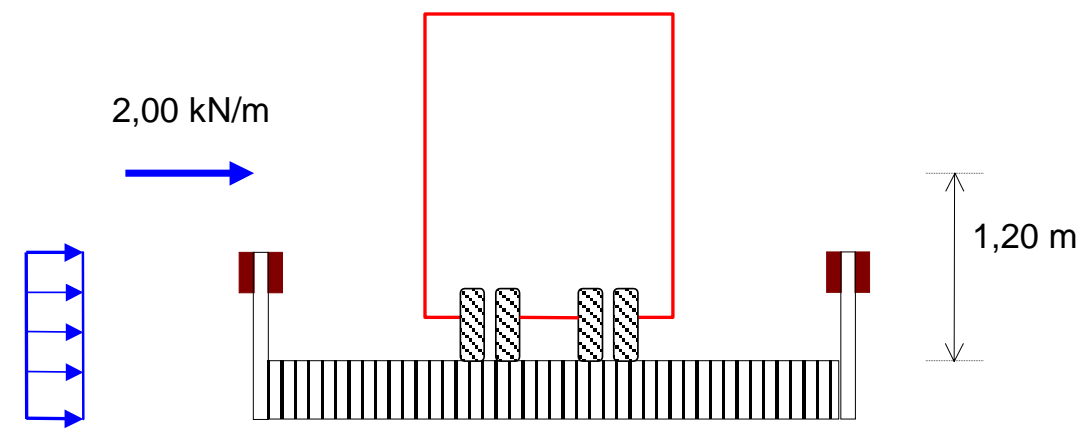

Figura 2.24 - Vento sobre Veículo.

- Pontes Ferroviárias.

Com valor característico igual a 3,00 kN/m (horizontal) aplicado a uma altura acima do topo dos trilhos de 2,40 m para bitola de 1,60m e 2,00 m para bitola métrica $(1,00 \mathrm{~m})$.

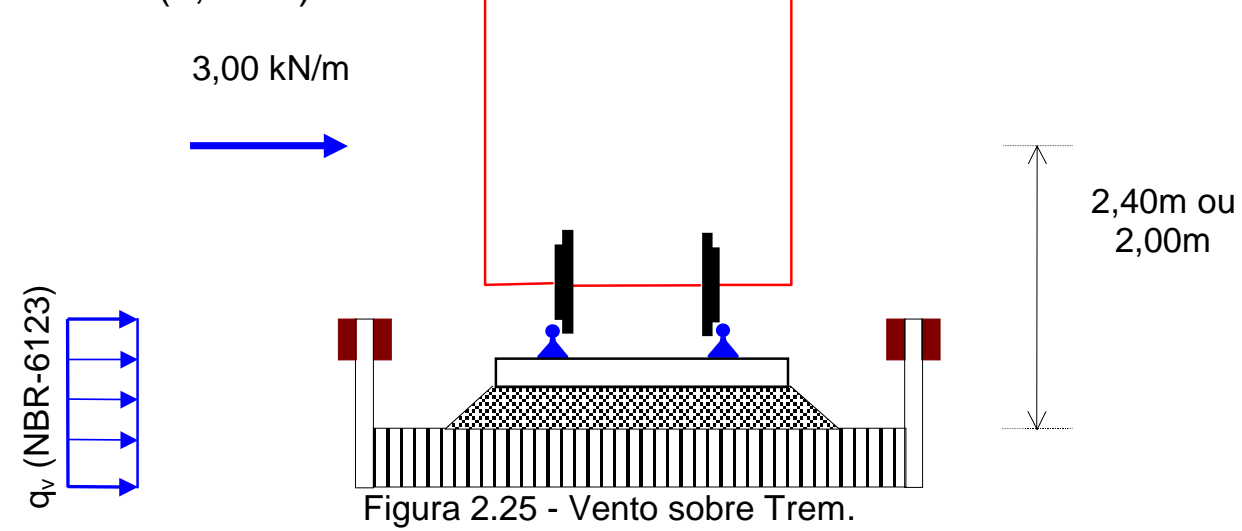


Para os elementos metálicos considerar a totalidade da força do vento.

\section{7) Impacto Lateral.}

Somente nas pontes ferroviárias provocadas pela folga entre rodas e trilhos. O valor da força de impacto lateral deve ser de $20 \%$ da carga do eixo mais pesado.

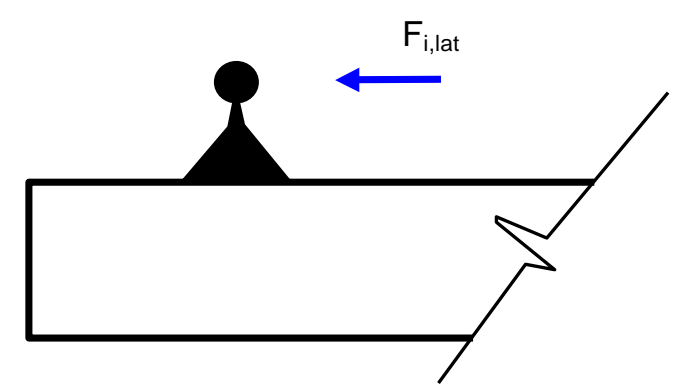

Figura 2.26 - Impacto Lateral.

Em pontes curvas não se deve somar os efeitos do impacto lateral com o da força centrífuga. Deve-se considerar o efeito mais desfavorável.

\section{8) Carga no Guarda-Corpo.}

Aplicada horizontalmente no corrimão.
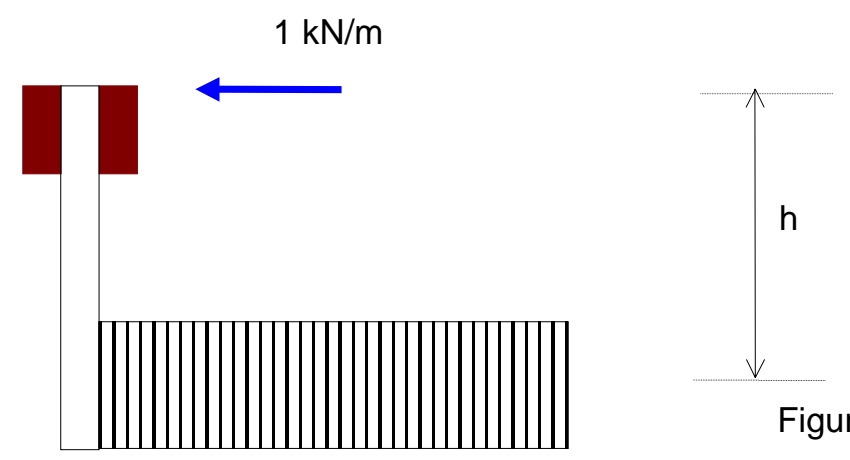

Figura 2.27 - Carga no Guarda-Corpo.

\section{9) Carga no Guarda-Rodas.}

Em pontes rodoviárias são verificadas para uma força aplicada horizontalmente no seu topo de $60 \mathrm{kN}$, sem impacto.

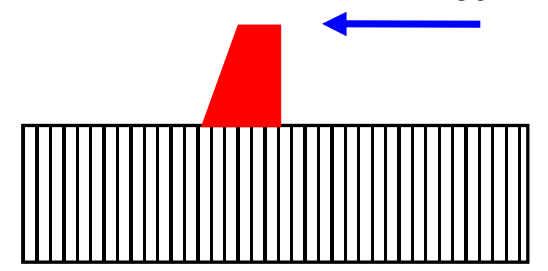

Figura 2.28 - Carga no Guarda-Rodas. 


\subsection{Combinações das Ações em Pontes de Madeira}

Na NBR 7190 (1997) estão definidas as combinações necessárias para verificar os estados limites últimos e os estados limites de utilização.

No caso específico de pontes de madeira as combinações geralmente se restringem às combinações últimas normais para os estados limites últimos e às combinações de longa duração para os estados limites de utilização definidas na NBR 7190 (1997). A simplificação acima reflete a consideração apenas das ações permanentes normais e do trem tipo associado ao seu efeito dinâmico principal que é o impacto, nas combinações mencionadas.

As combinações utilizam fatores de ponderação das ações as quais consideram as probabilidades de ocorrência simultâneas das ações e, ao mesmo tempo, consideram as variações que podem ocorrer nas avaliações do projetista.

Para a avaliação dos estados limites últimos são definidas três combinações possíveis. As combinações últimas normais, as combinações especiais (ou de construção) e as combinações excepcionais. Para a avaliação dos estados limites de utilização, podem ser efetuadas combinações de longa duração, média duração, curta duração ou instantânea, de acordo com a classe do carregamento da ação variável principal.

Nas combinações para os estados limites últimos, os coeficientes $\gamma_{G}$ das ações permanentes (tabelas 2.7 e 2.8) ponderam os valores das ações para os efeitos favoráveis e desfavoráveis. Quando, nas ações permanentes, o peso próprio da estrutura é maior que $75 \%$ da totalidade das ações permanentes, devem ser considerados os valores de ponderação da tabela 2.7 (pequena variabilidade) e quando não, os da tabela 2.8 (grande variabilidade). 
Tabela 2.7 - Ações permanentes de pequena variabilidade

\begin{tabular}{|l|c|c|}
\hline \multirow{2}{*}{ Combinações } & \multicolumn{2}{|c|}{ para efeitos } \\
\cline { 2 - 3 } & desfavoráveis & favoráveis \\
\hline Normais & $\gamma_{\mathrm{g}}=1,3$ & $\gamma_{\mathrm{g}}=1,0$ \\
\hline Especiais ou de Construção & $\gamma_{\mathrm{g}}=1,2$ & $\gamma_{\mathrm{g}}=1,0$ \\
\hline Excepcionais & $\gamma_{\mathrm{g}}=1,1$ & $\gamma_{\mathrm{g}}=1,0$ \\
\hline
\end{tabular}

Fonte NBR 7190/97

Tabela 2.8 - Ações permanentes de grande variabilidade

\begin{tabular}{|l|c|c|}
\hline \multirow{2}{*}{ Combinações } & \multicolumn{2}{|c|}{ para efeitos } \\
\cline { 2 - 3 } & desfavoráveis & favoráveis \\
\hline Normais & $\gamma_{\mathrm{g}}=1,4$ & $\gamma_{\mathrm{g}}=0,9$ \\
\hline Especiais ou de Construção & $\gamma_{\mathrm{g}}=1,3$ & $\gamma_{\mathrm{g}}=0,9$ \\
\hline Excepcionais & $\gamma_{\mathrm{g}}=1,2$ & $\gamma_{\mathrm{g}}=0,9$ \\
\hline
\end{tabular}

Nas combinações para os estados limites últimos, as ações variáveis são ponderadas através dos coeficientes $\gamma_{Q}$ de acordo com a natureza da ação apresentada na tabela $\mathbf{2 . 9}$.

Tabela 2.9 - Ações variáveis

\begin{tabular}{|l|c|c|}
\hline Combinações & $\begin{array}{c}\text { ações variáveis em geral } \\
\text { incluídas as cargas } \\
\text { acidentais móveis }\end{array}$ & $\begin{array}{c}\text { efeitos da } \\
\text { temperatura }\end{array}$ \\
\hline Normais & $\gamma_{\mathrm{Q}}=1,4$ & $\gamma_{\varepsilon}=1,2$ \\
\hline Especiais ou de Construção & $\gamma_{\mathrm{Q}}=1,2$ & $\gamma_{\varepsilon}=1,0$ \\
\hline Excepcionais & $\gamma_{\mathrm{Q}}=1,0$ & $\gamma_{\varepsilon}=0$ \\
\hline
\end{tabular}

Quando houver mais de uma ação variável a ser considerada, deve-se ponderar a probabilidade de ocorrência simultânea das mesmas através dos valores de $\psi_{\mathrm{j}}$ da tabela 2.10 . 
Tabela 2.10 - Fatores de combinação e de utilização - Síntese

\begin{tabular}{|l|c|c|c|}
\hline Ações em estruturas correntes & $\Psi_{0}$ & $\Psi_{1}$ & $\Psi_{2}$ \\
\hline - Variações uniformes de temperatura em relação & & & \\
à média anual local & 0,6 & 0,5 & 0,3 \\
- Pressão dinâmica do vento & 0,5 & 0,2 & 0 \\
\hline Cargas móveis e seus efeitos dinâmicos & $\Psi_{0}$ & $\Psi_{1}$ & $\Psi_{2}$ \\
\hline - Pontes de pedestres & 0,4 & 0,3 & 0,2 \\
- Pontes rodoviárias & 0,6 & 0,4 & 0,2 \\
- Pontes ferroviárias (não especializadas) & 0,8 & 0,6 & 0,4 \\
\hline
\end{tabular}

Fonte NBR 7190/97

\subsubsection{Combinações últimas normais (estado limite último)}

$$
F_{d}=\sum_{i=1}^{m} \gamma_{G i} F_{G i, k}+\gamma_{Q}\left[F_{Q 1, k}+\sum_{j=2}^{n} \psi_{0 j} F_{Q j, k}\right]
$$

onde $F_{G i, k}$ representa o valor característico das ações permanentes, $F_{Q 1, k} 0$ valor característico da ação variável considerada como ação principal para a combinação considerada e $\psi_{0 \mathrm{j}} F_{\mathrm{Qj}, \mathrm{k}}$, os valores reduzidos de combinação das demais ações variáveis, determinados de acordo com a tabela 2.10. Em casos especiais devem ser consideradas duas combinações referentes às ações permanentes: em uma delas, admite-se que as ações permanentes sejam desfavoráveis e na outra que sejam favoráveis à segurança.

\subsubsection{Combinações de longa duração (estados limites de utilização)}

As combinações de longa duração são consideradas no controle usual das deformações das estruturas.

Nestas combinações, todas as ações variáveis atuam com seus valores correspondentes à classe de longa duração. Estas combinações são expressas por:

$$
F_{d, u t i}=\sum_{i=1}^{m} F_{G i, k}+\sum_{j=1}^{n} \psi_{2 j} F_{Q j, k}
$$

onde os coeficientes $\psi_{2 \mathrm{j}}$ estão especificados na tabela 2.10. 


\subsection{Conceitos e Aplicações de Pontes Protendidas de Madeira}

\subsubsection{Introdução}

Neste item, estão apresentados os principais conceitos relacionados ao sistema de tabuleiros protendidos transversalmente de madeira tais como materiais, técnicas, aplicabilidade e viabilidade técnica.

\subsubsection{Sistema}

\section{Madeira}

O sistema de pontes de tabuleiro em madeira laminado longitudinalmente com protensão transversal utiliza peças de madeira de dimensões comerciais disponíveis. A seção transversal destas peças $(b \times h)$ geralmente possuem largura (b) de $5 \mathrm{~cm}$ e a altura (h), função do projeto, é da ordem de $20 \mathrm{~cm}$ a $40 \mathrm{~cm}$. Quanto ao comprimento (I) das peças, é possível encontrar de até $7 \mathrm{~m}$. Quando o vão livre da ponte ultrapassar esta dimensão deve-se utilizar algum sistema de emendas tais como o de juntas de topo (figura 2.29) ou emendas dentadas coladas (finger joints). As peças de madeira são serradas mas não aparelhadas.

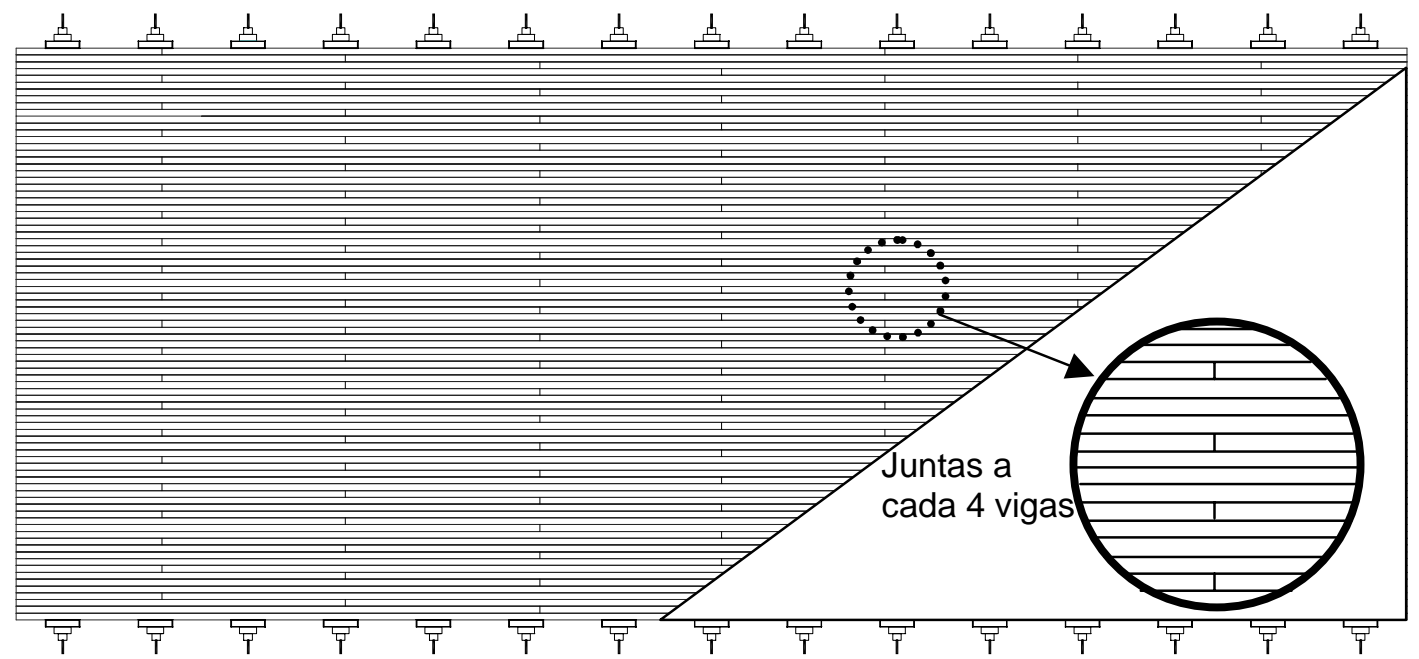

Figura 2.29 - Exemplo de Juntas de Topo adjacentes 


\section{Protensão}

O sistema de protensão geralmente é constituído por barras de aço, de diâmetros de $16 \mathrm{~mm}$ a $32 \mathrm{~mm}$, laminado a quente de alta resistência (ST 85/105 ou ST 105/125) da Dywidag. Atualmente, outros sistemas estão sendo utilizados tais como as cordoalhas de aço ou barras de fibra de carbono. Para o sistema Dywidag, a ancoragem é efetuada pelo conjunto comercial (placa de ancoragem quadrada ou retangular e porca sextavada figura 2.30) e uma placa de distribuição, quadrada ou retangular, de aço comum. A protensão é aplicada através de macacos hidráulicos (figura 2.32), também da Dywidag, com as características na figura 2.31.

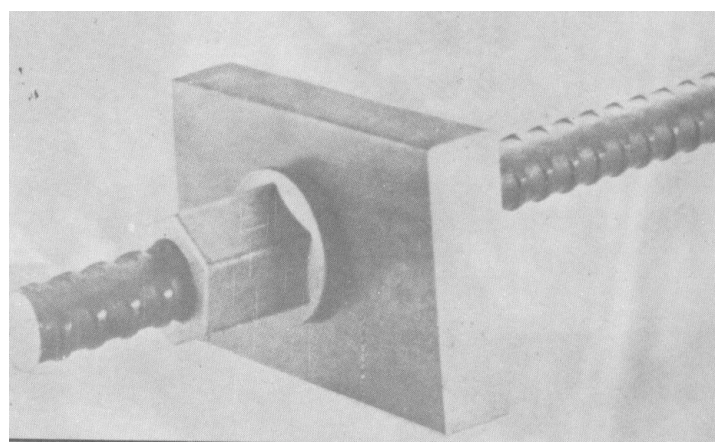

Figura 2.30 - Barra ( $\phi$ de 32mm) e sistema de ancoragem
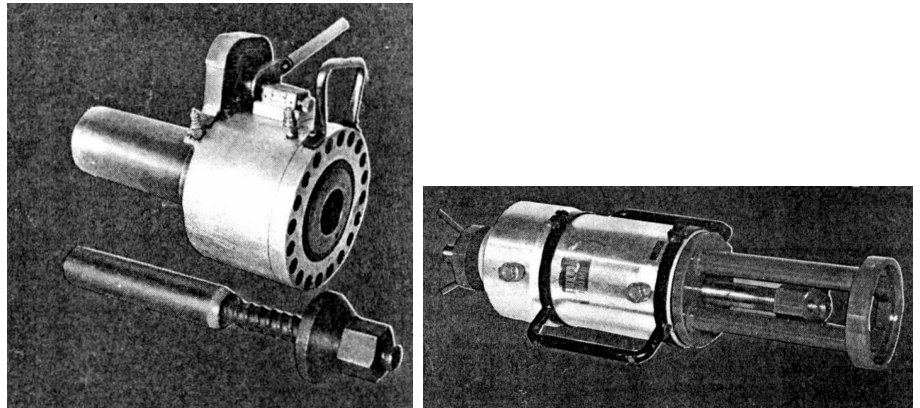

$60 \mathrm{Mp}$ - Série 05

Cap.: $590 \mathrm{kN}$

Curso: $50 \mathrm{~mm}$

Peso: $43,5 \mathrm{~kg}$

$25 \mathrm{Mp}$ - Série 01

Cap.: $245 \mathrm{kN}$

Curso: $100 \mathrm{~mm}$

Peso: $23 \mathrm{~kg}$

Figura 2.31 - Aplicação da Protensão - Cilindros
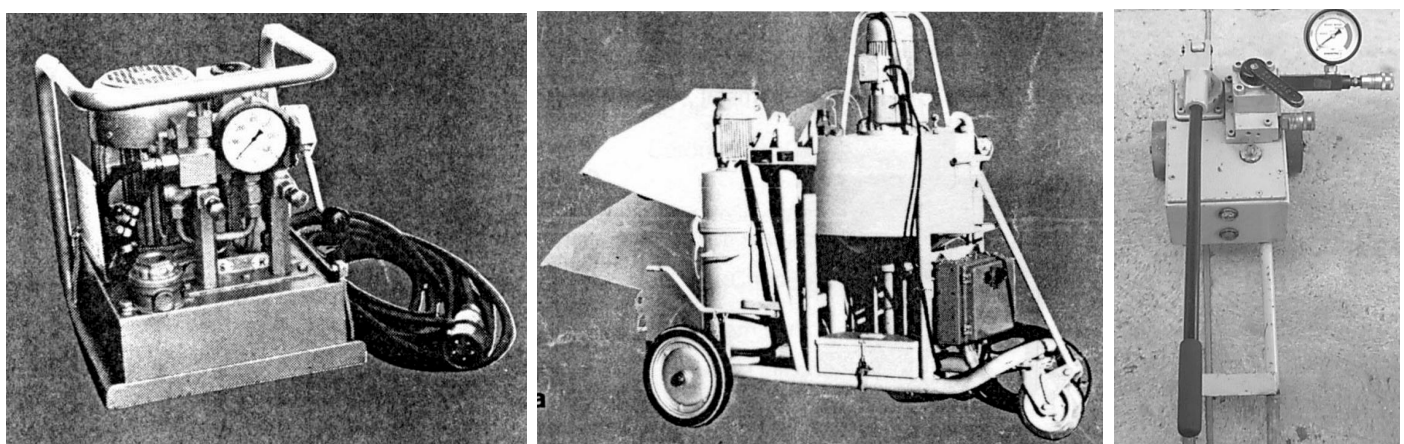

Figura 2.32 - Aplicação da Protensão - Bombas 


\section{Proteção}

Os elementos de proteção da ponte são os guarda-rodas e os guardacorpos detalhados na figura $\mathbf{2 . 3 3}$.

\section{Acessórios}

Outros acessórios utilizados na montagem e nas fixações dos dispositivos de proteção (guarda-rodas e guarda-corpos) e na fixação do tabuleiro na infra-estrutura são anéis, parafusos, porcas, arruelas, manta geotêxtil, etc.
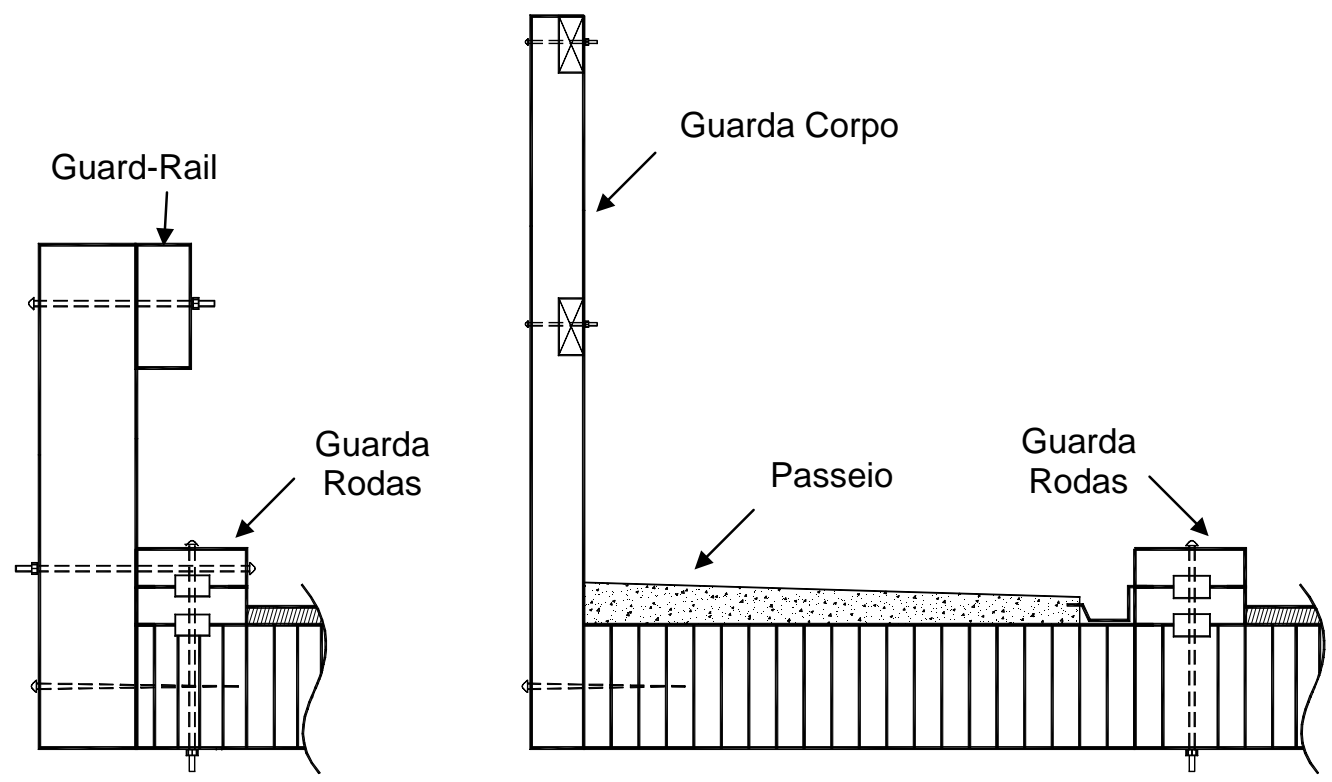

Figura 2.33 - Guarda-corpos e Guarda-rodas

\section{Tratamentos Preservativos}

Madeira: As peças de madeira devem ser tratadas com CCA ou Creosoto.

Protensão: As barras devem ser protegidas com pintura a base epóxi

Acessórios: Todos os parafusos, anéis, devem ser galvanizados. Pode-se utilizar da aplicação de pasta hidrorepelente na furação do tabuleiro e capas protetoras de PVC para garantirem durabilidade maior das barras e da ancoragem, respectivamente.

\section{Acabamentos}

Não há acabamentos especiais utilizados no sistema com tabuleiro laminado protendido. Para homegenização da pista de rolamento (e 
proteção) pode-se utilizar uma capa de concreto asfáltico ou concreto de cimento portland. Pode-se utilizar mantas de material geotêxtil para um melhor escoamento das águas pluviais.

\section{Infra-estrutura}

A infra-estrutura pode ser constituída por berços de concreto armado sobre estacas de concreto, aço ou madeira, gabiões, estacas e berço de madeira.

\subsubsection{Viabilidade do Sistema}

\section{Geometria:}

Pontes construídas com o sistema de tabuleiro laminado protendido transversalmente permitem vencer vãos de até $10 \mathrm{~m}$ com peças de seção transversal de até $40 \mathrm{~cm}$ de altura viabilizando uma elevada porcentagem das pontes correntemente construídas no país.

\section{Classes de Pontes:}

Para os vãos, definidos no item anterior, a serem cobertos pelo sistema pode-se construir pontes de qualquer classe definida pela NBR $7188 \mathrm{com}$ seus veículos e faixas sendo que a viabilidade econômica do sistema fica mais evidenciada para as classes 12 e 30 .

\section{Sistema:}

Para vãos maiores que $6 \mathrm{~m}$ pode se tornar inviável, pela disponibilidade e/ou pelo custo, a utilização de peças estruturais únicas ao longo de todo o comprimento. Este problema pode ser contornado pela utilização de juntas de topo. Obviamente a presença e a freqüência destas juntas faz com que o tabuleiro perca rigidez longitudinal e transversal, mas minora consideravelmente o custo com a madeira. Havendo a presença de juntas de topo, pode-se aplicar ao tabuleiro contra-flecha, minimizando os problemas de deformabilidade do sistema. O sistema possui, também, baixo consumo de madeira com volume total em torno de $0,35 \mathrm{~m}^{3}$ de madeira por $\mathrm{m}^{2}$ de ponte construída. Os sistemas de protensão geralmente são sistemas 
comerciais, difundidos no meio técnico, sendo que o custo não é tão elevado quanto seria o de sistemas especiais para este fim. Portanto, o sistema de tabuleiros laminados protendidos possui baixo custo por metro quadrado construído de ponte.

Para contornar as limitações do sistema com madeira maciça serrada podese utilizar de variações pelo uso de peças laminadas coladas, seções $T$ ou caixão (celular) como mostram, respectivamente, as figuras 2.34, 2.35 e 2.36 .

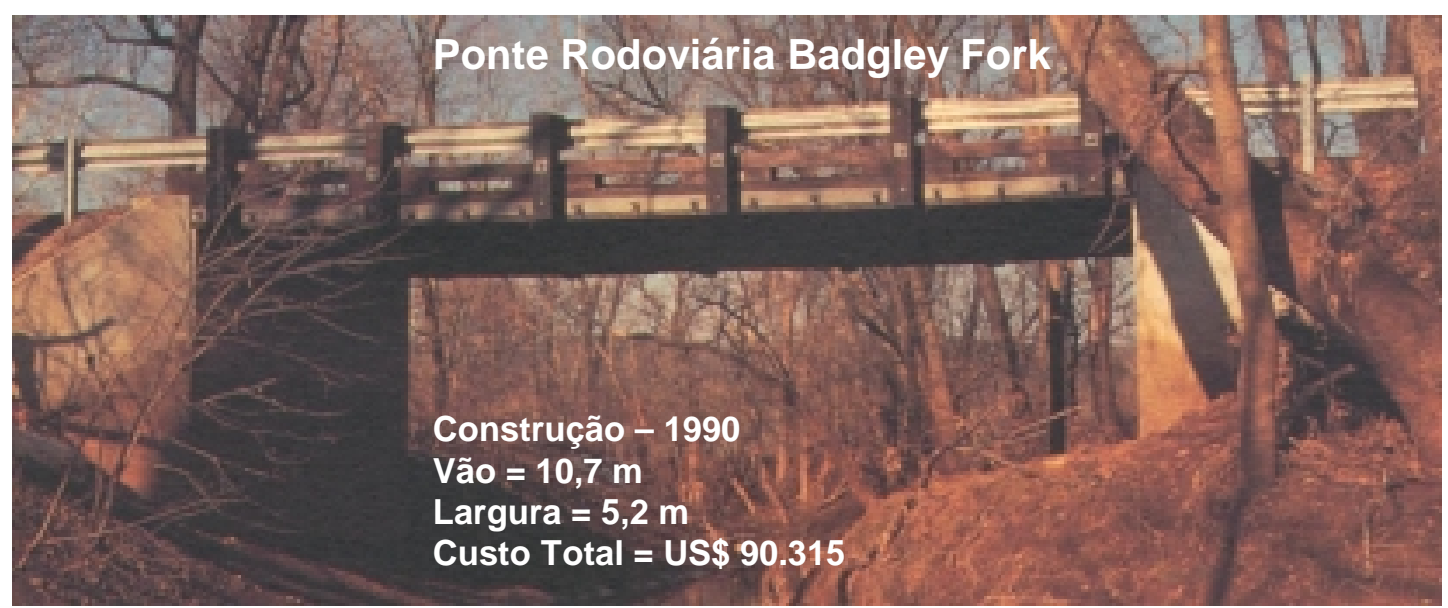

Figura 2.34 - Ponte Protendida Badgley Fork

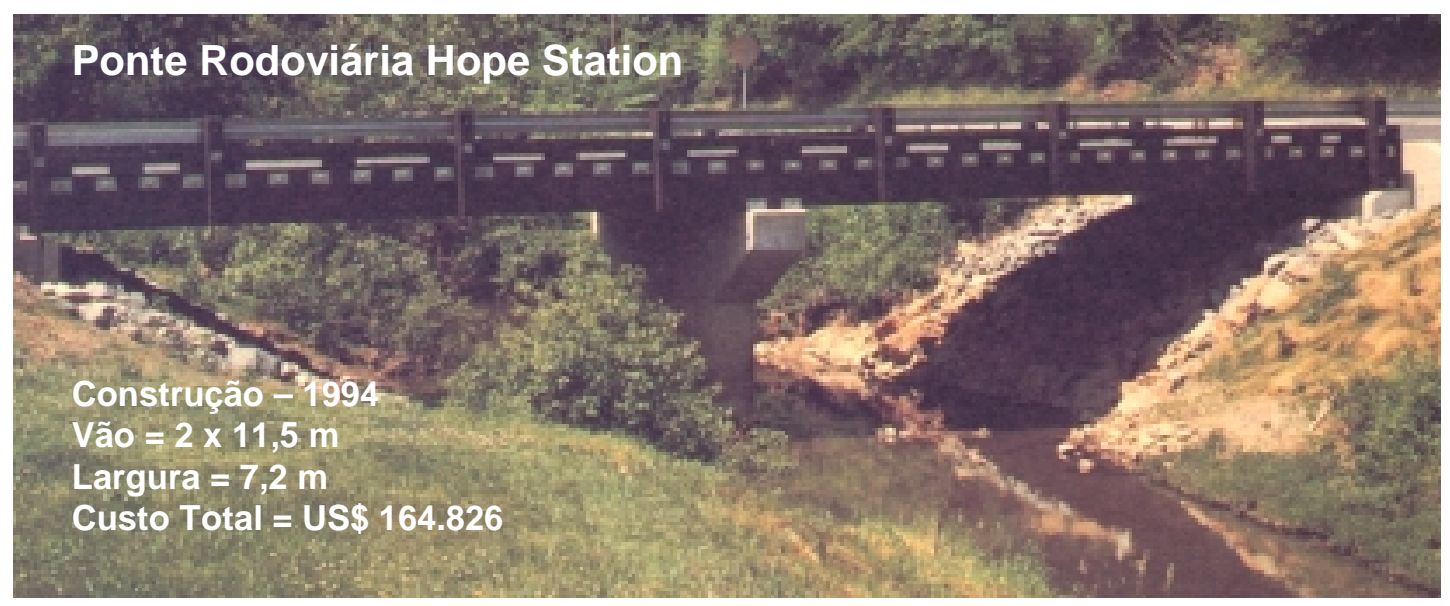

Figura 2.35 - Ponte Protendida Hope Station 


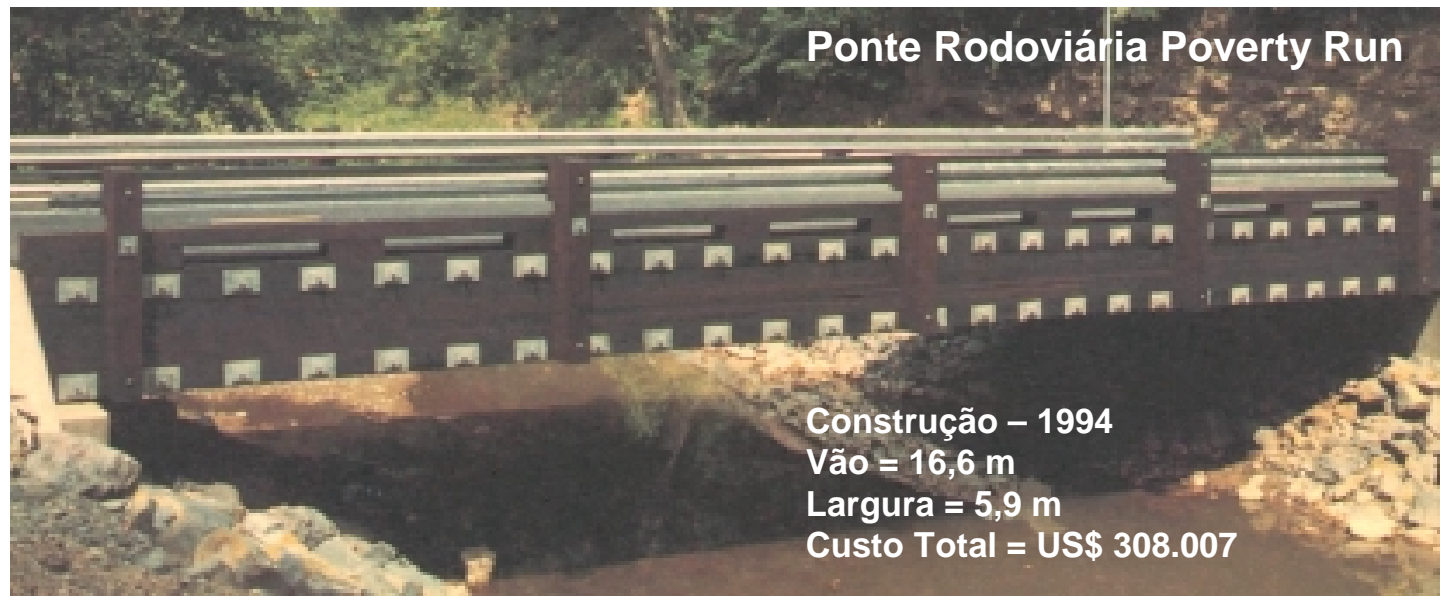

Figura 2.36 - Ponte Protendida Poverty Run

Normalização:

A nova NBR 7190/97 implementou ao meio técnico novos conceitos de projeto de estruturas em madeira. $\mathrm{O}$ seu texto complementa as disposições e procedimentos da NBR 7188/84. Neste contexto, vê-se que as pontes a serem construídas estarão dentro dos novos conceitos normativos de ações e resistência e rigidez dos materiais.

\section{Viabilidade Técnica:}

Baseados na produção acadêmica e nas várias obras construídas e analisadas verificam-se o elevado desempenho estrutural, a aplicabilidade nas suas variações, durabilidade elevada quando utilizado tratamento e dispositivos preservativos, as facilidades de fabricação (e também préfabricação) e montagem tanto in loco quanto na fábrica com baixo custo tecnológico.

\section{Viabilidade Econômica:}

O baixo consumo de madeira e o baixo custo do sistema de protensão associados a viabilidade técnica facilita a garantia de prazo de entrega da estrutura e possibilita um custo final competitivo com outros materiais e tecnologias existentes minimizando, inclusive, os custos de infraestrutura. 


\subsection{Estudo de Pontes Protendidas de Madeira no Brasil}

Até o momento ainda não existem pontes de madeira protendidas construídas no Brasil. O primeiro estudo foi o realizado por PRATA (1995) onde foi executada uma revisão bibliográfica geral sobre o tema pontes protendidas. PRATA analisou os parâmetros elásticos para a madeira de Eucalipto Citriodora submetida a um nível de protensão de $1410 \mathrm{kN} / \mathrm{m}^{2}$ obtendo as relações elásticas $E_{T}=0,03 E_{L}$ e $G_{L T}=0,044 E_{L}$; executou, também, uma análise preliminar da perda de protensão em peças quadradas de $22 \mathrm{~cm}$ de lado por $5 \mathrm{~cm}$ de espessura obtendo o gráfico da figura 2.37.

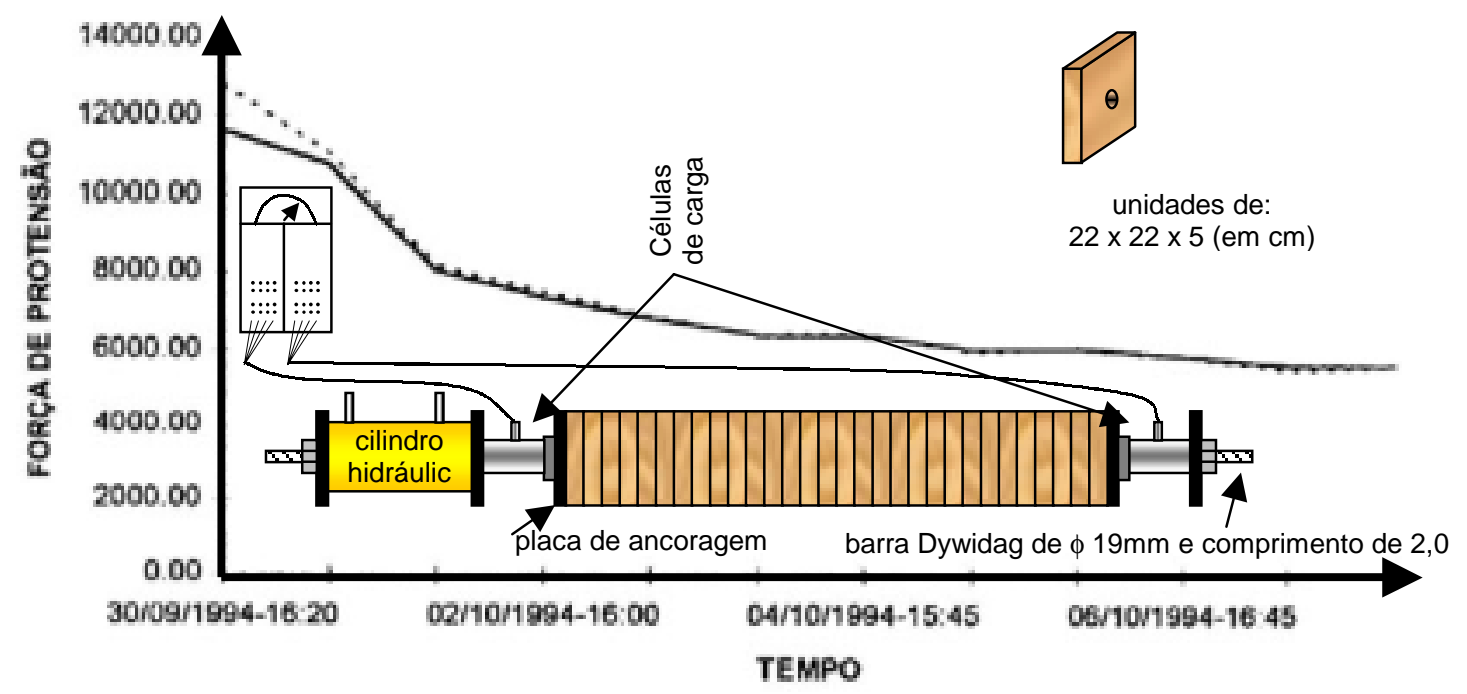

FIGURA 2.37 - Perda de Protensão: Resultados Experimentais PRATA (1995)

Em recente trabalho desenvolvido no LaMEM - SET - EESC - USP OKIMOTO (1997) verificou a aplicabilidade do sistema protendido transversalmente para as madeiras de reflorestamento eucaliptos e pinus, desenvolvendo diretrizes que orientam o projeto e dimensionamento destas estruturas. Os conceitos envolvidos nesse critério se baseiam nas diretrizes das normas nacionais NBR6120 (1980), NBR7188 (1984) e NBR7190 (1997), ou seja, nova abordagem para projetos em madeira com uma visão semi-probabilística das ações e resistência e o enquadramento do material em classes de resistência (tabelas 2.11 e 2.12). OKIMOTO (1997) estudou 
as propriedades do material aplicado ao sistema protendido para duas classes de resistências: C25 (Coníferas) e C40 (Dicotiledôneas) representadas, respectivamente, pela madeiras de Pinus Elliottii e Eucalipto Citriodora, para 5 níveis de protensão diferentes obtendo as relações elásticas das tabelas 2.13 e 2.14 (OKIMOTO \& CALIL - 1997b).

Tabela 2.11 - Classes de Resistência para Coníferas

Coníferas

(Valores na condição padrão de referência $U=12 \%$

\begin{tabular}{llllll} 
Classe & $f_{\mathrm{co}, \mathrm{k}}$ & $\mathrm{f}_{\mathrm{v}, \mathrm{k}}$ & $\mathrm{E}_{\mathrm{co}, \mathrm{m}}$ & $\begin{array}{l}\rho_{\mathrm{bas}, \mathrm{m}} \\
\left(\mathrm{Mg} / \mathrm{m}^{3}\right)\end{array}$ & $\begin{array}{l}\rho_{\text {apar }} \\
\left(\mathrm{kg} / \mathrm{m}^{3}\right)\end{array}$ \\
\hline C 20 & 20 & 4 & 3500 & 400 & 500 \\
C 25 & 25 & 5 & 8500 & 450 & 550 \\
C 30 & 30 & 6 & 14500 & 500 & 600 \\
\hline
\end{tabular}

Fonte: NBR 7190/97

Tabela 2.12 - Classes de Resistência para Dicotiledôneas

\section{Dicotiledôneas}

(Valores na condição padrão de referência $U=12 \%$

\begin{tabular}{llllll} 
Classe & $\mathrm{f}_{\mathrm{co}, \mathrm{k}}$ & $\mathrm{f}_{\mathrm{v}, \mathrm{k}}$ & $\begin{array}{l}\mathrm{E}_{\mathrm{co}, \mathrm{m}} \\
(\mathrm{MPa})\end{array}$ & $\begin{array}{l}\rho_{\mathrm{bas}, \mathrm{m}} \\
\left(\mathrm{kg} / \mathrm{m}^{3}\right)\end{array}$ & $\begin{array}{l}\rho_{\mathrm{apar}} \\
\left(\mathrm{kg} / \mathrm{m}^{3}\right)\end{array}$ \\
\hline C 20 & 20 & 4 & 9500 & 500 & 650 \\
C 30 & 30 & 5 & 14500 & 650 & 800 \\
C 40 & 40 & 6 & 19500 & 750 & 950 \\
C 60 & 60 & 8 & 24500 & 800 & 1000 \\
\hline
\end{tabular}

Fonte: NBR 7190/97

Diante destes resultados OKIMOTO (1997) propôs o nível de protensão de $700 \mathrm{kN} / \mathrm{m}^{2}$ como sendo o nível de projeto. Neste mesmo trabalho também foram estudados os efeitos da presença e da freqüência de juntas de topo (mecanismo que viabiliza a utilização de peças menores apesar de diminuir a rigidez longitudinal do tabuleiro). Esses resultados são apresentados na tabela 2.15. 
Tabela 2.13 - Resultados da Madeira de Pinus Elliottii (Coníferas C 25)

\begin{tabular}{|c|c|c|c|c|c|c|c|c|c|}
\hline \multicolumn{10}{|c|}{ Pinus Elliottii } \\
\hline \multirow{2}{*}{$\begin{array}{l}\text { Nível } \\
\text { Prot. }\end{array}$} & \multirow{2}{*}{$\begin{array}{l}0^{\circ} \\
P / w\end{array}$} & \multirow{2}{*}{$\begin{array}{l}+45^{\circ} \\
P / w\end{array}$} & \multirow{2}{*}{$\begin{array}{l}-45^{\circ} \\
P / w\end{array}$} & \multirow{2}{*}{$\begin{array}{l}\mathrm{G}_{\mathrm{LT}} \\
\mathrm{daN} / \mathrm{cm}^{2}\end{array}$} & \multirow{2}{*}{$\begin{array}{l}\mathrm{E}_{\mathrm{T}} \\
\mathrm{daN} / \mathrm{cm}^{2}\end{array}$} & \multirow[t]{2}{*}{$\mathrm{G}_{\mathrm{LT}} / \mathrm{E}_{\mathrm{L}}$} & \multirow[t]{2}{*}{$\mathrm{G}_{\mathrm{LT}} / \mathrm{E}_{\mathrm{L}}$} & \multirow[t]{2}{*}{$\mathrm{E}_{\mathrm{T}} / \mathrm{E}_{\mathrm{L}}$} & \multirow[t]{2}{*}{$\mathrm{E}_{\mathrm{T}} / \mathrm{E}_{\mathrm{L}}$} \\
\hline & & & & & & & & & \\
\hline 300 & 1845,96 & 658,44 & 13679,49 & 1177,6 & 944,0 & 0,0151 & 0,0161 & 0,0137 & 0,0137 \\
\hline 400 & & & & & & & 0,0174 & & 0,0158 \\
\hline 500 & 2436,60 & 848,19 & 12154,83 & 1554,4 & 1239,0 & 0,0200 & 0,0188 & 0,0180 & 0,0180 \\
\hline 600 & & & & & & & 0,0201 & & 0,0202 \\
\hline 700 & 2654,72 & 1049,04 & 11789,42 & 1693,6 & 1557,3 & 0,0218 & 0,0214 & 0,0226 & 0,0223 \\
\hline 800 & 2784,09 & 1102,27 & 11821,83 & 1776,1 & 1642,0 & 0,0228 & 0,0227 & 0,0238 & 0,0245 \\
\hline 900 & 2830,28 & 1237,36 & 11601,94 & 1805,6 & 1864,7 & 0,0232 & 0,0240 & 0,0270 & 0,0266 \\
\hline $\mathrm{L}=$ & 110 & 113 & & $\mathrm{~cm}$ & & & & & \\
\hline & 24,23 & 24,03 & & $\mathrm{~cm}$ & $\mathbf{G}_{\mathrm{LT}} / \mathbf{E}_{\mathrm{L}=}$ & 0,00216 & $\sigma_{N}$ & 0,00715 & \\
\hline $\mathrm{E}_{\mathrm{L}}=$ & 77734,1 & 68964,4 & & $\mathrm{daN} / \mathrm{cm}^{2}$ & $E_{T} / E_{L=}$ & 0,00132 & $\sigma_{N}+$ & 0,01218 & \\
\hline
\end{tabular}

Tabela 2.14 - Resultados da Madeira de Eucalipto Citriodora (Dicotiledôneas C 40)

\begin{tabular}{|c|c|c|c|c|c|c|c|c|c|}
\hline \multicolumn{10}{|c|}{ Eucalipto Citriodora } \\
\hline \multirow{2}{*}{$\begin{array}{l}\text { Nível } \\
\text { Prot. }\end{array}$} & \multirow{2}{*}{$\begin{array}{l}0^{\circ} \\
P / w\end{array}$} & \multirow{2}{*}{$\begin{array}{l}+45^{\circ} \\
\mathrm{P} / \mathrm{w}\end{array}$} & \multirow{2}{*}{$\begin{array}{l}-45^{\circ} \\
P / w\end{array}$} & \multirow{2}{*}{\multicolumn{2}{|c|}{$\begin{array}{l}\text { Gxy Ey } \\
\mathrm{kgf} / \mathrm{cm}^{2} \mathrm{kgf} / \mathrm{cm}^{2}\end{array}$}} & \multirow[t]{2}{*}{ Gxy/Ex } & \multirow[t]{2}{*}{ Ey/Ex } & \multirow[t]{2}{*}{ Gxy/Ex } & \multirow[t]{2}{*}{ Ey/Ex } \\
\hline & & & & & & & & & \\
\hline 300 & & & & & & & & 0,0115 & 0,0076 \\
\hline 400 & & & & & & & & 0,0119 & 0,0105 \\
\hline 500 & 3208,61 & 1662,14 & 18775,13 & 1801,6 & 1966,5 & 0,0121 & 0,0134 & 0,0123 & 0,0134 \\
\hline 600 & & & & & & & & 0,0126 & 0,0163 \\
\hline 700 & 3527,79 & 2268,14 & 18879,74 & 1980,8 & 2764,5 & 0,0133 & 0,0189 & 0,0130 & 0,0191 \\
\hline 800 & 3627,65 & 2627,08 & 18881,42 & 2036,9 & 3261,3 & 0,0137 & 0,0223 & 0,0134 & 0,0220 \\
\hline 900 & 3579,18 & 2835,41 & 16906,33 & 2009,7 & 3631,4 & 0,0135 & 0,0248 & 0,0138 & 0,0249 \\
\hline & 110 & 106 & & $\mathrm{~cm}$ & & & & & \\
\hline & 25,3 & 24,9 & & $\mathrm{~cm}$ & $\mathbf{G}_{\mathrm{LT}} / \mathbf{E}_{\mathrm{L}}$ & 0,0003 & $\sigma_{N}+$ & 0,01036 & \\
\hline $\mathrm{E}_{\mathrm{L}}=$ & 149207,2 & 146321,9 & & $\mathrm{kgf} / \mathrm{cm}^{2}$ & $E_{T} / E_{L}$ & 0,002 & $\sigma_{N}+$ & $-0,00101$ & \\
\hline
\end{tabular}


Tabela 2.15 - Fator de Redução de Rigidez - Comparativo com valores da literatura

\begin{tabular}{lcccccc}
\hline $\begin{array}{l}\text { Freqüência } \\
\text { de Juntas }\end{array}$ & \multicolumn{2}{l}{$\begin{array}{l}\text { Fator } \mathrm{C}_{\mathrm{bj}} \\
\text { Ritter }\end{array}$} & $\begin{array}{c}\text { Davalos } \\
(1992)\end{array}$ & $\begin{array}{c}\text { Resultados experimentais } \\
\text { obtidos }\end{array}$ & \multicolumn{2}{c}{$\begin{array}{c}\text { Resultados } \\
\text { ajustados por curvas }\end{array}$} \\
& $-1992)$ & $300 \mathrm{kN} / \mathrm{m}^{2}$ & $700 \mathrm{kN} / \mathrm{m}^{2}$ & $300 \mathrm{kN} / \mathrm{m}^{2}$ & $700 \mathrm{kN} / \mathrm{m}^{2}$ \\
\hline cada 2 & - & 0,66 & 0,71 & 0,66 & 0,71 \\
cada 4 & 0,80 & 0,85 & 0,84 & 0,86 & 0,84 & 0,88 \\
cada 5 & 0,85 & 0,90 & & & 0,88 & 0,91 \\
cada 6 & 0,88 & 0,93 & & & 0,91 & 0,94 \\
cada 7 & 0,90 & 0,96 & & & 0,93 & 0,95 \\
cada 8 & 0,93 & 0,98 & 0,99 & 0,99 & 0,95 & 0,97 \\
cada 9 & 0,93 & 0,99 & & & 0,96 & 0,98 \\
cada 10 & 0,94 & 1,00 & & & 0,97 & 0,99 \\
sem juntas & 1,00 & 1,00 & 1,00 & 1,00 & 1,00 & 1,00 \\
\hline
\end{tabular}

Finalmente, OKIMOTO (1997) propôs a utilização de um critério de dimensionamento com as seguintes diretrizes:

1) Definir a geometria e a classe da ponte

2) Definir a classe de resistência da madeira

3) Definir o lay-out do tabuleiro

4) Calcular a largura de distribuição da carga $D_{w}$

5) Estimar a altura do tabuleiro e calcular as propriedades efetivas da seção transversal

6) Calcular as ações permanentes e as solicitações na viga de seção $D_{W} x h$

7) Calcular as ações variáveis e as solicitações na viga de seção $D_{w} x h$

8) Verificar os estados limites últimos para combinações dos efeitos verticais

9) Calcular o deslocamento para as ações permanentes e impor uma contra-flecha, se possível

10) Calcular o deslocamento para as ações variáveis

11) Verificar os estados limites de utilização (deslocamentos)

12) Determinar o espaçamento das barras de protensão e a força necessária nos elementos

13) Projetar o sistema de ancoragem

14) Projetar a configuração dos apoios

15) Detalhar o projeto 
OKIMOTO (1997) obteve em seus estudos o entendimento das diretrizes 3 e 4 ("juntas de topo" e "parâmetros elásticos", respectivamente) mas verificou as necessidades de avaliação da perda de protensão com o tempo dos tabuleiros, do estudo da deformação lenta da madeira e da análise experimental em protótipos para a avaliação dos efeitos dinâmicos de carregamento, dos mecanismos de transferência das ações e do comportamento global da estrutura em serviço.

VELOSO (1999) estudou o comportamento das placas de madeira protendida onde procurou obter as propriedades elásticas de tabuleiros protendidos de madeira com ensaios de torção pura (figura 2.38) e flexão (figura 2.39). Foi avaliada a madeira de Jatobá.

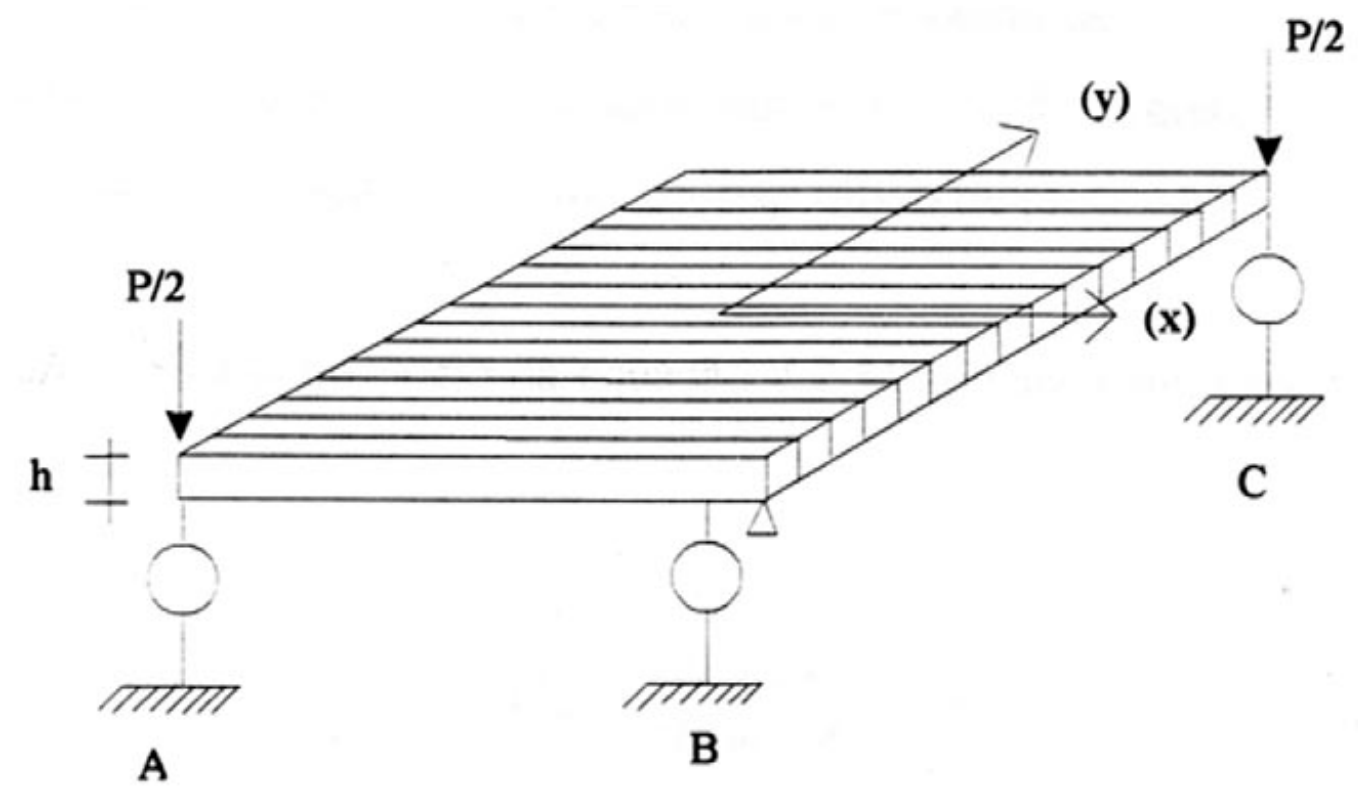

FIGURA 2.38 - Propriedade Elásticas das placa - Torção Pura- VELOSO (1998)
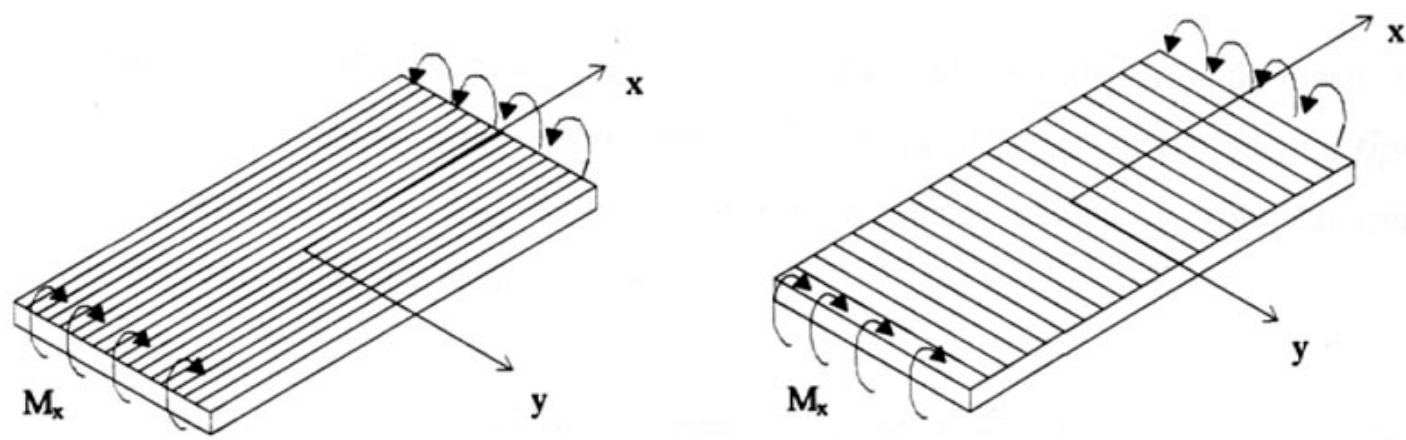

FIGURA 2.39 - Propriedade Elásticas das placa - Flexão Pura - VELOSO (1998) 


\subsection{Perda de Protensão}

Desde as primeiras aplicações da tecnologia de tabuleiros de madeira laminada protendida já se percebeu a importância de se avaliar as perdas de protensão ao longo do tempo.

O primeiro ponto a ser observado é que a perda de protensão deste sistema construtivo com o tempo pode ser compensada no momento da construção, montagem e aplicação da protensão no tabuleiro. Segundo TAYLOR \& CSAGOLY (1979) apud RITTER (1992) o comportamento do nível de protensão e o sistema de reprotensões adotados estão representados na figura $\mathbf{2 . 4 0}$ onde verifica-se que se o tabuleiro é protendido apenas na sua construção, a perda de protensão durante a vida útil será maior que $80 \%$, mas, se houver mais duas reprotensões (aos 3 dias e 8 semanas) a perda final não ultrapassaria $60 \%$ (já considerado uma pequena margem de segurança). Neste sentido, sugerem como protensão inicial um valor 2,5 vezes o valor de projeto e, no mínimo 2 reprotensões ao nível inicialmente aplicado, nos períodos de 2 dias e 8 semanas após a montagem.

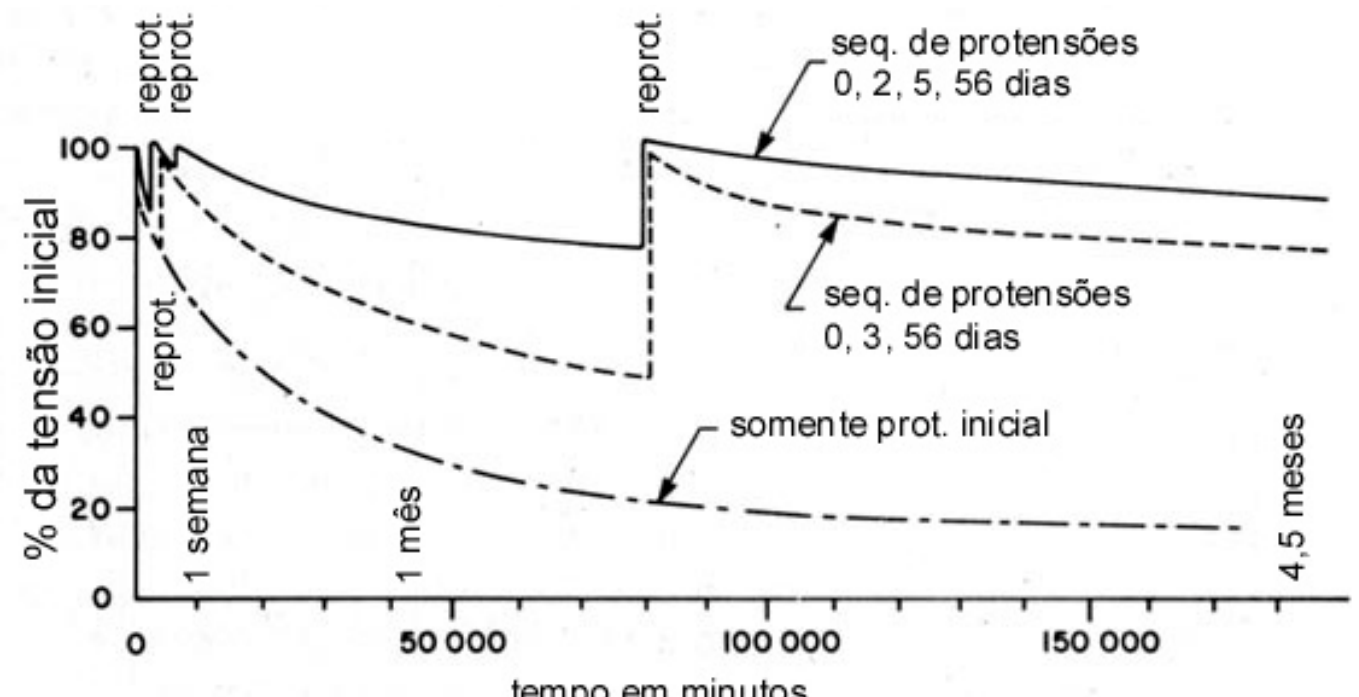

Figura 2.40 - Perda de Protensão e sistemas de Reprotensão TAYLOR \& CSAGOLY (1979) apud RITTER (1992)

Assim, a protensão a ser verificada é a inicial $\left(\sigma_{\mathrm{Ni}}\right)$ para duas condições básicas: 
1. Garantir a resistência a compressão normal da madeira do tabuleiro quando solicitada pela tensão de protensão:

$$
\sigma_{\mathrm{Ni}} \leq \mathrm{f}_{\mathrm{c} 90, \mathrm{~d}}
$$

2. Manter as tensões na barra de aço de alta resistência em níveis inferiores ao limite de escoamento:

$$
\sigma_{s} \leq \frac{f_{y}}{1,1}
$$

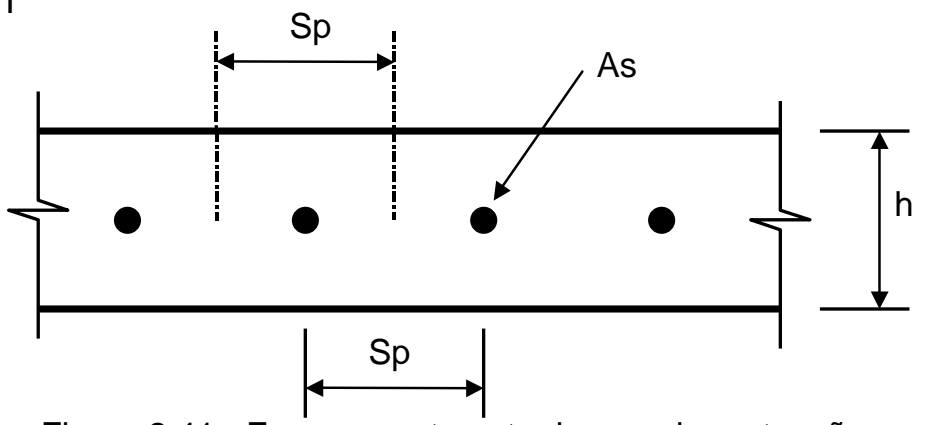

Figura 2.41 - Espaçamento entre barras de protensão

Portanto: $\mathrm{Sp}=\frac{\sigma_{\mathrm{s}} \cdot \mathrm{A}_{\mathrm{s}}}{\sigma_{\mathrm{Ni}} \cdot \mathrm{h}}$

OLIVA et al (1990) esperavam perdas de $50 \%$ da tensão inicial porque o OHBDC (Código canadense -1983) recomendava reprotender o tabuleiro por mais três vezes dentro das primeiras cinco semanas e dizia que ainda assim as perdas esperadas giravam em torno deste valor. Os autores afirmavam que estas perdas eram causadas, fundamentalmente, pela deformação lenta da madeira e relaxação das barras de aço. Realizaram ensaios com duração de 200 horas em conjuntos similares às proporções da ponte Herbert Creek (primeira ponte laminada protendida - 1976) e verificaram perdas de $60 \%$ para teores de umidade variáveis.

RITTER et al (1990) apresentam uma avaliação de performance de vários tabuleiros propendidos realizadas sob um programa norte americano de monitoramento. O programa foi administrado pelo Laboratório de Produtos Florestais - FPL pertencente ao Departamento Americano de Agricultura 
USDA. Em uma análise da perda de carga em barras de aço de uma das 23 pontes monitoradas é mostrado o gráfico da figura 2.42 que indica perdas maiores que $80 \%$.

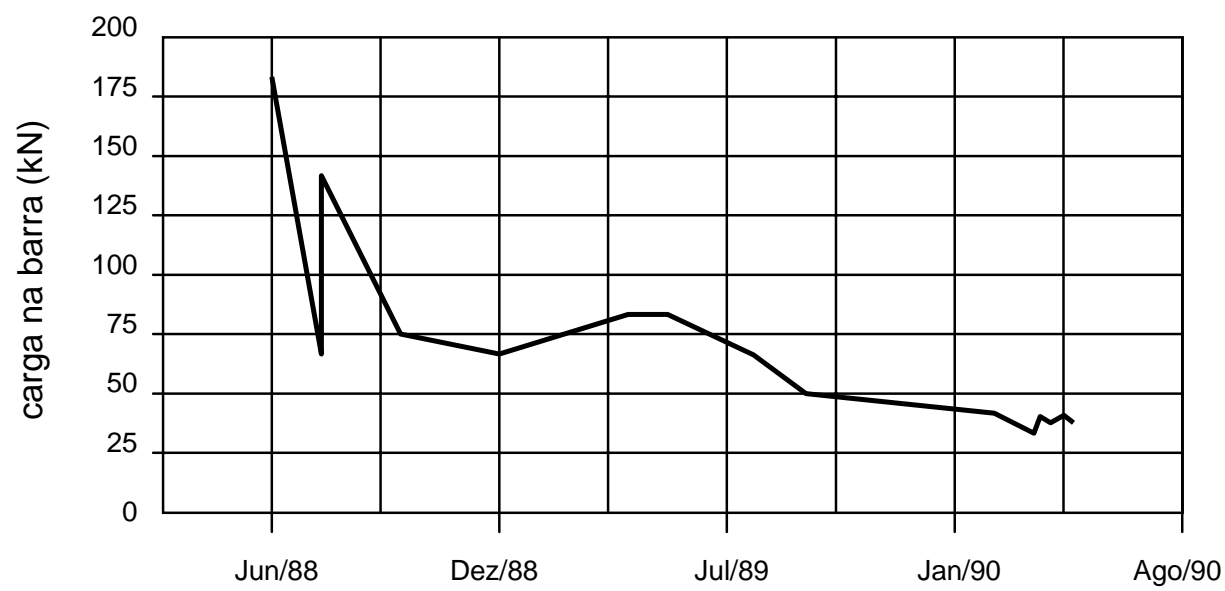

Figura 2.42 - Perda de Carga - RITTER et al (1990)

OLIVA et al (1990) citam ensaios realizados em tabuleiros de madeira apresentados por OLIVA \& DIMAKIS (1986) onde os níveis de protensão avaliados foram de 900 a $960 \mathrm{kPa}\left(\mathrm{kN} / \mathrm{m}^{2}\right)$. Os ensaios tiveram duração de 210 horas e houveram perdas superiores a $80 \%$ no período. Os gráficos são apresentados na figura $\mathbf{2 . 4 3}$.
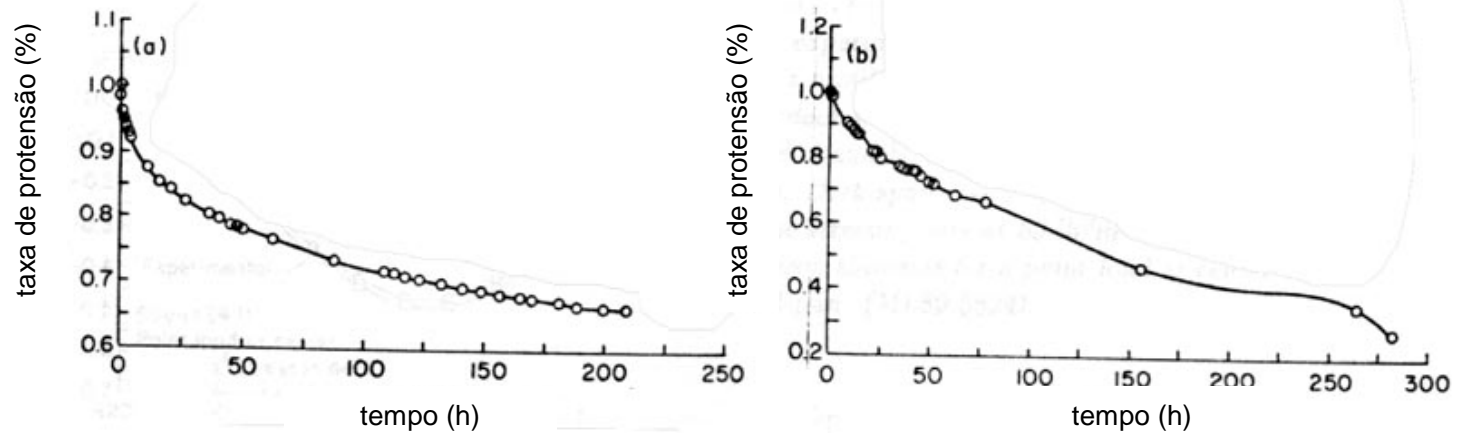

Figura 2.43 - Perda de Carga - RITTER et al (1990)

OLIVA et al (1990) comparam, na figura 2.44, as avaliações realizadas nas pontes Herbert Creek e Wheeler (avaliada por OLIVA \& DIMAKIS - 1986). 


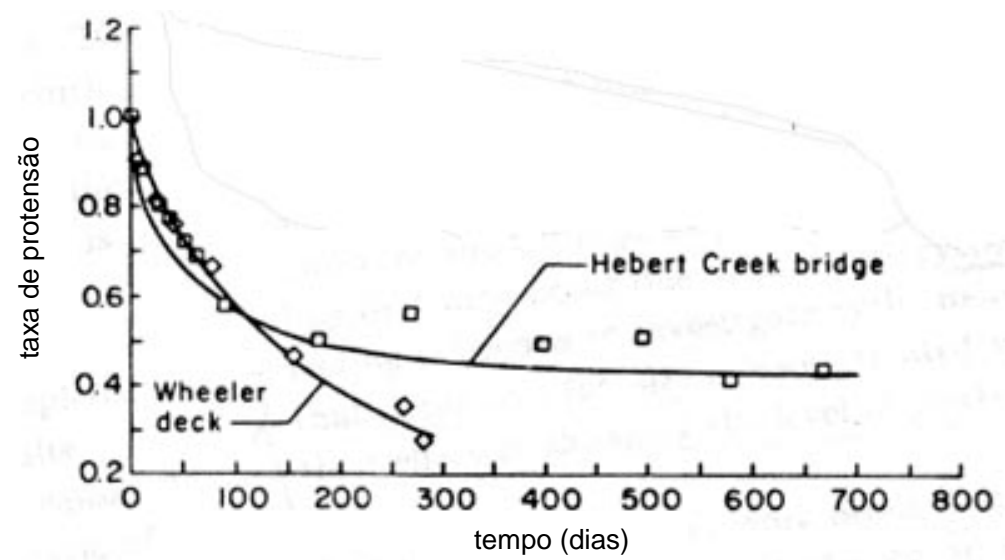

Figura 2.44 - Comparação da Perda de Protensão nas Ponte Herbert Creek e Wheeler

McCUTCHEON (1992) avaliou a ponte Mormon Creek por três anos e das quatro barras monitoradas apenas uma não ultrapassou o valor de $60 \%$ para as perdas. $O$ trabalho cita, também, que geralmente a perda de carga das barras são ocasionadas pela retração da madeira ao secar, esmagamento devido às tensões impostas, e deformação lenta da madeira. Ressalta-se que, neste caso, foi aplicada uma reprotensão aos 90 dias, aproximadamente.

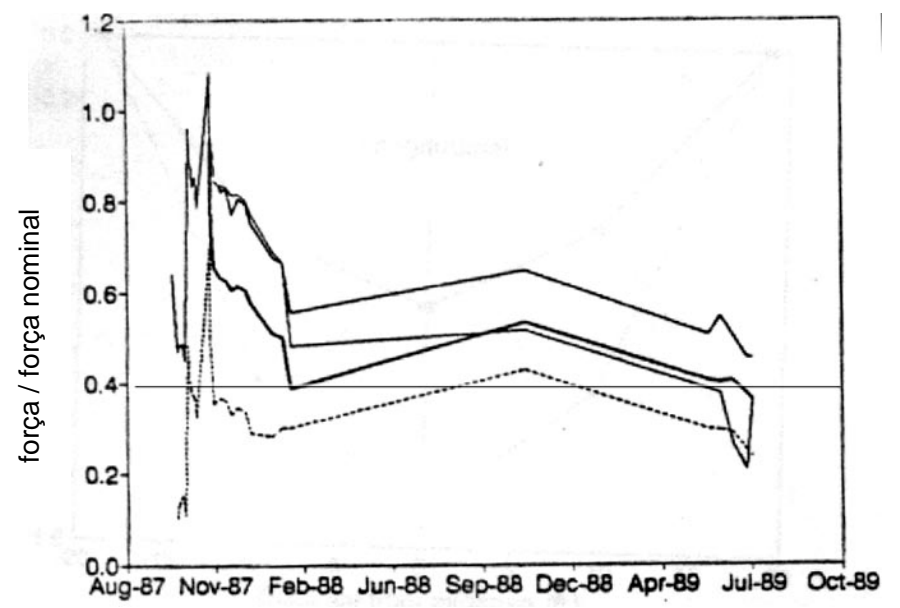

Figura 2.45-Perda de Protensão na Ponte Mormon Creek (1989-1991)

QUENNEVILLE \& DALEN (1994) realizaram um trabalho teórico e experimental utilizando a espécie de madeira de Douglas Fir em corpos-deprova com 3 peças de $38 \times 140 \times 700(\mathrm{~mm} \times \mathrm{mm} \times \mathrm{mm})$ dispostos como apresentado na figura 2.46 para dois níveis de umidade (50\% e $80 \%$ ) e vários históricos de tensão (com e sem reprotensão). Os corpos-de-prova foram monitorados por um tempo aproximado de 9 meses. A figura $\mathbf{2 . 4 7}$ 
mostra a tabela como as características de cada série ensaiada e as figuras 2.48 e 2.49 são exemplos desses resultados.

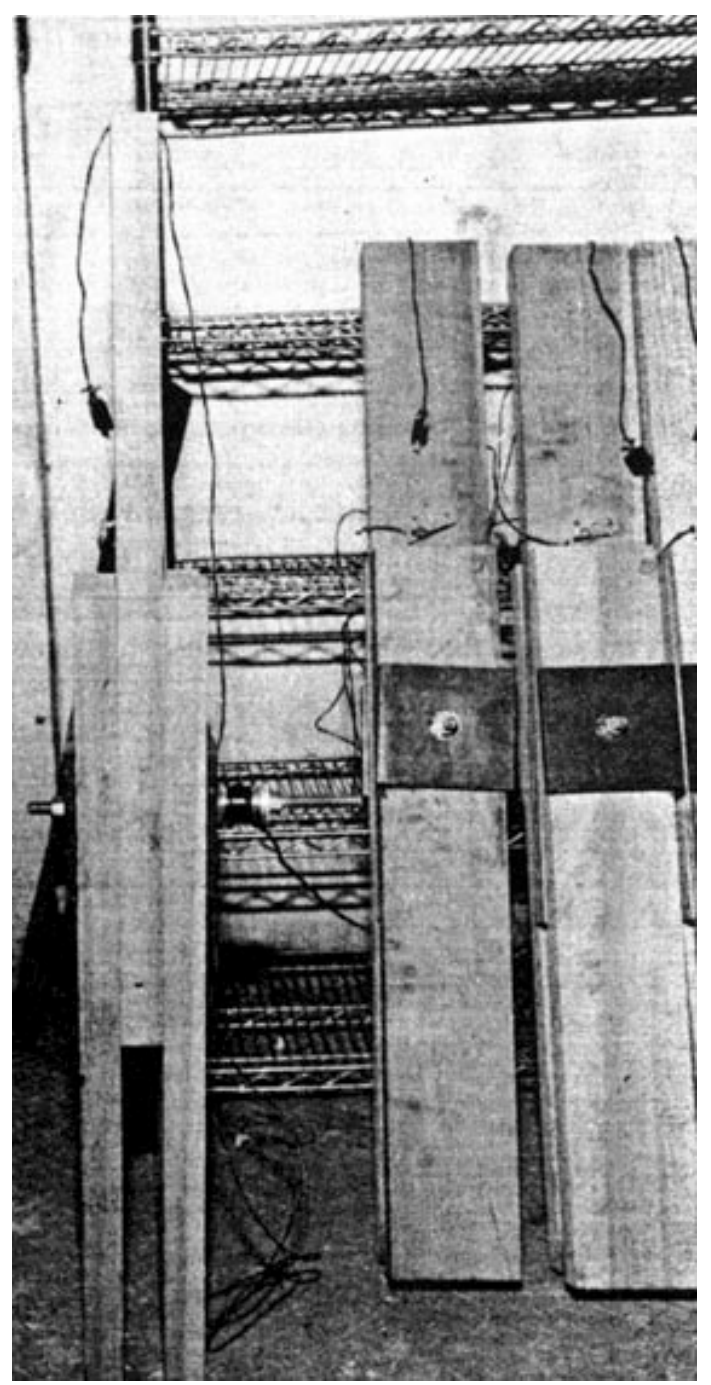

Figura 2.46 - Corpos-de-prova - QUENNEVILLE \& DALEN (1994)

TABLE 1. Resumo dos estudos de relaxação

\begin{tabular}{|c|c|c|c|c|}
\hline série & $\begin{array}{l}\text { Corpo-de- } \\
\text { prova }\end{array}$ & $\begin{array}{l}\text { duração } \\
\text { (dias) }\end{array}$ & $\begin{array}{c}\text { umidad } \\
e \\
\text { relativa }\end{array}$ & tratamento \\
\hline $\begin{array}{l}1 \\
2 \\
3 \\
4 \\
5 \\
6 \\
7 \\
8\end{array}$ & $\begin{array}{r}25-32 \\
1-8 \\
33-36 \\
9-12 \\
37-40 \\
13-16 \\
41-44 \\
17-20\end{array}$ & $\begin{array}{l}261 \\
241 \\
261 \\
241 \\
261 \\
241 \\
261 \\
241\end{array}$ & $\begin{array}{c}50 \\
80 \\
50-80 \\
80-50 \\
50 \\
80 \\
50 \\
80\end{array}$ & $\begin{array}{l}\text { sem alterações } \\
\text { sem alterações } \\
\text { alteração na umid. Relativa após } 112 \text { dias } \\
\text { alteração na umid. Relativa após } 99 \text { dias } \\
\text { reprotensão aos } 7 \text { e } 28 \text { dias } \\
\text { reprotensão aos } 7 \text { e } 28 \text { dias } \\
\text { reprotensão aos } 3,7,28 \text { e } 56 \text { dias } \\
\text { reprotensão aos } 3,7,28 \text { e } 56 \text { dias }\end{array}$ \\
\hline
\end{tabular}

Figura 2.47 - Tabela das série ensaiados por QUENNEVILLE \& DALEN (1994) 


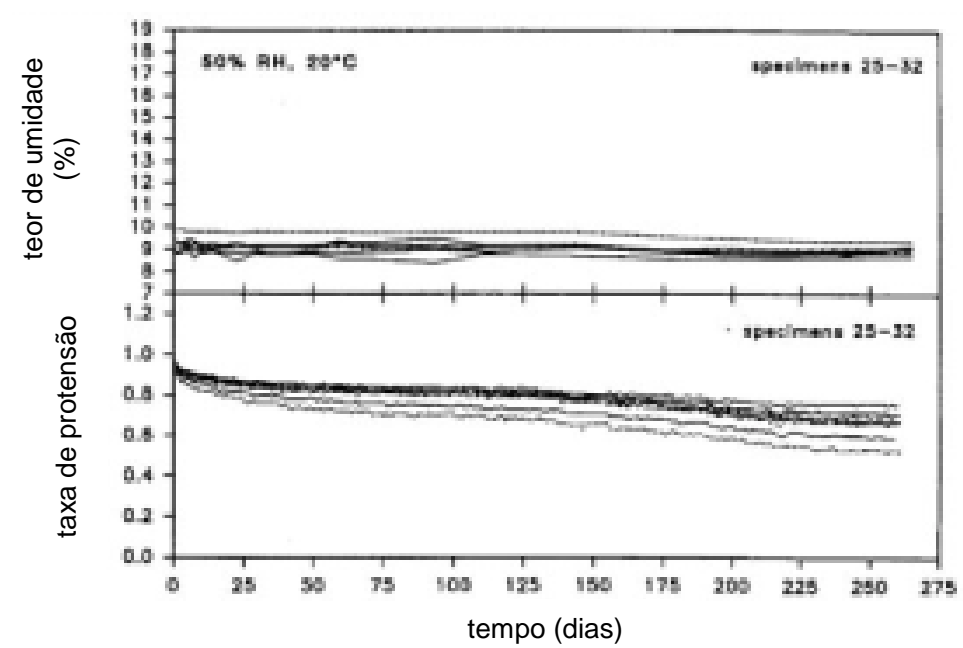

Figura 2.48 - Curvas de Perdas de Protensão e do Teor de Umidade

Série 1: Umidade ambiente de 50\%; sem reprotensão

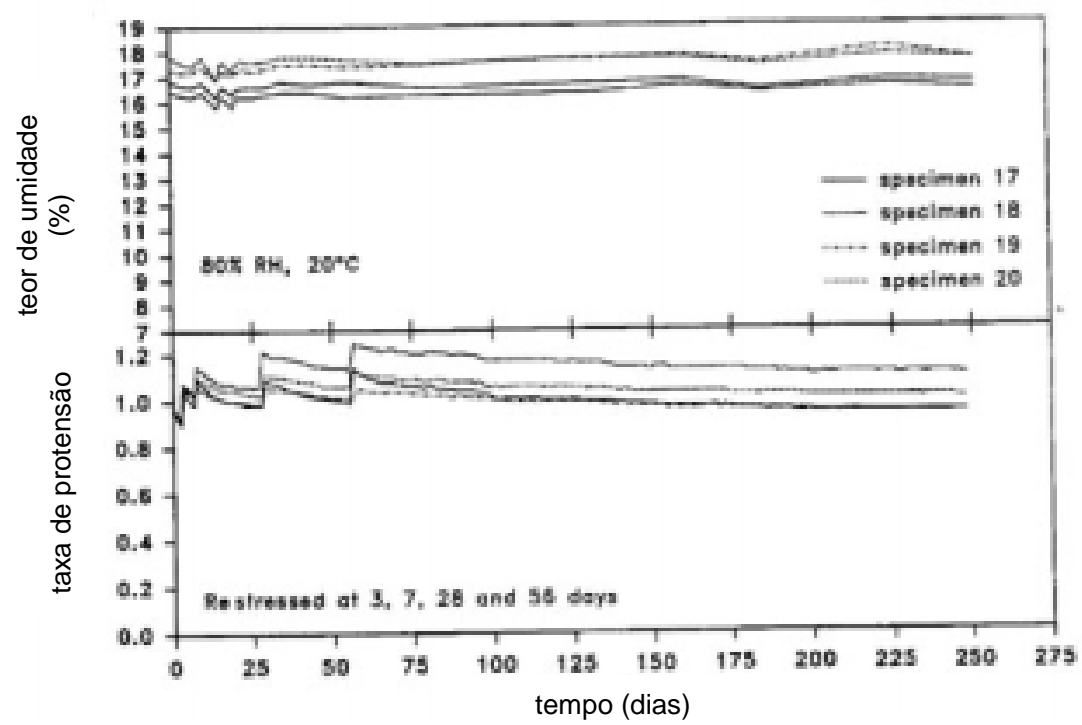

Figura 2.49 - Curvas de Perdas de Protensão e do Teor de Umidade

Série 8: Umidade ambiente de 80\%; reprotensões em 3, 7, 28 e 56 dias

Dentre as conclusões deste estudo experimental, ressalta-se que se mantidas constantes as condições de temperatura e umidade todos os corpos-de-prova estudados praticamente cessaram de perder protensão a partir do $8^{\circ}$ mês. No estudo teórico, complementar do experimental, QUENNEVILLE \& DALEN (1994) desenvolveram uma modelagem do comportamento reológico da perda de protensão nos tabuleiros de madeira que posteriormente foi calibrado com os estudos experimentais. $O$ modelo segue a configuração da figura 2.50 o qual é regido pela equação 2.1. 


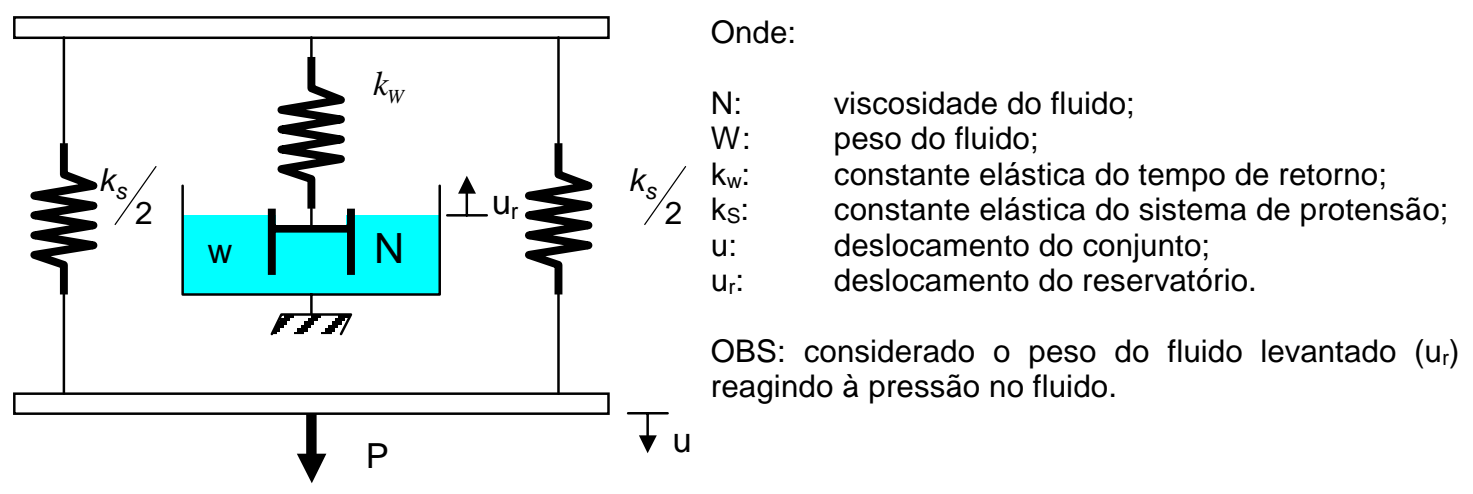

Figura 2.50 - Modelo Reológico de QUENNEVILLE \& DALEN (1994)

$P=\left(P_{0}-w \cdot u_{t}\right) \cdot e^{-C_{1} \cdot t}\left(1-\frac{w}{N \cdot C_{1}}\right)+w \cdot u_{r}$

onde: $\quad C_{1}=\frac{w}{N}+\frac{k_{s} \cdot k_{w}}{N \cdot\left(k_{s}+k_{w}\right)}$

$$
u_{r}=\frac{A}{1+e^{C(t-B)}}, A, B \text { e C são constantes }
$$

QUENNEVILLE \& DALEN (1996) apresentam um estudo aplicado diretamente aos tabuleiros laminados protendidos onde procuraram avaliar vários aspectos que julgavam importantes na perda de protensão ao longo do tempo. Um dos objetivos do estudo foi avaliar o efeito da rigidez do sistema de protensão na magnitude das perdas de protensão. Para tanto foram montados 60 corpos-de-prova de 10 peças (figura 2.51) para cada um dos 2 anos de avaliação. Foram armazenados em dois diferentes ambientes na temperatura de $20^{\circ} \mathrm{C}$ para umidades relativas de $50 \%$ (ano 1) e $80 \%$ (ano 2). Os corpos-de-prova foram divididos em 6 grupos com três variações da relação entre rigidez da barra de aço e das rigidezes das peças de madeira (para duas espécies diferentes). A figura 2.52 mostra as características dos corpos-de-prova utilizados. 


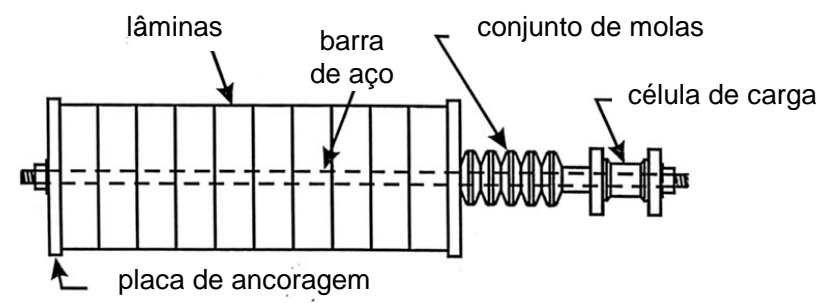

Figura 2.51 - Corpo-de-prova - Fonte: QUENNEVILLE \& DALEN (1996)

\begin{tabular}{|c|c|c|c|c|c|c|c|}
\hline grupo & $\begin{array}{c}\text { umidade } \\
\text { relativa (\%) }\end{array}$ & $\begin{array}{c}\text { seção } \\
\text { transv. }\end{array}$ & $\begin{array}{c}\text { comprim } \\
.\end{array}$ & molas & $\begin{array}{c}\text { taxa de } \\
\text { riaidez }\end{array}$ & $\begin{array}{c}\text { duração } \\
\text { (dias) }\end{array}$ & $\begin{array}{c}\text { taxa de áreas } \\
\text { (aco/madeira) }\end{array}$ \\
\hline A1-92 & 50 & $125 \times 125$ & 380 & no & 7 & 307 & 0.0049 \\
A2-92 & 50 & $125 \times 125$ & 380 & yes & 0.7 & 307 & -- \\
A3-92 & 50 & $125 \times 125$ & 380 & yes & 0.07 & 307 & - \\
C1-92 & 50 & $285 \times 285$ & 380 & no & 7 & 307 & 0.0048 \\
C2-92 & 50 & $285 \times 285$ & 380 & yes & 0.7 & 307 & - \\
C3-92 & 50 & $285 \times 285$ & 380 & yes & 0.07 & 307 & - \\
\hline A1-93 & 80 & $125 \times 125$ & 380 & no & 7 & 343 & 0.0049 \\
A2-93 & 80 & $125 \times 125$ & 380 & yes & 0.7 & 343 & - \\
A3-93 & 80 & $125 \times 125$ & 380 & yes & 0.07 & 343 & - \\
C1-93 & 80 & $285 \times 285$ & 380 & no & 7 & 343 & 0.0048 \\
C2-93 & 80 & $285 \times 285$ & 380 & yes & 0.7 & 343 & - \\
C3-93 & 80 & $285 \times 285$ & 380 & yes & 0.07 & 343 & - \\
\hline $2-94$ & 65 & $285 \times 285$ & 950 & yes & 0.7 & 285 & - \\
$3-94$ & 65 & $285 \times 285$ & 1900 & yes & 0.7 & 285 & - \\
$4-94$ & $65-50-65$ & $140 \times 570$ & 380 & yes & 0.7 & 285 & - \\
$5-94$ & $65-50$ & $140 \times 570$ & 380 & yes & 0.7 & 285 & - \\
$6-94$ & $55-50$ & $185 \times 434$ & 380 & yes & 0.7 & 285 & - \\
$7-94$ & $65-50-65$ & $185 \times 434$ & 380 & yes & 0.7 & 285 & - \\
$9-94$ & $65-50-65$ & $125 \times 125$ & 380 & yes & 0.07 & 285 & \\
\hline
\end{tabular}

Figura 2.52 - Características dos C. de Prova - Fonte: QUENNEVILLE \& DALEN (1996)

No terceiro ano, foram introduzidos mais alguns corpos-de-prova com o intuito de avaliar o efeitos de diferentes comprimentos e formas das faces protendidas. Trabalhou-se, então, com comprimentos de 380, 950 e 1900 $\mathrm{mm}$ e relações de forma 1 (quadrada), 0,25 e 0,43.
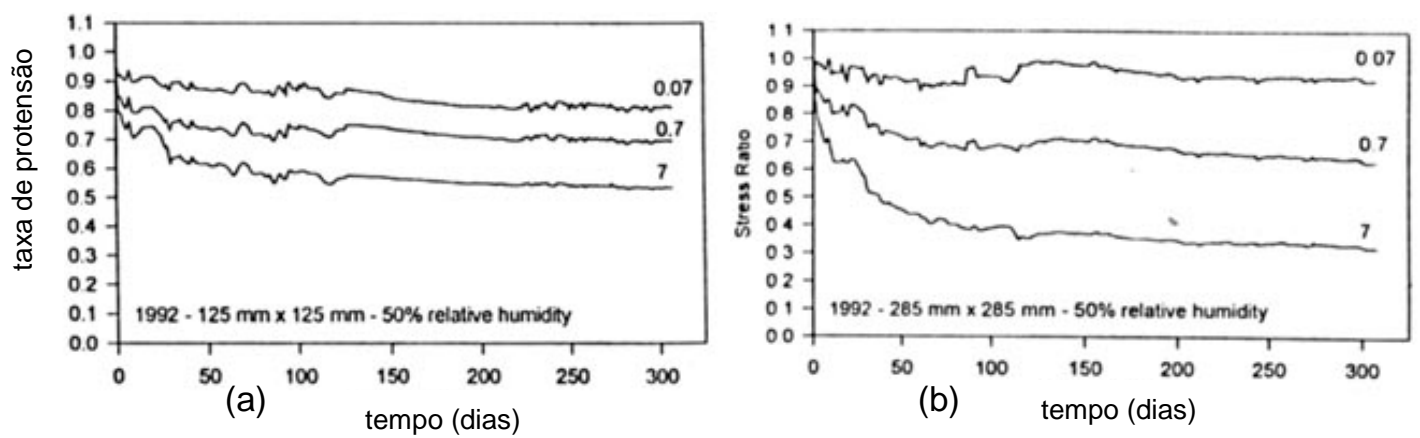

Figura 2.53 - Resultados da perda de protensão nas: a) Séries A; b) Séries C - Fonte:

QUENNEVILLE \& DALEN (1996) 
Nos resultados, puderam observar que as curvas de perda de protensão mostram claramente a grande influência da razão entre as rigidezes da barra de aço com a seção de madeira (figura 2.53). Apesar de que para a seção maior da série $C$ houveram perdas maiores para a razão 0,7 , as curvas estão próximas. Com relação aos efeitos do comprimento e do perímetro, concluíram que podem ser desprezados se for mantida a umidade constante (figura 2.54).

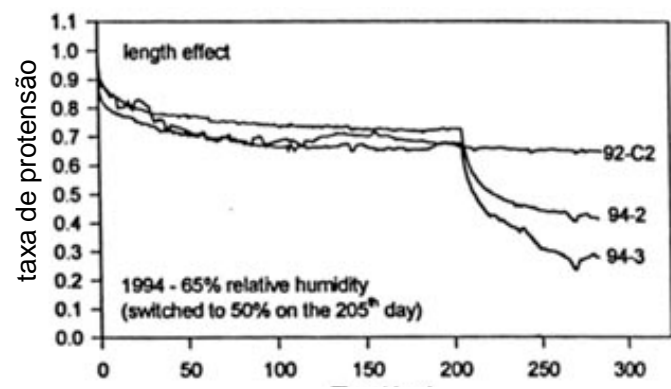

(a) tempo (dias)

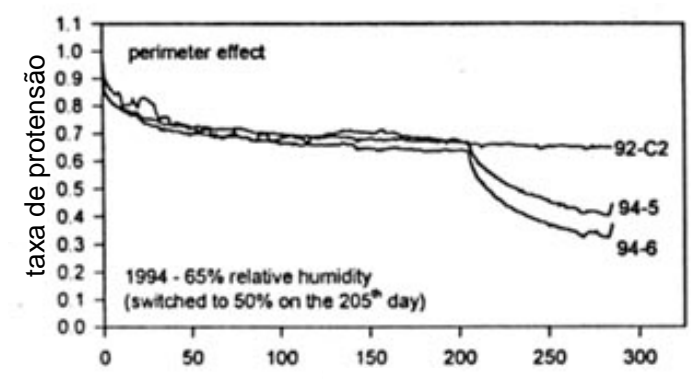

(b) tempo (dias)

Figura 2.54 - Resultados da Perda de Protensão: a) Efeito do Comprimento; b) Efeitos do Perímetro - Fonte: QUENNEVILLE \& DALEN (1996)

As curvas médias obtidas entre os anos de 92 (UR de 50\%) e 93 (UR de $80 \%$ ) foram ajustadas em um gráfico logarítmico do tempo t e normal.
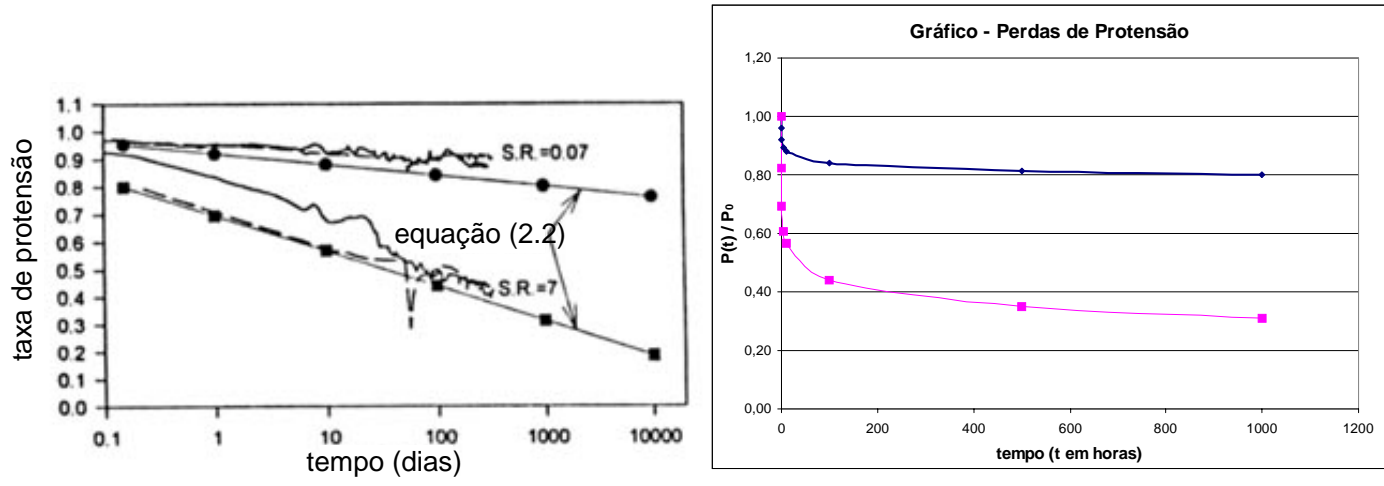

Figura 2.55 - Resultados da Perda de Protensão com o ajuste proposto - Fonte:

QUENNEVILLE \& DALEN (1996)

A equação que rege é:

$P / P_{0}=m \cdot \log (t)+b$

onde:

$$
\begin{aligned}
& m=-0,01266 S R-0,03911 \\
& b=-0,0325 S R+0,9223
\end{aligned}
$$


MOSES et al (1999) também realizaram ensaios de perdas de protensão para um período de 200 dias. Com peças de madeira de seção $140 \times 140$ $(\mathrm{mm} \times \mathrm{mm}$ ) e espessura de $38 \mathrm{~mm}$ elaboraram corpos-de-prova (figura 2.56) com dois comprimentos diferentes ( $380 \mathrm{~mm}$ e $760 \mathrm{~mm}$ ). Aplicaram um força nominal de $11,5 \mathrm{kN}$ nas barras de $15 \mathrm{~mm}$ de diâmetro e sujeitaram os corpos-de-prova a dois históricos de umidade diferentes. No primeiro histórico, a umidade com que trabalharam foi de $80 \%$ passando para $65 \%$ e depois voltando para $80 \%$; e, no segundo histórico, começaram com $50 \%$ passando para $65 \%$ e voltando para 50\%). Com esse procedimento quiseram avaliar a magnitude das deformações lentas e relacioná-las à perda de protensão. Foi efetuado uma modelagem teórica baseada no modelo de Kelvin (explicado no item seguinte).

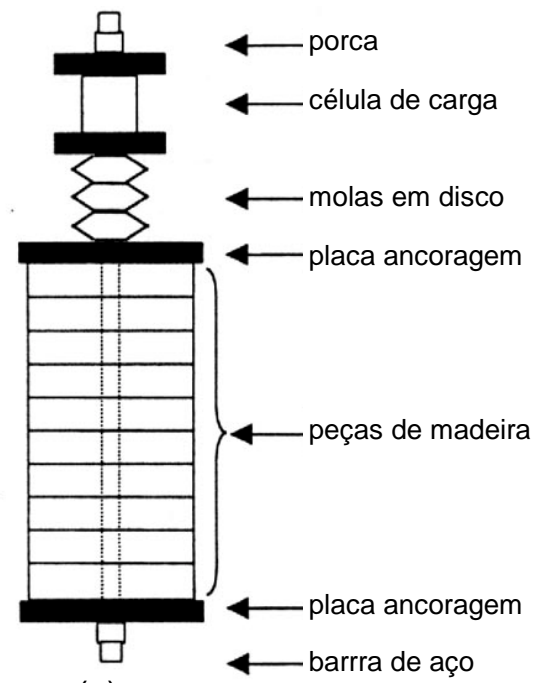

(a)

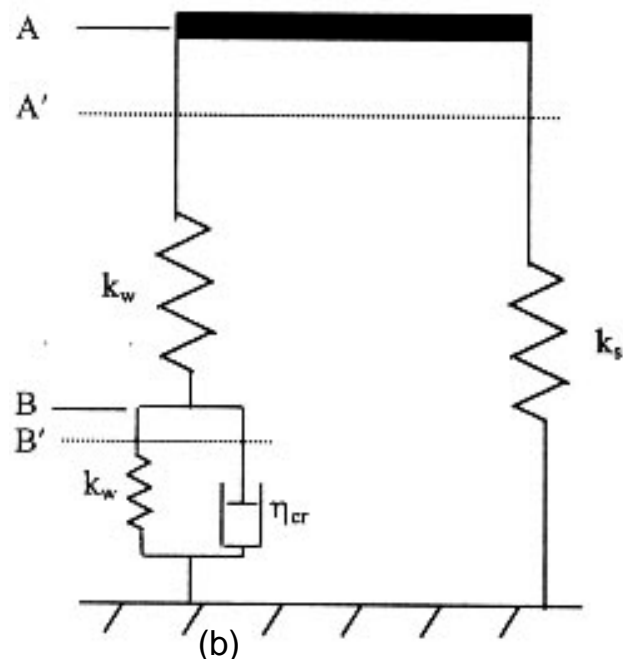

(b)

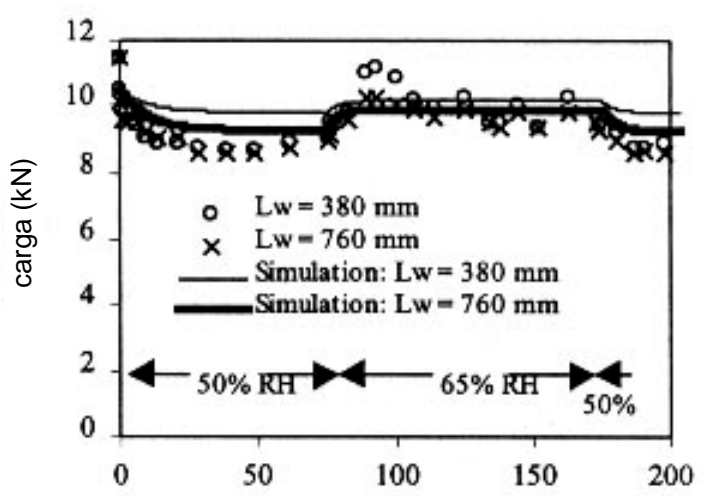

(d) tempo (dias)

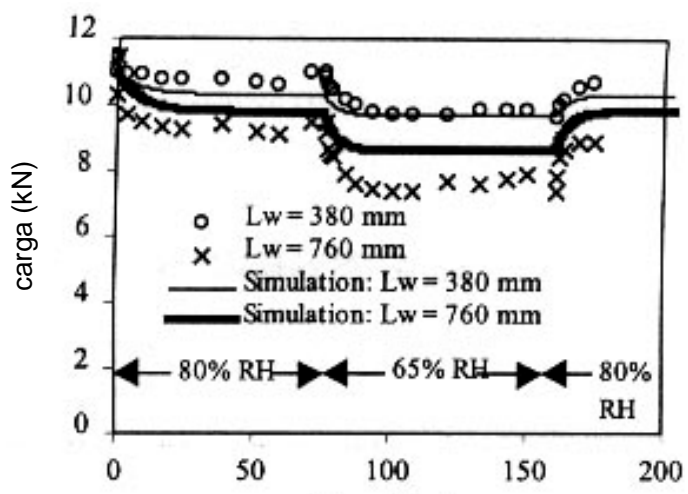

(c) tempo (dias)

Figura 2.56 - MOSES et al (1999) - a) Corpo-de-prova; b) Modelo Reológico utilizado; c) Série $80 \%=>65 \%=>80 \%$; d) Série $50 \%=>65 \%=>50 \%$. 
Realizaram uma avaliação paramétrica de fatores como seções transversais, comprimentos dos corpos-de-prova, rigidez do sistema de protensão e níveis iniciais de protensão. Seu modelo leva em conta apenas a deformação lenta da madeira, rigidez do sistema de protensão e variações de umidade do ar. Sugere-se a realização de análises não lineares para verificar as relações carga/deslocamentos.
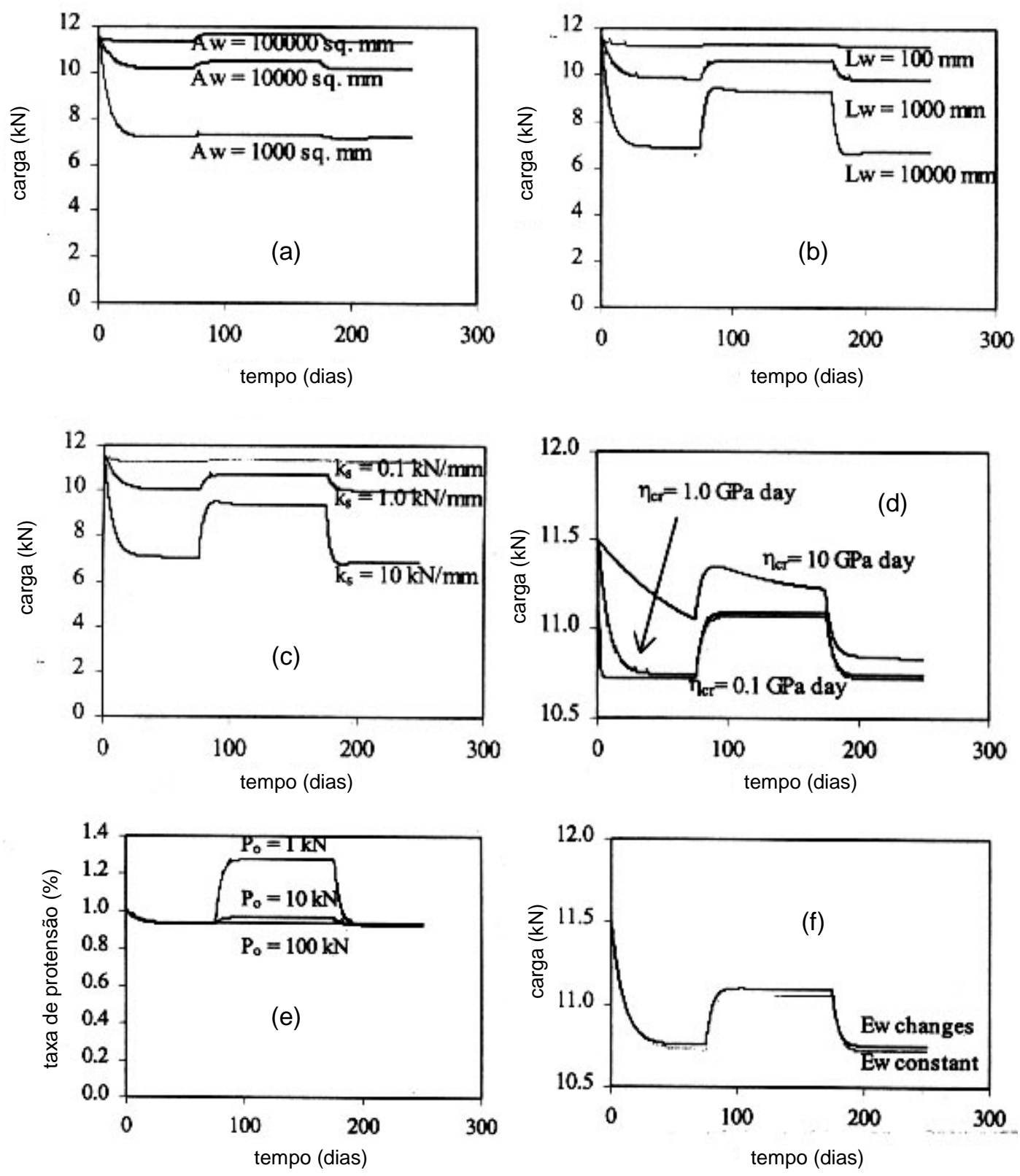

Figura 2.57 - MOSES et al (1999) - Ajustes para variações de: a) Seção transversal; b) Comprimentos; c) Constantes Elásticas; d) Parâmetro de Viscosidade; e) Níveis de Protensão Inicial; f) Módulos de Elasticidade. 
Concluíram pelos resultados, que para minimizar os efeitos da deformação lenta que ocorre no primeiros 75 dias após a protensão, sob condições de temperatura e umidade constantes, deve-se preferir seções transversais maiores e comprimentos menores de corpos-de-prova. Se o que se deseja é minimizar os efeitos das variações ambientais, deve-se trabalhar com seções transversais maiores, níveis de protensão elevados e comprimentos pequenos (larguras menores dos tabuleiros).

\subsection{Viscoelasticidade}

Dentro da engenharia de estruturas os materiais de construção são, geralmente, dimensionados para trabalharem na sua fase elástica. Com a evolução das ferramentas matemáticas e do conhecimentos específicos de cada material já é possível para alguns deles, o equacionamento teórico de seus comportamentos, na chamada fase plástica.

Segundo BUCHANAN ${ }^{1}$ (1999) o comportamento viscoelástico pode ser dividido em:

- deformação lenta: onde aparecem deformações ao longo do tempo para tensões constantes;

- relaxação: onde perdas de tensão ocorrem sem modificações nas deformações;

- taxa constante de deformação: onde perdas de tensão ocorrem devidas as modificações nas deformações;

BUCHANAN (1999) se diz favorável a utilização de modelagem téorica porque, geralmente, estes tipos de experimentos são demorados e onerosos tornando-os, às vezes, impossível de se avaliar.

${ }^{1}$ BUCHANAN, D.R. Viscoelasticity. Página WWW -

http://courses.ncsu.edu/classes/te201001/viscoelasticity/index.htm - 17 de Fevereiro de 1998. Visitada em 01 de Junho de 1999. 
A deformação lenta na madeira solicitada à compressão normal às fibras é particularmente importante pois neste tipo de solicitação a fase elástica é muito pequena. Isto tornaria inviável a utilização do material para estas situações de projeto se não pudéssemos dimensionar os elementos além da fase elástica. O problema se agrava quando esta solicitação normal se prolonga por muito tempo.

Nos tabuleiros protendidos de madeira a compressão normal é a solicitação que permite considerar os elementos lineares trabalhando em conjunto na forma de placa. Esta tensão de compressão normal é projetada para permanecer por toda vida útil da madeira, e, apesar de não ultrapassar os valores normalizados de projeto provocam grandes deformações e, no caso destes tabuleiros, faz com que as forças de protensão diminuam.

Nestas condições, o estudo da deformação lenta na solicitação da compressão normal às fibras é imprescindível para o perfeito entendimento do sistema protendido transversal. Por BODIG \& JAYNE (1982), a deformação lenta é definida como a deformação que ocorre em um elemento ao longo do tempo quando submetida a um carregamento constante (figura 2.58).

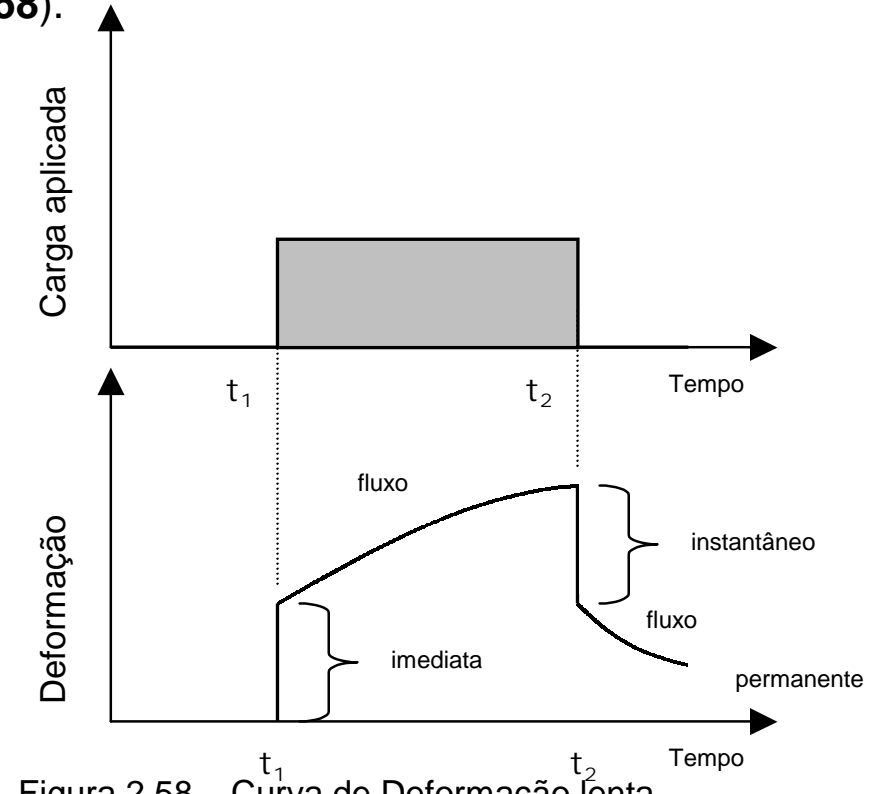

Figura 2.58 - Curva de Deformação lenta 
BODIG \& JAYNE (1982) apresentam os seguintes modelos matemáticos da reologia para descrever a Deformação Lenta (figuras 2.59 e 2.60):

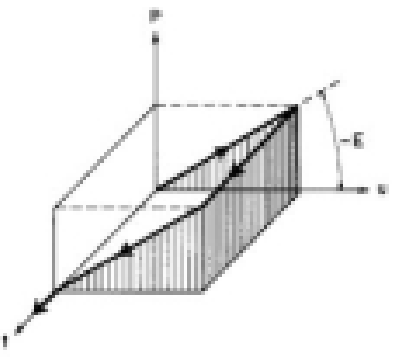

Mola de Hooke

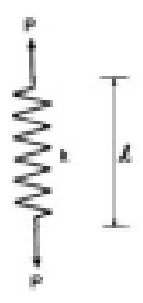

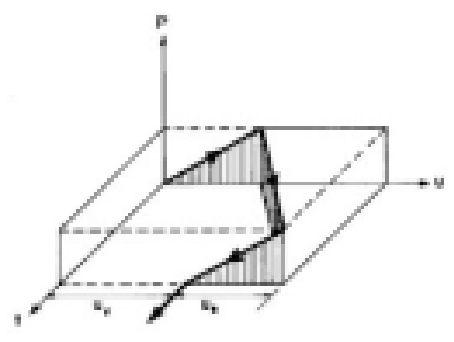

Corpo de Maxwell
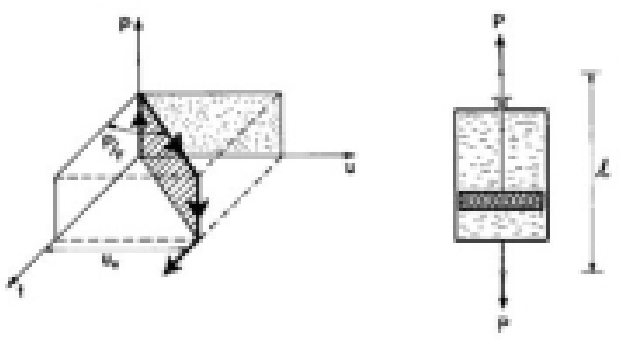

Amortecedor de Newton

Figura 2.59 - Modelos Matemáticos de Hooke e Newton

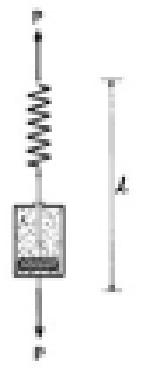

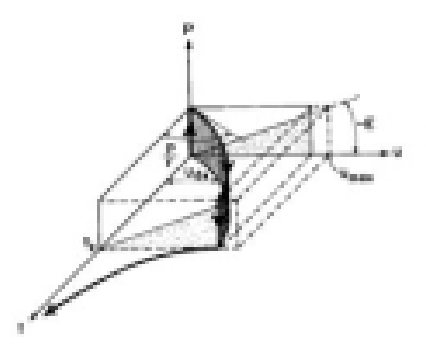

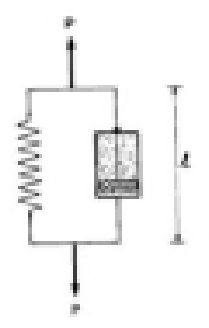

Corpo de Kelvin

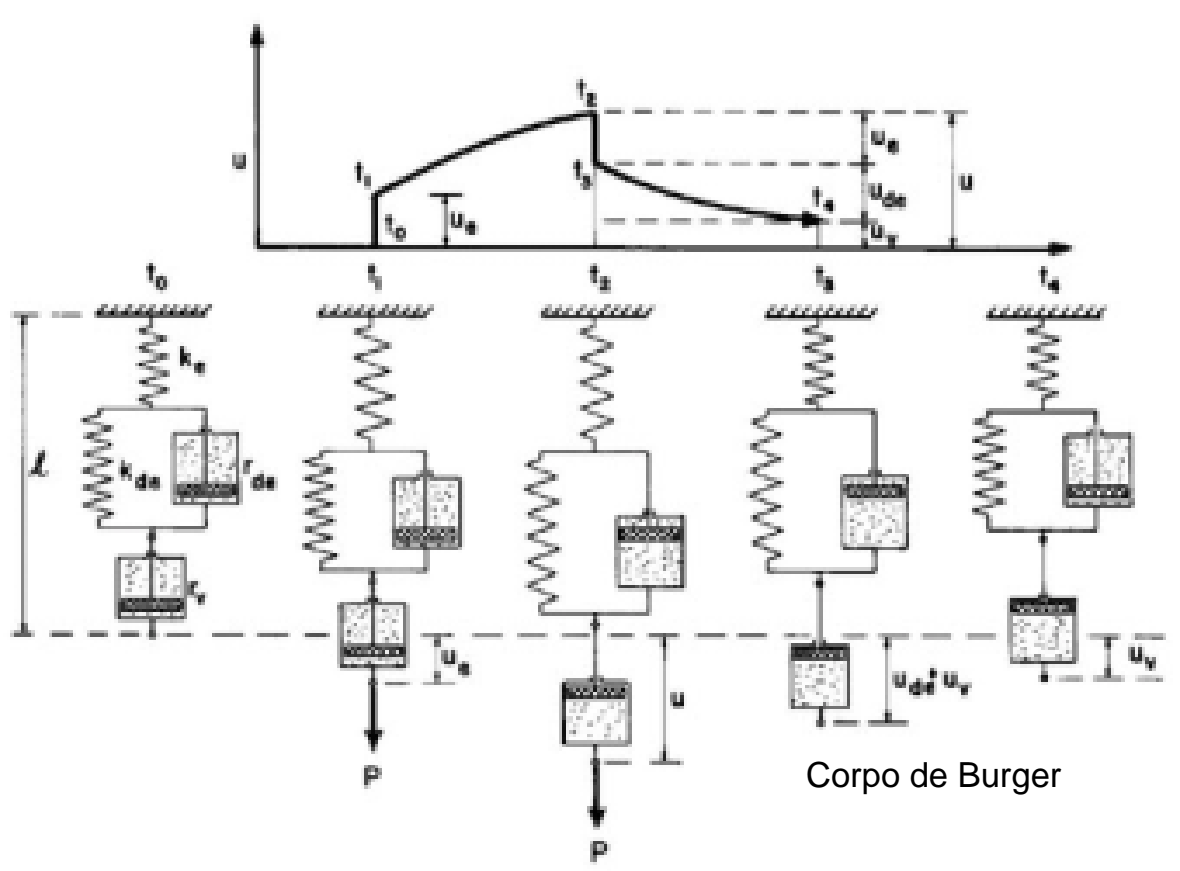

Figura 2.60 - Modelos Matemáticos de Maxwell, Kelvin e Burger 
BODIG \& JAYNE (1982) afirmam ainda que o modelo de Burger pode ser utilizado para a representação da deformação lenta, bastando encontrar os parâmetros viscoelásticos. Além destes modelos, apresentam outros baseados em métodos empíricos para descrever a deformação lenta tais como os da tabela 2.16 .

Tabela 2.16 - Equações empíricas da reologia - Fonte BODIG \& JAYNE (1982)

\begin{tabular}{lll}
\hline Nome & Equação & constantes \\
\hline Parabólica & $\gamma=\gamma_{0}+a \cdot t^{m}$ & $\mathrm{a}, \mathrm{m}$ \\
Logarítmica & $\gamma=a+b \cdot \log (t)$ & $\mathrm{a}, \mathrm{m}$ \\
Polinomial & $\gamma=a+b \cdot t^{1 / n}+c \cdot t^{2 / n}+d \cdot t^{3 / n}$ & $\mathrm{a}, \mathrm{b}, \mathrm{c}, \mathrm{d}, \mathrm{m}$ \\
\hline
\end{tabular}

FRIDLEY (1992) adota o modelo de Burger para o comportamento na deformação lenta que define três parcelas de deformação da equação 2.3.

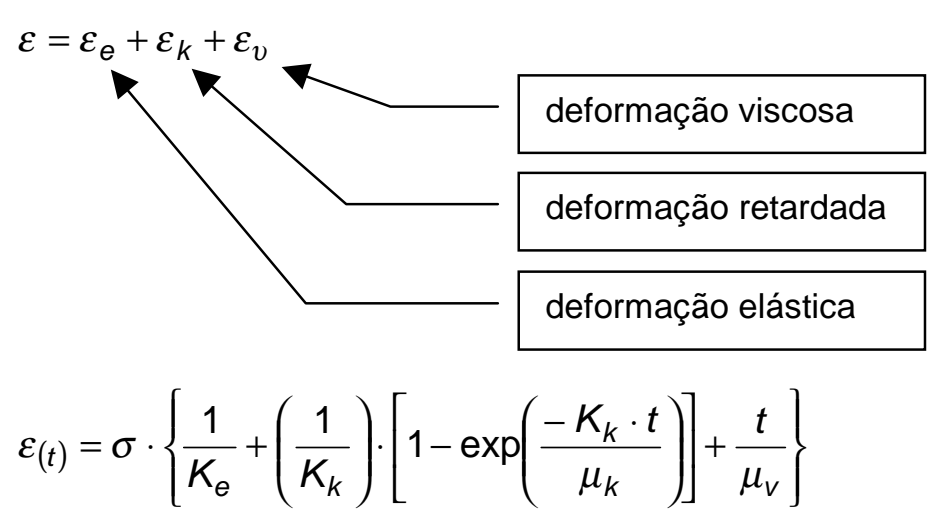

onde define as seguintes constantes:

Tabela 2.17 - Valores das constantes para o Modelo de Burger - Fonte FRIDLEY (1992)

\begin{tabular}{lccc}
\hline parâmetros $\mathrm{p} / \mathrm{d}$. lenta & $15 \%$ umidade & $19 \%$ umidade & $28 \%$ umidade \\
$\mathrm{K}_{\mathrm{e}}\left(10^{6} \mathrm{psi}\right)$ & 1,68 & 1,56 & 1,31 \\
$\mathrm{~K}_{\mathrm{k}}\left(10^{6} \mathrm{psi}\right)$ & 2,77 & 2,17 & 1,63 \\
$\mu_{\mathrm{k}}\left(10^{10} \mathrm{psi}-\mathrm{min}\right)$ & 4,56 & 3,36 & 1,79 \\
$\mu_{\mathrm{v}}\left(10^{14} \mathrm{psi}-\mathrm{min}\right)$ & 5,56 & 4,44 & 3,24 \\
\hline
\end{tabular}




\subsection{Conclusões}

$\mathrm{Na}$ literatura avaliada percebe-se a utilização de protótipos ou obras comerciais de pontes protendidas para a análise das perdas de protensão. É evidente que este fato permite a avaliação do comportamento em campo mas, de uma forma global, o estudo em laboratório possibilita um melhor controle das condições climáticas e solicitações no tabuleiro permitindo controlá-las nas análises. Por outro lado, modelos ou corpos-de-prova podem não representar corretamente as propriedades dos tabuleiros tais como os corpos-de-prova de QUENNEVILLE \& DALEN (1994) da figura 2.46. Em QUENNEVILLE \& DALEN (1996) e em MOSES (1999) os corposde-prova (figuras 2.51 e 2.56a, respectivamente) representam de forma mais adequada o sistema laminado protendido permitindo analisar separadamente os fatores que influenciam a perda de protensão. Outro fator verificado é que a classe (e o tipo) da madeira não é analisado conjuntamente. Isto é, provavelmente, conseqüência da pequena variabilidade de espécies destes países.

A revisão bibliográfica efetuada justifica a necessidade do estudo da perda de protensão em tabuleiros de madeira laminada protendida. Esclarece, também, que um dos principais fatores que influenciam tais perdas é a deformação lenta na madeira submetida por tensões de compressão normal às fibras. A literatura expõe, também, outros fatores que podem afetar as perdas de protensão como as relações de áreas entre as barras de aço e a madeira protendida. RITTER (1992) recomenda utilizar relações de áreas de aço-madeira menores que 0,0016 .

Outra necessidade verificada é a avaliação de protótipos em laboratório para que possamos confirmar o desempenho destas estruturas construídas com materiais disponíveis no Brasil. 
O estudo destes tópicos permitirá dimensionar e construir estas estruturas racionalmente e com segurança. Estes conhecimentos deverão ser transferidos ao meio técnico e científico eficientemente para que promova a efetiva utilização desta importante tecnologia e incentive novas pesquisas sobre o tema. 


\section{MATERIAIS E MÉTODOS}

3.1 Introdução

Da revisão bibliográfica realizada, observa-se a necessidade de avaliação das perdas de protensão que ocorrem em tabuleiros laminados protendidos. Vários fatores devem ser estudados para se verificar qual e quanto é a influência de cada um.

Verifica-se, também, a necessidade de avaliação de segurança em protótipos em laboratório antes de recomendar a tecnologia ao meio técnico. Portanto, devem ser avaliados protótipos do tabuleiro laminado protendido.

Para estas finalidades são aqui apresentadas as metodologias teórica e experimental necessárias para adquirir o conhecimento para o projeto e construção de pontes protendidas no Brasil.

\subsection{Metodologia Teórica}

A parte teórica foi dividida em quatro itens:

Análise Teórica da Deformação Lenta;

Nesta etapa serão avaliados os modelos matemáticos que podem representar o comportamento do material madeira quando submetidos a tensões de longa duração na direção normal às suas fibras. Serão comparados ao comportamento experimental obtido nos ensaios de deformação lenta. Dentre as possíveis associações de molas (Hooke), amortecedores (Newton), corpos de Kelvin (associação em paralelo de mola 
e amortecedor) e de Maxwell (associação em série de mola e amortecedor) acredita-se que a associação dos modelos de Hooke e de Kelvin seja mais adequada que o modelo de Burger (associação em série dos corpos de Kelvin e Maxwell) já que não estamos interessados na curva negativa (recuperação da deformação). Os modelos estão esquematizados abaixo.
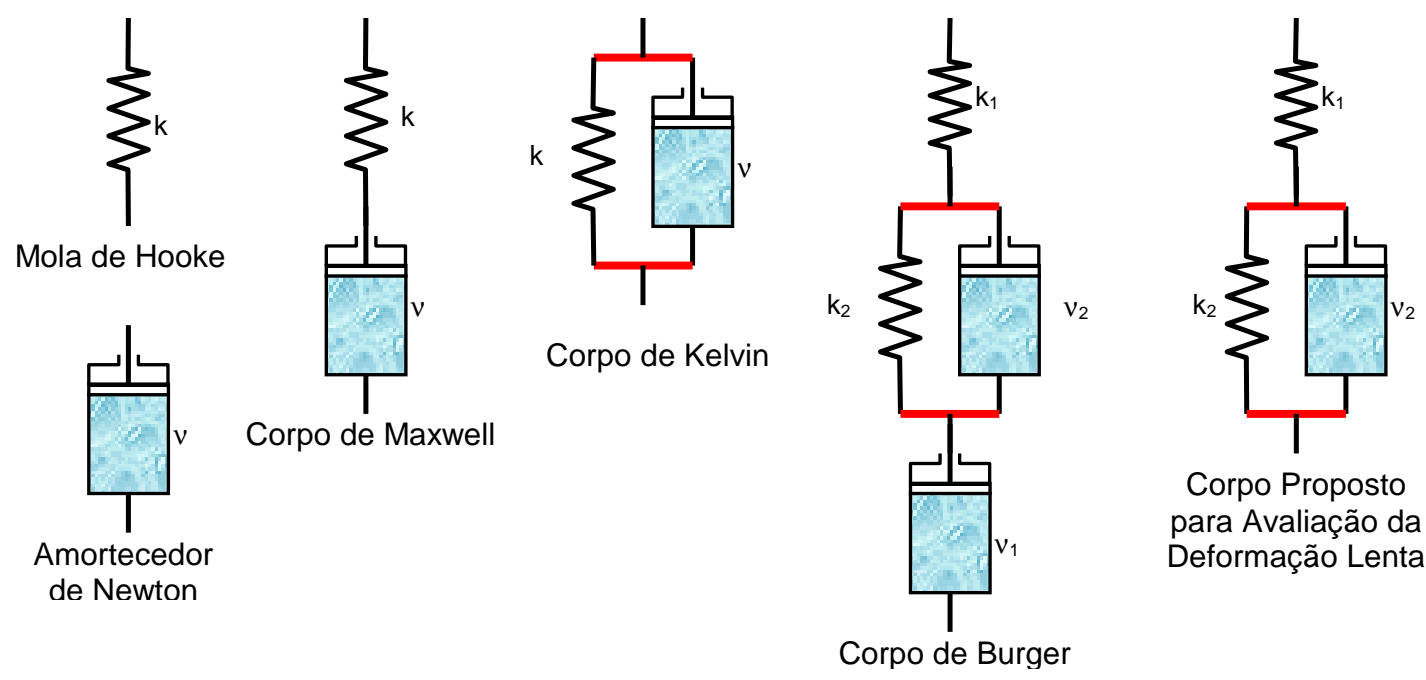

para Avaliação da Deformação Lenta

Figura 3.1 - Modelos matemáticos para representar a deformação lenta

A formulação do modelo proposto é:

$$
\Rightarrow \quad \delta_{(t)}=\frac{P}{k_{1}}+\frac{P}{k_{2}}\left(1-e^{-t / \tau}\right), \operatorname{com} \tau=\frac{v_{2}}{k_{2}} \begin{aligned}
& \mathrm{t}=\text { tempo } \\
& v=\text { viscosidade }
\end{aligned}
$$

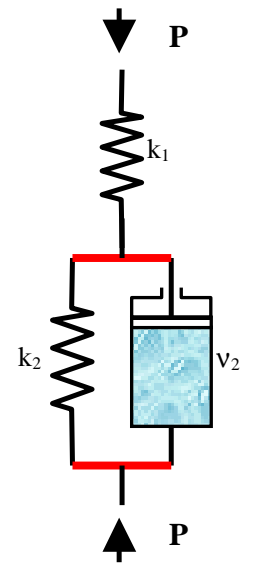

Baseados nos resultados pode-se ajustar para algumas formulações empíricas, também, tais como potenciais, logarítmicas, racionais, etc. 
$\checkmark$ Análise Teórica da Relaxação;

Dos ensaios de perda de protensão pode-se ajustar, baseado na literatura estudada, um modelo de relaxação do conjunto segundo um dos modelos abaixo a serem avaliados.

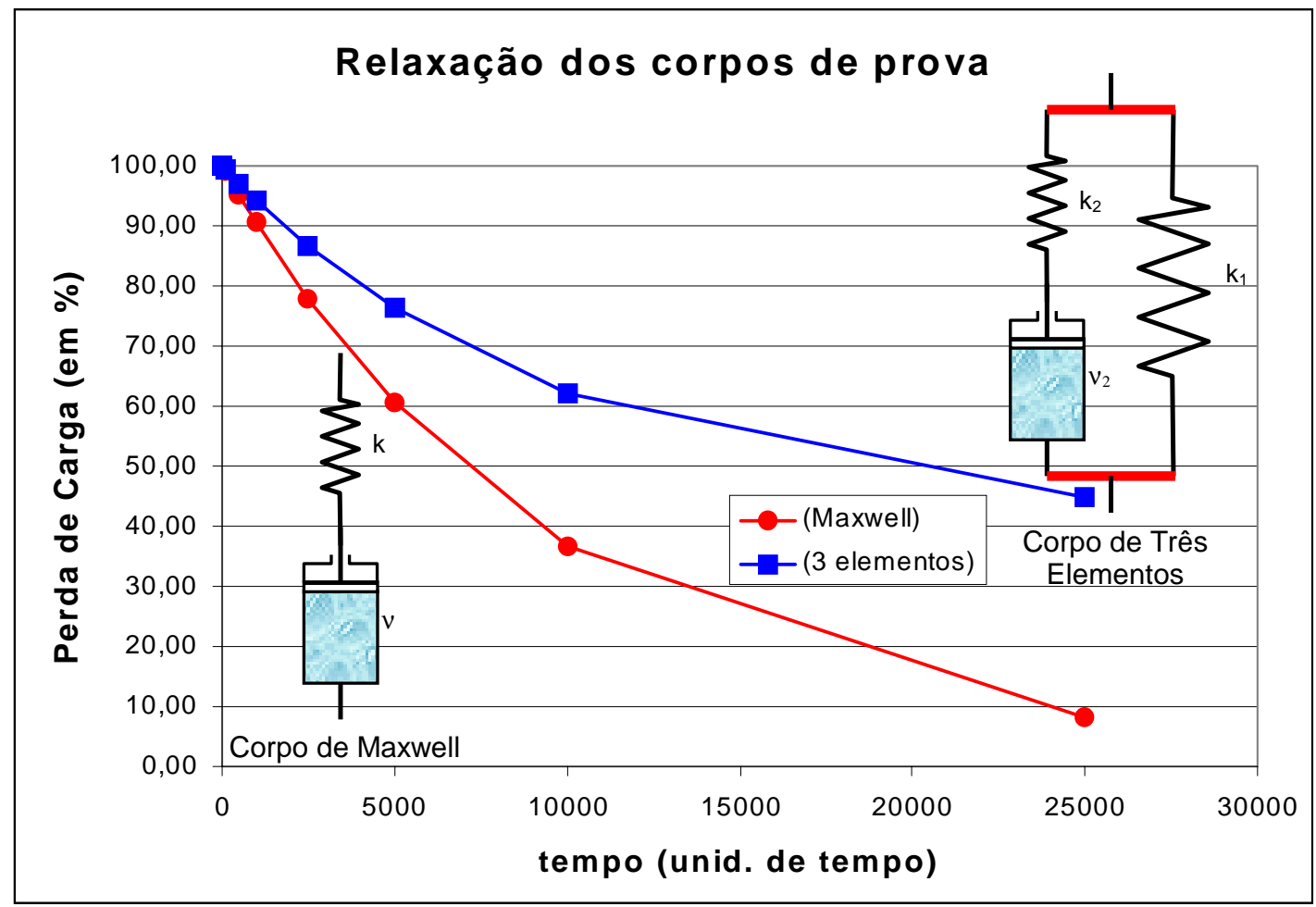

Figura 3.2 - Modelos matemáticos representando graficamente a relaxação

As formulações são:

Para o Corpo de Maxwell: $P_{(t)}=P_{(0)} \cdot e^{-t / \tau}$, com $\tau=\frac{v}{k}$

Para o Corpo de Três elementos: $\quad P_{(t)}=P_{(1)}+P_{(2)} \cdot e^{-t / \tau_{2}}$, com $\tau_{2}=\frac{v_{2}}{k_{2}}$

$\checkmark$ Diretrizes de dimensionamento do PPM v. 3.0;

As diretrizes básicas foram as propostas por OKIMOTO (1997) devendo haver alterações naquelas que são objetos de estudo desta pesquisa. Estas abordagens serão implementadas no critério de dimensionamento proposto por esta tese e utilizado no programa PPM v. 3.0. 
$\checkmark$ Rotina de Cálculo utilizada no AEP v. 1.0

A estrutura do programa AEP v. 1.0 (Análise Estrutural de Placas) está baseada no seguinte fluxograma.

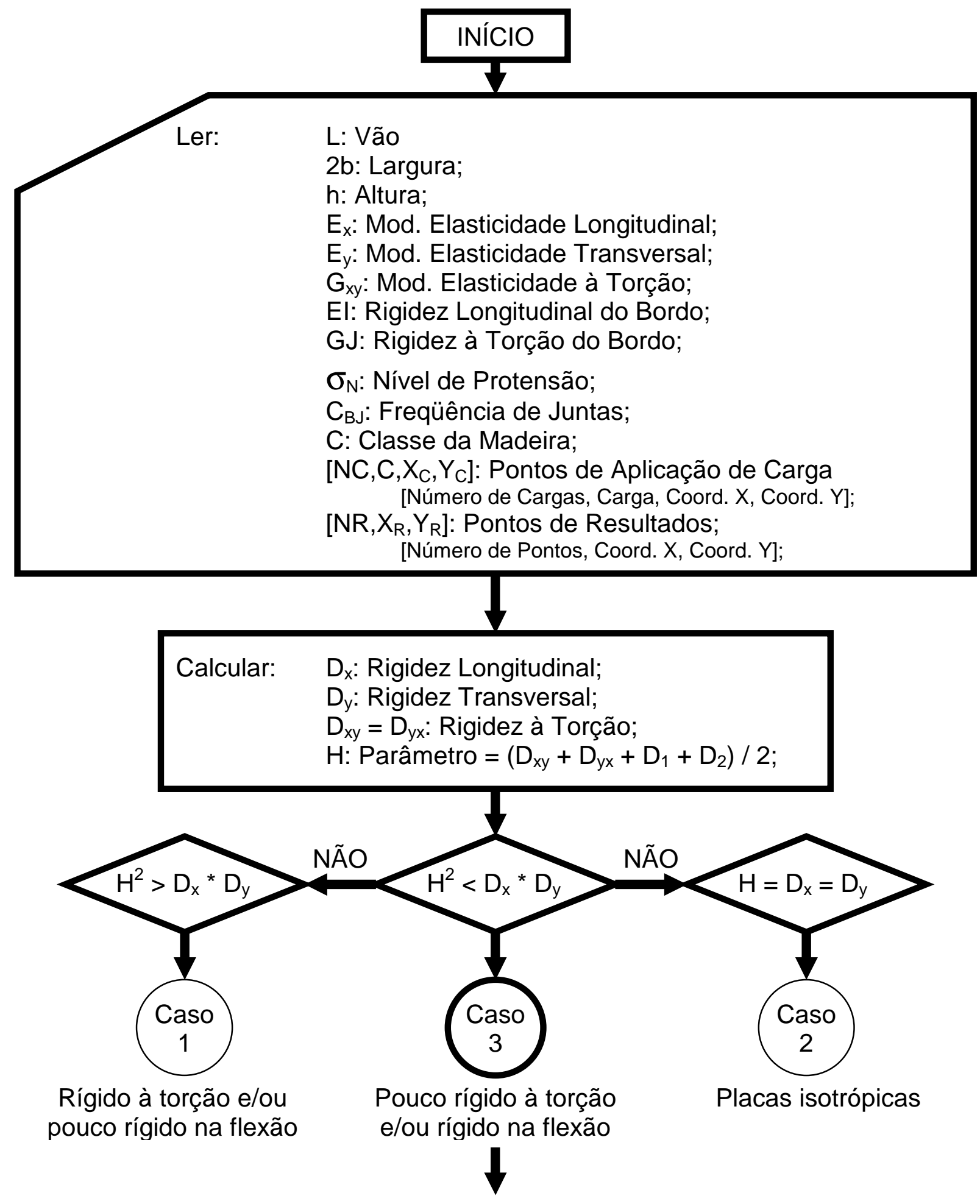


Calcular: $\quad r_{3}$ : Rigidez Longitudinal;

$r_{4}$ : Rigidez Transversal;

$\alpha$ : Nível de Protensão;

$\beta$ : Nível de Protensão;

$\theta$ : Nível de Protensão;

FOR I $=$ to NR

$\mathrm{FORI}=$ to $\mathrm{NC}$

(número de pontos de aplicação de cargas!)

$F O R I=$ to $\mathrm{N}$

(número de divisões da série harmônica!)

Calcular parâmetros: $\quad r_{3} ; r_{4} ; \alpha_{N} ; \beta_{3} ; \beta_{4}$;

Calcular constantes: $\quad a_{1} ; b_{1} ; c_{1} ; d_{1}$;

$\mathrm{a}_{3} ; \mathrm{b}_{3} ; \mathrm{c}_{3} ; \mathrm{d}_{3}$;

Calcular coeficientes: $\quad \mathrm{S}_{1} ; \mathrm{S}_{2} ; \mathrm{S}_{3} ; \mathrm{S}_{4}$;

Calcular parâmetros: $\quad \xi_{1}$

A; B; C; D;

$\psi$;

Se $\xi_{1}>\psi \quad$ calcular: $\quad \mathrm{K}_{1} ; \mathrm{K}_{2}$;

Se $\xi_{1}<\psi \quad$ calcular: $\quad \mathrm{K}_{1} ; \mathrm{K}_{2}$;

$\mathrm{Se} \xi_{1} \neq \psi \quad$ calcular: $\quad \mathrm{K}_{3} ; \mathrm{K}_{4}$;

Se $\xi_{1}=\psi \quad$ calcular: $\quad \mathrm{K}_{1} ; \mathrm{K}_{2} ; \mathrm{K}_{3} ; \mathrm{K}_{4}$;

NEXT N

Calcular Valores de:

$w ; M_{x} ; M_{y} ; M_{x y} ; M_{y x}$;

$\mathrm{V}_{\mathrm{x}} ; \mathrm{V}_{\mathrm{y}} ; \mathrm{W}_{\text {Placa }} ; \mathrm{M}_{\mathrm{xPlaca}} ;$

Imprimir Valores de:

$\mathrm{w} ; \mathrm{M}_{\mathrm{x}} ; \mathrm{M}_{\mathrm{y}} ; \mathrm{M}_{\mathrm{xy}} ; \mathrm{M}_{\mathrm{yx}} ;$

$\mathrm{V}_{\mathrm{x}} ; \mathrm{V}_{\mathrm{y}} ; \mathrm{W}_{\text {Placa }} ; \mathrm{M}_{\mathrm{xPlaca}} ;$

NEXT NC

Calcular Valores Máximos de: $\quad w ; M_{x} ; M_{y} ; M_{x y} ; M_{y x}$;

$\mathrm{V}_{\mathrm{x}} ; \mathrm{V}_{\mathrm{y}} ; \mathrm{w}_{\text {Placa }} ; \mathrm{M}_{\mathrm{xPlaca}} ;$

NEXT NR

Imprimir Valores Máximos de: $\quad w ; M_{x} ; M_{y} ; M_{x y} ; M_{y x}$;

$\mathrm{V}_{\mathrm{x}} ; \mathrm{V}_{\mathrm{y}} ; \mathrm{W}_{\text {Placa }} ; \mathrm{M}_{\mathrm{xPlaca}}$; 
O equacionamento foi baseado na formulação de placas submetidas a carregamentos distribuídos em pequenas áreas e pode ser analisada em profundidade em CUSENS, A.R. \& PAMA, R.P. (1975).

A figura 3.3 apresenta o esquema de uma placa.

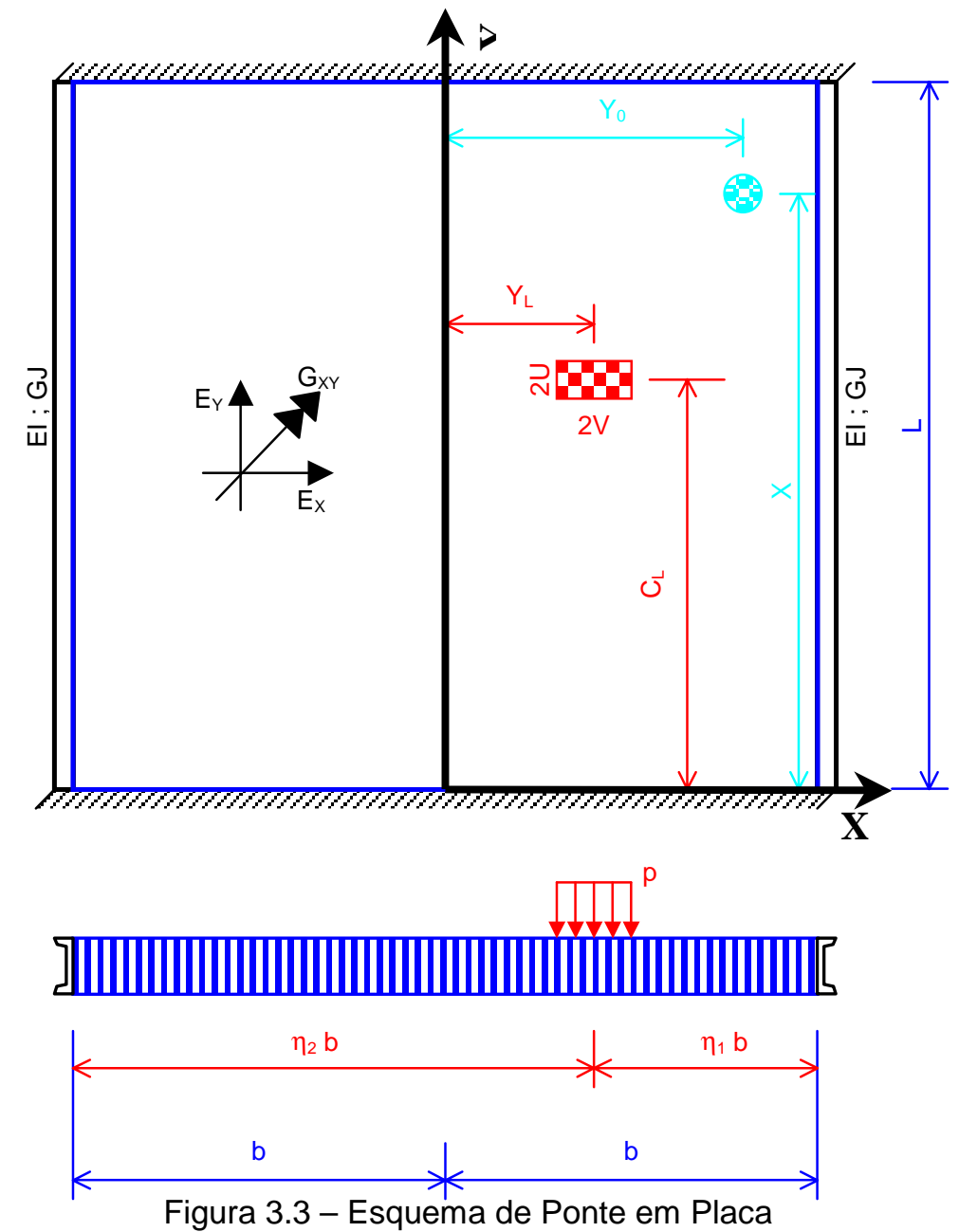

$D_{x}=E_{x} \cdot \frac{t^{3}}{12}$

$D_{Y}=E_{Y} \cdot \frac{t^{3}}{12}$

$D_{X Y}=D_{Y X}=G_{X Y} \cdot \frac{t^{3}}{12}$

$D_{1}=D_{2}=0$

$H=\frac{\left(D_{X Y}+D_{Y X}\right)}{2}$ 


$$
\begin{aligned}
& r_{3}=\sqrt{\frac{1}{2} \sqrt{\frac{D_{X}}{D_{Y}}}+\frac{H}{D_{Y}}} \\
& r_{4}=\sqrt{\frac{1}{2} \sqrt{\frac{D_{X}}{D_{Y}}}-\frac{H}{D_{Y}}} \\
& \alpha=\frac{\left(D_{X Y}+D_{Y X}\right)}{\left(2 \cdot \sqrt{\left(D_{X} \cdot D_{Y}\right)}\right)} \\
& \theta=\frac{B}{2 \cdot L} \cdot\left(\frac{D_{X}}{D_{Y}}\right)^{0,25} \\
& \beta=\frac{(2 \cdot \pi \cdot \theta)}{\sqrt{\alpha}} \\
& \psi=\frac{V}{b} \\
& \alpha_{n}=\frac{n \pi}{L} \\
& Y_{1}=Y_{0}-Y_{L} \\
& \xi_{1}=A B S\left(\frac{Y_{1}}{b}\right) \\
& \xi_{0}=\left(\frac{Y_{0}}{b}\right) \\
& \beta_{3}=\alpha_{n} \cdot b \cdot r_{3} \\
& \beta_{4}=\alpha_{n} \cdot b \cdot r_{4} \\
& \eta_{1}=\frac{\left(b-Y_{L}\right)}{b} \\
& \eta_{2}=2-\eta_{1} \\
& a_{1}=\left[D_{2}-D_{Y} \cdot\left(r_{3}{ }^{2}-r_{4}{ }^{2}\right)\right] \cdot \cosh \left(\beta_{3}\right) \cdot \cos \left(\beta_{4}\right)+2 \cdot D_{Y} \cdot r_{3} \cdot r_{4} \cdot \operatorname{senh}\left(\beta_{3}\right) \cdot \operatorname{sen}\left(\beta_{4}\right)+ \\
& +G \cdot J \cdot \alpha_{n} \cdot r_{3} \cdot \operatorname{senh}\left(\beta_{3}\right) \cdot \cos \left(\beta_{4}\right)-G \cdot J \cdot \alpha_{n} \cdot r_{4} \cdot \cosh \left(\beta_{3}\right) \cdot \operatorname{sen}\left(\beta_{4}\right)
\end{aligned}
$$


$b_{1}=\left[D_{2}-D_{Y} \cdot\left(r_{3}^{2}-r_{4}^{2}\right)\right] \cdot \cosh \left(\beta_{3}\right) \cdot \operatorname{sen}\left(\beta_{4}\right)-2 \cdot D_{Y} \cdot r_{3} \cdot r_{4} \cdot \operatorname{senh}\left(\beta_{3}\right) \cdot \cos \left(\beta_{4}\right)+$ $+G \cdot J \cdot \alpha_{n} \cdot r_{3} \cdot \operatorname{senh}\left(\beta_{3}\right) \cdot \operatorname{sen}\left(\beta_{4}\right)+G \cdot J \cdot \alpha_{n} \cdot r_{4} \cdot \cosh \left(\beta_{3}\right) \cdot \cos \left(\beta_{4}\right)$ $c_{1}=\left[D_{2}-D_{Y} \cdot\left(r_{3}{ }^{2}-r_{4}^{2}\right)\right] \cdot \operatorname{senh}\left(\beta_{3}\right) \cdot \cos \left(\beta_{4}\right)+2 \cdot D_{Y} \cdot r_{3} \cdot r_{4} \cdot \cosh \left(\beta_{3}\right) \cdot \operatorname{sen}\left(\beta_{4}\right)+$ $+G \cdot J \cdot \alpha_{n} \cdot r_{3} \cdot \cosh \left(\beta_{3}\right) \cdot \cos \left(\beta_{4}\right)-G \cdot J \cdot \alpha_{n} \cdot r_{4} \cdot \operatorname{senh}\left(\beta_{3}\right) \cdot \operatorname{sen}\left(\beta_{4}\right)$ $d_{1}=\left[D_{2}-D_{Y} \cdot\left(r_{3}{ }^{2}-r_{4}{ }^{2}\right)\right] \cdot \operatorname{senh}\left(\beta_{3}\right) \cdot \operatorname{sen}\left(\beta_{4}\right)-2 \cdot D_{Y} \cdot r_{3} \cdot r_{4} \cdot \cosh \left(\beta_{3}\right) \cdot \cos \left(\beta_{4}\right)+$ $+G \cdot J \cdot \alpha_{n} \cdot r_{3} \cdot \cosh \left(\beta_{3}\right) \cdot \operatorname{sen}\left(\beta_{4}\right)+G \cdot J \cdot \alpha_{n} \cdot r_{4} \cdot \operatorname{senh}\left(\beta_{3}\right) \cdot \cos \left(\beta_{4}\right)$

$a_{3}=\left\lfloor r_{3} \cdot\left(D_{2}+D_{X Y}+D_{Y X}\right)-D_{Y} \cdot\left(r_{3}^{3}-3 \cdot r_{3} \cdot r_{4}^{2}\right)\right] \cdot \operatorname{senh}\left(\beta_{3}\right) \cdot \cos \left(\beta_{4}\right)+$ $-\left[r_{4} \cdot\left(D_{2}+D_{X Y}+D_{Y X}\right)+D_{Y} \cdot\left(r_{4}^{3}-3 \cdot r_{4} \cdot r_{3}^{2}\right)\right] \cdot \cosh \left(\beta_{3}\right) \cdot \operatorname{sen}\left(\beta_{4}\right)+$ $+E \cdot I \cdot \alpha_{n} \cdot \cosh \left(\beta_{3}\right) \cdot \cos \left(\beta_{4}\right)$

$b_{3}=\left[r_{3} \cdot\left(D_{2}+D_{X Y}+D_{Y X}\right)-D_{Y} \cdot\left(r_{3}{ }^{3}-3 \cdot r_{3} \cdot r_{4}{ }^{2}\right)\right] \cdot \operatorname{senh}\left(\beta_{3}\right) \cdot \operatorname{sen}\left(\beta_{4}\right)+$ $+\left[r_{4} \cdot\left(D_{2}+D_{X Y}+D_{Y X}\right)+D_{Y} \cdot\left(r_{4}^{3}-3 \cdot r_{4} \cdot r_{3}^{2}\right)\right] \cdot \cosh \left(\beta_{3}\right) \cdot \cos \left(\beta_{4}\right)+$ $+E \cdot I \cdot \alpha_{n} \cdot \cosh \left(\beta_{3}\right) \cdot \operatorname{sen}\left(\beta_{4}\right)$

$c_{3}=\left\lfloor r_{3} \cdot\left(D_{2}+D_{X Y}+D_{Y X}\right)-D_{Y} \cdot\left(r_{3}{ }^{3}-3 \cdot r_{3} \cdot r_{4}^{2}\right)\right] \cdot \cosh \left(\beta_{3}\right) \cdot \cos \left(\beta_{4}\right)-$ $-\left[r_{4} \cdot\left(D_{2}+D_{X Y}+D_{Y X}\right)+D_{Y} \cdot\left(r_{4}^{3}-3 \cdot r_{4} \cdot r_{3}^{2}\right)\right] \cdot \operatorname{senh}\left(\beta_{3}\right) \cdot \operatorname{sen}\left(\beta_{4}\right)+$ $+E \cdot I \cdot \alpha_{n} \cdot \operatorname{senh}\left(\beta_{3}\right) \cdot \cos \left(\beta_{4}\right)$

$d_{3}=\left[r_{3} \cdot\left(D_{2}+D_{X Y}+D_{Y X}\right)-D_{Y} \cdot\left(r_{3}^{3}-3 \cdot r_{3} \cdot r_{4}^{2}\right)\right] \cdot \cosh \left(\beta_{3}\right) \cdot \operatorname{sen}\left(\beta_{4}\right)+$ $+\left[r_{4} \cdot\left(D_{2}+D_{X Y}+D_{Y X}\right)+D_{Y} \cdot\left(r_{4}^{3}-3 \cdot r_{4} \cdot r_{3}^{2}\right)\right] \cdot \operatorname{senh}\left(\beta_{3}\right) \cdot \cos \left(\beta_{4}\right)+$ $+E \cdot I \cdot \alpha_{n} \cdot \operatorname{senh}\left(\beta_{3}\right) \cdot \operatorname{sen}\left(\beta_{4}\right)$

$S_{1}=\frac{1}{\left(r_{3}^{2}+r_{4}^{2}\right)}\left\langle\left\{G \cdot J \cdot \alpha_{n}-\frac{r_{3} \cdot\left[D_{2}-D_{Y} \cdot\left(r_{3}^{2}+r_{4}^{2}\right)\right]}{\left(r_{3}^{2}+r_{4}^{2}\right)}\right\} \times\right.$

$\times\left\{\left[r_{3} \cdot \operatorname{sen}\left(\beta_{4} \cdot\left(\eta_{1}-\psi\right)\right)+r_{4} \cdot \cos \left(\beta_{4} \cdot\left(\eta_{1}-\psi\right)\right)\right] \cdot e^{-\beta_{3} \cdot\left(\eta_{1}-\psi\right)}-\right.$ $\left.-\left[r_{3} \cdot \operatorname{sen}\left(\beta_{4} \cdot\left(\eta_{1}+\psi\right)\right)+r_{4} \cdot \cos \left(\beta_{4} \cdot\left(\eta_{1}+\psi\right)\right)\right] \cdot e^{-\beta_{3} \cdot\left(\eta_{1}+\psi\right)}\right\}_{-}$ $-\left\{\frac{r_{4} \cdot\left[D_{2}+D_{Y} \cdot\left(r_{3}^{2}+r_{4}^{2}\right)\right]}{\left(r_{3}^{2}+r_{4}^{2}\right)}\right\} \times$

$\times\left\{\left[r_{3} \cdot \cos \left(\beta_{4} \cdot\left(\eta_{1}-\psi\right)\right)-r_{4} \cdot \operatorname{sen}\left(\beta_{4} \cdot\left(\eta_{1}-\psi\right)\right)\right] \cdot e^{-\beta_{3} \cdot\left(\eta_{1}-\psi\right)}-\right.$ $\left.\left.-\left[r_{3} \cdot \cos \left(\beta_{4} \cdot\left(\eta_{1}+\psi\right)\right)-r_{4} \cdot \operatorname{sen}\left(\beta_{4} \cdot\left(\eta_{1}+\psi\right)\right)\right] \cdot e^{-\beta_{3} \cdot\left(\eta_{1}+\psi\right)}\right\}\right)$ 
74

$$
\begin{aligned}
& S_{2}=\frac{1}{\left(r_{3}^{2}+r_{4}^{2}\right)} /\left\{G \cdot J \cdot \alpha_{n}-\frac{r_{3} \cdot\left[D_{2}-D_{Y} \cdot\left(r_{3}^{2}+r_{4}^{2}\right)\right]}{\left(r_{3}^{2}+r_{4}^{2}\right)}\right\} \times \\
& \times\left\{\left[r_{3} \cdot \operatorname{sen}\left(\beta_{4} \cdot\left(\eta_{2}-\psi\right)\right)+r_{4} \cdot \cos \left(\beta_{4} \cdot\left(\eta_{2}-\psi\right)\right)\right] \cdot e^{-\beta_{3} \cdot\left(\eta_{2}-\psi\right)}-\right. \\
& \left.-\left[r_{3} \cdot \operatorname{sen}\left(\beta_{4} \cdot\left(\eta_{2}+\psi\right)\right)+r_{4} \cdot \cos \left(\beta_{4} \cdot\left(\eta_{2}+\psi\right)\right)\right] \cdot e^{-\beta_{3} \cdot\left(\eta_{2}+\psi\right)}\right\}- \\
& -\left\{\frac{r_{4} \cdot\left[D_{2}+D_{Y} \cdot\left(r_{3}^{2}+r_{4}{ }^{2}\right)\right]}{\left(r_{3}^{2}+r_{4}^{2}\right)}\right\} \times \\
& \times\left\{\left[r_{3} \cdot \cos \left(\beta_{4} \cdot\left(\eta_{2}-\psi\right)\right)-r_{4} \cdot \operatorname{sen}\left(\beta_{4} \cdot\left(\eta_{2}-\psi\right)\right)\right] \cdot e^{-\beta_{3} \cdot\left(\eta_{2}-\psi\right)}-\right. \\
& \left.-\left[r_{3} \cdot \cos \left(\beta_{4} \cdot\left(\eta_{2}+\psi\right)\right)-r_{4} \cdot \operatorname{sen}\left(\beta_{4} \cdot\left(\eta_{2}+\psi\right)\right)\right] \cdot e^{-\beta_{3} \cdot\left(\eta_{2}+\psi\right)}\right\}
\end{aligned}
$$

$$
\begin{aligned}
& S_{3}=\frac{1}{\left(r_{3}^{2}+r_{4}^{2}\right)^{2}}\left\langle\left\{\left[D_{Y} \cdot\left(r_{4}^{2}-r_{3}^{2}\right)+D_{2}+D_{X Y}+D_{Y X}\right] \cdot\left(r_{3}^{2}+r_{4}^{2}\right)-E \cdot I \cdot \alpha_{n} \cdot r_{3}\right\} \times\right. \\
& \times\left\{\left[r_{3} \cdot \operatorname{sen}\left(\beta_{4} \cdot\left(\eta_{1}-\psi\right)\right)+r_{4} \cdot \cos \left(\beta_{4} \cdot\left(\eta_{1}-\psi\right)\right)\right] \cdot e^{-\beta_{3} \cdot\left(\eta_{1}-\psi\right)}-\right. \\
& \left.-\left[r_{3} \cdot \operatorname{sen}\left(\beta_{4} \cdot\left(\eta_{1}+\psi\right)\right)+r_{4} \cdot \cos \left(\beta_{4} \cdot\left(\eta_{1}+\psi\right)\right)\right] \cdot e^{-\beta_{3} \cdot\left(\eta_{1}+\psi\right)}\right\}+ \\
& +\left\{2 \cdot D_{Y} \cdot r_{3} \cdot r_{4}\left(r_{3}^{2}+r_{4}^{2}\right)-E \cdot I \cdot \alpha_{n} \cdot r_{4}\right\} \times \\
& \times\left\{\left[r_{3} \cdot \cos \left(\beta_{4} \cdot\left(\eta_{1}-\psi\right)\right)-r_{4} \cdot \operatorname{sen}\left(\beta_{4} \cdot\left(\eta_{1}-\psi\right)\right)\right] \cdot e^{-\beta_{3} \cdot\left(\eta_{1}-\psi\right)}-\right. \\
& \left.\left.-\left[r_{3} \cdot \cos \left(\beta_{4} \cdot\left(\eta_{1}+\psi\right)\right)-r_{4} \cdot \operatorname{sen}\left(\beta_{4} \cdot\left(\eta_{1}+\psi\right)\right)\right] \cdot e^{-\beta_{3} \cdot\left(\eta_{1}+\psi\right)}\right\}\right\rangle
\end{aligned}
$$

$$
\begin{aligned}
& S_{4}=\frac{1}{\left(r_{3}{ }^{2}+r_{4}^{2}\right)^{2}}\left\langle\left\{\left[D_{Y} \cdot\left(r_{4}^{2}-r_{3}^{2}\right)+D_{2}+D_{X Y}+D_{Y X}\right] \cdot\left(r_{3}^{2}+r_{4}^{2}\right)+E \cdot I \cdot \alpha_{n} \cdot r_{3}\right\} \times\right. \\
& \times\left\{\left[r_{3} \cdot \operatorname{sen}\left(\beta_{4} \cdot\left(\eta_{2}-\psi\right)\right)+r_{4} \cdot \cos \left(\beta_{4} \cdot\left(\eta_{2}-\psi\right)\right)\right] \cdot e^{-\beta_{3} \cdot\left(\eta_{2}-\psi\right)}-\right. \\
& \left.-\left[r_{3} \cdot \operatorname{sen}\left(\beta_{4} \cdot\left(\eta_{2}+\psi\right)\right)+r_{4} \cdot \cos \left(\beta_{4} \cdot\left(\eta_{2}+\psi\right)\right)\right] \cdot e^{-\beta_{3} \cdot\left(\eta_{2}+\psi\right)}\right\}_{-} \\
& -\left\{2 \cdot D_{Y} \cdot r_{3} \cdot r_{4}\left(r_{3}{ }^{2}+r_{4}^{2}\right)-E \cdot I \cdot \alpha_{n} \cdot r_{4}\right\} \times \\
& \times\left\{\left[r_{3} \cdot \cos \left(\beta_{4} \cdot\left(\eta_{2}-\psi\right)\right)-r_{4} \cdot \operatorname{sen}\left(\beta_{4} \cdot\left(\eta_{2}-\psi\right)\right)\right] \cdot e^{-\beta_{3} \cdot\left(\eta_{2}-\psi\right)}-\right. \\
& \left.\left.-\left[r_{3} \cdot \cos \left(\beta_{4} \cdot\left(\eta_{2}+\psi\right)\right)-r_{4} \cdot \operatorname{sen}\left(\beta_{4} \cdot\left(\eta_{2}+\psi\right)\right)\right] \cdot e^{-\beta_{3} \cdot\left(\eta_{2}+\psi\right)}\right\}\right\rangle
\end{aligned}
$$

$$
\begin{aligned}
& A=\frac{\left(S_{1}+S_{2}\right) \cdot d_{3}-\left(S_{3}-S_{4}\right) \cdot d_{1}}{2 \cdot\left(a_{1} \cdot d_{3}-a_{3} \cdot d_{1}\right)} \\
& B=\frac{\left(S_{1}-S_{2}\right) \cdot c_{3}-\left(S_{3}+S_{4}\right) \cdot c_{1}}{2 \cdot\left(b_{1} \cdot c_{3}-b_{3} \cdot c_{1}\right)} \\
& C=\frac{\left(S_{3}+S_{4}\right) \cdot b_{1}-\left(S_{1}-S_{2}\right) \cdot b_{3}}{2 \cdot\left(b_{1} \cdot c_{3}-b_{3} \cdot c_{1}\right)}
\end{aligned}
$$


$D=\frac{\left(S_{3}-S_{4}\right) \cdot a_{1}-\left(S_{1}+S_{2}\right) \cdot a_{3}}{2 \cdot\left(a_{1} \cdot d_{3}-a_{3} \cdot d_{1}\right)}$

$K_{A}^{*}=A \cdot\left\{\cosh \left(\beta_{3} \cdot \xi_{0}\right) \cdot \cos \left(\beta_{4} \cdot \xi_{0}\right)\right\}+$

$+B \cdot\left\{\cosh \left(\beta_{3} \cdot \xi_{0}\right) \cdot \operatorname{sen}\left(\beta_{4} \cdot \xi_{0}\right)\right\}_{+}$

$+C \cdot\left\{\operatorname{senh}\left(\beta_{3} \cdot \xi_{0}\right) \cdot \cos \left(\beta_{4} \cdot \xi_{0}\right)\right\}+$

$+D \cdot\left\{\operatorname{senh}\left(\beta_{3} \cdot \xi_{0}\right) \cdot \operatorname{sen}\left(\beta_{4} \cdot \xi_{0}\right)\right\}$

$K_{B}^{*}=A \cdot\left\{\begin{array}{l}\left(r_{3}^{2}-r_{4}^{2}\right) \cdot \cosh \left(\beta_{3} \cdot \xi_{0}\right) \cdot \cos \left(\beta_{4} \cdot \xi_{0}\right)- \\ -2 \cdot r_{3} \cdot r_{4} \cdot \operatorname{senh}\left(\beta_{3} \cdot \xi_{0}\right) \cdot \operatorname{sen}\left(\beta_{4} \cdot \xi_{0}\right)\end{array}\right\}+$

$+B \cdot\left\{\begin{array}{l}\left(r_{3}{ }^{2}-r_{4}{ }^{2}\right) \cdot \cosh \left(\beta_{3} \cdot \xi_{0}\right) \cdot \operatorname{sen}\left(\beta_{4} \cdot \xi_{0}\right)+ \\ +2 \cdot r_{3} \cdot r_{4} \cdot \operatorname{senh}\left(\beta_{3} \cdot \xi_{0}\right) \cdot \cos \left(\beta_{4} \cdot \xi_{0}\right)\end{array}\right\}+$

$+C \cdot\left\{\begin{array}{l}\left(r_{3}^{2}-r_{4}^{2}\right) \cdot \operatorname{senh}\left(\beta_{3} \cdot \xi_{0}\right) \cdot \cos \left(\beta_{4} \cdot \xi_{0}\right)- \\ -2 \cdot r_{3} \cdot r_{4} \cdot \cosh \left(\beta_{3} \cdot \xi_{0}\right) \cdot \operatorname{sen}\left(\beta_{4} \cdot \xi_{0}\right)\end{array}\right\}+$

$+D \cdot\left\{\begin{array}{l}\left(r_{3}^{2}-r_{4}^{2}\right) \cdot \operatorname{senh}\left(\beta_{3} \cdot \xi_{0}\right) \cdot \operatorname{sen}\left(\beta_{4} \cdot \xi_{0}\right)+ \\ +2 \cdot r_{3} \cdot r_{4} \cdot \cosh \left(\beta_{3} \cdot \xi_{0}\right) \cdot \cos \left(\beta_{4} \cdot \xi_{0}\right)\end{array}\right\}$

$K_{C}^{*}=A \cdot\left\{r_{3} \cdot \operatorname{senh}\left(\beta_{3} \cdot \xi_{0}\right) \cdot \cos \left(\beta_{4} \cdot \xi_{0}\right)-r_{4} \cdot \cosh \left(\beta_{3} \cdot \xi_{0}\right) \cdot \operatorname{sen}\left(\beta_{4} \cdot \xi_{0}\right)\right\}_{+}$

$+B \cdot\left\{r_{3} \cdot \operatorname{senh}\left(\beta_{3} \cdot \xi_{0}\right) \cdot \operatorname{sen}\left(\beta_{4} \cdot \xi_{0}\right)+r_{4} \cdot \cosh \left(\beta_{3} \cdot \xi_{0}\right) \cdot \cos \left(\beta_{4} \cdot \xi_{0}\right)\right\}+$

$+C \cdot\left\{r_{3} \cdot \cosh \left(\beta_{3} \cdot \xi_{0}\right) \cdot \cos \left(\beta_{4} \cdot \xi_{0}\right)-r_{4} \cdot \operatorname{senh}\left(\beta_{3} \cdot \xi_{0}\right) \cdot \operatorname{sen}\left(\beta_{4} \cdot \xi_{0}\right)\right\}_{+}$

$+D \cdot\left\{r_{3} \cdot \cosh \left(\beta_{3} \cdot \xi_{0}\right) \cdot \operatorname{sen}\left(\beta_{4} \cdot \xi_{0}\right)+r_{4} \cdot \operatorname{senh}\left(\beta_{3} \cdot \xi_{0}\right) \cdot \cos \left(\beta_{4} \cdot \xi_{0}\right)\right\}$

$K_{D}^{*}=A \cdot\left\{\begin{array}{l}\left(r_{3}{ }^{3}-3 \cdot r_{3} \cdot r_{4}{ }^{2}\right) \cdot \operatorname{senh}\left(\beta_{3} \cdot \xi_{0}\right) \cdot \cos \left(\beta_{4} \cdot \xi_{0}\right)+ \\ +\left(r_{4}{ }^{3}-3 \cdot r_{4} \cdot r_{3}{ }^{2}\right) \cdot \cosh \left(\beta_{3} \cdot \xi_{0}\right) \cdot \operatorname{sen}\left(\beta_{4} \cdot \xi_{0}\right)\end{array}\right\}+$

$+B \cdot\left\{\begin{array}{l}\left(r_{3}{ }^{3}-3 \cdot r_{3} \cdot r_{4}{ }^{2}\right) \cdot \operatorname{senh}\left(\beta_{3} \cdot \xi_{0}\right) \cdot \operatorname{sen}\left(\beta_{4} \cdot \xi_{0}\right)- \\ -\left(r_{4}{ }^{3}-3 \cdot r_{4} \cdot r_{3}{ }^{2}\right) \cdot \cosh \left(\beta_{3} \cdot \xi_{0}\right) \cdot \cos \left(\beta_{4} \cdot \xi_{0}\right)\end{array}\right\}+$

$+C \cdot\left\{\begin{array}{l}\left(r_{3}{ }^{3}-3 \cdot r_{3} \cdot r_{4}{ }^{2}\right) \cdot \cosh \left(\beta_{3} \cdot \xi_{0}\right) \cdot \cos \left(\beta_{4} \cdot \xi_{0}\right)+ \\ +\left(r_{4}{ }^{3}-3 \cdot r_{4} \cdot r_{3}\right) \cdot \operatorname{senh}\left(\beta_{3} \cdot \xi_{0}\right) \cdot \operatorname{sen}\left(\beta_{4} \cdot \xi_{0}\right)\end{array}\right\}+$

$+D \cdot\left\{\begin{array}{l}\left(r_{3}{ }^{3}-3 \cdot r_{3} \cdot r_{4}{ }^{2}\right) \cdot \cosh \left(\beta_{3} \cdot \xi_{0}\right) \cdot \operatorname{sen}\left(\beta_{4} \cdot \xi_{0}\right)- \\ -\left(r_{4}{ }^{3}-3 \cdot r_{4} \cdot r_{3}{ }^{2}\right) \cdot \operatorname{senh}\left(\beta_{3} \cdot \xi_{0}\right) \cdot \cos \left(\beta_{4} \cdot \xi_{0}\right)\end{array}\right\}$ 
Para: $\xi_{1}>\psi$

$$
\begin{aligned}
& K_{1}^{*}=\frac{D_{X}}{4 \cdot D_{Y} \cdot r_{3} \cdot r_{4}} \cdot\left[\frac{1}{\left(r_{3}^{2}+r_{4}^{2}\right)^{2}} \cdot\left\{\begin{array}{l}
{\left[\begin{array}{l}
2 \cdot r_{3} \cdot r_{4} \cdot \cos \left(\beta_{4} \cdot\left(\xi_{1}-\psi\right)\right)+ \\
+\left(r_{3}^{2}-r_{4}^{2}\right) \cdot \operatorname{sen}\left(\beta_{4} \cdot\left(\xi_{1}-\psi\right)\right)
\end{array}\right] \cdot e^{-\beta_{3} \cdot\left(\xi_{1}-\psi\right)}-} \\
-\left[\begin{array}{l}
2 \cdot r_{3} \cdot r_{4} \cdot \cos \left(\beta_{4} \cdot\left(\xi_{1}+\psi\right)\right)+ \\
+\left(r_{3}^{2}-r_{4}^{2}\right) \cdot \operatorname{sen}\left(\beta_{4} \cdot\left(\xi_{1}+\psi\right)\right)
\end{array}\right] \cdot e^{-\beta_{3} \cdot\left(\xi_{1}+\psi\right)}
\end{array}\right\}+K_{A}^{*}\right] \\
& K_{2}^{*}=\frac{D_{X}}{4 \cdot D_{Y} \cdot r_{3} \cdot r_{4}} \cdot\left[\operatorname{sen}\left(\beta_{4} \cdot\left(\xi_{1}-\psi\right)\right) \cdot e^{-\beta_{3} \cdot\left(\xi_{1}-\psi\right)}-\operatorname{sen}\left(\beta_{4} \cdot\left(\xi_{1}+\psi\right)\right) \cdot e^{-\beta_{3} \cdot\left(\xi_{1}+\psi\right)}+K_{B}^{*}\right]
\end{aligned}
$$

Para: $\xi_{1}<\psi$

$$
\left.\begin{array}{l}
K_{1}^{*}=\frac{D_{X}}{4 \cdot D_{Y} \cdot r_{3} \cdot r_{4}} \cdot\left[\frac{1}{\left(r_{3}^{2}+r_{4}^{2}\right)^{2}} \cdot\left\{\begin{array}{l}
4 \cdot r_{3} \cdot r_{4}+ \\
{\left[\begin{array}{l}
\left(r_{4}^{2}-r_{3}^{2}\right) \cdot \operatorname{sen}\left(\beta_{4} \cdot\left(\psi+\xi_{1}\right)\right)- \\
-2 \cdot r_{3} \cdot r_{4} \cdot \cos \left(\beta_{4} \cdot\left(\psi+\xi_{1}\right)\right)
\end{array}\right] \cdot e^{-\beta_{3} \cdot\left(\psi+\xi_{1}\right)}+} \\
{\left[\begin{array}{l}
\left(r_{4}^{2}-r_{3}^{2}\right) \cdot \operatorname{sen}\left(\beta_{4} \cdot\left(\psi-\xi_{1}\right)\right)- \\
-2 \cdot r_{3} \cdot r_{4} \cdot \cos \left(\beta_{4} \cdot\left(\psi-\xi_{1}\right)\right)
\end{array}\right] \cdot e^{-\beta_{3} \cdot\left(\psi-\xi_{1}\right)}}
\end{array}\right]+K_{A}^{*}\right.
\end{array}\right]
$$

Para: $\xi_{1} \neq \psi$

$$
\begin{aligned}
& K_{3}^{*}=\frac{1}{4 \cdot r_{3} \cdot r_{4}} \cdot\left[\frac{ \pm 1}{\left(r_{3}^{2}+r_{4}^{2}\right)} \cdot\left\{\begin{array}{l}
\left.\left.\left[\begin{array}{l}
r_{3} \cdot \operatorname{sen}\left(\beta_{4} \cdot\left(\xi_{1}+\psi\right)\right)+ \\
+r_{4} \cdot \cos \left(\beta_{4} \cdot\left(\xi_{1}+\psi\right)\right) \cdot e^{-\beta_{3}\left(\xi_{1}+\psi\right)}
\end{array}\right]-\left[\begin{array}{l}
r_{3} \cdot \operatorname{sen}\left(\beta_{4} \cdot\left(\xi_{1}-\psi\right)\right)+ \\
+r_{4} \cdot \cos \left(\beta_{4} \cdot\left(\xi_{1}-\psi\right)\right) \cdot e^{-\beta_{3} \cdot\left(\xi_{1}-\psi\right)}
\end{array}\right]\right\}+K_{C}^{*}\right] \\
K_{4}^{*}=\frac{1}{4 \cdot r_{3} \cdot r_{4}} \cdot \pm 1 \cdot\left\{\begin{array}{l}
{\left[\begin{array}{l}
r_{4} \cdot \cos \left(\beta_{4} \cdot\left(\xi_{1}-\psi\right)\right)- \\
-r_{3} \cdot \operatorname{sen}\left(\beta_{4} \cdot\left(\xi_{1}-\psi\right)\right)
\end{array}\right] \cdot e^{-\beta_{3} \cdot\left(\xi_{1}-\psi\right)}-} \\
-\left[\begin{array}{l}
r_{4} \cdot \cos \left(\beta_{4} \cdot\left(\xi_{1}+\psi\right)\right)- \\
-r_{3} \cdot \operatorname{sen}\left(\beta_{4} \cdot\left(\xi_{1}+\psi\right)\right)
\end{array}\right] \cdot e^{-\beta_{3}\left(\xi_{1}+\psi\right)}
\end{array}\right\}+K_{D}^{*}
\end{array}\right]\right.
\end{aligned}
$$


Para: $\xi_{1}=0$

$$
\begin{aligned}
& K_{1}^{*}=\frac{D_{X}}{4 \cdot D_{Y} \cdot r_{3} \cdot r_{4}} \cdot\left[\frac{2}{\left(r_{3}^{2}+r_{4}^{2}\right)^{2}} \cdot\left\{2 \cdot r_{3} \cdot r_{4}-\left[\begin{array}{l}
2 \cdot r_{3} \cdot r_{4} \cdot \cos \left(\beta_{4} \cdot \psi\right)+ \\
+\left(r_{3}^{2}-r_{4}^{2}\right) \cdot \operatorname{sen}\left(\beta_{4}\right)
\end{array}\right] \cdot e^{-\beta_{3} \cdot \psi}\right\}+K_{A}^{*}\right] \\
& K_{2}^{*}=\frac{D_{X}}{4 \cdot D_{Y} \cdot r_{3} \cdot r_{4}} \cdot\left[-2 \cdot \operatorname{sen}\left(\beta_{4} \cdot \psi\right) \cdot e^{-\beta_{3} \cdot \psi}+K_{B}^{*}\right] \\
& K_{3}^{*}=\frac{1}{4 \cdot r_{3} \cdot r_{4}} \cdot K_{C}^{*} \\
& K_{4}^{*}=\frac{1}{4 \cdot r_{3} \cdot r_{4}} \cdot K_{D}^{*} \\
& W=\frac{P \cdot L^{4}}{u \cdot V \cdot \pi^{5} \cdot D_{X}} \cdot \sum_{n=1}^{\infty}\left[\frac{1}{n^{5}}\left(\operatorname{sen}\left(\alpha_{n} \cdot U\right) \cdot \operatorname{sen}\left(\alpha_{n} \cdot X_{C}\right) \cdot \operatorname{sen}\left(\alpha_{n} \cdot X_{R}\right)\right) \cdot\left(K_{1}^{*}\right)\right] \\
& M_{X}=\frac{P \cdot L^{2}}{u \cdot V \cdot \pi^{3}} \cdot \sum_{n=1}^{\infty}\left[\frac{1}{n^{3}}\left(\operatorname{sen}\left(\alpha_{n} \cdot U\right) \cdot \operatorname{sen}\left(\alpha_{n} \cdot X_{C}\right) \cdot \operatorname{sen}\left(\alpha_{n} \cdot X_{R}\right)\right) \cdot\left(K_{1}^{*}-\frac{D_{1}}{D_{X}} \cdot K_{2}^{*}\right)\right] \\
& M_{Y}=\frac{-P \cdot L^{2}}{U \cdot V \cdot \pi^{3}} \cdot \sum_{n=1}^{\infty}\left[\frac{1}{n^{3}}\left(\operatorname{sen}\left(\alpha_{n} \cdot U\right) \cdot \operatorname{sen}\left(\alpha_{n} \cdot X_{C}\right) \cdot \operatorname{sen}\left(\alpha_{n} \cdot X_{R}\right)\right) \cdot\left(\frac{D_{Y}}{D_{X}} \cdot K_{2}^{*}-\frac{D_{2}}{D_{X}} \cdot K_{1}^{*}\right)\right] \\
& V_{X}=\frac{P \cdot L}{u \cdot V \cdot \pi^{2}} \cdot \sum_{n=1}^{\infty}\left[\frac{1}{n^{2}}\left(\operatorname{sen}\left(\alpha_{n} \cdot U\right) \cdot \operatorname{sen}\left(\alpha_{n} \cdot X_{C}\right) \cdot \cos \left(\alpha_{n} \cdot X_{R}\right)\right) \cdot\left(K_{1}^{*}-\frac{D_{1}+D_{Y X}}{D_{X}} \cdot K_{2}^{*}\right)\right] \\
& M_{X Y}=-M_{Y X}=\frac{P \cdot L^{2}}{U \cdot V \cdot \pi^{2}} \cdot \sum_{n=1}^{\infty}\left[\frac{1}{n^{2}}\left(\operatorname{sen}\left(\alpha_{n} \cdot U\right) \cdot \operatorname{sen}\left(\alpha_{n} \cdot X_{C}\right) \cdot \operatorname{sen}\left(\alpha_{n} \cdot X_{R}\right)\right) \cdot\left(K_{4}^{*}-\frac{D_{2}+D_{X Y}}{D_{Y}} \cdot K_{3}^{*}\left(\operatorname{sen}\left(\alpha_{n} \cdot U\right) \cdot \operatorname{sen}\left(\alpha_{n} \cdot X_{C}\right) \cdot \cos \left(\alpha_{n} \cdot X_{R}\right)\right) \cdot\left(\frac{D_{X Y}}{D_{Y}} \cdot K_{3}^{*}\right)\right]\right.
\end{aligned}
$$




\subsection{Metodologia Experimental}

Na parte experimental pretende-se estudar vários tópicos. São eles:

- comportamento da madeira quando submetida à compressão normal às fibras em carregamentos de longa duração;

- análise da perda de protensão para diferentes classes de resistência, sistemas de protensão, níveis de protensão, relações entre área de aço e área de madeira e condições de umidade;

- análise da perda de protensão de tabuleiros em laboratório e pontes em campo;

- verificação do comportamento estrutural de tabuleiros sob carregamento estático visando avaliar a segurança do sistema.

A metodologia experimental, a seguir, é apresentada em três tópicos. No primeiro, são apresentados os materiais e os procedimentos de ensaio da análise de fluência de conjuntos de peças de madeira submetidos a uma compressão normal às fibras constante. No segundo tópico, veremos os corpos-de-prova utilizados nas análises de perda de protensão. Finalizando, são apresentadas as pontes que forneceram subsídios para uma análise de perda de protensão ao longo de 4 anos, aproximadamente.

\subsubsection{Análise de Fluência;}

O comportamento ao longo do tempo da madeira quando submetida a compressão normal às fibras foi estudado bem como o comportamento de conjuntos de 12 elementos representando o tabuleiros protendido. Estes ensaios proporcionaram valores de deformabilidade individual da madeira e dos conjuntos ao longo do tempo. 


\section{Madeira}

26 peças de $6 \mathrm{~cm} \times 16 \mathrm{~cm} \times 60 \mathrm{~cm}$ de Pinus Taeda;

26 peças de $6 \mathrm{~cm}$ x $16 \mathrm{~cm}$ x 60cm de Eucalipto Citriodora;

Corpos-de-prova de compressão paralela, compressão normal e deformação lenta;
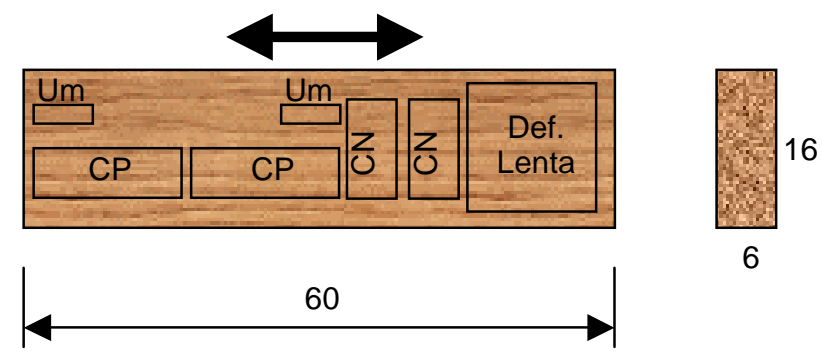

\section{Acessórios}

Relógios comparadores, termômetro e filme plástico

\section{Equipamentos}

Pórtico de Ensaio de Deformação Lenta (figura 3.4)

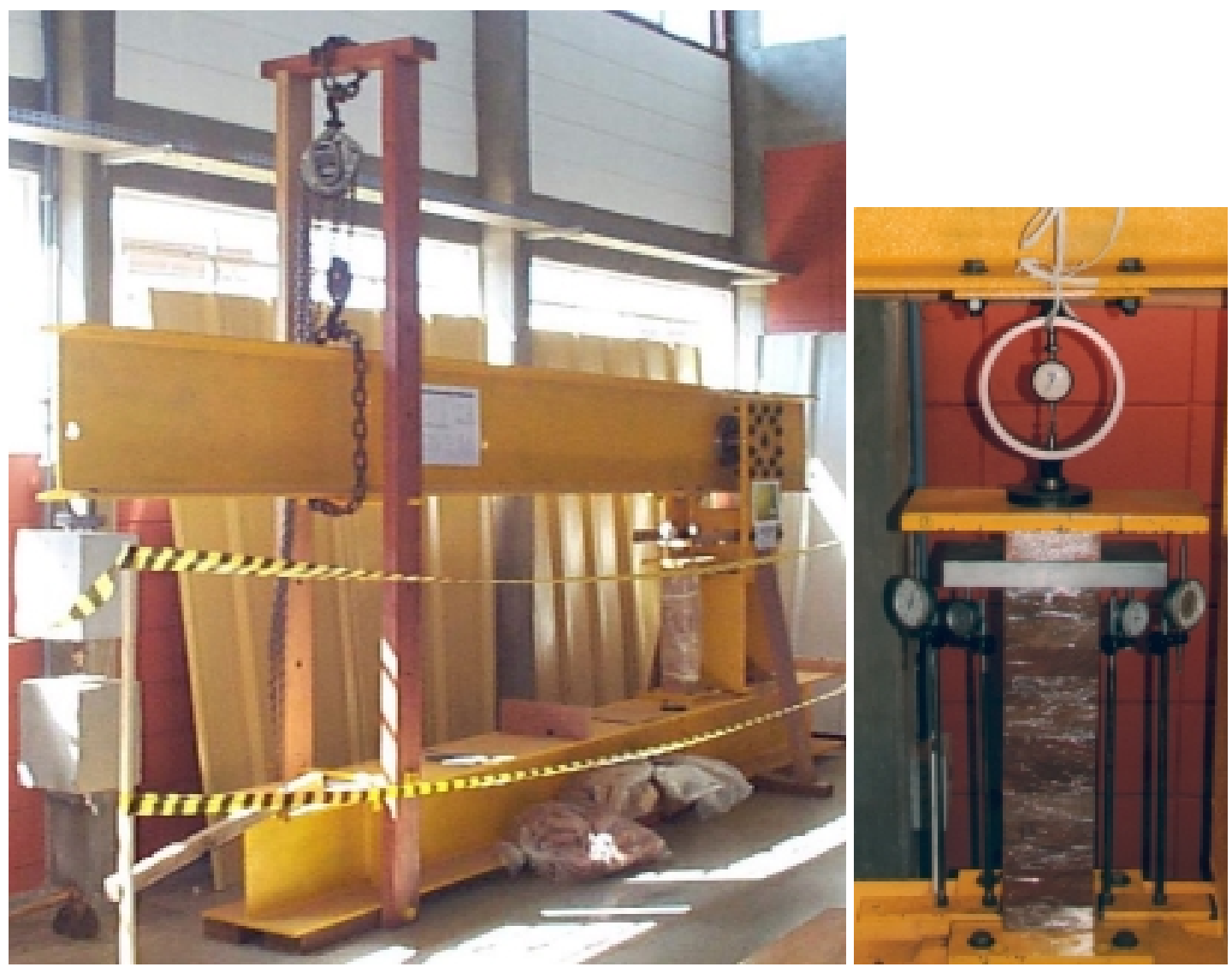

Figura 3.4 - Pórtico de ensaio de Deformação lenta e Corpo-de-prova 


\section{Procedimentos de Ensaio}

1. Caracterização dos lotes de Madeira utilizados nos modelos Foi efetuada a caracterização simplificada pois se tratam de espécies de madeira já avaliadas por laboratórios. Portanto, foram realizados ensaios de compressão paralela às fibras como previsto na NBR 7190/1997 bem como ensaios de compressão normal às fibras visto que é a solicitação mais importante do sistema protendido. Foram analisadas as classes de resistência C25 (Pinus) e C40 (Eucalipto Citriodora).

\section{Ensaios de Deformação Lenta}

Foram realizados 4 ensaios no período de 8 meses totalizando 60 dias para cada corpo-de-prova nos quais foi aplicada uma tensão de 0,175 kN/cm², equivalente a uma força de, aproximadamente, $30 \mathrm{kN}$. Esta tensão equivale a 2,5 o valor do nível de protensão de projeto de $0,07 \mathrm{kN} / \mathrm{cm}^{2}$. Foram controladas as variáveis temperatura, umidade e deslocamentos no corpode-prova. A madeira utilizada foi retirada de lotes caracterizados com ensaios de compressão paralela e normal às fibras.

O esquema dos corpos-de-prova ensaiados está apresentado na figura 3.5. Foi avaliada em série uma peça individual de $13 \mathrm{~cm} \times 13 \mathrm{~cm} \times 5 \mathrm{~cm}$ e um conjunto de 12 peças de madeira de seção $13 \mathrm{~cm} \times 13 \mathrm{~cm} \times 5 \mathrm{~cm}$ formando um elemento laminado de $60 \mathrm{~cm}$ de altura.
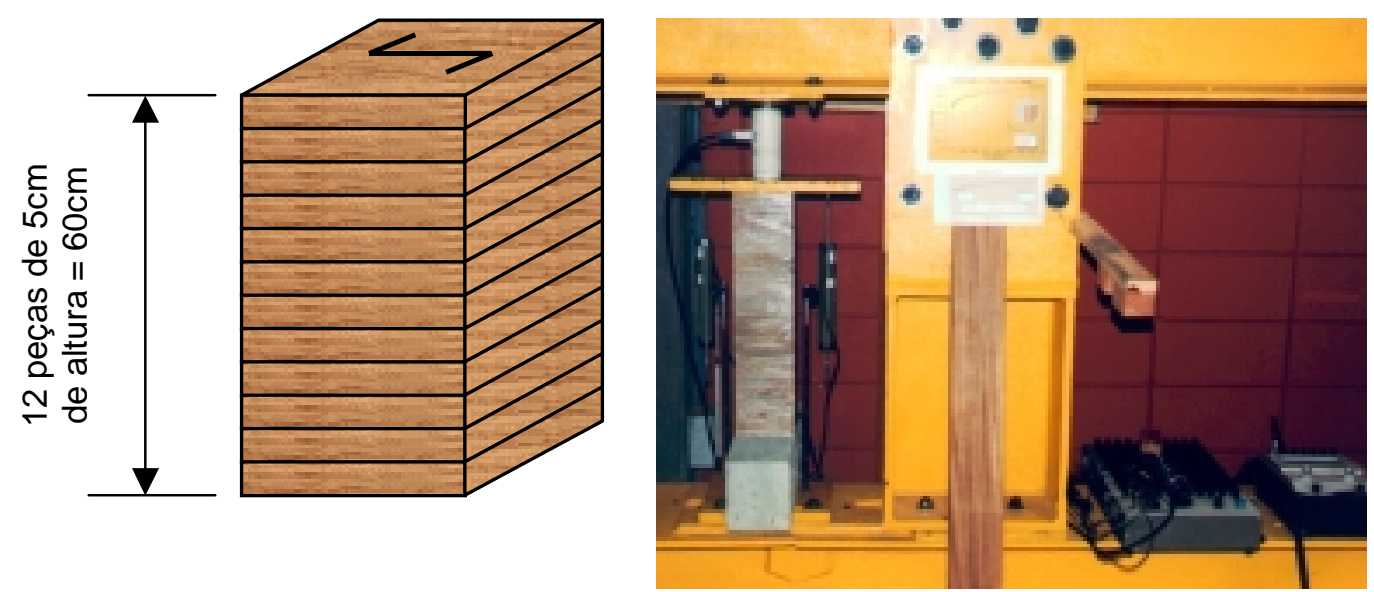

Figura 3.5 - Esquema dos Corpos-de-prova para o Ensaio de Deformação Lenta. 
3.3.2 Análise da Perda de Protensão em Corpos-de-prova;

Constitui uma parte experimental importante do trabalho. Os resultados obtidos contribuirão para o entendimento da protensão ao longo do tempo bem como as principais variáveis responsáveis pelo fenômeno. Neste sentido, será possível manipular tais variáveis em projeto propiciando qualidade e durabilidade à obra.

Em primeiro lugar são apresentados os materiais e procedimentos para corpos-de-prova constituídos por conjuntos de 20 peças de $13 \mathrm{~cm} \times 13 \mathrm{~cm}$ por $5 \mathrm{~cm}$ de espessura protendidos por uma barra de aço. Em seguida, apresentam-se os tabuleiros constituídos por 20 vigas de $5 \mathrm{~cm} \times 20 \mathrm{~cm}$ por $480 \mathrm{~cm}$ de comprimento protendidos por 4 barras de aço.

Corpos-de-prova Discretos.

\section{Madeira}

216 peças de $5 \mathrm{~cm} \times 20 \mathrm{~cm} \times 65 \mathrm{~cm}$ de Pinus Taeda;

216 peças de $5 \mathrm{~cm} \times 20 \mathrm{~cm} \times 65 \mathrm{~cm}$ de Eucalipto Citriodora;

Corpos-de-prova de Compressão paralela, compressão normal e perda de protensão;

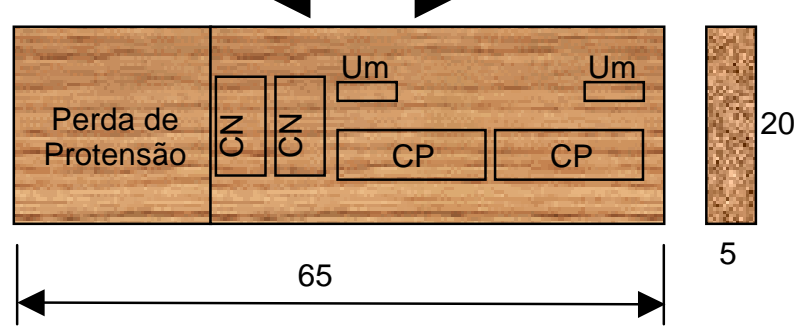

\section{Elementos de Aço}

\section{Dywidag e Outros}

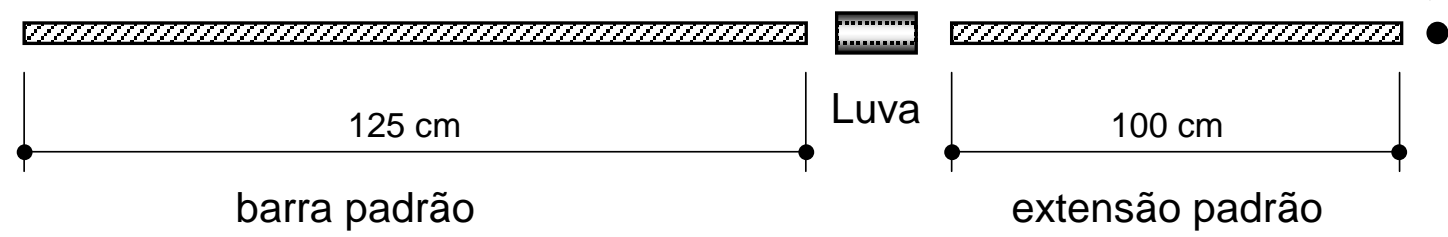




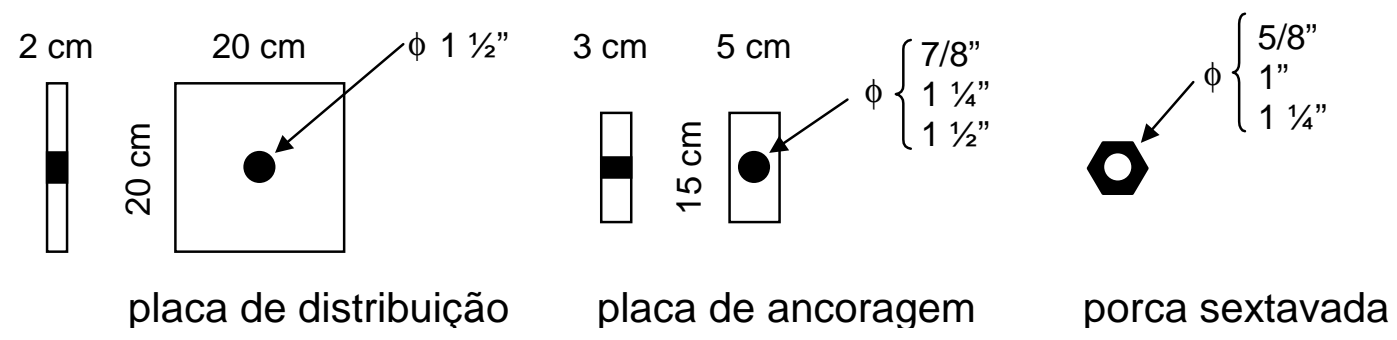

- 4 barras $\phi=16 \mathrm{~mm}$ (ST 110-125) $-\mathrm{c}=125 \mathrm{~cm}$ da Dywidag;

1 extensão de barra $\phi=16 \mathrm{~mm}$ (ST 110-125) $-\mathrm{c}=100 \mathrm{~cm}$ da Dywidag;

1 luva $\phi=16 \mathrm{~mm}$ da Dywidag;

8 porcas sextavadas para $\phi=16 \mathrm{~mm}$ da Dywidag;

8 placas de ancoragem (SAE 1020);

8 placas de distribuição (SAE 1020);

- 6 barras $\phi=25 \mathrm{~mm}$ (ST 85-105) $-\mathrm{c}=125 \mathrm{~cm}$ da Dywidag;

1 extensão de barra $\phi=25 \mathrm{~mm}$ (ST 85-105) $-\mathrm{c}=100 \mathrm{~cm}$ da Dywidag;

1 luva $\phi=25 \mathrm{~mm}$ da Dywidag;

12 porcas sextavadas para $\phi=25 \mathrm{~mm}$ da Dywidag;

12 placas de ancoragem (SAE 1020);

12 placas de distribuição (SAE 1020);

- 4 barras $\phi=32 \mathrm{~mm}$ (ST 85-105) $-\mathrm{c}=125 \mathrm{~cm}$ da Dywidag;

1 extensão de barra $\phi=32 \mathrm{~mm}$ (ST 85-105) $-\mathrm{c}=100 \mathrm{~cm}$ da Dywidag;

1 luva $\phi=32 \mathrm{~mm}$ da Dywidag;

8 porcas sextavadas para $\phi=32 \mathrm{~mm}$ da Dywidag;

8 placas de ancoragem (SAE 1020);

8 placas de distribuição (SAE 1020);

- 2 barras $\phi=25 \mathrm{~mm}$ (SAE 1045 e SAE 4340) $-\mathrm{c}=125 \mathrm{~cm}$;

1 extensão de barra $\phi=32 \mathrm{~mm}(\mathrm{SAE}-1045)-c=100 \mathrm{~cm}$;

1 luva $\phi=25 \mathrm{~mm}$;

4 porcas sextavadas para $\phi=25 \mathrm{~mm}$; 


\section{Acessórios}

12 células de carga $(250 \mathrm{kN})$, termômetro e filme plástico

\section{Equipamentos}

Sistema de Aquisição de Dados MICROMEASUREMENTS

\section{Procedimentos de Ensaio}

1. Caracterização dos lotes de Madeira utilizados nos modelos Foi efetuada a caracterização simplificada pois se trata de espécies de madeira já avaliadas por laboratórios. Portanto foram realizados ensaios de compressão paralela às fibras como previsto na NBR 7190/1997 bem como ensaios de compressão normal às fibras.

\section{Ensaios de Perda de Protensão}

Foram montados 32 corpos-de-prova principais, e outros 32 secundários, constituídos por conjuntos de 20 peças de madeira de seção $20 \mathrm{~cm} \times 20 \mathrm{~cm} \times$ $5 \mathrm{~cm}$ de espessura, arranjadas como mostra a figura 3.6, formando um elemento laminado de aproximadamente $100 \mathrm{~cm}$ de comprimento submetido a uma tensão por meio de um sistema de protensão.

As variáveis principais estudas são:

Teor de Umidade (U\%):

Classe de Resistência (C.R.):

Diâmetro da Barra $(\phi)$ :

Nível de Protensão de Projeto $\left(\sigma_{N}\right)$ :

Nível de Protensão Inicial $\left(\sigma_{\mathrm{Ni}}\right)$ :

$$
\begin{array}{ll}
\text { U }=12 \% & U=20 \% \\
\text { C.R. }=\text { C25C } & \text { C.R. }=\text { C40D } \\
\phi=16 \mathrm{~mm} & \phi=32 \mathrm{~mm} \\
\sigma_{\mathrm{N}}=700 \mathrm{kPa} & \sigma_{\mathrm{N}}=1000 \mathrm{kPa} \\
\sigma_{\mathrm{N}}=1750 \mathrm{kPa} & \sigma_{\mathrm{N}}=2500 \mathrm{kPa}
\end{array}
$$

As variáveis consideradas principais na perda de protensão de tabuleiros protendidos foram estudadas através do planejamento fatorial de experimentos onde as " $\mathrm{k}$ " variáveis serão analisadas para dois valores diferentes. Foram necessários, então, $2^{k}\left(2^{4}=16\right)$ corpos-de-prova para combinar todas as variações possíveis. Com o intuito de se avaliar o erro de cada observação realizada será efetuada uma série adicional de 16 réplicas 
dos corpos-de-prova. A tabela 3.1 apresenta os diagramas de sinais das variáveis principais nos 32 corpos-de-prova.
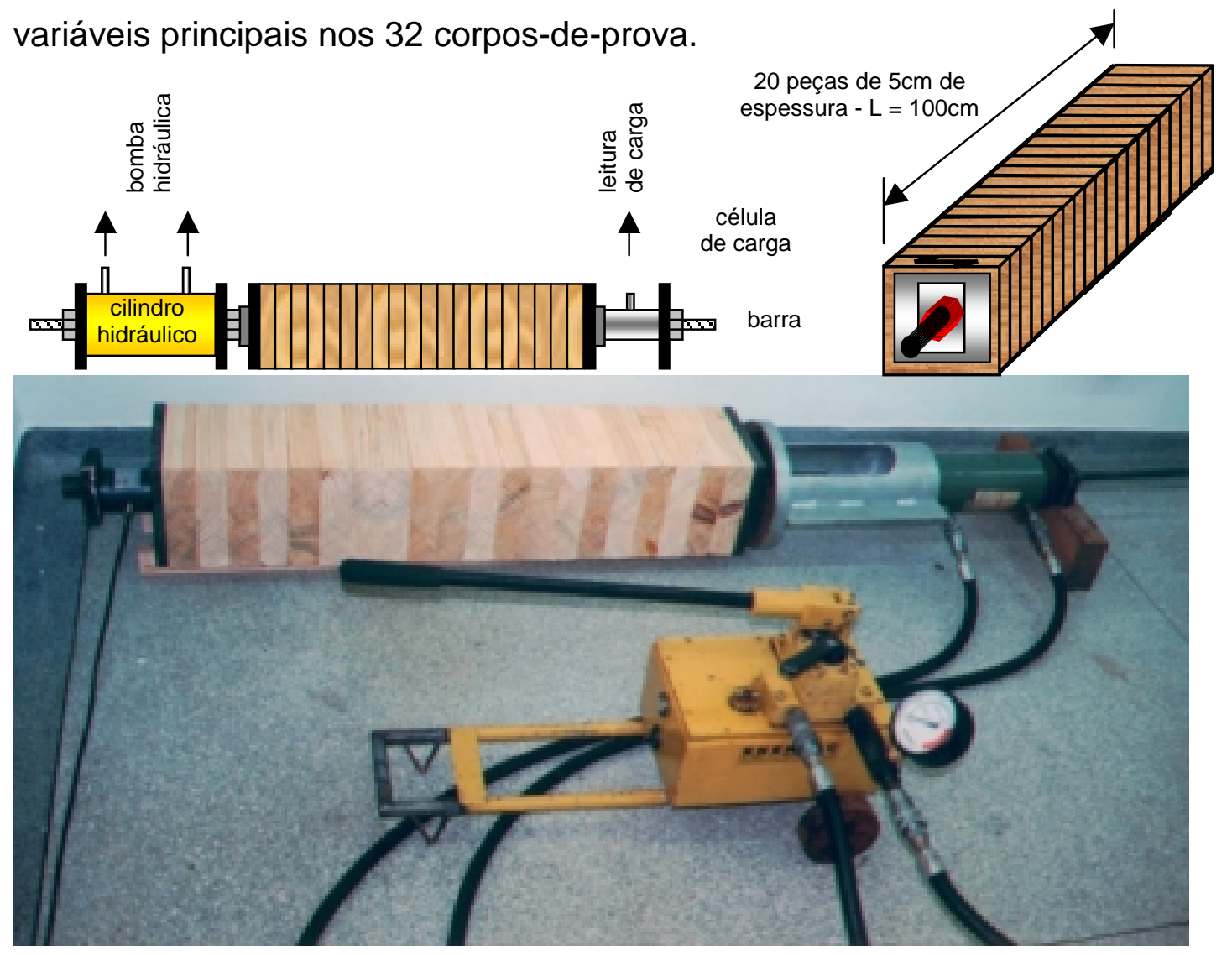

Figura 3.6 - Corpo-de-prova para o Ensaio de Perda de Protensão.

Tabela 3.1 - Perda de Protensão - Diagrama de sinais das Variáveis Principais

\begin{tabular}{ccccc}
\hline Ensaio & Umidade & $\begin{array}{c}\text { Classe de } \\
\text { Resistência }\end{array}$ & Diâmetro & $\begin{array}{c}\text { Tensão de Protensão } \\
\text { de Projeto }\end{array}$ \\
\hline 1A/1B & - & - & - & - \\
\hline 2A/2B & - & - & - & + \\
\hline 3A/3B & - & - & + & - \\
\hline 4A/4B & - & - & + & - \\
\hline 5A/5B & - & + & - & + \\
\hline $6 \mathrm{~A} / 6 \mathrm{~B}$ & - & + & - & - \\
\hline 7A/7B & - & + & + & + \\
\hline $8 \mathrm{~A} / 8 \mathrm{~B}$ & - & + & + & - \\
\hline 9A/9B & + & - & - & + \\
\hline 10A/10B & + & - & - & - \\
\hline 11A/11B & + & - & + & + \\
\hline 12A/12B & + & - & + & - \\
\hline $13 \mathrm{~A} / 13 \mathrm{~B}$ & + & + & - & + \\
\hline 14A/14B & + & + & - & - \\
\hline 15A/15B & + & + & + & + \\
\hline $16 \mathrm{~A} / 16 \mathrm{~B}$ & + & + & + & \\
\hline
\end{tabular}


Sendo que + e - são os dois níveis diferentes de cada uma das variáveis principais pode-se visualizar os 32 corpos-de-prova na tabela 3.2, a seguir:

Tabela 3.2 - Perda de Protensão - Ensaios das Variáveis Principais

\begin{tabular}{|c|c|c|c|c|}
\hline Ensaio & Umidade & $\begin{array}{c}\text { Classe de } \\
\text { Resistência }\end{array}$ & Diâmetro & $\begin{array}{c}\text { Tensão de Protensão } \\
\text { de Projeto }\end{array}$ \\
\hline 1A/1B & U12\% & C25C & $\phi 16$ & $\sigma 700$ \\
\hline $2 A / 2 B$ & U12\% & C25C & $\phi 16$ & $\sigma 1000$ \\
\hline 3A/3B & U12\% & C25C & $\phi 32$ & $\sigma 700$ \\
\hline 4A/4B & U12\% & C25C & $\phi 32$ & $\sigma 1000$ \\
\hline $5 A / 5 B$ & U12\% & C40D & $\phi 16$ & $\sigma 700$ \\
\hline 6A/6B & U12\% & C40D & $\phi 16$ & $\sigma 1000$ \\
\hline 7A/7B & U12\% & C40D & $\phi 32$ & $\sigma 700$ \\
\hline $8 \mathrm{~A} / 8 \mathrm{~B}$ & U12\% & C40D & $\phi 32$ & $\sigma 1000$ \\
\hline 9A/9B & U20\% & C25C & $\phi 16$ & $\sigma 700$ \\
\hline 10A/10B & U20\% & C25C & $\phi 16$ & $\sigma 1000$ \\
\hline 11A/11B & U20\% & C25C & $\phi 32$ & $\sigma 700$ \\
\hline 12A/12B & U20\% & C25C & $\phi 32$ & $\sigma 1000$ \\
\hline 13A/13B & U20\% & C40D & $\phi 16$ & $\sigma 700$ \\
\hline 14A/14B & U20\% & C40D & $\phi 16$ & $\sigma 1000$ \\
\hline 15A/15B & U20\% & C40D & $\phi 32$ & $\sigma 700$ \\
\hline 16A/16B & U20\% & C40D & $\phi 32$ & $\sigma 1000$ \\
\hline
\end{tabular}

Sendo $\mathrm{Y}$ os valores da Perda de Protensão e $\mathrm{X}_{1}, \ldots, \mathrm{X}_{4}$ as variáveis principais, será obtida uma equação do tipo:

$$
\begin{aligned}
Y=a_{0} & +a_{1} X_{1}+a_{2} X_{2}+a_{3} X_{3}+a_{4} X_{4}+ \\
& +a_{1} a_{2} X_{1} X_{2}+a_{1} a_{3} X_{1} X_{3}+a_{1} a_{4} X_{1} X_{4}+ \\
& +a_{2} a_{3} X_{2} X_{3}+a_{2} a_{4} X_{2} X_{4}+a_{3} a_{4} X_{3} X_{4}
\end{aligned}
$$

onde:

$$
\begin{aligned}
P \%= & \sigma_{f} / \sigma_{i}=a_{0}+a_{1}(U \%)+a_{2}(C R)+a_{3}(\phi)+a_{4}\left(\sigma_{P}\right)+ \\
& +a_{1} a_{2}(U \% \cdot C R)+a_{1} a_{3}(U \% \cdot \phi)+a_{1} a_{4}\left(U \% \cdot \sigma_{P}\right)+ \\
& +a_{2} a_{3}(C R \cdot \phi)+a_{2} a_{4}\left(C R \cdot \sigma_{P}\right)+a_{3} a_{4}\left(\phi \cdot \sigma_{P}\right)
\end{aligned}
$$

onde cada variável tem a sua influência nos valores da perda de protensão:

Perdas $\%=($ fator 1$)(U \%)+($ fator 2$)(C R)+($ fator 3$)(\phi)+($ fator 4$)\left(\sigma_{P}\right)$

e os erros de cada observação serão lidos pelo desvio padrão dado por: 
$s_{i}^{2}=d_{i}^{2} / 2$, onde $d_{i}$ é a diferença de leitura da variável $i$.

Além destes experimentos foram realizados ensaios com corpos-de-prova semelhantes para as variáveis secundárias. A diferença de classificação entre as variáveis é que para as secundárias não haverá avaliação estatística com as combinações. Foram realizados ensaios pontuais que poderão ser comparados com os da série principal.

As variáveis secundárias estudadas foram:
Teor de Umidade (U\%):
$U=\leq 10 \%$
$\mathrm{U}=$ var. $\%$
Reprotensões (Rep.):
+2 rep.
+3 rep.
Diâmetro da Barra $(\phi)$ :
$\phi=12,7 \mathrm{~mm}$
$\phi=25 \mathrm{~mm}$
Tipo de Aço de Protensão
Dywidag
C.P. $190 \mathrm{RB}$

A metodologia de ensaios previu a duração inicial de 2 meses para cada ensaio com base nos resultados preliminares. A composição das tabelas 3.3 a 3.7 foi realizada para facilitar o controle das variáveis e a disponibilidade de materiais e acessórios tais como células de carga, barras de aço e madeira. Os ensaios foram realizados da seguinte forma:

Tabela 3.3 - Perda de Protensão $-1^{\circ}-2^{\circ}$ mês

\begin{tabular}{|c|c|c|c|c|}
\hline $\begin{array}{l}\text { Célula } \\
\text { de carga }\end{array}$ & Umidade & $\begin{array}{l}\text { Classe de } \\
\text { Resistência }\end{array}$ & Diâmetro & $\begin{array}{c}\text { Tensão de Protensão } \\
\text { de Projeto }\end{array}$ \\
\hline 1 & U12\% & C25C & $\phi 16$ & $\sigma 700$ \\
\hline 2 & U12\% & C25C & $\phi 16$ & $\sigma 1000$ \\
\hline 3 & U12\% & C25C & $\phi 32$ & $\sigma 700$ \\
\hline 4 & U12\% & C25C & $\phi 32$ & $\sigma 1000$ \\
\hline 5 & U12\% & C40D & $\phi 16$ & $\sigma 700$ \\
\hline 6 & U12\% & C40D & $\phi 16$ & $\sigma 1000$ \\
\hline 7 & U12\% & C40D & $\phi 32$ & $\sigma 700$ \\
\hline 8 & U12\% & C40D & $\phi 32$ & $\sigma 1000$ \\
\hline $\bar{z}$ & Ūं & $\bar{C} 2 \overline{5} \bar{C}$ & $\phi 25$ & $\sigma 700$ \\
\hline 10 & U12\% & C25C & $\phi 25$ & $\sigma 1000$ \\
\hline 11 & U12\% & C25C & $\phi 12,7(C P 190 R B)$ & $\sigma 700$ \\
\hline 12 & U12\% & $C 25 C$ & $\phi 12,7(C P 190 R B)$ & $\sigma 1000$ \\
\hline
\end{tabular}


Tabela 3.4 - Perda de Protensão - $3^{\circ}$ - $4^{\circ}$ mês

\begin{tabular}{|c|c|c|c|c|}
\hline $\begin{array}{l}\text { Célula } \\
\text { de carga }\end{array}$ & Umidade & $\begin{array}{l}\text { Classe de } \\
\text { Resistência }\end{array}$ & Diâmetro & $\begin{array}{c}\text { Tensão de Protensão } \\
\text { de Projeto }\end{array}$ \\
\hline 1 & U20\% & C25C & $\phi 16$ & $\sigma 700$ \\
\hline 2 & U20\% & $\mathrm{C} 25 \mathrm{C}$ & $\phi 16$ & $\sigma 1000$ \\
\hline 3 & U20\% & $\mathrm{C} 25 \mathrm{C}$ & $\phi 32$ & $\sigma 700$ \\
\hline 4 & U20\% & $\mathrm{C} 25 \mathrm{C}$ & $\phi 32$ & $\sigma 1000$ \\
\hline 5 & U20\% & C40D & $\phi 16$ & $\sigma 700$ \\
\hline 6 & U20\% & C40D & $\phi 16$ & $\sigma 1000$ \\
\hline 7 & U20\% & C40D & $\phi 32$ & $\sigma 700$ \\
\hline-8 & $\begin{array}{l}\text { U2 } \\
\text { U20\% }\end{array}$ & C40D & $\phi 32$ & $-\sigma 1000$ \\
\hline 10 & U20\% & $C 40 D$ & $\phi 25$ & $\sigma 1000$ \\
\hline 11 & U20\% & C25C & $\phi 12,7(C P 190 R B)$ & $\sigma 700$ \\
\hline 12 & U20\% & $C 40 D$ & $\phi 12,7(C P 190 R B)$ & $\sigma 1000$ \\
\hline
\end{tabular}

Tabela 3.5 - Perda de Protensão - $5^{\circ}$ - $6^{\circ}$ mês - Repetição

\begin{tabular}{ccccc}
\hline $\begin{array}{c}\text { Célula } \\
\text { de carga }\end{array}$ & Umidade & $\begin{array}{c}\text { Classe de } \\
\text { Resistência }\end{array}$ & Diâmetro & $\begin{array}{c}\text { Tensão Protensão } \\
\text { de Projeto }\end{array}$ \\
\hline 1 & $\mathrm{U} 12 \%$ & C25C & $\phi 16$ & $\sigma 700$ \\
2 & $\mathrm{U} 12 \%$ & C25C & $\phi 16$ & $\sigma 1000$ \\
3 & $\mathrm{U} 12 \%$ & C25C & $\phi 32$ & $\sigma 700$ \\
4 & $\mathrm{U} 12 \%$ & C25C & $\phi 32$ & $\sigma 1000$ \\
5 & $\mathrm{U} 12 \%$ & C40D & $\phi 16$ & $\sigma 700$ \\
6 & $\mathrm{U} 12 \%$ & C40D & $\phi 16$ & $\sigma 1000$ \\
7 & $\mathrm{U} 12 \%$ & C40D & $\phi 32$ & $\sigma 700$ \\
8 & $\mathrm{U} 12 \%$ & C40D & $\phi 32$ & $\sigma 1000$ \\
-9 & $U 12 \%$ & $C 40 D$ & $\phi 25$ & $\sigma 700$ \\
10 & $U 12 \%$ & $C 40 D$ & $\phi 25$ & $\sigma 1000$ \\
11 & $U 12 \%$ & $C 40 D$ & $\phi 12,7(C P 190 R B)$ & $\sigma 700$ \\
12 & $U 12 \%$ & $C 40 D$ & $\phi 12,7(C P 190 R B)$ & $\sigma 1000$ \\
13 & $U 20 \%$ & $C 25 C$ & $\phi 25$ & $\sigma 700(+2 r e)$ \\
14 & $U 20 \%$ & $C 25 C$ & $\phi 25$ & $\sigma 700(+3 r e)$ \\
15 & $U 20 \%$ & $C 40 D$ & $\phi 25$ & $\sigma 700(+2 r e)$ \\
16 & $U 20 \%$ & $C 40 D$ & $\phi 25$ & $\sigma 700(+3 r e)$ \\
\hline
\end{tabular}


Tabela 3.6 - Perda de Protensão - $7^{\circ}$ - $8^{\circ}$ mês - Repetição

\begin{tabular}{ccccc}
\hline $\begin{array}{c}\text { Célula } \\
\text { de carga }\end{array}$ & Umidade & $\begin{array}{c}\text { Classe de } \\
\text { Resistência }\end{array}$ & Diâmetro & $\begin{array}{c}\text { Tensão Protensão } \\
\text { de Projeto }\end{array}$ \\
\hline 1 & U20\% & C25C & $\phi 16$ & $\sigma 700$ \\
2 & U20\% & C25C & $\phi 16$ & $\sigma 1000$ \\
3 & U20\% & C25C & $\phi 32$ & $\sigma 700$ \\
4 & U20\% & C25C & $\phi 32$ & $\sigma 1000$ \\
5 & U20\% & C40D & $\phi 16$ & $\sigma 700$ \\
6 & U20\% & C40D & $\phi 16$ & $\sigma 1000$ \\
7 & U20\% & C40D & $\phi 32$ & $\sigma 700$ \\
8 & U20\% & C40D & $\phi 32$ & $\sigma 1000$ \\
-9 & $U 12 \%$ & C25C & $\phi 25$ & $\sigma 700(+2 r e)$ \\
10 & $U 12 \%$ & C25C & $\phi 25$ & $\sigma 700(+3 r e)$ \\
11 & $U 12 \%$ & $C 40 D$ & $\phi 25$ & $\sigma 700(+2 r e)$ \\
12 & $U 12 \%$ & C40D & $\phi 25$ & $\sigma 700(+3 r e)$ \\
13 & $U 12 \%$ & $C 40 D$ & $\phi 25$ & $\sigma 1000(+2 r e)$ \\
14 & $U 12 \%$ & $C 40 D$ & $\phi 25$ & $\sigma 1000(+3 r e)$ \\
15 & $U<10 \%$ & $C 25 C$ & $\phi 12,7(C P 190 R B)$ & $\sigma 700$ \\
16 & $U<10 \%$ & $C 25 C$ & $\phi 12,7(C P 190 R B)$ & $\sigma 700$ \\
\hline
\end{tabular}

Tabela 3.7 - Perda de Protensão - $9^{\circ}$ - $10^{\circ}$ mês - Secagem e Variações

\begin{tabular}{|c|c|c|c|c|}
\hline $\begin{array}{l}\text { Célula } \\
\text { de carga }\end{array}$ & Umidade & $\begin{array}{c}\text { Classe de } \\
\text { Resistência }\end{array}$ & Diâmetro & $\begin{array}{l}\text { Tensão Protensão } \\
\text { de Projeto }\end{array}$ \\
\hline 1 & U20\%->U12\% & C25C & $\phi 16$ & $\sigma 700$ \\
\hline 2 & U20\%->U12\% & C25C & $\phi 16$ & $\sigma 1000$ \\
\hline 3 & U20\%->U12\% & C25C & $\phi 32$ & $\sigma 700$ \\
\hline 4 & U20\%->U12\% & C25C & $\phi 32$ & $\sigma 1000$ \\
\hline 5 & U20\%->U12\% & C40D & $\phi 16$ & $\sigma 700$ \\
\hline 6 & U20\%->U12\% & C40D & $\phi 16$ & $\sigma 1000$ \\
\hline 7 & U20\%->U12\% & C40D & $\phi 32$ & $\sigma 700$ \\
\hline 8 & U20\%->U12\% & C40D & $\phi 32$ & $\sigma 1000$ \\
\hline- & U12\%-> $20 \%$ & C25C & $\phi 25$ & $\sigma 700$ (+2re) \\
\hline 10 & U12\%->U20\% & C25C & $\phi 25$ & $\sigma 700(+3 r e)$ \\
\hline 11 & U12\% & C25C & $\phi 25$ & $\sigma 1000(+2 r e)$ \\
\hline 12 & U12\% & C25C & $\phi 25$ & $\sigma 1000(+3 r e)$ \\
\hline 13 & U20\% & $C 40 D$ & $\phi 25$ & $\sigma 1000(+2 r e)$ \\
\hline 14 & U20\% & $C 40 D$ & $\phi 25$ & $\sigma 1000(+3 r e)$ \\
\hline 15 & $U<10 \%->U 12 \%$ & C25C & $\phi 12,7(C P 190 R B)$ & $\sigma 700$ \\
\hline 16 & $U<10 \%->U 12 \%$ & C25C & $\phi 12,7(C P 190 R B)$ & $\sigma 700$ \\
\hline
\end{tabular}


O corpos-de-prova das células de 1 a 8 dos 4 primeiros meses (tabela $3.3 \mathrm{e}$ 3.4) correspondem aos 16 corpos-de-prova do fatorial $2^{4}$, e os corpos-deprova das mesmas células nos 4 meses seguintes correspondem às suas respectivas repetições. As outras combinações avaliaram as variáveis secundárias. Os corpos-de-prova da tabela 3.7 avaliarão, basicamente, as variações de umidade nos corpos-de-prova.

Essa metodologia permitiu avaliar, sob diferentes teores de umidade, o fenômeno da perda de protensão de diferentes sistemas de protensão, diferentes relações entre área de aço e área de madeira (ou relações de rigidezes aço por madeira), diferentes níveis de protensão, diferentes históricos de reprotensão e diferentes classes de resistência da madeira.

\subsubsection{Tabuleiros como Corpos-de-prova}

Foram montados dois tabuleiros com madeira de Pinus de dimensões de $100 \mathrm{~cm} \times 480 \mathrm{~cm}$ por $20 \mathrm{~cm}$ de altura e protendidos por quatro barras de aço da Dywidag de diâmetros $16 \mathrm{~mm}$ e $32 \mathrm{~mm}$. O tabuleiro com barras de $16 \mathrm{~mm}$ foi instrumentado com células de carga nas barras e transdutores de deslocamentos na sua face superior.

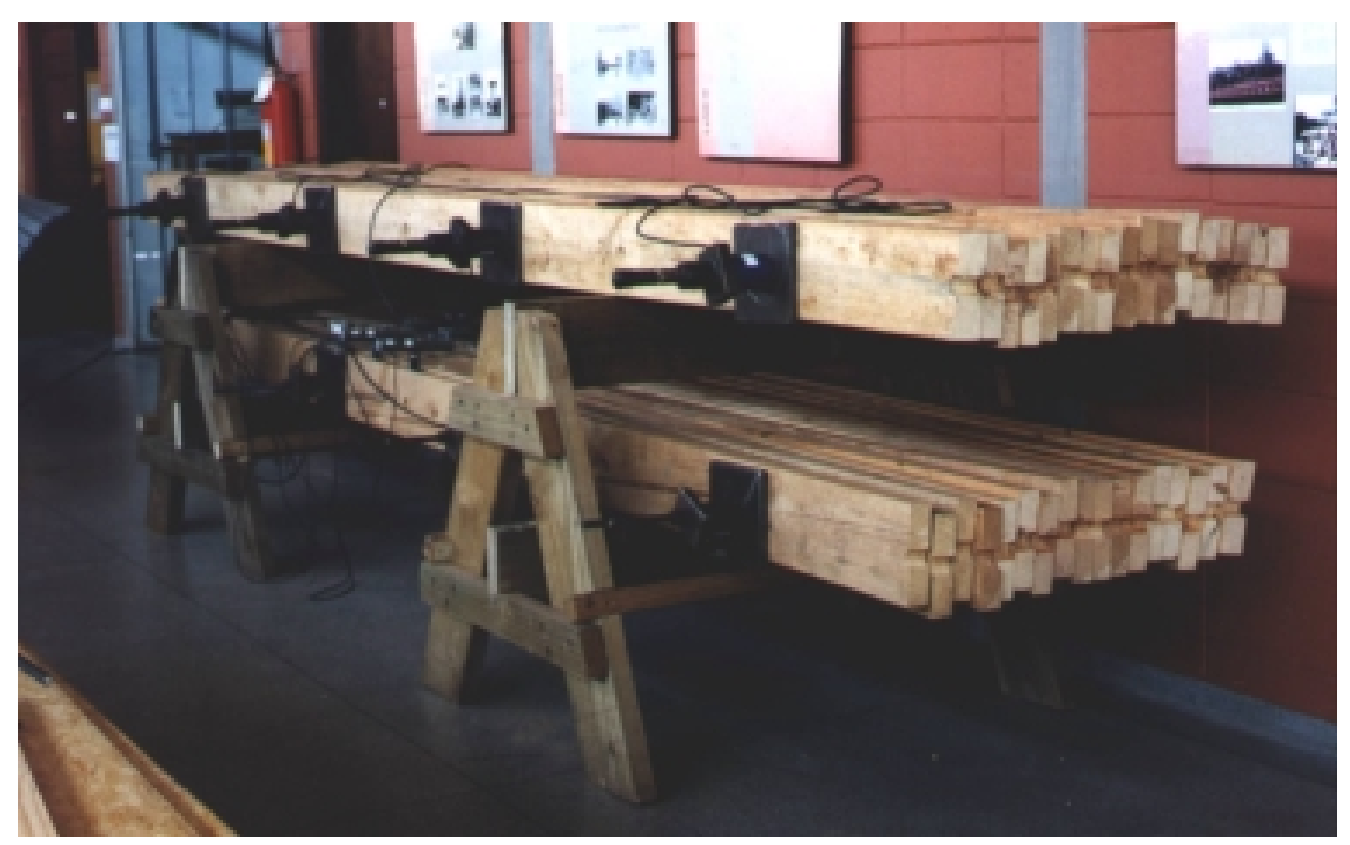

Figura 3.7 - Tabuleiros para o Ensaio de Perda de Protensão. 


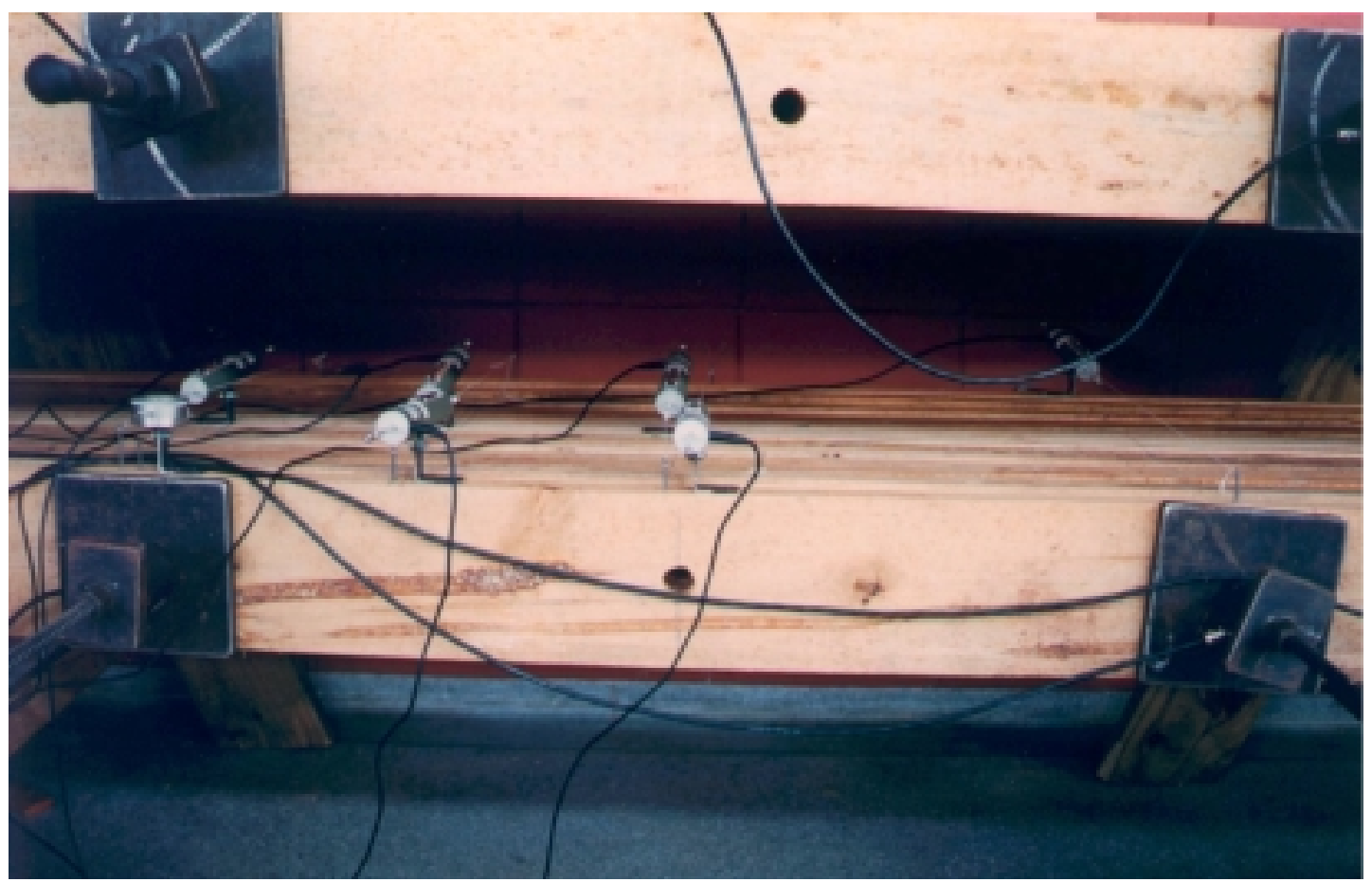

Figura 3.8 - Instrumentação dos Tabuleiros para o Ensaio de Perda de Protensão.

\subsubsection{Ensaios de Pontes em Campo;}

Foram analisadas duas pontes dos EUA, Estado da Pensivânia. A primeira, do município de Lancaster chamada Millcross Road (figura 3.9) e a Ponte Birch Creek, do município de Sullivan (figura 3.10) com dados de nível de protensão e prova de carga.

A Lancaster tem um vão de $760 \mathrm{~cm}$ por $800 \mathrm{~cm}$ de largura sendo que a altura é de $41 \mathrm{~cm}$ foi construída com madeira Red Oak. Sullivan tem $640 \mathrm{~cm}$ de vão, $980 \mathrm{~cm}$ de largura e, também, $41 \mathrm{~cm}$ de altura e foi construída com a madeira American Beech. Ambas "hardwoods" freqüentemente aplicadas em pontes.

Ficha da Millcross Road / Lancaster

Construída em: 1992

Prova de Carga em: 06/04/1998

Inspecionada por: Jim/Carlito

Tráfego: Alto 


\begin{tabular}{|l|l|}
\hline Comprimento $(\mathrm{cm})$ & 640 \\
\hline Largura(cm) & 879 \\
\hline Vãos & 1 \\
\hline Faixas de Tráfego & 2 \\
\hline Dimensões $(\mathrm{cm})$ & $7.5 \times 41-3$ "x16" \\
\hline Espécie & Red Oak \\
\hline Juntas de topo & 1 a cada 3 - espaçamento a cada 4 ft \\
\hline Tratamento Preservativo & Creosote \\
\hline Barras de Protensão & 6 \\
\hline Célula de Carga 1 & $3 a$. barra \\
\hline Célula de Carga 2 & $4 a$. barra \\
\hline Diâmetro das Barras(cm) & 2.5 \\
\hline Espaçamento das Barras $(\mathrm{cm})$ & 122 \\
\hline Fabricante da Barra & willians \\
\hline Ancoragem & Perfil U $35 \times 2$ \\
\hline Superfície de Rolamento & Asfalto $-6 \mathrm{~cm}$ \\
\hline
\end{tabular}

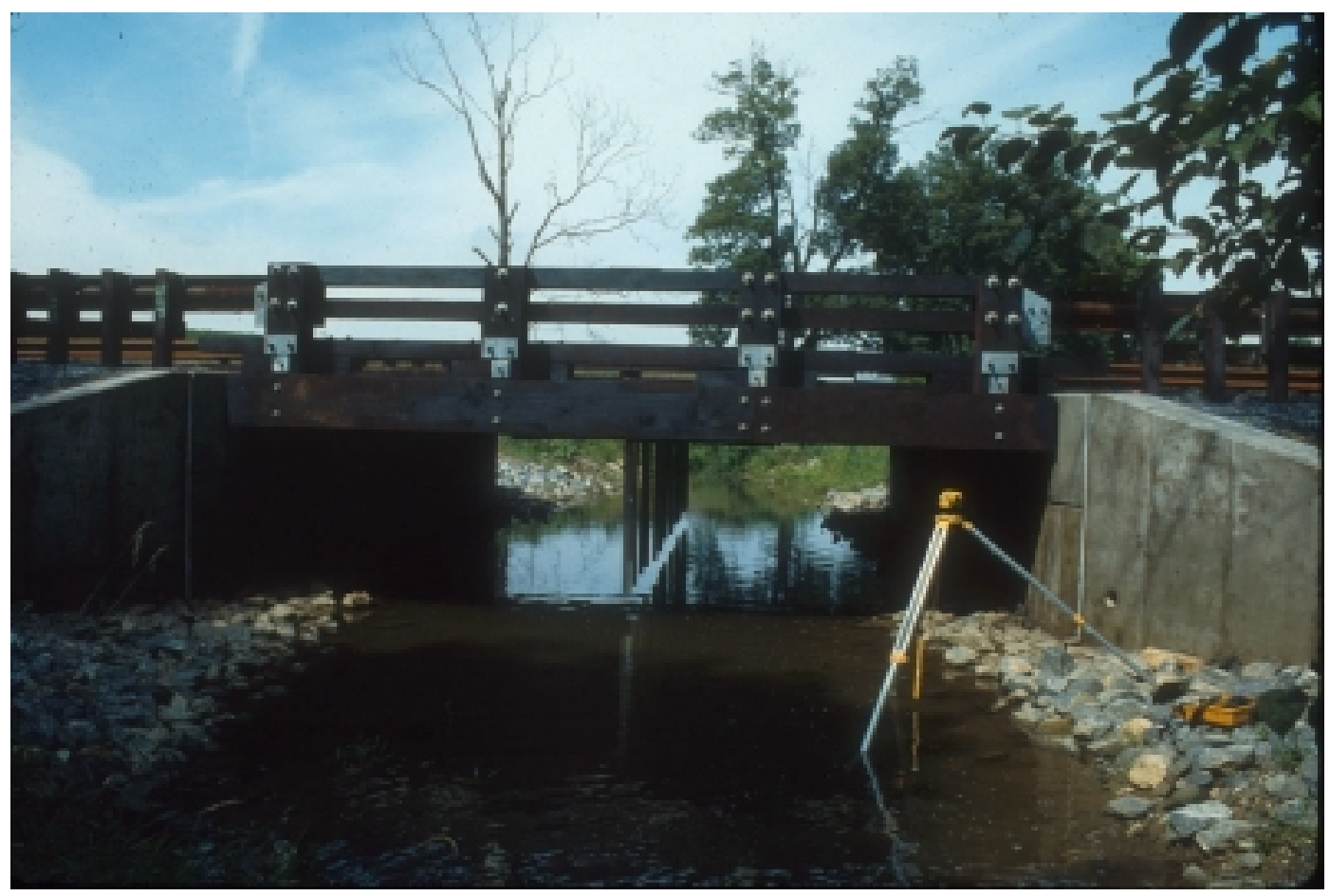

Figura 3.9 - Ponte Millcross Road - Lancaster 
Ficha da Birch Creek/Sullivan

Construída em: 1991

Prova de Carga em: 06/30/1998

Inspecionada por: Jim/Carlito

Tráfego: Baixo

\begin{tabular}{|l|l|}
\hline Comprimento (cm) & 762 \\
\hline Largura(cm) & 793 \\
\hline Vãos & 1 \\
\hline Faixas de Tráfego & 2 \\
\hline Dimensões (cm) & $7.5 \times 41$ - 3"x16" \\
\hline Espécie & American Beech \\
\hline Juntas de topo & 1 a cada 3 - espaçamento a cada 3 ft \\
\hline Tratamento Preservativo & Creosote \\
\hline Barras de Protensão & 8 \\
\hline Célula de Carga 1 & $3 a$. barra \\
\hline Célula de Carga 2 & $6 a$. barra \\
\hline Diâmetro das Barras(cm) & 2.5 \\
\hline Espaçamento das Barras (cm) & 97 - 38” \\
\hline Fabricante da Barra & dywidag \\
\hline Ancoragem & Perfil U 35 x 2 \\
\hline Superfície de Rolamento & Asfalto - 6 cm \\
\hline
\end{tabular}

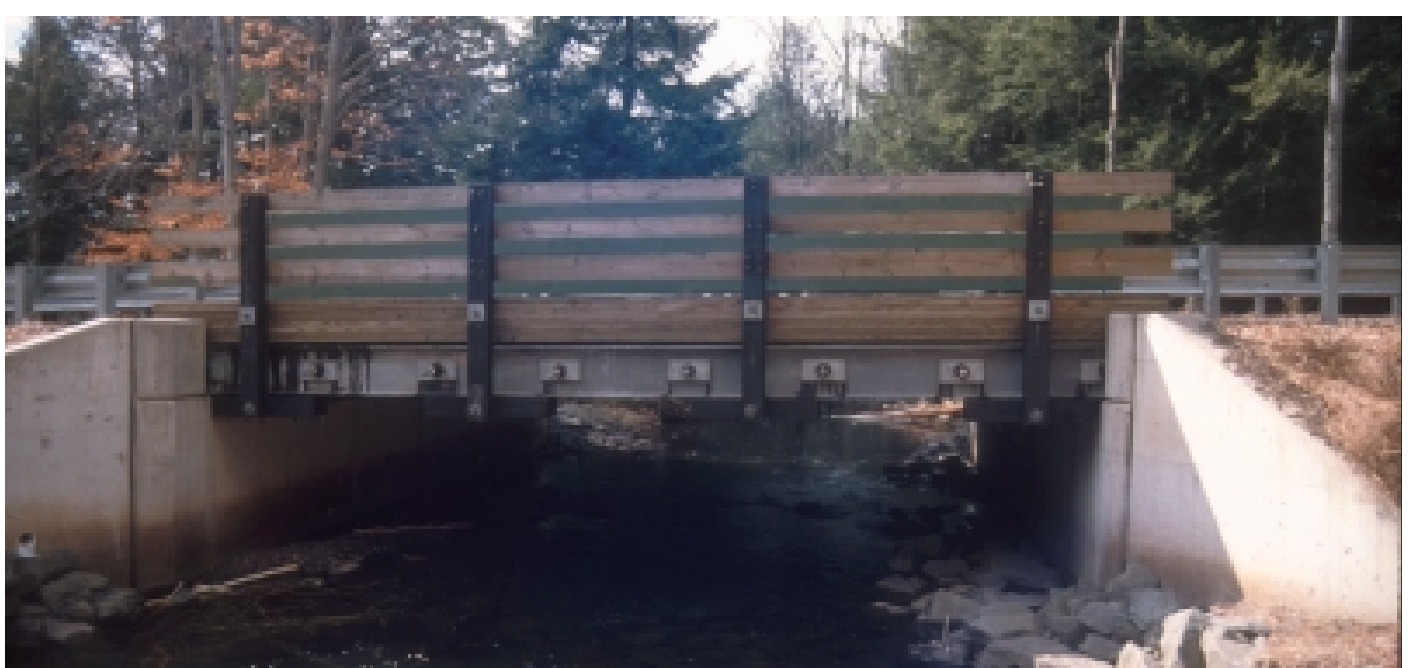

Figura 3.10 - Ponte Birch Creek - Sullivan 


\subsubsection{Sistematização dos Resultados}

Todas estas análise tiveram por finalidade determinar alguns parâmetros importantes de projeto e dimensionamento das estruturas protendidas, no que diz respeito às perdas de protensão.

Com o conhecimento adquirido dos mecanismos de deformação lenta da madeira e das perdas de protensão para os tabuleiros foi possível optar por disposições de nível de protensão inicial e sistematização de reprotensões através de valores de majoração da tensão de projeto adotada.

Portanto, estes fatores integrados a um critério de dimensionamento adequado à normalização e materiais nacionais permitem a execução de projetos de pontes com tabuleiro de madeira laminada protendida. Este trabalho propõe ainda, a elaboração de um programa computacional didático de projeto e dimensionamento destas estruturas que possua grande quantidade de informações técnicas e científicas. 


\section{RESULTADOS E DISCUSSÕES}

4.1 Introdução

Neste capítulo estão os resultados das análises teóricas e experimentais efetuadas no trabalho bem como discussões geradas pelos mesmos. Os resultados são apresentados em quatro grandes blocos. O primeiro corresponde ao item 4.2 que expõe os resultados das análises de fluência da madeira à compressão normal às fibras. No bloco seguinte, as análises de perda de protensão estão divididas em perda de protensão em corposde-prova (item 4.3), em tabuleiros (item 4.4) e em pontes (item 4.5), apresentando valores da variação da tensão inicial ao longo do tempo e as influências das variáveis envolvidas na pesquisa. No terceiro bloco são apresentados os resultados da construção e aplicação de dois programas relacionados aos tabuleiros protendidos de pontes. O primeiro (item 4.6) trata-se do PPM v. 3.0 que projeta e dimensiona pontes protendidas de madeira e, ao estar integrado ao AEP v. 1.0, proporciona a possibilidade de análise estrutural do tabuleiro quando submetidos a carregamentos móveis, isto é, presença de veículo(s). Na seqüência (item 4.7), é apresentado uma versão isolada do AEP v. 1.0, que difere da versão integrada ao PPM por permitir a aplicação de uma ou mais cargas isoladas independentes dos padrões métricos de eixos e rodas dos veículos. No último bloco, são apresentados os resultados de análise estruturais das pontes analisadas no item 4.5 na forma de provas de carga efetuadas nas pontes, análises estruturais através dos programas SAP2000 e AEP v. 1.0. 
A estrutura deste capítulo está baseada na apresentação dos resultados e, posteriormente, nas discussões.

É importante salientar neste ponto, que a metodologia apresentada reflete o que a pesquisa pretendeu abordar e forma como deveria ter sido realizada esta abordagem. Infelizmente, os resultados obtidos nos ensaios de perdas de protensão em corpos-de-prova mostraram que a metodologia está equivocada quanto à elaboração destes corpos-de-prova.

Portanto, a obtenção de dados destes ensaios, a metodologia de análise dos dados (análise estatística) e, naturalmente, a integração dos dados destes ensaios com os resultados dos ensaios de fluência foram comprometidos.

\subsection{Análise de Fluência}

Foram caracterizadas as madeiras de pinus taeda e de eucalipto citriodora. Foram analisados 4 (quatro) corpos-de-prova representado as duas classes de resistência da madeira em dois teores de umidade. A figura 4.1 apresenta o corpo-de-prova sob ensaio e a instrumentação e o equipamento de aquisição de dados da Kyowa.
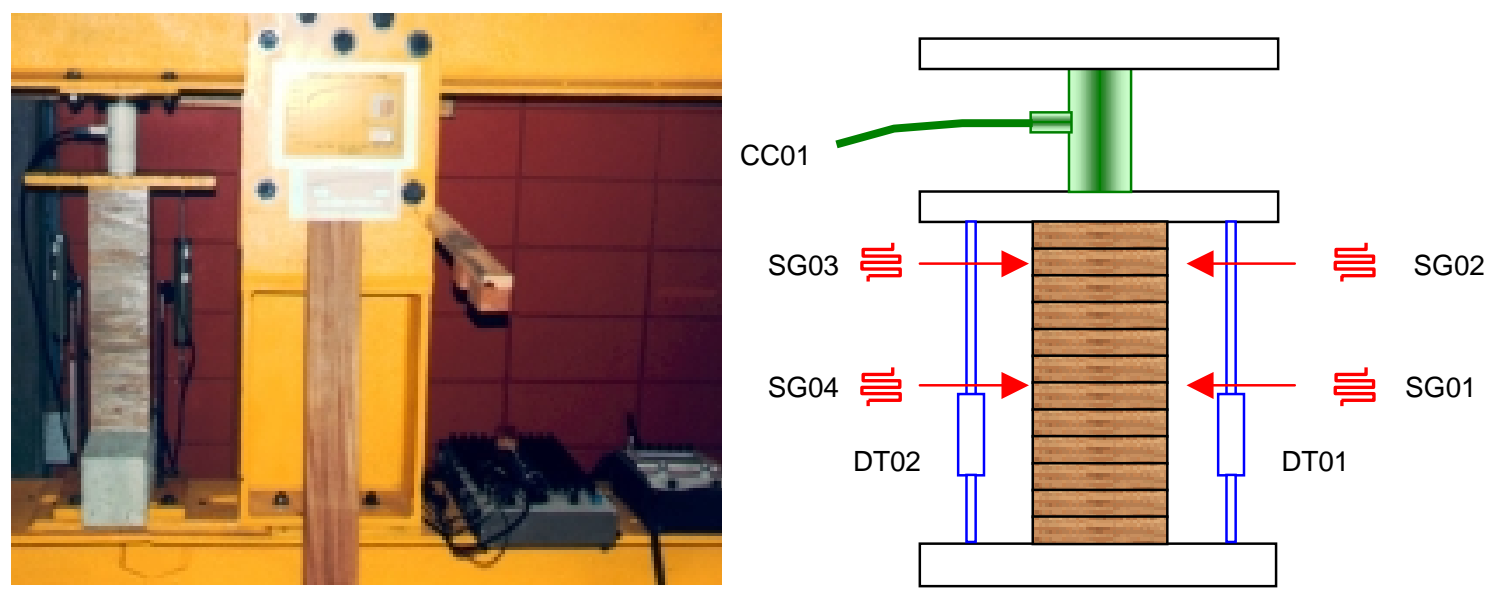

Figura 4.1 - Corpo-de-prova de Deformação Lenta 
(6) Laboratório de Madeiras e de Estruturas de Madeira

Plarlha de EREaios
COMPRESBAO PARALELA AS FIBAAS

Eneaio Phus Taeda

C.P. 01 OL 01

Datk: snovish

Projeso. PCNTES PROTENOIDUS DE MAOEIRA - DOUTORAMENTO

Usuaris: FEFALANDO S. OKIMOTO (peitura

Técrico: JAMME GALINOO (Garga) o ARNhLOO (letura)

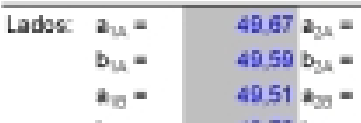

$49.592 \operatorname{mindx}=4.96$ वा

$40.41 \mathrm{~b}_{\operatorname{mina}}=4.95 \mathrm{ar}$

$48.70 \mathrm{bes}=$

6078 bistose

497 का

Comprimertos $=15 \mathrm{~cm} \quad$ Comprimertos de trabaho $\Delta H=10 \mathrm{em}$

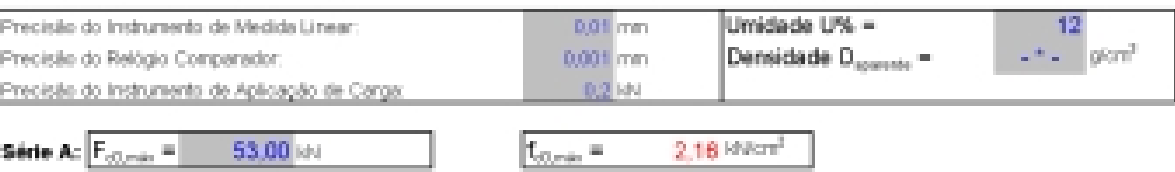

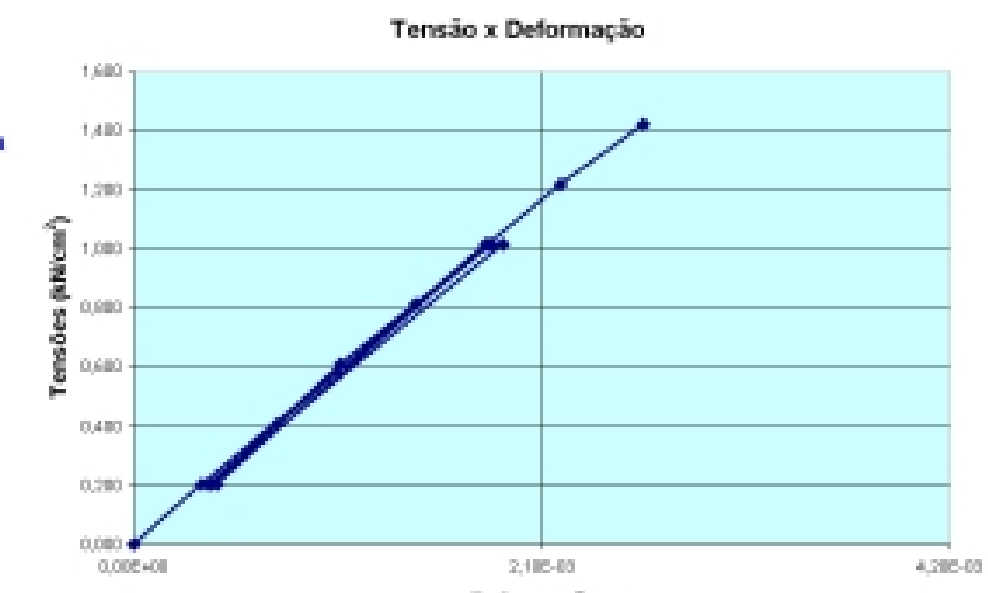

Detormaçés

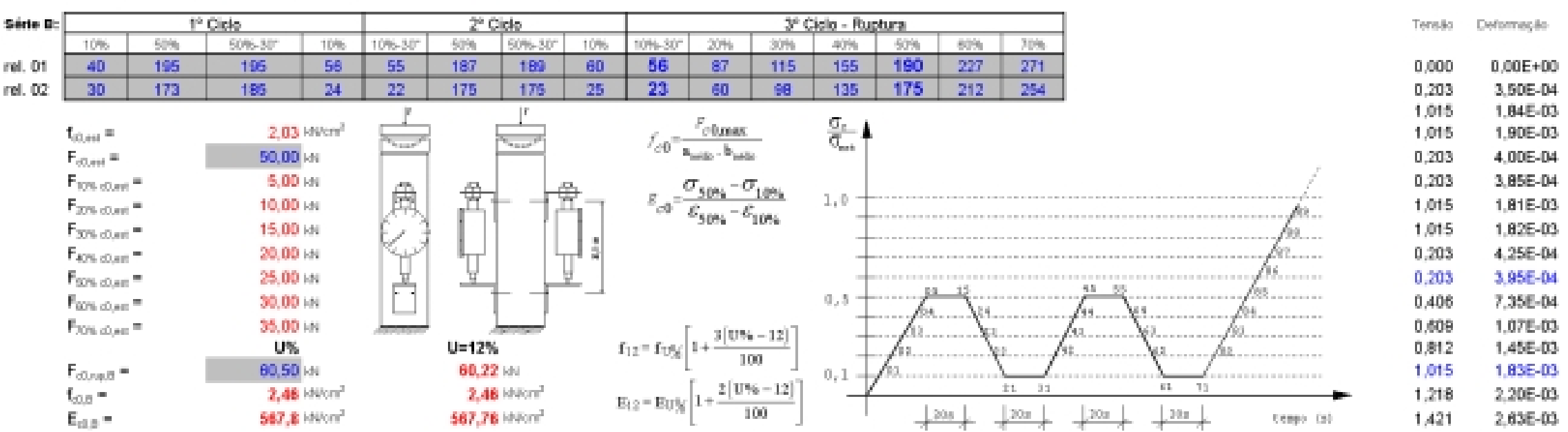

Figura 4.2 - Caracterização das Madeiras de Pinus Taeda: Compressão paralela 
(2) Labaratónio de Madeiras e de Estruturas de Madeira

Planter de Enalios

Envia Phess Tanda

CN. of of or

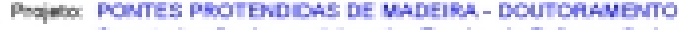

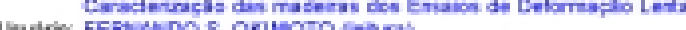

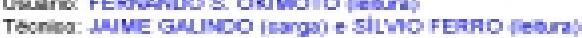

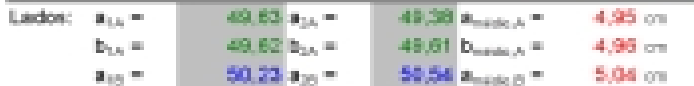

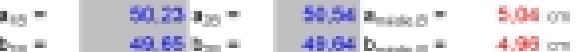

Coeprimetse $-10 \mathrm{ar}$ Compenerion de trazaho $\triangle \mathrm{H}=10 \mathrm{~cm}$

\begin{tabular}{|c|c|c|c|}
\hline 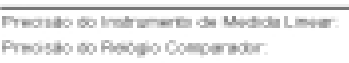 & 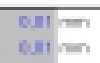 & 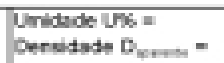 & $13,4 \%$ \\
\hline
\end{tabular}

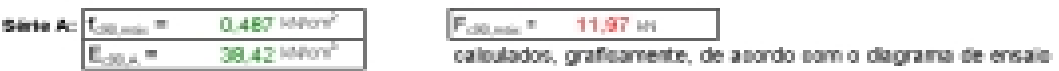

$\sin 0$

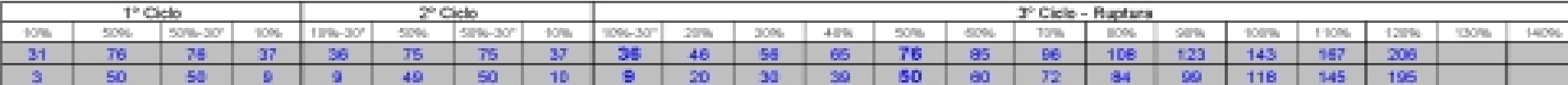

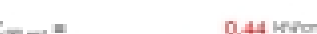

Fan:- $\quad 0.44$ wets

Find 11,06 ind

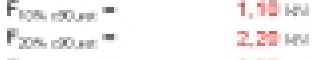

Fon sone $=$

Fen +00 :-

Fine $20,0=$

Fion axion

Fron $\cos ^{2}=$

Fimisen

Fon $0000=$

Fros buse

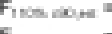

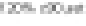

$F_{x \rightarrow 0=0}=$

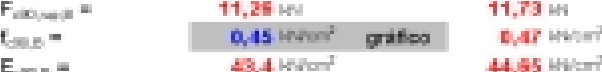

3.30100

$4,48 \mathrm{knd}$

5,50 ind

6,60

$3.90 \mathrm{sec}$

200 ind

$11,00 \mathrm{wow}$

1.28

1,25
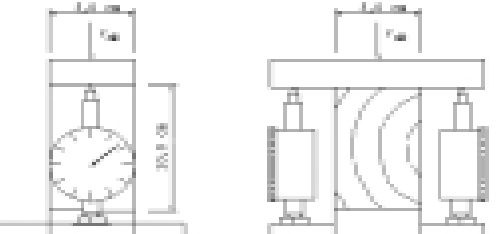

$\log _{x \rightarrow 3} x_{\text {eximax }}$

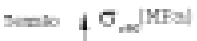

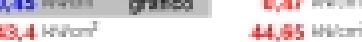

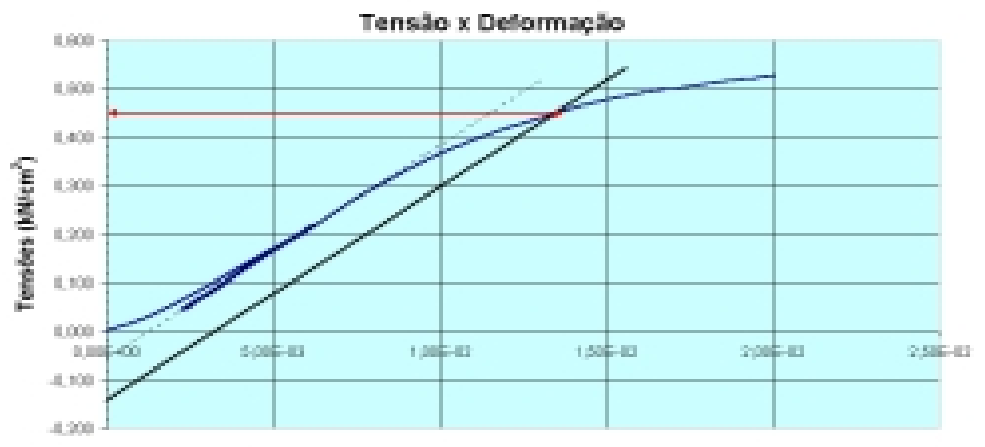

Deformascies

Figura 4.3 - Caracterização das Madeiras de Pinus Taeda: Compressão normal 
Laboratório de Madeiras e de Estruturas de Madeira

Planitu de Ensaios COMPRESSALO PARaLELa As FIERAS

Ensaio Eucalipto Citriodora C.P. 01 DL 03

Data: atovines

Projeto: PONTES PROTENDIDAS DE MADEIRA - DOUTORAMENTO Caracteriza:ajo das maderas dos Emsaios de Ceformaço Lenta Usuario: FEFEANDO S. OKIMOTO

TÉcrico: JAIME GALLINDO (earga) SILVO (etura) e ARNALLO (hatura)

\begin{tabular}{|c|c|c|c|c|}
\hline \multirow[t]{4}{*}{ Lados: } & $a_{i n}=$ & $50.23 \mathrm{a} \times \mathrm{x}=$ & $50.29 \mathbf{a}_{\text {mesch }}$ & $5.00 \mathrm{~cm}$ \\
\hline & $b_{\mu}=$ & $49.77 b_{24}=$ & $49,96 b_{\text {mita } A}=$ & $4.59 \mathrm{~cm}$ \\
\hline & $*_{\text {id }}=$ & $49.91 \mathrm{a}_{S D}=$ & $50,07 a_{\text {midso }}=$ & $5.00 \mathrm{~cm}$ \\
\hline & $b_{16}=$ & $50.08 \mathrm{~b}_{38}=$ & $50,10 b_{n, R}=$ & $5.01 \mathrm{ctn}$ \\
\hline
\end{tabular}

Comprimentos $=15 \mathrm{~cm} \quad$ Comprimentos de tristho $\triangle H=10 \mathrm{~cm}$

\begin{tabular}{|c|c|c|c|}
\hline Preciaba do indrumints da Medida Liner & $0,01 \mathrm{~mm}$ & U-misade U\% = & 13,4 \\
\hline 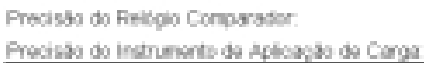 & $\begin{array}{r}0.001 \mathrm{~mm} \\
0.2 \mathrm{LN}\end{array}$ & Densidace $D_{\text {worns }}$ - & $\therefore g\left(\pi^{\prime}\right.$ \\
\hline
\end{tabular}

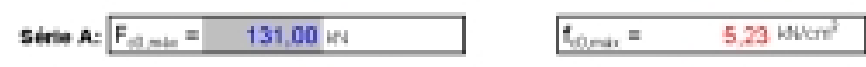

\begin{tabular}{|c|c|c|c|c|c|c|c|c|c|c|c|c|c|c|}
\hline \multicolumn{4}{|c|}{$f^{\circ}$ Cislo } & \multicolumn{4}{|c|}{$2^{3}$ Cido } & \multicolumn{7}{|c|}{$3^{\circ}$ Ciclo - Ruphura } \\
\hline $50 \mathrm{~s}$ & $60 \mathrm{~h}$ & $\operatorname{ses}, \mathrm{NO}^{\circ}$ & $10 \mathrm{kh}$ & $104=80$ & $\operatorname{son}$ & $\operatorname{sen} 80$ & $100 \mathrm{~m}$ & $10 \mathrm{~s}-80^{\circ}$ & $20 \mathrm{~h}$ & $30 \mathrm{~h}$ & $40 \mathrm{~h}$ & $60 \mathrm{~s}$ & $0 \%$ & mos \\
\hline 50 & 245 & 250 & 110 & 115 & 255 & 260 & 118 & 114 & 153 & 180 & 218 & 265 & 310 & 395 \\
\hline 13 & 180 & 186 & 32 & 30 & 191 & 185 & 32 & 32 & 66 & 100 & 167 & 196 & 250 & 390 \\
\hline
\end{tabular}

\begin{tabular}{|l|l|l|}
\hline 50 & 245 & 250 \\
\hline 13 & 180 & 186 \\
\hline
\end{tabular}

$t_{a m}=$

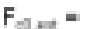

5,19 weren?

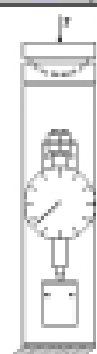

\begin{tabular}{|l|l|l|}
\hline 155 & 260 & 118 \\
\hline 191 & 195 & 32 \\
\hline
\end{tabular}

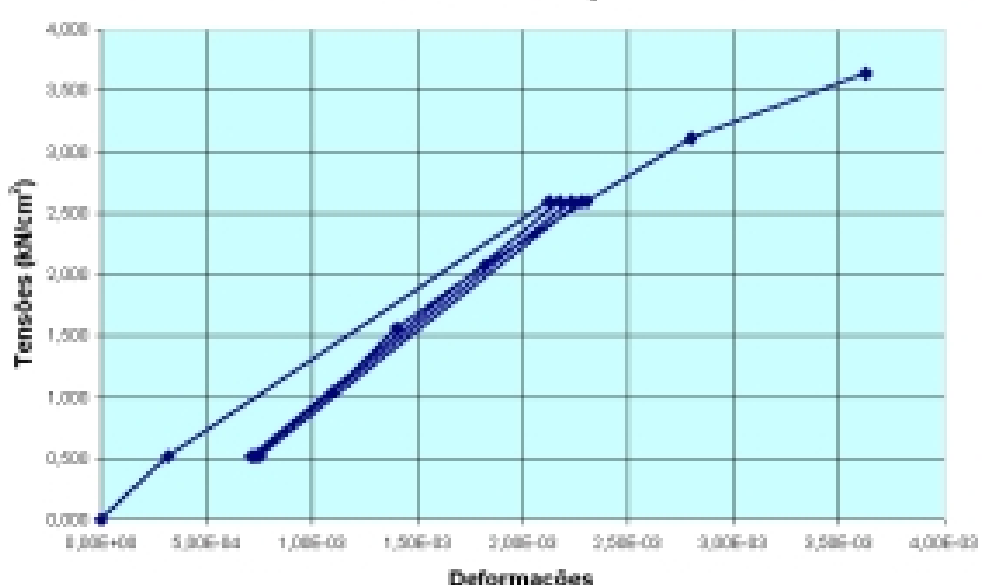

Deformał̧̧es

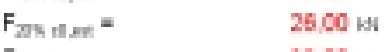

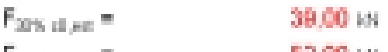

$\mathrm{F}_{\sin \mathrm{ang}}=$

Fien in $=$

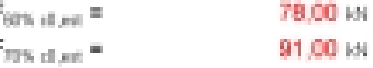

$1.00 \mathrm{ks}$

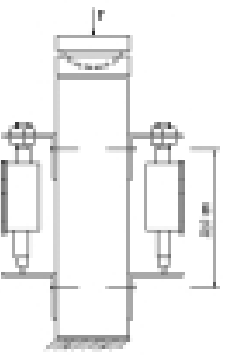

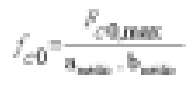

$\varepsilon_{\infty} \frac{\sigma_{\operatorname{ses}}-\sigma_{105}}{\varepsilon_{\text {son }}-\varepsilon_{100}}$

$\frac{\sigma_{0}}{\sigma_{m}}+1$

Tenste Duremays

$0,000 \quad 0,00 E+\infty 0$

$0.519 \quad 3.15 \mathrm{E}-\mathrm{O}$

$2.596 \quad 2,13 \mathrm{E}-60$

2, $896 \quad 18 \mathrm{E}-00$

$0,519 \quad 7,10 E-04$

0.518 7.25E-04

$2,506 \quad 2,23 \mathrm{E}-00$

$2,596 \quad 2.28 \mathrm{E}-60$

$0,519 \quad 7,50 \mathrm{E}-04$

$0.519 \quad 7,30 E-04$

$1,008 \quad 1,10 E-00$

$1557 \quad 1,40 E-000$

$\mathrm{F}_{\mathrm{am}, 0,0}=$

UN

$t_{a t}=$

$117.00 \mathrm{~ms}$

$\mathrm{E}_{00 \mathrm{~b}}=$

4,67 wowr?

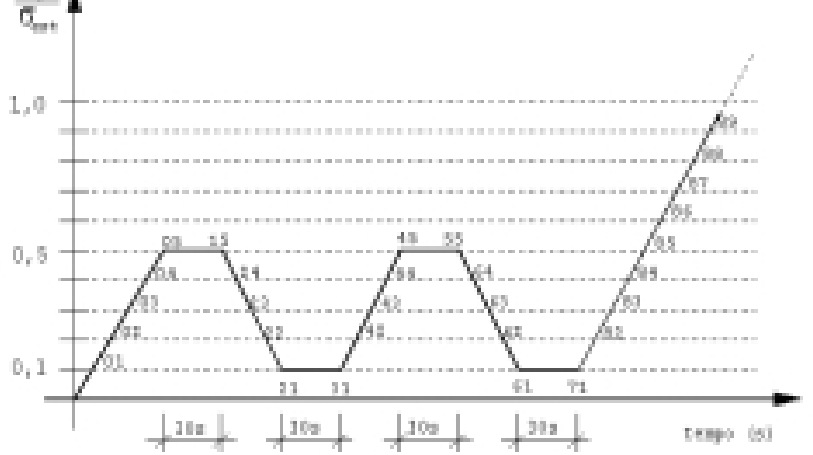

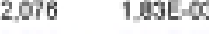

$\mathrm{U}=12 \%$

4,97 wown

1956. 31 huent

$f_{12}=f_{v S \%}\left[1+\frac{3(U \%-12)}{100}\right]$

$E_{12}=E_{u} \times\left[1+\frac{2[\mathrm{~L} \%-12]}{100}\right]$

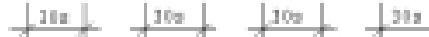

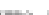

$3.115 \quad 280 \mathrm{E}-00$

Figura 4.4 - Caracterização das Madeiras de Eucalipto Citriodora: Compressão paralela 
Laboratório de Madeiras e de Estruturas de Madeirs

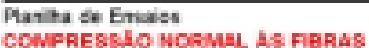

Enasia Excollono Chrodadar CN Di DL as

Proins: POWTES PEOTEMCILAS DE MHOERA- DOUTORAMENTO

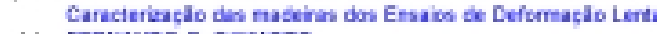

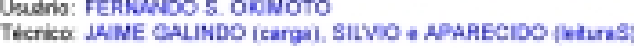

\begin{tabular}{|c|c|c|c|}
\hline $3 \ldots$ & $42.912 \mathrm{x}=$ & 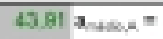 & $4.34 \mathrm{~m}$ \\
\hline Du. & $41.81 b_{2}=$ & $41.59 \mathrm{~b}$ and & $4.16 \mathrm{~m}$ \\
\hline 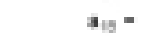 & $42, a b \times x_{i s}=$ & 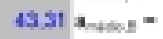 & $4,31 \mathrm{~m}$ \\
\hline$b_{1}=$ & $49,42 \mathrm{~b}_{x}=$ & 41.26 b. & $4.43 \mathrm{~m}$ \\
\hline
\end{tabular}

Compinotios $=10 \mathrm{~cm} \quad$ Comprimertse de tratakto $\mathrm{AH}=10 \mathrm{~cm}$

\begin{tabular}{|c|c|c|c|}
\hline 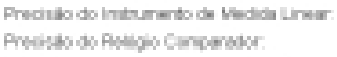 & 0,017 & 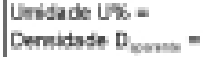 & 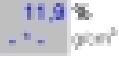 \\
\hline
\end{tabular}

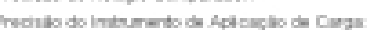

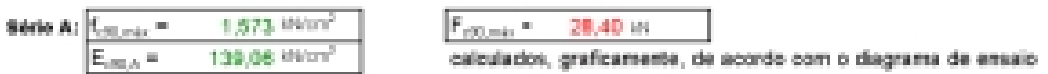

serio

\begin{tabular}{|c|c|c|c|c|c|c|c|c|c|c|c|c|c|c|c|c|c|c|c|c|c|}
\hline \multicolumn{4}{|c|}{ Fogh } & \multicolumn{4}{|c|}{7 Cich } & \multicolumn{14}{|c|}{$y$ Cich-Rertra } \\
\hline $1 \mathrm{WW}$ & 500 & $5006-3 \sigma^{\circ}$ & $10 \mathrm{~m}$ & 60 as -39 & & $30 \mathrm{ser}-30$ & $6 \mathrm{~s}$ & 1000 & & & & 500 & 50 & 300 & $\tan$ & $\operatorname{sen}$ & 1000 & 1000 & $150 \mathrm{k}$ & vom & 4005 \\
\hline 45 & 96 & 100 & 61 & 65 & 100 & 102 & 64 & 63 & $\pi 3$ & 82 & 92 & 102 & 114 & 128 & 145 & 165 & 188 & 220 & 270 & & \\
\hline-4 & 45 & 48 & 6 & 5 & 46 & 49 & 7 & 6 & 16 & 27 & 39 & 48 & 40 & 73 & 82 & 112 & 134 & 168 & 212 & & \\
\hline
\end{tabular}

1.57 weres

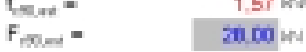

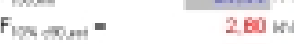

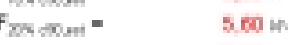

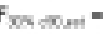

Fersom "

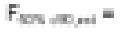

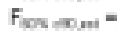

Finosinat $=$

Fionsonat

$f^{\prime x}=$

$f^{2}=$

Fration $=$

$F_{1}=0$

Fiescom=
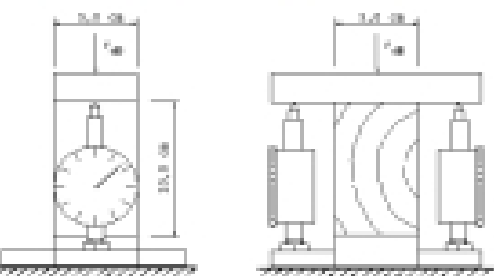

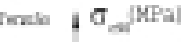

$14.00 \mathrm{kt}$

16600 in

$240 \mathrm{He}$

$25.20 \mathrm{wm}$

20 $00 \mathrm{mu}$

3060 is

$3920 \mathrm{wi}$

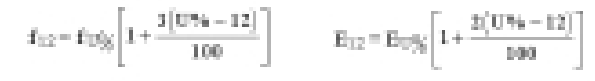

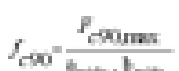

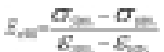

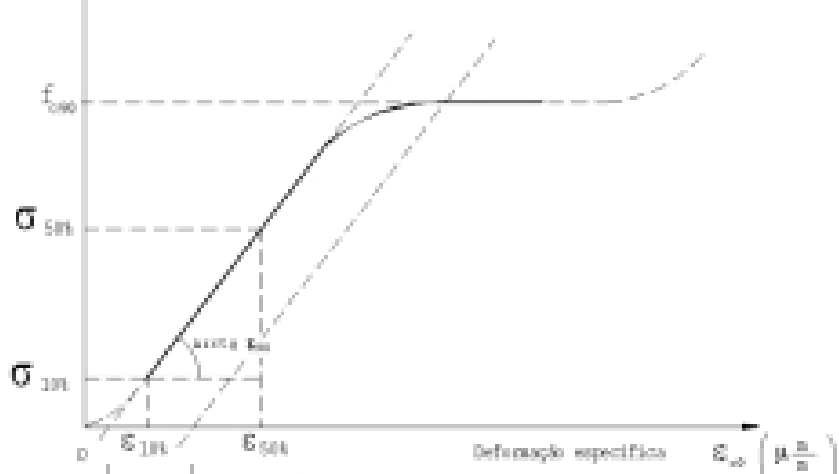

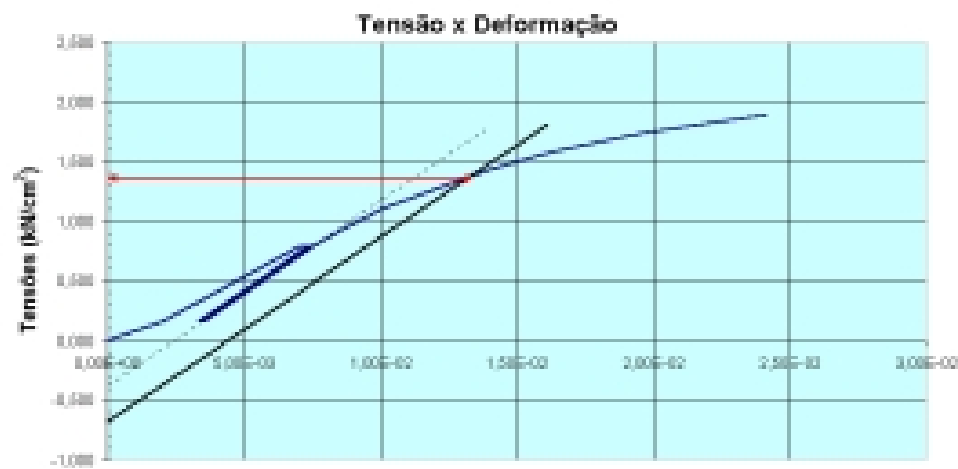

Defoenaços

Figura 4.5 - Caracterização das Madeiras de Eucalipto Citriodora: Compressão normal 


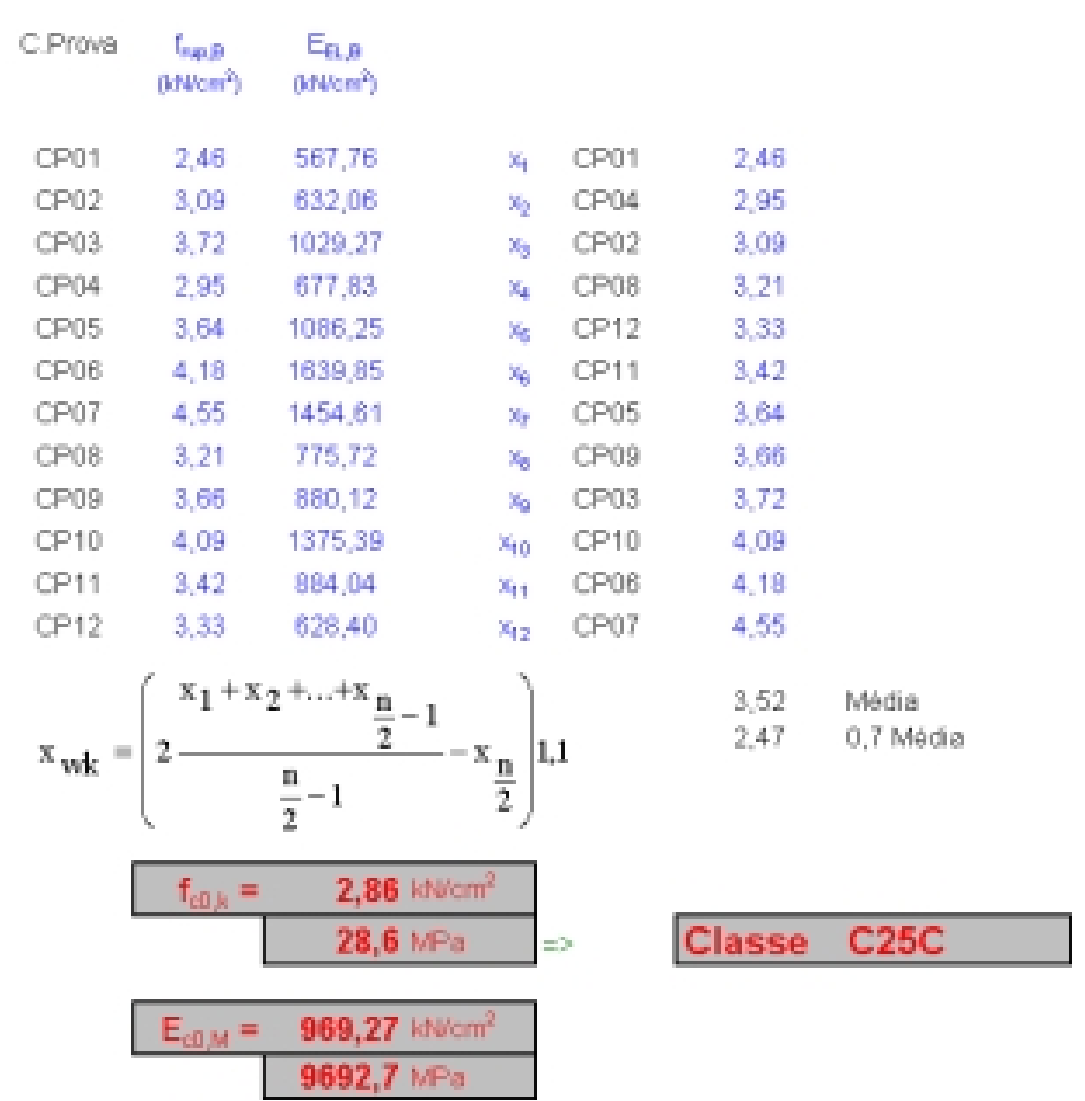

Figura 4.6 - Resultados da Caracterização - Pinus Taeda

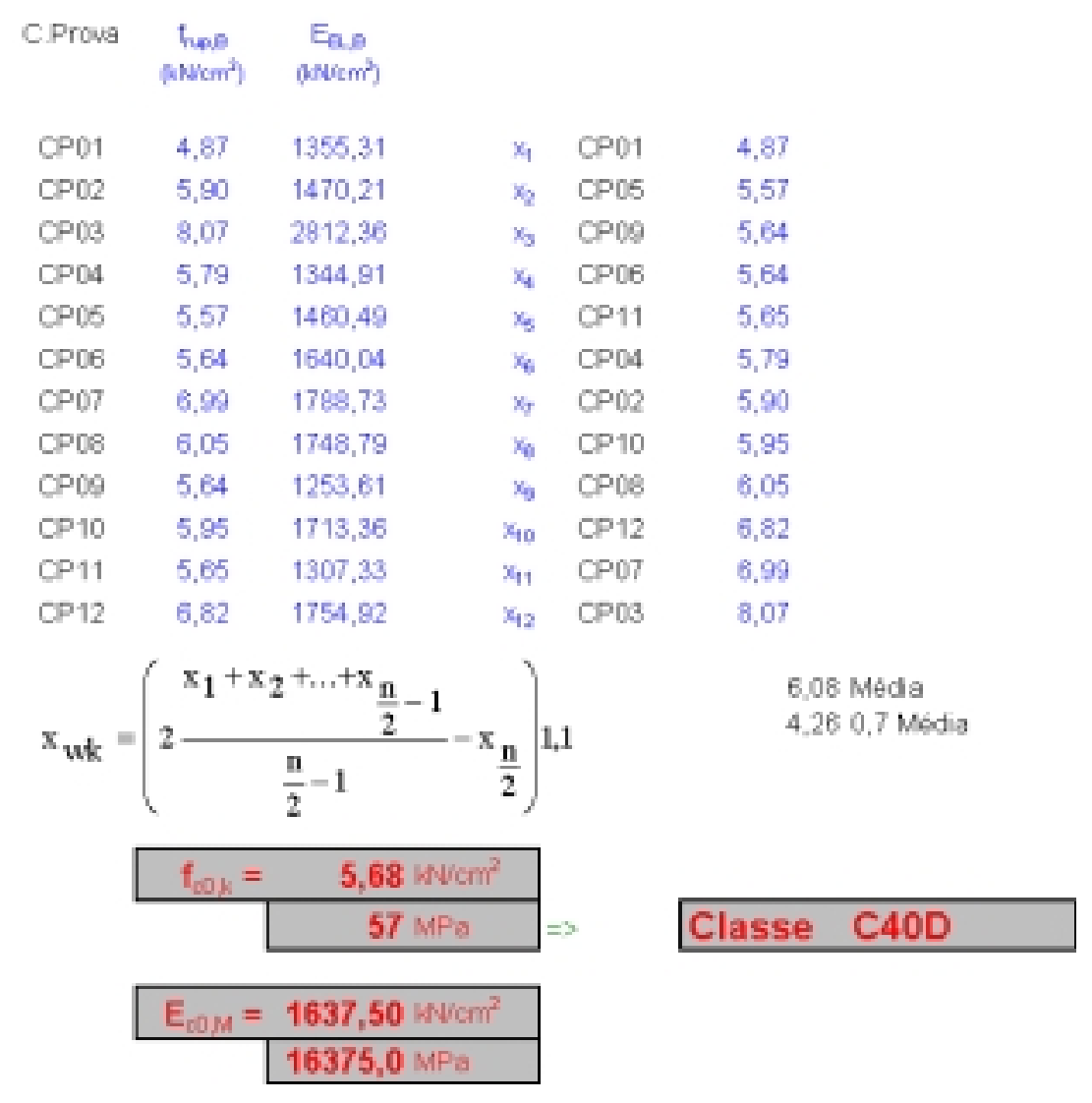

Figura 4.7 - Resultados da Caracterização - Eucalipto Citriodora 
Pode-se verificar que as classes de resistência C25C para o Pinus E C40D para o Eucalipto estão de acordo com o esperado.

A seguir são apresentados os resultados para os corpos-de-prova de Eucalipto a $12 \%$ de umidade, Eucalipto a $20 \%$ de umidade, Pinus a $12 \%$ de umidade e Pinus a $20 \%$ de umidade. Em primeiro lugar, é apresentada uma parte da tabela de dados seguida pelo gráfico da fluência da madeira medida por transdutores e strain gages. Na seqüência, é apresentado um ajuste dos resultados (tabela e gráfico) em equações exponenciais. Quando houveram aquisições de dados de umidade e temperatura, foram apresentados gráficos de deslocamentos, deformações que os relacionam.

Para entender os conteúdos das colunas da tabela de aquisição de resultados a seguir:

- DT,méd (Kyowa): Leitura média de deslocamentos medidos pelo sistema de aquisição KYOWA conectados aos dois transdutores de deslocamentos;

a DT,méd (Relógio): Leitura média de deslocamentos medidos nos ponteiros dos dois transdutores de deslocamentos;

a DT,méd: Média das leituras de deslocamentos dos dois transdutores de deslocamentos;

a Deform. (Kyowa): Cálculo de deformações através de DT,méd (Kyowa);

a Deform. (Relógio): Cálculo de deformações através de DT,méd (Relógio);

- SG,sup: Média dos valores de deformações obtidas pelos dois straingages superiores;

- SG,inf: Média dos valores de deformações obtidas pelos dois straingages inferiores;

- SG,méd: Média dos valores de deformações entre SG,sup e SG,inf; 
Corpo-de-prova: Madeira de Eucalipto - U=12\%

\begin{tabular}{|c|c|c|c|c|c|c|c|c|c|c|}
\hline $\begin{array}{l}\text { Tempo } \\
\text { (dias) }\end{array}$ & $\begin{array}{c}\text { Célula de Carga } \\
\qquad(\mathrm{kN})\end{array}$ & $\begin{array}{l}\text { DT,méd } \\
\text { (Kyowa) }\end{array}$ & $\begin{array}{l}\text { DT,méd } \\
\text { (Relógio) }\end{array}$ & DT,méd & $\begin{array}{l}\text { Deform. } \\
\text { (Kyowa) }\end{array}$ & $\begin{array}{l}\text { Deform. } \\
\text { (Relógio) }\end{array}$ & Deform. & SG,sup & SG,inf & $\begin{array}{l}\text { SG,méd } \\
\text { (pontual) }\end{array}$ \\
\hline 0,00 & 0,00 & 0,00 & 0,00 & 0,00 & $0,00 \mathrm{E}+00$ & $0,00 \mathrm{E}+00$ & $0,00 \mathrm{E}+00$ & $0,0 \mathrm{E}+00$ & $0,0 \mathrm{E}+00$ & $0,0 \mathrm{E}+00$ \\
\hline 0,00 & 24,40 & 2,77 & 2,90 & 2,83 & $-4,62 \mathrm{E}-03$ & $-4,83 \mathrm{E}-03$ & $-4,72 \mathrm{E}-03$ & $-2,1 \mathrm{E}-03$ & $-1,6 \mathrm{E}-03$ & $-1,8 \mathrm{E}-03$ \\
\hline 0,01 & 24,17 & 2,85 & 3,01 & 2,93 & $-4,75 \mathrm{E}-03$ & $-5,01 \mathrm{E}-03$ & $-4,88 \mathrm{E}-03$ & $-2,2 \mathrm{E}-03$ & $-1,6 \mathrm{E}-03$ & $-1,9 \mathrm{E}-03$ \\
\hline 0,02 & 24,40 & 2,85 & 3,03 & 2,94 & $-4,75 \mathrm{E}-03$ & $-5,05 E-03$ & $-4,90 \mathrm{E}-03$ & $-2,2 E-03$ & $-1,7 \mathrm{E}-03$ & $-1,9 \mathrm{E}-03$ \\
\hline 0,03 & 24,40 & 2,88 & 3,05 & 2,96 & $-4,80 \mathrm{E}-03$ & $-5,08 \mathrm{E}-03$ & $-4,94 \mathrm{E}-03$ & $-2,2 \mathrm{E}-03$ & $-1,6 \mathrm{E}-03$ & $-1,9 \mathrm{E}-03$ \\
\hline 0,05 & 24,17 & 2,88 & 3,07 & 2,97 & $-4,80 \mathrm{E}-03$ & $-5,11 \mathrm{E}-03$ & $-4,95 \mathrm{E}-03$ & $-2,2 \mathrm{E}-03$ & $-1,6 \mathrm{E}-03$ & $-1,9 \mathrm{E}-03$ \\
\hline 0,12 & 24,40 & 2,91 & 3,10 & 3,00 & $-4,85 \mathrm{E}-03$ & $-5,17 \mathrm{E}-03$ & $-5,01 \mathrm{E}-03$ & $-2,3 E-03$ & $-1,6 \mathrm{E}-03$ & $-1,9 \mathrm{E}-03$ \\
\hline 0,23 & 24,40 & 2,91 & 3,13 & 3,02 & $-4,85 \mathrm{E}-03$ & $-5,22 \mathrm{E}-03$ & $-5,03 E-03$ & $-2,2 \mathrm{E}-03$ & $-1,5 \mathrm{E}-03$ & $-1,9 \mathrm{E}-03$ \\
\hline 1,07 & 24,40 & 3,22 & 3,30 & 3,26 & $-5,36 \mathrm{E}-03$ & $-5,49 E-03$ & $-5,43 E-03$ & $-2,6 \mathrm{E}-03$ & $-1,7 \mathrm{E}-03$ & $-2,1 \mathrm{E}-03$ \\
\hline 2,07 & 24,40 & 3,28 & 3,38 & 3,33 & $-5,47 \mathrm{E}-03$ & $-5,63 E-03$ & $-5,55 \mathrm{E}-03$ & -2,7E-03 & $-1,8 \mathrm{E}-03$ & $-2,2 \mathrm{E}-03$ \\
\hline 2,43 & 24,40 & 3,28 & 3,37 & 3,33 & $-5,47 \mathrm{E}-03$ & $-5,62 \mathrm{E}-03$ & $-5,54 \mathrm{E}-03$ & $-2,5 E-03$ & $-1,7 \mathrm{E}-03$ & $-2,1 \mathrm{E}-03$ \\
\hline 3,01 & 24,40 & 3,44 & 3,53 & 3,48 & $-5,73 E-03$ & $-5,88 \mathrm{E}-03$ & $-5,80 \mathrm{E}-03$ & $-3,0 \mathrm{E}-03$ & $-2,0 \mathrm{E}-03$ & $-2,5 \mathrm{E}-03$ \\
\hline 3,07 & 24,40 & 3,42 & 3,53 & 3,47 & $-5,70 \mathrm{E}-03$ & $-5,88 \mathrm{E}-03$ & $-5,79 \mathrm{E}-03$ & $-2,9 \mathrm{E}-03$ & $-1,9 \mathrm{E}-03$ & $-2,4 \mathrm{E}-03$ \\
\hline 8,46 & 24,40 & 3,53 & 3,61 & 3,57 & $-5,88 \mathrm{E}-03$ & $-6,02 \mathrm{E}-03$ & $-5,95 \mathrm{E}-03$ & $-3,1 \mathrm{E}-03$ & $-2,0 \mathrm{E}-03$ & $-2,5 \mathrm{E}-03$ \\
\hline 9,16 & 24,40 & 3,53 & 3,62 & 3,57 & $-5,88 \mathrm{E}-03$ & $-6,03 E-03$ & $-5,96 \mathrm{E}-03$ & $-3,2 \mathrm{E}-03$ & $-2,1 \mathrm{E}-03$ & $-2,6 \mathrm{E}-03$ \\
\hline 10,03 & 24,40 & 3,59 & 3,70 & 3,65 & $-5,98 \mathrm{E}-03$ & $-6,17 \mathrm{E}-03$ & $-6,08 \mathrm{E}-03$ & $-3,4 \mathrm{E}-03$ & $-2,4 E-03$ & $-2,9 \mathrm{E}-03$ \\
\hline 10,17 & 24,40 & 3,54 & 3,68 & 3,61 & $-5,91 \mathrm{E}-03$ & $-6,13 \mathrm{E}-03$ & $-6,02 \mathrm{E}-03$ & $-3,3 E-03$ & $-2,2 \mathrm{E}-03$ & $-2,7 \mathrm{E}-03$ \\
\hline 11,03 & 24,40 & 3,64 & 3,76 & 3,70 & $-6,06 \mathrm{E}-03$ & $-6,27 \mathrm{E}-03$ & $-6,16 \mathrm{E}-03$ & $-3,5 E-03$ & $-2,6 \mathrm{E}-03$ & $-3,0 \mathrm{E}-03$ \\
\hline 11,25 & 24,40 & 3,57 & 3,71 & 3,64 & $-5,96 \mathrm{E}-03$ & $-6,18 \mathrm{E}-03$ & $-6,07 \mathrm{E}-03$ & $-3,3 E-03$ & $-2,2 \mathrm{E}-03$ & $-2,8 \mathrm{E}-03$ \\
\hline 12,05 & 24,40 & 3,64 & 3,75 & 3,69 & $-6,06 \mathrm{E}-03$ & $-6,25 \mathrm{E}-03$ & $-6,16 \mathrm{E}-03$ & $-3,5 \mathrm{E}-03$ & $-2,4 E-03$ & $-2,9 \mathrm{E}-03$ \\
\hline 12,43 & 24,40 & 3,61 & 3,73 & 3,67 & $-6,01 \mathrm{E}-03$ & $-6,21 E-03$ & $-6,11 E-03$ & $-3,3 E-03$ & $-2,3 E-03$ & $-2,8 \mathrm{E}-03$ \\
\hline 13,07 & 24,40 & 3,64 & 3,75 & 3,69 & $-6,06 \mathrm{E}-03$ & $-6,25 E-03$ & $-6,16 \mathrm{E}-03$ & $-3,4 \mathrm{E}-03$ & $-2,3 E-03$ & $-2,9 \mathrm{E}-03$ \\
\hline 13,24 & 24,40 & 3,61 & 3,73 & 3,67 & $-6,01 \mathrm{E}-03$ & $-6,21 \mathrm{E}-03$ & $-6,11 \mathrm{E}-03$ & $-3,2 \mathrm{E}-03$ & $-2,2 \mathrm{E}-03$ & $-2,7 E-03$ \\
\hline 17,14 & 24,40 & 3,62 & 3,69 & 3,66 & $-6,04 \mathrm{E}-03$ & $-6,15 \mathrm{E}-03$ & $-6,09 \mathrm{E}-03$ & $-3,4 \mathrm{E}-03$ & $-2,2 \mathrm{E}-03$ & $-2,8 \mathrm{E}-03$ \\
\hline 17,31 & 24,40 & 3,56 & 3,65 & 3,60 & $-5,93 \mathrm{E}-03$ & $-6,08 \mathrm{E}-03$ & $-6,01 \mathrm{E}-03$ & $-3,2 \mathrm{E}-03$ & $-2,0 \mathrm{E}-03$ & $-2,6 \mathrm{E}-03$ \\
\hline 18,05 & 24,40 & 3,59 & 3,70 & 3,65 & $-5,98 \mathrm{E}-03$ & $-6,17 \mathrm{E}-03$ & $-6,08 \mathrm{E}-03$ & $-3,4 \mathrm{E}-03$ & $-2,3 E-03$ & $-2,8 \mathrm{E}-03$ \\
\hline
\end{tabular}




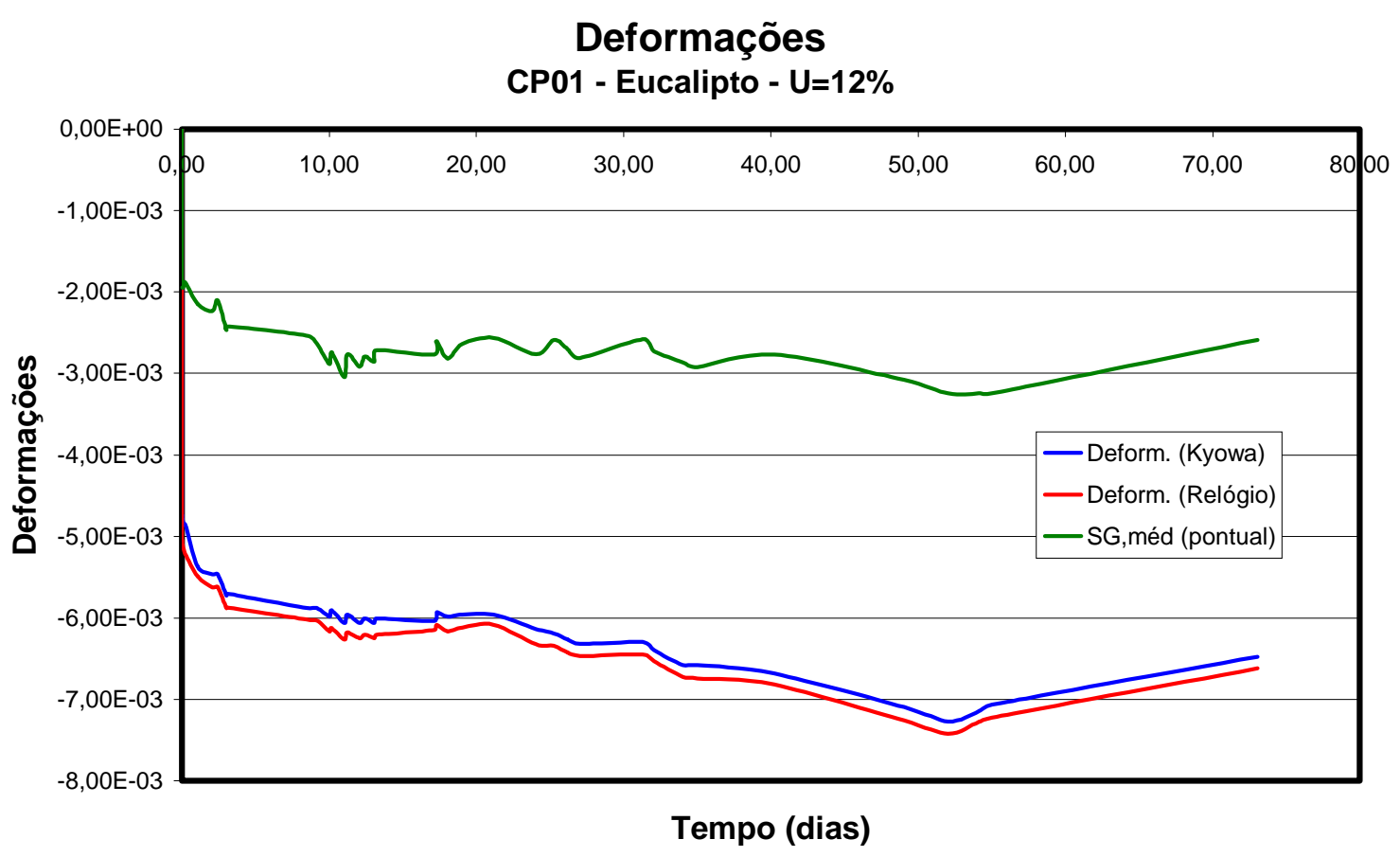

Foram realizados dois ajustes diferentes para avaliar o comportamento dos deslocamentos ao longo do tempo. Os resultados de deslocamentos que serviram de dados para os ajustes não incluíram os deslocamentos imediatos.

Ambos ajustes são exponenciais, com a diferença que no segundo, a curva passa pelo ponto $[0,0]$.

Equações de ajuste:

$$
\begin{array}{ccc}
\left.Y=Y 0+A e^{\wedge}(-x / B)\right)=> & d=1,57-1,30188^{*} e^{\wedge}(-t / 28,15556) \\
\left.Y=A\left(1-e^{\wedge}(B t)\right)\right) \quad \Rightarrow \quad & d=1,265696^{*}\left(1-e^{\wedge}\left(-0,080838^{*} t\right)\right) \\
& \text { Onde: } \quad \begin{array}{c}
d=\text { deslocamento em mm; } \\
t=\text { tempo em dias }
\end{array}
\end{array}
$$

A mesma avaliação foi realizada para os outros três corpos-de-prova. 
Tabela de Ajuste dos Deslocamentos

\begin{tabular}{|c|c|c|c|}
\hline Tempo & $\begin{array}{l}\text { Deslocamentos } \\
\text { (mm) }\end{array}$ & $\begin{array}{c}\text { Ajuste }\left(y=y 0+A e^{\wedge}(-x / B)\right) \\
d=1,57-1,30188^{\star} e^{\wedge}(- \\
t / 28,15556)\end{array}$ & $\begin{array}{c}\text { Ajuste }\left(y=A\left(1-e^{\wedge}(B t)\right)\right) \\
d=1,265696^{*}\left(1-e^{\wedge}(-\right. \\
\left.\left.0,080838^{\star} t\right)\right)\end{array}$ \\
\hline 0,00 & 0,00 & 0,27 & 0,00 \\
\hline 0,01 & 0,09 & 0,27 & 0,00 \\
\hline 0,02 & 0,10 & 0,27 & 0,00 \\
\hline 0,03 & 0,13 & 0,27 & 0,00 \\
\hline 0,05 & 0,14 & 0,27 & 0,01 \\
\hline 0,12 & 0,17 & 0,27 & 0,01 \\
\hline 0,23 & 0,18 & 0,28 & 0,02 \\
\hline 1,07 & 0,42 & 0,32 & 0,11 \\
\hline 2,07 & 0,49 & 0,36 & 0,20 \\
\hline 2,43 & 0,49 & 0,38 & 0,23 \\
\hline 3,01 & 0,65 & 0,40 & 0,27 \\
\hline 3,07 & 0,64 & 0,40 & 0,28 \\
\hline 8,46 & 0,73 & 0,61 & 0,63 \\
\hline 9,16 & 0,74 & 0,63 & 0,66 \\
\hline 10,03 & 0,81 & 0,66 & 0,70 \\
\hline 10,17 & 0,77 & 0,66 & 0,71 \\
\hline 11,03 & 0,86 & 0,69 & 0,75 \\
\hline 11,25 & 0,80 & 0,70 & 0,76 \\
\hline 12,05 & 0,86 & 0,72 & 0,79 \\
\hline 12,43 & 0,83 & 0,73 & 0,80 \\
\hline 13,07 & 0,86 & 0,75 & 0,83 \\
\hline 13,24 & 0,83 & 0,76 & 0,83 \\
\hline 17,14 & 0,82 & 0,86 & 0,95 \\
\hline 17,31 & 0,77 & 0,87 & 0,95 \\
\hline 18,05 & 0,81 & 0,88 & 0,97 \\
\hline 19,07 & 0,79 & 0,91 & 0,99 \\
\hline 21,16 & 0,78 & 0,96 & 1,04 \\
\hline
\end{tabular}

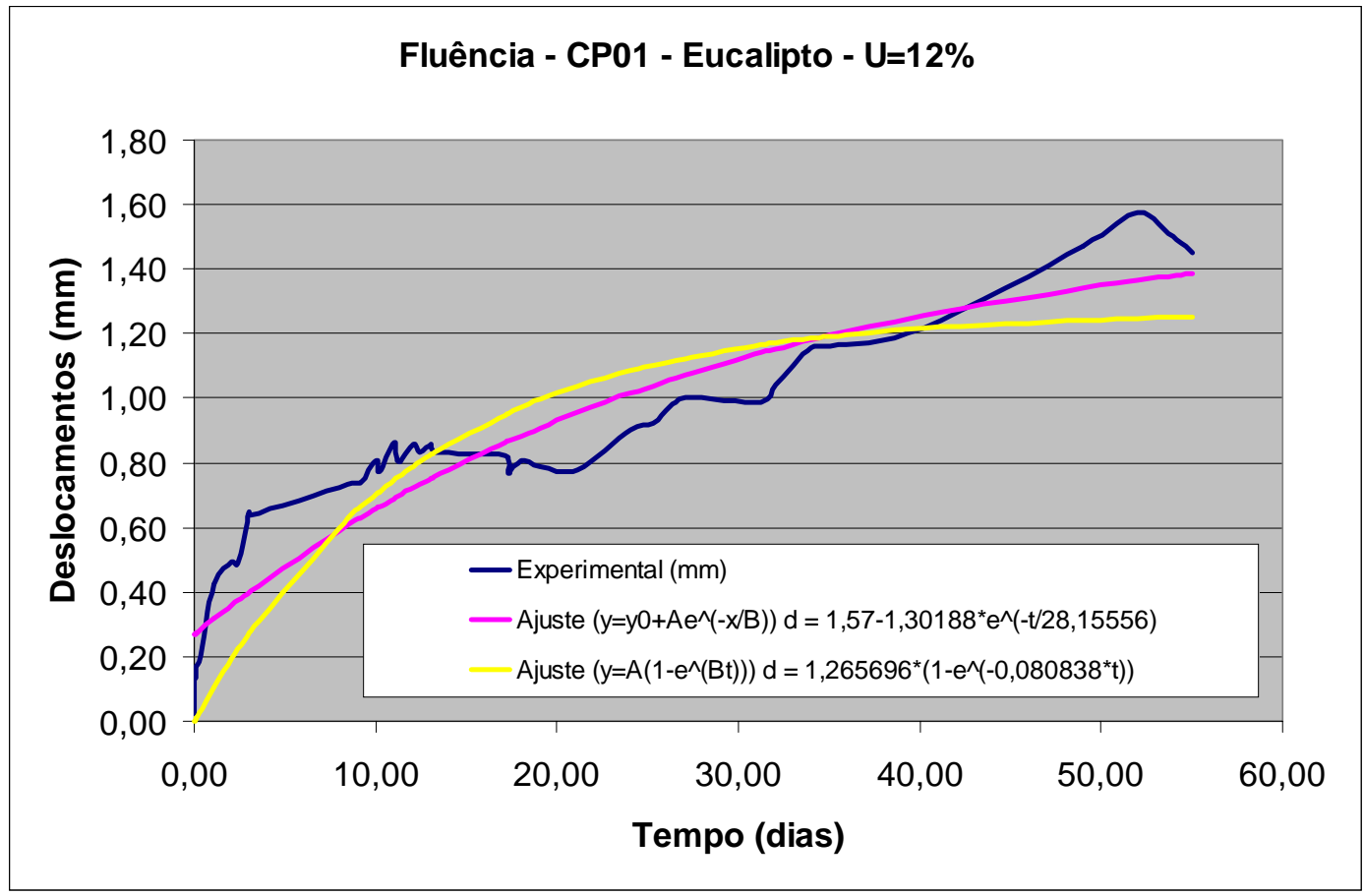


Para o corpo-de-prova de Eucalipto citriodora a 12\% de umidade:

$\mathrm{P}=29,58 \mathrm{kN}$

Carga aplicada

$\delta_{i}=2,83 \mathrm{~mm}$

Deslocamento inicial

Do modelo proposto:

$\delta_{t}=\delta_{(\text {Hooke) }}+\delta_{(\text {Kelvin })}$

$\delta_{t}=\frac{P}{k_{1}}+\frac{P}{k_{2}}\left(1-e^{(-t / \tau)}\right)$

Da segunda equação de ajuste:

$\Rightarrow \delta_{t}=2,83+1,27 \cdot\left(1-e^{(-t / 12,37)}\right)$

Portanto: $\quad\left\{\begin{array}{l}\frac{P}{k_{1}}=2,83 \mathrm{~mm} \Rightarrow k_{1}=10,45 \mathrm{kN} / \mathrm{mm} \\ \frac{P}{k_{2}}=1,27 \mathrm{~mm} \Rightarrow k_{2}=23,29 \mathrm{kN} / \mathrm{mm} \\ \tau=\frac{v_{2}}{k_{2}}=12,37 \mathrm{~s} \Rightarrow v_{2}=288,1 \mathrm{kN} / \mathrm{mm} / \mathrm{s}\end{array}\right.$

Em termos de deformação específica, podemos dizer:

$\varepsilon_{t}=\varepsilon_{\text {(Hooke) }}+\varepsilon_{(\text {Kelvin) }}$

$\varepsilon_{t}=\frac{2,83}{600}+\frac{1,27}{600}\left(1-e^{(-t / 12,37)}\right)$

$\varepsilon_{t}=4,72 \times 10^{-3}+2,12 \times 10^{-3}\left(1-e^{(-t / 12,37)}\right)$

$\varepsilon_{t}=\frac{\sigma}{E_{i}}+\frac{\sigma}{E_{f}}\left(1-e^{(-t / \tau)}\right)$

Como $\mathrm{P}=29,58 \mathrm{kN}$ e A $=13 \times 13=269 \mathrm{~cm}^{2}$, temos que: $\sigma=0,175 \mathrm{kN} / \mathrm{cm}^{2}$

Portanto: $\quad\left\{\begin{array}{l}\frac{\sigma}{E_{i}}=4,72 \times 10^{-3} \Rightarrow E_{i}=37,1 \mathrm{kN} / \mathrm{cm}^{2} \cong 371 \mathrm{MPa} \\ \frac{\sigma}{E_{f}}=2,12 \times 10^{-3} \Rightarrow E_{f}=82,7 \mathrm{kN} / \mathrm{cm}^{2} \cong 827 \mathrm{MPa}\end{array}\right.$

Como para $t \rightarrow+\infty \Rightarrow \delta_{(\text {Kelvin })} \rightarrow 1,27 \mathrm{~mm} \Rightarrow\left\{\begin{array}{c}\delta_{\text {total }} \rightarrow 4,10 \mathrm{~mm} \\ \varepsilon_{\text {total }} \rightarrow 6,83 \times 10^{-3}\end{array}\right.$

$$
E_{\text {total }}=25,6 \mathrm{kN} / \mathrm{cm}^{2} \cong 256 \mathrm{MPa}
$$

Valor sem sentido prático! 
Corpo-de-prova: Madeira de Eucalipto - $U=20 \%$

\begin{tabular}{|c|c|c|c|c|c|c|c|c|c|c|}
\hline $\begin{array}{c}\text { Tempo } \\
\text { (dias) }\end{array}$ & $\begin{array}{c}\text { Célula de } \\
\text { Carga } \\
(\mathrm{kN})\end{array}$ & DT,méd & $\begin{array}{l}\text { Deform. } \\
\text { (Kyowa) }\end{array}$ & $\begin{array}{l}\text { Deform. } \\
\text { (Relógio) }\end{array}$ & Deform. & SG,sup & SG,inf & $\begin{array}{l}\text { SG,méd } \\
\text { (pontual) }\end{array}$ & $\begin{array}{l}\text { Temperatura } \\
\left({ }^{\circ} \mathrm{C}\right)\end{array}$ & $\begin{array}{l}\text { Umidade } \\
\qquad \%)\end{array}$ \\
\hline 0,00 & 19,71 & 3,13 & $-5,03 E-03$ & $-5,42 \mathrm{E}-03$ & $-5,22 \mathrm{E}-03$ & -1,2E-03 & $-4,5 E-05$ & $-6,3 E-04$ & 25,00 & 73,00 \\
\hline 0,01 & 25,81 & 3,33 & $-5,44 E-03$ & $-5,68 E-03$ & -5,56E-03 & -1,3E-03 & 5,0E-06 & $-6,3 E-04$ & 25,00 & 70,00 \\
\hline 0,02 & 25,81 & 3,37 & $-5,52 E-03$ & -5,73E-03 & $-5,62 E-03$ & -1,3E-03 & 2,8E-05 & $-6,4 \mathrm{E}-04$ & 26,00 & 68,00 \\
\hline 0,03 & 25,81 & 3,38 & $-5,52 E-03$ & $-5,76 E-03$ & $-5,64 \mathrm{E}-03$ & -1,3E-03 & 3,3E-05 & $-6,5 E-04$ & 26,00 & 68,00 \\
\hline 0,05 & 25,58 & 3,39 & $-5,52 E-03$ & -5,79E-03 & $-5,65 E-03$ & -1,3E-03 & 4,0E-05 & $-6,5 E-04$ & 26,00 & 68,00 \\
\hline 0,06 & 25,81 & 3,42 & -5,57E-03 & -5,83E-03 & $-5,70 \mathrm{E}-03$ & -1,4E-03 & 5,5E-05 & $-6,5 E-04$ & 26,30 & 70,00 \\
\hline 0,07 & 25,34 & 3,43 & -5,57E-03 & $-5,85 E-03$ & -5,71E-03 & $-1,3 E-03$ & 6,5E-05 & $-6,4 \mathrm{E}-04$ & 26,40 & 68,00 \\
\hline 0,09 & 25,81 & 3,46 & $-5,65 E-03$ & $-5,88 E-03$ & -5,76E-03 & -1,4E-03 & 7,5E-05 & $-6,4 \mathrm{E}-04$ & 26,50 & 66,00 \\
\hline 0,11 & 25,81 & 3,47 & $-5,65 E-03$ & -5,91E-03 & -5,78E-03 & -1,3E-03 & 9,3E-05 & $-6,1 \mathrm{E}-04$ & 26,80 & 64,00 \\
\hline 0,16 & 25,81 & 3,50 & $-5,72 E-03$ & $-5,95 E-03$ & $-5,84 \mathrm{E}-03$ & -1,3E-03 & 1,3E-04 & $-5,6 E-04$ & 27,40 & 60,00 \\
\hline 0,20 & 25,81 & 3,51 & $-5,72 E-03$ & $-5,98 E-03$ & $-5,85 E-03$ & -3,9E-04 & 1,6E-04 & -1,2E-04 & 27,80 & 60,00 \\
\hline 0,24 & 26,28 & 3,53 & -5,77E-03 & $-6,01 \mathrm{E}-03$ & $-5,89 \mathrm{E}-03$ & -3,3E-04 & 1,8E-04 & -7,6E-05 & 27,60 & 61,00 \\
\hline 0,28 & 26,05 & 3,55 & $-5,80 E-03$ & $-6,05 E-03$ & -5,92E-03 & $-3,2 E-04$ & 1,7E-04 & -7,1E-05 & 27,00 & 63,00 \\
\hline 0,41 & 26,28 & 3,63 & $-5,95 E-03$ & $-6,15 E-03$ & $-6,05 E-03$ & $-3,5 E-04$ & 1,3E-04 & $-1,1 \mathrm{E}-04$ & 26,50 & 66,00 \\
\hline 0,53 & 26,28 & 3,69 & $-6,03 E-03$ & $-6,28 E-03$ & $-6,16 \mathrm{E}-03$ & $-4,4 \mathrm{E}-04$ & 8,5E-05 & -1,8E-04 & 26,00 & 70,00 \\
\hline 0,91 & 26,05 & 3,90 & $-6,44 \mathrm{E}-03$ & $-6,56 \mathrm{E}-03$ & $-6,50 \mathrm{E}-03$ & $-6,7 \mathrm{E}-04$ & -1,3E-04 & $-4,0 \mathrm{E}-04$ & 24,50 & 78,00 \\
\hline 1,07 & 26,05 & 3,93 & $-6,47 E-03$ & $-6,62 E-03$ & $-6,54 \mathrm{E}-03$ & $-6,7 E-04$ & -1,3E-04 & $-4,0 \mathrm{E}-04$ & 25,00 & 76,00 \\
\hline 1,53 & 26,28 & 4,02 & $-6,62 E-03$ & -6,77E-03 & $-6,69 E-03$ & -7,1E-04 & -1,4E-04 & $-4,2 E-04$ & 24,00 & 72,00 \\
\hline 1,91 & 26,05 & 4,14 & $-6,80 \mathrm{E}-03$ & $-6,98 E-03$ & $-6,89 E-03$ & -8,6E-04 & $-3,4 E-04$ & $-6,0 \mathrm{E}-04$ & 23,00 & 75,00 \\
\hline 2,20 & 26,28 & 4,12 & $-6,80 \mathrm{E}-03$ & $-6,94 \mathrm{E}-03$ & -6,87E-03 & -7,4E-04 & -1,7E-04 & $-4,6 \mathrm{E}-04$ & 26,00 & 66,00 \\
\hline 2,91 & 26,05 & 4,27 & -7,03E-03 & -7,18E-03 & -7,11E-03 & -1,1E-03 & $-4,4 E-04$ & -7,6E-04 & 23,30 & 78,00 \\
\hline 3,11 & 26,05 & 4,26 & -7,01E-03 & -7,18E-03 & -7,09E-03 & $-9,6 E-04$ & -3,3E-04 & $-6,4 \mathrm{E}-04$ & 25,80 & 73,00 \\
\hline 3,95 & 26,05 & 4,36 & -7,16E-03 & -7,38E-03 & -7,27E-03 & -1,2E-03 & $-4,9 E-04$ & $-8,2 E-04$ & 25,00 & 70,00 \\
\hline 4,11 & 26,05 & 4,36 & -7,19E-03 & -7,36E-03 & -7,27E-03 & -1,0E-03 & -3,9E-04 & -7,2E-04 & 26,90 & 68,00 \\
\hline 4,28 & 25,81 & 4,32 & -7,09E-03 & -7,30E-03 & -7,19E-03 & -8,8E-04 & $-2,8 E-04$ & $-5,8 E-04$ & 28,20 & 61,00 \\
\hline
\end{tabular}


Deformações

CP02 - Eucalipto - U=20\%

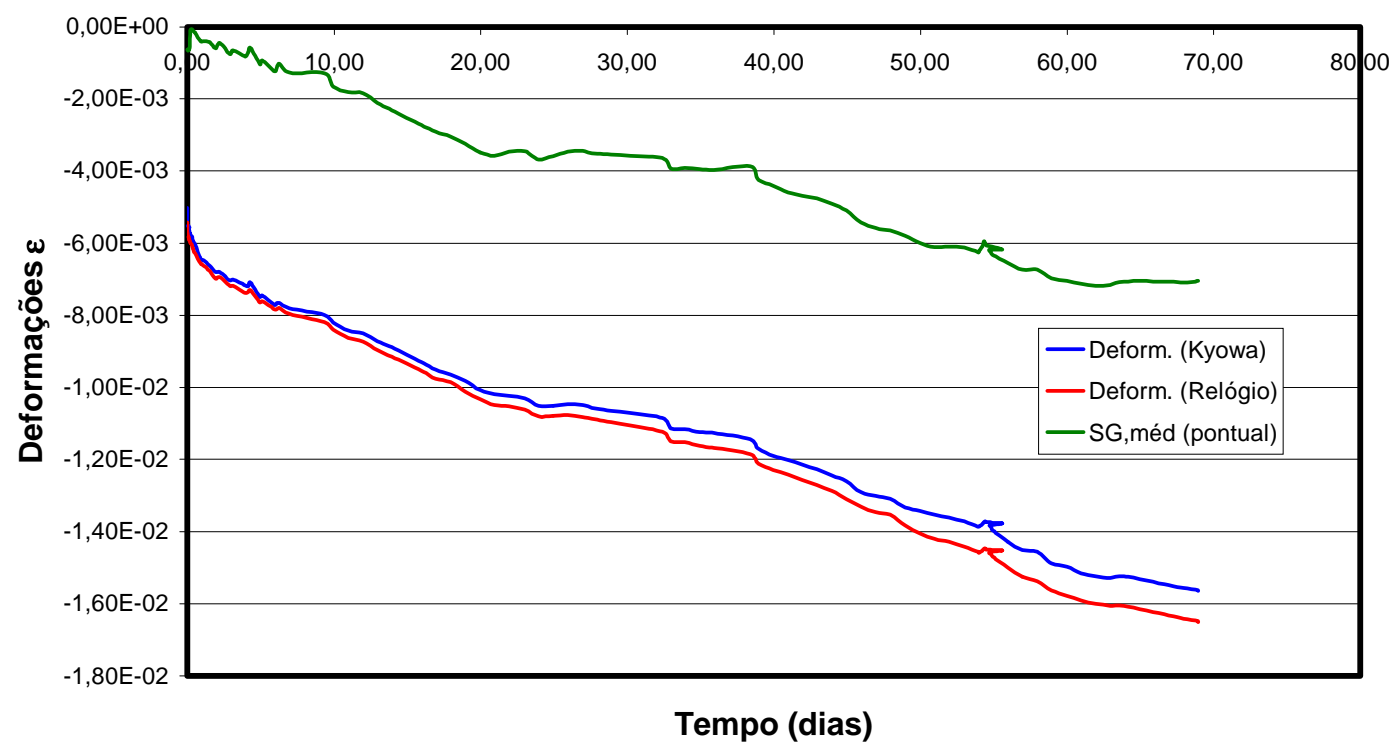

Relações com Temperatura e Umidade CP02 - Eucalipto - U=20\%

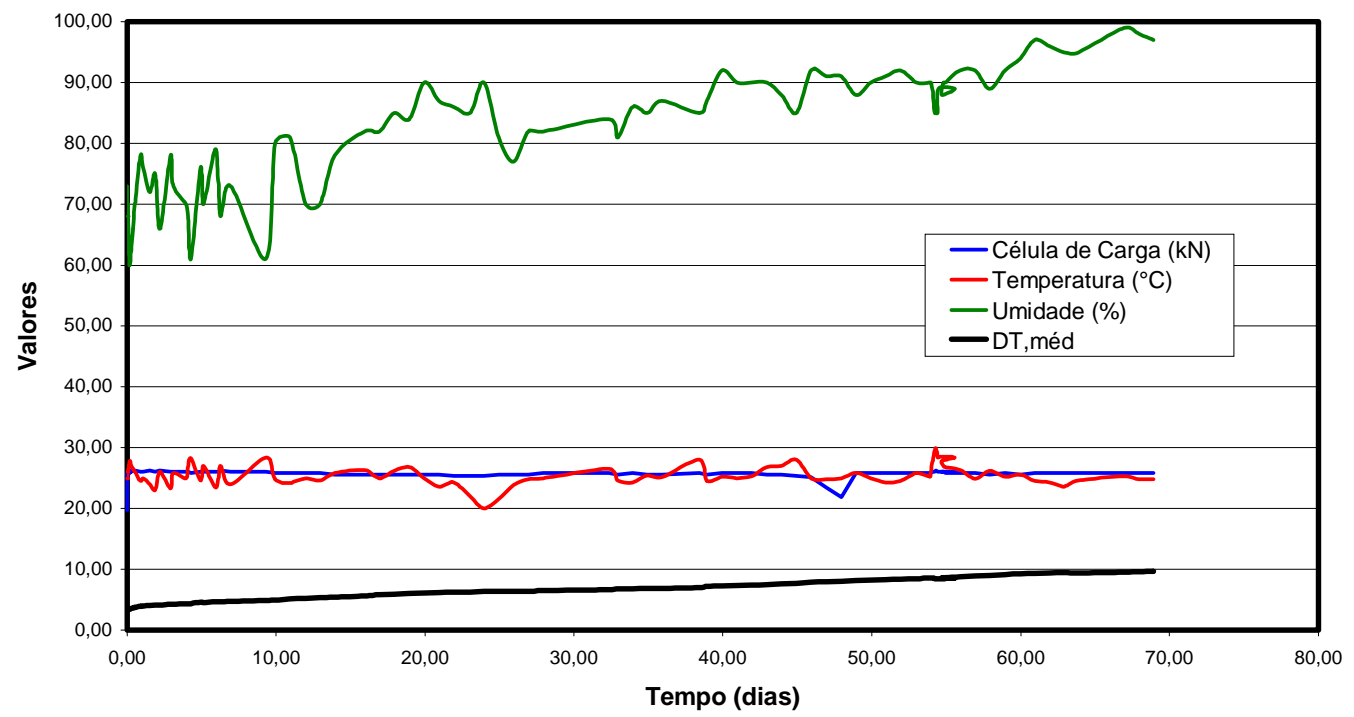

Equações de ajuste:

$$
\begin{aligned}
& \left.Y=Y 0+A e^{\wedge}(-x / B)\right) \Rightarrow \quad d=6,51-6,15^{\star} e^{\wedge}(-t / 34,37448) \\
& \left.Y=A\left(1-e^{\wedge}(B t)\right)\right) \quad \Rightarrow \quad d=8,100353^{*}\left(1-e^{\wedge}\left(-0,020611^{\star} t\right)\right) \\
& \text { Onde: } \quad \mathrm{d}=\text { deslocamento em } \mathrm{mm} \text {; } \\
& \mathrm{t}=\text { tempo em dias }
\end{aligned}
$$


Tempo

(dias)

0,00

0,01

0,02

0,03

0,05

0,06

0,41

0,53

0,91

1,07

1,53

1,91

2,20

2,91

3,11

3,95

4,11

4,28

4,95

5,11

62,95

63,89

66,95

67,95

68,91

68,95
Deslocamentos

(mm)

0,00

0,20

0,24

0,25

0,26

0,28

0,50

0,56

0,77

0,79

0,88

1,00

0,99

1,13

1,12

1,23

1,23

1,18

1,41

1,38

6,27

6,26

6,41

6,46

6,50

6,51
Ajuste $\left(\mathrm{y}=\mathrm{y} 0+\mathrm{A} \mathrm{e}^{\wedge}(-\mathrm{x} / \mathrm{B})\right)$ $d=6,51-6,15^{\star} e^{\wedge}(-$ $\mathrm{t} / 34,37448)$

0,36

0,36

0,36

0,37

0,37

0,37

0,43

0,45

0,52

0,55

0,63

0,69

0,74

0,86

0,89

1,03

1,05

1,08

1,18

1,21

5,52

5,55

5,63

5,66

5,68

5,68
Ajuste $\left(\mathrm{y}=\mathrm{A}\left(1-\mathrm{e}^{\wedge}(\mathrm{Bt})\right)\right)$

$d=8,100353^{*}\left(1-e^{\wedge}(-\right.$ $\left.0,020611^{\star} \mathrm{t}\right)$ )

0,00

0,00

0,00

0,01

0,01

0,01

0,07

0,09

0,15

0,18

0,25

0,31

0,36

0,47

0,50

0,63

0,66

0,68

0,79

0,81

5,89

5,93

6,06

6,10

6,14

6,14

Fluência - CP02 - Eucalipto - U=20\%

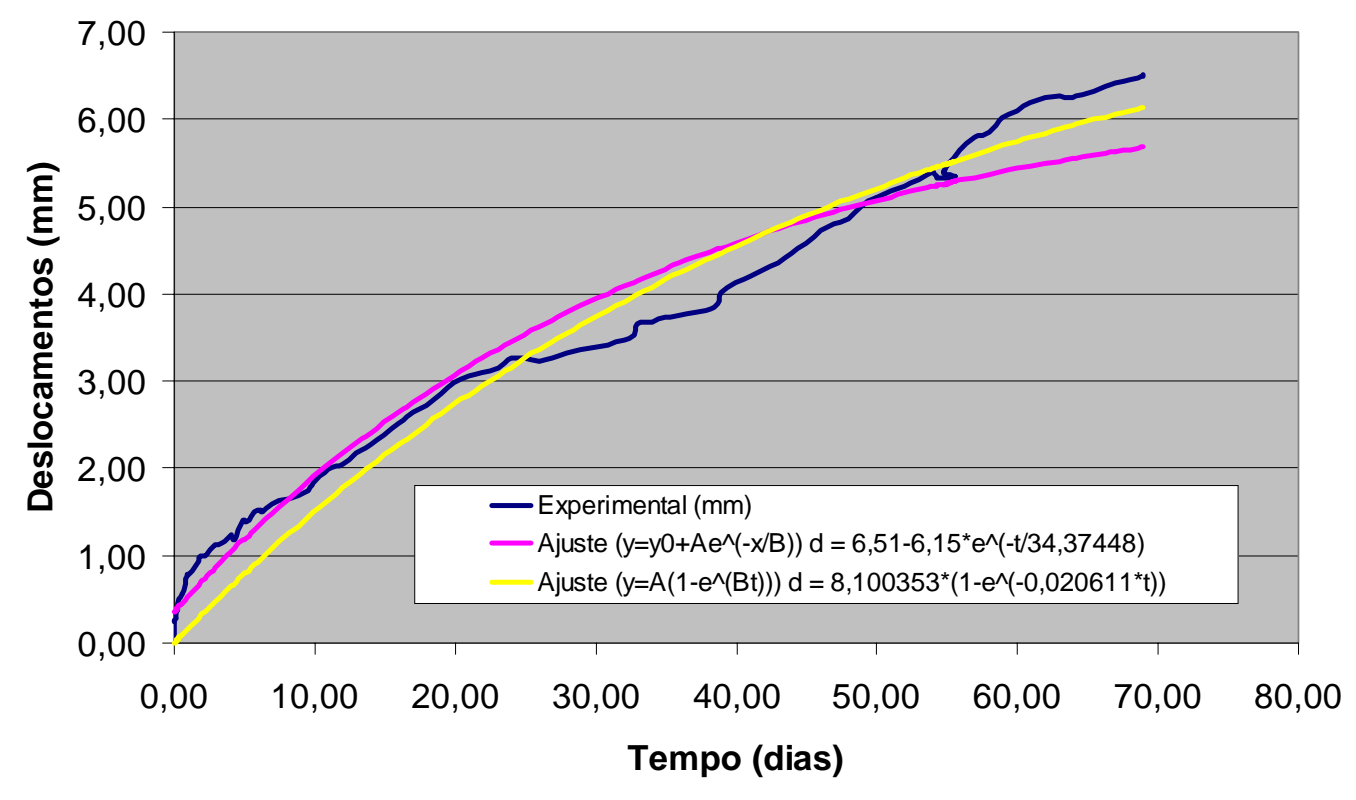


Para o corpo-de-prova de Eucalipto citriodora a 20\% de umidade:

$\mathrm{P}=29,58 \mathrm{kN}$

Carga aplicada

$\delta_{i}=3,13 \mathrm{~mm}$

Deslocamento inicial

Do modelo proposto:

$\delta_{t}=\delta_{(\text {Hooke) }}+\delta_{(\text {Kelvin })}$

$\delta_{t}=\frac{P}{k_{1}}+\frac{P}{k_{2}}\left(1-e^{(-t / \tau)}\right)$

Da segunda equação de ajuste:

$\Rightarrow \delta_{t}=3,13+8,10 \cdot\left(1-e^{(-t / 48,52)}\right)$

Portanto: $\quad\left\{\begin{array}{c}\frac{P}{k_{1}}=3,13 \mathrm{~mm} \Rightarrow k_{1}=9,45 \mathrm{kN} / \mathrm{mm} \\ \frac{P}{k_{2}}=8,10 \mathrm{~mm} \Rightarrow k_{2}=3,65 \mathrm{kN} / \mathrm{mm} \\ \tau=\frac{v_{2}}{k_{2}}=48,52 \mathrm{~s} \Rightarrow v_{2}=177,2 \mathrm{kN} / \mathrm{mm} / \mathrm{s}\end{array}\right.$

Em termos de deformação específica, podemos dizer:

$\varepsilon_{t}=\varepsilon_{\text {(Hooke) }}+\varepsilon_{(\text {Kelvin) }}$

$\varepsilon_{t}=\frac{3,13}{600}+\frac{8,10}{600}\left(1-e^{(-t / 48,52)}\right)$

$\varepsilon_{t}=5,22 \times 10^{-3}+13,50 \times 10^{-3}\left(1-e^{(-t / 48,52)}\right)$

$\varepsilon_{t}=\frac{\sigma}{E_{i}}+\frac{\sigma}{E_{f}}\left(1-e^{(-t / \tau)}\right)$

Como $\sigma=0,175 \mathrm{kN} / \mathrm{cm}^{2}$

Portanto: $\quad\left\{\begin{array}{l}\frac{\sigma}{E_{i}}=5,22 \times 10^{-3} \Rightarrow E_{i}=33,5 \mathrm{kN} / \mathrm{cm}^{2} \cong 335 \mathrm{MPa} \\ \frac{\sigma}{E_{f}}=13,50 \times 10^{-3} \Rightarrow E_{f}=13,0 \mathrm{kN} / \mathrm{cm}^{2} \cong 130 \mathrm{MPa}\end{array}\right.$

$$
t \rightarrow+\infty \Rightarrow \delta_{(\text {Kelvin })} \rightarrow 8,10 \mathrm{~mm} \Rightarrow\left\{\begin{array}{c}
\delta_{\text {total }} \rightarrow 11,23 \mathrm{~mm} \\
\varepsilon_{\text {total }} \rightarrow 18,72 \times 10^{-3}
\end{array}\right.
$$


Corpo-de-prova: Madeira de Pinus - U=12\%

\begin{tabular}{|c|c|c|c|c|c|c|c|c|c|c|}
\hline $\begin{array}{l}\text { Tempo } \\
\text { (dias) }\end{array}$ & $\begin{array}{c}\text { Célula de Carga } \\
\qquad(\mathrm{kN})\end{array}$ & DT,méd & $\begin{array}{l}\text { Deform. } \\
\text { (Kyowa) }\end{array}$ & $\begin{array}{l}\text { Deform. } \\
\text { (Relógio) }\end{array}$ & Deform. & SG,sup & SG,inf & $\begin{array}{l}\text { SG,méd } \\
\text { (pontual) }\end{array}$ & $\begin{array}{c}\text { Temperatura } \\
\left({ }^{\circ} \mathrm{C}\right)\end{array}$ & $\begin{array}{l}\text { Umidade } \\
\qquad(\%)\end{array}$ \\
\hline 0,00 & 0,00 & 0,00 & $0,00 E+00$ & $0,00 \mathrm{E}+00$ & $0,00 E+00$ & $0,0 \mathrm{E}+00$ & $0,0 \mathrm{E}+00$ & $0,0 \mathrm{E}+00$ & 22,60 & 54,00 \\
\hline 0,00 & 20,18 & 4,01 & $-6,36 \mathrm{E}-03$ & $-7,01 \mathrm{E}-03$ & $-6,68 \mathrm{E}-03$ & $-2,4 \mathrm{E}-04$ & $-6,8 \mathrm{E}-04$ & -4,6E-04 & 23,90 & 51,00 \\
\hline 0,02 & 23,47 & 4,28 & $-6,92 E-03$ & $-7,36 \mathrm{E}-03$ & -7,14E-03 & $-3,8 E-04$ & $-8,0 \mathrm{E}-04$ & -5,9E-04 & 25,40 & 47,00 \\
\hline 0,03 & 23,47 & 4,33 & $-7,00 \mathrm{E}-03$ & $-7,44 \mathrm{E}-03$ & -7,22E-03 & $-3,8 E-04$ & $-8,1 \mathrm{E}-04$ & $-6,0$ E-04 & 25,50 & 46,00 \\
\hline 0,04 & 23,00 & 4,36 & -7,03E-03 & -7,50E-03 & -7,26E-03 & $-3,9 E-04$ & $-8,0 \mathrm{E}-04$ & $-6,0 \mathrm{E}-04$ & 25,60 & 46,00 \\
\hline 0,05 & 22,53 & 4,39 & -7,05E-03 & -7,57E-03 & -7,31E-03 & $-4,1 \mathrm{E}-04$ & $-8,1 E-04$ & $-6,1 E-04$ & 25,90 & 44,00 \\
\hline 0,06 & 21,35 & 4,40 & $-7,05 \mathrm{E}-03$ & $-7,61 \mathrm{E}-03$ & -7,33E-03 & $-4,1 \mathrm{E}-04$ & $-8,0 \mathrm{E}-04$ & $-6,1 \mathrm{E}-04$ & 25,90 & 43,00 \\
\hline 0,07 & 21,35 & 4,43 & $-7,10 \mathrm{E}-03$ & -7,67E-03 & -7,39E-03 & $-4,1 \mathrm{E}-04$ & $-8,0 \mathrm{E}-04$ & $-6,0$ E-04 & 26,00 & 43,00 \\
\hline 0,08 & 23,47 & 4,49 & -7,26E-03 & -7,72E-03 & -7,49E-03 & $-4,4 \mathrm{E}-04$ & $-8,4 \mathrm{E}-04$ & $-6,4 \mathrm{E}-04$ & 26,40 & 42,00 \\
\hline 0,10 & 23,47 & 4,52 & -7,28E-03 & -7,77E-03 & -7,53E-03 & $-4,3 E-04$ & $-8,4 \mathrm{E}-04$ & $-6,3 E-04$ & 26,60 & 40,00 \\
\hline 0,13 & 20,65 & 4,50 & $-7,18 \mathrm{E}-03$ & $-7,83 \mathrm{E}-03$ & -7,51E-03 & $-4,1 \mathrm{E}-04$ & $-8,1 \mathrm{E}-04$ & $-6,1 \mathrm{E}-04$ & 27,00 & 39,00 \\
\hline 0,17 & 20,65 & 4,59 & $-7,31 \mathrm{E}-03$ & -7,99E-03 & $-7,65 \mathrm{E}-03$ & $-3,5 E-04$ & -7,2E-04 & $-5,3 E-04$ & 28,10 & 36,00 \\
\hline 0,21 & 23,00 & 4,70 & $-7,54 \mathrm{E}-03$ & $-8,12 \mathrm{E}-03$ & -7,83E-03 & -3,3E-04 & -7,2E-04 & $-5,2 E-04$ & 28,80 & 34,00 \\
\hline 0,25 & 23,00 & 4,77 & -7,67E-03 & $-8,24 \mathrm{E}-03$ & -7,96E-03 & $-3,1 \mathrm{E}-04$ & $-6,9 E-04$ & $-5,0 E-04$ & 29,00 & 34,00 \\
\hline 0,37 & 21,35 & 4,98 & -7,98E-03 & $-8,63 \mathrm{E}-03$ & $-8,30 \mathrm{E}-03$ & -3,7E-04 & -7,6E-04 & $-5,6 \mathrm{E}-04$ & 28,80 & 38,00 \\
\hline 0,46 & 21,12 & 5,04 & $-8,03 E-03$ & -8,77E-03 & $-8,40 E-03$ & $-4,4 \mathrm{E}-04$ & $-8,5 E-04$ & $-6,5 E-04$ & 27,90 & 42,00 \\
\hline 1,00 & 21,12 & 5,33 & -8,54E-03 & $-9,22 E-03$ & -8,88E-03 & -1,0E-03 & $-1,5 \mathrm{E}-03$ & -1,3E-03 & 23,90 & 52,00 \\
\hline 1,13 & 20,65 & 5,32 & -8,47E-03 & $-9,27 E-03$ & -8,87E-03 & $-1,0 \mathrm{E}-03$ & $-1,4 \mathrm{E}-03$ & -1,2E-03 & 26,30 & 44,00 \\
\hline 1,25 & 20,65 & 5,34 & $-8,47 \mathrm{E}-03$ & $-9,32 E-03$ & -8,89E-03 & $-9,0$ E-04 & $-1,3 \mathrm{E}-03$ & -1,1E-03 & 27,90 & 42,00 \\
\hline 2,00 & 21,59 & 5,54 & -8,82E-03 & $-9,65 E-03$ & $-9,24 \mathrm{E}-03$ & -1,4E-03 & $-1,8 \mathrm{E}-03$ & -1,6E-03 & 23,50 & 50,00 \\
\hline 4,50 & 21,35 & 6,02 & $-9,52 E-03$ & $-1,06 E-02$ & $-1,00 \mathrm{E}-02$ & $-1,2 \mathrm{E}-03$ & $-1,5 E-03$ & -1,4E-03 & 28,80 & 36,00 \\
\hline 5,00 & 26,52 & 6,36 & -1,04E-02 & $-1,08 \mathrm{E}-02$ & -1,06E-02 & -1,7E-03 & $-2,0 \mathrm{E}-03$ & -1,9E-03 & 25,80 & 36,00 \\
\hline 5,96 & 26,75 & 6,59 & $-1,08 \mathrm{E}-02$ & $-1,12 \mathrm{E}-02$ & $-1,10 \mathrm{E}-02$ & $-2,5 E-03$ & $-2,9 E-03$ & -2,7E-03 & 24,40 & 55,00 \\
\hline 7,00 & 26,75 & 6,69 & $-1,10 \mathrm{E}-02$ & $-1,13 \mathrm{E}-02$ & -1,11E-02 & $-2,5 E-03$ & $-2,9 E-03$ & -2,7E-03 & 21,30 & 44,00 \\
\hline
\end{tabular}



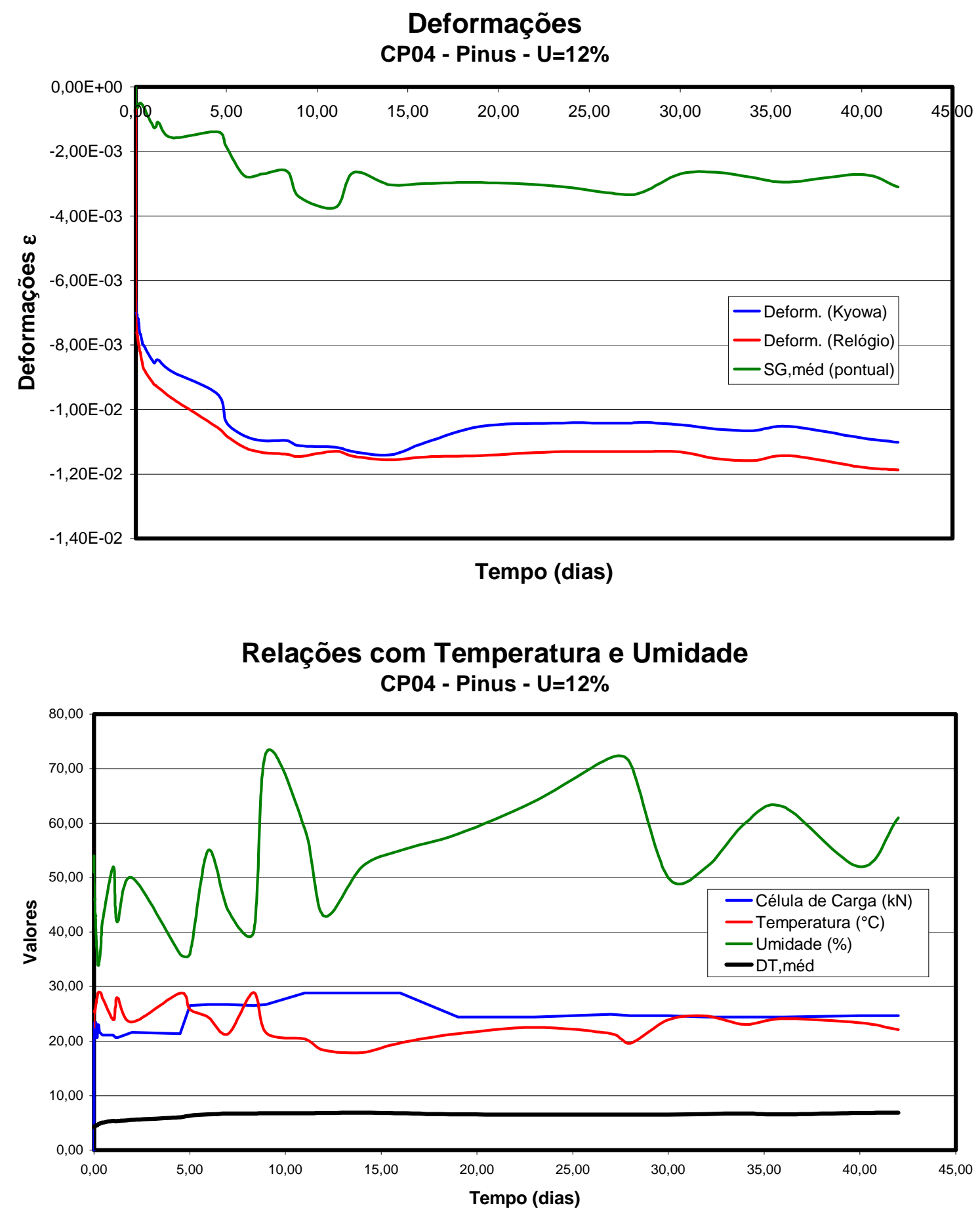

Equações de ajuste:

$$
\begin{array}{lll}
\left.Y=Y 0+A e^{\wedge}(-x / B)\right) & \Rightarrow & d=2,66673-2,307335^{\star} e^{\wedge}(-t / 2,175615) \\
\left.Y=A\left(1-e^{\wedge}(B t)\right)\right) & \Rightarrow & d=2,619824^{\star}\left(1-e^{\wedge}\left(-0,746971^{\star} t\right)\right)
\end{array}
$$

Onde: $\quad \mathrm{d}=$ deslocamento em $\mathrm{mm}$;

$\mathrm{t}=$ tempo em dias 


\begin{tabular}{|c|c|c|c|}
\hline $\begin{array}{l}\text { Tempo } \\
\text { (dias) }\end{array}$ & $\begin{array}{l}\text { Deslocamentos } \\
\qquad(\mathrm{mm})\end{array}$ & $\begin{array}{c}\text { Ajuste }\left(y=y 0+A e^{\wedge}(-x / B)\right) \\
d=2,66673-2,307335^{\star} e^{\wedge}(- \\
t / 2,175615)\end{array}$ & $\begin{array}{c}\text { Ajuste }\left(\mathrm{y}=\mathrm{A}\left(1-\mathrm{e}^{\wedge}(\mathrm{Bt})\right)\right) \\
\mathrm{d}=2,619824^{\star}\left(1-\mathrm{e}^{\wedge}(-\right. \\
\left.\left.0,746971^{\star} \mathrm{t}\right)\right)\end{array}$ \\
\hline 0,00 & 0,00 & 0,36 & 0,00 \\
\hline 0,01 & 0,19 & 0,37 & 0,02 \\
\hline 0,02 & 0,28 & 0,38 & 0,04 \\
\hline 0,03 & 0,32 & 0,39 & 0,06 \\
\hline 0,04 & 0,35 & 0,40 & 0,08 \\
\hline 0,05 & 0,38 & 0,41 & 0,10 \\
\hline 0,06 & 0,39 & 0,42 & 0,12 \\
\hline 0,07 & 0,42 & 0,44 & 0,14 \\
\hline 0,08 & 0,48 & 0,45 & 0,16 \\
\hline 0,10 & 0,51 & 0,47 & 0,20 \\
\hline 0,13 & 0,49 & 0,49 & 0,23 \\
\hline 0,17 & 0,58 & 0,53 & 0,31 \\
\hline 0,21 & 0,69 & 0,57 & 0,38 \\
\hline 0,25 & 0,76 & 0,61 & 0,45 \\
\hline 0,29 & 0,81 & 0,65 & 0,51 \\
\hline 0,37 & 0,97 & 0,72 & 0,64 \\
\hline 0,46 & 1,03 & 0,80 & 0,76 \\
\hline 1,00 & 1,32 & 1,21 & 1,38 \\
\hline 1,13 & 1,31 & 1,29 & 1,49 \\
\hline 27,00 & 2,51 & 2,67 & 2,62 \\
\hline 28,00 & 2,50 & 2,67 & 2,62 \\
\hline 30,00 & 2,53 & 2,67 & 2,62 \\
\hline 32,00 & 2,63 & 2,67 & 2,62 \\
\hline 34,00 & 2,66 & 2,67 & 2,62 \\
\hline 40,00 & 2,79 & 2,67 & 2,62 \\
\hline 42,00 & 2,86 & 2,67 & 2,62 \\
\hline 44,00 & 2,86 & & 2.62 \\
\hline
\end{tabular}

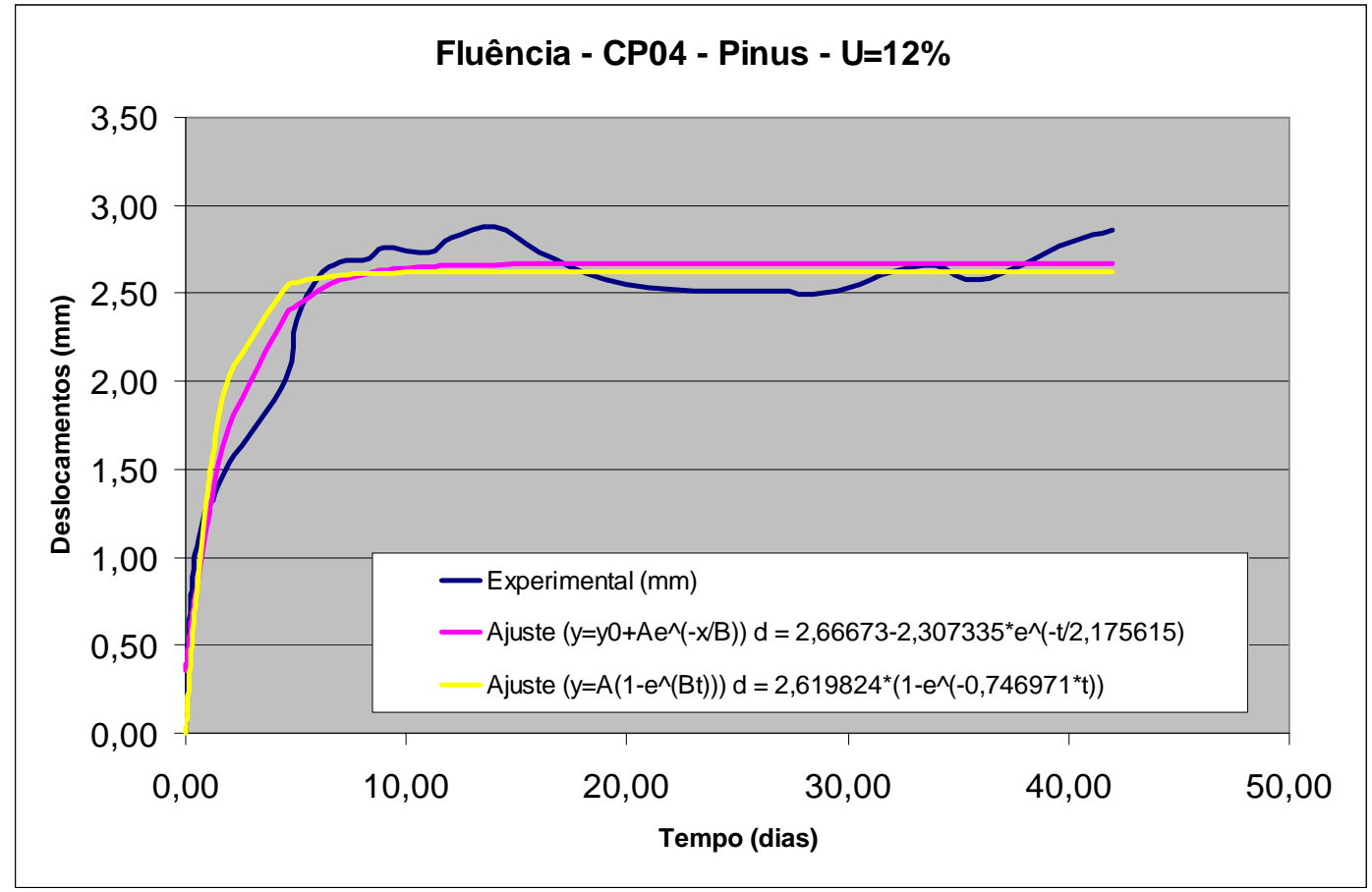


Para o corpo-de-prova de Pinus a $12 \%$ de umidade:

$\mathrm{P}=29,58 \mathrm{kN}$

Carga aplicada

$\delta_{i}=4,01 \mathrm{~mm}$

Deslocamento inicial

Do modelo proposto:

$\delta_{t}=\delta_{(\text {Hooke) }}+\delta_{(\text {Kelvin })}$

$\delta_{t}=\frac{P}{k_{1}}+\frac{P}{k_{2}}\left(1-e^{(-t / \tau)}\right)$

Da segunda equação de ajuste:

$\Rightarrow \delta_{t}=4,01+2,62 \cdot\left(1-e^{(-t / 1,34)}\right)$

Portanto: $\quad\left\{\begin{array}{l}\frac{P}{k_{1}}=4,01 \mathrm{~mm} \Rightarrow k_{1}=7,38 \mathrm{kN} / \mathrm{mm} \\ \frac{P}{k_{2}}=2,62 \mathrm{~mm} \Rightarrow k_{2}=11,29 \mathrm{kN} / \mathrm{mm} \\ \tau=\frac{v_{2}}{k_{2}}=1,34 \mathrm{~s} \Rightarrow v_{2}=15,1 \mathrm{kN} / \mathrm{mm} / \mathrm{s}\end{array}\right.$

Em termos de deformação específica, podemos dizer:

$\varepsilon_{t}=\varepsilon_{\text {(Hooke) }}+\varepsilon_{(\text {Kelvin) }}$

$\varepsilon_{t}=\frac{4,01}{600}+\frac{2,62}{600}\left(1-e^{(-t / 1,34)}\right)$

$\varepsilon_{t}=6,68 \times 10^{-3}+4,37 \times 10^{-3}\left(1-e^{(-t / 1,34)}\right)$

$\varepsilon_{t}=\frac{\sigma}{E_{i}}+\frac{\sigma}{E_{f}}\left(1-e^{(-t / \tau)}\right)$

Como $\sigma=0,175 \mathrm{kN} / \mathrm{cm}^{2}$

Portanto:

$$
\begin{aligned}
& \left\{\begin{array}{l}
\frac{\sigma}{E_{i}}=6,68 \times 10^{-3} \Rightarrow E_{i}=26,2 \mathrm{kN} / \mathrm{cm}^{2} \cong 262 \mathrm{MPa} \\
\frac{\sigma}{E_{f}}=4,37 \times 10^{-3} \Rightarrow E_{f}=40,1 \mathrm{kN} / \mathrm{cm}^{2} \cong 401 \mathrm{MPa}
\end{array}\right. \\
& t \rightarrow+\infty \Rightarrow \delta_{(\text {Kelvin })} \rightarrow 2,62 \mathrm{~mm} \Rightarrow\left\{\begin{array}{c}
\delta_{\text {total }} \rightarrow 6,63 \mathrm{~mm} \\
\varepsilon_{\text {total }} \rightarrow 11,05 \times 10^{-3}
\end{array}\right.
\end{aligned}
$$


Corpo-de-prova: Madeira de Pinus - U=20\%

\begin{tabular}{|c|c|c|c|c|c|c|c|c|c|c|}
\hline $\begin{array}{l}\text { Tempo } \\
\text { (dias) }\end{array}$ & $\begin{array}{l}\text { Célula de Carga } \\
\qquad(\mathrm{kN})\end{array}$ & DT,méd & $\begin{array}{l}\text { Deform. } \\
\text { (Kyowa) }\end{array}$ & $\begin{array}{l}\text { Deform. } \\
\text { (Relógio) }\end{array}$ & Deform. & SG,sup & SG,inf & $\begin{array}{l}\text { SG,méd } \\
\text { (pontual) }\end{array}$ & $\begin{array}{c}\text { Temperatura } \\
\left({ }^{\circ} \mathrm{C}\right)\end{array}$ & $\begin{array}{l}\text { Umidade } \\
(\%)\end{array}$ \\
\hline 0,00 & 0,00 & 0,00 & $0,00 \mathrm{E}+00$ & $0,00 \mathrm{E}+00$ & $0,00 \mathrm{E}+00$ & $0,0 E+00$ & $0,0 E+00$ & $0,0 \mathrm{E}+00$ & 0,00 & 0,00 \\
\hline 0,00 & 26,05 & 8,44 & $-1,42 \mathrm{E}-02$ & $-1,39 \mathrm{E}-02$ & $-1,41 \mathrm{E}-02$ & $-4,6 \mathrm{E}-04$ & $-6,8 \mathrm{E}-04$ & $-5,7 \mathrm{E}-04$ & 0,00 & 0,00 \\
\hline 0,00 & 26,05 & 8,44 & $-1,42 \mathrm{E}-02$ & $-1,39 \mathrm{E}-02$ & $-1,41 \mathrm{E}-02$ & $-4,6 \mathrm{E}-04$ & $-6,8 \mathrm{E}-04$ & $-5,7 \mathrm{E}-04$ & 0,00 & 0,00 \\
\hline 0,01 & 25,58 & 8,72 & $-1,46 \mathrm{E}-02$ & $-1,44 \mathrm{E}-02$ & $-1,45 \mathrm{E}-02$ & $-5,9 \mathrm{E}-04$ & $-1,0 \mathrm{E}-03$ & $-8,2 \mathrm{E}-04$ & 0,00 & 0,00 \\
\hline 0,01 & 26,52 & 8,91 & $-1,50 \mathrm{E}-02$ & $-1,48 \mathrm{E}-02$ & $-1,49 \mathrm{E}-02$ & $-6,4 \mathrm{E}-04$ & $-1,2 \mathrm{E}-03$ & $-9,1 \mathrm{E}-04$ & 0,00 & 0,00 \\
\hline 0,02 & 26,52 & 9,04 & $-1,52 \mathrm{E}-02$ & $-1,50 \mathrm{E}-02$ & $-1,51 \mathrm{E}-02$ & $-6,7 \mathrm{E}-04$ & $-1,3 \mathrm{E}-03$ & $-1,0 \mathrm{E}-03$ & 0,00 & 0,00 \\
\hline 0,03 & 26,28 & 9,13 & $-1,53 \mathrm{E}-02$ & $-1,51 \mathrm{E}-02$ & $-1,52 \mathrm{E}-02$ & $-7,4 \mathrm{E}-04$ & $-1,4 \mathrm{E}-03$ & $-1,1 \mathrm{E}-03$ & 0,00 & 0,00 \\
\hline 0,03 & 26,28 & 9,22 & $-1,54 \mathrm{E}-02$ & $-1,53 \mathrm{E}-02$ & $-1,54 \mathrm{E}-02$ & $-8,0$ E-04 & $-1,5 \mathrm{E}-03$ & $-1,1 \mathrm{E}-03$ & 0,00 & 0,00 \\
\hline 0,04 & 26,28 & 9,30 & $-1,56 \mathrm{E}-02$ & $-1,54 \mathrm{E}-02$ & $-1,55 \mathrm{E}-02$ & $-8,0$ E-04 & $-1,5 \mathrm{E}-03$ & $-1,2 \mathrm{E}-03$ & 0,00 & 0,00 \\
\hline 0,06 & 26,28 & 9,47 & $-1,59 \mathrm{E}-02$ & $-1,57 \mathrm{E}-02$ & $-1,58 \mathrm{E}-02$ & $-8,4 \mathrm{E}-04$ & $-1,7 \mathrm{E}-03$ & $-1,2 \mathrm{E}-03$ & 26,30 & 0,00 \\
\hline 0,08 & 26,28 & 9,60 & $-1,61 \mathrm{E}-02$ & $-1,59 \mathrm{E}-02$ & $-1,60 \mathrm{E}-02$ & $-8,7 \mathrm{E}-04$ & $-1,8 \mathrm{E}-03$ & $-1,3 \mathrm{E}-03$ & 27,00 & 0,00 \\
\hline 0,13 & 26,75 & 9,91 & $-1,66 \mathrm{E}-02$ & $-1,64 \mathrm{E}-02$ & $-1,65 \mathrm{E}-02$ & -9,7E-04 & $-2,0 \mathrm{E}-03$ & $-1,5 \mathrm{E}-03$ & 27,30 & 60,00 \\
\hline 0,17 & 26,75 & 10,07 & $-1,69 \mathrm{E}-02$ & $-1,67 \mathrm{E}-02$ & $-1,68 \mathrm{E}-02$ & $-1,0 \mathrm{E}-03$ & $-2,1 \mathrm{E}-03$ & $-1,6 \mathrm{E}-03$ & 27,30 & 60,00 \\
\hline 0,21 & 26,98 & 10,25 & -1,72E-02 & -1,70E-02 & $-1,71 \mathrm{E}-02$ & $-1,1 \mathrm{E}-03$ & $-2,3 E-03$ & $-1,7 \mathrm{E}-03$ & 27,70 & 57,00 \\
\hline 0,29 & 26,98 & 10,61 & $-1,78 \mathrm{E}-02$ & $-1,76 \mathrm{E}-02$ & $-1,77 \mathrm{E}-02$ & $-1,3 \mathrm{E}-03$ & $-2,6 \mathrm{E}-03$ & $-1,9 \mathrm{E}-03$ & 27,90 & 57,00 \\
\hline 0,38 & 26,98 & 10,85 & $-1,82 \mathrm{E}-02$ & $-1,80 \mathrm{E}-02$ & $-1,81 \mathrm{E}-02$ & $-1,4 \mathrm{E}-03$ & $-2,7 \mathrm{E}-03$ & $-2,1 \mathrm{E}-03$ & 26,80 & 57,00 \\
\hline 0,46 & 26,98 & 11,01 & $-1,85 \mathrm{E}-02$ & $-1,82 \mathrm{E}-02$ & $-1,83 E-02$ & $-1,5 \mathrm{E}-03$ & $-2,9 E-03$ & $-2,2 \mathrm{E}-03$ & 24,00 & 55,00 \\
\hline 0,96 & 26,28 & 11,38 & $-1,91 \mathrm{E}-02$ & $-1,88 \mathrm{E}-02$ & $-1,90 \mathrm{E}-02$ & $-2,2 \mathrm{E}-03$ & $-3,7 \mathrm{E}-03$ & $-3,0 \mathrm{E}-03$ & 23,70 & 65,00 \\
\hline 1,04 & 26,52 & 11,42 & $-1,92 \mathrm{E}-02$ & $-1,89 \mathrm{E}-02$ & $-1,90 \mathrm{E}-02$ & $-2,3 \mathrm{E}-03$ & $-3,8 \mathrm{E}-03$ & $-3,1 \mathrm{E}-03$ & 25,50 & 66,00 \\
\hline 1,17 & 26,75 & 11,55 & $-1,94 \mathrm{E}-02$ & $-1,91 \mathrm{E}-02$ & $-1,92 \mathrm{E}-02$ & $-2,2 \mathrm{E}-03$ & $-3,7 \mathrm{E}-03$ & $-3,0 \mathrm{E}-03$ & 27,20 & 60,00 \\
\hline 1,96 & 26,75 & 12,11 & $-2,04 \mathrm{E}-02$ & $-2,00 \mathrm{E}-02$ & $-2,02 E-02$ & $-3,0$ E-03 & $-4,7 \mathrm{E}-03$ & $-3,8 E-03$ & 23,90 & 70,00 \\
\hline 2,08 & 26,75 & 12,16 & $-2,04 \mathrm{E}-02$ & $-2,01 \mathrm{E}-02$ & $-2,03 E-02$ & $-2,9 E-03$ & $-4,6 \mathrm{E}-03$ & $-3,8 E-03$ & 26,90 & 63,00 \\
\hline 2,92 & 26,75 & 12,67 & $-2,13 \mathrm{E}-02$ & $-2,09 \mathrm{E}-02$ & $-2,11 \mathrm{E}-02$ & $-3,3 E-03$ & $-5,2 \mathrm{E}-03$ & $-4,3 \mathrm{E}-03$ & 23,00 & 72,00 \\
\hline 3,17 & 26,75 & 12,76 & $-2,15 \mathrm{E}-02$ & $-2,11 \mathrm{E}-02$ & $-2,13 E-02$ & $-3,3 \mathrm{E}-03$ & $-5,1 \mathrm{E}-03$ & $-4,2 \mathrm{E}-03$ & 28,10 & 55,00 \\
\hline 6,96 & 26,75 & 14,03 & $-2,35 \mathrm{E}-02$ & $-2,33 \mathrm{E}-02$ & $-2,34 \mathrm{E}-02$ & $-4,8 \mathrm{E}-03$ & $-7,4 \mathrm{E}-03$ & $-6,1 \mathrm{E}-03$ & 25,00 & 75,00 \\
\hline 6,96 & 26,75 & 14,03 & $-2,35 \mathrm{E}-02$ & $-2,33 \mathrm{E}-02$ & $-2,34 \mathrm{E}-02$ & $-4,8 \mathrm{E}-03$ & $-7,4 \mathrm{E}-03$ & $-6,1 \mathrm{E}-03$ & 25,00 & 75,00 \\
\hline
\end{tabular}




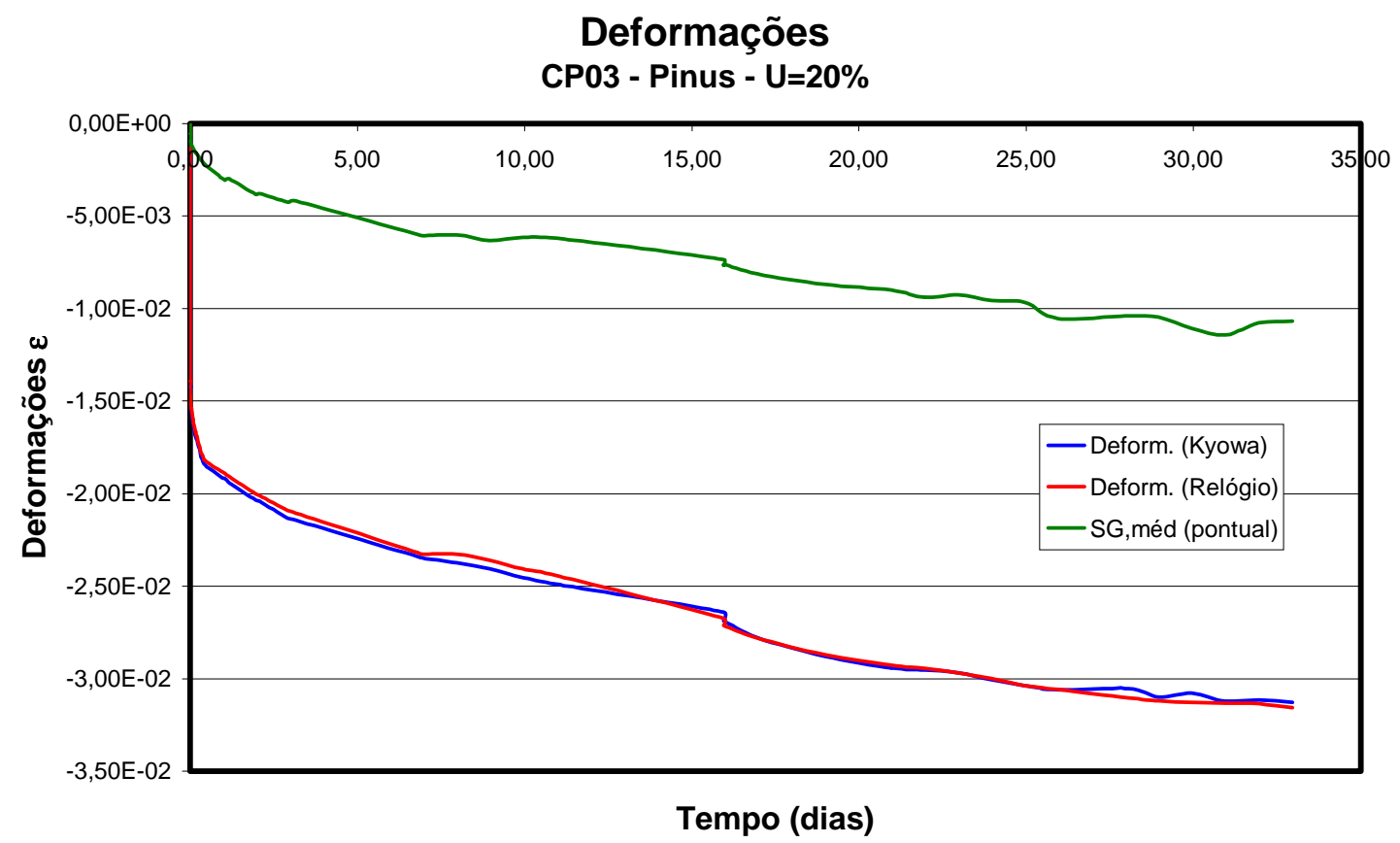

Relações com Temperatura e Umidade CP03 - Pinus - U=20\%

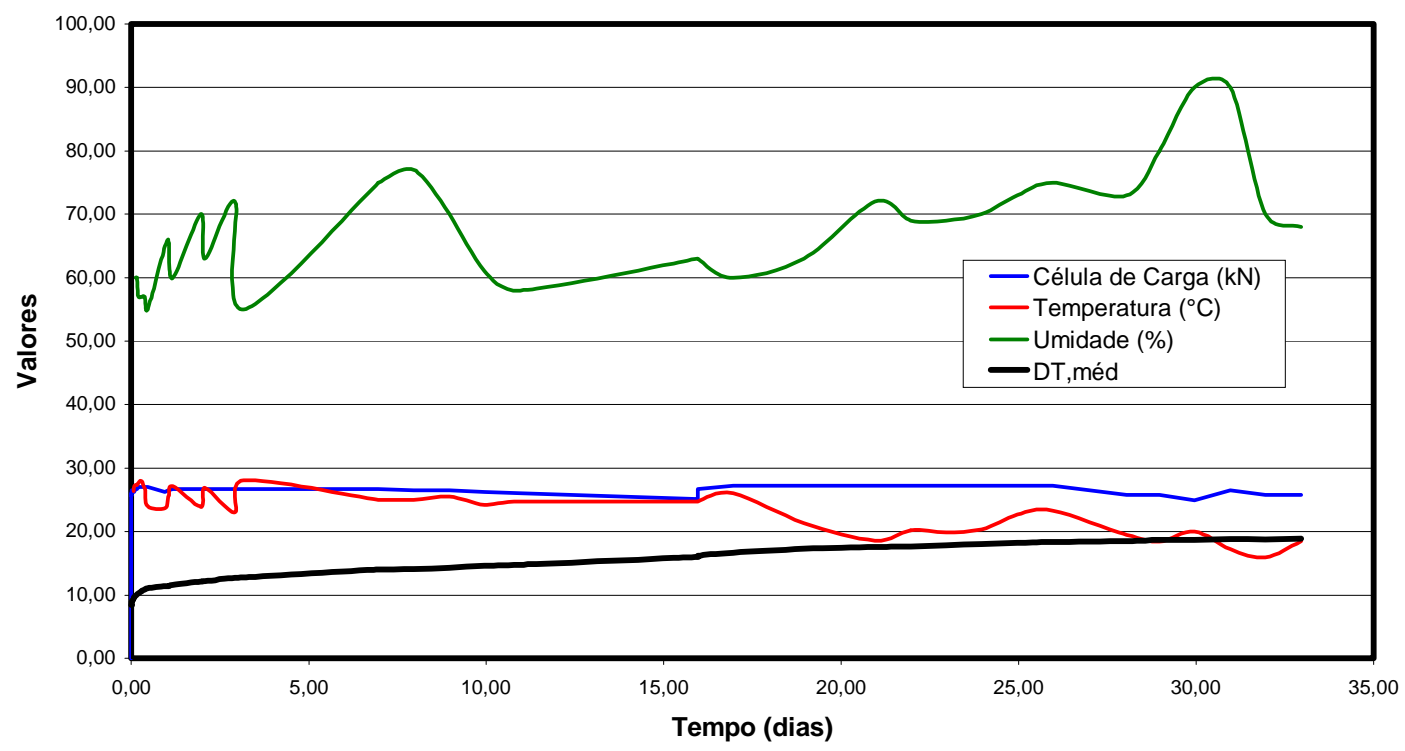

Equações de ajuste:

$$
\begin{aligned}
\left.Y=Y 0+A e^{\wedge}(-x / B)\right) \Rightarrow & d=10,41-9,0796^{*} e^{\wedge}(-t / 10,95293) \\
\left.Y=A\left(1-e^{\wedge}(B t)\right)\right) \quad \Rightarrow \quad & d=9,903073^{\star}\left(1-e^{\wedge}\left(-0,128586^{\star} t\right)\right) \\
& \text { Onde: } \quad \begin{array}{l}
d=\text { deslocamento em mm; } \\
t=\text { tempo em dias }
\end{array}
\end{aligned}
$$




$\begin{array}{cccc}\text { Tempo } & \text { Deslocamentos } & \begin{array}{c}\text { Ajuste }\left(\mathrm{y}=\mathrm{y} 0+A \mathrm{~A}^{\wedge}(-\mathrm{x} / \mathrm{B})\right) \\ \mathrm{d}=10,41-9,0796^{\star} \mathrm{e}^{\wedge}(- \\ \mathrm{t} / 10,95293)\end{array} & \begin{array}{c}\text { Ajuste }\left(\mathrm{y}=\mathrm{A}\left(1-\mathrm{e}^{\wedge}(\mathrm{Bt})\right)\right) \\ \mathrm{d}=9,903073^{\star}\left(1-\mathrm{e}^{\wedge}(-\right.\end{array} \\ \begin{array}{ccc}\left.0,128586^{\star} \mathrm{t}\right) \\ \text { (dias) }\end{array} & (\mathrm{mm}) & 1,33 & 0,00 \\ 0,00 & 0,00 & 1,34 & 0,01 \\ 0,01 & 0,28 & 1,34 & 0,02 \\ 0,01 & 0,47 & 1,35 & 0,03 \\ 0,02 & 0,60 & 1,35 & 0,04 \\ 0,03 & 0,69 & 1,36 & 0,04 \\ 0,03 & 0,78 & 1,70 & 0,57 \\ 0,46 & 2,57 & 2,09 & 1,15 \\ 0,96 & 2,94 & 2,15 & 1,24 \\ 1,04 & 2,98 & 2,25 & 1,38 \\ 1,17 & 3,11 & 2,82 & 2,20 \\ 1,96 & 3,67 & 2,90 & 2,33 \\ 2,08 & 3,72 & 3,45 & 3,10 \\ 2,92 & 4,23 & 3,61 & 3,31 \\ 3,17 & 4,32 & 5,60 & 5,86 \\ 6,96 & 5,59 & 5,60 & 5,86 \\ 6,96 & 5,59 & 6,02 & 6,34 \\ 7,96 & 5,66 & 8,30 & 8,63 \\ 15,96 & 7,76 & 8,30 & 8,63 \\ 15,96 & 7,76 & 8,48 & 8,78 \\ 16,96 & 8,23 & 8,80 & 9,04 \\ 18,96 & 8,80 & 9,07 & 9,23 \\ 20,96 & 9,16 & 9,82 & 9,69 \\ 29,96 & 10,17 & 9,87 & 9,72 \\ 30,96 & 10,32 & 9,92 & 9,74 \\ 31,96 & 10,31 & 9,96 & 9,76 \\ 32,96 & 10,41 & & \end{array}$

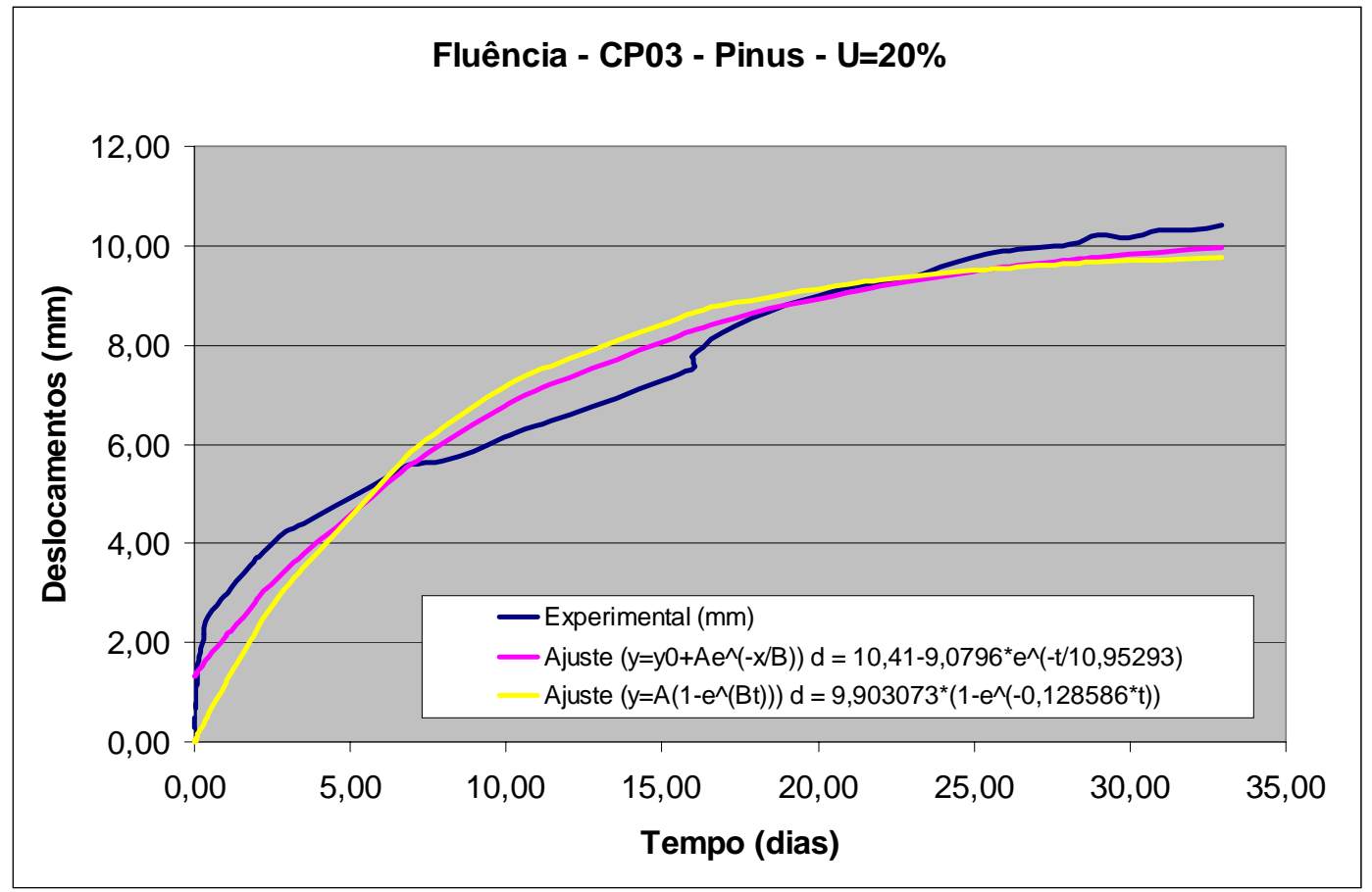

Para o corpo-de-prova de Pinus a 20\% de umidade: 
$\mathrm{P}=29,58 \mathrm{kN}$

Carga aplicada

$\delta_{i}=8,44 \mathrm{~mm}$

Deslocamento inicial

Do modelo proposto:

$\delta_{t}=\delta_{\text {(Hooke) }}+\delta_{\text {(Kelvin) }}$
$\delta_{t}=\frac{P}{k_{1}}+\frac{P}{k_{2}}\left(1-e^{(-t / \tau)}\right)$

Da segunda equação de ajuste:

$\Rightarrow \delta_{t}=8,44+9,90 \cdot\left(1-e^{(-t / 7,78)}\right)$

Portanto: $\quad\left\{\begin{array}{l}\frac{P}{k_{1}}=8,44 \mathrm{~mm} \Rightarrow k_{1}=3,50 \mathrm{kN} / \mathrm{mm} \\ \frac{P}{k_{2}}=9,90 \mathrm{~mm} \Rightarrow k_{2}=2,99 \mathrm{kN} / \mathrm{mm} \\ \tau=\frac{v_{2}}{k_{2}}=7,78 \mathrm{~s} \Rightarrow v_{2}=23,24 \mathrm{kN} / \mathrm{mm} / \mathrm{s}\end{array}\right.$

Em termos de deformação específica, podemos dizer:

$\varepsilon_{t}=\varepsilon_{(\text {Hooke) }}+\varepsilon_{(\text {Kelvin })}$

$\varepsilon_{t}=\frac{8,44}{600}+\frac{9,90}{600}\left(1-e^{(-t / 7,78)}\right)$

$\varepsilon_{t}=14,07 \times 10^{-3}+16,50 \times 10^{-3}\left(1-e^{(-t / 7,78)}\right)$

$\varepsilon_{t}=\frac{\sigma}{E_{i}}+\frac{\sigma}{E_{f}}\left(1-e^{(-t / \tau)}\right)$

Como $\sigma=0,175 \mathrm{kN} / \mathrm{cm}^{2}$

Portanto:

$$
\begin{aligned}
& \left\{\begin{array}{l}
\frac{\sigma}{E_{i}}=14,07 \times 10^{-3} \Rightarrow E_{i}=12,4 \mathrm{kN} / \mathrm{cm}^{2} \cong 124 \mathrm{MPa} \\
\frac{\sigma}{E_{f}}=16,50 \times 10^{-3} \Rightarrow E_{f}=10,6 \mathrm{kN} / \mathrm{cm}^{2} \cong 106 \mathrm{MPa}
\end{array}\right. \\
& t \rightarrow+\infty \Rightarrow \delta_{(\text {Kelvin) }} \rightarrow 9,90 \mathrm{~mm} \Rightarrow\left\{\begin{array}{c}
\delta_{\text {total }} \rightarrow 18,34 \mathrm{~mm} \\
\varepsilon_{\text {total }} \rightarrow 30,57 \times 10^{-3}
\end{array}\right.
\end{aligned}
$$

No quadro a seguir, apresentam-se os valores dos coeficientes de ajuste e dos resultados obtidos pela manipulação do modelo teórico proposto com estes coeficientes. 


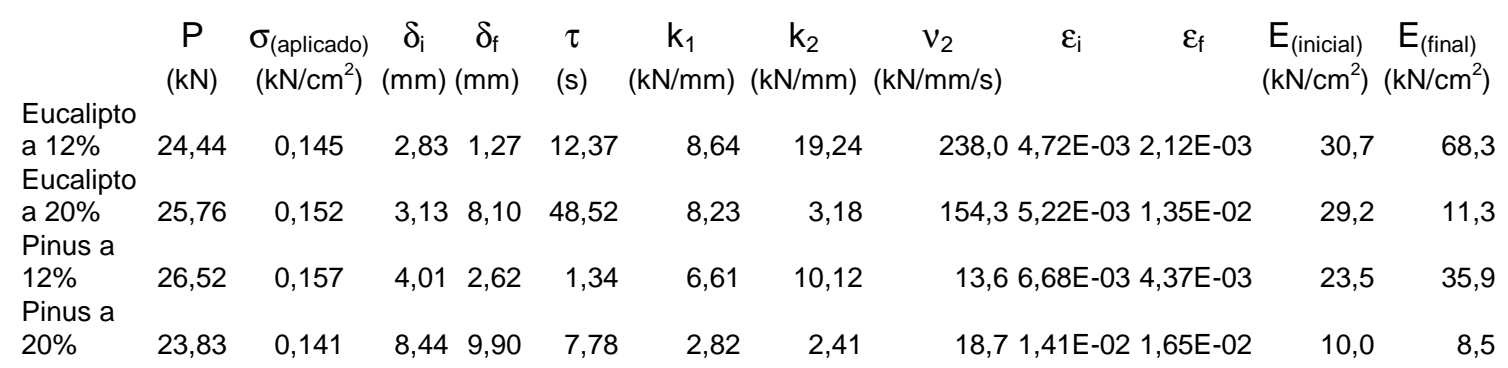

Coeficientes de Ajuste

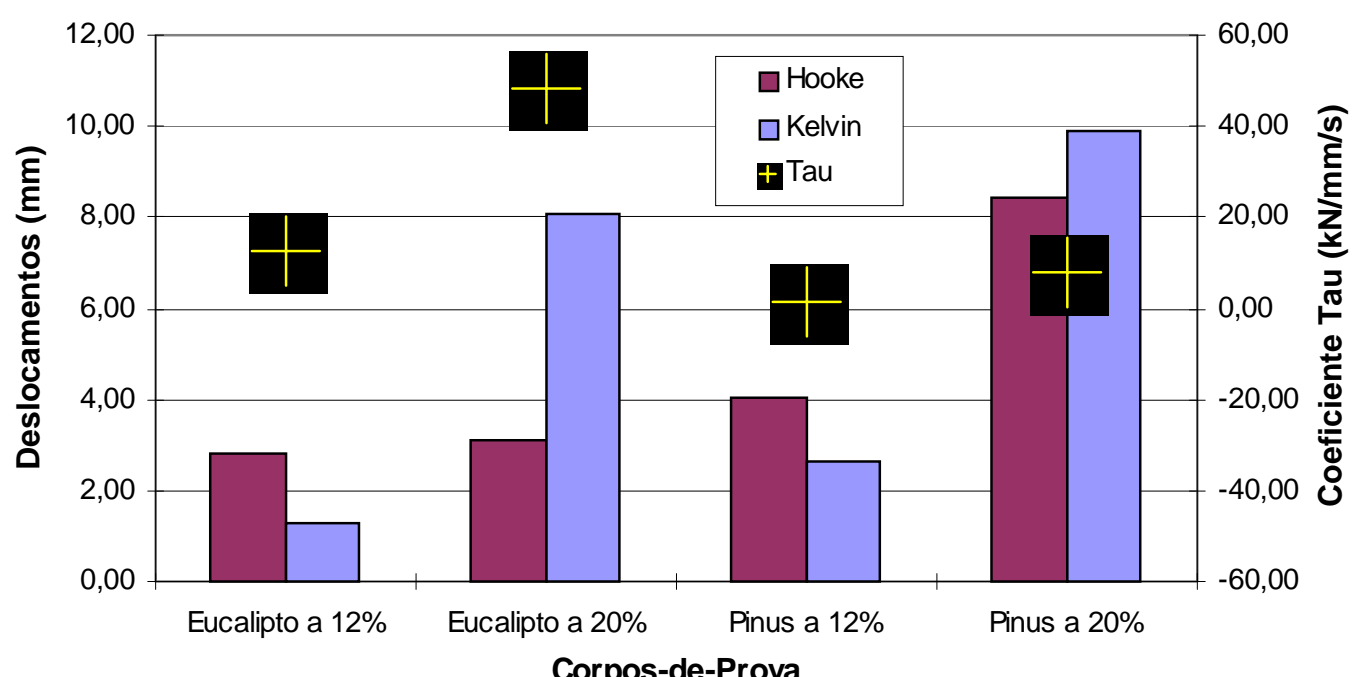

Deslocamentos nos C.P.

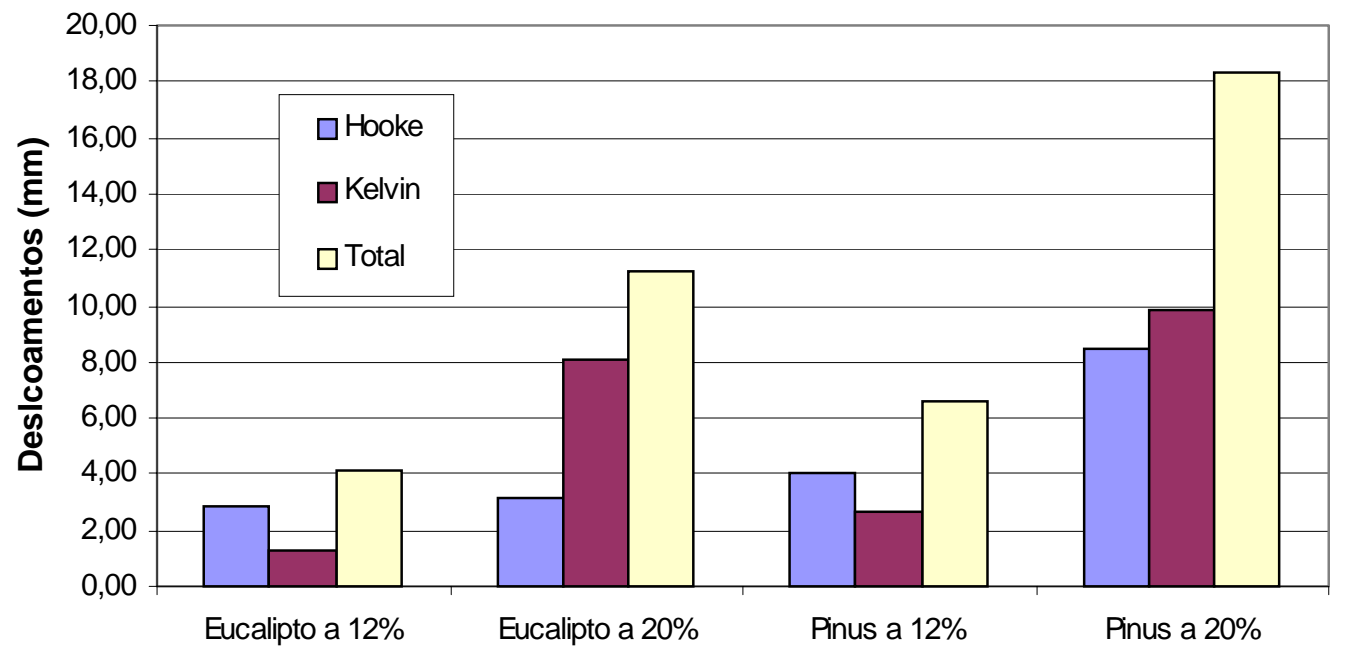

Corpos-de-Prova

Dos quatro corpos de prova avaliados, podemos afirmar que quando o teor de umidade é de $12 \%$, tanto o C.P. de Pinus como o de Eucalipto têm um comportamento mais estável com deslocamentos imediatos elevados mas estabilizando ao longo do tempo. Os deslocamentos imediatos elevados devem-se ao fato de o corpo de prova, estando seco, as acomodações iniciais são maiores provocando grandes deslocamentos não inerentes à deformação própria do material madeira. Quando a umidade está a $20 \%$ estes deslocamentos iniciais são proporcionalmente menores mas não há uma estabilização ao longo do tempo como no primeiro teor de umidade. 
Módulos de Elasticidade

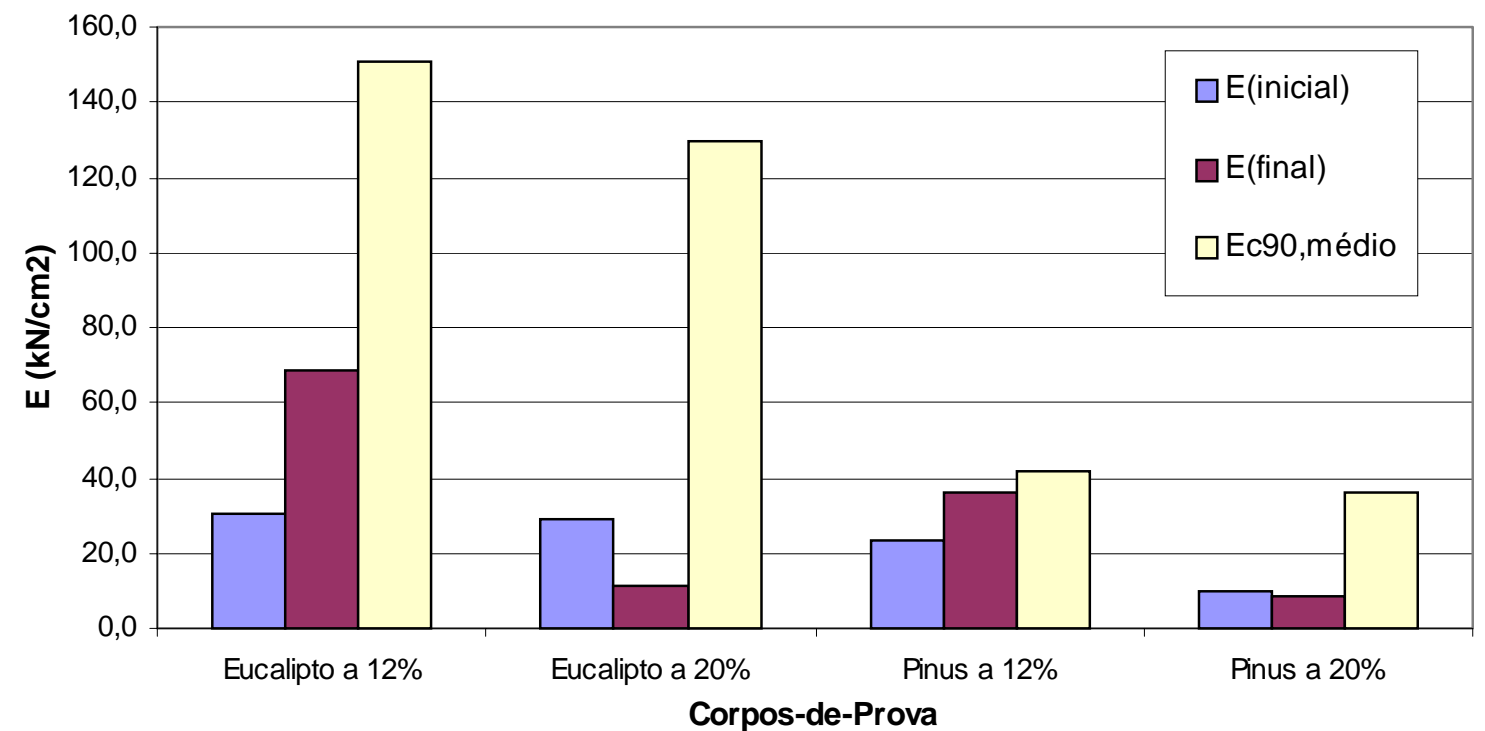

Nas formulações dos ajustes, também é verificado o fato exposto acima, indicando que formulações de padrão assintótico se aplicam aos teores de umidade baixos e padrões exponenciais, aos teores de umidade mais elevados.

\begin{tabular}{|c|c|c|c|c|c|c|c|c|c|}
\hline Madeira & $E_{c 90, \text { méd }}$ & $\begin{array}{c}\mathrm{E}_{\mathrm{i}, \text { total }} \\
\text { (Relógios) } \\
(\mathrm{MPa})\end{array}$ & $\begin{array}{c}E_{f, \text { total }} \\
\text { (Relógios) } \\
\text { (MPa) }\end{array}$ & $\begin{array}{l}\mathrm{E}_{\mathrm{i}, \text { total }} \\
\text { (Strain- } \\
\text { gages) } \\
\text { (MPa) }\end{array}$ & $\begin{array}{l}E_{\text {f,total }} \\
\text { (Strain- } \\
\text { gages) } \\
\text { (MPa) }\end{array}$ & $\begin{array}{c}E_{\mathrm{i}, \text { total }} \\
(\mathrm{SG}-\mathrm{PC} \\
\text { Superior) } \\
(\mathrm{MPa})\end{array}$ & $\begin{array}{c}E_{f, t o t a l} \\
(S G-P G \\
\text { Superior) } \\
(\mathrm{MPa})\end{array}$ & $\begin{array}{c}\mathrm{E}_{\mathrm{i}, \text { total }} \\
(\mathrm{SG}-\mathrm{PC} \\
\text { Inferior }) \\
(\mathrm{MPa})\end{array}$ & $\begin{array}{c}\mathrm{E}_{\mathrm{f}, \text { total }} \\
(\mathrm{SG}-\mathrm{PC} \\
\text { Inferior) } \\
(\mathrm{MPa})\end{array}$ \\
\hline E.C. $12 \%$ & 1506,7 & 306,1 & 594,4 & 782,9 & 1035,0 & 689,6 & 800,2 & 905,4 & 1464,7 \\
\hline E.C. $20 \%$ & 1298,9 & 291,2 & 139,4 & 2413,2 & 198,1 & 1251,3 & 230,7 & 33784,3 & 243,6 \\
\hline Pin. $12 \%$ & 419,9 & 210,4 & 293,2 & 3073,4 & 530,6 & 5858,6 & 478,3 & 2083,1 & 595,8 \\
\hline Pin. $20 \%$ & 362,0 & 111,6 & 89,2 & 2771,3 & 155,5 & 3448,9 & 171,1 & 2316,3 & 142,5 \\
\hline
\end{tabular}

Módulos de Elasticidade

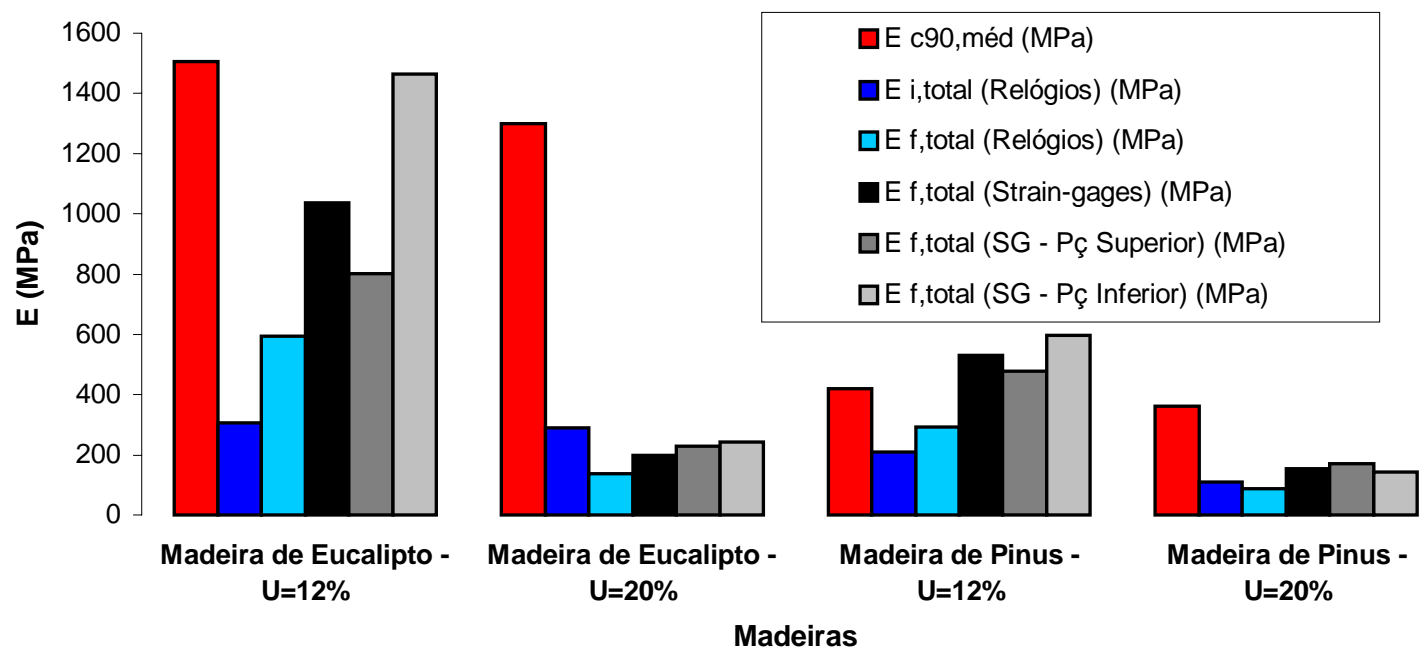

As propriedades elásticas verificam que, como os deslocamentos imediatos possuem uma grande parcela de acomodação do conjunto, os módulos de elasticidade iniciais são baixos. Por outro lado, os módulos definidos através de strain gages se aproximaram dos valores reais do material na umidade $12 \%$. 
Quando a umidade era de $20 \%$, os valores obtidos pelos strain gages ficaram no mesmo patamar dos obtidos por transdutores de deslocamentos.

A seguir são apresentados os resultados das análises mecânicas dos materiais para as leituras de transdutores e strain gages ao longo dos conjuntos e, também, para as peças individuais.

\section{Madeira de Eucalipto - U=12\%}

No Corpo-de-prova:

\begin{tabular}{|c|c|c|c|c|}
\hline$H=$ & $60 \mathrm{~cm}$ & & & \\
\hline$\Delta \mathrm{h}_{\mathrm{i}}=$ & $-2,83 \mathrm{~mm}$ & & & \\
\hline$\varepsilon_{\mathrm{i}}=$ & $-4,72 \mathrm{E}-03$ & & & \\
\hline$\sigma_{\text {méd }}=$ & $0,145 \mathrm{kN} / \mathrm{cm}^{2}$ & $\Rightarrow$ & $\sigma_{\text {méd }}=$ & $1,45 \mathrm{MPa}$ \\
\hline$E_{i}=$ & $30,61 \mathrm{kN} / \mathrm{cm}^{2}$ & $\Rightarrow>$ & $E_{i}=$ & $306,12 \mathrm{MPa}$ \\
\hline$\Delta \mathrm{h}_{\mathrm{f}}=$ & $-1,45 \mathrm{~mm}$ & & & \\
\hline$\varepsilon_{f}=$ & $-2,43 E-03$ & & & \\
\hline$\sigma_{\text {méd }}=$ & $0,145 \mathrm{kN} / \mathrm{cm}^{2}$ & & & \\
\hline$E_{f}=$ & $59,44 \mathrm{kN} / \mathrm{cm}^{2}$ & $\Rightarrow$ & $E_{i}=$ & $594,44 \mathrm{MPa}$ \\
\hline
\end{tabular}

Pelos Strain gages

\begin{tabular}{|c|c|c|c|c|}
\hline$\varepsilon_{\mathrm{i}}=$ & $-1,85 E-03$ & & & \\
\hline$\sigma_{\text {méd }}=$ & $0,145 \mathrm{kN} / \mathrm{cm}^{2}$ & $\Rightarrow$ & $\sigma_{\text {méd }}=$ & $1,45 \mathrm{MPa}$ \\
\hline$E_{i}=$ & $78,29 \mathrm{kN} / \mathrm{cm}^{2}$ & $=>$ & $E_{i}=$ & $782,88 \mathrm{MPa}$ \\
\hline$\varepsilon_{f}=$ & $-1,40 E-03$ & & & \\
\hline$\sigma_{\text {méd }}=$ & $0,145 \mathrm{kN} / \mathrm{cm}^{2}$ & & & \\
\hline$E_{f}=$ & $103,50 \mathrm{kN} / \mathrm{cm}^{2}$ & $\Rightarrow$ & $E_{i}=$ & $1034,97 \mathrm{MPa}$ \\
\hline
\end{tabular}

Nas peça individual - Superior

\begin{tabular}{|c|c|c|c|c|}
\hline$\varepsilon_{\mathrm{i}}=$ & $-2,10 E-03$ & & & \\
\hline$\sigma_{\text {méd }}=$ & $0,145 \mathrm{kN} / \mathrm{cm}^{2}$ & & & \\
\hline$E_{i}=$ & $68,96 \mathrm{kN} / \mathrm{cm}^{2}$ & $=>$ & $\mathrm{E}_{\mathrm{i}}=$ & $689,57 \mathrm{MPa}$ \\
\hline$\varepsilon_{\mathrm{f}}=$ & $-1,81 E-03$ & & & \\
\hline$\sigma_{\text {méd }}=$ & $0,145 \mathrm{kN} / \mathrm{cm}^{2}$ & & & \\
\hline$E_{f}=$ & $80,02 \mathrm{kN} / \mathrm{cm}^{2}$ & $\Rightarrow$ & $E_{f}=$ & $800,21 \mathrm{MPa}$ \\
\hline
\end{tabular}

Nas peça individual - Inferior

\begin{tabular}{|c|c|c|c|c|}
\hline$\varepsilon_{\mathrm{i}}=$ & $-1,60 \mathrm{E}-03$ & & & \\
\hline$\sigma_{\text {méd }}=$ & $0,145 \mathrm{kN} / \mathrm{cm}^{2}$ & & & \\
\hline$E_{i}=$ & $90,54 \mathrm{kN} / \mathrm{cm}^{2}$ & $\Rightarrow$ & $E_{i}=$ & $905,40 \mathrm{MPa}$ \\
\hline$\varepsilon_{\mathrm{f}}=$ & $-9,88 E-04$ & & & \\
\hline$\sigma_{\text {méd }}=$ & $0,145 \mathrm{kN} / \mathrm{cm}^{2}$ & & & \\
\hline$E_{f}=$ & $146,47 \mathrm{kN} / \mathrm{cm}^{2}$ & $\Rightarrow$ & $E_{f}=$ & $1464,68 \mathrm{MPa}$ \\
\hline
\end{tabular}


Madeira de Eucalipto - U=20\%

No Corpo-de-prova:

\begin{tabular}{|c|c|c|c|c|}
\hline $\mathrm{H}=$ & $60 \mathrm{~cm}$ & & & \\
\hline$\Delta \mathrm{h}_{\mathrm{i}}=$ & $-3,13 \mathrm{~mm}$ & & & \\
\hline$\varepsilon_{\mathrm{i}}=$ & $-5,22 E-03$ & & & \\
\hline$\sigma_{\text {méd }}=$ & $0,152 \mathrm{kN} / \mathrm{cm}^{2}$ & $=>$ & $\sigma_{\text {méd }}=$ & 1,52MPa \\
\hline$E_{i}=$ & $29,12 \mathrm{kN} / \mathrm{cm}^{2}$ & $=>$ & $E_{i}=$ & $291,17 \mathrm{MPa}$ \\
\hline$\Delta \mathrm{h}_{\mathrm{f}}=$ & $-6,51 \mathrm{~mm}$ & & & \\
\hline$\varepsilon_{\mathrm{f}}=$ & $-1,09 E-02$ & & & \\
\hline$\sigma_{\text {méd }}=$ & $0,152 \mathrm{kN} / \mathrm{cm}^{2}$ & & & \\
\hline$E_{f}=$ & $13,94 \mathrm{kN} / \mathrm{cm}^{2}$ & $=>$ & $E_{i}=$ & $139,35 \mathrm{MPa}$ \\
\hline
\end{tabular}

\section{Pelos Strain gages}

\begin{tabular}{|c|c|c|c|c|}
\hline$\varepsilon_{\mathrm{i}}=$ & $-6,30 \mathrm{E}-04$ & & & \\
\hline$\sigma_{\text {méd }}=$ & $0,152 \mathrm{kN} / \mathrm{cm}^{2}$ & $=>$ & $\sigma_{\text {méd }}=$ & $1,52 \mathrm{MPa}$ \\
\hline$E_{i}=$ & $241,32 \mathrm{kN} / \mathrm{cm}^{2}$ & $=>$ & $E_{i}=$ & $2413,16 \mathrm{MPa}$ \\
\hline$\varepsilon_{\mathrm{f}}=$ & $-7,68 \mathrm{E}-03$ & & & \\
\hline$\sigma_{\text {méd }}=$ & $0,152 \mathrm{kN} / \mathrm{cm}^{2}$ & & & \\
\hline$E_{f}=$ & $19,81 \mathrm{kN} / \mathrm{cm}^{2}$ & $\Rightarrow>$ & $E_{i}=$ & $198,08 \mathrm{MPa}$ \\
\hline
\end{tabular}

Nas peça individual - Superior

\begin{tabular}{|c|c|c|c|c|}
\hline$\varepsilon_{\mathrm{i}}=$ & $-1,22 E-03$ & & & \\
\hline$\sigma_{\text {méd }}=$ & $0,152 \mathrm{kN} / \mathrm{cm}^{2}$ & & & \\
\hline$E_{i}=$ & $125,13 \mathrm{kN} / \mathrm{cm}^{2}$ & $\Rightarrow$ & $\mathrm{E}_{\mathrm{i}}=$ & $1251,27 \mathrm{MPa}$ \\
\hline$\varepsilon_{\mathrm{f}}=$ & $-6,59 \mathrm{E}-03$ & & & \\
\hline$\sigma_{\text {méd }}=$ & $0,152 \mathrm{kN} / \mathrm{cm}^{2}$ & & & \\
\hline$E_{f}=$ & $23,07 \mathrm{kN} / \mathrm{cm}^{2}$ & $\Rightarrow$ & $E_{f}=$ & $230,70 \mathrm{MPa}$ \\
\hline
\end{tabular}

Nas peça individual - Inferior

\begin{tabular}{|c|c|c|c|c|}
\hline$\varepsilon_{\mathrm{i}}=$ & $-4,50 E-05$ & & & \\
\hline$\sigma_{\text {méd }}=$ & $0,152 \mathrm{kN} / \mathrm{cm}^{2}$ & & & \\
\hline$E_{i}=$ & $3378,43 \mathrm{kN} / \mathrm{cm}^{2}$ & $\Rightarrow$ & $\mathrm{E}_{\mathrm{i}}=$ & $33784,31 \mathrm{MPa}$ \\
\hline$\varepsilon_{\mathrm{f}}=$ & $-6,24 E-03$ & & & \\
\hline$\sigma_{\text {méd }}=$ & $0,152 \mathrm{kN} / \mathrm{cm}^{2}$ & & & \\
\hline$E_{f}=$ & $24,36 \mathrm{kN} / \mathrm{cm}^{2}$ & $=>$ & $E_{f}=$ & $243,64 \mathrm{MPa}$ \\
\hline
\end{tabular}


Madeira de Pinus - U=12\%

No Corpo-de-prova:

\begin{tabular}{|c|c|c|c|c|}
\hline $\mathrm{H}=$ & $60 \mathrm{~cm}$ & & & \\
\hline$\Delta \mathrm{h}_{\mathrm{i}}=$ & $-4,01 \mathrm{~mm}$ & & & \\
\hline$\varepsilon_{\mathrm{i}}=$ & $-6,68 \mathrm{E}-03$ & & & \\
\hline$\sigma_{\text {méd }}=$ & $0,141 \mathrm{kN} / \mathrm{cm}^{2}$ & $\Rightarrow$ & $\sigma_{\text {méd }}=$ & $1,41 \mathrm{MPa}$ \\
\hline$E_{i}=$ & $21,04 \mathrm{kN} / \mathrm{cm}^{2}$ & $=>$ & $E_{i}=$ & $210,40 \mathrm{MPa}$ \\
\hline$\Delta \mathrm{h}_{\mathrm{f}}=$ & $-2,86 \mathrm{~mm}$ & & & \\
\hline$\varepsilon_{f}=$ & $-4,79 E-03$ & & & \\
\hline$\sigma_{\text {méd }}=$ & $0,141 \mathrm{kN} / \mathrm{cm}^{2}$ & & & \\
\hline$E_{f}=$ & $29,32 \mathrm{kN} / \mathrm{cm}^{2}$ & $=>$ & $E_{i}=$ & $293,24 \mathrm{MPa}$ \\
\hline
\end{tabular}

Pelos Strain gages

$\begin{array}{rcccr}\varepsilon_{i}= & -4,58 \mathrm{E}-04 & & & \\ \sigma_{\text {méd }} & 0,141 \mathrm{kN} / \mathrm{cm}^{2} & \Rightarrow & \sigma_{\text {méd }} & 1,41 \mathrm{MPa} \\ E_{i}= & 307,34 \mathrm{kN} / \mathrm{cm}^{2} & \Rightarrow & E_{i}= & 3073,38 \mathrm{MPa} \\ \varepsilon_{f}= & -2,65 \mathrm{E}-03 & & & \\ \sigma_{\text {méd }}= & 0,141 \mathrm{kN} / \mathrm{cm}^{2} & & & \\ E_{f}= & 53,06 \mathrm{kN} / \mathrm{cm}^{2} & \Rightarrow & E_{i}= & 530,59 \mathrm{MPa}\end{array}$

Nas peça individual - Superior

\begin{tabular}{|c|c|c|c|c|}
\hline$\varepsilon_{\mathrm{i}}=$ & $-2,40 E-04$ & & & \\
\hline$\sigma_{\text {méd }}=$ & $0,141 \mathrm{kN} / \mathrm{cm}^{2}$ & & & \\
\hline$E_{i}=$ & $585,86 \mathrm{kN} / \mathrm{cm}^{2}$ & $=>$ & $E_{i}=$ & $5858,63 \mathrm{MPa}$ \\
\hline$\varepsilon_{f}=$ & $-2,94 E-03$ & & & \\
\hline$\sigma_{\text {méd }}=$ & $0,141 \mathrm{kN} / \mathrm{cm}^{2}$ & & & \\
\hline$E_{f}=$ & $47,83 \mathrm{kN} / \mathrm{cm}^{2}$ & $\Rightarrow>$ & $E_{f}=$ & $478,26 \mathrm{MPa}$ \\
\hline
\end{tabular}

Nas peça individual - Inferior

\begin{tabular}{|c|c|c|c|c|}
\hline$\varepsilon_{\mathrm{i}}=$ & $-6,75 E-04$ & & & \\
\hline$\sigma_{\text {méd }}=$ & $0,141 \mathrm{kN} / \mathrm{cm}^{2}$ & & & \\
\hline $\mathrm{E}_{\mathrm{i}}=$ & $208,31 \mathrm{kN} / \mathrm{cm}^{2}$ & $\Rightarrow$ & $E_{i}=$ & $2083,07 \mathrm{MPa}$ \\
\hline$\varepsilon_{f}=$ & $-2,36 \mathrm{E}-03$ & & & \\
\hline$\sigma_{\text {méd }}=$ & $0,141 \mathrm{kN} / \mathrm{cm}^{2}$ & & & \\
\hline$E_{f}=$ & $59,58 \mathrm{kN} / \mathrm{cm}^{2}$ & $=>$ & $E_{f}=$ & $595,79 \mathrm{MPa}$ \\
\hline
\end{tabular}


Madeira de Pinus - U=20\%

No Corpo-de-prova:

\begin{tabular}{|c|c|c|c|c|}
\hline $\mathrm{H}=$ & $60 \mathrm{~cm}$ & & & \\
\hline$\Delta \mathrm{h}_{\mathrm{i}}=$ & $-8,44 \mathrm{~mm}$ & & & \\
\hline$\varepsilon_{\mathrm{i}}=$ & $-1,41 \mathrm{E}-02$ & & & \\
\hline$\sigma_{\text {méd }}=$ & $0,157 \mathrm{kN} / \mathrm{cm}^{2}$ & $\Rightarrow$ & $\sigma_{\text {méd }}=$ & $1,57 \mathrm{MPa}$ \\
\hline$E_{i}=$ & $11,16 \mathrm{kN} / \mathrm{cm}^{2}$ & $=>$ & $E_{i}=$ & $111,56 \mathrm{MPa}$ \\
\hline$\Delta \mathrm{h}_{\mathrm{f}}=$ & $-10,41 \mathrm{~mm}$ & & & \\
\hline$\varepsilon_{f}=$ & $-1,76 E-02$ & & & \\
\hline$\sigma_{\text {méd }}=$ & $0,157 \mathrm{kN} / \mathrm{cm}^{2}$ & & & \\
\hline$E_{f}=$ & $8,92 \mathrm{kN} / \mathrm{cm}^{2}$ & $\Rightarrow$ & $E_{i}=$ & $89,19 \mathrm{MPa}$ \\
\hline
\end{tabular}

Pelos Strain gages

$\begin{array}{rllll}\varepsilon_{\mathrm{i}}= & -5,66 \mathrm{E}-04 & & & \\ \sigma_{\text {méd }} & 0,157 \mathrm{kN} / \mathrm{cm}^{2} & \Rightarrow & \sigma_{\text {méd }} & 1,57 \mathrm{MPa} \\ E_{i}= & 277,13 \mathrm{kN} / \mathrm{cm}^{2} & \Rightarrow & E_{i}= & 2771,33 \mathrm{MPa} \\ \varepsilon_{f}= & -1,01 \mathrm{E}-02 & & & \\ \sigma_{\text {méd }}= & 0,157 \mathrm{kN} / \mathrm{cm}^{2} & & & \\ E_{f}= & 15,55 \mathrm{kN} / \mathrm{cm}^{2} & \Rightarrow & E_{i}= & 155,47 \mathrm{MPa}\end{array}$

Nas peça individual - Superior

\begin{tabular}{|c|c|c|c|c|}
\hline$\varepsilon_{\mathrm{i}}=$ & $-4,55 E-04$ & & & \\
\hline$\sigma_{\text {méd }}=$ & $0,157 \mathrm{kN} / \mathrm{cm}^{2}$ & & & \\
\hline $\mathrm{E}_{\mathrm{i}}=$ & $344,89 \mathrm{kN} / \mathrm{cm}^{2}$ & $\Rightarrow>$ & $E_{i}=$ & $3448,93 \mathrm{MPa}$ \\
\hline$\varepsilon_{\mathrm{f}}=$ & $-9,17 E-03$ & & & \\
\hline$\sigma_{\text {méd }}=$ & $0,157 \mathrm{kN} / \mathrm{cm}^{2}$ & & & \\
\hline$E_{f}=$ & $17,11 \mathrm{kN} / \mathrm{cm}^{2}$ & $=>$ & $E_{f}=$ & $171,08 \mathrm{MPa}$ \\
\hline
\end{tabular}

Nas peça individual - Inferior

\begin{tabular}{|c|c|c|c|c|}
\hline$\varepsilon_{\mathrm{i}}=$ & $-6,78 E-04$ & & & \\
\hline$\sigma_{\text {méd }}=$ & $0,157 \mathrm{kN} / \mathrm{cm}^{2}$ & & & \\
\hline$E_{i}=$ & $231,63 \mathrm{kN} / \mathrm{cm}^{2}$ & $\Rightarrow$ & $E_{i}=$ & $2316,26 \mathrm{MPa}$ \\
\hline$\varepsilon_{f}=$ & $-1,10 \mathrm{E}-02$ & & & \\
\hline$\sigma_{\text {méd }}=$ & $0,157 \mathrm{kN} / \mathrm{cm}^{2}$ & & & \\
\hline$E_{f}=$ & $14,25 \mathrm{kN} / \mathrm{cm}^{2}$ & $\Rightarrow$ & $E_{f}=$ & $142,47 \mathrm{MPa}$ \\
\hline
\end{tabular}




\subsection{Análise de Perda de Protensão em Corpos de Prova}

A metodologia previa experimentação de pelo menos $32\left(2 \times 2^{4}\right)$ corpos de prova para que se pudesse avaliar estatisticamente as variáveis principais que são classe de resistência, umidade, diâmetro e nível de protensão. Os resultados obtidos não foram satisfatórios no sentido de comprovar as expectativas da literatura e, conseqüentemente, da metodologia.

Assim, são apresentados a seguir, os resultados obtidos nos ensaios de perda de protensão em corpos de prova de três conjuntos ensaiados como ilustra as tabelas 4.1, 4.2 e 4.3 .

Os conjuntos também não seguiram o esquema da metodologia devido à disponibilidade de materiais e à maior facilidade de controlar a umidade se todos os corpos-de-prova estivessem do mesmo teor de umidade.

Nas figuras 4.8 e 4.9 pode-se observar a sala climatizada construída no LaMEM para abrigar os corpos de prova bem como a instrumentação e equipamentos de aquisição de dados utilizados. O computador foi trocado por um Notebook mais avançado.

Tabela 4.1 - Perda de Protensão - $1^{\circ}$ Conjunto Ensaiado

\begin{tabular}{c|c|c|c|c}
\hline 1 & $\mathrm{U} 12 \%$ & $\mathrm{C} 25 \mathrm{C}$ & $\phi 16$ & $\sigma 700$ \\
\hline 2 & $\mathrm{U} 12 \%$ & $\mathrm{C} 25 \mathrm{C}$ & $\phi 16$ & $\sigma 1000$ \\
\hline 3 & $\mathrm{U} 12 \%$ & $\mathrm{C} 25 \mathrm{C}$ & $\phi 16$ & $\sigma 700$ \\
\hline 4 & $\mathrm{U} 12 \%$ & $\mathrm{C} 25 \mathrm{C}$ & $\phi 16$ & $\sigma 1000$ \\
\hline 5 & $\mathrm{U} 12 \%$ & $\mathrm{C} 25 \mathrm{C}$ & $\phi 25$ & $\sigma 700$ \\
\hline 6 & $\mathrm{U} 12 \%$ & $\mathrm{C} 25 \mathrm{C}$ & $\phi 25$ & $\sigma 1000$ \\
\hline 7 & $\mathrm{U} 12 \%$ & $\mathrm{C} 25 \mathrm{C}$ & $\phi 25$ & $\sigma 700$ \\
\hline 8 & $\mathrm{U} 12 \%$ & $\mathrm{C} 25 \mathrm{C}$ & $\phi 25$ & $\sigma 1000$ \\
\hline 9 & $\mathrm{U} 12 \%$ & $\mathrm{C} 25 \mathrm{C}$ & $\phi 32$ & $\sigma 700$ \\
\hline 10 & $\mathrm{U} 12 \%$ & $\mathrm{C} 25 \mathrm{C}$ & $\phi 32$ & $\sigma 1000$ \\
\hline 11 & $\mathrm{U} 12 \%$ & $\mathrm{C} 25 \mathrm{C}$ & $\phi 32$ & $\sigma 700$ \\
\hline 12 & $\mathrm{U} 12 \%$ & $\mathrm{C} 25 \mathrm{C}$ & $\phi 32$ & $\sigma 1000$ \\
\hline
\end{tabular}


Tabela 4.2 - Perda de Protensão - $2^{\circ}$ Conjunto Ensaiado

\begin{tabular}{c|c|c|c|c}
\hline 1 & U20\% & C25C & $\phi 16$ & $\sigma 700$ \\
\hline 2 & U20\% & C25C & $\phi 16$ & $\sigma 1000$ \\
\hline 3 & U20\% & C25C & $\phi 25$ & $\sigma 700$ \\
\hline 4 & U20\% & C25C & $\phi 25$ & $\sigma 1000$ \\
\hline 5 & U20\% & C25C & $\phi 32$ & $\sigma 700$ \\
\hline 6 & U20\% & C25C & $\phi 32$ & $\sigma 1000$ \\
\hline 7 & U20\% & C40D & $\phi 16$ & $\sigma 700$ \\
\hline 8 & U20\% & C40D & $\phi 16$ & $\sigma 1000$ \\
\hline 9 & U20\% & C40D & $\phi 25$ & $\sigma 700$ \\
\hline 10 & U20\% & C40D & $\phi 25$ & $\sigma 1000$ \\
\hline 11 & U20\% & C40D & $\phi 32$ & $\sigma 700$ \\
\hline 12 & U20\% & C40D & $\phi 32$ & $\sigma 1000$ \\
\hline
\end{tabular}

Tabela 4.3 - Perda de Protensão - $3^{\circ}$ Conjunto Ensaiado

\begin{tabular}{c|c|c|c|c}
\hline 1 & $\mathrm{U} 12 \%$ & $\mathrm{C} 25 \mathrm{C}$ & $\phi 25-1045$ & $\sigma 700$ \\
\hline 2 & $\mathrm{U} 12 \%$ & $\mathrm{C} 25 \mathrm{C}$ & $\phi 25-4340$ & $\sigma 700$ \\
\hline 3 & $\mathrm{U} 12 \%$ & $\mathrm{C} 25 \mathrm{C}$ & $\phi 25$ & $\sigma 2 \mathrm{Re}$ \\
\hline 4 & $\mathrm{U} 12 \%$ & $\mathrm{C} 25 \mathrm{C}$ & $\phi 25$ & $\sigma 3 \mathrm{Re}$ \\
\hline
\end{tabular}

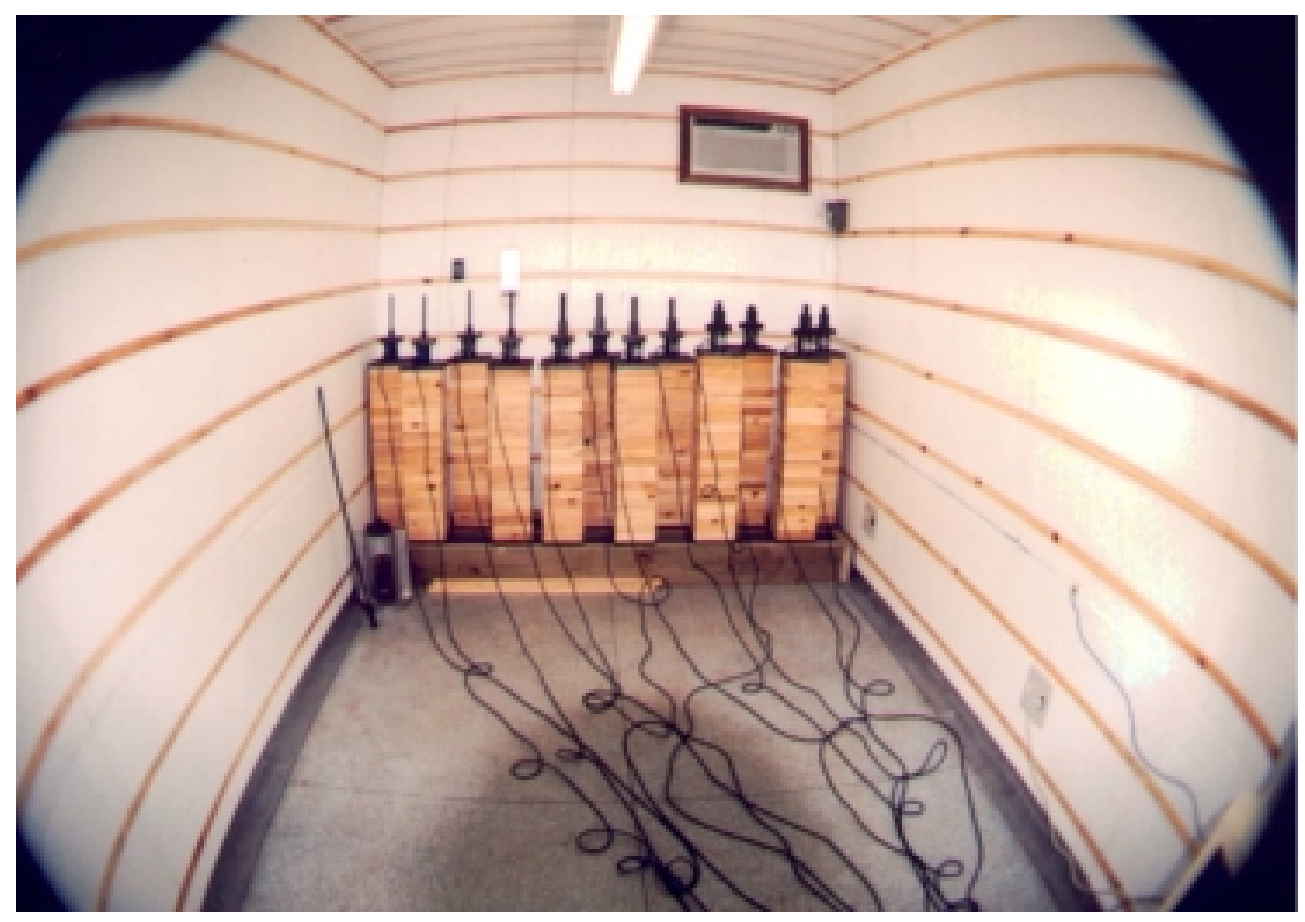

Figura 4.8 - Sala Climatizada $-1^{\circ}$ Conjunto de C.P. 


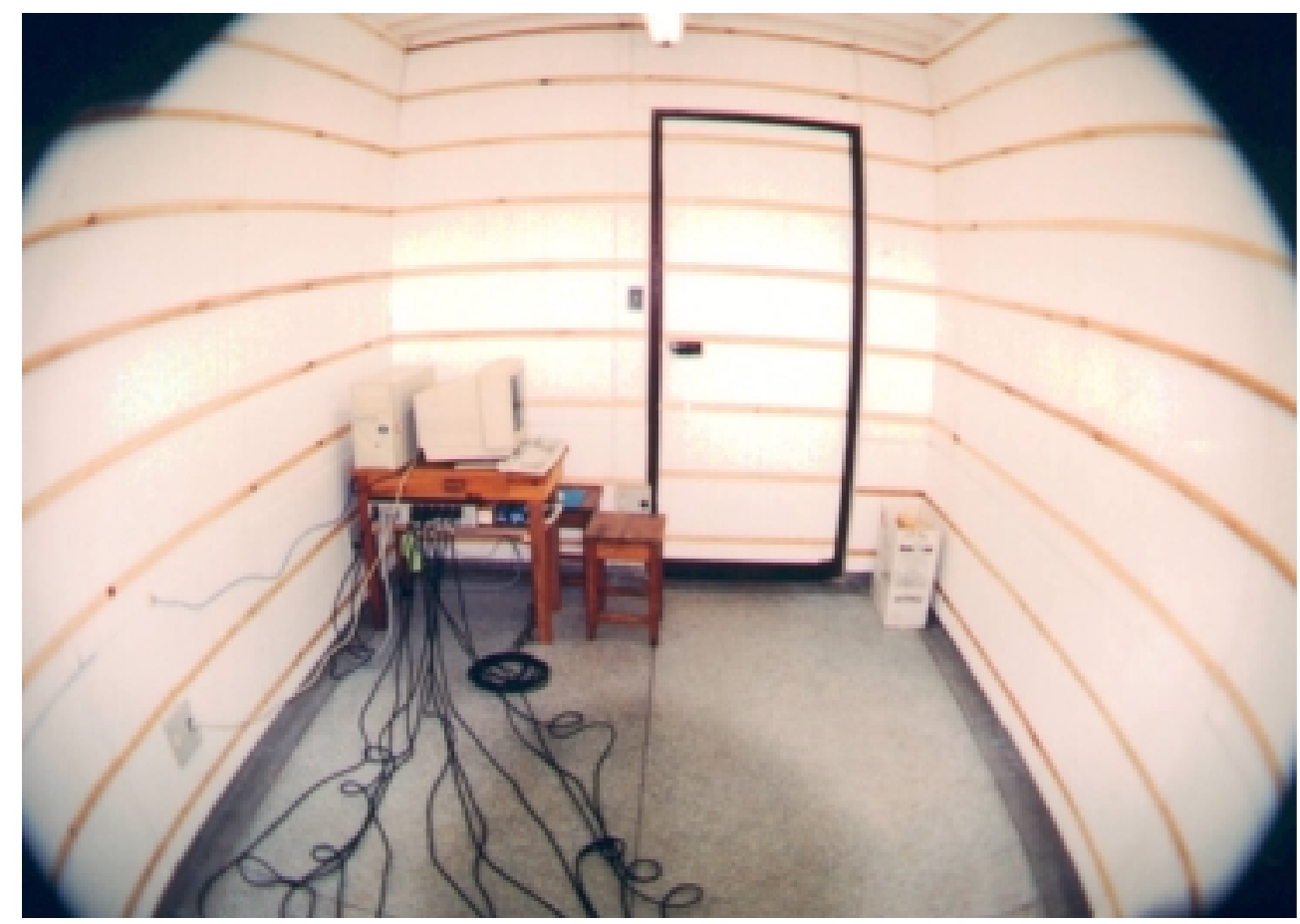

Figura 4.9 - Sala Climatizada - Equipamento de Aquisição de Dados

Os resultados da experimentação em corpos de prova para a análise de perda de protensão nos forneceu, basicamente, valores da carga remanescente ao longo do tempo. A seguir são apresentados os resultados sistematizados da seguinte forma: Primeiramente, é apresentada a planilha de dados obtida por cada um dos dois conjuntos de 12 C.P. Por se tratar de planilhas grandes, é mostrada apenas parte delas para uma visualização e entendimento gerais. Em seguida, é apresentado um gráfico geral de perda de carga ao longo do tempo apenas para visualização já que torna-se difícil qualquer tentativa de análise por este gráfico. Estas análise podem ser efetuadas a partir dos gráficos seguintes que mostram as influências de variáveis separadamente, tais como diâmetro, nível de tensão, umidade e classe de resistência.

É importante lembrar, neste momento, que as tensões impostas aos corpos-deprova correspondem a 2,5 vezes os valores de projeto de $700 \mathrm{kPa}$ e $1000 \mathrm{kPa}$. 
Primeiro conjunto de 12 corpos de Prova

$\begin{array}{ccc}\text { Corpo de Prova } 01 & \text { Corpo de Prova 02 } & \text { Corpo de Prova 03 } \\ \text { P-12\%-16-700 } & \text { P-12\%-16-1000 } & \text { P-12\%-16-700 }\end{array}$

$\begin{array}{rccccc}\text { Scan ID } & \begin{array}{c}\text { Date } \\ \text { 02/06/2000 }\end{array} & \begin{array}{c}\text { Time } \\ 1\end{array} & \begin{array}{c}\text { Time } \\ \text { (segundos) }\end{array} & \begin{array}{c}\text { Time } \\ \text { (horas) }\end{array} & \begin{array}{c}\text { Time } \\ \text { (dias) }\end{array} \\ 2 & 02 / 06 / 2000 & 15: 17: 32 & \mathbf{3 0 0} & \mathbf{0 , 0} & \mathbf{0} \\ 3 & 02 / 06 / 2000 & 15: 22: 32 & \mathbf{6 0 0} & \mathbf{0 , 2} & \mathbf{0} \\ 4 & 02 / 06 / 2000 & 15: 27: 32 & \mathbf{9 0 0} & \mathbf{0 , 2} & \mathbf{0} \\ 5 & 02 / 06 / 2000 & 15: 32: 32 & \mathbf{1 2 0 0} & \mathbf{0 , 3} & \mathbf{0} \\ 6 & 02 / 06 / 2000 & 15: 37: 32 & \mathbf{1 5 0 0} & \mathbf{0 , 4} & \mathbf{0} \\ 7 & 02 / 06 / 2000 & 15: 42: 32 & \mathbf{1 8 0 0} & \mathbf{0 , 5} & \mathbf{0} \\ 8 & 02 / 06 / 2000 & 15: 47: 32 & \mathbf{2 1 0 0} & \mathbf{0 , 6} & \mathbf{0} \\ 9 & 02 / 06 / 2000 & 15: 52: 32 & \mathbf{2 4 0 0} & \mathbf{0 , 7} & \mathbf{0} \\ 10 & 02 / 06 / 2000 & 15: 57: 32 & \mathbf{2 7 0 0} & \mathbf{0 , 8} & \mathbf{0} \\ 11 & 02 / 06 / 2000 & 16: 02: 32 & \mathbf{3 0 0 0} & \mathbf{0 , 8} & \mathbf{0} \\ 12 & 02 / 06 / 2000 & 16: 10: 20 & \mathbf{3 4 6 8} & \mathbf{1 , 0} & \mathbf{0} \\ 13 & 02 / 06 / 2000 & 16: 15: 20 & \mathbf{3 7 6 8} & \mathbf{1 , 0} & \mathbf{0} \\ 14 & 02 / 06 / 2000 & 16: 20: 20 & \mathbf{4 0 6 8} & \mathbf{1 , 1} & \mathbf{0} \\ 15 & 02 / 06 / 2000 & 16: 25: 20 & \mathbf{4 3 6 8} & \mathbf{1 , 2} & \mathbf{0} \\ 16 & 02 / 06 / 2000 & 16: 30: 20 & \mathbf{4 6 6 8} & \mathbf{1 , 3} & \mathbf{0} \\ 17 & 02 / 06 / 2000 & 16: 35: 20 & \mathbf{4 9 6 8} & \mathbf{1 , 4} & \mathbf{0} \\ 18 & 02 / 06 / 2000 & 16: 40: 20 & \mathbf{5 2 6 8} & \mathbf{1 , 5} & \mathbf{0} \\ 19 & 02 / 06 / 2000 & 16: 45: 20 & \mathbf{5 5 6 8} & \mathbf{1 , 5} & \mathbf{0} \\ 20 & 02 / 06 / 2000 & 16: 50: 20 & \mathbf{5 8 6 8} & \mathbf{1 , 6} & \mathbf{0} \\ 21 & 02 / 06 / 2000 & 16: 55: 20 & \mathbf{6 1 6 8} & \mathbf{1 , 7} & \mathbf{0} \\ 22 & 02 / 06 / 2000 & 17: 00: 20 & \mathbf{6 4 6 8} & \mathbf{1 , 8} & \mathbf{0} \\ 23 & 02 / 06 / 2000 & 17: 05: 20 & \mathbf{6 7 6 8} & \mathbf{1 , 9} & \mathbf{0} \\ 24 & 02 / 06 / 2000 & 17: 10: 20 & \mathbf{7 0 6 8} & \mathbf{2 , 0} & \mathbf{0} \\ 25 & 02 / 06 / 2000 & 17: 15: 20 & \mathbf{7 3 6 8} & \mathbf{2 , 0} & \mathbf{0} \\ 26 & 02 / 06 / 2000 & 17: 20: 20 & \mathbf{7 6 6 8} & \mathbf{2 , 1} & \mathbf{0} \\ 27 & 02 / 06 / 2000 & 17: 25: 20 & \mathbf{7 9 6 8} & \mathbf{2 , 2} & \mathbf{0}\end{array}$

$\mathrm{kN}$
$-0,1$
0,0
$-0,1$
$-0,1$
0,1
3,0
2,9
83,2
69,1
68,3
67,7
67,0
66,8
66,5
66,2
65,9
65,7
65,5
65,3
65,1
64,9
64,9
64,7
64,6
64,4
64,3
64,2

$\mathrm{kN}$
0,0
35,2
106,0
107,2
104,0
102,5
101,4
100,5
99,8
99,2
98,7
98,0
97,6
97,3
97,0
96,6
96,4
96,0
95,7
95,5
95,3
95,1
94,9
94,7
94,5
94,3
94,2

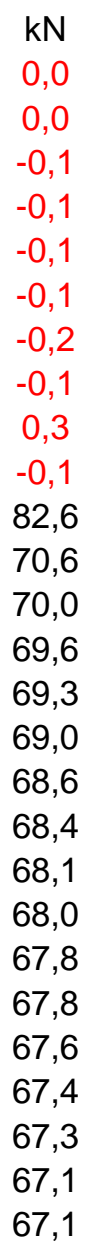




\section{Perda de Protensão}

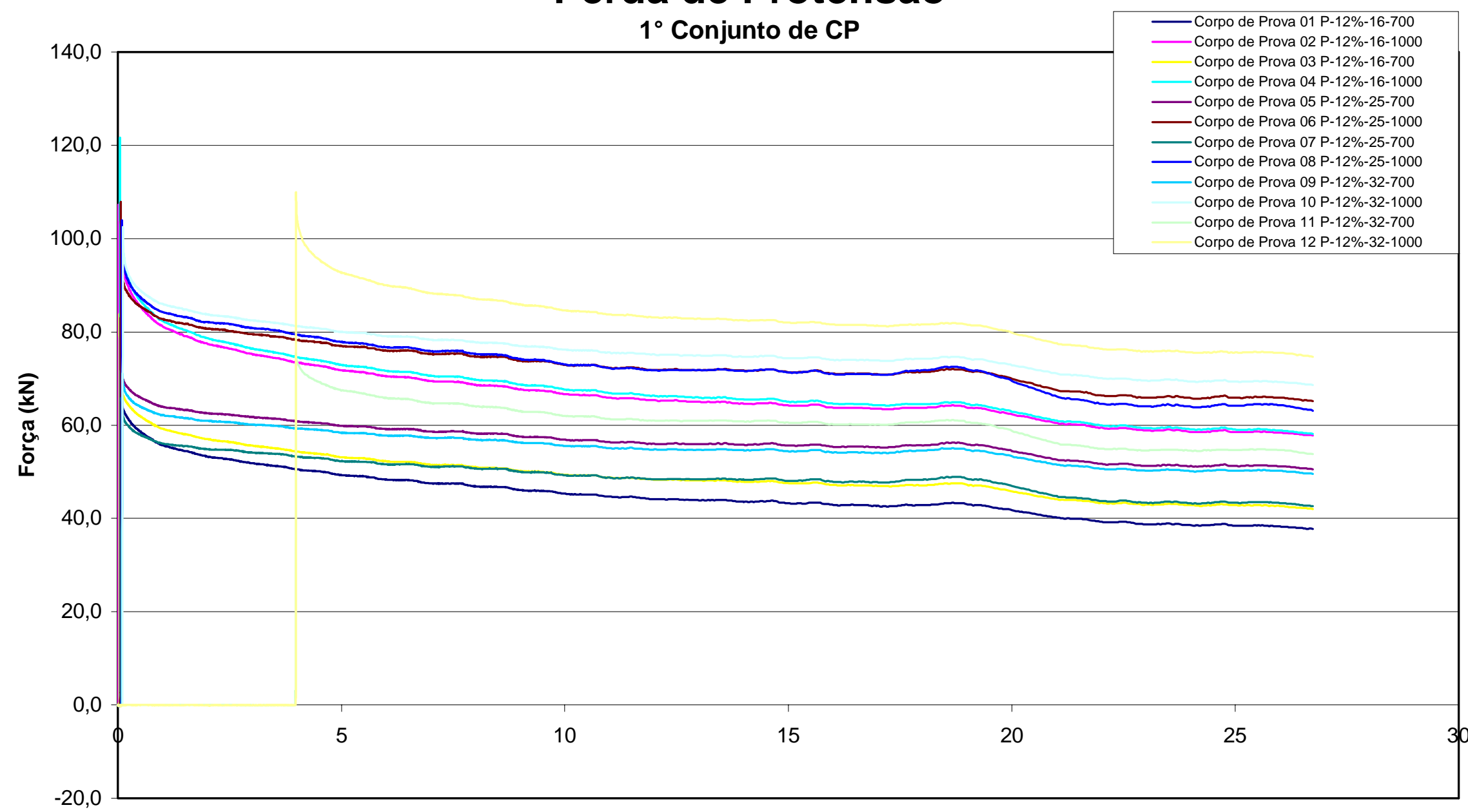

Tempo (dias) 


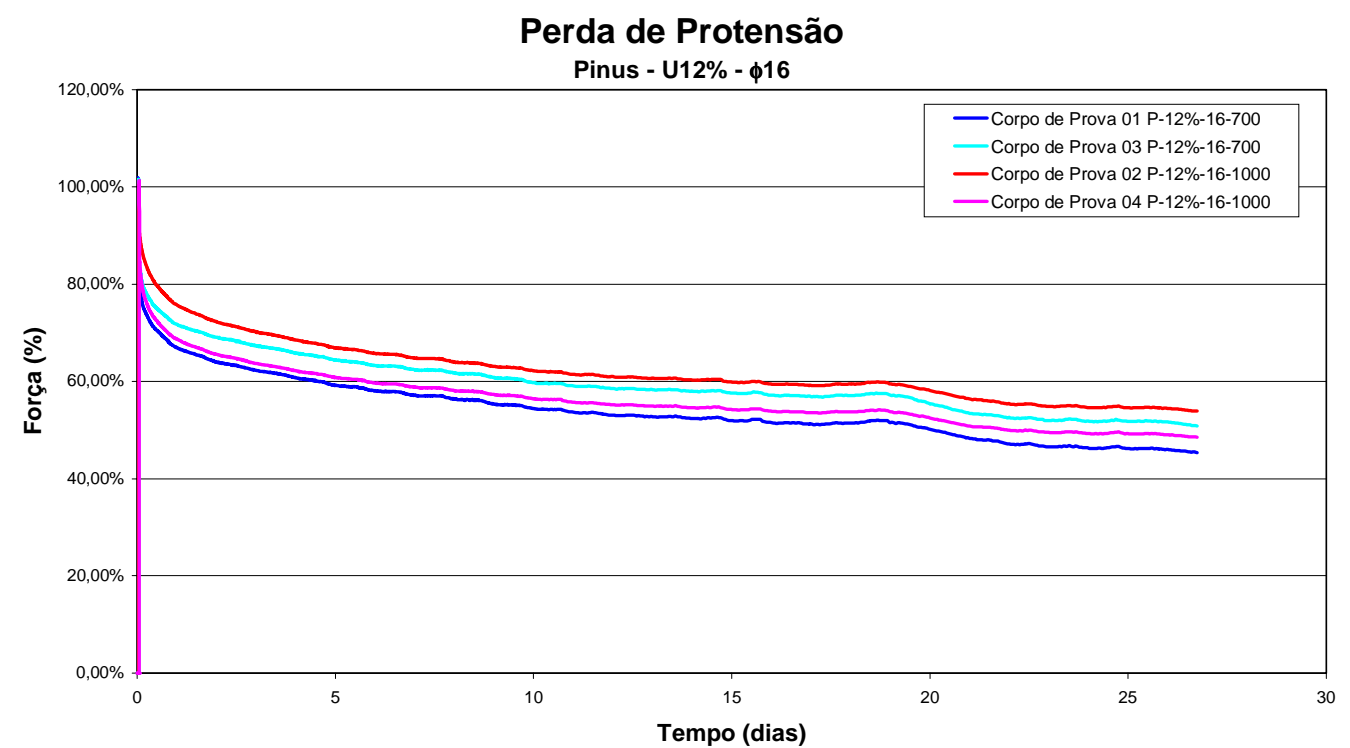

Perda de Protensão

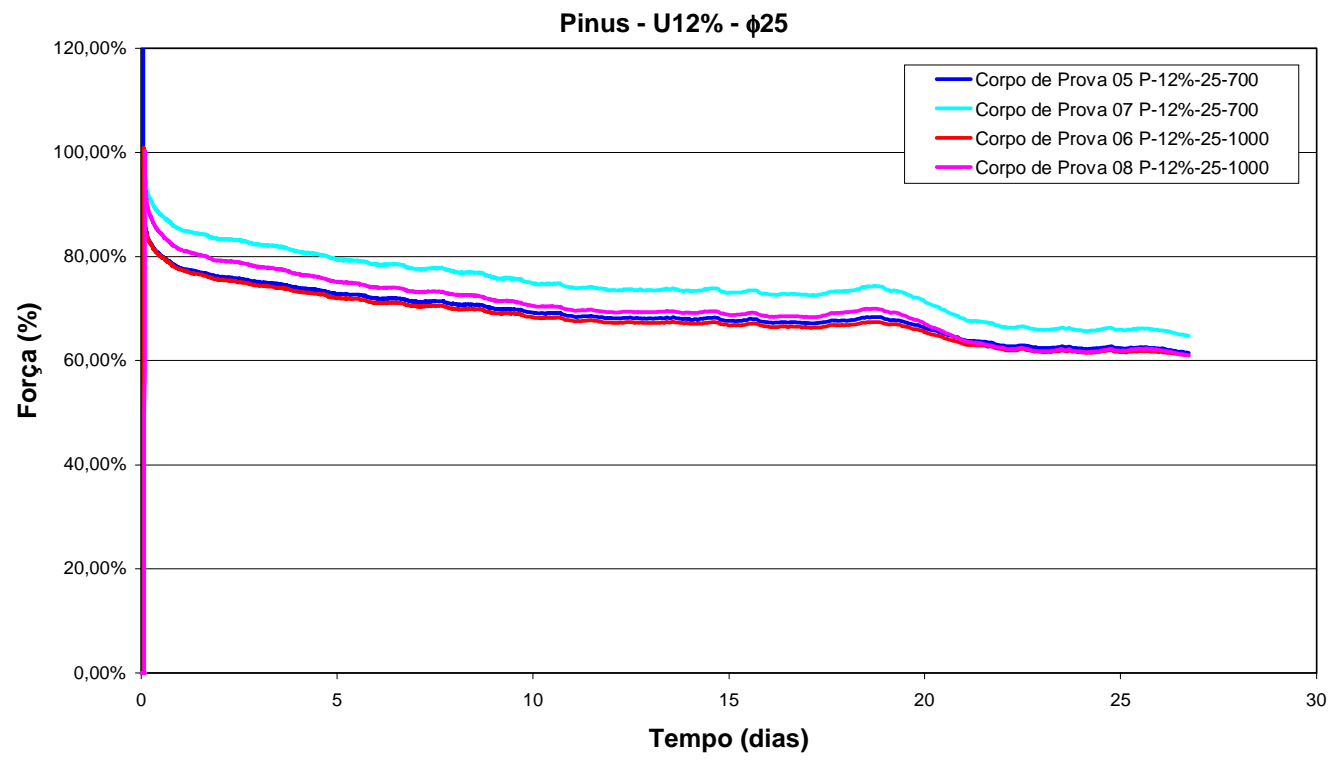

Perda de Protensão

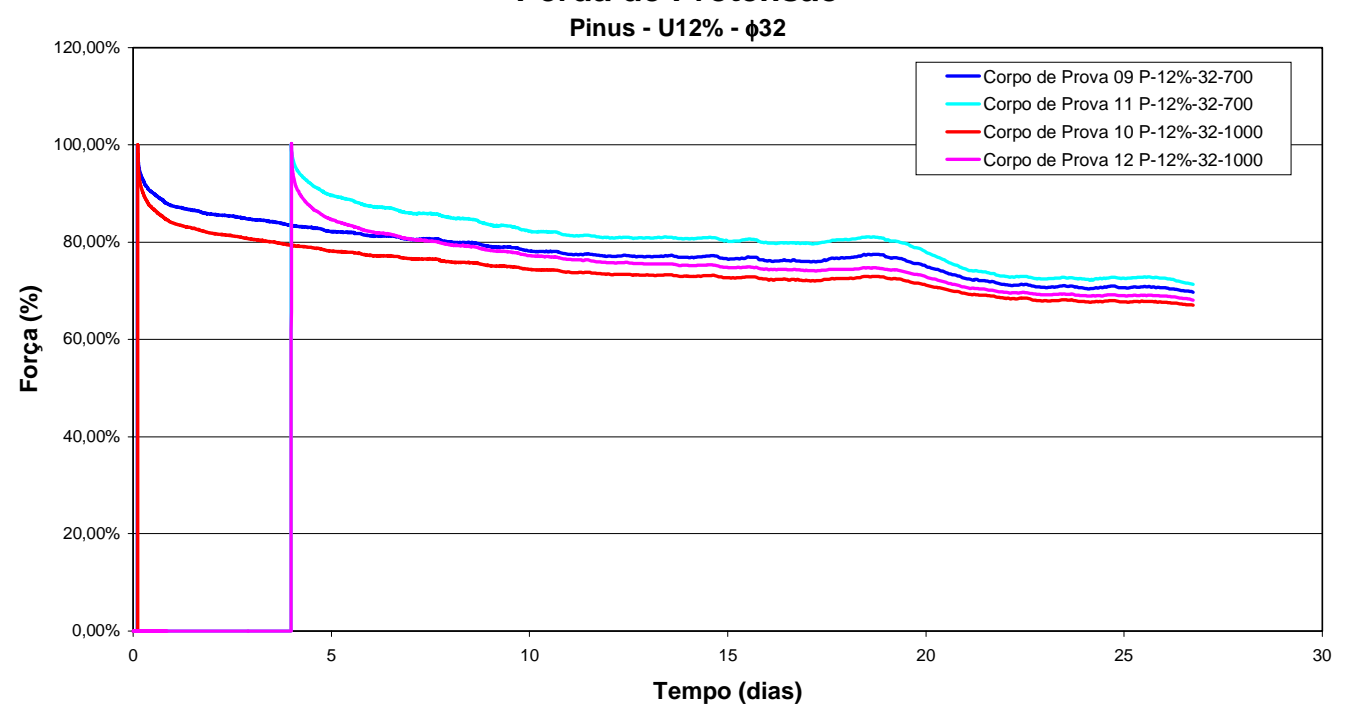



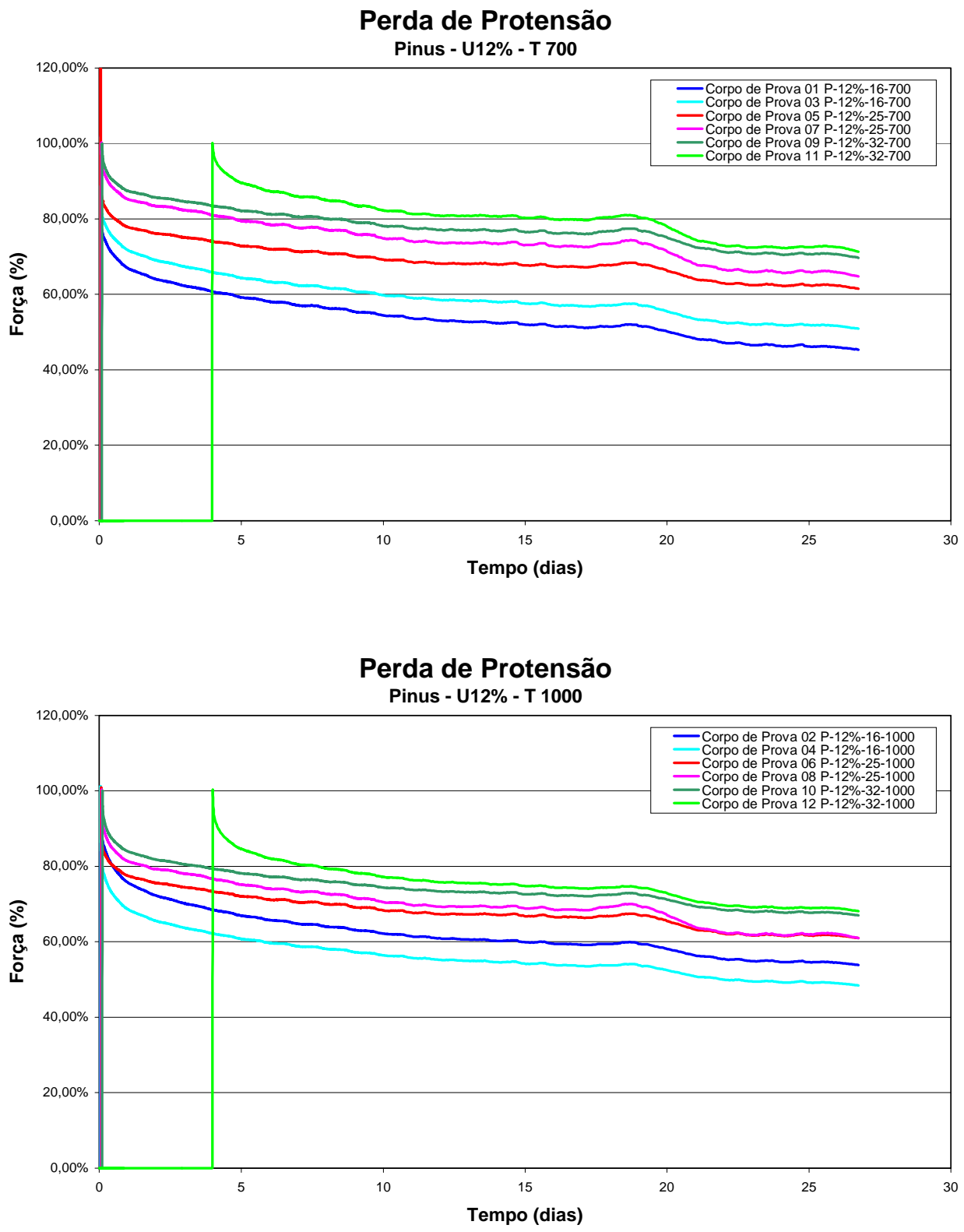
Segundo conjunto de 12 corpos de Prova

$\begin{array}{rccccc}\text { Scan ID } & \text { Date } & \text { Time } & \begin{array}{c}\text { Time } \\ \text { (segundos) }\end{array} & \begin{array}{c}\text { Time } \\ \text { (horas) }\end{array} & \begin{array}{c}\text { Time } \\ \text { (dias) }\end{array} \\ 1 & 14 / 11 / 2000 & 15: 45: 09 & \mathbf{0} & \mathbf{0 , 0} & \mathbf{0} \\ 2 & 14 / 11 / 2000 & 15: 45: 19 & \mathbf{1 0} & \mathbf{0 , 0} & \mathbf{0} \\ 3 & 14 / 11 / 2000 & 16: 45: 19 & \mathbf{3 6 1 0} & \mathbf{1 , 0} & \mathbf{0} \\ 73 & 17 / 11 / 2000 & 13: 48: 36 & \mathbf{2 5 2 2 0 7} & \mathbf{7 0 , 1} & \mathbf{3} \\ 74 & 17 / 11 / 2000 & 14: 48: 36 & \mathbf{2 5 5 8 0 7} & \mathbf{7 1 , 1} & \mathbf{3} \\ 75 & 17 / 11 / 2000 & 15: 48: 36 & \mathbf{2 5 9 4 0 7} & \mathbf{7 2 , 1} & \mathbf{3} \\ 76 & 17 / 11 / 2000 & 16: 48: 36 & \mathbf{2 6 3 0 0 7} & \mathbf{7 3 , 1} & \mathbf{3} \\ 77 & 17 / 11 / 2000 & 17: 29: 04 & \mathbf{2 6 5 4 3 5} & \mathbf{7 3 , 7} & \mathbf{3} \\ 78 & 17 / 11 / 2000 & 18: 29: 04 & \mathbf{2 6 9 0 3 5} & \mathbf{7 4 , 7} & \mathbf{3} \\ 79 & 17 / 11 / 2000 & 19: 29: 04 & \mathbf{2 7 2 6 3 5} & \mathbf{7 5 , 7} & \mathbf{3} \\ 80 & 17 / 11 / 2000 & 20: 29: 04 & \mathbf{2 7 6 2 3 5} & \mathbf{7 6 , 7} & \mathbf{3} \\ 81 & 17 / 11 / 2000 & 21: 29: 04 & \mathbf{2 7 9 8 3 5} & \mathbf{7 7 , 7} & \mathbf{3} \\ 82 & 17 / 11 / 2000 & 22: 29: 04 & \mathbf{2 8 3 4 3 5} & \mathbf{7 8 , 7} & \mathbf{3} \\ 83 & 17 / 11 / 2000 & 23: 29: 04 & \mathbf{2 8 7 0 3 5} & \mathbf{7 9 , 7} & \mathbf{3} \\ 84 & 18 / 11 / 2000 & 00: 29: 04 & \mathbf{2 9 0 6 3 5} & \mathbf{8 0 , 7} & \mathbf{3} \\ 85 & 18 / 11 / 2000 & 01: 29: 04 & \mathbf{2 9 4 2 3 5} & \mathbf{8 1 , 7} & \mathbf{3} \\ 86 & 18 / 11 / 2000 & 02: 29: 04 & \mathbf{2 9 7 8 3 5} & \mathbf{8 2 , 7} & \mathbf{3} \\ 87 & 18 / 11 / 2000 & 03: 29: 04 & \mathbf{3 0 1 4 3 5} & \mathbf{8 3 , 7} & \mathbf{3} \\ 88 & 18 / 11 / 2000 & 04: 29: 04 & \mathbf{3 0 5 0 3 5} & \mathbf{8 4 , 7} & \mathbf{4} \\ 89 & 18 / 11 / 2000 & 05: 29: 04 & \mathbf{3 0 8 6 3 5} & \mathbf{8 5 , 7} & \mathbf{4} \\ 90 & 18 / 11 / 2000 & 06: 29: 04 & \mathbf{3 1 2 2 3 5} & \mathbf{8 6 , 7} & \mathbf{4} \\ 91 & 18 / 11 / 2000 & 07: 29: 04 & \mathbf{3 1 5 8 3 5} & \mathbf{8 7 , 7} & \mathbf{4} \\ 92 & 18 / 11 / 2000 & 08: 29: 04 & \mathbf{3 1 9 4 3 5} & \mathbf{8 8 , 7} & \mathbf{4} \\ 93 & 18 / 11 / 2000 & 09: 29: 04 & \mathbf{3 2 3 0 3 5} & \mathbf{8 9 , 7} & \mathbf{4} \\ 94 & 18 / 11 / 2000 & 10: 29: 04 & \mathbf{3 2 6 6 3 5} & \mathbf{9 0 , 7} & \mathbf{4} \\ 95 & 18 / 11 / 2000 & 11: 29: 04 & \mathbf{3 3 0 2 3 5} & \mathbf{9 1 , 7} & \mathbf{4} \\ 96 & 18 / 11 / 2000 & 12: 29: 04 & \mathbf{3 3 3 8 3 5} & \mathbf{9 2 , 7} & \mathbf{4} \\ 97 & 18 / 11 / 2000 & 13: 29: 04 & \mathbf{3 3 7 4 3 5} & \mathbf{9 3 , 7} & \mathbf{4} \\ 98 & 18 / 11 / 2000 & 14: 29: 04 & \mathbf{3 4 1 0 3 5} & \mathbf{9 4 , 7} & \mathbf{4} \\ & & & & & \end{array}$

CP 01 CP 02 CP 03

Euc - 20\% - f16 - T700 Euc - 20\% - f16 - T1000 Pinus - 20\% - f16 - T700

$\mathrm{kN}$
0,0
0,0
0,0
0,0
71,4
69,3
68,2
67,5
66,6
65,9
65,4
64,8
64,4
64,0
63,7
63,4
63,1
63,0
62,7
62,4
62,2
62,0
61,8
61,7
61,4
61,3
61,3
61,2
60,9

kN

0,0

0,0

0,0

$-0,1$

$-0,1$

59,5

52,9

51,0

49,1

47,8

46,9

46,1

45,5

44,9

44,4

44,0

43,6

43,3

42,9

42,6

42,3

41,9

41,8

41,5

41,3

41,1

41,0

40,7 


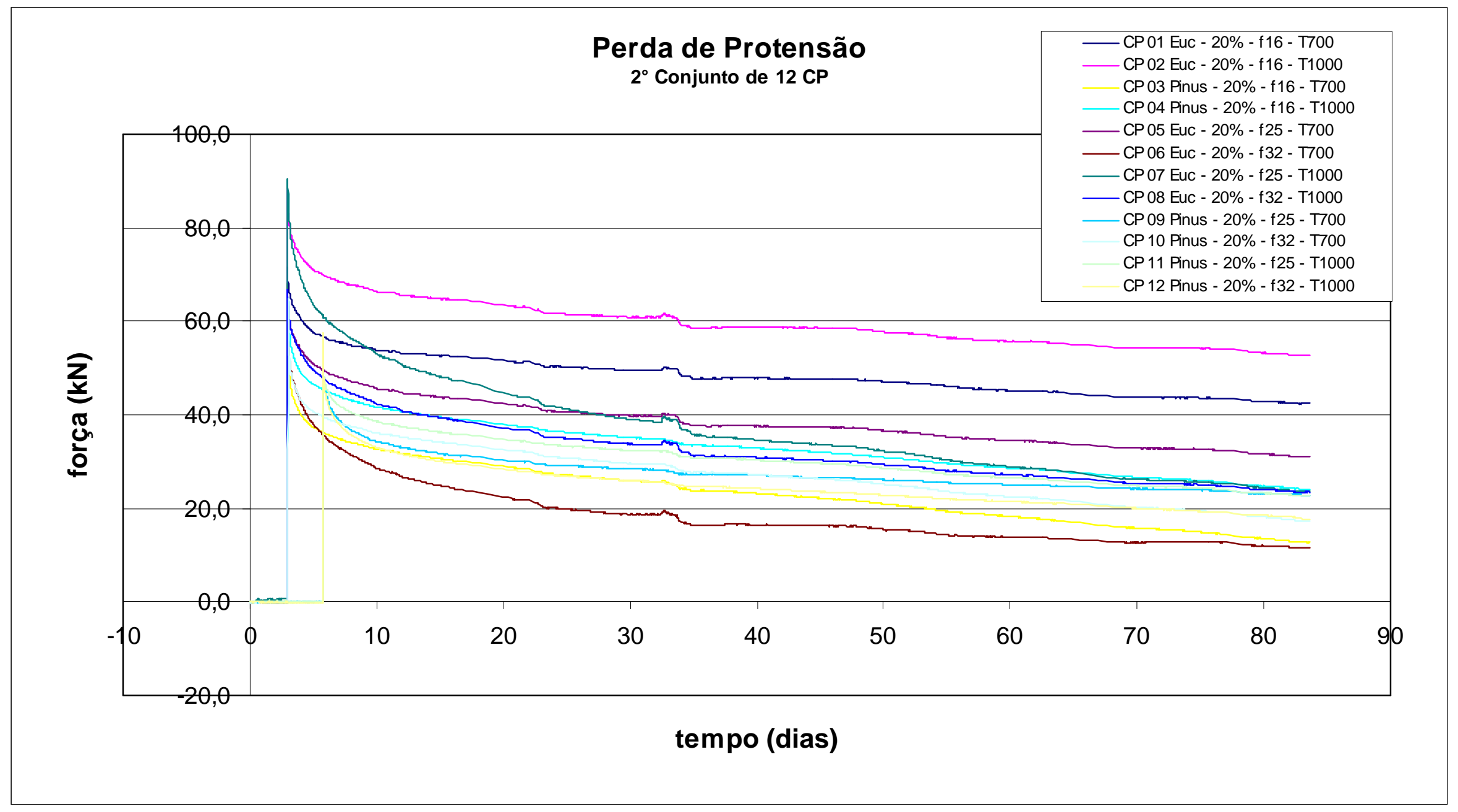


Perda de Protensão

Eucalipto Citriodora - U20\%

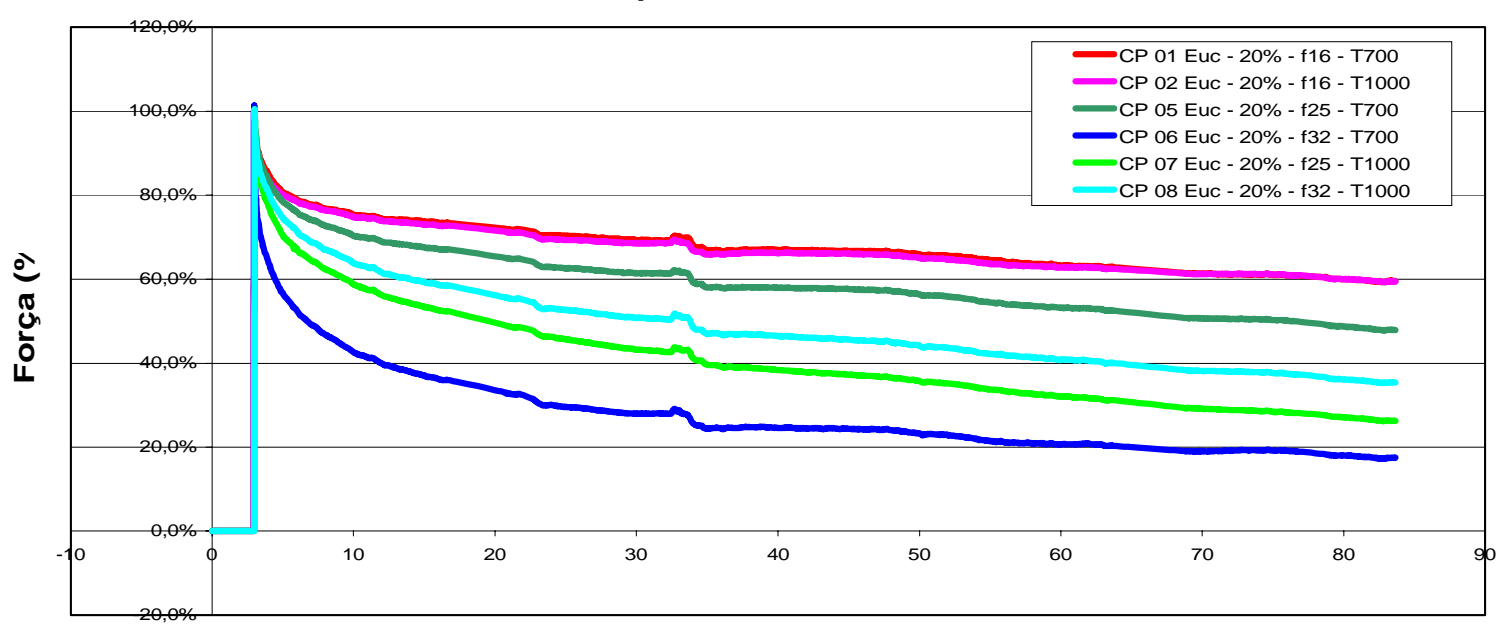

Tempo (dias)

Perda de Protensão

Pinus - U20\%

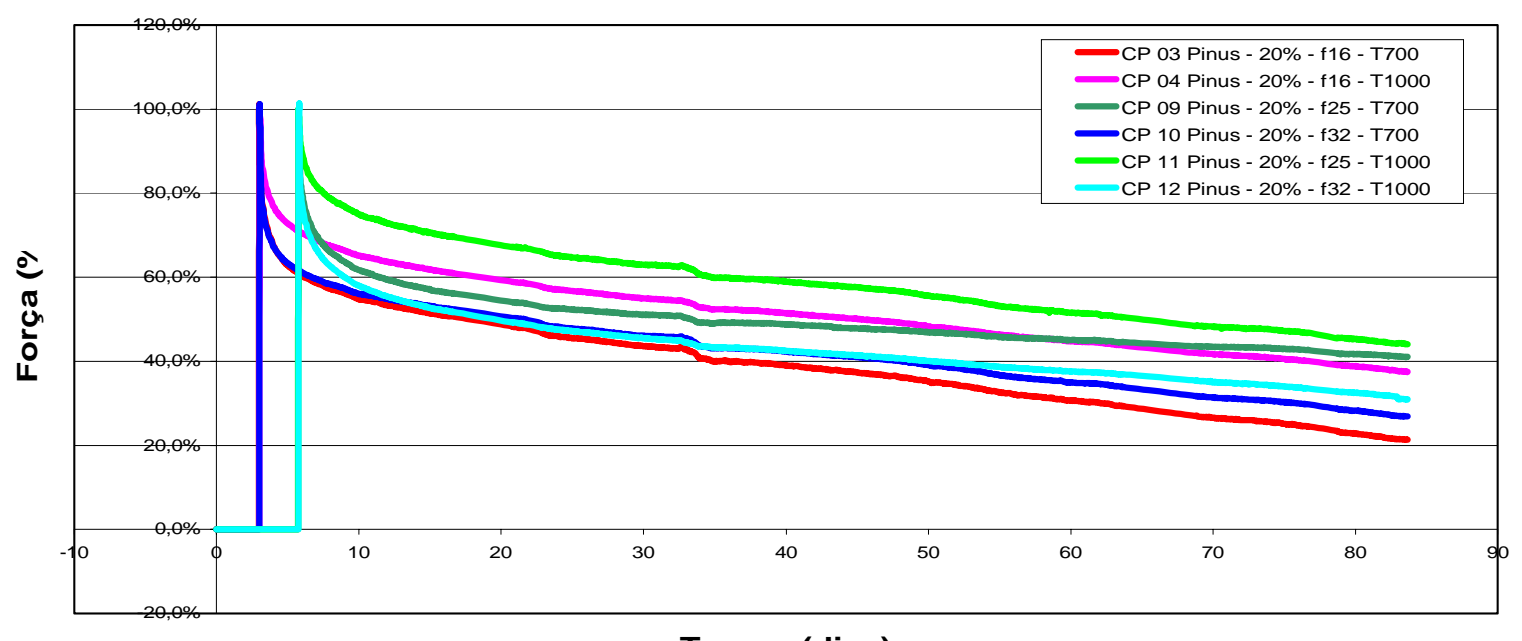

Tempo (dias)

Perda de Protensão

Pinus e Eucalipto - U20\% - \$ 16

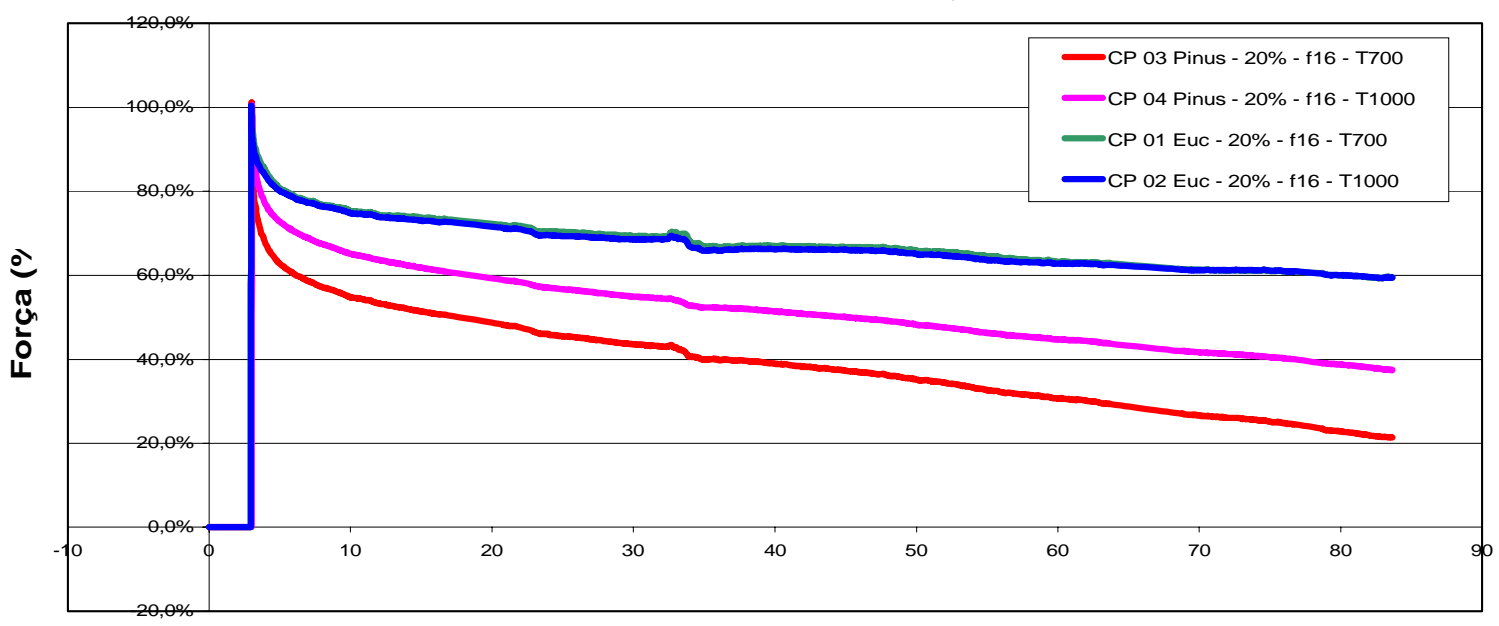

Tempo (dias) 
Perda de Protensão

Pinus e Eucalipto - U20\% - \$ 25

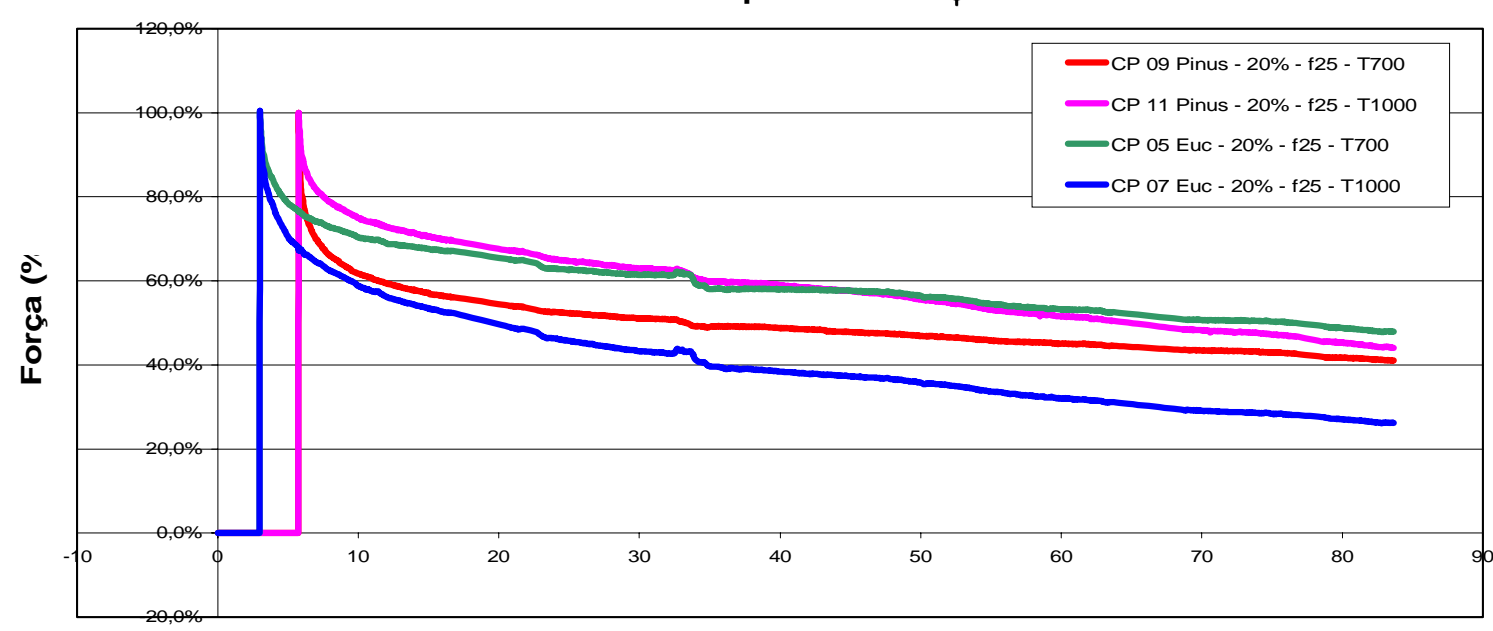

Tempo (dias)

Perda de Protensão

Pinus e Eucalipto - U20\% - $\phi 32$

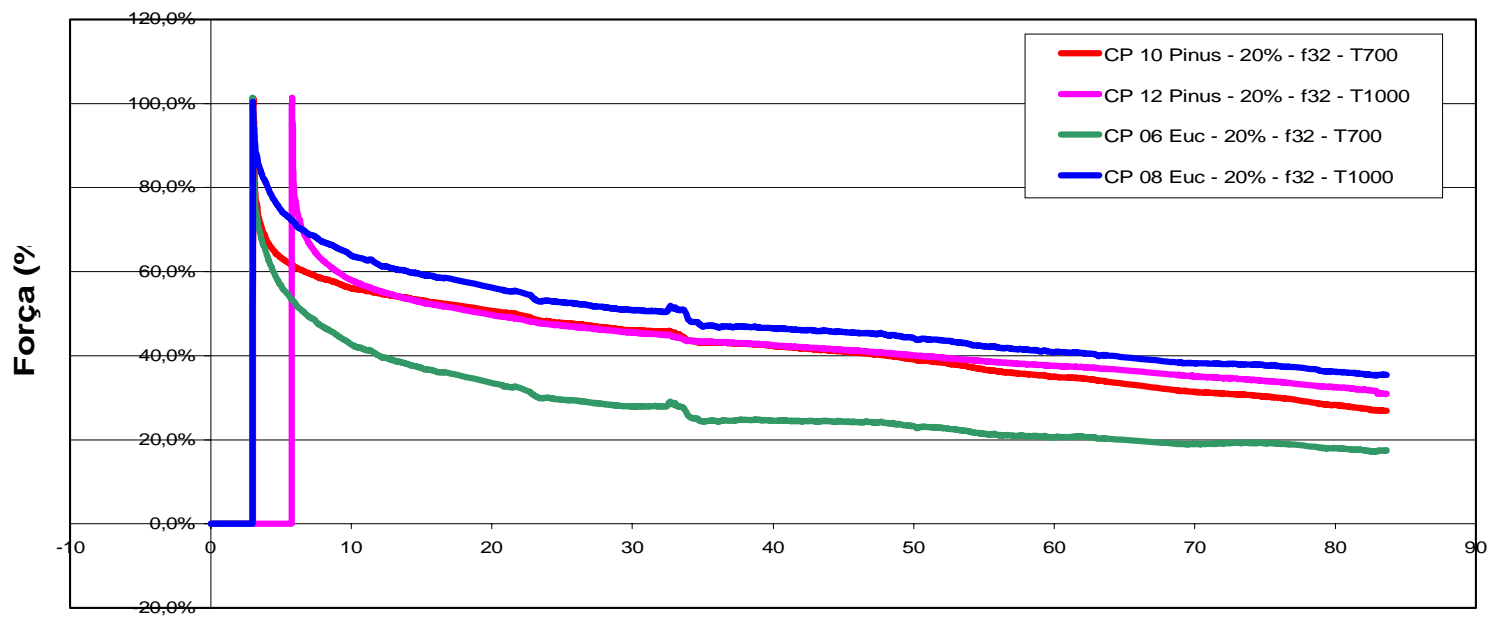

Tempo (dias)

Perda de Protensão

Pinus e Eucalipto - U20\% - T 700

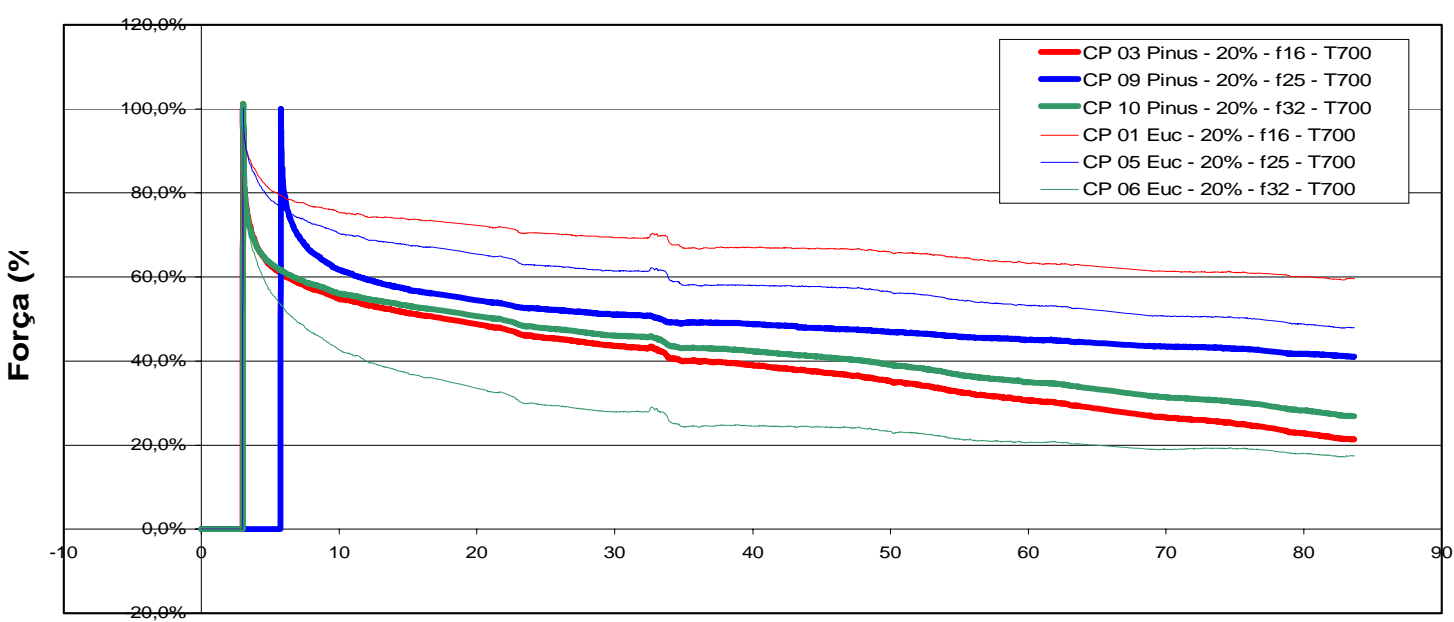

Tempo (dias) 
Perda de Protensão

Pinus e Eucalipto - U20\% - T 1000

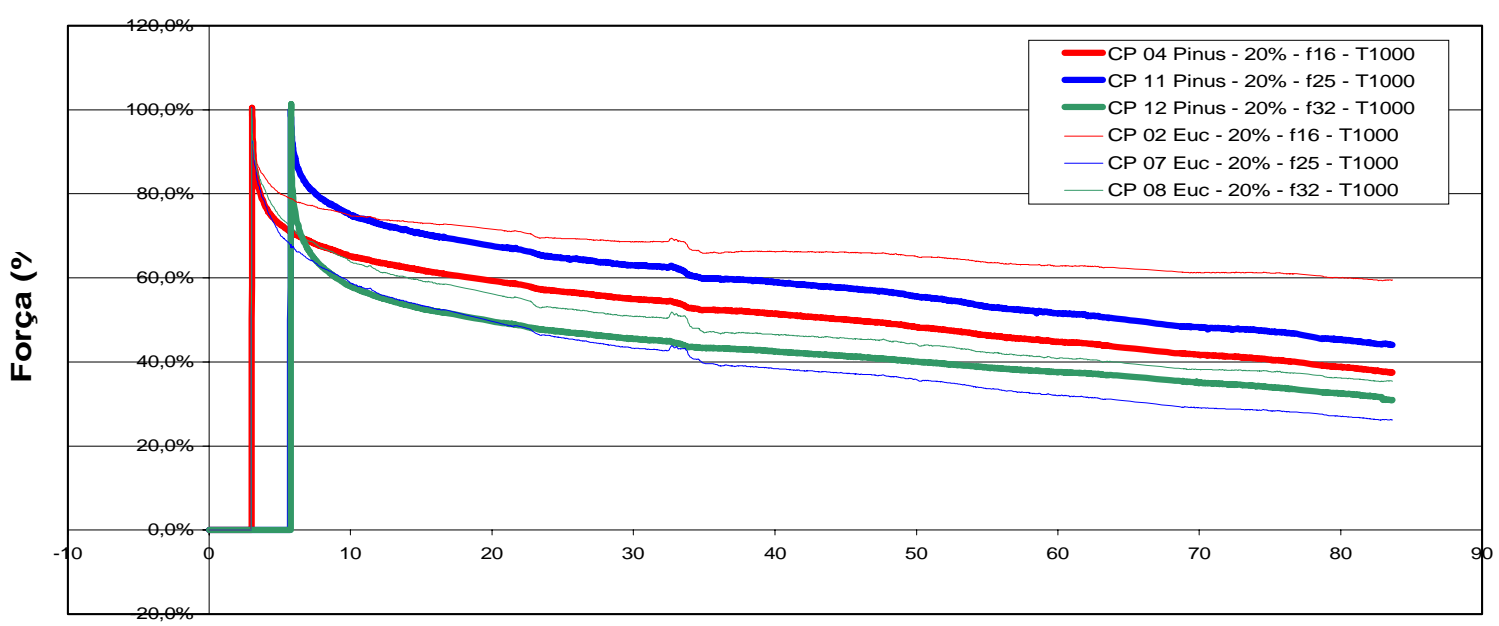

Tempo (dias)

No primeiro conjunto de 12 C.P. todos os corpos de prova são de Pinus, portanto não há gráficos que analisam esta variável como no segundo conjunto.

Em seguida são apresentados os resultados do terceiro conjunto onde apenas quatro C.P. foram executados para que se pudesse procurar influências de novas varáveis (consideradas secundárias anteriormente) como aços SAE1045 e SAE4340 e histórico de reprotensões (2 ou 3).

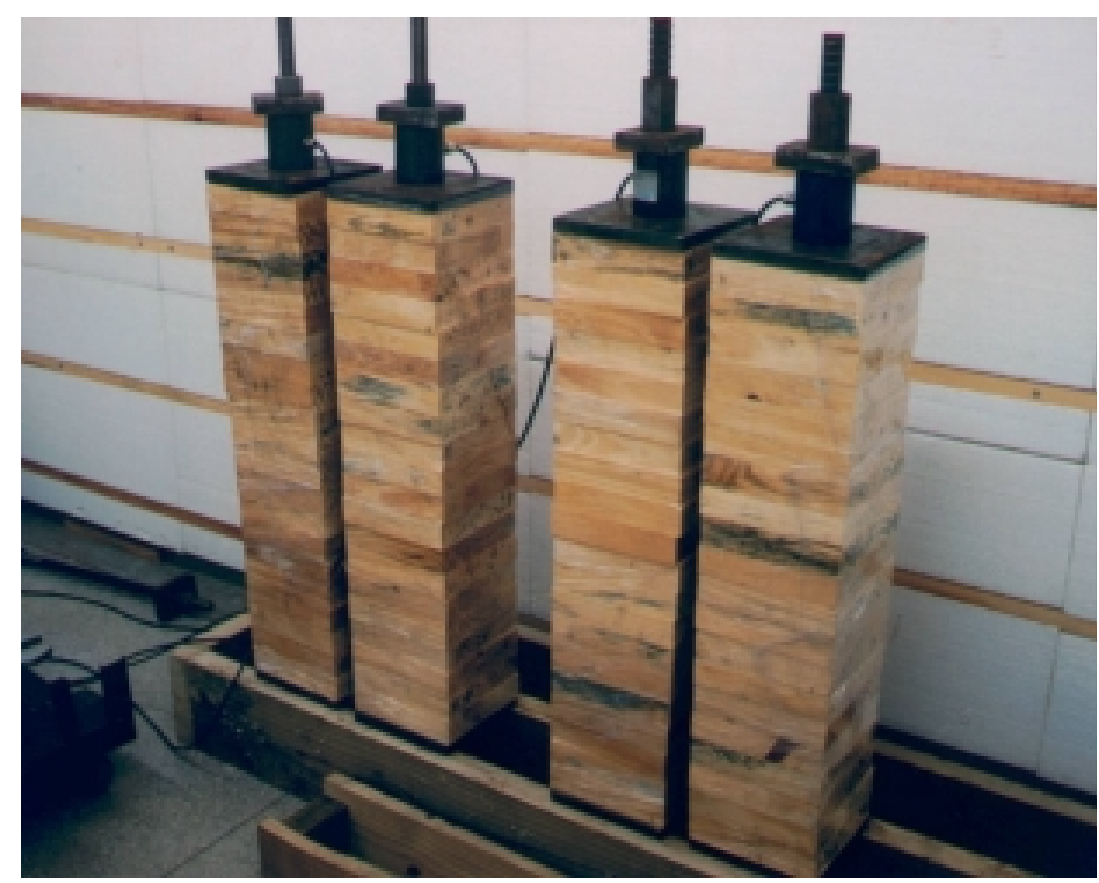

Figura 4.10 - Corpos de Prova do terceiro conjunto (tabela 4.3) 
Corpo de Prova 1 - Pinus - Aço SAE 1045 com d=25mm - U=12\%

\begin{tabular}{|c|c|c|c|c|c|c|c|c|c|c|}
\hline Data & Hora & $\begin{array}{c}\text { Tempo } \\
\text { (dias) }\end{array}$ & $\begin{array}{c}\text { Célula de } \\
\text { Carga } 08 \\
(\mathrm{kN})\end{array}$ & & $\begin{array}{c}\text { Temperatura } \\
\left({ }^{\circ} \mathrm{C}\right)\end{array}$ & $\begin{array}{l}\text { Umidade } \\
(\%)\end{array}$ & $\begin{array}{l}\text { Med. Linear } \\
\text { Direita }\end{array}$ & $\begin{array}{l}\text { Med. Linear } \\
\text { Esquerda }\end{array}$ & $\begin{array}{l}\text { Med. Linear } \\
\text { Face } 1\end{array}$ & $\begin{array}{l}\text { Med. Linear } \\
\text { Face } 2\end{array}$ \\
\hline $12 / 09 / 2001$ & 09:20:00 & 0 & 0,00 & $0,0 \%$ & - & - & 90,4 & 90,3 & 19,4 & 20,2 \\
\hline $12 / 09 / 2001$ & 09:20:00 & 0 & 78,00 & $100,0 \%$ & - & - & 88,3 & 88,0 & 19,6 & 20,2 \\
\hline $12 / 09 / 2001$ & 09:22:12 & 0 & 74,55 & $95,6 \%$ & - & - & - & - & - & - \\
\hline $12 / 09 / 2001$ & 09:37:12 & 0 & 69,37 & $88,9 \%$ & - & - & - & - & - & - \\
\hline $12 / 09 / 2001$ & 09:48:00 & 0 & 67,95 & $87,1 \%$ & - & - & - & - & - & - \\
\hline $12 / 09 / 2001$ & $09: 51: 25$ & 0 & 67,54 & $86,6 \%$ & - & - & - & - & - & - \\
\hline $12 / 09 / 2001$ & 10:06:25 & 0 & 66,61 & $85,4 \%$ & - & - & - & - & - & - \\
\hline $12 / 09 / 2001$ & $10: 21: 25$ & 0 & 66,03 & $84,7 \%$ & - & - & - & - & - & - \\
\hline $12 / 09 / 2001$ & $10: 36: 25$ & 0 & 65,33 & $83,8 \%$ & - & - & - & - & - & - \\
\hline $12 / 09 / 2001$ & $10: 51: 25$ & 0 & 64,75 & $83,0 \%$ & - & - & - & - & - & - \\
\hline $12 / 09 / 2001$ & 11:06:25 & 0 & 64,37 & $82,5 \%$ & - & - & - & - & - & - \\
\hline $12 / 09 / 2001$ & $11: 21: 25$ & 0 & 63,96 & $82,0 \%$ & - & - & - & - & - & - \\
\hline $12 / 09 / 2001$ & $11: 51: 25$ & 0 & 63,21 & $81,0 \%$ & - & - & - & - & - & - \\
\hline $12 / 09 / 2001$ & $12: 06: 25$ & 0 & 62,89 & $80,6 \%$ & - & - & - & - & - & - \\
\hline $12 / 09 / 2001$ & $12: 21: 25$ & 0 & 62,65 & $80,3 \%$ & - & - & - & - & - & - \\
\hline $12 / 09 / 2001$ & $12: 36: 25$ & 0 & 62,39 & $80,0 \%$ & - & - & - & - & - & - \\
\hline $12 / 09 / 2001$ & $12: 51: 25$ & 0 & 62,19 & $79,7 \%$ & - & - & - & - & - & - \\
\hline $12 / 09 / 2001$ & 13:06:25 & 0 & 62,04 & $79,5 \%$ & - & - & - & - & - & - \\
\hline $12 / 09 / 2001$ & $13: 21: 25$ & 0 & 61,87 & $79,3 \%$ & - & - & - & - & - & - \\
\hline $12 / 09 / 2001$ & $13: 36: 25$ & 0 & 61,66 & $79,1 \%$ & - & - & - & - & - & - \\
\hline $12 / 09 / 2001$ & $13: 51: 25$ & 0 & 61,43 & $78,8 \%$ & - & - & - & - & - & - \\
\hline $12 / 09 / 2001$ & 14:06:25 & 0 & 61,31 & $78,6 \%$ & - & - & - & - & - & - \\
\hline $12 / 09 / 2001$ & 14:21:25 & 0 & 61,11 & $78,3 \%$ & - & - & - & - & - & - \\
\hline
\end{tabular}


Corpos de Prova - Pinus - U12\% - $\phi 25$ - T700

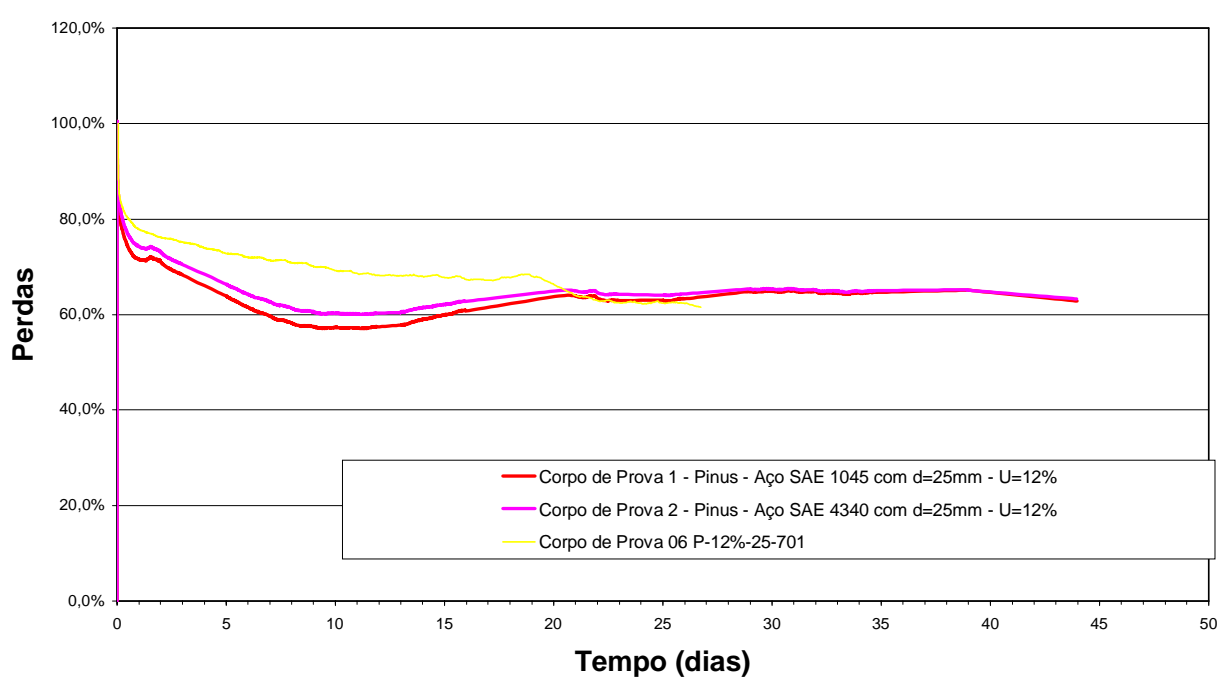

Corpos de Prova - Pinus - U12\% - $\phi 25$

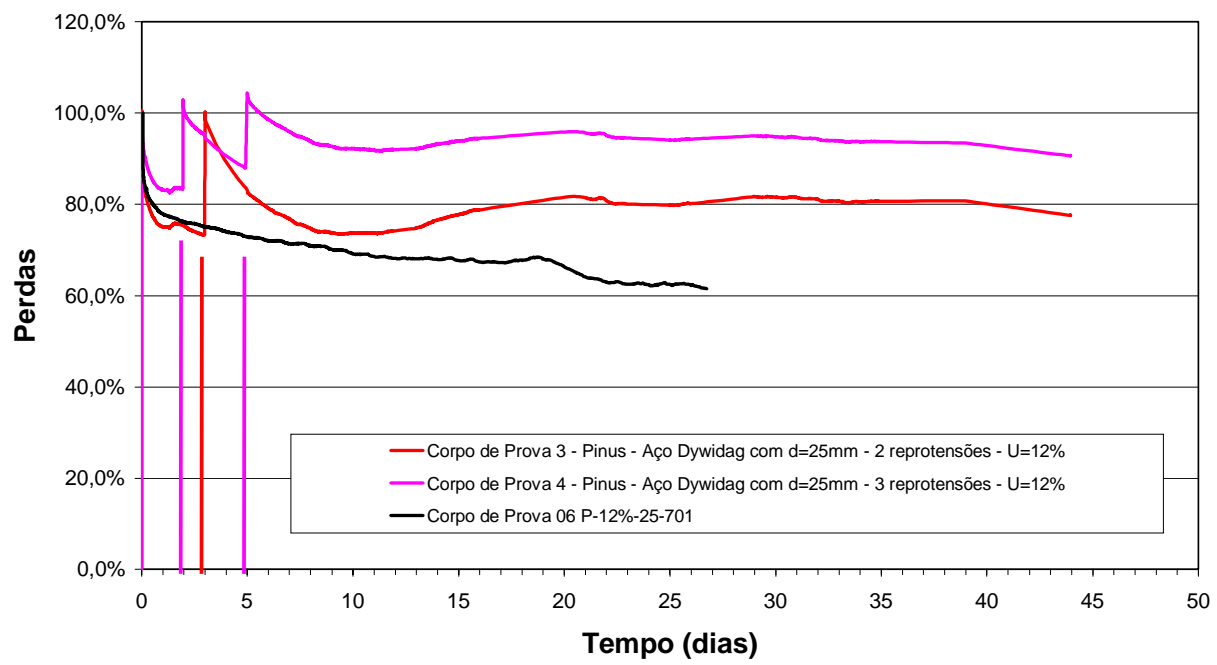

No primeiro conjunto, como só houveram corpos de prova de pinus e na umidade $12 \%$ pôde-se avaliar apenas variações de diâmetro e de nível de tensão.

Ao contrário do que se esperava, as perdas maiores ocorreram para os diâmetros menores, na ordem 16 >> 25 >> 32 . 
As perdas relacionadas aos níveis de protensão de $700 \mathrm{kPa}$ e $1000 \mathrm{kPa}$ ficaram muito próximas, girando em torno de $25 \%$ para o diâmetro de $32 \mathrm{~mm}$ e $40 \%$ para o de $16 \mathrm{~mm}$ nos 30 dias.

No segundo conjunto pôde-se verificar o que se esperava para o Eucalipto citriodora já que as perdas foram maiores para diâmetros maiores. Para $\phi$ de 16, as perdas ficaram em $30 \%$, para $\phi$ de 25 em $60 \%$ e para $\phi$ de 32 em $70 \%$. Para o pinus não foram verificadas variações significativas, sendo que para qualquer diâmetro, as perdas ficaram em torno de $70 \%$. Essa foi apenas uma estimativa generalizada já que para alguns corpos de prova não foi possível aplicar a tensão de 1000kPa.

No terceiro conjunto apenas 4 (quatro) corpos de prova foram executados. Desejava-se obter alguns dados a respeito das reprotensões e da utilização de outros materiais como barras de protensão.

No gráfico comparativo de barras de aço para corpos de prova de Pinus a $12 \%$ com $\phi$ de $25 \mathrm{~mm}$ e nível de protensão de $700 \mathrm{kPa}$ não houveram variações significativas. Apesar das perdas iniciais nos aços SAE terem sido maiores, ao longo do tempo, essas diferenças tornam-se menos significantes.

Os dois históricos de reprotensões ( $1^{\circ}-0,3$ dias e $2^{\circ}-0,2,5$ dias) mostraram-se eficientes já que as perdas em 45 dias ficaram abaixo de $20 \%$. O mesmo corpo de prova, isto é, corpo de prova de Pinus a $12 \%$ com $\phi$ de $25 \mathrm{~mm}$ e nível de protensão de $700 \mathrm{kPa}$, já havia perdido quase $40 \%$ em apenas 30 dias.

Em resumo, verifica-se que não é recomendável a utilização de madeiras saturadas. As perdas nestes casos são elevadas, acima de $70 \%$ já nos primeiros meses. Por outro lado, estes valores de perdas não diferem dos encontrados na figura 2.40 que é da ordem de $65 \%$ no primeiro mês (sem 
reprotensão). Quando trabalhou-se com as madeiras no teor padrão (12\%), as perdas nos primeiros meses não ultrapassou os $40 \%$, ficando abaixo dos valores mencionados da figura 2.40. Também para madeiras a $12 \%$, verificou-se perdas inferiores a $20 \%$ quando os conjuntos foram submetidos à reprotensões. Novamente, os valores se equivalem aos da figura 2.40 .

Assim, fica evidente que os valores sugeridos pela literatura de 2,5 e 1,25 como multiplicadores dos valores da tensão de projeto para tabuleiros com duas reprotensões e com três reprotensões, respectivamente, é coerente com os resultados obtido neste trabalho. 
4.4 Análise de Perdas de Protensão em Tabuleiros

Foram construídos 2 (dois) tabuleiros de $100 \mathrm{~cm}$ por $480 \mathrm{~cm}$ por $20 \mathrm{~cm}$ de altura. O objetivo foi sublimar pequenas interferências que deveriam estar ocorrendo corpos-de-prova e que não pôde-se controlar. Estas possíveis interferências poderiam ser as causas dos problemas encontrados nos corpos-de-prova. Trata-se da própria variabilidade do material madeira, da presença de nós e rachaduras e outros elementos que interferem mais no corpo de prova de $20 \mathrm{~cm}$ x $20 \mathrm{~cm}$ por $100 \mathrm{~cm}$, sendo provável, influenciarem menos em faces de $20 \mathrm{~cm}$ por $480 \mathrm{~cm}$.

Os tabuleiros (figura 4.11) foram instrumentados com células de carga e transdutores de deslocamentos bem como foram tomadas medidas lineares sobre as faces superiores a cada $30 \mathrm{~cm}$ do comprimento..

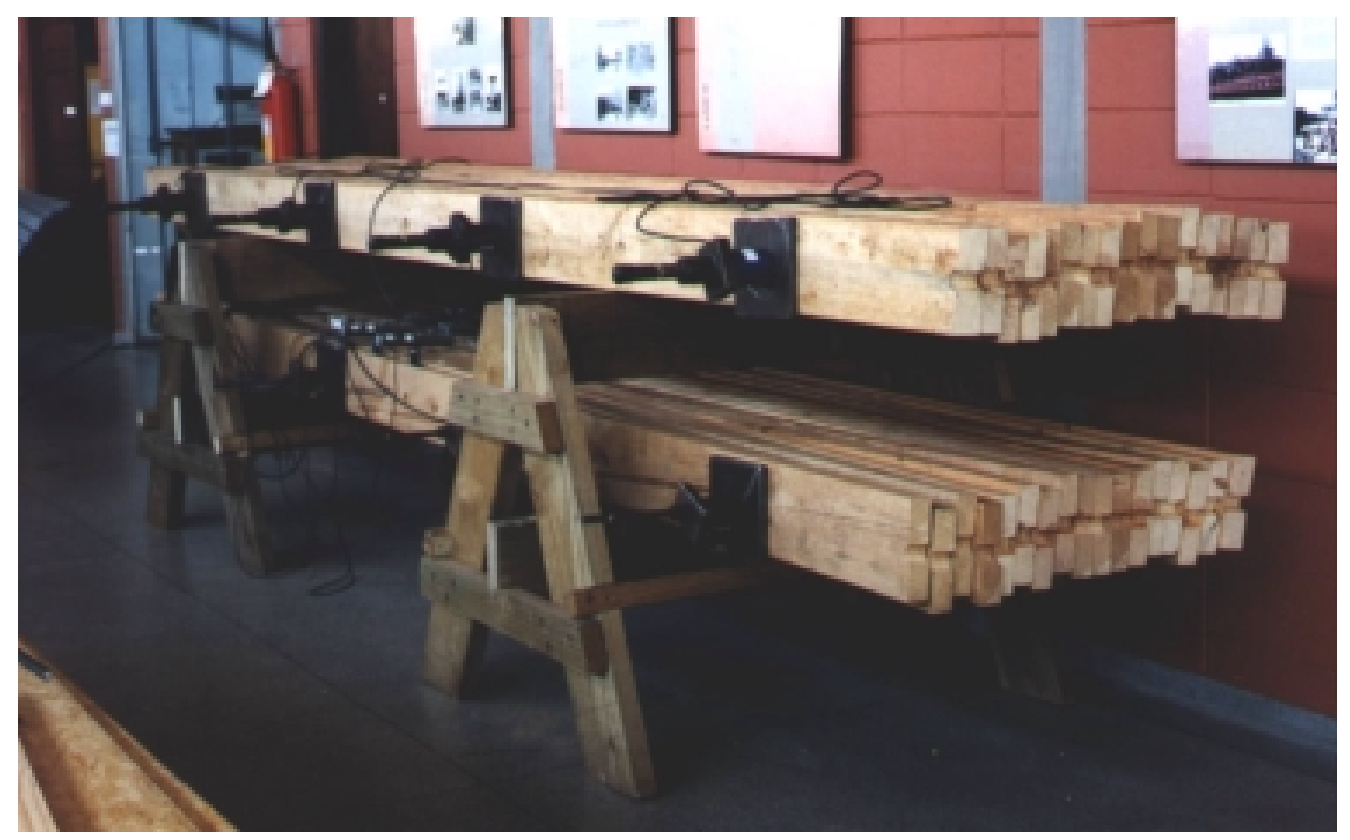

Figura 4.11 -Tabuleiros ensaiados (fig. 3.7)

A seguir, apresentam-se as planilhas de dados seguidas pelo esquema de montagem incluindo os valores das medições lineares efetuadas. 
Tabuleiro com barras de $16 \mathrm{~mm}$

\begin{tabular}{|c|c|c|c|c|c|c|c|c|c|}
\hline & & & & $\begin{array}{l}\text { Tabuleiro } \\
01-15 \mathrm{~mm} \\
\text { Célula } \\
1(01) / 4\end{array}$ & $\begin{array}{l}\text { Tabuleiro } \\
-01-15 \mathrm{~mm} \\
\text { Célula } \\
2(02) / 4\end{array}$ & $\begin{array}{l}\text { Tabuleiro } \\
\text {-01-15mm } \\
\text { Célula } \\
3(03) / 4\end{array}$ & $\begin{array}{l}\text { Tabuleiro } \\
-01-15 \mathrm{~mm} \\
\text { Célula } \\
4(04) / 4\end{array}$ & Média das Forças & Média das Forças \\
\hline Scan ID & Date & Time & $\begin{array}{l}\text { Tempo } \\
\text { (horas) }\end{array}$ & $\mathrm{kN}$ & $\mathrm{kN}$ & $\mathrm{kN}$ & $\mathrm{kN}$ & $\mathrm{kN}$ & $(\%)$ \\
\hline 1 & $31 / 08 / 2001$ & $10: 47: 23$ & 0,00 & 0,0 & 0,1 & 0,0 & 0,0 & & \\
\hline 200 & 05/09/2001 & $14: 33: 02$ & & 0,1 & 0,0 & 0,0 & 0,0 & & \\
\hline 201 & 05/09/2001 & $14: 48: 02$ & & 0,2 & 25,5 & 32,2 & 36,2 & & \\
\hline 202 & 05/09/2001 & $14: 48: 15$ & & 0,2 & 25,5 & 32,1 & 36,1 & & \\
\hline 203 & 05/09/2001 & $14: 49: 11$ & & 0,1 & 25,4 & 32,0 & 36,1 & & \\
\hline 204 & 05/09/2001 & $14: 51: 36$ & & 0,2 & 25,3 & 31,7 & 35,9 & & \\
\hline 205 & 05/09/2001 & $14: 55: 38$ & & 54,4 & 23,2 & 31,4 & 36,7 & & \\
\hline 206 & 05/09/2001 & $15: 10: 38$ & & 51,8 & 59,2 & 114,9 & 57,5 & & \\
\hline 207 & 05/09/2001 & $15: 24: 21$ & 0,00 & $\underline{110,5}$ & $\underline{121,4}$ & $\underline{104,9}$ & $\underline{119,0}$ & $\underline{114,0}$ & $100,0 \%$ \\
\hline 208 & 05/09/2001 & $15: 30: 16$ & 0,10 & 109,0 & 119,2 & 103,9 & 116,9 & 112,2 & $98,5 \%$ \\
\hline 209 & 05/09/2001 & $15: 45: 16$ & 0,35 & 107,0 & 116,5 & 102,2 & 114,7 & 110,1 & $96,6 \%$ \\
\hline 210 & 05/09/2001 & $16: 00: 16$ & 0,60 & 105,8 & 115,0 & 101,0 & 113,4 & 108,8 & $95,5 \%$ \\
\hline 211 & 05/09/2001 & $16: 15: 16$ & 0,85 & 104,9 & 113,9 & 100,2 & 112,5 & 107,9 & $94,7 \%$ \\
\hline 212 & 05/09/2001 & $16: 30: 16$ & 1,10 & 104,2 & 113,2 & 99,5 & 111,9 & 107,2 & $94,1 \%$ \\
\hline 213 & 05/09/2001 & $16: 45: 16$ & 1,35 & 103,6 & 112,5 & 99,0 & 111,2 & 106,6 & $93,5 \%$ \\
\hline 214 & 05/09/2001 & $17: 00: 16$ & 1,60 & 103,0 & 112,0 & 98,5 & 110,7 & 106,1 & $93,1 \%$ \\
\hline 215 & 05/09/2001 & $17: 15: 16$ & 1,85 & 102,6 & 111,6 & 98,0 & 110,3 & 105,6 & $92,7 \%$ \\
\hline 216 & 05/09/2001 & $17: 30: 16$ & 2,10 & 102,2 & 111,1 & 97,6 & 109,9 & 105,2 & $92,3 \%$ \\
\hline 217 & 05/09/2001 & $17: 45: 16$ & 2,35 & 101,8 & 110,7 & 97,2 & 109,5 & 104,8 & $92,0 \%$ \\
\hline 218 & 05/09/2001 & 18:00:16 & 2,60 & 101,5 & 110,3 & 96,9 & 109,2 & 104,5 & $91,7 \%$ \\
\hline 219 & 05/09/2001 & $18: 15: 16$ & 2,85 & 101,2 & 110,0 & 96,6 & 108,9 & 104,2 & $91,4 \%$ \\
\hline 220 & 05/09/2001 & $18: 20: 19$ & 2,93 & 101,0 & 109,9 & 96,5 & 108,8 & 104,0 & $91,3 \%$ \\
\hline 221 & 05/09/2001 & $18: 20: 31$ & 2,94 & 101,1 & 109,9 & 96,5 & 108,8 & 104,1 & $91,3 \%$ \\
\hline
\end{tabular}


Tabuleiro com barras de $16 \mathrm{~mm}$

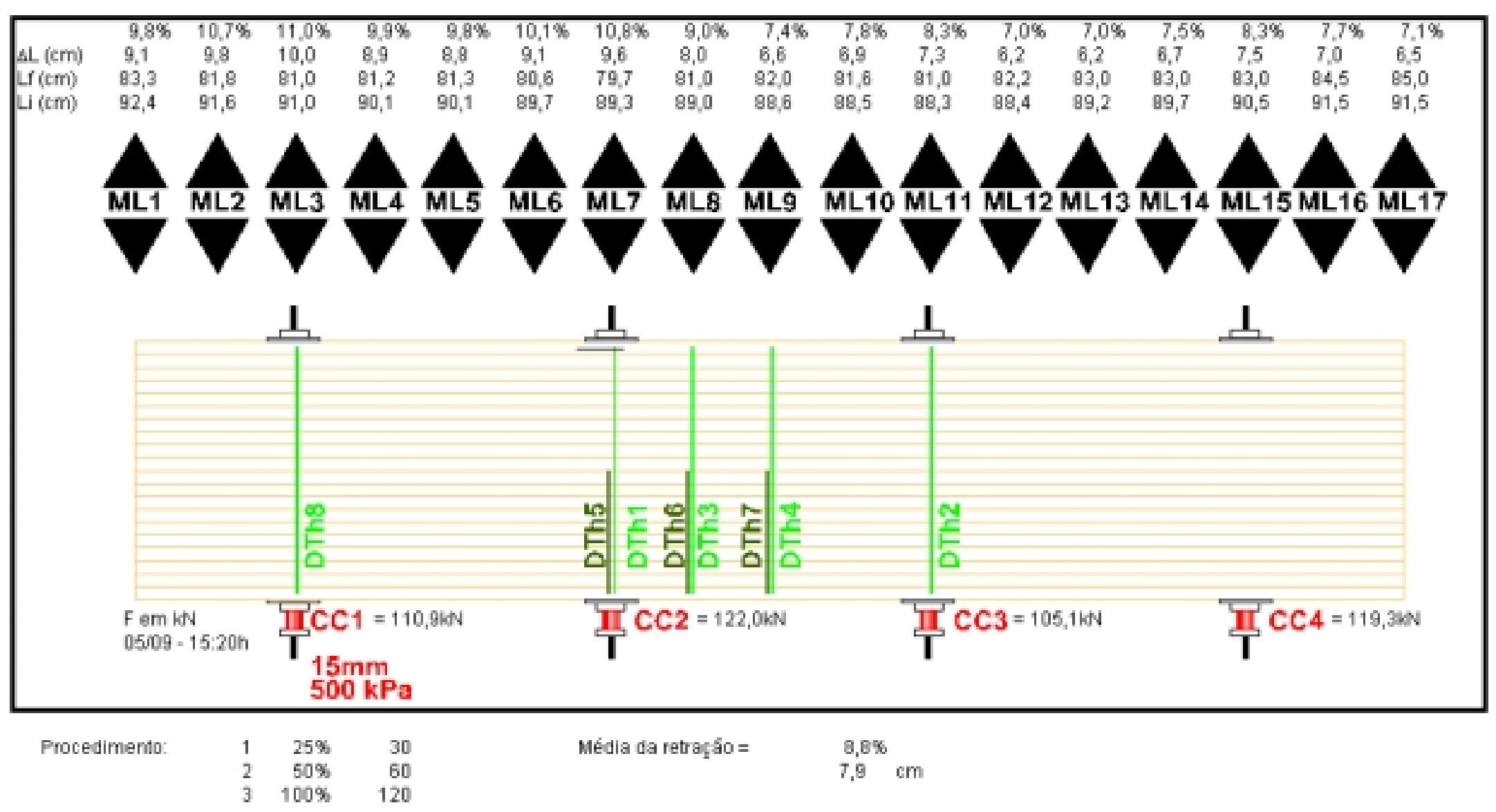


Tabuleiro com barras de $32 \mathrm{~mm}$

\begin{tabular}{|c|c|c|c|c|c|c|c|c|c|}
\hline & & & & $\begin{array}{l}\text { Tabuleiro } \\
02-32 \mathrm{~mm} \\
\text { Célula } \\
1(05) / 4\end{array}$ & $\begin{array}{l}\text { Tabuleiro } \\
\text {-02-32mm } \\
\text { Célula } \\
2(06) / 4\end{array}$ & $\begin{array}{l}\text { Tabuleiro } \\
\text {-02-32mm } \\
\text { Célula } \\
3(07) / 4\end{array}$ & $\begin{array}{l}\text { Tabuleiro } \\
\text {-02-32mm } \\
\text { Célula } \\
4(12) / 4\end{array}$ & Média das Forças & Média das Forç \\
\hline Scan ID & Date & Time & $\begin{array}{l}\text { Tempo } \\
\text { (horas) }\end{array}$ & $\mathrm{kN}$ & $\mathrm{kN}$ & $\mathrm{kN}$ & $\mathrm{kN}$ & $\mathrm{kN}$ & $(\%)$ \\
\hline 1 & $31 / 08 / 2001$ & $10: 47: 23$ & 0,00 & 0,1 & 0,1 & 0,0 & 0,0 & & \\
\hline 177 & 05/09/2001 & 09:03:57 & & $-0,1$ & $-0,5$ & $-0,1$ & $-0,1$ & & \\
\hline 178 & 05/09/2001 & 09:18:57 & & 0,3 & $-0,6$ & $-0,3$ & 34,0 & & \\
\hline 179 & 05/09/2001 & 09:33:57 & & 0,0 & 21,3 & 31,4 & 18,5 & & \\
\hline 180 & 05/09/2001 & 09:48:57 & & 30,9 & 20,8 & 27,9 & 33,9 & & \\
\hline 181 & 05/09/2001 & $10: 03: 57$ & & 29,2 & 66,7 & 25,3 & 56,7 & & \\
\hline 182 & 05/09/2001 & 10:18:57 & & 68,4 & 56,6 & 64,0 & 55,9 & & \\
\hline 183 & 05/09/2001 & 10:33:57 & & 96,7 & 55,0 & 61,9 & 55,5 & & \\
\hline 184 & 05/09/2001 & 10:48:57 & & 97,0 & 54,5 & 60,6 & 55,0 & & \\
\hline 185 & 05/09/2001 & $11: 03: 57$ & & 127,8 & 54,3 & 58,7 & 122,1 & & \\
\hline 186 & 05/09/2001 & $11: 18: 57$ & 0,00 & 123,2 & 122,2 & 124,0 & 118,2 & 121,9 & $100,0 \%$ \\
\hline 187 & 05/09/2001 & $11: 33: 57$ & 0,25 & 121,3 & 119,2 & 120,5 & 116,5 & 119,3 & $97,9 \%$ \\
\hline 188 & 05/09/2001 & 11:48:57 & 0,50 & 119,9 & 117,4 & 118,7 & 115,3 & 117,8 & $96,7 \%$ \\
\hline 189 & 05/09/2001 & $12: 03: 57$ & 0,75 & 118,8 & 116,2 & 117,5 & 114,5 & 116,8 & $95,8 \%$ \\
\hline 190 & 05/09/2001 & 12:18:57 & 1,00 & 118,1 & 115,3 & 116,6 & 113,7 & 115,9 & $95,1 \%$ \\
\hline 191 & 05/09/2001 & 12:33:57 & 1,25 & 117,3 & 114,5 & 115,8 & 113,2 & 115,2 & $94,5 \%$ \\
\hline 192 & 05/09/2001 & 12:48:57 & 1,50 & 116,7 & 113,9 & 115,1 & 112,6 & 114,6 & $94,0 \%$ \\
\hline 193 & 05/09/2001 & 13:03:57 & 1,75 & 116,2 & 113,3 & 114,5 & 112,1 & 114,0 & $93,5 \%$ \\
\hline 194 & 05/09/2001 & 13:18:57 & 2,00 & 115,7 & 112,8 & 114,0 & 111,7 & 113,5 & $93,1 \%$ \\
\hline 195 & 05/09/2001 & 13:33:57 & 2,25 & 115,2 & 112,3 & 113,5 & 111,3 & 113,1 & $92,8 \%$ \\
\hline 196 & 05/09/2001 & 13:48:57 & 2,50 & 114,7 & 111,9 & 113,1 & 111,0 & 112,7 & $92,4 \%$ \\
\hline 197 & 05/09/2001 & 14:03:57 & 2,75 & 114,3 & 111,5 & 112,7 & 110,7 & 112,3 & $92,1 \%$ \\
\hline 198 & 05/09/2001 & $14: 15: 29$ & 2,94 & 114,0 & 111,2 & 112,4 & 110,4 & 112,0 & $91,9 \%$ \\
\hline
\end{tabular}


Tabuleiro com barras de $32 \mathrm{~mm}$

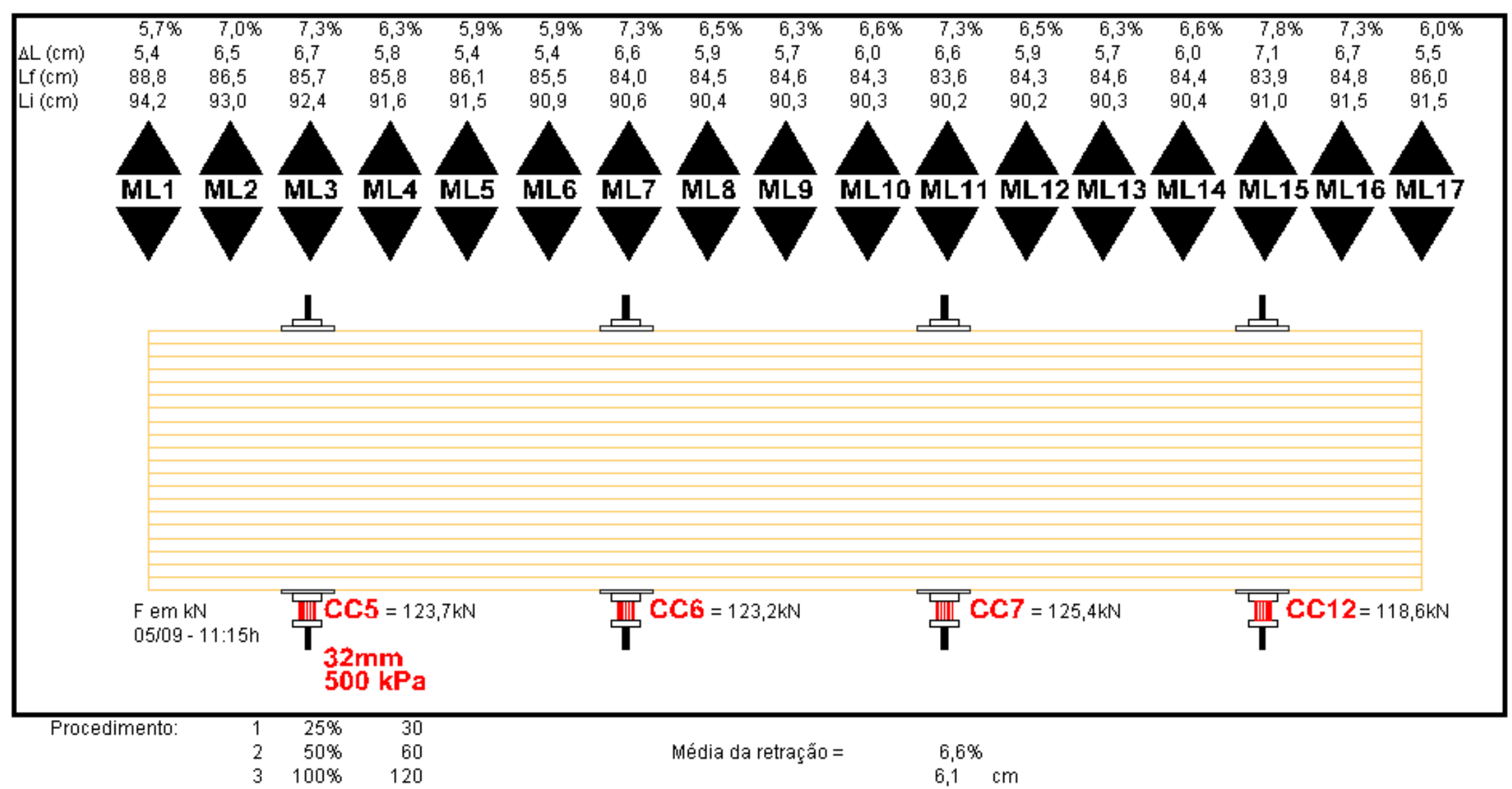




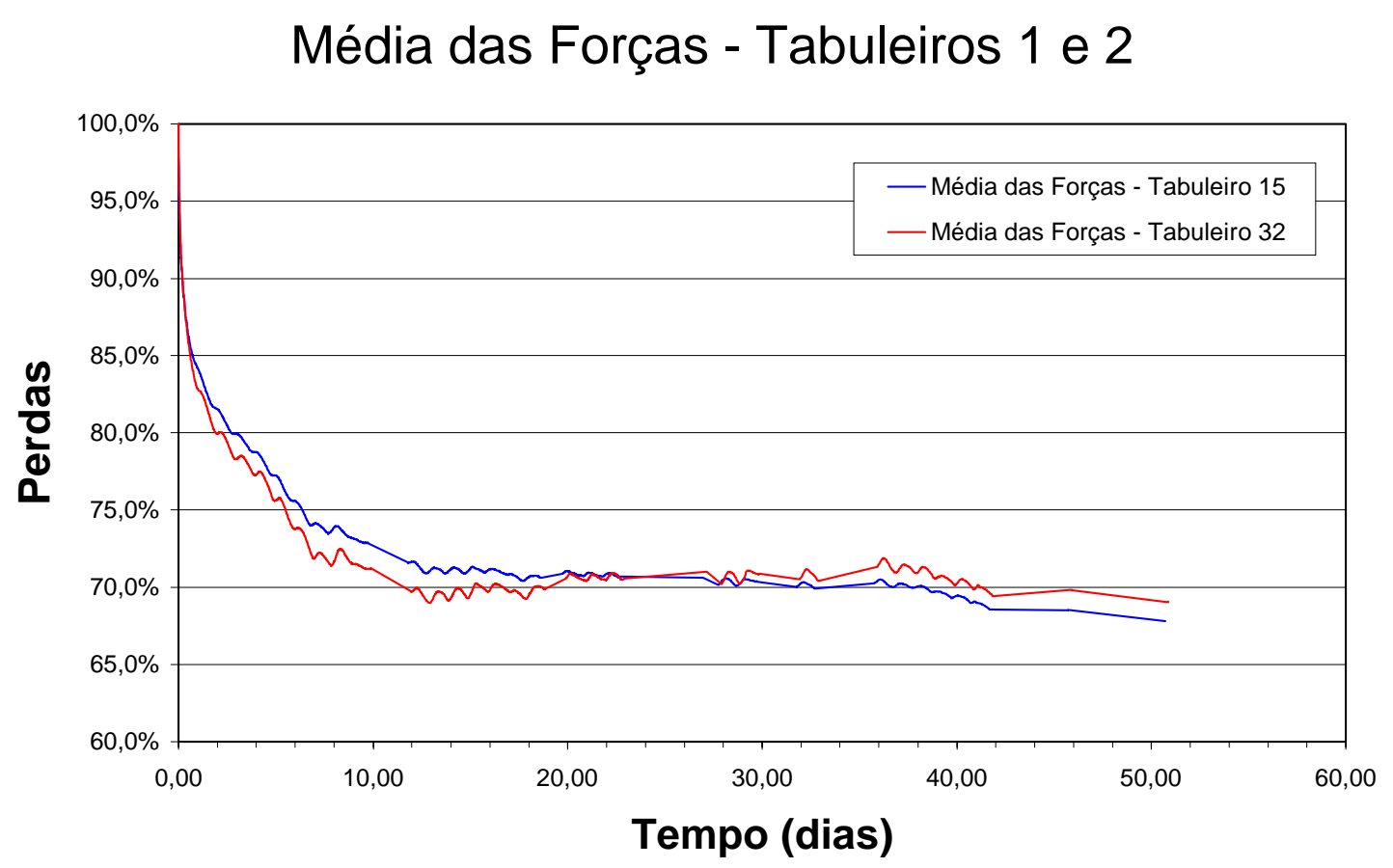

Os valores de deslocamentos transversais imediatos à aplicação da protensão foram de, aproximadamente, $8 \%$. Sugere-se, então, a majoração de $10 \%$ na quantidade de peças necessárias para efetuar uma largura de tabuleiro bem como nos comprimentos das barras de protensão.

O tabuleiro com $\phi$ de $32 \mathrm{~mm}$ perdeu mais no início que o tabuleiro com $\phi$ de $16 \mathrm{~mm}$ mas uma diferença pequena. Por outro lado ele recuperou mais com o aumento de temperatura e umidade ocorrida a partir do $20^{\circ}$ dia.

É importante afirmar que as perdas dos dois tabuleiros foram menores que nos corpos de prova. Este fato é mais relevante porque o nível de protensão aplicado nos tabuleiro foi de apenas $500 \mathrm{kPa}$, em função dos limites da barra de $16 \mathrm{~mm}$. As perdas foram de $30 \%$ no $50^{\circ}$ dia. Ainda assim, os valores foram mais conservadores que os sugeridos pela figura 2.40 . 
4.5 Análise de Perdas de Protensão em Pontes

Foram analisadas duas pontes avaliadas pelo Prof. Carlito Calil Jr. Ambas pertencem ao Estado da Pensilvânia - EUA de diferentes municípios.

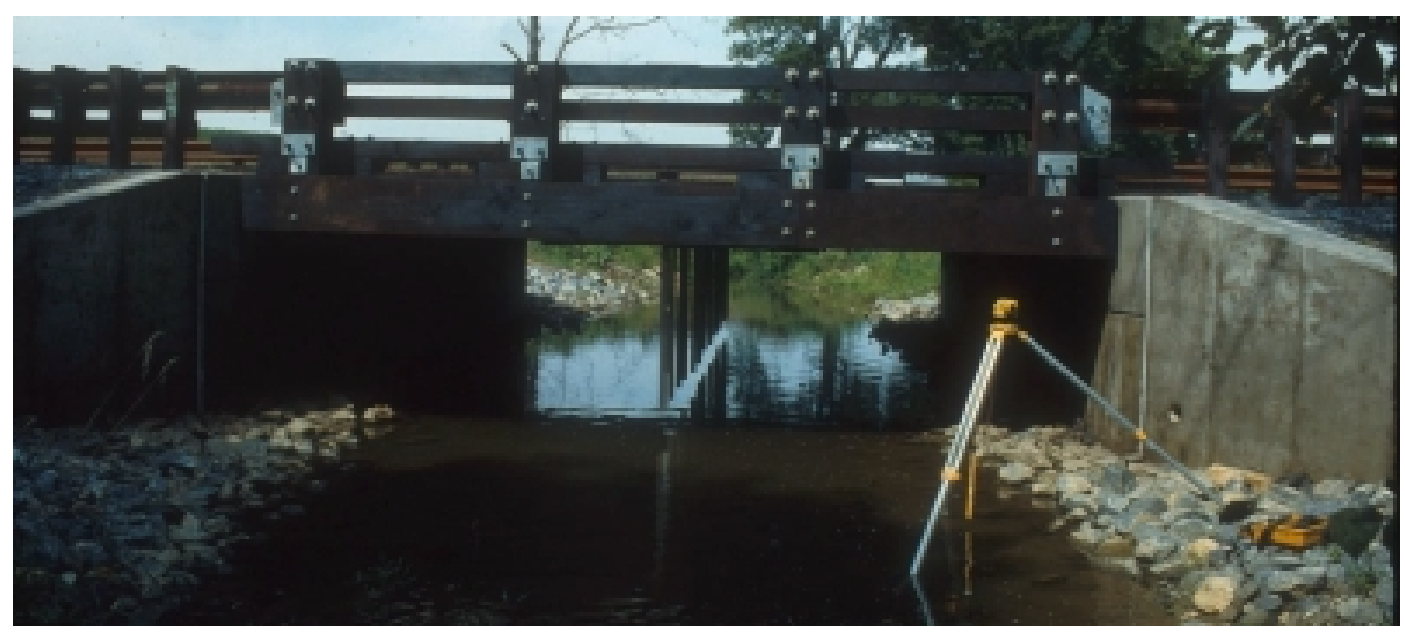

Figura 4.12 - Millcross Road (Red Oak - L= 760cm, B=800cm; h=41cm) - Lancaster (fig. 3.9)

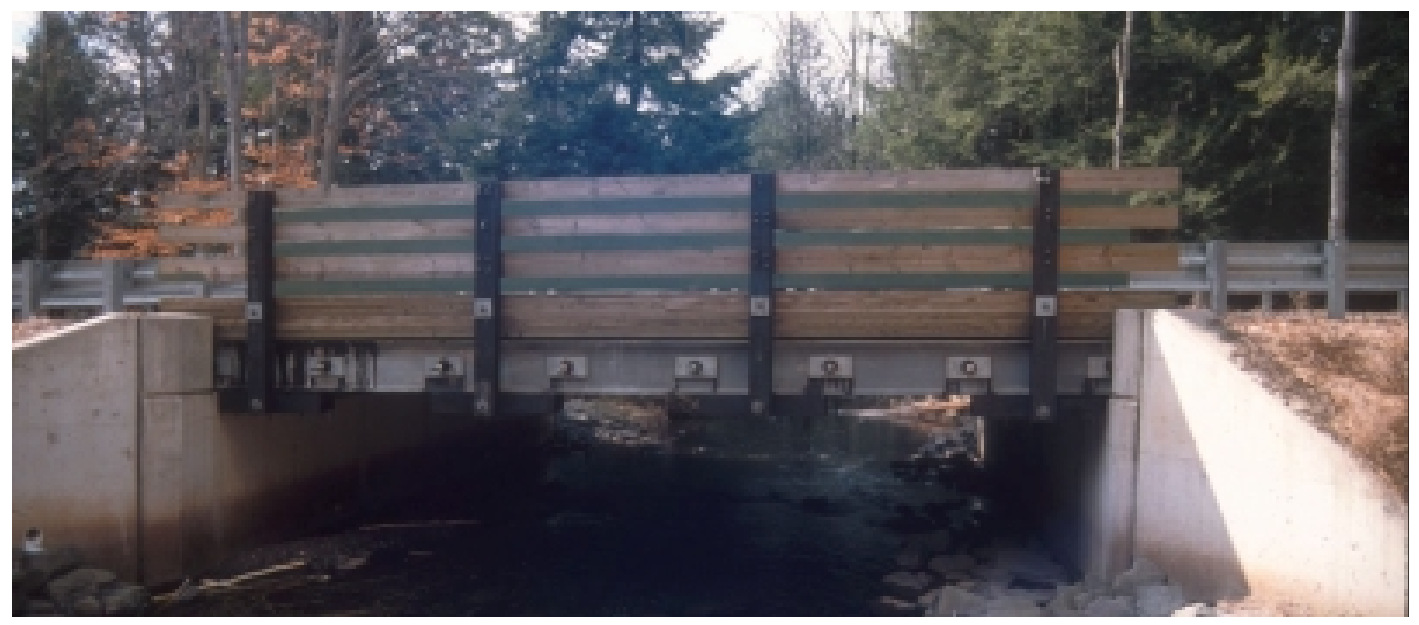

Figura 4.13 - Birch Creek (American Beech - L=640cm, B=980cm; h=41cm) - Sullivan (fig. 3.10)

A seguir estão parte das planilhas de dados e gráficos de perda de carga ao longo do tempo, perdas e a temperatura interna, perdas e umidade relativa, as 24 horas de um dia quente e de um dia frio para cada uma das pontes. 
Ponte Lancaster

\begin{tabular}{|c|c|c|c|c|c|c|c|c|c|}
\hline Tempo & $\begin{array}{c}\text { Temperatura } \\
\text { Externa } \\
\left({ }^{\circ} \mathrm{C}\right)\end{array}$ & $\begin{array}{c}\text { Temperat. } \\
\text { Interna } 1 \\
\left({ }^{\circ} \mathrm{C}\right)\end{array}$ & $\begin{array}{l}\text { Temperat. } \\
\text { Interna } 2 \\
\left({ }^{\circ} \mathrm{C}\right)\end{array}$ & $\begin{array}{l}\text { Temperatura } \\
\text { Interna } \\
\left({ }^{\circ} \mathrm{C}\right)\end{array}$ & $\begin{array}{l}\text { Célula de } \\
\text { Carga } 1 \\
\text { (kN) }\end{array}$ & $\begin{array}{c}\text { Célula de } \\
\text { Carga } 2 \\
(k N)\end{array}$ & $\begin{array}{l}\text { Células de } \\
\text { Carga } \\
\text { (kN) }\end{array}$ & $\begin{array}{c}\text { Células de } \\
\text { Carga } \\
(\%)\end{array}$ & $\begin{array}{c}\text { Umidade } \\
\text { Relativa } \\
\text { (\%) }\end{array}$ \\
\hline 20/08/1997 12:00 & 17,9 & 24,4 & 24,3 & 24,4 & 155,5 & 150,6 & 153,0 & $100,0 \%$ & 0,0 \\
\hline 20/08/1997 14:00 & 17,7 & 24,3 & 24,2 & 24,3 & 154,0 & 149,5 & 151,8 & $99,2 \%$ & 0,0 \\
\hline 20/08/1997 16:00 & 17,5 & 24,1 & 23,9 & 24,0 & 153,0 & 148,7 & 150,9 & $98,6 \%$ & 0,0 \\
\hline 20/08/1997 18:00 & 17,8 & 23,9 & 23,8 & 23,9 & 152,4 & 148,2 & 150,3 & $98,2 \%$ & 0,0 \\
\hline 20/08/1997 20:00 & 18,4 & 23,8 & 23,6 & 23,7 & 151,8 & 147,6 & 149,7 & $97,8 \%$ & 0,0 \\
\hline 20/08/1997 22:00 & 18,4 & 23,7 & 23,6 & 23,6 & 151,4 & 147,3 & 149,3 & $97,6 \%$ & 0,0 \\
\hline 21/08/1997 00:00 & 18,2 & 23,6 & 23,5 & 23,6 & 150,9 & 146,8 & 148,9 & $97,3 \%$ & 0,0 \\
\hline 21/08/1997 02:00 & 18,7 & 23,6 & 23,4 & 23,5 & 150,6 & 146,5 & 148,5 & $97,1 \%$ & 0,0 \\
\hline 21/08/1997 04:00 & 18,0 & 23,4 & 23,4 & 23,4 & 150,2 & 146,1 & 148,1 & $96,8 \%$ & 0,0 \\
\hline 21/08/1997 06:00 & 17,5 & 23,4 & 23,3 & 23,3 & 149,6 & 145,6 & 147,6 & $96,5 \%$ & 0,0 \\
\hline 21/08/1997 08:00 & 17,7 & 23,3 & 23,2 & 23,3 & 149,2 & 145,1 & 147,2 & $96,2 \%$ & 0,0 \\
\hline 21/08/1997 10:00 & 18,5 & 23,1 & 23,1 & 23,1 & 149,2 & 145,1 & 147,2 & $96,2 \%$ & 0,0 \\
\hline 21/08/1997 12:00 & 21,9 & 23,0 & 22,9 & 23,0 & 150,2 & 146,2 & 148,2 & $96,8 \%$ & 0,0 \\
\hline 21/08/1997 14:00 & 24,2 & 22,9 & 22,9 & 22,9 & 152,4 & 148,3 & 150,3 & $98,2 \%$ & 0,0 \\
\hline 21/08/1997 16:00 & 26,2 & 23,1 & 23,2 & 23,2 & 154,9 & 151,2 & 153,1 & $100,0 \%$ & 0,0 \\
\hline 21/08/1997 18:00 & 25,9 & 23,3 & 23,4 & 23,4 & 156,5 & 152,8 & 154,6 & $101,1 \%$ & 0,0 \\
\hline 21/08/1997 20:00 & 23,5 & 23,3 & 23,4 & 23,4 & 156,2 & 152,5 & 154,3 & $100,9 \%$ & 0,0 \\
\hline 21/08/1997 22:00 & 20,3 & 23,5 & 23,6 & 23,5 & 155,4 & 151,8 & 153,6 & $100,4 \%$ & 0,0 \\
\hline 22/08/1997 00:00 & 19,4 & 23,5 & 23,5 & 23,5 & 154,5 & 151,0 & 152,8 & $99,8 \%$ & 0,0 \\
\hline 22/08/1997 02:00 & 17,4 & 23,4 & 23,4 & 23,4 & 153,6 & 150,1 & 151,9 & $99,2 \%$ & 0,0 \\
\hline
\end{tabular}



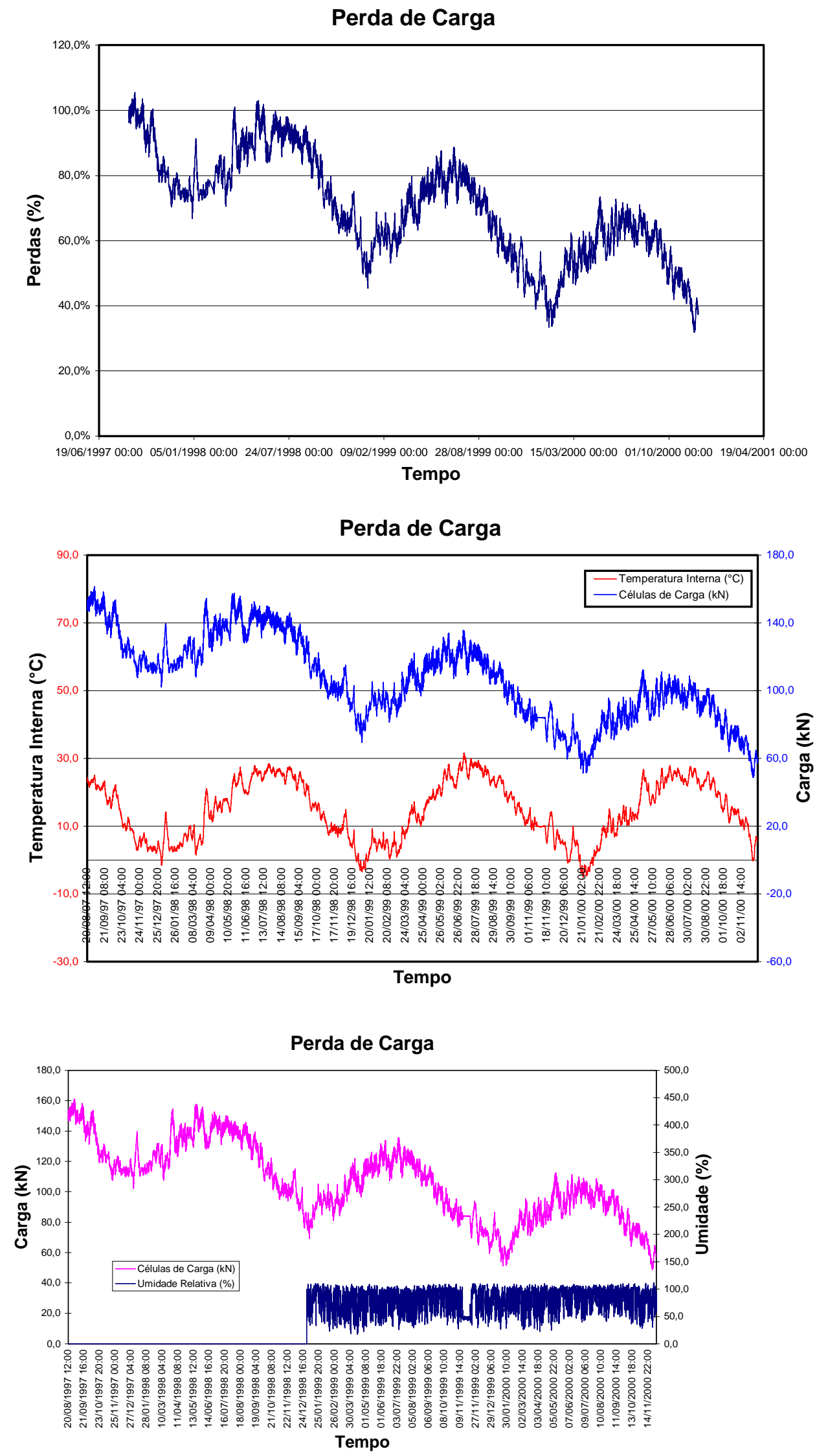
Dia Quente (25/06/2000)

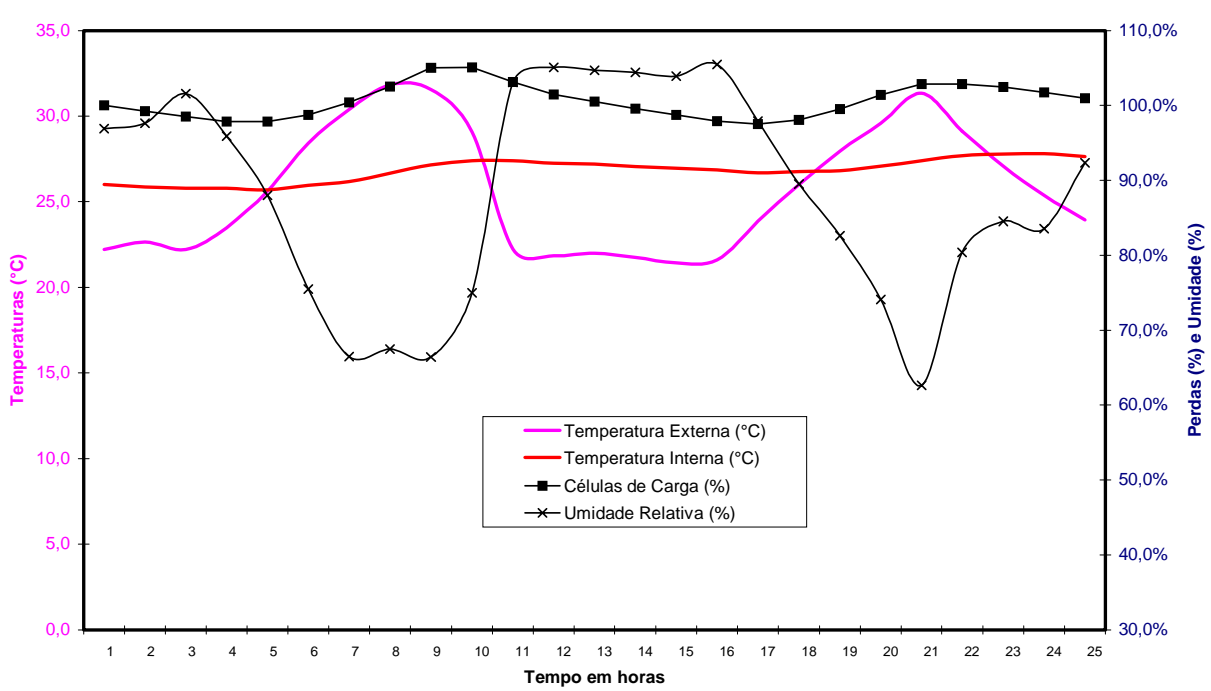

Dia Frio $(24 / 12 / 2000)$

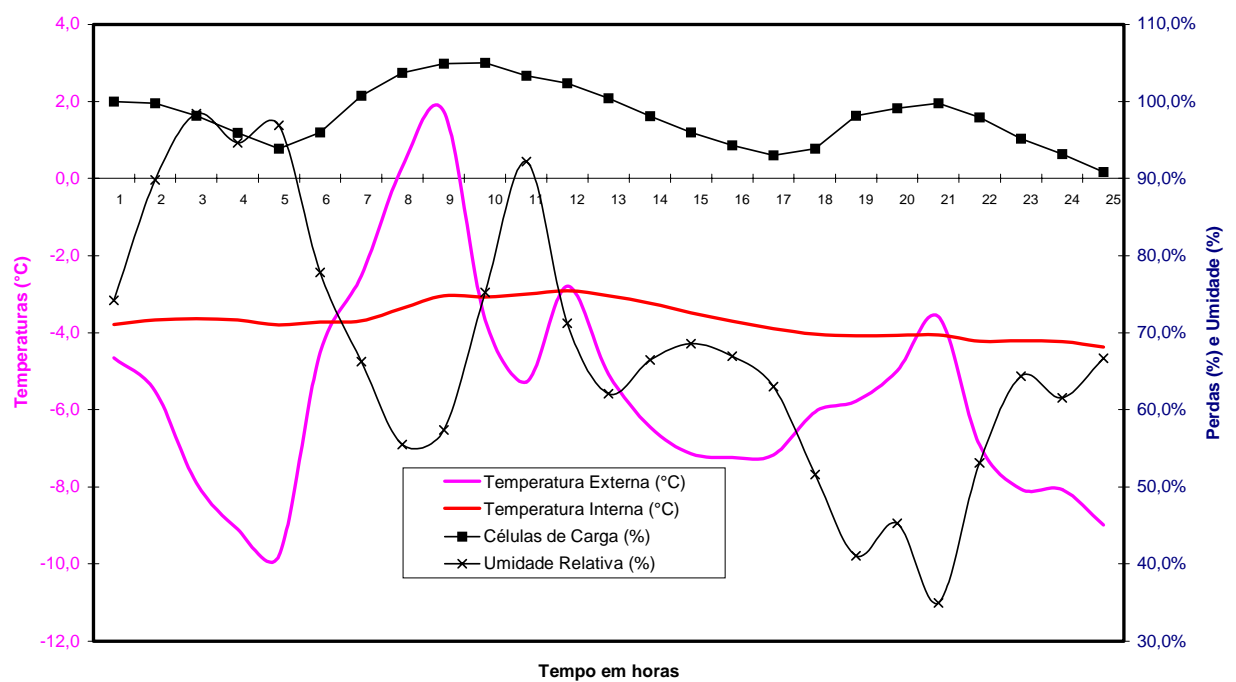


Ponte Sullivan

\begin{tabular}{|c|c|c|c|c|c|c|c|c|c|}
\hline Tempo & $\begin{array}{c}\text { Temperatura } \\
\text { Externa } \\
\left({ }^{\circ} \mathbf{C}\right)\end{array}$ & $\begin{array}{c}\text { Temperatura } \\
\text { Interna } 1 \\
\left({ }^{\circ} \mathrm{C}\right)\end{array}$ & $\begin{array}{c}\text { Temperatura } \\
\text { Interna } 2 \\
\left({ }^{\circ} \mathrm{C}\right)\end{array}$ & $\begin{array}{c}\text { Temperatura } \\
\text { Interna } \\
\left({ }^{\circ} \mathrm{C}\right)\end{array}$ & $\begin{array}{c}\text { Célula de } \\
\text { Carga } 1 \\
\text { (kN) }\end{array}$ & $\begin{array}{c}\text { Célula de } \\
\text { Carga } 2 \\
\text { (kN) }\end{array}$ & $\begin{array}{c}\text { Células de } \\
\text { Carga } \\
\text { (kN) }\end{array}$ & $\begin{array}{c}\text { Células de } \\
\text { Carga } \\
(\%)\end{array}$ & $\begin{array}{c}\text { Umidade } \\
\text { Relativa } \\
\text { (\%) }\end{array}$ \\
\hline 08/08/1997 10:00 & 18,5 & 17,3 & 17,4 & 17,3 & 171,7 & 183,9 & 177,8 & $100,0 \%$ & 0,0 \\
\hline 08/08/1997 12:00 & 21,6 & 17,6 & 17,6 & 17,6 & 173,2 & 185,8 & 179,5 & $101,0 \%$ & 0,0 \\
\hline 08/08/1997 14:00 & 21,1 & 17,9 & 18,0 & 18,0 & 174,6 & 187,6 & 181,1 & $101,9 \%$ & 0,0 \\
\hline 08/08/1997 16:00 & 21,7 & 18,3 & 18,4 & 18,4 & 175,6 & 188,5 & 182,0 & $102,4 \%$ & 0,0 \\
\hline 08/08/1997 18:00 & 20,0 & 18,6 & 18,7 & 18,7 & 176,1 & 189,0 & 182,6 & $102,7 \%$ & 0,0 \\
\hline 08/08/1997 20:00 & 17,9 & 18,8 & 18,9 & 18,9 & 176,0 & 188,8 & 182,4 & $102,6 \%$ & 0,0 \\
\hline 08/08/1997 22:00 & 14,2 & 18,6 & 18,9 & 18,8 & 175,3 & 188,0 & 181,7 & $102,2 \%$ & 0,0 \\
\hline 09/08/1997 00:00 & 12,6 & 18,5 & 18,7 & 18,6 & 174,6 & 187,1 & 180,8 & $101,7 \%$ & 0,0 \\
\hline 09/08/1997 02:00 & 11,6 & 18,1 & 18,4 & 18,3 & 173,8 & 186,2 & 180,0 & $101,2 \%$ & 0,0 \\
\hline 09/08/1997 04:00 & 10,6 & 17,8 & 18,0 & 17,9 & 172,9 & 185,2 & 179,1 & $100,7 \%$ & 0,0 \\
\hline 09/08/1997 06:00 & 9,6 & 17,4 & 17,7 & 17,6 & 172,1 & 184,2 & 178,2 & $100,2 \%$ & 0,0 \\
\hline 09/08/1997 08:00 & 12,3 & 17,2 & 17,5 & 17,4 & 171,7 & 183,8 & 177,7 & $99,9 \%$ & 0,0 \\
\hline 09/08/1997 10:00 & 19,3 & 17,6 & 17,7 & 17,7 & 172,4 & 184,7 & 178,6 & $100,4 \%$ & 0,0 \\
\hline 09/08/1997 12:00 & 22,8 & 18,1 & 18,1 & 18,1 & 173,8 & 186,7 & 180,3 & $101,4 \%$ & 0,0 \\
\hline 09/08/1997 14:00 & 24,2 & 18,7 & 18,6 & 18,6 & 175,8 & 189,2 & 182,5 & $102,6 \%$ & 0,0 \\
\hline 09/08/1997 16:00 & 24,4 & 19,3 & 19,3 & 19,3 & 177,3 & 190,7 & 184,0 & $103,5 \%$ & 0,0 \\
\hline 09/08/1997 18:00 & 23,6 & 19,5 & 19,7 & 19,6 & 177,7 & 190,9 & 184,3 & $103,6 \%$ & 0,0 \\
\hline 09/08/1997 20:00 & 19,7 & 19,7 & 20,0 & 19,8 & 177,4 & 190,5 & 184,0 & $103,5 \%$ & 0,0 \\
\hline 09/08/1997 22:00 & 16,0 & 19,6 & 19,9 & 19,7 & 176,7 & 189,6 & 183,2 & $103,0 \%$ & 0,0 \\
\hline 10/08/1997 00:00 & 14,5 & 19,3 & 19,6 & 19,5 & 175,8 & 188,4 & 182,1 & $102,4 \%$ & 0,0 \\
\hline
\end{tabular}



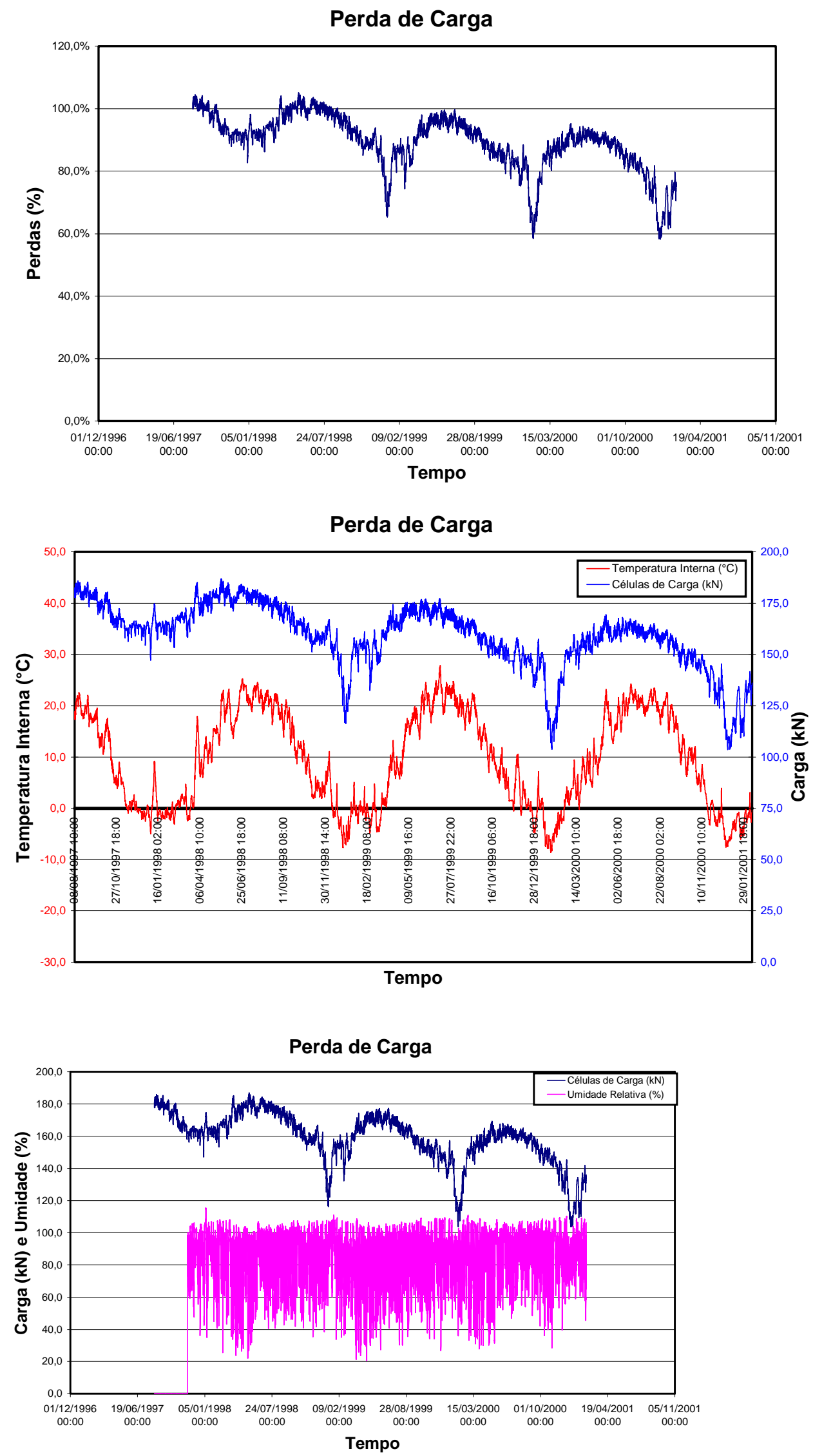
Dia Quente (25/06/1998)

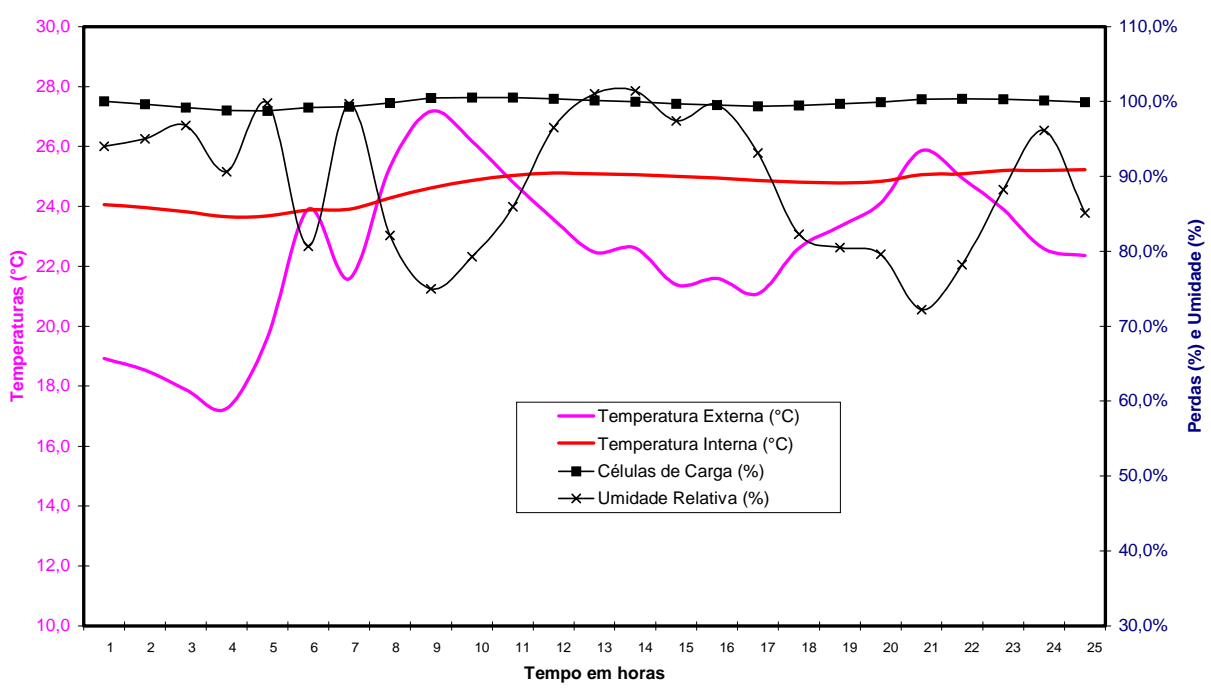

Dia Frio (22/12/1997)

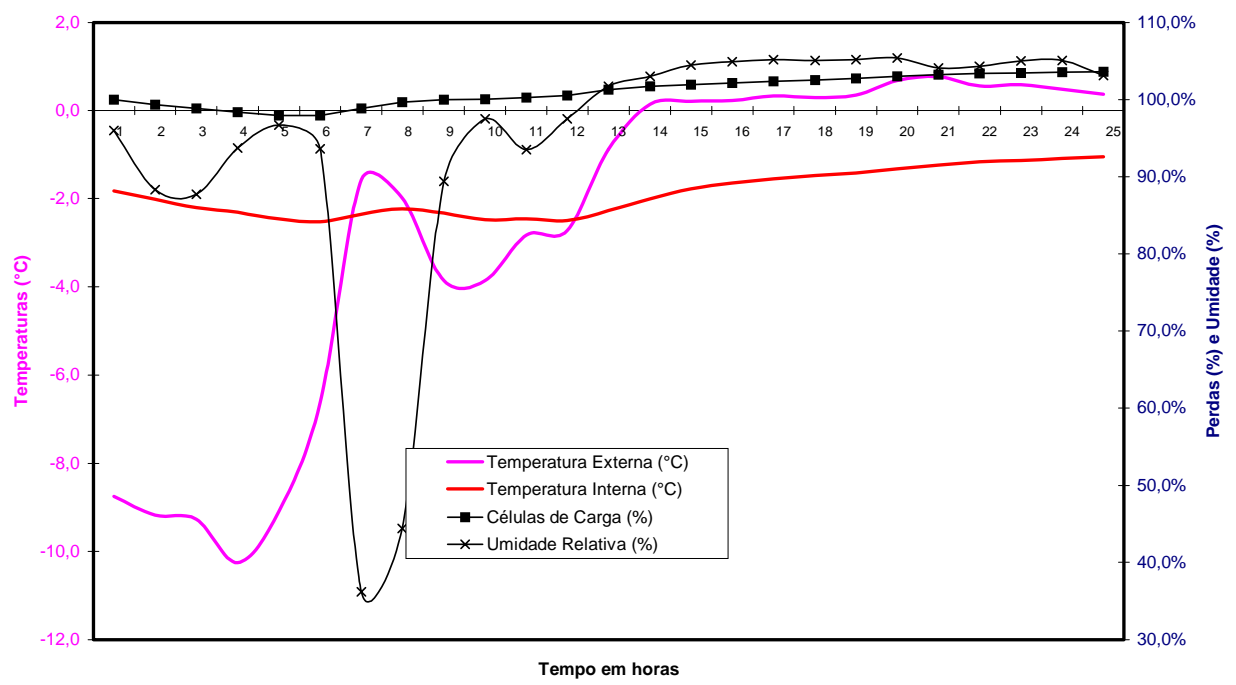

Foram realizadas provas de carga nas duas pontes e obtidos deslocamentos em vários pontos de suas seções centrais. Estudos destas provas de carga encontram-se no item 4.8 , adiante.

As pontes de Lancaster e Sullivan foram avaliadas por aproximadamente 3,5 anos com leituras de carga, temperatura externa, temperatura interna e 
umidade relativa do ar, de duas em duas horas permitindo visualização ao longo de todo o tempo bem como variações diárias.

No tabuleiro da ponte de Lancaster as perdas foram de $60 \%$ enquanto no de Sullivan foi apenas de $30 \%$. Como ambas foram construídas com hardwoods (apesar de diferentes espécies, elas possuem características muito próximas.) e ambas foram submetidas às mesmas condições climáticas, as diferenças nas perdas se devem a outros fatores.

Em primeiro lugar o nível de protensão inicial de Sullivan foi de $500 \mathrm{kPa}$ contra apenas $300 \mathrm{kPa}$ de Lancaster. As barras são de mesmo diâmetro $(25 \mathrm{~mm})$ o que faz com que as tensões nelas sejam, ambas, baixas.

Outro fator importante foi a utilização das pontes. Enquanto o tráfego da ponte de Lancaster é alto na de Sullivan é baixo.

Os espaçamentos entre barras e os níveis de tensão nas barras não devem influenciar muito já que a ancoragem em ambas as pontes utilizou-se de perfís metálicos $U$ nas extremidades. Esta utilização faz com que, em ambos os casos, a distribuição dos níveis de tensão sejam imediatos, minimizando, assim, efeitos do número de barras e da tensão nela. 
4.6 Programa de Projeto e Dimensionamento - PPM v3.0

O PPM v. 3.0 foi desenvolvido para integrar este trabalho de doutoramento em engenharia de estruturas, orientado pelo Prof. Dr Carlito Calil Junior, o qual utiliza a ferramenta de programação Delphi, para a plataforma Windows 95 ou superior. Houve a participação do aluno Ricardo C. Stamato, da área da Ciência da Computação, através de Iniciação Científica para a realização deste programa computacional.

O programa utiliza o critério de dimensionamento para pontes protendidas de madeira cujas diretrizes foram estudadas e sugeridas por OKIMOTO, F.S. (1997). As diretrizes são discriminadas a seguir e podem ser estudadas com mais detalhes em OKIMOTO, F.S. \& CALIL JR, C. (1998) com exemplos de aplicação ou na seção de ajuda do próprio programa PPM v. 3.0.
A) Definir a geometria e a classe da ponte
B) Definir a classe de resistência da madeira
C) Definir a configuração do tabuleiro
D) Calcular a largura efetiva $\left(D_{w}\right)$ de distribuição da carga
E) Estimar a altura do tabuleiro e calcular as propriedades efetivas da seção transversal

F) Calcular as ações permanentes e as solicitações na viga de seção $D_{w} x h$

G) Calcular as ações variáveis e as solicitações na viga de seção $D_{w} \times h$

H) Verificar os estados limites últimos para combinações dos efeitos verticais

I) Calcular o deslocamento para as ações permanentes e impor uma contraflecha, se possível.

J) Calcular os deslocamentos para as ações variáveis

K) Verificar os estados limites de utilização (deslocamentos)

L) Determinar o espaçamento das barras de protensão e a força necessária nos elementos

M) Projetar o sistema de ancoragem

N) Projetar a configuração dos apoios

O) Detalhar o projeto 
As características principais do PPM V. 3.0 são a facilidade de utilização e a grande quantidade de informações técnicas, de procedimento e de controle inseridas na seção Ajuda e nas próprias telas. A estrutura do PPM V. 3.0 baseia-se na existência de uma única tela de entrada de dados e outra de saída de resultados com o intuito de concentrar as decisões de projetos. Possui, ainda, telas adicionais de fabricação e montagem da estrutura (informativas), de detalhamento e lista de materiais (resultados) e outra que presta serviços como esclarecimentos adicionais e endereços de contato dos autores. $\mathrm{O}$ arquivo de ajuda PPM.hlp tem o intuito de orientar o usuário com informações técnicas, científica e de procedimento com seus quatro itens: Manual do Usuário, Conceitos e Aplicações, Critério de Dimensionamento e Bibliografia Recomendada. Na figura 4.14, apresentase a estrutura do PPM V. 3.0 e a tela Sobre o PPM.

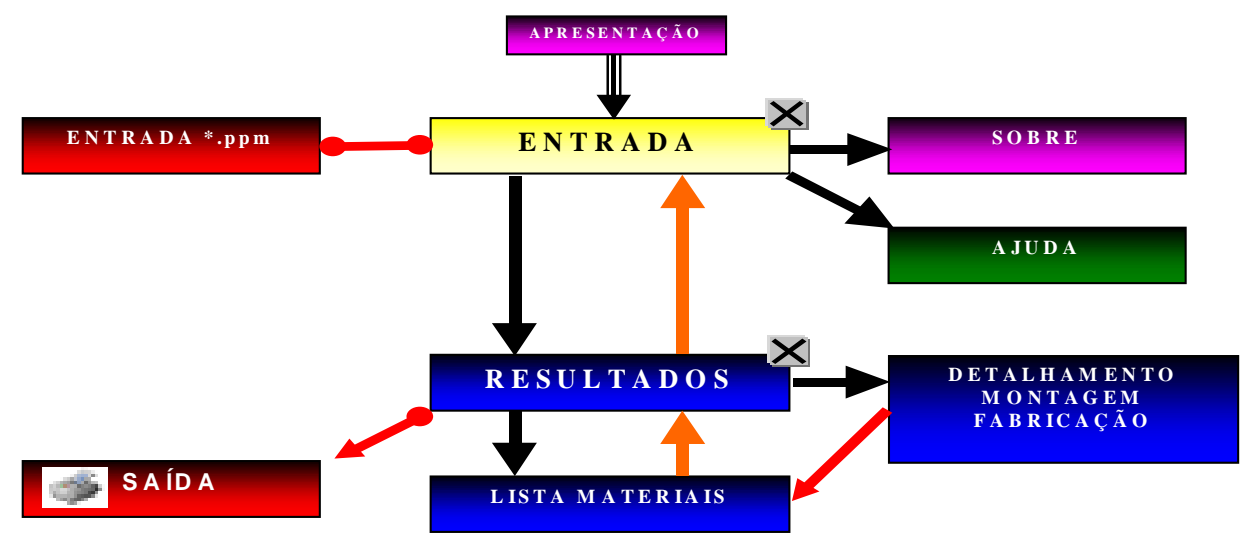

Figura 4.14a - Estrutura do PPM V. 3.0

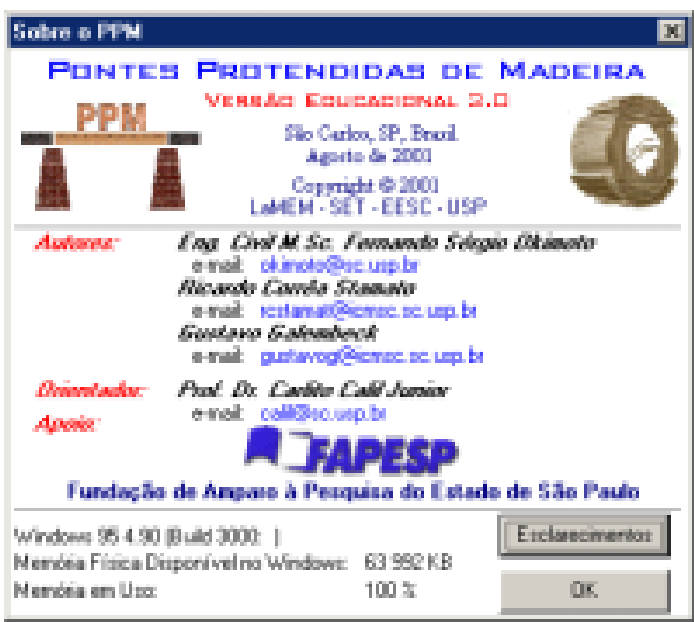

Figura 4.14b - Sobre o PPM Ed 1.0

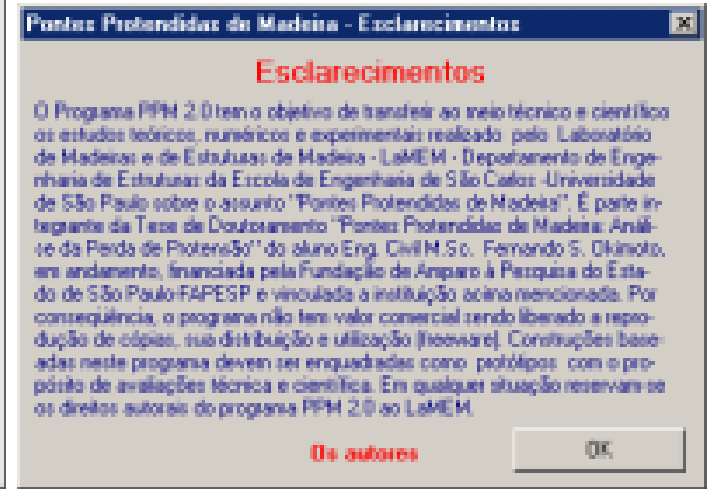

Figura 4.14c - Esclarecimentos 
O programa PPM V. 3.0 possui uma tela única de entrada de dados. Praticamente todos os dados são escolhidos a partir de uma barra de opções que por um lado restringe a aplicabilidade do sistema mas ao mesmo tempo orienta para as opções mais correntes de sua utilização. Possui menu de comandos e barras de ferramentas que possibilitam criar, abrir e salvar arquivos de dados para futuras referências, alterar parâmetros internos, documentação técnica completa e dicas de utilização do programa.

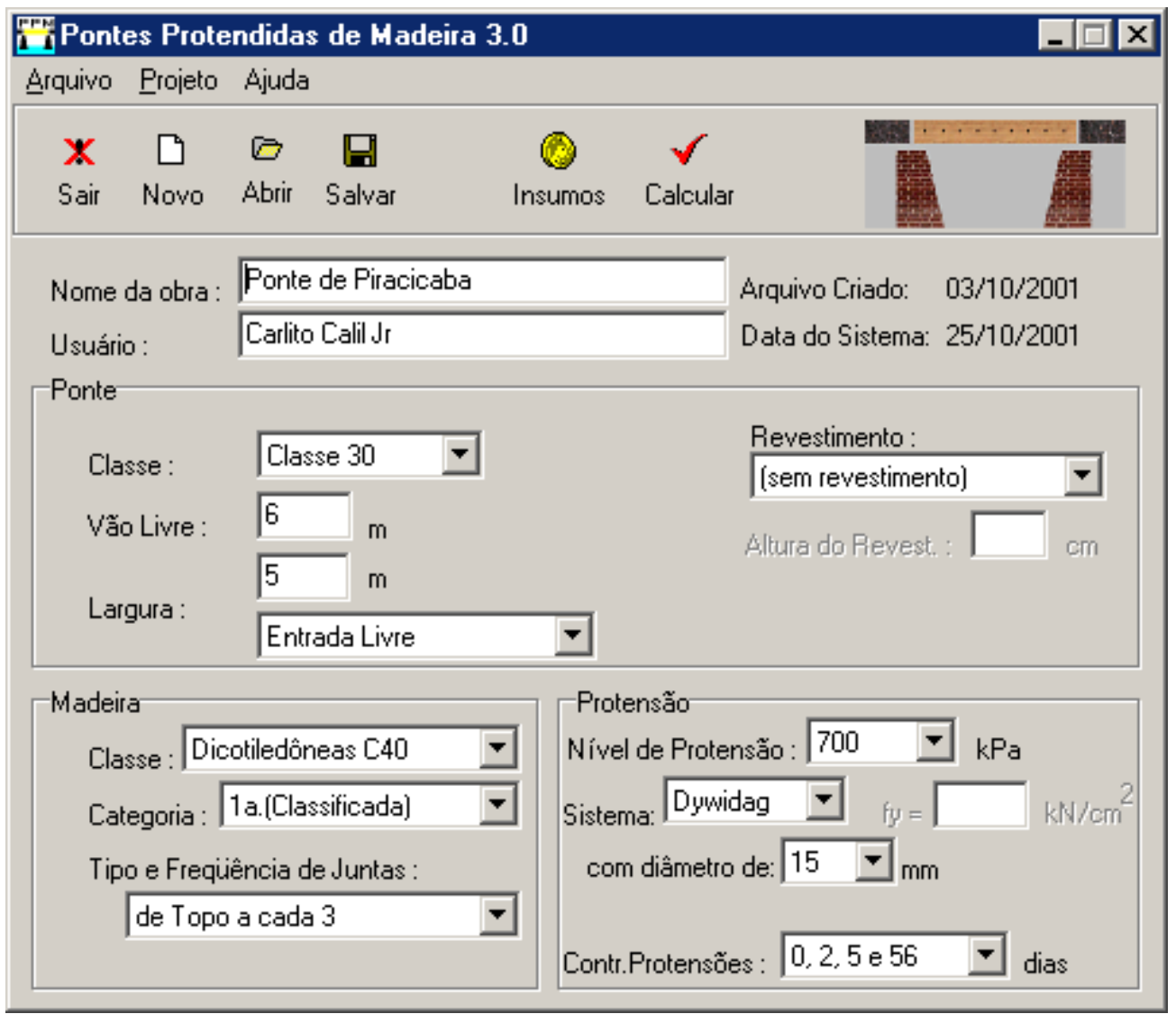

Figura 4.15 - Tela de Entrada do PPM V. 3.0

O programa PPM V. 3.0 possui, também, uma tela única de resultados com os principais elementos do projeto possibilitando ao usuário a verificação de viabilidade técnica e econômica do projeto. A interatividade com a tela de entrada possibilita testes de diferentes decisões de projeto. Deste ponto pode-se imprimir os principais dados e resultados do projeto bem como visualizar telas quantitativas dos materiais (figura 4.19) e qualitativas de detalhes de projeto, fabricação e montagem (figuras 4.17 e 4.18 ) de estruturas de pontes de madeira com o sistema protendido. 


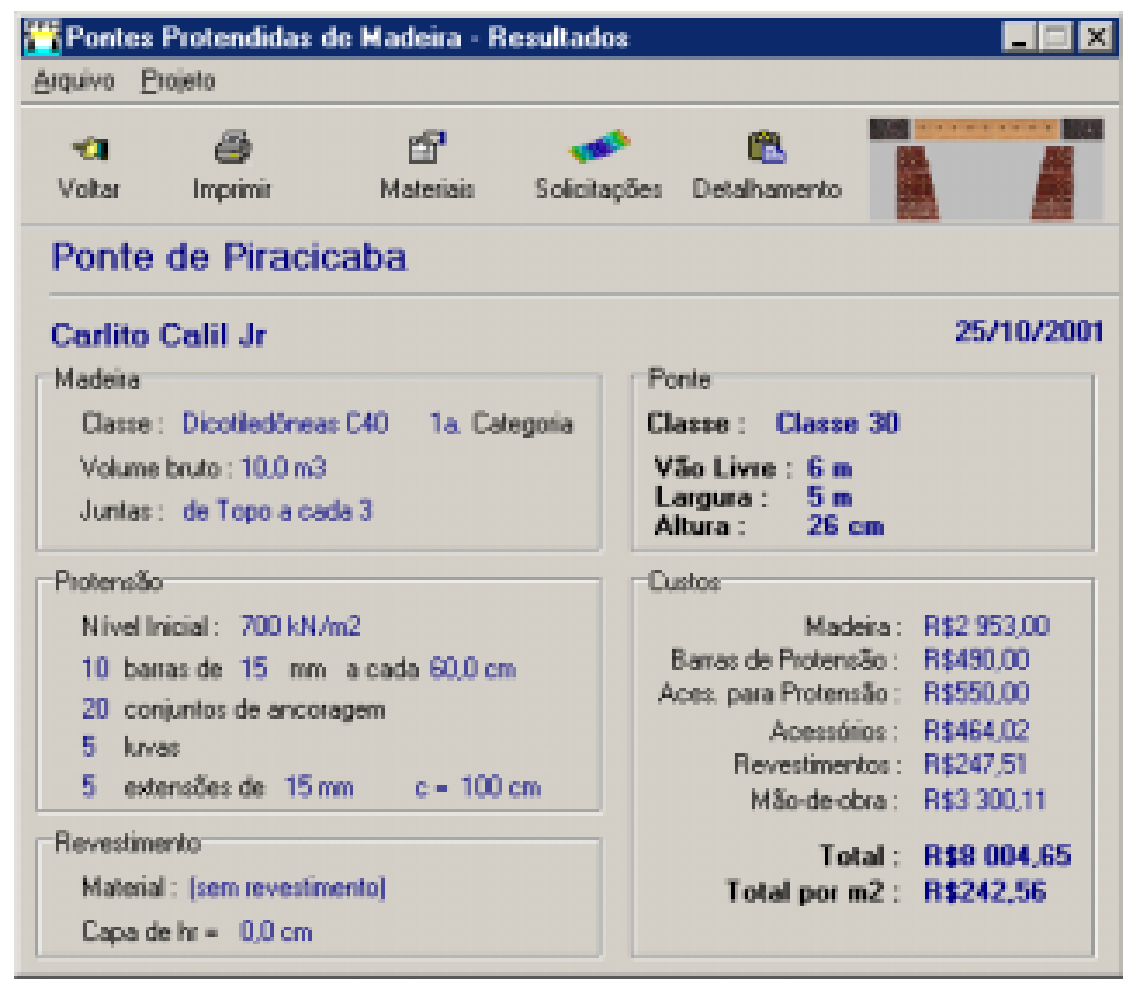

Figura 4.16 - Tela de Resultados do PPM V. 3.0

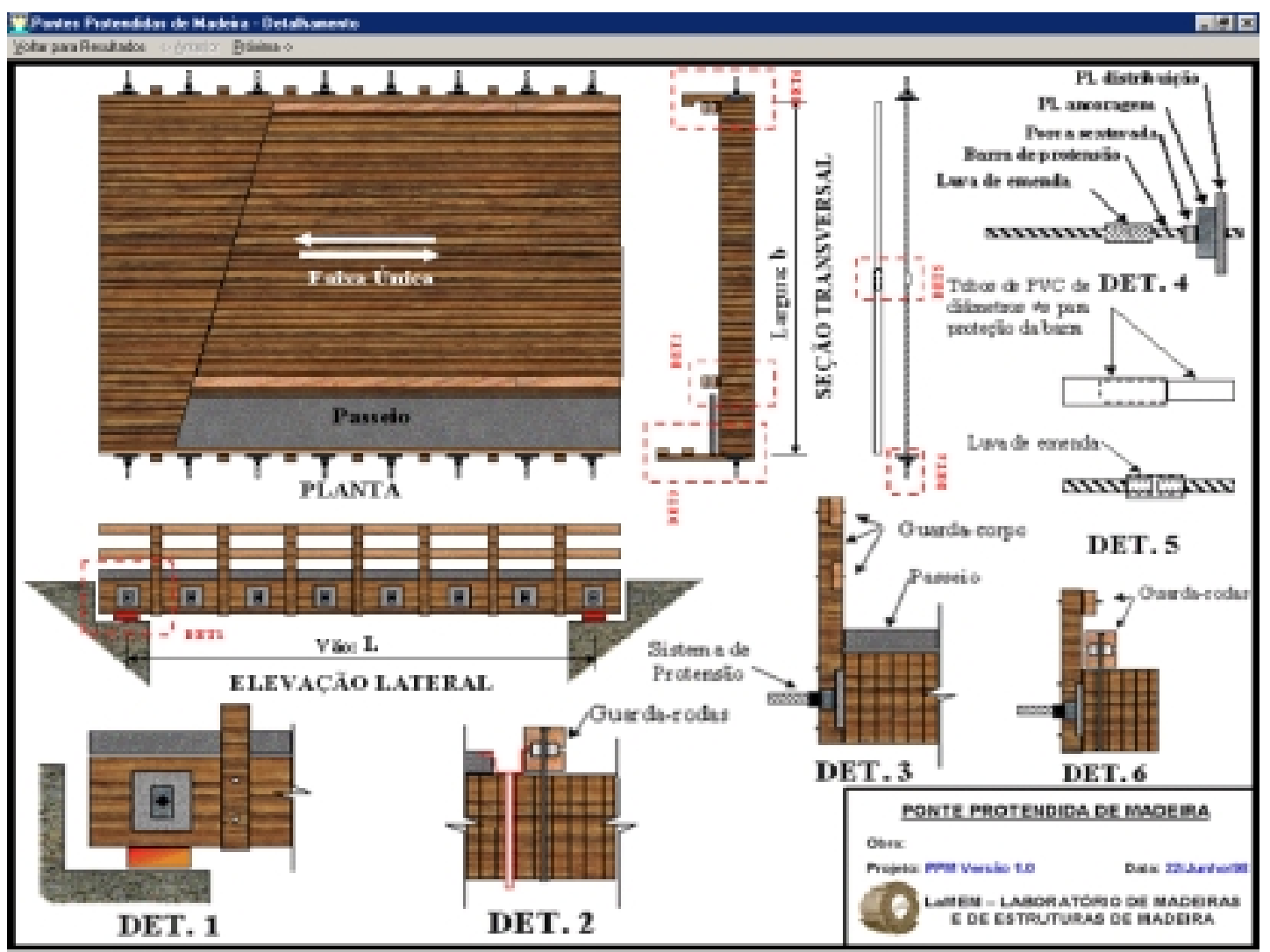

Figura 4.17 - Tela 1 de Detalhamento do PPM V. 3.0 


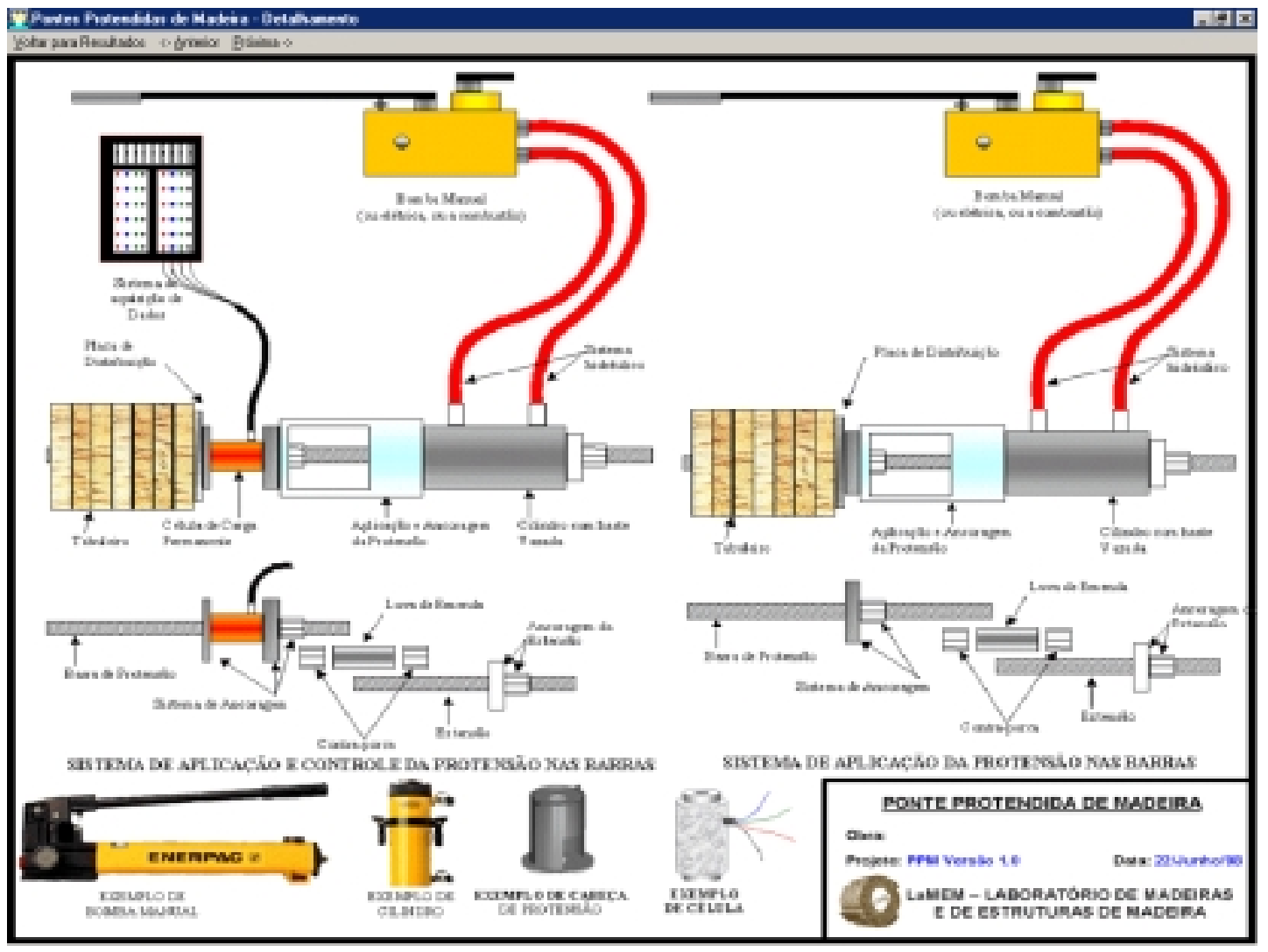

Figura 4.18 - Tela 3 de Detalhamento do PPM V. 3.0

As páginas 154 e 155 são criadas em um arquivo e impressas pelo PPM v. 3.0. foi utilizado um exemplo qualquer que nada diz respeito às análise realizadas aqui. 


\title{
Pontes Protendidas de Madeira
}

\author{
versão educacional 3.0
}

\section{LaMEM - SET - EESC - USP}

\author{
Projeto: Ponte de Piracicaba \\ Usuário: Carlito Calil Jr \\ Data: 03/10/2001
}

\section{Dados e Resultados}

1. Do Projeto

\section{Ponte:}

Classe: Classe 30

Vão livre $=6,00 \mathrm{~m}$

Comprimento total do tabuleiro $=6,60 \mathrm{~m}$

Largura $=5,00 \mathrm{~m}$

Número de faixas $=1$

Número de passeios $=1$

Altura $=26 \mathrm{~cm}$

Nível de Protensão de Projeto $=700 \mathrm{kN} / \mathrm{m} 2$

Nível de Protensão Inicial $=875$ kN/m2

Tipo de Revestimento:

Sobrecarga $=2,00 \mathrm{kN} / \mathrm{m} 2$

Sem Revestimento

1 Passeio em Concreto Armado com $\mathrm{h}=7.5 \mathrm{~cm}$

Volume de 1,24 m3

Juntas: de Topo a cada 3

Coeficiente $\mathrm{Cbj}=0,78$

Comprimento de Apoio $L p=20 \mathrm{~cm}$

Proteção: Madeira tratada com Creosoto

Solicitações:

Reações Rg,k $=20 \mathrm{kN}$

Reações (envoltória) Rq,k = 114 kN

Cortante Vg,k $=20 \mathrm{kN}$

Cortante (envoltória) Vq,k $=114 \mathrm{kN}$

Momentos Mg,k = $2998 \mathrm{kN} . \mathrm{cm}$

Momentos (envoltória) Mq,k $=15000$ kN.cm

Deslocamentos $\delta$ gmáx $=-0,5 \mathrm{~cm}$

Deslocamentos (envoltória) $\delta q m a ́ x=-2,3 \mathrm{~cm}$

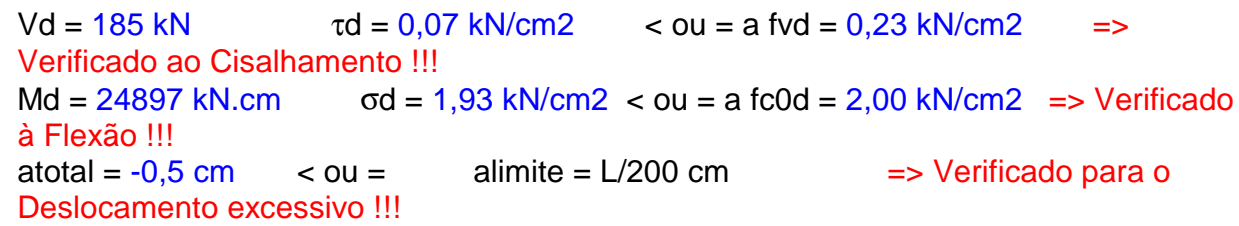




\section{Da Madeira}

Umidade: $\quad$ Estável em 12\% (Padrão NBR 7190/97)

Classe: Dicotiledôneas C40

Volume Bruto: $8,58 \mathrm{~m} 3$

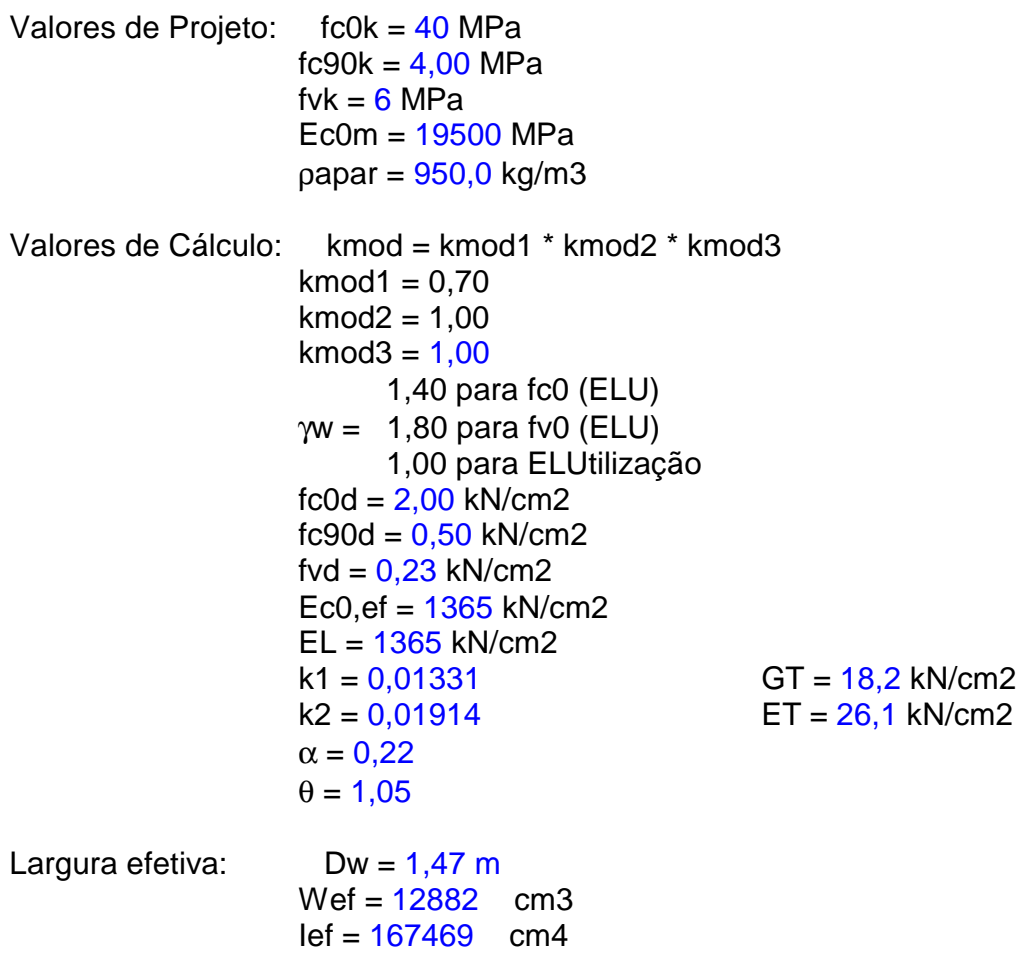

3. Do Sistema de Protensão

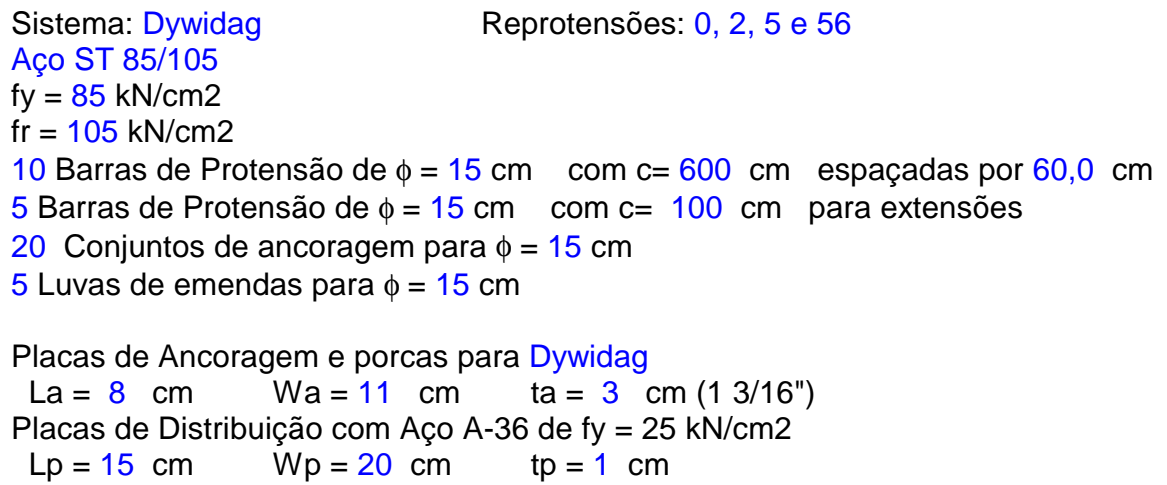

4. Custos

Madeira:

RS 2953,00

Acess. para protensão: RS 550,00

Acessórios: RS 464,02

Revestimentos: RS 247,51

Mão de Obra: $\quad$ RS 3300,11

TOTAL: $\quad$ RS 8004,65

RS 242,56 por m2 


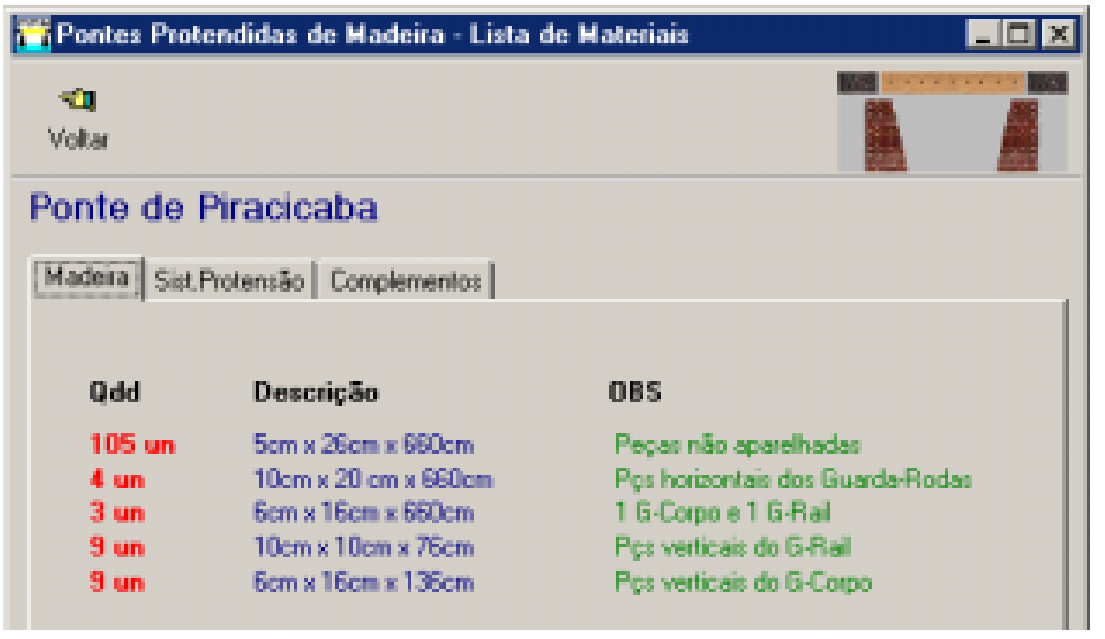

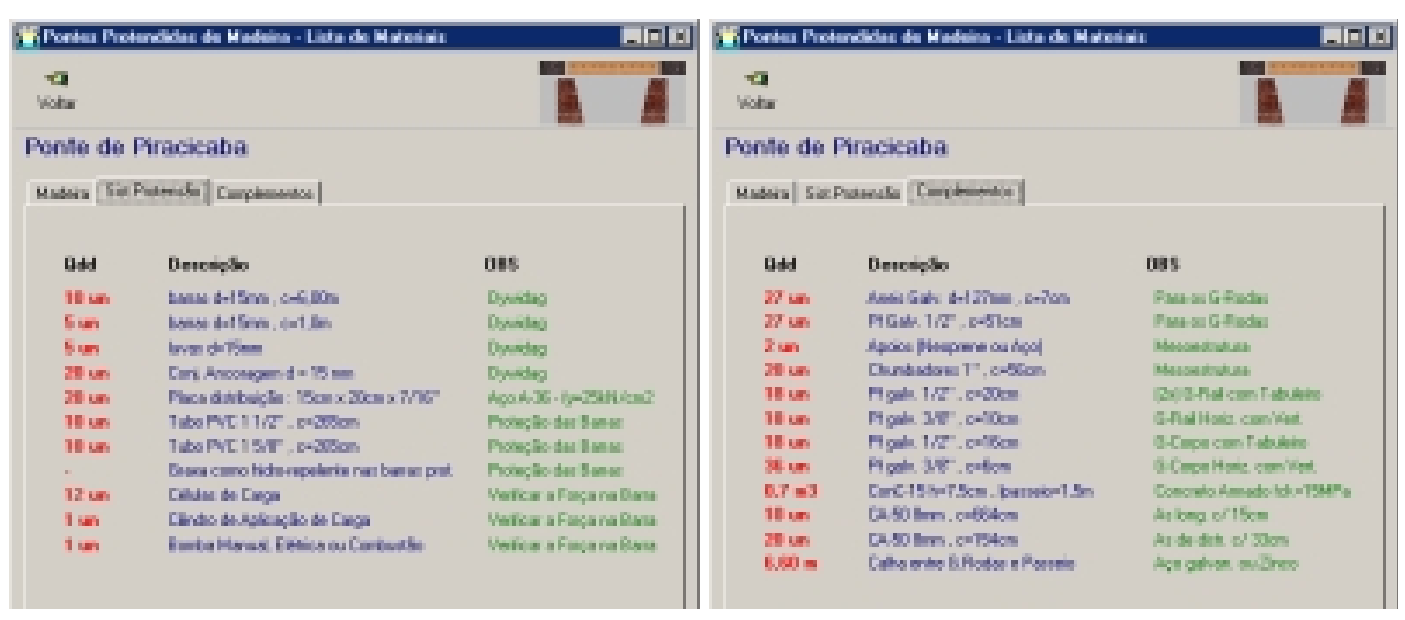

Figura 4.19 - Telas da Lista de Materiais do PPM V. 3.0

Atenção especial deve ser dada ao arquivo de ajuda do PPM. O arquivo PPM.hlp possui uma documentação extensa sobre o tema "Pontes Protendidas de Madeira" (figuras 4.20, 4.21 e 4.22).

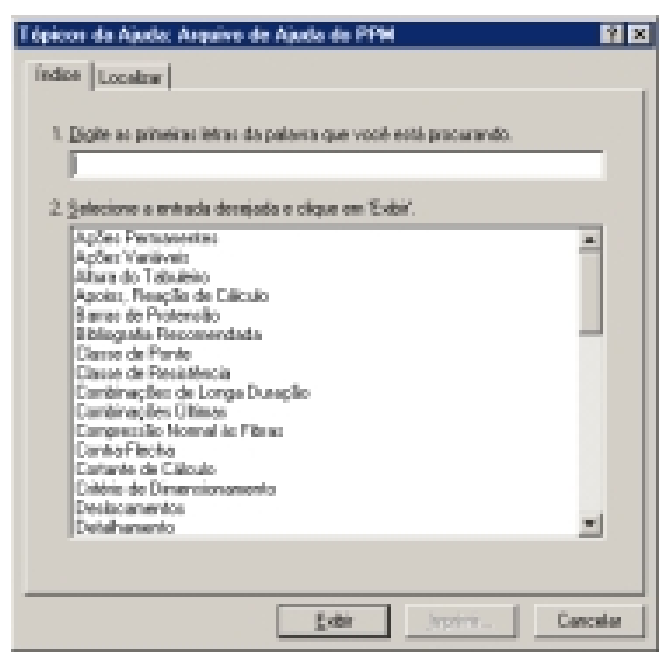

Figura 4.20 - Tópicos da Ajuda do PPM V. 3.0: - Índice 


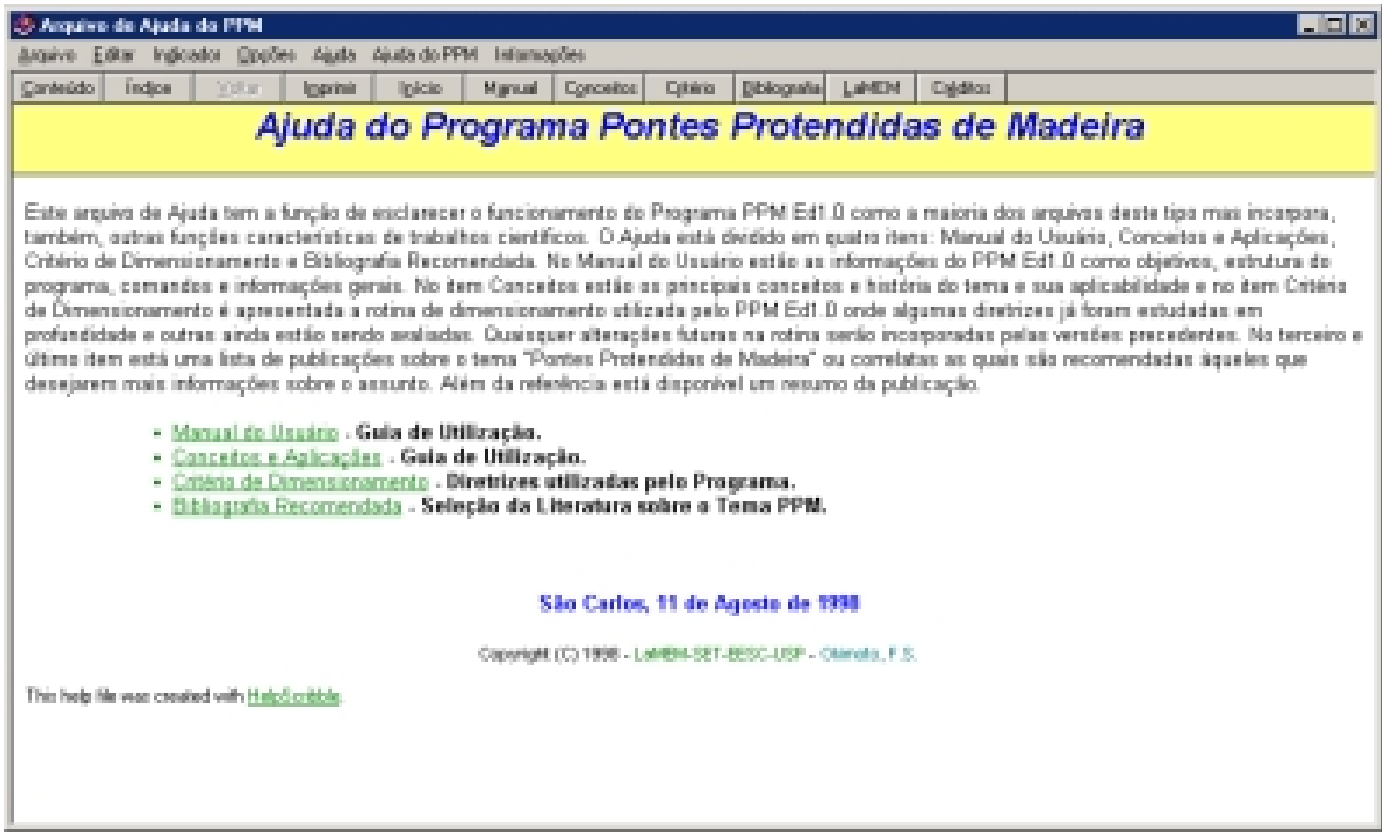

Figura 4.21 - Tela Inicial do arquivo de Ajuda do PPM V. 3.0

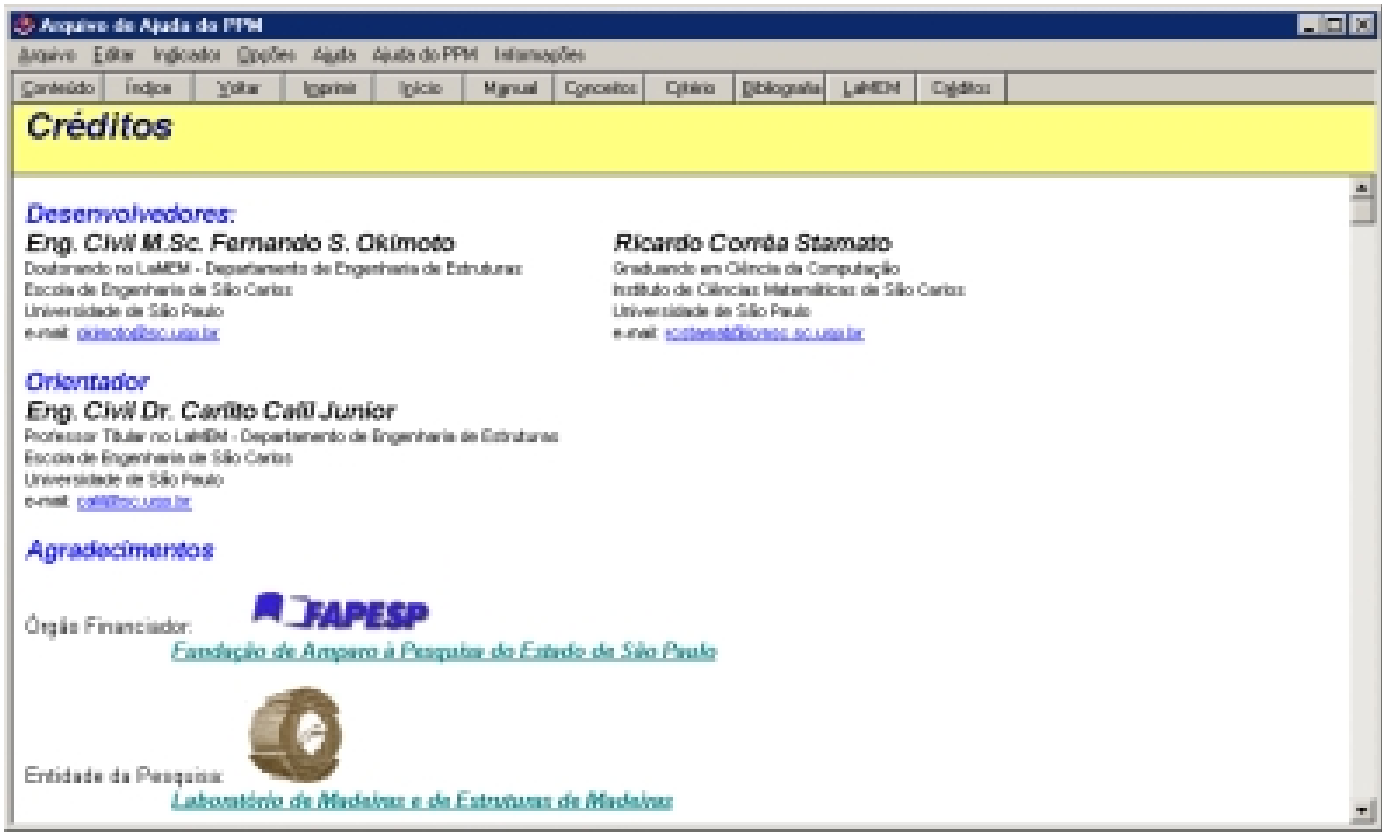

Figura 4.22 - Tela de Créditos do arquivo de Ajuda do PPM V. 3.0

Assim como as publicações eletrônicas têm se afirmado como um dos veículos de transferência de informação sem limitações geográficas, o PPM V. 3.0 deverá se mostrar um eficiente veículo de transferência das informações adquiridas pelas pesquisas deste tema ao ser distribuído para pesquisadores da área ou obtido na página WWW do LaMEM. 
No programa PPM v. 3.0 foi integrado o software AEP v. 1.0.

Apresentaremos, aqui, apenas a tela principal (figura 4.23) que foi alterada para permitir a aplicação de cargas através de veículos (figura 4.24)

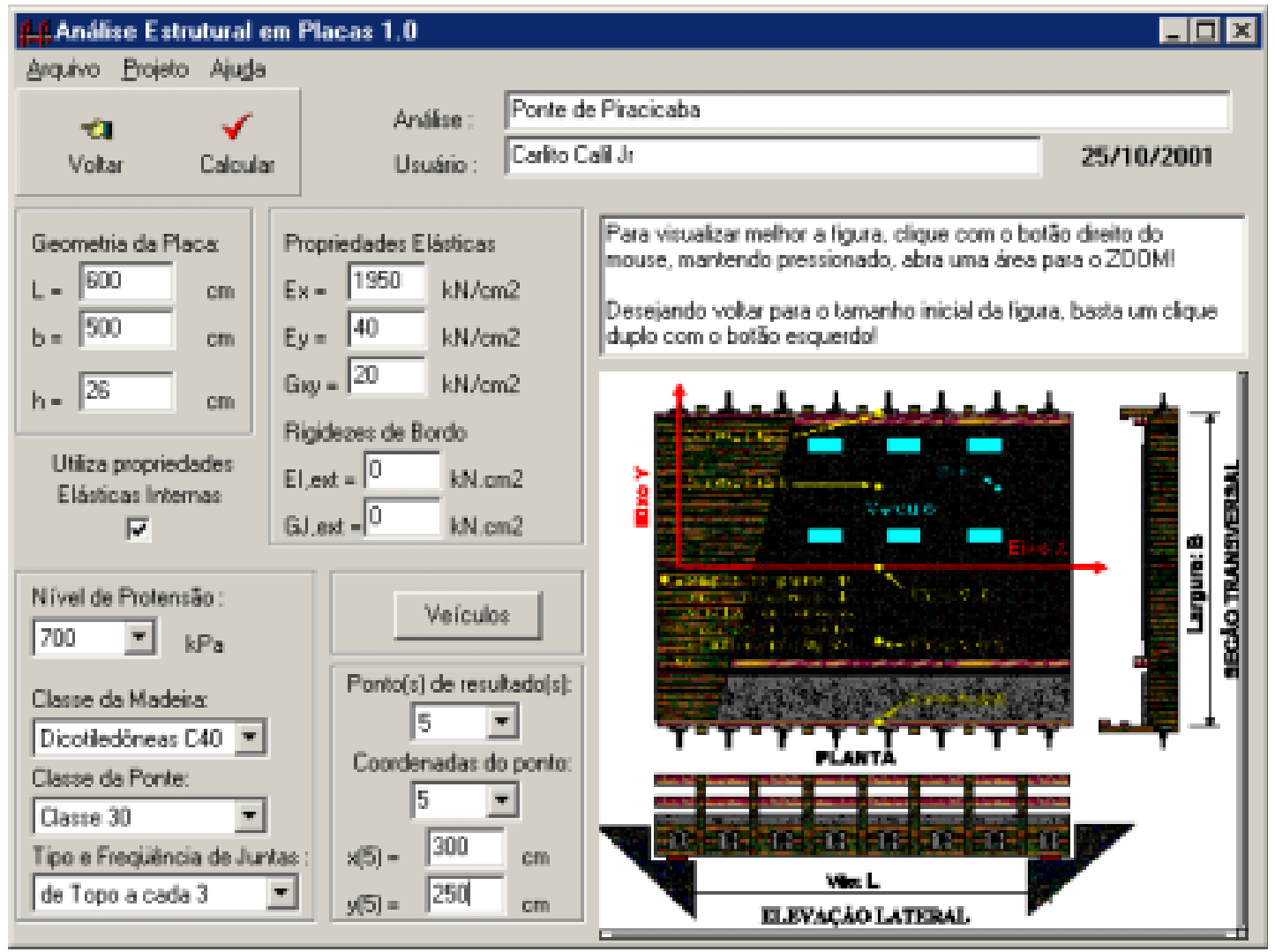

Figura 4.23 - Tela Principal do AEP v. 1.0 - Integrado

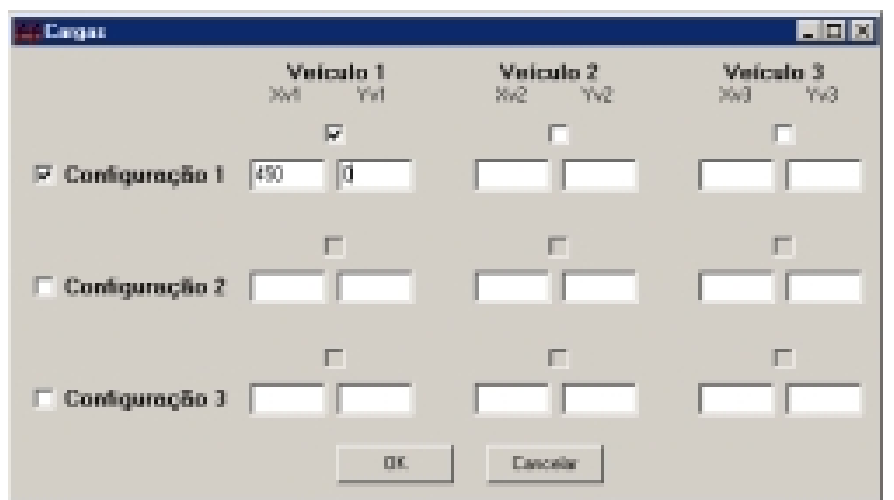

Figura 4.24 - Tela de Veículos para o AEP v. 1.0 - Integrado 
4.7 Programa de Análise Estrutural de Placas - AEP v1.0

O programa AEP v. 1.0 segue a formulação da metodologia ao trabalhar com séries de Fourier com carregamentos distribuídos em pequenas áreas (patch loads).

O programa AEP v. 1.0 foi desenvolvido a partir de uma rotina em linguagem BASIC utilizada pelo Prof. Calil nos EUA. Foi contratado o aluno de graduação Gustavo Galembeck da Ciência da Computação para auxiliar no desenvolvimento.

A seguir, são apresentadas as telas Sobre (figura 4.25) e a tela principal (figura 4.26) onde difere do AEP v. 1.0 Integrada pela ausência de cargas de veículos e a possibilidade de posicionar de 1 a 10 cargas isoladas sobre o tabuleiro.

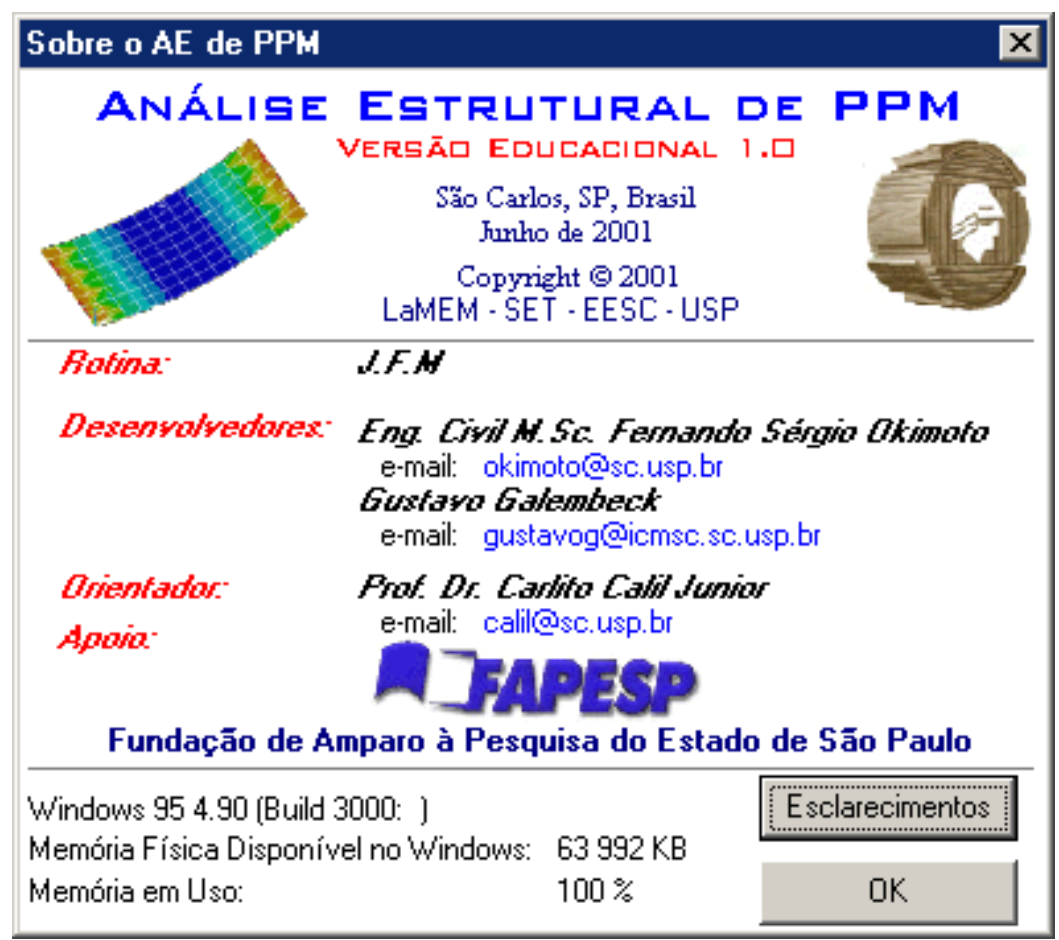

Figura 4.25 - Tela Sobre do AEP v. 1.0 


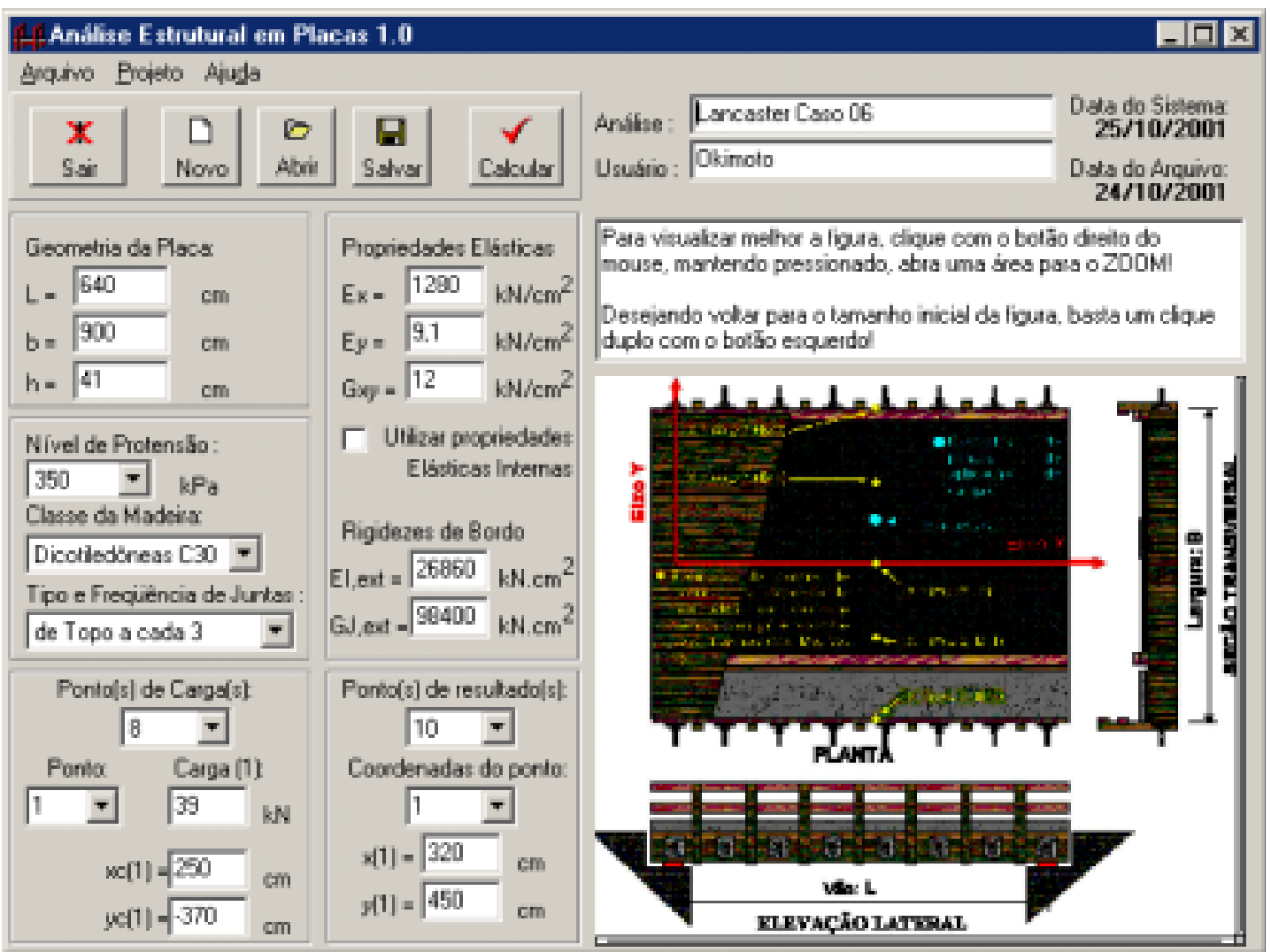

Figura 4.26 - Tela Principal do AEP v. 1.0

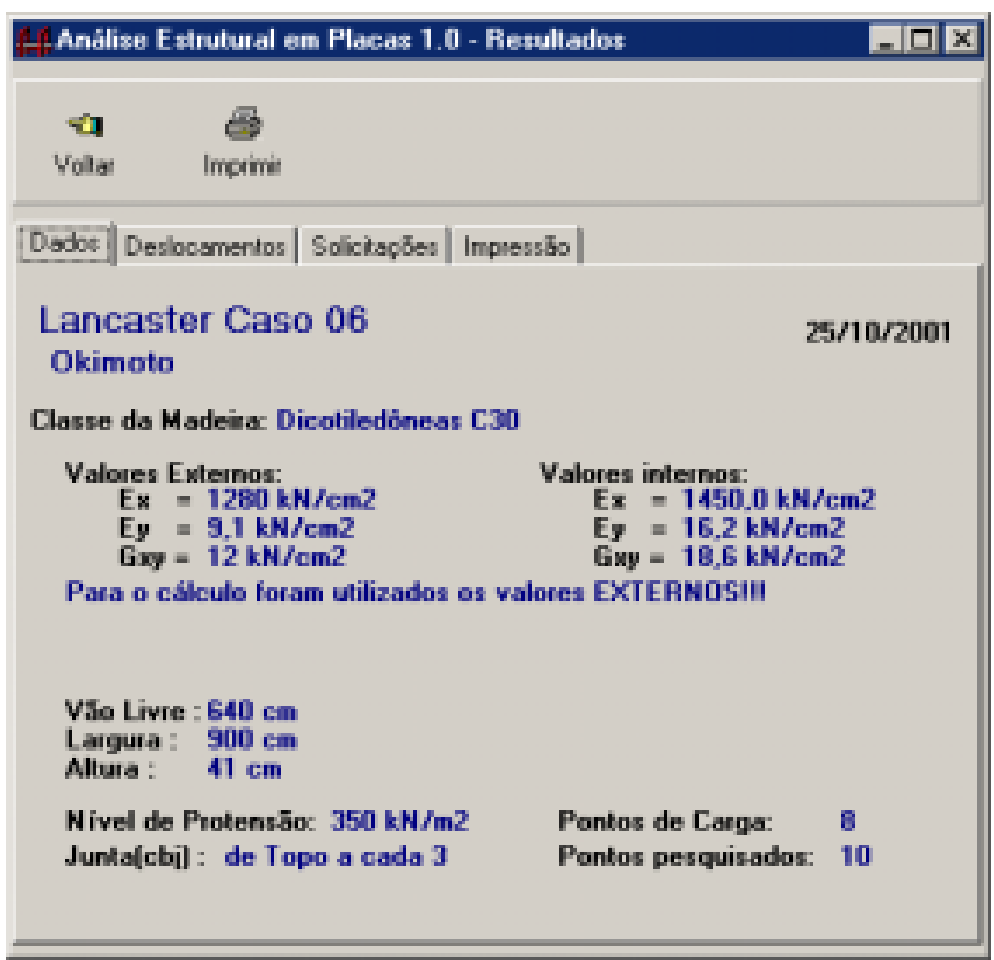

Figura 4.27 - Tela Resultados do AEP v. 1.0 - Dados 


Volat 8

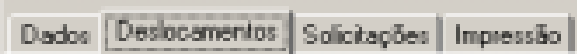

Pontos Deslocamentos venticais

$x$ (cm),$[\mathrm{cm}] \quad$ w.placa w, vige

$320450 \quad[\mathrm{~cm}] \quad[\mathrm{cm}]$

$\begin{array}{llll}320 & 450 & 0.17 & 0.30 \\ 320 & 430 & 0.24 & 0.30\end{array}$

$\begin{array}{llll}320 & 370 & 0.38 & 0.30\end{array}$

$\begin{array}{llll}320 & 300 & \mathbf{0 . 3 5} & \mathbf{0 . 3 0}\end{array}$

$\begin{array}{llll}320 & 240 & 0.35 & 0.30\end{array}$

$\begin{array}{llll}320 & 180 & 0,37 & 0,30\end{array}$

$\begin{array}{llll}320 & 120 & 0,24 & 0,30\end{array}$

$320 \quad 60 \quad 0,10 \quad 0,30$

$\begin{array}{llll}320 & 0 & 0,05 & 0,30\end{array}$

$320 \quad 60 \quad 0.11 \quad 0,30$

$\begin{array}{llll}\text { w.mix, placs }=\mathbf{0 . 3 8} & & X_{\text {mbx }} & Y_{\text {madx }} \\ \text { w.mix. viga }=0,30 & \mathrm{~cm} & {[\mathrm{~cm}]} & {[\mathrm{cm}]} \\ & & 320 & 370\end{array}$

Figura 4.28 - Tela Resultados do AEP v. 1.0 - Deslocamentos

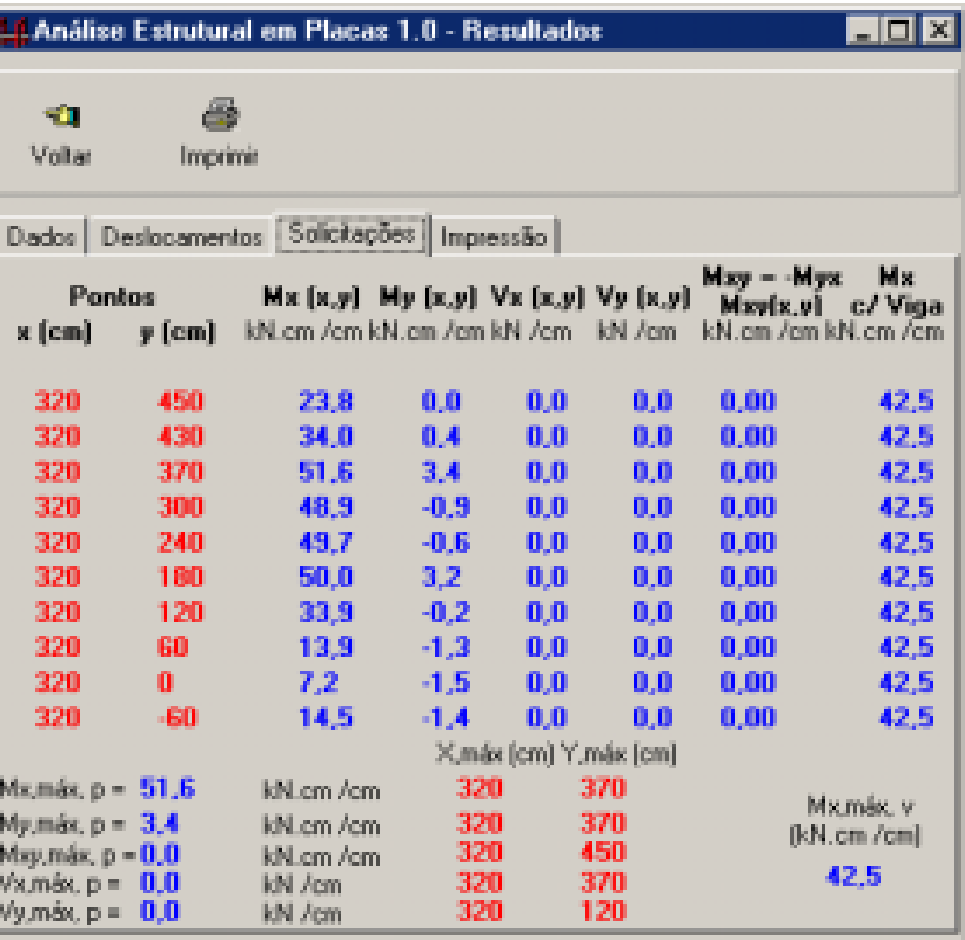

Figura 4.29 - Tela Resultados do AEP v. 1.0 - Solicitações 


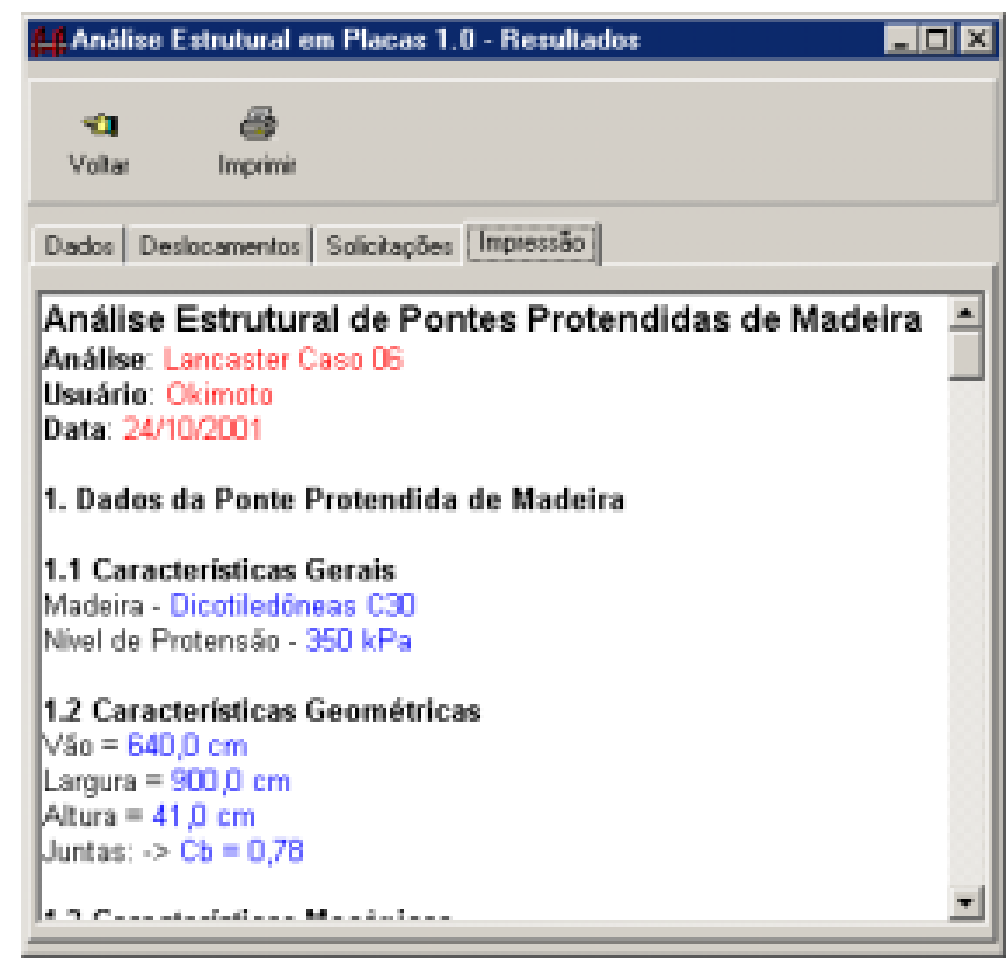

Figura 4.30 - Tela Resultados do AEP v. 1.0 - Impressão

As figuras 4.27 a $\mathbf{4 . 3 0}$ apresentam os resultados de um exemplo de análise estrutural. Foi utilizado um dos arquivos da prova de carga na ponte de Lancaster. De forma fácil e rápida é possível visualizar todos os resultados de deslocamentos, momentos e cortantes nos pontos investigados.

Desejando imprimir, basta clicar no botão imprimir e é criado um arquivo, como o mostrado na figura 4.30, e impresso como apresentado nas próximas 5 páginas.

Finalizando, é apresentado, na figura 4.31, a tela inicial do arquivo de ajuda do AEP v. 1.0 o qual, também, servirá como divulgador das pontes em placas protendidas. 


\section{Análise Estrutural de Pontes Protendidas de Madeira}

Análise: Lancaster Caso 06

Usuário: Okimoto

Data: $24 / 10 / 2001$

\section{Dados da Ponte Protendida de Madeira}

\subsection{Características Gerais}

Madeira - Dicotiledôneas C30

Nível de Protensão - 350 kPa

\subsection{Características Geométricas}

Vão $=640,0 \mathrm{~cm}$

Largura $=900,0 \mathrm{~cm}$

Altura $=41,0 \mathrm{~cm}$

Juntas: $->\mathrm{Cb}=0,78$

\subsection{Características Mecânicas}

Para o cálculo foram utilizados os valores EXTERNOS!!!

$E x=1280,0 \mathrm{kN} / \mathrm{cm} 2$

$\mathrm{Ey}=9,1 \mathrm{kN} / \mathrm{cm} 2$

$\mathrm{Gxy}=12,0 \mathrm{kN} / \mathrm{cm} 2$

Rigidez El no bordo $=2,686 \mathrm{E} 8 \mathrm{kN} . \mathrm{cm} 2$

Rigidez GJ no bordo $=98400$ kN.cm2

$\mathrm{Dx}=5734227,2 \mathrm{kN} . \mathrm{cm}$

Dy $=52265,1 \mathrm{kN} . \mathrm{cm}$

$\mathrm{Dxy}=\mathrm{Dyx}=68921,0 \mathrm{kN} . \mathrm{cm}$

$r 3=2,430$

$r 4=2,140$

$\alpha=0,126$

$\theta=2,280$

$\beta=40,300$

\subsection{Análise Realizada}

Análise com 8 carga(s) aplicada(s)

1a. Carga de $39,0 \mathrm{kN}$, aplicada em: $(250,0 ;-370,0)$

2a. Carga de $39,0 \mathrm{kN}$, aplicada em: $(390,0 ;-370,0)$ 
3a. Carga de $39,0 \mathrm{kN}$, aplicada em: $(250,0 ;-180,0)$

4a. Carga de $39,0 \mathrm{kN}$, aplicada em: $(390,0 ;-180,0)$

5a. Carga de $37,5 \mathrm{kN}$, aplicada em: $(250,0 ; 180,0)$

6 a. Carga de $37,5 \mathrm{kN}$, aplicada em: $(390,0 ; 180,0)$

7a. Carga de $37,5 \mathrm{kN}$, aplicada em: $(250,0 ; 370,0)$

8 a. Carga de $37,5 \mathrm{kN}$, aplicada em: $(390,0 ; 370,0)$

Foi(ram) analisado(s) 10 pontos do tabuleiro

Ponto 1 em ( 320 ; 450)

Ponto 2 em ( 320; 430)

Ponto 3 em ( $320 ; 370)$

Ponto 4 em ( 320; 300)

Ponto 5 em ( $320 ; 240)$

Ponto 6 em ( $320 ; 180)$

Ponto 7 em ( $320 ; 120)$

Ponto 8 em ( 320; 60)

Ponto 9 em ( $320 ; 0)$

Ponto 10 em ( $320 ;-60)$

\subsection{Resultados de Deslocamentos e Solicitações Internas}

Resultados no Ponto ( 320,450 )

$$
\begin{aligned}
& \mathrm{w}(320,0 ; 450,0)=0,170 \mathrm{~cm} \\
& \operatorname{Mx}(320,0 ; 450,0)=23,8 \mathrm{kN} . \mathrm{cm} / \mathrm{cm} \\
& \operatorname{My}(320,0 ; 450,0)=0,0 \mathrm{kN} . \mathrm{cm} / \mathrm{cm} \\
& \operatorname{Mxy}(320,0 ; 450,0)=0,0 \mathrm{kN} . \mathrm{cm} / \mathrm{cm} \\
& \operatorname{Myx}(320,0 ; 450,0)=0,0 \mathrm{kN} . \mathrm{cm} / \mathrm{cm} \\
& \operatorname{Vx}(320,0 ; 450,0)=0,000 \mathrm{kN} / \mathrm{cm} \\
& \operatorname{Vy}(320,0 ; 450,0)=-0,014 \mathrm{kN} / \mathrm{cm} \\
& \mathrm{w}, \operatorname{viga}(320,0 ; 450,0)=0,300 \mathrm{~cm} \\
& \operatorname{Mx}, \operatorname{viga}(320,0 ; 450,0)=42,5 \mathrm{kN} . \mathrm{cm} / \mathrm{cm}
\end{aligned}
$$

Resultados no Ponto ( 320,430$)$

$$
\begin{aligned}
& w(320,0 ; 430,0)=0,240 \mathrm{~cm} \\
& \operatorname{Mx}(320,0 ; 430,0)=34,0 \mathrm{kN} . \mathrm{cm} / \mathrm{cm} \\
& \operatorname{My}(320,0 ; 430,0)=0,4 \mathrm{kN} . \mathrm{cm} / \mathrm{cm} \\
& \operatorname{Mxy}(320,0 ; 430,0)=0,0 \mathrm{kN} . \mathrm{cm} / \mathrm{cm}
\end{aligned}
$$


$\operatorname{Myx}(320,0 ; 430,0)=0,0 \mathrm{kN} . \mathrm{cm} / \mathrm{cm}$

$\mathrm{Vx}(320,0 ; 430,0)=0,000 \mathrm{kN} / \mathrm{cm}$

$\mathrm{Vy}(320,0 ; 430,0)=-0,029 \mathrm{kN} / \mathrm{cm}$

w,viga $(320,0 ; 430,0)=0,300 \mathrm{~cm}$

$M x, \operatorname{viga}(320,0 ; 430,0)=42,5 \mathrm{kN} . \mathrm{cm} / \mathrm{cm}$

Resultados no Ponto ( 320,370 )

$$
\begin{aligned}
& \mathrm{w}(320,0 ; 370,0)=0,380 \mathrm{~cm} \\
& \operatorname{Mx}(320,0 ; 370,0)=51,6 \mathrm{kN} . \mathrm{cm} / \mathrm{cm} \\
& \operatorname{My}(320,0 ; 370,0)=3,4 \mathrm{kN} . \mathrm{cm} / \mathrm{cm} \\
& \operatorname{Mxy}(320,0 ; 370,0)=0,0 \mathrm{kN} . \mathrm{cm} / \mathrm{cm} \\
& \operatorname{Myx}(320,0 ; 370,0)=0,0 \mathrm{kN} . \mathrm{cm} / \mathrm{cm} \\
& \operatorname{Vx}(320,0 ; 370,0)=0,000 \mathrm{kN} / \mathrm{cm} \\
& \operatorname{Vy}(320,0 ; 370,0)=0,009 \mathrm{kN} / \mathrm{cm} \\
& \mathrm{w}, \operatorname{viga}(320,0 ; 370,0)=0,300 \mathrm{~cm} \\
& \operatorname{Mx}, \operatorname{viga}(320,0 ; 370,0)=42,5 \mathrm{kN} . \mathrm{cm} / \mathrm{cm}
\end{aligned}
$$

Resultados no Ponto ( 320,300 )

$$
\begin{aligned}
& \mathrm{w}(320,0 ; 300,0)=0,350 \mathrm{~cm} \\
& \operatorname{Mx}(320,0 ; 300,0)=48,9 \mathrm{kN} . \mathrm{cm} / \mathrm{cm} \\
& \operatorname{My}(320,0 ; 300,0)=-0,9 \mathrm{kN} . \mathrm{cm} / \mathrm{cm} \\
& \operatorname{Mxy}(320,0 ; 300,0)=0,0 \mathrm{kN} . \mathrm{cm} / \mathrm{cm} \\
& \operatorname{Myx}(320,0 ; 300,0)=0,0 \mathrm{kN} . \mathrm{cm} / \mathrm{cm} \\
& \operatorname{Vx}(320,0 ; 300,0)=0,000 \mathrm{kN} / \mathrm{cm} \\
& \operatorname{Vy}(320,0 ; 300,0)=0,026 \mathrm{kN} / \mathrm{cm} \\
& \mathrm{w}, \operatorname{viga}(320,0 ; 300,0)=0,300 \mathrm{~cm} \\
& \operatorname{Mx}, \operatorname{viga}(320,0 ; 300,0)=42,5 \mathrm{kN} . \mathrm{cm} / \mathrm{cm}
\end{aligned}
$$

Resultados no Ponto ( 320,240 )

$$
\begin{aligned}
& w(320,0 ; 240,0)=0,350 \mathrm{~cm} \\
& M x(320,0 ; 240,0)=49,7 \mathrm{kN} . \mathrm{cm} / \mathrm{cm} \\
& \operatorname{My}(320,0 ; 240,0)=-0,6 \mathrm{kN} . \mathrm{cm} / \mathrm{cm} \\
& \operatorname{Mxy}(320,0 ; 240,0)=0,0 \mathrm{kN} . \mathrm{cm} / \mathrm{cm} \\
& \operatorname{Myx}(320,0 ; 240,0)=0,0 \mathrm{kN} . \mathrm{cm} / \mathrm{cm} \\
& \operatorname{Vx}(320,0 ; 240,0)=0,000 \mathrm{kN} / \mathrm{cm} \\
& \operatorname{Vy}(320,0 ; 240,0)=-0,037 \mathrm{kN} / \mathrm{cm}
\end{aligned}
$$


$\mathrm{w}, \operatorname{viga}(320,0 ; 240,0)=0,300 \mathrm{~cm}$

Mx,viga $(320,0 ; 240,0)=42,5 \mathrm{kN} . \mathrm{cm} / \mathrm{cm}$

Resultados no Ponto ( 320,180 )

$\mathrm{w}(320,0 ; 180,0)=0,370 \mathrm{~cm}$

$\operatorname{Mx}(320,0 ; 180,0)=50,0 \mathrm{kN} . \mathrm{cm} / \mathrm{cm}$

$\operatorname{My}(320,0 ; 180,0)=3,2 \mathrm{kN} . \mathrm{cm} / \mathrm{cm}$

$\operatorname{Mxy}(320,0 ; 180,0)=0,0 \mathrm{kN} . \mathrm{cm} / \mathrm{cm}$

$\operatorname{Myx}(320,0 ; 180,0)=0,0 \mathrm{kN} . \mathrm{cm} / \mathrm{cm}$

$\mathrm{Vx}(320,0 ; 180,0)=0,000 \mathrm{kN} / \mathrm{cm}$

$\mathrm{Vy}(320,0 ; 180,0)=-0,005 \mathrm{kN} / \mathrm{cm}$

w,viga $(320,0 ; 180,0)=0,300 \mathrm{~cm}$

Mx,viga $(320,0 ; 180,0)=42,5 \mathrm{kN} . \mathrm{cm} / \mathrm{cm}$

Resultados no Ponto ( 320,120$)$

$$
\begin{aligned}
& \mathrm{w}(320,0 ; 120,0)=0,240 \mathrm{~cm} \\
& \operatorname{Mx}(320,0 ; 120,0)=33,9 \mathrm{kN} . \mathrm{cm} / \mathrm{cm} \\
& \operatorname{My}(320,0 ; 120,0)=-0,2 \mathrm{kN} . \mathrm{cm} / \mathrm{cm} \\
& \operatorname{Mxy}(320,0 ; 120,0)=0,0 \mathrm{kN} . \mathrm{cm} / \mathrm{cm} \\
& \operatorname{Myx}(320,0 ; 120,0)=0,0 \mathrm{kN} . \mathrm{cm} / \mathrm{cm} \\
& \operatorname{Vx}(320,0 ; 120,0)=0,000 \mathrm{kN} / \mathrm{cm} \\
& \operatorname{Vy}(320,0 ; 120,0)=0,037 \mathrm{kN} / \mathrm{cm} \\
& \mathrm{w}, \operatorname{viga}(320,0 ; 120,0)=0,300 \mathrm{~cm} \\
& \operatorname{Mx}, \operatorname{viga}(320,0 ; 120,0)=42,5 \mathrm{kN} . \mathrm{cm} / \mathrm{cm}
\end{aligned}
$$

Resultados no Ponto ( 320,60 )

$$
\begin{aligned}
& \mathrm{w}(320,0 ; 60,0)=0,100 \mathrm{~cm} \\
& \operatorname{Mx}(320,0 ; 60,0)=13,9 \mathrm{kN} . \mathrm{cm} / \mathrm{cm} \\
& \operatorname{My}(320,0 ; 60,0)=-1,3 \mathrm{kN} . \mathrm{cm} / \mathrm{cm} \\
& \operatorname{Mxy}(320,0 ; 60,0)=0,0 \mathrm{kN} . \mathrm{cm} / \mathrm{cm} \\
& \operatorname{Myx}(320,0 ; 60,0)=0,0 \mathrm{kN} . \mathrm{cm} / \mathrm{cm} \\
& \operatorname{Vx}(320,0 ; 60,0)=0,000 \mathrm{kN} / \mathrm{cm} \\
& \operatorname{Vy}(320,0 ; 60,0)=0,008 \mathrm{kN} / \mathrm{cm} \\
& \mathrm{w}, \operatorname{viga}(320,0 ; 60,0)=0,300 \mathrm{~cm} \\
& \operatorname{Mx}, \operatorname{viga}(320,0 ; 60,0)=42,5 \mathrm{kN} . \mathrm{cm} / \mathrm{cm}
\end{aligned}
$$


Resultados no Ponto ( 320,0$)$

$$
\begin{aligned}
& \mathrm{w}(320,0 ; 0,0)=0,052 \mathrm{~cm} \\
& \operatorname{Mx}(320,0 ; 0,0)=7,2 \mathrm{kN} . \mathrm{cm} / \mathrm{cm} \\
& \operatorname{My}(320,0 ; 0,0)=-1,5 \mathrm{kN} . \mathrm{cm} / \mathrm{cm} \\
& \operatorname{Mxy}(320,0 ; 0,0)=0,0 \mathrm{kN} . \mathrm{cm} / \mathrm{cm} \\
& \operatorname{Myx}(320,0 ; 0,0)=0,0 \mathrm{kN} . \mathrm{cm} / \mathrm{cm} \\
& \operatorname{Vx}(320,0 ; 0,0)=0,000 \mathrm{kN} / \mathrm{cm} \\
& \operatorname{Vy}(320,0 ; 0,0)=0,000 \mathrm{kN} / \mathrm{cm} \\
& \mathrm{w}, \operatorname{viga}(320,0 ; 0,0)=0,300 \mathrm{~cm} \\
& \operatorname{Mx}, \operatorname{viga}(320,0 ; 0,0)=42,5 \mathrm{kN} . \mathrm{cm} / \mathrm{cm}
\end{aligned}
$$

Resultados no Ponto ( $320,-60$ )

$$
\begin{aligned}
& \mathrm{w}(320,0 ;-60,0)=0,110 \mathrm{~cm} \\
& \operatorname{Mx}(320,0 ;-60,0)=14,5 \mathrm{kN} . \mathrm{cm} / \mathrm{cm} \\
& \operatorname{My}(320,0 ;-60,0)=-1,4 \mathrm{kN} . \mathrm{cm} / \mathrm{cm} \\
& \operatorname{Mxy}(320,0 ;-60,0)=0,0 \mathrm{kN} . \mathrm{cm} / \mathrm{cm} \\
& \operatorname{Myx}(320,0 ;-60,0)=0,0 \mathrm{kN} . \mathrm{cm} / \mathrm{cm} \\
& \operatorname{Vx}(320,0 ;-60,0)=0,000 \mathrm{kN} / \mathrm{cm} \\
& \operatorname{Vy}(320,0 ;-60,0)=-0,008 \mathrm{kN} / \mathrm{cm} \\
& \mathrm{w}, \operatorname{viga}(320,0 ;-60,0)=0,300 \mathrm{~cm} \\
& \text { Mx,viga }(320,0 ;-60,0)=42,5 \mathrm{kN} . \mathrm{cm} / \mathrm{cm}
\end{aligned}
$$

\section{Valores Máximos}

$$
\begin{aligned}
& \text { wPlateMax }(320,0 ; 370,0)=0,380 \mathrm{~cm} \\
& \operatorname{MxPlateMax}(320,0 ; 370,0)=51,6 \mathrm{kN} . \mathrm{cm} / \mathrm{cm} \\
& \text { MyPlateMax }(320,0 ; 370,0)=3,4 \mathrm{kN} . \mathrm{cm} / \mathrm{cm} \\
& \text { VxPlateMax }(320,0 ; 370,0)=0,000 \mathrm{kN} / \mathrm{cm} \\
& \text { VyPlateMax }(320,0 ; 120,0)=0,037 \mathrm{kN} / \mathrm{cm} \\
& \text { MxyPlateMax }(320,0 ; 450,0)=0,00 \mathrm{kN} . \mathrm{cm} / \mathrm{cm} \\
& \text { wBeamMax }=0,300 \mathrm{~cm} \\
& \text { MxBeamMax }=42,5 \mathrm{kN} . \mathrm{cm} / \mathrm{cm}
\end{aligned}
$$




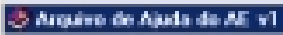

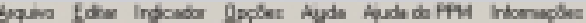

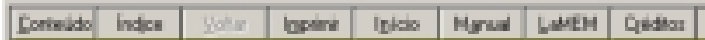

\section{Ajuda do Programa Análise Estrutural de Placas}

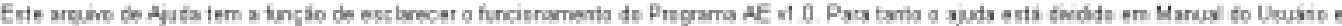

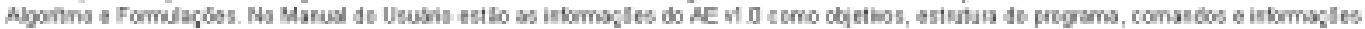

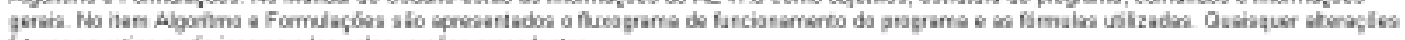

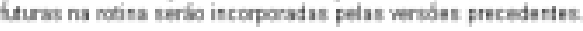

- Masud da Ususina - Guia de Utifizaçio.

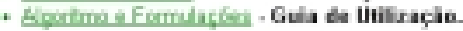

Sho Carles, the Setemine de zon

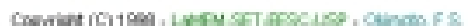

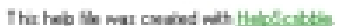

Figura 4.31 - Tela do arquivo Ajuda do AEP v. 1.0 
4.8 Análise Estrutural de Placas via Prova de Carga, SAP200 e AEP v.1.0

Foram realizadas provas de carga nas pontes de Lancaster e Sullivan. $\mathrm{Na}$ primeira, houveram 6 (seis) posicionamentos diferentes de veículo(s) e na de Sullivan, apenas 3 (três).

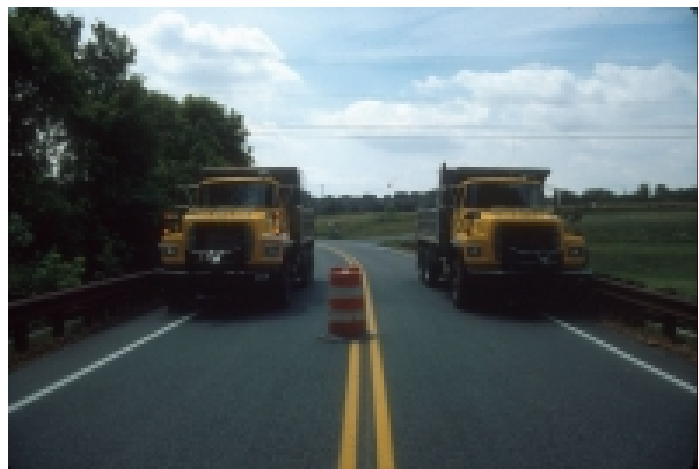

Figura 4.32 - Prova de Carga na Lancaster

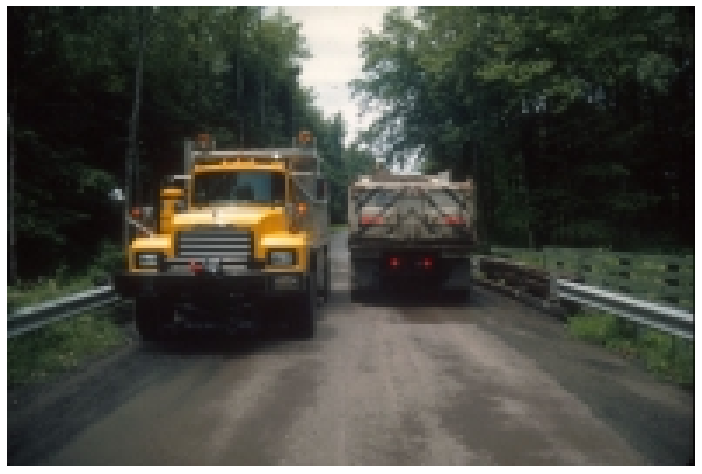

Figura 4.33 - Prova de Carga na Sullivan

Foi utilizado a versão 7.12 do SAP2000 Non Linear cuja tela Sobre é apresentada abaixo (figura 4.34).

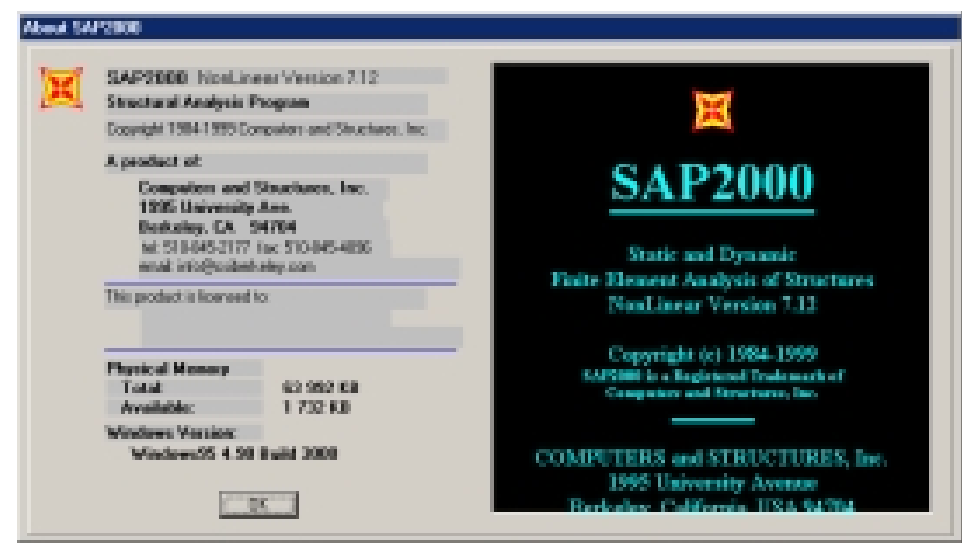

Figura 4.34 - Tela About SAP2000 Non Linear

A seguir são apresentados os dados comparativos das provas de carga e suas simulações computacionais. As figuras são apenas dos primeiros casos de carga das pontes mas os gráficos seguintes apresentam todos os casos. Por último, também ilustrativo, são apresentados os momentos obtidos pelas simulações no SAP2000 e no AEP. 
Lancaster

\begin{tabular}{|c|c|c|c|c|c|c|c|c|c|c|c|c|c|c|c|c|c|}
\hline Estaçẫo de Leitura & 1 & 2 & 3 & 4 & 5 & 6 & 7 & 8 & $\mathbf{9}$ & 10 & 11 & 12 & 13 & 14 & 15 & 16 & 17 \\
\hline $\begin{array}{l}\text { Posiç̧âo (cm) } \\
\text { Carregamento } 1\end{array}$ & -450 & -430 & -370 & -300 & -240 & -180 & -120 & -60 & $\mathbf{0}$ & 60 & 120 & 180 & 240 & 300 & 370 & 430 & 450 \\
\hline Posiçẫo e Valor das Cargas ( $\mathrm{kN}$ ) & & & & & $\downarrow 39$ & & & $\downarrow 39$ & & & & & & & & & \\
\hline Deslocamentos - P. Carga $(\mathrm{cm})$ & $-0,10$ & $-0,10$ & $-0,20$ & $-0,30$ & $-0,60$ & $-0,50$ & $-0,53$ & $-0,50$ & $-0,40$ & $-0,20$ & $-0,10$ & 0,00 & 0,00 & 0,00 & 0,00 & 0,00 & 0,00 \\
\hline Deslocamentos - Sap2000 $(\mathrm{cm})$ & $-0,04$ & $-0,05$ & $-0,08$ & $-0,15$ & $-0,22$ & $-0,21$ & $-0,21$ & $-0,21$ & $-0,15$ & $-0,08$ & $-0,04$ & $-0,02$ & $-0,01$ & 0,00 & 0,00 & 0,00 & 0,00 \\
\hline Deslocamentos - A.EP (cm) & 0,03 & 0,00 & $-0,09$ & $-0,27$ & $-0,40$ & $-0,39$ & $-0,39$ & $-0,40$ & $-0,26$ & $-0,11$ & $-0,03$ & 0,01 & 0,01 & 0,01 & 0,00 & 0,00 & 0,00 \\
\hline \multicolumn{18}{|l|}{ Carregamento 2} \\
\hline Posiçấo e Valor das Cargas ( $\mathrm{kN}$ ) & & & & & & & & & & $\downarrow 37,5$ & & & $\downarrow 37,5$ & & & & \\
\hline Deslocamentos - P. Carga (cm) & 0,00 & 0,00 & 0,00 & 0,00 & 0,00 & 0,00 & $-0,03$ & $-0,10$ & $-0,40$ & $-0,40$ & $-0,60$ & $-0,50$ & $-0,40$ & $-0,23$ & $-0,20$ & 0,00 & 0,00 \\
\hline Deslocamentos - Sap2000 $(\mathrm{cm})$ & 0,00 & 0,00 & 0,00 & 0,00 & $-0,01$ & $-0,02$ & $-0,04$ & $-0,08$ & $-0,14$ & $-0,21$ & $-0,20$ & $-0,20$ & $-0,21$ & $-0,14$ & $-0,07$ & $-0,04$ & $-0,04$ \\
\hline \multicolumn{18}{|l|}{ Carregamento 3} \\
\hline Posição e Valor das Cargas ( $\mathrm{kN}$ ) & & & & & $\downarrow 39$ & & & $\downarrow 39$ & & $\downarrow 37,5$ & & & $\downarrow 37,5$ & & & & \\
\hline Deslocamentos - P. Carga $(\mathrm{cm})$ & $-0,10$ & $-0,10$ & $-0,20$ & $-0,30$ & $-0,60$ & $-0,50$ & $-0,53$ & $-0,70$ & $-0,70$ & $-0,70$ & $-0,60$ & $-0,60$ & $-0,50$ & $-0,23$ & $-0,20$ & 0,00 & 0,00 \\
\hline Deslocamentos - Sap2000 $(\mathrm{cm})$ & $-0,04$ & $-0,05$ & $-0,08$ & $-0,15$ & $-0,22$ & $-0,22$ & $-0,24$ & $-0,29$ & $-0,29$ & $-0,29$ & $-0,24$ & $-0,22$ & $-0,21$ & $-0,15$ & $-0,07$ & $-0,04$ & $-0,04$ \\
\hline Deslocamentos - A.EP (cm) & 0,03 & 0,00 & $-0,09$ & $-0,26$ & $-0,39$ & $-0,38$ & $-0,41$ & $-0,51$ & $-0,51$ & $-0,49$ & $-0,40$ & $-0,37$ & $-0,38$ & $-0,25$ & $-0,09$ & 0,00 & 0,03 \\
\hline \multicolumn{18}{|l|}{ Carregamento 4} \\
\hline Posiçẫo e Valor das Cargas (kN) & & & $\downarrow 39$ & & & $\downarrow 39$ & & & & & & & & & & & \\
\hline P. Carga $(\mathrm{cm})$ & $-0,30$ & $-0,30$ & $-0,40$ & $-0,40$ & $-0,50$ & $-0,60$ & $-0,40$ & $-0,23$ & $-0,10$ & $-0,10$ & 0,00 & $-0,10$ & 0,00 & 0,00 & 0,00 & 0,00 & 0,00 \\
\hline \multicolumn{18}{|l|}{ Carregamento 5} \\
\hline Posiçẫo e Valor das Cargas (kN) & & & & & & & & & & & & $\downarrow 37,5$ & & & $\downarrow 37,5$ & & \\
\hline Deslocamentos - P. Carga (cm) & 0,00 & 0,00 & 0,00 & 0,0 & 0,00 & 0,0 & 0,00 & $-0,03$ & $\mathbf{0 , 0 0}$ & $-0,10$ & $-0,20$ & $-0,40$ & $-0,40$ & $-0,50$ & $-0,43$ & $-0,40$ & $-0,30$ \\
\hline Deslocamentos - Sap2000 $(\mathrm{cm})$ & 0,00 & 0,00 & 0,00 & 0,00 & 0,00 & 0,00 & $-0,01$ & $-0,02$ & $-0,04$ & $-0,08$ & $-0,14$ & $-0,20$ & $-0,20$ & $-0,21$ & $-0,29$ & $-0,37$ & $-0,43$ \\
\hline Deslocamentos - A.EP (cm) & 0,00 & 0,00 & 0,00 & 0,00 & 0,00 & 0,01 & 0,01 & 0,01 & $-0,03$ & $-0,11$ & $-0,25$ & $-0,38$ & $-0,36$ & $-0,35$ & $-0,38$ & $-0,24$ & $-0,17$ \\
\hline \multicolumn{18}{|l|}{ Carregamento 6} \\
\hline Posiçẫo e Valor das Carge & & & $\downarrow 39$ & & & $\downarrow 39$ & & & & & & $\downarrow 37,5$ & & & $\downarrow 37,5$ & & \\
\hline Deslocamentos - P. Carga (cm) & $-0,30$ & $-0,40$ & $-0,50$ & $-0,50$ & $-0,50$ & $-0,40$ & $-0,33$ & $-0,20$ & $-0,20$ & $-0,20$ & $-0,40$ & $-0,50$ & $-0,50$ & $-0,53$ & $-0,40$ & $-0,20$ & $-0,20$ \\
\hline Deslocamentos - Sap2000 (cm) & $-0,44$ & $-0,38$ & $-0,30$ & $-0,22$ & $-0,22$ & $-0,21$ & $-0,15$ & $-0,09$ & $-0,07$ & $-0,09$ & $-0,15$ & $-0,21$ & $-0,20$ & $-0,21$ & $-0,29$ & $-0,37$ & $-0,43$ \\
\hline Deslocamentos - A.EP (cm) & $-0,18$ & $-0,25$ & $-0,39$ & $-0,37$ & $-0,37$ & $-0,38$ & $-0,25$ & $-0,11$ & $-0,05$ & $-0,10$ & $-0,24$ & $-0,37$ & $-0,35$ & $-0,35$ & $-0,38$ & $-0,24$ & $-0,17$ \\
\hline
\end{tabular}




\section{Lancaster - Caso 1}
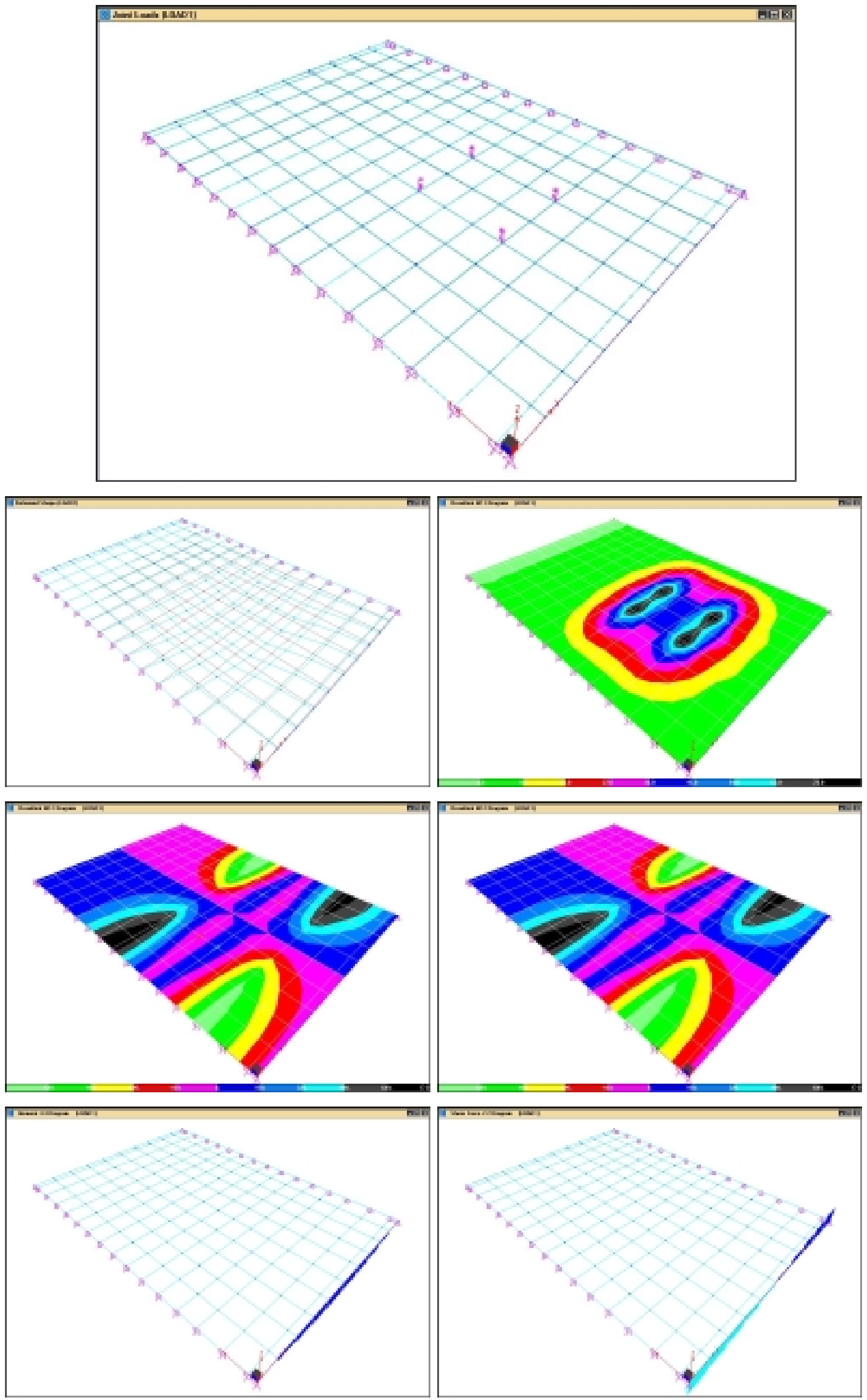


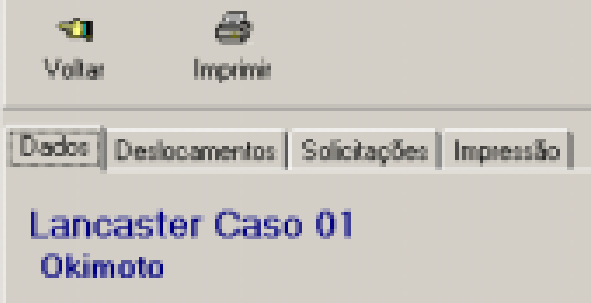

Classe da Madeia: Dicotiledōneas C30

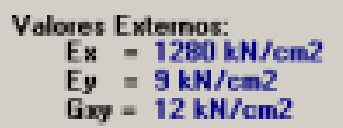

Pasa o cśslculo foram utilizados os valores EXTERNOSIII

Vฮือ Livie : $640 \mathrm{~cm}$

Largura : $900 \mathrm{~cm}$

Altura : $41 \mathrm{~cm}$

Nivel de Protensāo: $350 \mathrm{kN} / \mathrm{m} 2$

Junla(cbi) : de Topo a cada 3

Pantos de Catga: 4

Pontos pesquisados: 10

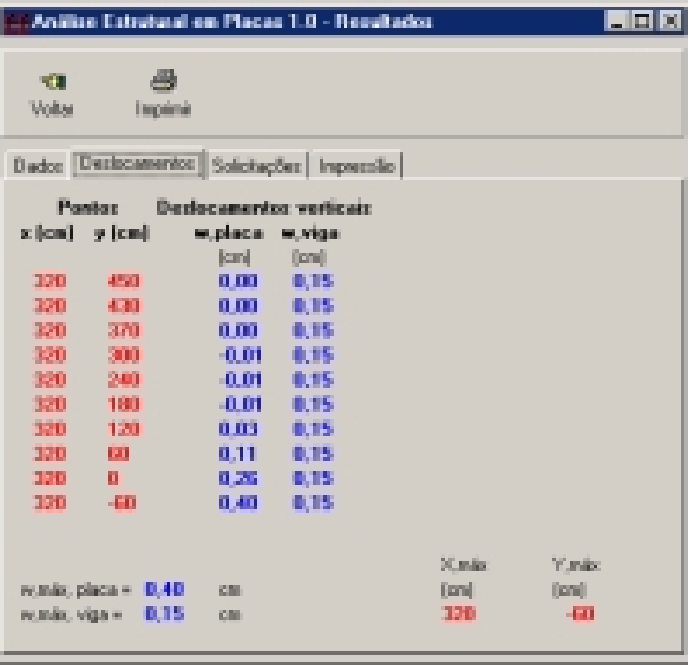

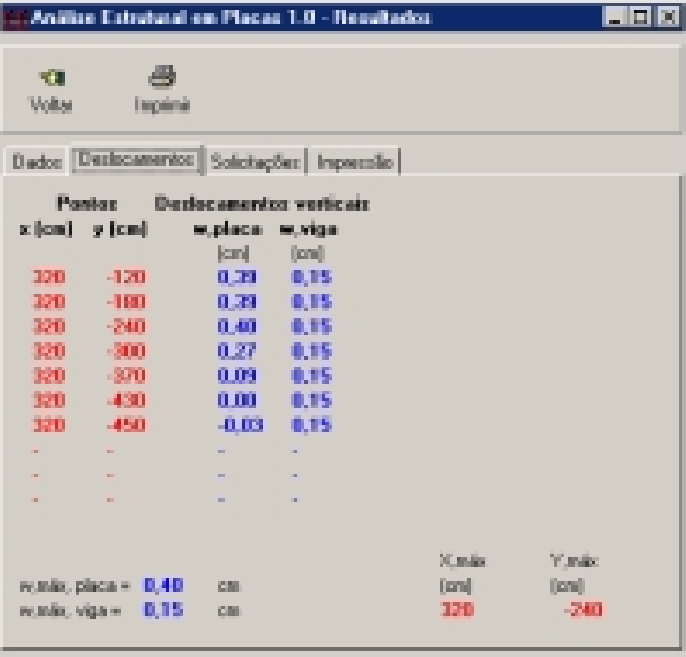

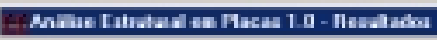

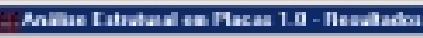

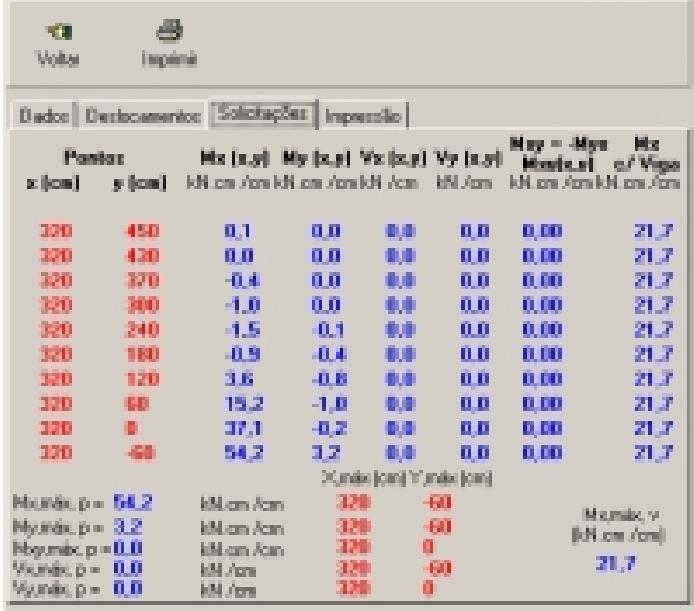

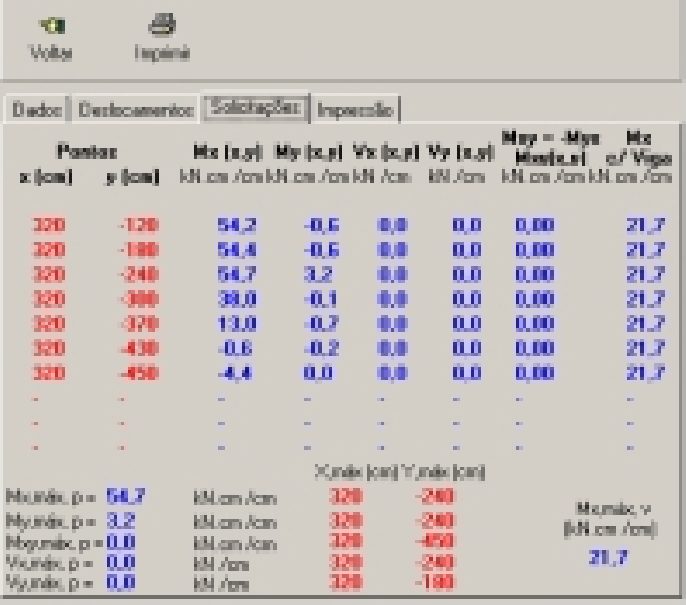


Lancaster - C01 - Deslocamentos na Seção central

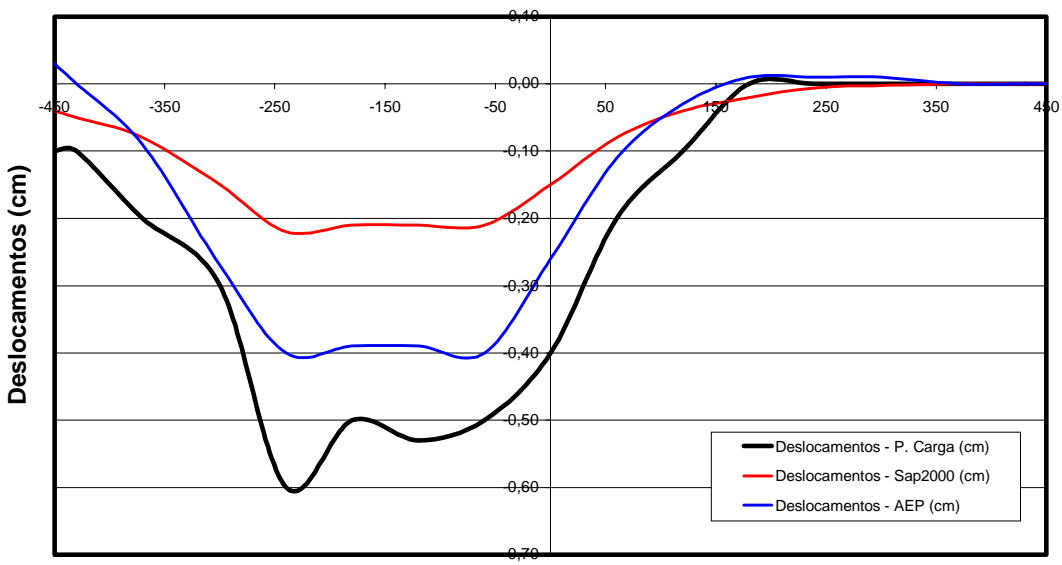

Posição (cm)

Lancaster - C02 - Deslocamentos na Seção central

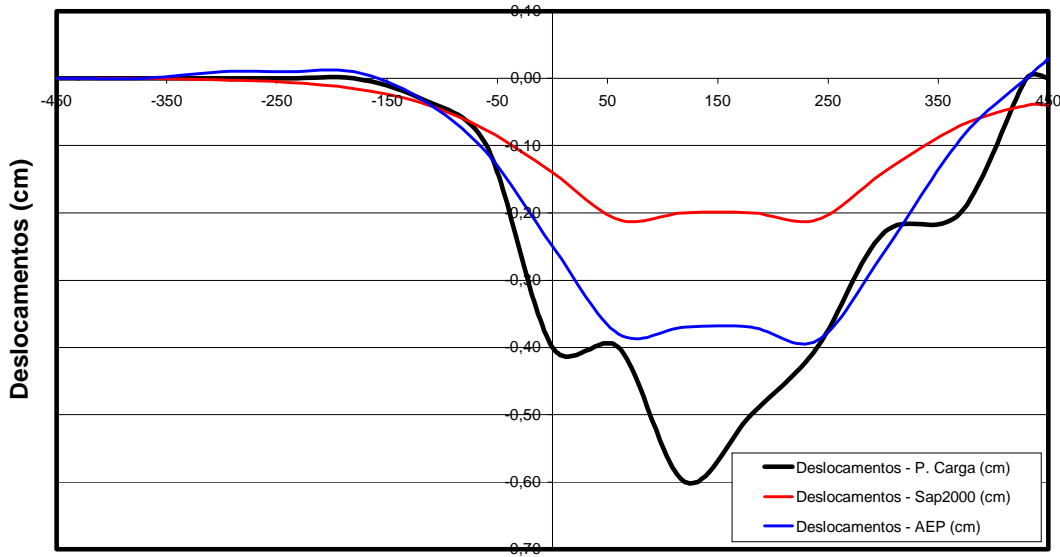

Posição (cm)

Lancaster - C03 - Deslocamentos na Seção central

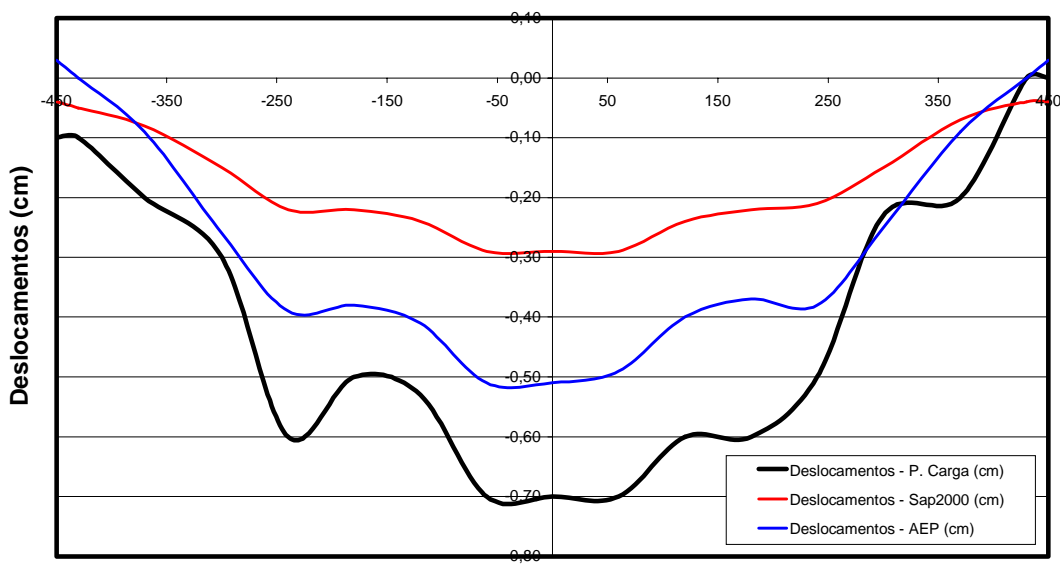

Posição (cm) 
Lancaster - C04 - Deslocamentos na Seção central

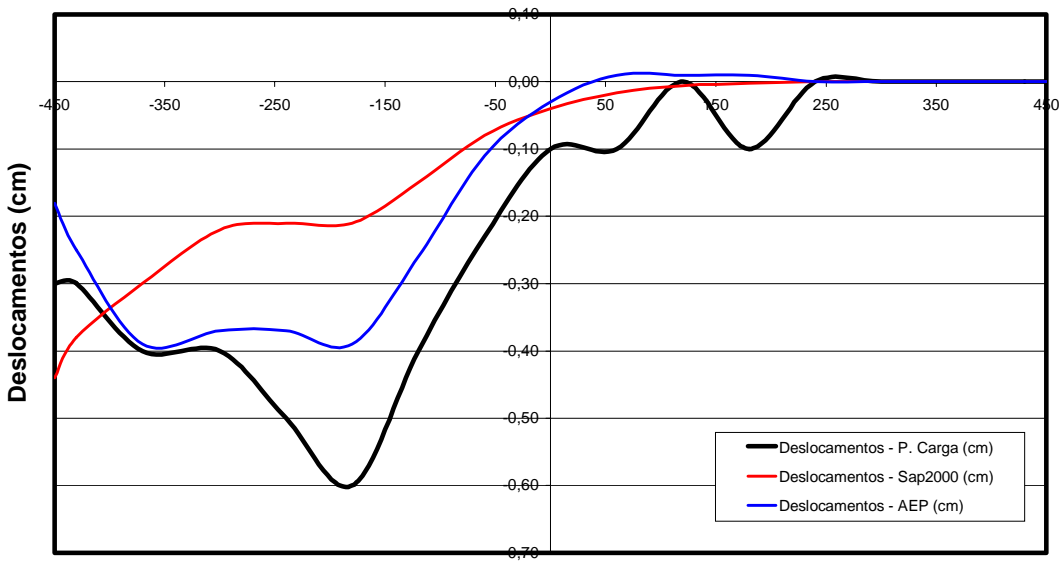

Posição (cm)

Lancaster - C05 - Deslocamentos na Seção central

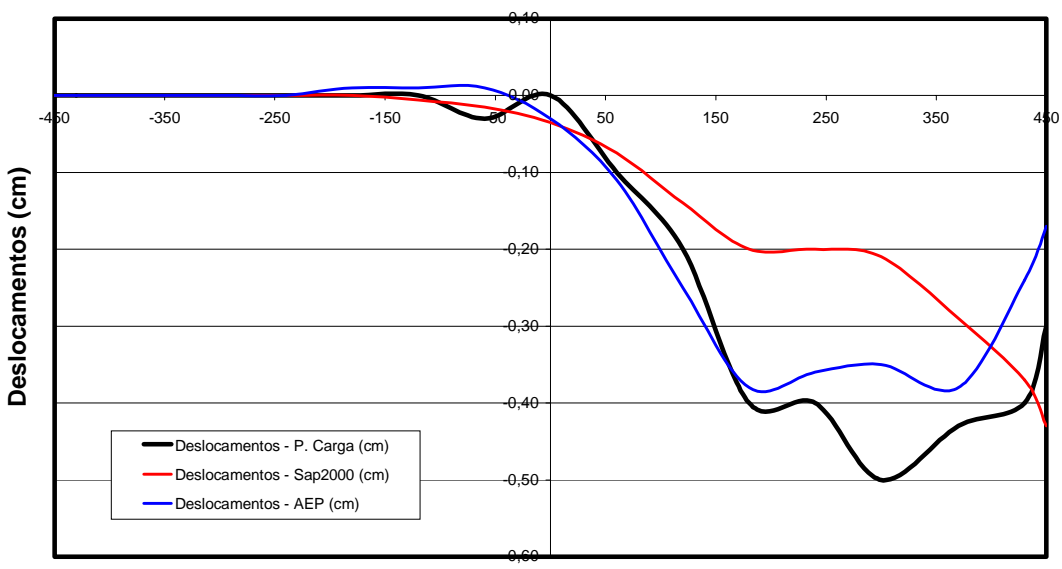

Posição $(\mathrm{cm})$

Lancaster - C06 - Deslocamentos na Seção central

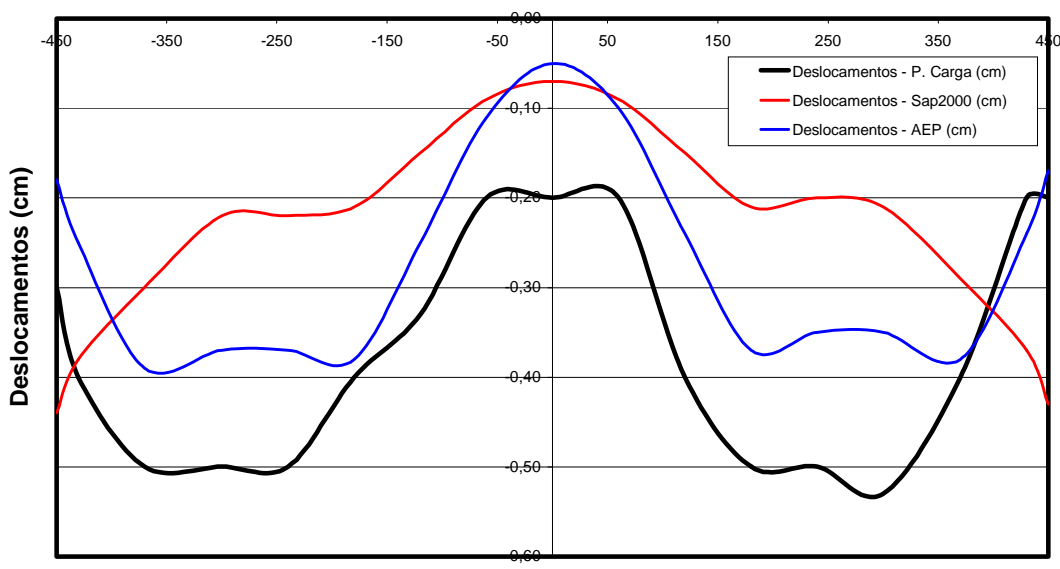

Posição (cm) 


\section{Sullivan}

\begin{tabular}{|c|c|c|c|c|c|c|c|c|c|c|c|c|c|c|}
\hline $\begin{array}{l}\text { Estaçẫo de Leitura } \\
\text { Posiçấo (cm) } \\
\text { Carregamento } 1\end{array}$ & $\begin{array}{c}1 \\
-400\end{array}$ & $\begin{array}{c}2 \\
-310\end{array}$ & $\begin{array}{c}3 \\
-240\end{array}$ & $\begin{array}{c}4 \\
-180\end{array}$ & $\begin{array}{c}5 \\
-120\end{array}$ & $\begin{array}{c}6 \\
-60\end{array}$ & $\begin{array}{l}7 \\
0\end{array}$ & $\begin{array}{c}8 \\
60\end{array}$ & $\begin{array}{c}9 \\
120\end{array}$ & $\begin{array}{c}10 \\
180\end{array}$ & $\begin{array}{c}11 \\
240\end{array}$ & $\begin{array}{c}12 \\
310\end{array}$ & $\begin{array}{c}13 \\
400\end{array}$ & $\begin{array}{c}14 \\
580\end{array}$ \\
\hline Posiçẫo e Valor das Cargas (kN) & & & $\downarrow 58,5$ & & & $\downarrow 58,5$ & & & & & & & & \\
\hline Deslocamentos - P. Carga $(\mathrm{cm})$ & $-0,16$ & $-0,46$ & $-0,63$ & $-0,68$ & $-0,73$ & $-0,70$ & 0,58 & $-0,33$ & $-0,22$ & $-0,13$ & $-0,09$ & $-0,04$ & $-0,03$ & 0,00 \\
\hline Deslocamentos - Sap2000 (cm) & $-0,48$ & $-0,58$ & $-0,71$ & $-0,71$ & $-0,70$ & $-0,67$ & 0,51 & $-0,33$ & $-0,20$ & $-0,11$ & $-0,05$ & $-0,02$ & $-0,01$ & 0,00 \\
\hline Deslocamentos - AEP (cm) & $-0,10$ & $-0,63$ & $-0,97$ & $-1,02$ & $-1,01$ & $-0,95$ & 0,69 & $-0,39$ & $-0,18$ & $-0,05$ & 0,01 & 0,03 & 0,02 & 0,00 \\
\hline \multicolumn{15}{|l|}{ Carregamento 2} \\
\hline Posiçẫo e Valor das Cargas ( $(\mathrm{kN})$ & & & & & & & & $\downarrow 58,5$ & & & $\downarrow 58,5$ & & & \\
\hline Deslocamentos - P. Carga $(\mathrm{cm})$ & 0,00 & 0,00 & $-0,01$ & $-0,05$ & $-0,18$ & $-0,33$ & $\mathbf{0 , 5 8}$ & $-0,70$ & $-0,68$ & $-0,68$ & $-0,60$ & $-0,39$ & $-0,18$ & 0,00 \\
\hline Sap2000 (cm) & $-0,01$ & $-0,02$ & $-0,05$ & $-0,11$ & $-0,20$ & $-0,33$ & 0,51 & $-0,67$ & $-0,70$ & $-0,70$ & $-0,68$ & $-0,48$ & $-0,24$ & $-0,01$ \\
\hline Deslocamentos - AEP (cm) & 0,03 & 0,03 & 0,01 & $-0,05$ & $-0,18$ & $-0,39$ & $\mathbf{0 , 6 8}$ & $-0,94$ & $-1,00$ & $-1,00$ & $-0,94$ & $-0,64$ & $-0,25$ & 0,08 \\
\hline \multicolumn{15}{|l|}{ Carregamento 3} \\
\hline Posiçẫo e Valor das Cargas (kN) & & & $\downarrow 58,5$ & & & $\downarrow 58,5$ & & $\downarrow 58,5$ & & & $\downarrow 58,5$ & & & \\
\hline Deslocamentos - P. Carga (cm) & $-0,2$ & $-0,5$ & $-0,7$ & $-0,7$ & $-0,9$ & $-1,0$ & $-1,1$ & $-1,1$ & $-0,9$ & $-0,8$ & $-0,7$ & $-0,4$ & $-0,2$ & 0,0 \\
\hline Deslocamentos - Sap2000 (cm) & $-0,47$ & $-0,60$ & $-0,77$ & $-0,82$ & $-0,90$ & $-1,01$ & $-1,03$ & $-1,01$ & $-0,90$ & $-0,81$ & $-0,73$ & $-0,51$ & $-0,24$ & $-0,01$ \\
\hline Deslocamentos - AEP (cm) & $-0,08$ & $-0,61$ & $-0,96$ & $-1,07$ & $-1,19$ & $-1,34$ & $-1,37$ & $-1,33$ & $-1,17$ & $-1,05$ & $-0,93$ & $-0,61$ & $-0,23$ & 0,07 \\
\hline
\end{tabular}


Sullivan - Caso 1
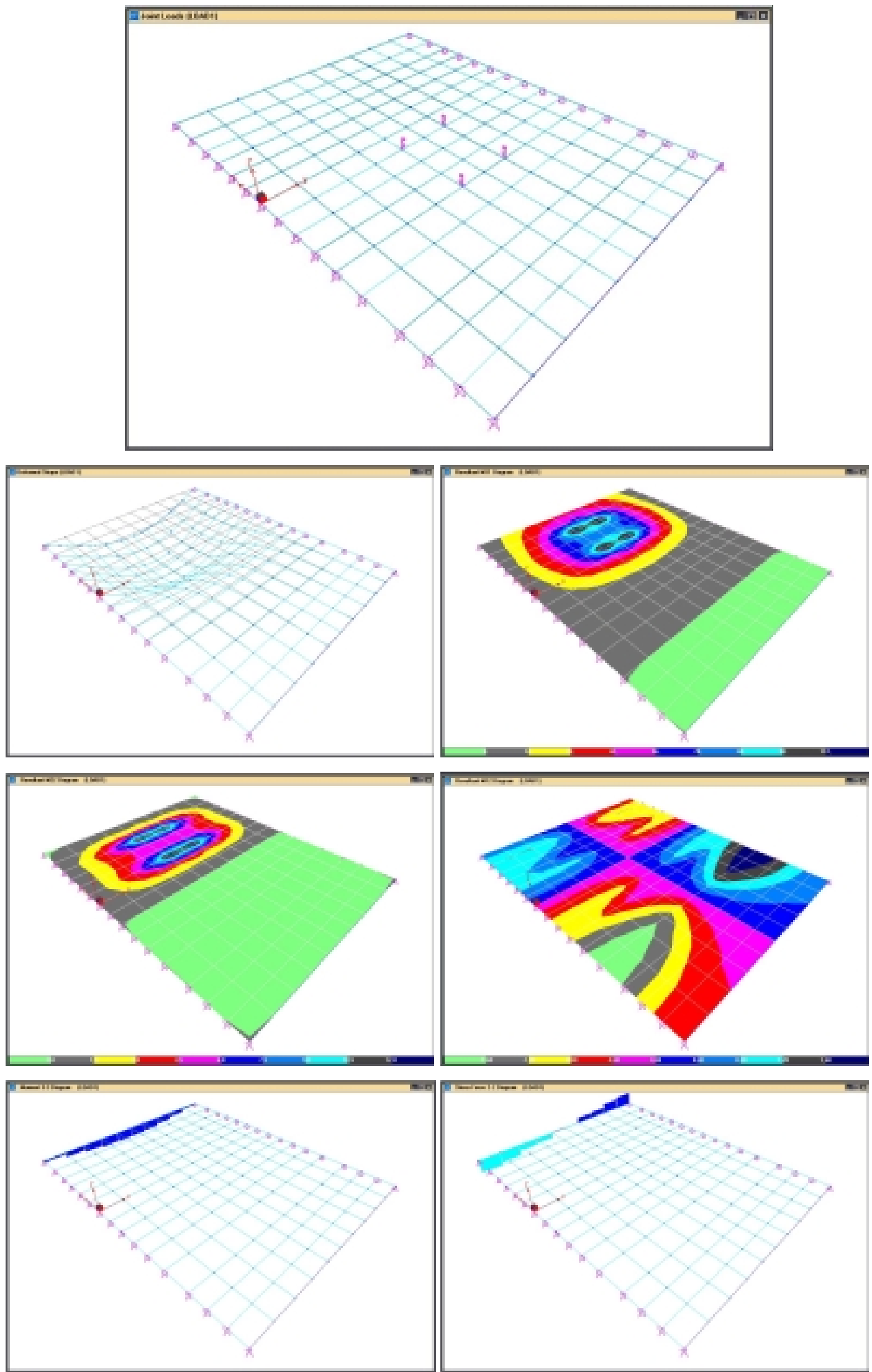


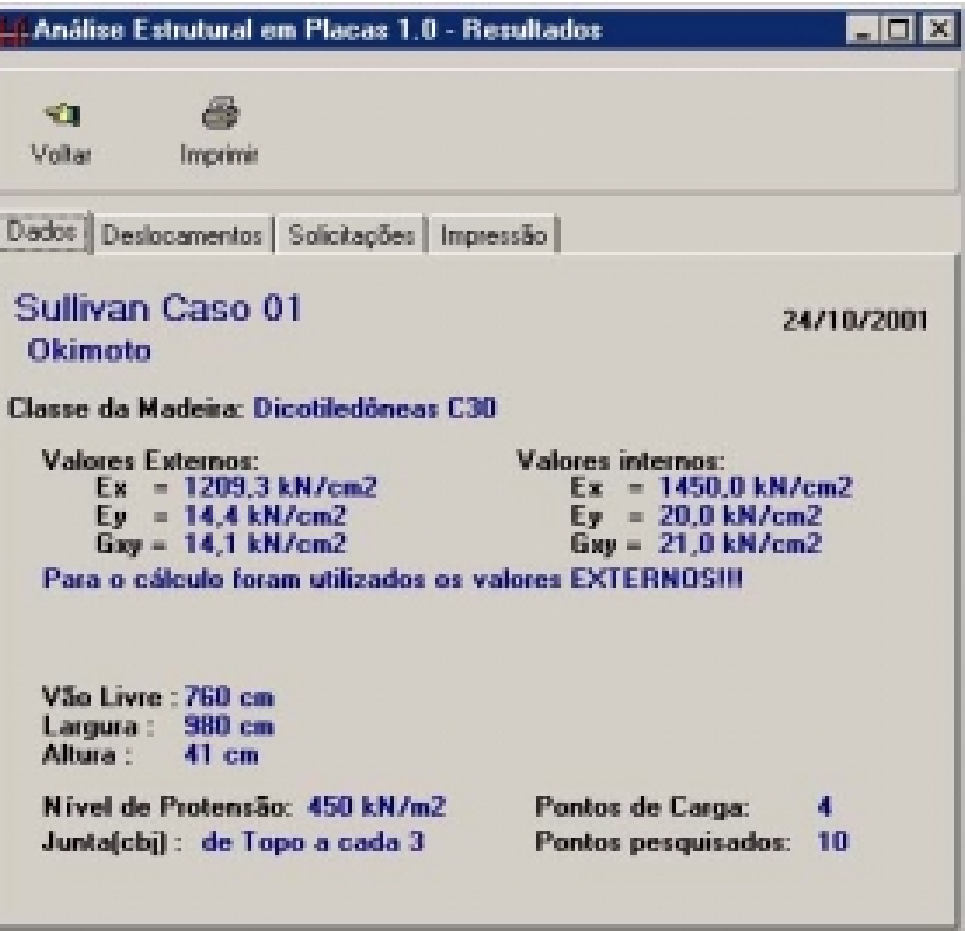

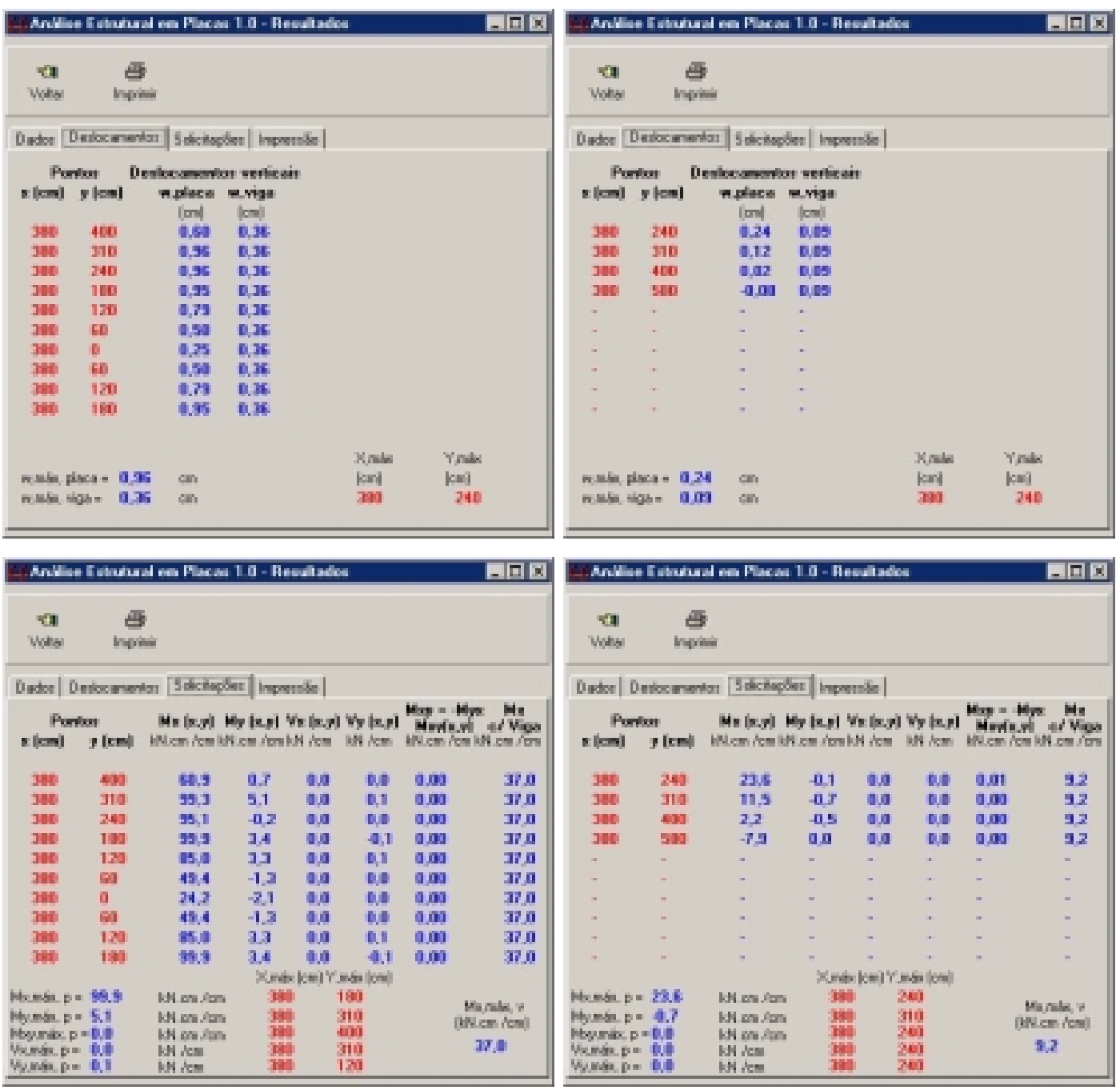


Sullivan - C01 - Deslocamentos na Seção central

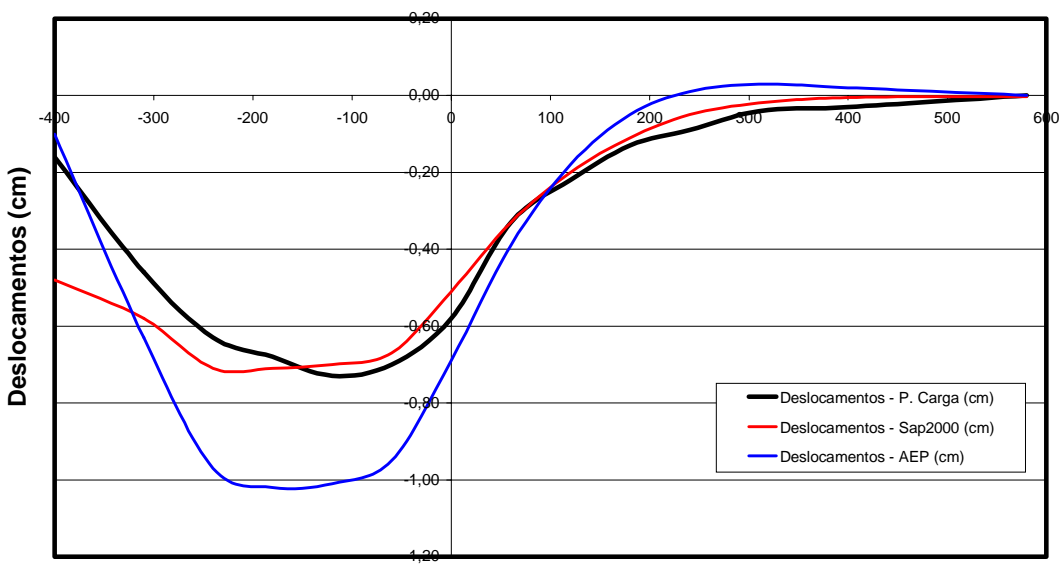

Posição (cm)

Sullivan - C02 - Deslocamentos na Seção central

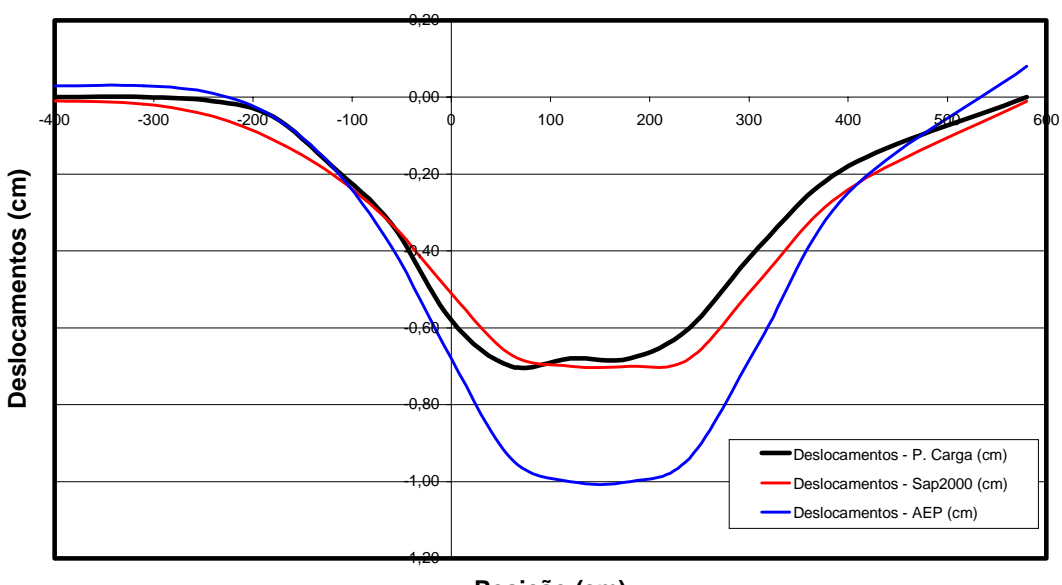

Posição (cm)

Sullivan - C03 - Deslocamentos na Seção central

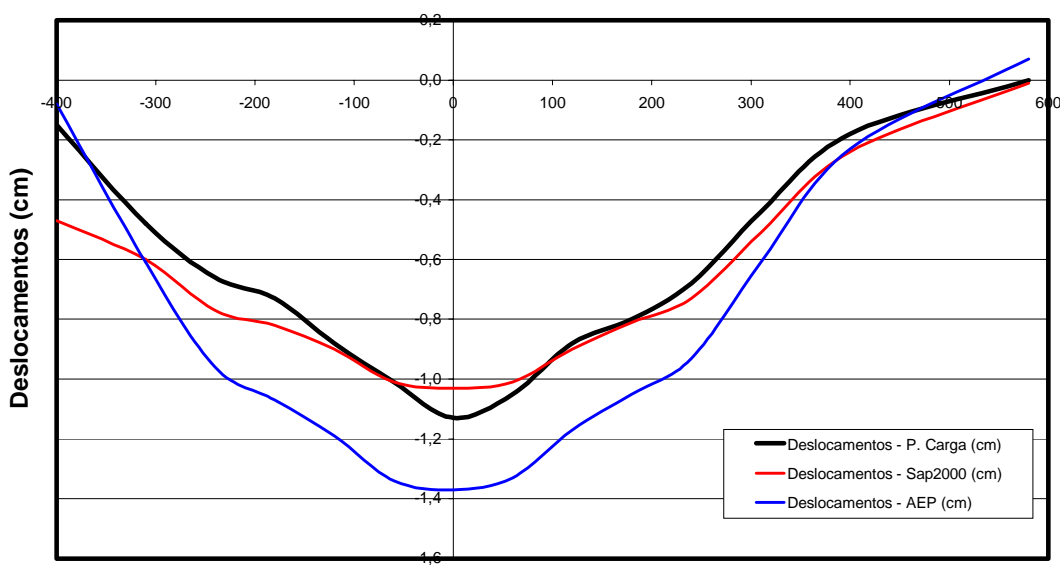

Posição (cm) 


\section{'Sullivan}

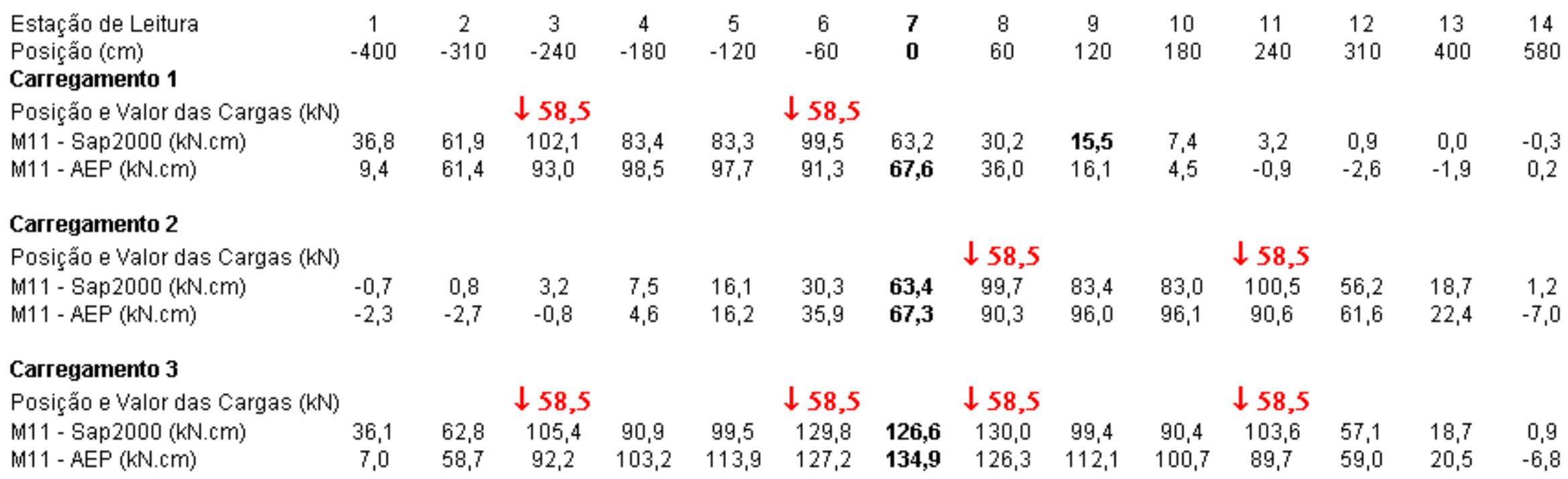




\section{Sullivan - C01 - Momentos M11 na Seção central}

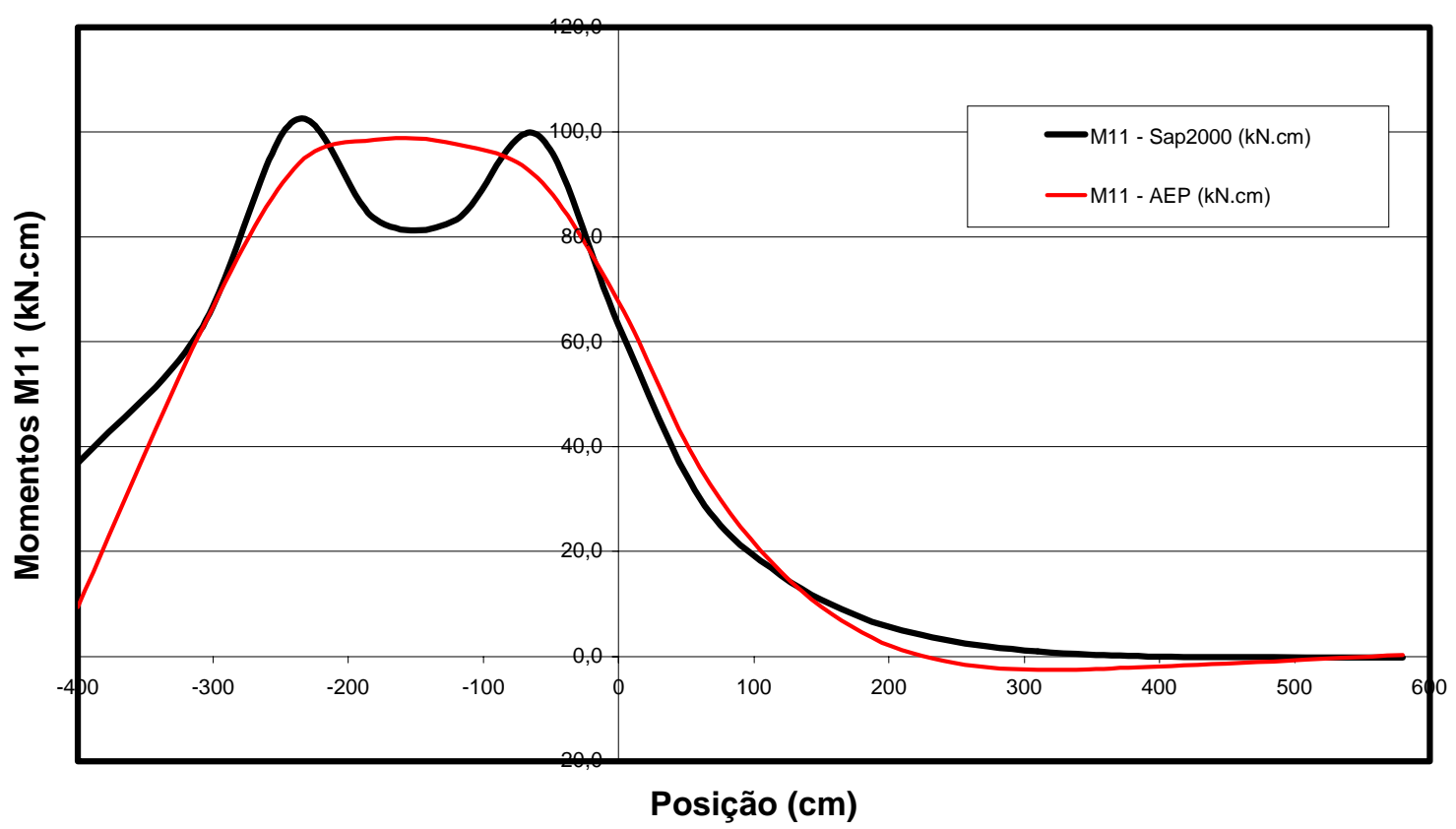

Pôde-se verificar que as simulações nos programas computacionais foram próximas a provas de carga realizadas. Destaca-se que em Lancaster o AEP v. 1.0 ficou muito mais próximo das provas de carga em todos os casos de carregamento, inclusive com melhor ajuste transversal o que significa melhor compatibilidade das propriedades transversais que no SAP2000. Já nos casos de Sullivan, os ajustes do AEP foram mais conservadores que o real mas não muito distante. 


\section{CONCLUSÕES}

Os resultados permitem obter várias conclusões a respeito do trabalho tanto quanto às perdas de protensão como nos outros tópicos pesquisados.

Em primeiro lugar, vê-se que os ensaios de fluência do material madeira verificaram que sempre deve ser utilizado o material na classe de umidade 1 (Umidade relativa $\leq 65 \%$ com a madeira em um teor de $12 \%$ ) para ambas as classes de resistência mas principalmente para madeiras mais moles (Pinus). Madeiras saturadas permanecem continuamente a se deformarem, gerando assim, perdas maiores. Utilizando madeiras na classe de umidade 1, o padrão assintótico pode ser aplicado com segurança na modelagem do material.

Com relação às perdas de protensão em corpos de prova, verificou-se que as dimensões reduzidas dos corpos de prova ensaiados não são adequadas nas análises tal como a literatura descreve por serem susceptíveis às variáveis que devem ser isoladas nas análises de laboratório como influências térmicas e de umidade, presenças de defeitos anatômicos, etc. As variações de diâmetro, também, não influenciaram como divulgado na literatura sendo mais importante o nível de protensão aplicado. Ainda verificou-se que há a possibilidade de utilização de outros aços como alternativa aos da Dywidag sem perda da qualidade do sistema de protensão. As reprotensões se mostraram importante mecanismo para manter um nível mínimo de projeto. Elas absorvem a acomodação inicial e as primeiras deformações elásticas verificadas nos ensaios de fluência, permitindo que as barras trabalhem apenas na faixa elástica do material 
madeira.

Como resultados, conclui-se que os valores multiplicadores sugeridos na literatura (2,5, para tabuleiros para duas reprotensões e 1,25 para três) são coerentes com os resultados obtidos nos ensaios de perdas de protensão deste trabalho, principalmente de mantido o critério de utilização de madeiras com teor de umidade em $12 \%$.

Percebe-se que a fluência da madeira submetida à compressão normal às fibras é responsável por praticamente toda a perda de carga nas barras se descartadas as variações de umidade. Isso, porque a ordem de grandeza das deformações ocorridas ao longo do ensaio é elevada para os corpos de prova e a projeção futura destas, obtidas nos ajustes, são maiores ainda.

Nos tabuleiros foi possível verificar que as perdas são menores que nos corpos de prova individuais, indicando que as influências de algumas variáveis são minimizadas em conjuntos maiores como tabuleiros ou pontes completas. Verificou-se que deve ser considerada uma majoração de $10 \%$ na largura no sentido de mais peças de madeira e maiores comprimentos nas barras de aço para cumprir a largura de projeto. Como o espaçamento utilizado nos tabuleiros foi de $120 \mathrm{~cm}$, percebeu-se a necessidade de melhorar a ancoragem com perfis contínuos ou chapas maiores para evitar esmagamento local ou limitações nas cargas das barras.

Nas pontes verificou-se que o nível de protensão maior sugere menores perdas ao longo do tempo. O volume de tráfego também deve ser considerado em projeto já que as perdas na ponte de tráfego alto foram consideravelmente maiores. Quanto maior o volume de tráfego, maiores devem ser as medidas preventivas de perdas de carga. A influência da temperatura nos valores da carga também é importante majorando, ainda mais, a necessidade de utilizar madeiras com baixos teores de umidade. A umidade relativa do ar não apresentou grande importância no caso, mas 
acredita-se que ao extrair ou impor umidade ao material ela faz com que o material diminua ou aumente, respectivamente, seu volume alterando os valores da protensão aumentando, mais uma vez, a importância de utilizar madeira a $12 \%$.

Os programas de computador PPM e AEP são elementos fundamentais deste trabalho porque eles permitirão a divulgação plena de todas as pesquisas realizadas sobre o assunto. As facilidades de se projetar, dimensionar e verificar pontes protendidas, serão incentivos para os profissionais a utilizá-los. Como se tratam de programas de domínio público distribuído pela rede mundial, não haverá concorrência com programas comerciais de projeto e análise estrutural.

Para continuação da pesquisa, sugerem-se os temas que abordem avaliações de pontes em campo com materiais diversos, bem como sobre disposições construtivas relacionadas ao nível de protensão utilizado e aos históricos de reprotensões. Havendo a necessidade de avaliação de corpos de prova para as perdas de protensão, sugere-se a utilização de seção transversal maior que a de $20 \mathrm{~cm} \times 20 \mathrm{~cm}$, aqui estudada.

Sugere-se, também, a implementação de outros arranjos estruturais utilizados em pontes protendidas de madeira ao programa PPM e a utilização do AEP para as ações permanentes, isto é, distribuídas. 
ANEXOS 
ANEXO 1: CD-ROM com os Programas PPM v.3.0 e AEP v. 1.0

Encontra-se na parte interna da contra-capa. 


\section{REFERÊNCIAS BIBLIOGRÁFICAS}

ASSOCIAÇÃO BRASILEIRA DE NORMAS TÉCNICAS (1984). NBR-8681 - Ações e segurança nas estruturas.

ASSOCIAÇÃO BRASILEIRA DE NORMAS TÉCNICAS (1985). NBR-7189 Cargas móveis para projeto estrutural de obras rodoviárias.

ASSOCIAÇÃO BRASILEIRA DE NORMAS TÉCNICAS (1986). NBR-7187 -

Projeto e execução de pontes de concreto armado e protendido. ASSOCIAÇÃO BRASILEIRA DE NORMAS TÉCNICAS (1988). NBR-6123 -

Forças devidas ao vento em edificações.

ASSOCIAÇÃO BRASILEIRA DE NORMAS TÉCNICAS. (1980). NBR 6120 -

Cargas para o Cálculo de Estruturas de Edificações. Rio de Janeiro, RJ.

ASSOCIAÇÃO BRASILEIRA DE NORMAS TÉCNICAS. (1984). NBR 7188 -

Carga Móvel em Ponte Rodoviária e Passarela de Pedestre: procedimento.

Rio de Janeiro, RJ.

ASSOCIAÇÃO BRASILEIRA DE NORMAS TÉCNICAS. (1997). NBR 7190 -

Projeto de Estruturas em Madeira: procedimento. Rio de Janeiro, RJ.

BODIG, J. \& JAYNE, B.A. (1982). Mechanics of Wood and wood composites. Ed.

Van Nostrand Reinhold Company. New York.

CUSENS, A.R. \& PAMA, R.P. (1975). Bridge Deck Analysis. Editora John Wiley Sons, London. 1975.

EL DEBS, M.K. \& TAKEIA, T.. (1995). Pontes de concreto - Notas de aula, fascículo 2 - Ações nas pontes. EESC. São Carlos, 1995.

FLORESTAR ESTATíSTICO. (1995). Situação Florestal do Estado. São Paulo, v.2, n.6, nov.1994/fev.1995. 
FRIDLEY, K. J. (1992). Designing for creep in wood structures. Forest Products Journal. Vol. 42. Número 3. Páginas 23-28. 1992.

HELLMEISTER, J. C. (1978). Pontes de eucalipto citriodora. São Carlos, SP. LaMEM/EESC/USP. 1978. Tese de Livre-Docência

McCUTCHEON, W.J. (1992). The Mormon Creek Bridge -Performance After Three Years. USDA-FS-FPL, Research Paper, FLP-RP-509. Madison, Wisconsin. Abril 1992.

MOSES, D.M.; DALEN, K.V. \& QUENNEVILLE, J.H.P. (1999). Time-dependent behaviour of transversely prestressed timer laminates. Pacific Timber Engineering Conference, PTEC. Rotorua, Nova Zelândia. pgs 422-428. Março, 1999.

O'CONNOR, C. (1975): Pontes - Superestruturas. Vol. 2. Livros Técnicos e Científicos Editora S.A / EDUSP, Rio de Janeiro. 211 pgs.

OKIMOTO, F.S. (1997) Pontes Protendidas de Madeira: Parâmetros de Projeto. Dissertação apresentada à Escola de Engenharia de São Carlos - USP como requisito (Defesa) para a obtenção do título de mestre em Engenharia de Estruturas. São Carlos, Agosto, 1997.

OKIMOTO, F.S. \& CALIL JR, C. (1997). Pontes Protendidas de Madeira: Uma alternativa para as Vias Rurais. In XXVI CONGRESSO BRASILEIRO DE ENGENHARIA AGRÍCOLA - CONBEA. Campina Grande, Paraíba, Julho de 1997.

OKIMOTO, F.S. \& CALIL JR, C. (1998). Pontes Protendidas de Madeira: Critério de Dimensionamento. In VI ENCONTRO BRASILEIRO EM MADEIRAS E EM ESTRUTURAS DE MADEIRA - EBRAMEM., v.2, p.313-324. Florianópolis, SC, 1998.

OLIVA, M.G. \& DIMAKIS, A.G. (1988). Behavior of Stress-Laminated Timber Highway Bridge. Journal of Structural Engineering, ASCE. V114, N08, pgs 1850-1869, Agosto 1988.

OLIVA, M.G. et al. (1990). Stress-Laminated Wood Bridge Decks - Experimental and Analytical Evaluations. USDA, FS, FPL, Research Paper, FPL-RP-495. Madison, Wisconsin. Março 1990.

OLIVA, M.G.; TUOMI, R.L. \& DIMAKIS, A.G. (1986). New Ideas for Timber Bridges. Transportation Research Record, TRB, no 1053. Washington, D.C. 
National Research Council, pg 59-65.

PFEIL, W. Pontes em concreto armado. 2 Volumes. LTC. 4a. Ed. Rio de Janeiro, 1990.

PNB-428 (1974) - Pontes e viadutos ferroviários. Cargas para o projeto.

PRATA, D.G. (1995). Pontes Protendidas de Madeira. São Carlos, 1995. 311p.

Tese (Doutorado) - Escola de Engenharia de São Carlos, Universidade de São

Paulo.

QUENNEVILLE, J.H.P. \& DALEN, K.V. (1994). Relaxation Behavior of Prestressed Wood Assemblies - Part 1: Experimental Study. Canadian Journal of Civil Engineering, CJCE. V21, N05, pgs 736-743, Outubro 1994.

QUENNEVILLE, J.H.P. \& DALEN, K.V. (1994). Relaxation Behavior of Prestressed Wood Assemblies - Part 2: Theoretical Study. Canadian Journal of Civil Engineering, CJCE. V21, N05, pgs 744-751, Outubro 1994.

QUENNEVILLE, P. \& DALEN, K.V. (1996): Parameters Affecting Stress Losses in

Stress-Laminated Timber Bridge Decks. Quoted in: International Wood Engineering Conference - October 28-31,1996 - Vol.II - 06 p.

RITTER, M.A. (1992). Timber Bridges - Design, Construction, Inspection, and Maintenance, Chapter 9: Design of Longitudinal Stress-Laminated Deck Superstructures. USDA-FS-FPL, Engineering Staff, EM-7700-8. Madison, Wisconsin. Agosto 1992.

RITTER, M.A. et al. (1990). Performance os Stress-Laminated Brigdes. Wood Design Focus. Vol.01, no. 3. pgs 12-16. 1990.

STEINMAN, D.B. (1961): Famous Bridges on the World. Dover Publications, INC., New York. 54 pgs.

TAYLOR, R.J. \& CSAGOLY, P.F. (1979). Transverse Post-Tensioning of Longitudinally Laminated Timber Bridge Decks. Research Report, RR220. Ontario Ministry of Transportation and Communications, OMT. Downsview, Ontario, Canada. 1979.

TAYLOR, R.J. \& KEITH, J. (1994). The Past, Present and Future of Stress Laminated Timber Bridges. Pacific Timber Engineering Conference, PTEC. Gold Coast, Austrália. Volume 2, pgs 113-122. Julho 1994.

TAYLOR, R.J. \& WALSH, H. (1983). Prototype Prestressed Wood Bridge. Transportation Research Record, TRB, no.950. Washington, D.C. National 
Research Council, pg 110-122.

USUKI, S. et al. (1994). Stress Laminated Timber Deck Bridges in Japan. Pacific Timber Engineering Conference, PTEC. Gold Coast, Austrália. Volume 2, pgs 156-161. Julho 1994.

VELOSO, L.A.C.M. (1999). Estudo do comportamento das placas de madeira protendida. Dissertação de mestrado apresentada à Escola Politécnica - USP. São Paulo, Março de 1999. 


\section{BIBLIOGRAFIA COMPLEMENTAR}

ACCORSI, M. \& SARISLEY, E. (1989). Implementing Stress-Laminated Timber

Bridge Technology for Connecticut Bridge Construction. University of Connecticut. Connecticut, . Junho 1989.

BAKHT, B. \& JAEGER, L.G. (1985). Bridge Analysis Simplified. McGraw-Hill Book Company, 294p.

BAKHT, B. \& JAEGER, L.G. (1991). Load Sharing Factors in Timber Bridge Design. Canadian Journal of Civil Engineering, CJCE. V18, no.2, pgs 312-319, Abril 1991.

BAKHT, B. \& JAEGER, L.G. (1992). Simplified Methods of Bridge Analysis for the Third Edition of OHBDC. Canadian Journal of Civil Engineering, CJCE. V19, N04, pgs 551-559, Agosto 1992.

CREWS, K. (1991). Guideline Design Procedures for Douglas Fir Longitudinal Stress Laminated Decks. AUSTIM - Australian-U.S. Timber Program. Novembro 1991.

CREWS, K. (1994). Design Procedures for Stress Laminated Timber Bridge Decks in Australia. Pacific Timber Engineering Conference, PTEC. Gold Coast, Austrália. Volume 2, pgs 131-137. Julho 1994.

CREWS, K. et al. (1994). State of the Art Research - Stress Laminated Timber Bridge Decks Australia and North America. Pacific Timber Engineering Conference, PTEC. Gold Coast, Austrália. Volume 2, pgs 123-130. Julho 1994. DAVALOS, J.F. \& PETRO, S.H. (1993). Design, Construction, and Quality Control Guidelines for Stress-Laminated Timber Bridges Decks. Federal Highway Administration - FHWA. FHWA-RD-91-120, Final Report, 58 pgs, Setembro de 1993.

DAVALOS, J.F. \& SALIM, H.A. (1992). Design of Stress-Laminated T-System 
Timber Bridges. National Hardwood Timber Bridge Conference 1992, Timber Bridge Information Resource Center - TBIRC, USDA-FS-Northeastern Area.

DIAS, A.A. (1987). Contribuição para o Estudo da Distribuição Transversal de Cargas em Pontes de Madeira. São Carlos, 1987. 152p. Dissertação (Mestrado) - Escola de Engenharia de São Carlos, Universidade de São Paulo. DICKSON, B. \& GANGARAO, H.V.S. (1989). Field Monitoring of a Stressed Timber Bridge Over Elk Two-Mile Creek. 6th Annual International Bridge Conference. Paper IBC-89-48. Pittsburgh, Pennsylvania. Junho 1989.

DORTON, R.A. \& BAKHT, B. (1983). The Ontario Bridge Code: Second Edition. Transportation Research Record, TRB, no.950. Washington, D.C. National Research Council, pg 88-110.

DUWADI, S.R. \& RITTER, M.A. (1991). Status of Research on Timber Bridges and Related Topics. Federal Highway Administration e USDA-FS-FPL.

GANGARAO, H.V.S. (1990). Research and Development of Stressed-Timber Brigde Systems at West Virginia University. Wood Design Focus. Vol.01, no. 3. pgs 08-10.

JAEGER, L.G. \& BAKHT, B. (1990). Effect of Butt Joints on the Flexural Stiffness of Laminated Timber Bridges. Canadian Journal of Civil Engineering, CJCE. V17, N5, pgs 859-864, Outubro 1990.

LEE, P.D.H.; RITTER, M.A. \& TRICHE, M. (1995). Standard Plans for Southern Pine Bridges. USDA-FS-FPL, General Technical Report, GTR-84. Madison, Wisconsin. Setembro 1995. 26p.

McCUTCHEON, W.J.; GUTKOWSKI, R.M. \& MOODY, R.C. (1986). Performance and Reabilitation of Timber Bridges. Transportation Research Record, TRB, no.1053. Washington, D.C. National Research Council, pg 65-69.

MOODY, R.C. RITTER, M.A. \& GANGARAO,H.S. (1990). Applicatiosn of Wood Materials for Innovative Bridges Systems. Proceedings of 1st Materials Engineering Congress '90, ASCE, Denver, Colorado. pgs 423-432, Agosto 1990. 
MUCHMORE, F.W. (1986). Designing Timber Bridges for Long Life. Transportation Research Record, TRB, no.1053. Washington, D.C. National Research Council, pg 12-17.

NASCIMENTO,M.L.; LAHR,F.A.R.; CALIL JR.,C. (1993). Pontes Laminadas Protendidas Com Madeiras de Dicotiledôneas. In: I Encontro Regional em Madeiras e em Estruturas de Madeira. São Paulo. Anais, Vol. 2, pgs 77-88. São Paulo, Escola Politécnica - Universidade de São Paulo.

OLIVA, M.G.; DIMAKIS, A.G. \& RITTER, M.A. (1987). Development and Use of Stress Laminated Timber Deck Bridges. Proceedings of the sessions at Structures Congress '87 related to Bridges and Transmission Line Structures, ASCE, Orlando, Florida. pgs 249-255, Agosto 1987.

OLIVA, M.G.; RITTER, M.A. \& DIMAKIS, A.G. (1988). Stress Laminated Timber Deck Bridges: Prototype Project. Proceedings of the "1988 International Conference on Timber Engineering”. Washington D.C. pgs 645-649, Setembro 1988.

OU, F.L. \& WELLER, C. (1986). An Overview of Timber Bridges. Transportation Research Record, TRB, no.1053. Washington, D.C. National Research Council, pg 1-12. 1986.

QUENNEVILLE, J.H.P. \&. DALEN, K.V. (1990). Prestress Level in StressLaminated Timber Bridges. Discussion in Journal of Structural Engineering, ASCE. V116, N11, pgs 2283-2285, Novembro 1990.

RIBEIRO, G.O. (1986). Determinação de Propriedades Elásticas e de Resistência dos Compensados Estruturais, Capítulo 7: Ensaios de Torção em Placas. São Carlos, 1986. pgs 148-185. Dissertação (Mestrado) - Escola de Engenharia de São Carlos, Universidade de São Paulo.

RITTER, M.A. \& OLIVA, M.G. (1990). Field Performance of U.S. Stress-Laminated Wood Bridges. Proceedings of 1990 International Timber Engineering Conference, Steering Committee of the International Timber Engineering Conference, Tokio, Japão. Vol. 2, pgs 564-569, Outubro 1990.

RITTER, M.A. \& WILLIANSON, T.G. (1995). Maintenance Practices of Wood Bridges. Proceedings of Structures Congress '95. ASCE, Boston, MA. pgs 290293, Abril 1995.

RITTER, M.A. (1993). Current Timber Bridges Research and Development in the 
United States. USDA-FS-FPL, Report. Madison, Wisconsin. Janeiro 1993.

RITTER, M.A. et al. (1991). Methods for Assessing the Field Performance of Stress-Laminated Timber Bridges. Proceedings of the "1991 International Conference on Timber Engineering". Londres, Inglaterra. pgs 3319-3326, Setembro 1991.

RITTER, M.A. et al. (1993). Development and Evaluation of the Teal River StressLaminated Gluelam Bridge. Report to Transportation Research Boad Annual Meeting. USDA-FS-FPL. Madison, Wisconsin. Janeiro 1993.

RITTER, M.A.; MOODY, R. \& DUWADI, S. (1994). U.S. Timber Bridge Research. Pacific Timber Engineering Conference, PTEC. Gold Coast, Austrália. Volume 2, pgs 148-155. Julho 1994.

SALES, A. (1991). Características de Resistência Mecânica de Algumas Espécies de Eucalipto do Estado de São Paulo. São Carlos, 1991. 204p. Dissertação (Mestrado) - Escola de Engenharia de São Carlos, Universidade de São Paulo. SARISLEY, E.F. (1990). Construction Methods and Costs of Stress-Laminated Timber Bridges. Journal of Structural Engineering, ASCE. V116, N09, pgs 432447, Setembro 1990.

STANDARDS ASSOCIATION OF AUSTRALIA. (1994). Australian Standard Timber Structures. Draft. Australia. 1994.

STANFILL-McMILLAN, K. \& KAINZ, J.A. (1995). Factors Influencing Timber Bridge Performance. Proceedings of Structures Congress '95. ASCE, Boston, MA. pgs 294-297, Abril 1995.

TAYLOR, R.; RITTER, M.A. (1994). Durabilty in Stress Laminated Timber Bridges. Pacific Timber Engineering Conference, PTEC. Gold Coast, Austrália. Volume 1, pgs 686-694. Julho 1994.

TAYLOR, R.J. (1988). Field Applications of Prestress Laminated Wood Bridge Decks. Canadian Journal of Civil Engineering, CJCE. V15, N03, pgs 477-485, Junho 1988. 
TIMBER BRIDGES INITIATIVE. (1993). Superstructure Costs Report on Project Funded Bridges 1989-1993. Timber Bridge Information Resource Center TBIRC, USDA-FS-Northeastern Area. Agosto 1993.

UNIVERSIDADE DE SÃO PAULO. (1996). Serviço de Biblioteca. Diretrizes para Elaboração de Dissertações e Teses na EESC-USP. 2.ed. São Carlos.

WACKER, J.P. \& RITTER, M.A. (1992). Field Performance of Timber Bridges - 1.

Teal River Stress-Laminated Deck Bridge. USDA-FS-FPL, Research Paper, FLP-RP-515. Madison, Wisconsin. Dezembro 1992.

WECHSLER, M.B. (1990). Bridge Evaluation for Multipresence of Vehicles. Discussion in Journal of Structural Engineering, ASCE. V116, N03, pgs 334336, Março 1990.

WIPF, T.J.; RITTER, M.A. \& DUWADI, S.R. (1995). Dynamic Evaluation of Wood Bridges. Proceedings of Structures Congress '95. ASCE, Boston, MA. pgs 1-4, Abril 1995. 